
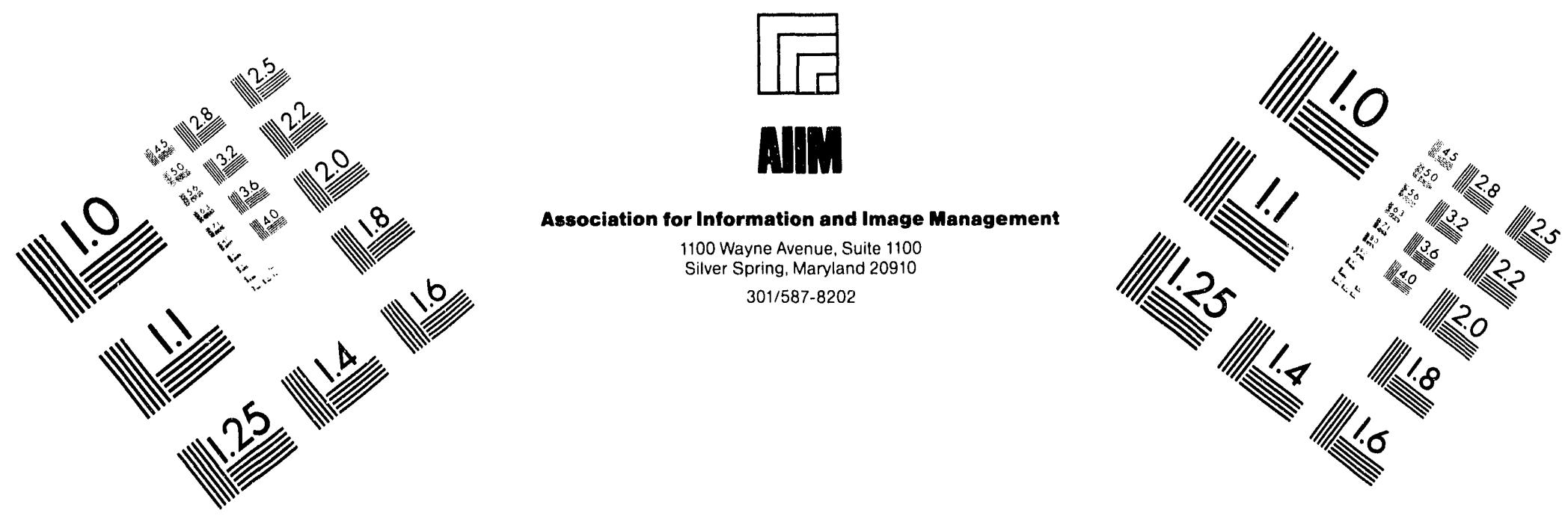

Centimeter

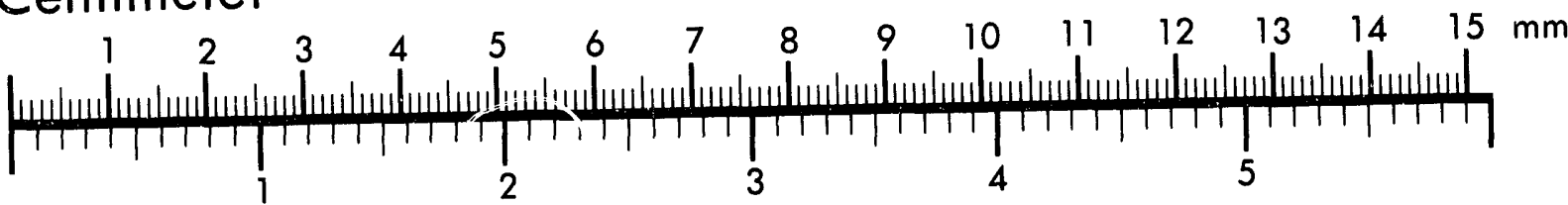

Inches
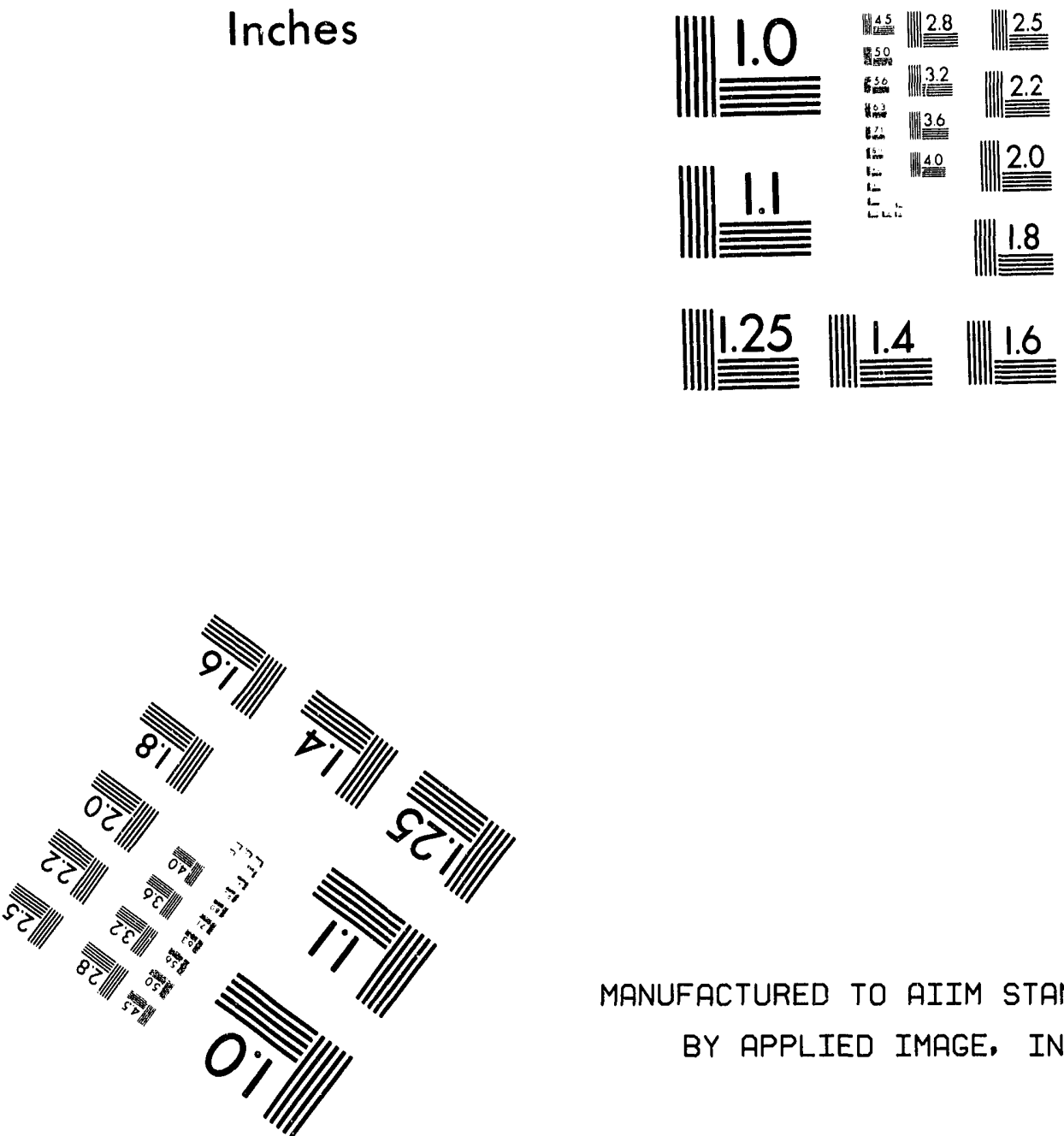

MANUFACTURED TO AIIM STANDARDS

BY APPLIED IMAGE, INC.

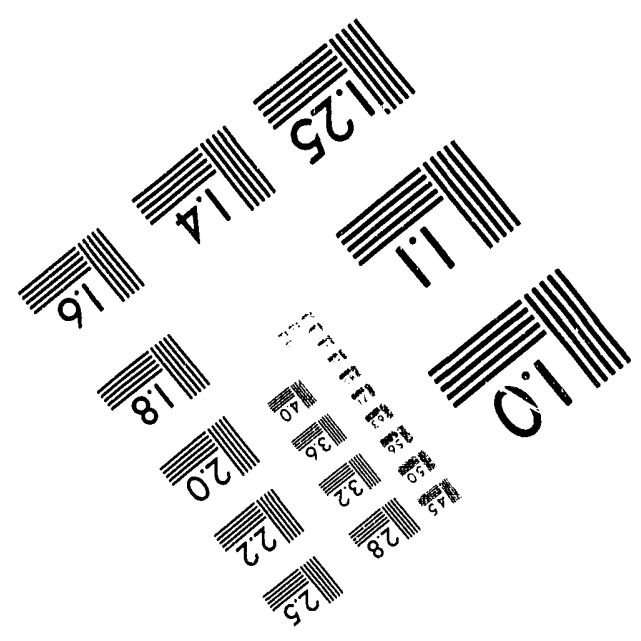



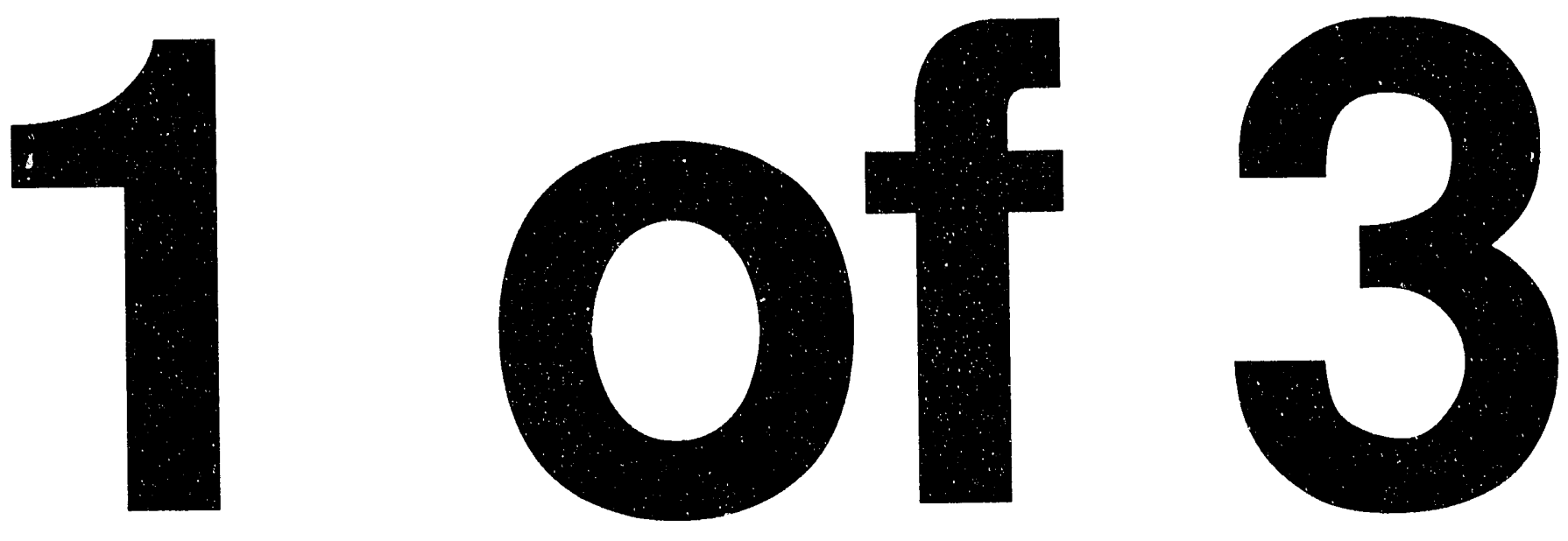


\title{
Development of an Advanced, Continuous \\ Mild Gasification Process for the \\ Production of Co-Products \\ Technical Evaluation
}

Final Report

\author{
Robert O. Ness, Jr. \\ Brian Runge \\ Laura Sharp
}

Work Performed Under Contract No.: DE-AC21-87MC24267

For

U.S. Department of Energy

Office of Fossil Energy

Morgantown Energy Technology Center

P.O. Box 880

Morgantown, West Virginia 26507-0880

\author{
By \\ University of North Dakota \\ Energy \& Environmental Research Center \\ Box 8213 \\ University Station \\ Grand Forks, North Dakota 58202-8213
}

November 1992 


\section{EDITORS AND CONTRIBUTING AUTHORS}

ENERGY AND ENVIRONMENTAL RESEARCH CENTER

Everett Sondreal

Warrack Willson

Robert Ness, Jr.

Ronald Timpe

Ted Aulich

Daniel Stepan

Richard Shockey

Laura Sharp

Brian Runge

Brian Young

Mark Musich

Yufu Li

AMAX RESEARCH AND DEVELOPMENT CENTER

Mahesh Jha

Mark Berggren

Frank Hogsett

Bob McCormick

PELLET TECHNOLOGY CORPORATION

James Coburn

\section{PROGRAM CONTRIBUTORS}

J.E. SINOR CONSULTANTS INC.

Jerry Sinor

INTERCONTINENTAL ECONERGY ASSOCIATES, INC.

Leonard Seglin

\section{PUBLICATIONS}

ENERGY AND ENVIRONMENTAL RESEARCH CENTER

Julie Entzminger

Carol Stancyk

Don Cox

Ann Olsen

Graphics Department

Office Services 


\section{TABLE OF CONTENTS}

Page

LIST OF FIGURES $\ldots \ldots \ldots \ldots \ldots \ldots \ldots \ldots \ldots \ldots \ldots \ldots \ldots \ldots$

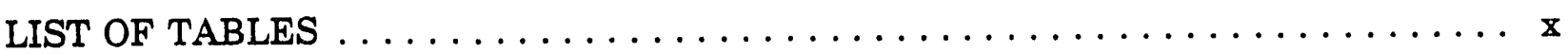

LIST OF APPENDICES $\ldots \ldots \ldots \ldots \ldots \ldots \ldots \ldots \ldots \ldots \ldots \ldots \ldots \ldots \ldots$

EXECUTIVE SUMMARY $\ldots \ldots \ldots \ldots \ldots \ldots \ldots \ldots \ldots \ldots \ldots \ldots \ldots \ldots \ldots$ xvi

1.0 INTRODUCTION $\ldots \ldots \ldots \ldots \ldots \ldots \ldots \ldots \ldots \ldots \ldots \ldots \ldots \ldots \ldots$

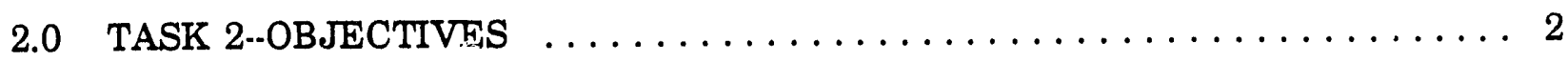

3.0 TASK 2-EXPERIMENTAL TEST MATRIX $\ldots \ldots \ldots \ldots \ldots \ldots \ldots \ldots$

4.0 SUMMARY OF FEED COALS AND PRELIMINARY YIELD DETERMINATIONS 4

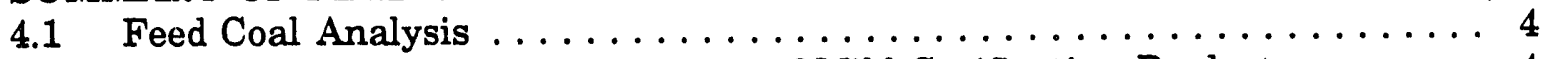

4.2 Projected Yield and Characteristics of Mild Gasification Products . . . . 4

5.0 RESULTS OF TESTS ON WYODAK COAL ................ 10

5.1 The Effect of Temperature and Steam/Nitrogen Partial Pressure on Wyodak

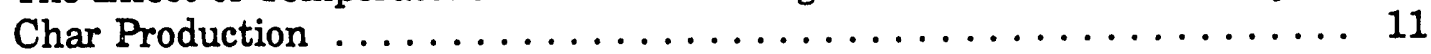

5.2 The Effect of Temperature and Steam/Nitrogen/Carbon Dioxide Partial Pressure on Wyodak Condensable Production . . . . . . . . . . . 11

5.3 The Effect of Temperature and Steam/Nitrogen Partial Pressure on Wyodak

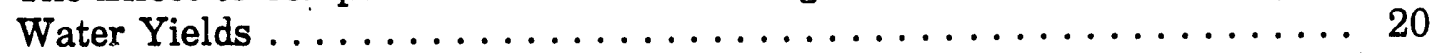

5.4 The Effect of Temperature and Steam/Nitrogen Partial Pressure on Wyodak

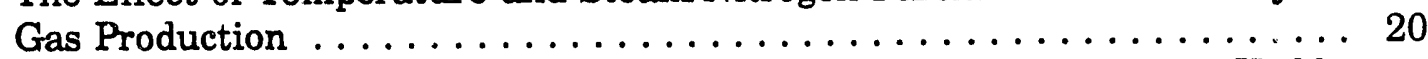

5.5 The Effect of Steam in Three Gas Atmospheres on Wyodak Product Yields at

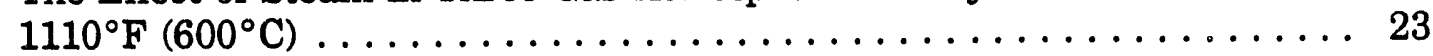

5.6 The Effect of Temperature and Steam/Carbon Dioxide Partial Pressure on

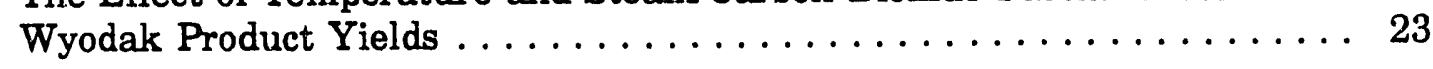

6.0 RESULTS OF TESTS COMPLETED ON ILLINOIS NO. 6 COAL . . . . . . 34

7.0 RESULTS FROM TESTS ON INDIANA NO. 3 COAL ............. 35

7.1 Direct Injection of Indiana No. 3 Coal into a Char Bed . . . . . . . . 35

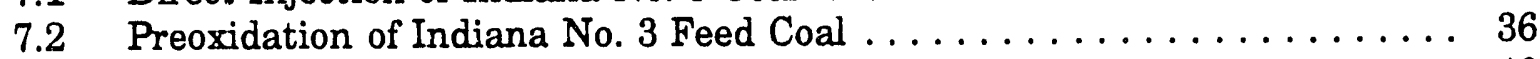

7.3 In-Bed Oxidation of Indiana No. 3 Coal $\ldots \ldots \ldots \ldots \ldots \ldots \ldots \ldots$

7.4 Staged Heating of Indiana No. 3 Coal ................. 40

7.4.1 The Effect of Temperature and Steam/Nitrogen Partial Pressure on Indiana No. 3 Char Yields . . . ............... 41

7.4.2 The Effect of Temperature and Steam/Nitrogen Partial Pressure on Indiana No. 3 Condensable Yields . . . . . . . . . . . . . 41

7.4.3 The Effect of Temperature and Steam/Nitrogen Partial Pressure on

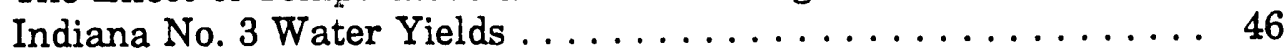


7.4.4 The Effect of Temperature and Steam/Nitrogen Partial Pressure on Indiana No. 3 Gas Yields ................... 46

7.5 Results of Bench-Scale Indiana No. 3 Wastewater Tests . . . . . . . . 46

7.5.1 Wastewater Characteristics .................... 46

7.5.2 Equipment Description ....................... 46

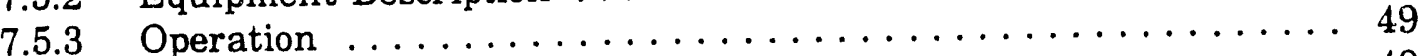

7.5.4 Results and Discussion .................... 49

7.5.5 Conclusions of Wastewater Treatment Study $\ldots \ldots \ldots \ldots \ldots \quad 50$

8.0 RESULTS OF TESTS ON CANNELTON COAL ............... 51

8.1 The Effect of Temperature on Cannelton Char Yields ............. 51

8.2 The Effect of Temperature on Cannelton Condensable Yields ........ 51

8.3 The Effect of Temperature on Cannelton Gas Yields ............ 51

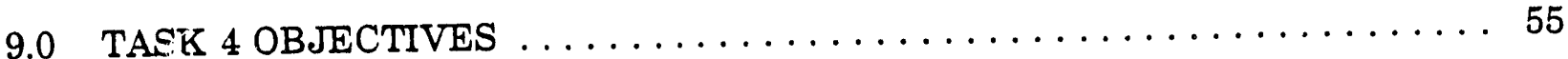

10.0 RESULTS FROM TESTS ON THE PROCESS RESEARCH UNIT (PRU) . . . . 56

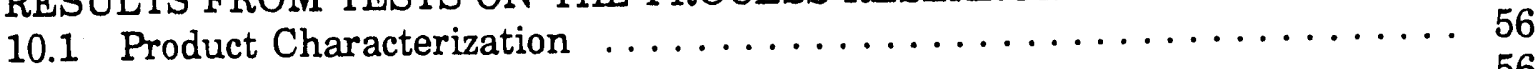

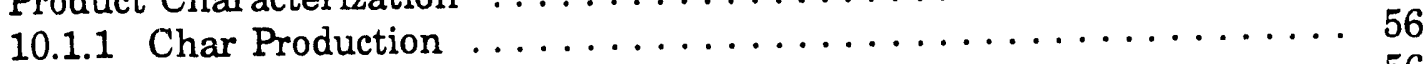

10.1.1.1 Wyodak Char Production ..................... 56

10.1.1.2 Indiana No. 3 Char Production $\ldots \ldots \ldots \ldots \ldots \ldots \ldots \ldots, 59$

10.1.2 Condensable Production $\ldots \ldots \ldots \ldots \ldots \ldots \ldots \ldots \ldots \ldots, \ldots \ldots \ldots$

10.1.2.1 Wyodak Condensable Production ................. 59

10.1.2.2 Indiana Condensable Production $\ldots \ldots \ldots \ldots \ldots \ldots \ldots \ldots 9$

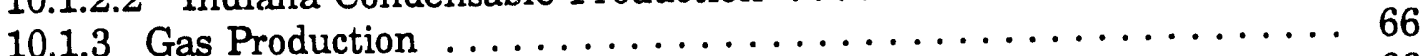

10.1.3.1 Wyodak Gas Production ..................... 66

10.1.3.2 Indiana No. 3 Gas Production $\ldots \ldots \ldots \ldots \ldots \ldots \ldots \ldots 66$

10.1.4 Wastewater Treatment $\ldots \ldots \ldots \ldots \ldots \ldots \ldots \ldots \ldots \ldots 66 \ldots \ldots \ldots \ldots \ldots$

11.0 SULFUR AND ASH REDUCTION VIA IN SITU AND PHYSICAL SEPARATION FOR CHAR UPGRADING $\ldots \ldots \ldots \ldots \ldots \ldots \ldots \ldots \ldots \ldots \ldots \ldots \ldots$

11.1 Dry Gravity Separation of the Indiana No. 3 Feed Coal . . . . . . . . 73

11.2 Lab, CFBR, Bench, and PRU Carbonizer Sulfur Reduction Tests ...... 75

11.2.1 In Situ Sulfur Reduction Techniques ............... 77

11.2.1.1 The Effect of Temperature and Steam/Nitrogen Partial Pressure on the Sulfur Content in Wyodak Char .............. 77

11.2.1.2 The Effect of Reaction Conditions on the Sulfur Content of Indiana No. 3 Char Produced in a TGA ............... 77

11.2 Detailed Analyses of the Chemical and Physical Forms of Sulfur in Indiana No. 3 Coal Char Prepared by TGA ................. 84

11.3 The Effect of Process Conditions on the Sulfur Content of Indiana No. 3 Char Produced in the $1 \cdot 1 \mathrm{lb} / \mathrm{hr}$ CFBR $\ldots \ldots \ldots \ldots \ldots \ldots \ldots \ldots \ldots . \ldots . \ldots$

11.4 Detailed Chemical and Physical Analyses of Indiana No. 3 Coal Char Prepared in the 1. to $4-\mathrm{lb} / \mathrm{hr}$ CFBR . . . . . . . . . . . . . . . . . 89

11.5 Magnetic Upgrading of Carbonizer Char . . . . . . . . . . . . 97

11.6 Heavy Liquids Gravity Separation Feasibility Studies ........... 97 
TABLE OF CONTENTS (continued)

Page

11.7 High-Temperature Calcination of Char for Sulfur Reduction . . . . . 100 11.7.1 Preliminary Calcining Tests for Sulfur Capture using Staged Heating in the CFBR ........................ 100

11.7.2 Final Calcining Tests using PRU Cleaned Char in the CFBR . . . 113

12.0 METALLURGICAL COKE SUBSTITUTE TEST RESULTS . . . . . . . . . . 115

12.1 Pelletizing of Char using Inorganic Binders (PTC Process) . . . . . . . 115

12.1.1 Pelletizing of Wyodak Char with Limestone Addition . . . . . . . 116

12.1.2 Agglomeration Tests - Carbon Agglomerates . . . . . . . . . 118

12.1.3 Agglomeration Tests - Carbon-Bearing Iron Ore Pellets . . . . . 118

12.1.4 Pelletizing of Wyodak Char Without Limestone Addition . . . . . . 122

12.1.5 Pelletizing of Indiana No. 3 Char . . . . . . . . . . . . 122

12.2 Briquetting of Char Using Organic Binders $\ldots \ldots \ldots \ldots \ldots \ldots \ldots . \ldots 122$

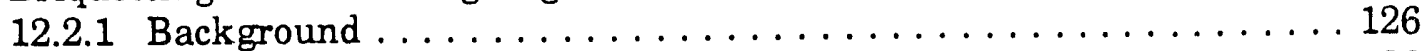

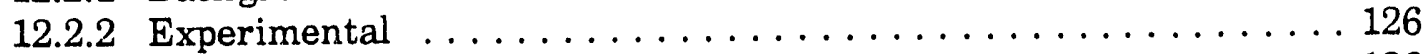

12.2.2.1 Char Characterization . . . . . . . . . . . . . . . 126

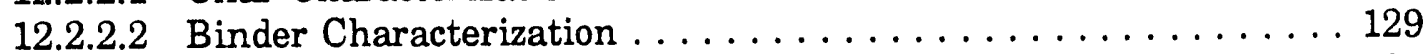

12.2.2.3 Tableting Procedure . . . . . . . . . . . . . . . . . 129

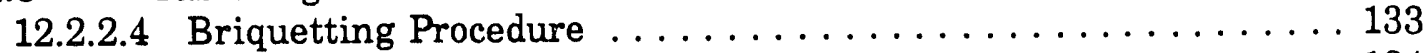

12.2.2.5 Oven-Curing and Coking ..................... 134

12.2.2.6 Strength and Stability Testing $\ldots \ldots \ldots \ldots \ldots \ldots \ldots \ldots \ldots \ldots$

12.2 .3 Results . . . . . . . . . . . . . . . . . . . . . . 135

12.2.3.1 Tableting Formulation .................... 135

12.2.3.1.1 Evaluation of Green Tablets . . . . . . . . . . . . 137

12.2.3.1.2 Evaluation of Air-Cured Tablets . . . . . . . . . . . 138

12.2.3.1.3 Evaluation of Oven-Cured and Coked Tablets .......... 140

12.2.3.2 Briquetting Formulation $\ldots \ldots \ldots \ldots \ldots \ldots \ldots \ldots \ldots \ldots$

12.2.3.2.1 Evaluation of Green Briquettes . . . . . . . . . . . 148

12.2.3.2.2 Evaluation of Briquettes after Air-Curing, Oven-Curing, and Coking ............................ 149

12.2.3.2.2.1 Briquette Volume, Weight, and Density ............ 149

12.2.3.2.2.2 Mechanical Strength . . . . . . . . . . . . . . . 149

12.2.3.2.2.3 Water Resistance . . . . . . . . . . . . . . 153

12.2.3.2.2.4 Proximate and Ultimate Properties . . . . . . . . . . 155

12.2.3.2.2.5 Weight Loss from Oven-Curing and Coking . . . . . . . . 157

12.2.3.2.2.6 Carbon Dioxide Reactivity . . . . . . . . . . . . . 158

12.2.4 Conclusions . . . . . . . . . . . . . . . . . . . . . . . 159

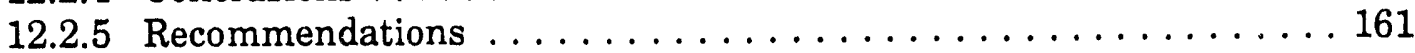

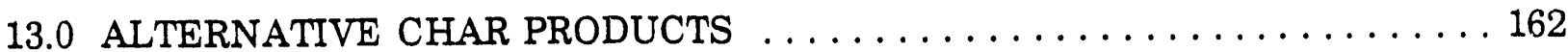

13.1 Pelletized Activated Carbon Production for the Capture of $\mathrm{SO}_{2} \ldots \ldots \ldots 162$

13.1.1 Pellet Production Using the PTC Process .............. 162

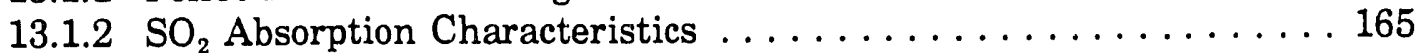

13.2 Methanation of Wyodak Char ........................ 165 
TABLE OF CONTENTS (continued)

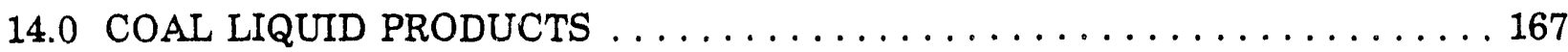

14.1 Anode Binder Production from Indiana No. 3 Condensables . . . . . . . 167

14.2 Specialty Chemical Production . . . . . . . . . . . . . . . . . 169

$14.3 \quad$ Diesel Fuel Additives $\ldots \ldots \ldots \ldots \ldots \ldots \ldots \ldots \ldots \ldots \ldots \ldots \ldots$

15.0 SUMMARIES AND CONCLUSIONS $\ldots \ldots \ldots \ldots \ldots \ldots \ldots \ldots \ldots \ldots \ldots$

15.1 The Effect of Process Conditions on Char Yield and Char Quality for Indiana

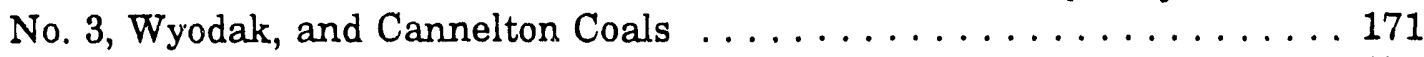

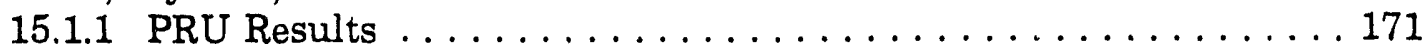

15.1.2 CFBR Test Results ...................... 172

15.2 The Effect of Process Conditions on Condensable and Gas Yields ...... 172

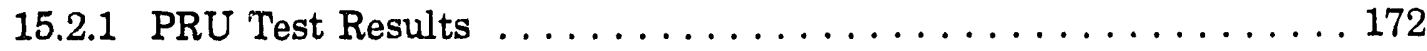

15.2.2 CFBR Test Results . ...................... 173

15.3 The Effect of Gas Atmosphere Including Steam on Liquid Yield and Quality (CFBR Test Results) ......................... 174

15.4 The Effect of Process Conditions on Sulfur Removal ............. 175

15.6 Results of Char Upgrading for the Production of Metallurgical Coke Substitutes using Inorganic Binders (PTC Process) . . . . . . . . 177

15.8 Results of Char Upgrading for the Production of Activated Carbon . . . 180

15.9 Results of Condensable Upgrading for the Production of Anode Grade Carbdro

15.10 Results of Condensable Upgrading for the Production of Cresylic Acid . .. 181

15.11 Results of Condensable Upgrading for the Production of Diesel Fuel Additives1

15.12 Program Recommendations . . . . . . . . . . . . . . . . . . 181

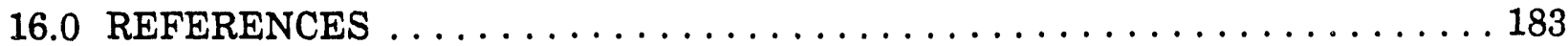




\section{LIST OF FIGURES}

Figure

1 Thermograms of Indiana No. 3, Illirıois No. 6, and Wyodak Coals (heating rate $210^{\circ} \mathrm{F}\left(100^{\circ} \mathrm{C}\right)$, $\left.\min ., 1290^{\circ} \mathrm{F}\left(700^{\circ} \mathrm{C}\right), \max .\right) \ldots \ldots \ldots \ldots \ldots \ldots$

2 Simulated distillation of condensables (based on normal alkanes from pyrolysis/GS/MS unit) ........................ 9

3 The effect of temperature and steam/nitrogen partial pressure on Wyodak char

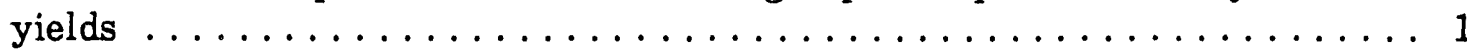

4 The effect of temperature and steam/nitrogen partial pressure on Wyodak char

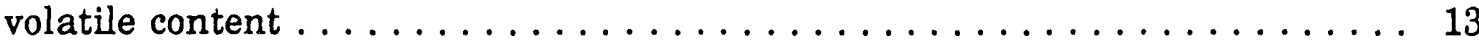

5 The effect of temperature and steam/nitrogen partial pressure on Wyodak char

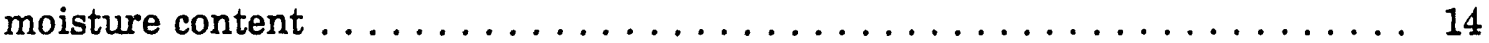

6 The effect of temperature and steam/nitrogen partial pressure on Wyodak char ash content .............................. 14

7 The effect of temperature and steam/nitrogen partial pressure on Wyodak char

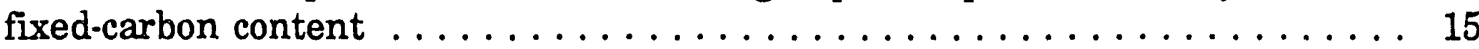

8 The effect of temperature and steam/nitrogen partial pressure on Wyodak condensable yields

9 The effect of temperature and steam/nitrogen partial pressure on Wyodak

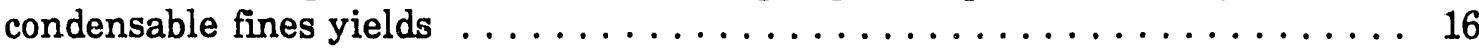

10 Wyodak char fines particle-size distribution $\ldots \ldots \ldots \ldots \ldots \ldots$

11 Proton NMR spectrum of condensables from Wyodak coal . . . . . . . . 21

12 The effect of temperature and steam/nitrogen partial pressure on Wyodak water

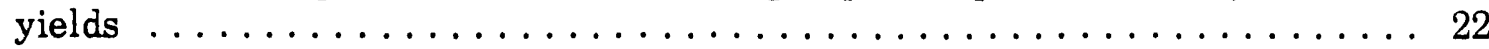

13 The $\epsilon$ ffect of temperature and steam/nitrogen partial pressure on Wyodak gas yields

14 The effect of temperature and steam/nitrogen partial pressure on Wyodak $\mathrm{CO}_{2}$ yields

15 The effect of temperature and steam/nitrogen partial pressure on Wyodak $\mathrm{H}_{2}$ yields

16 The effect of temperature and steam/nitrogen partial pressure on Wyodak $\mathrm{CH}_{4}$ yields 


\section{LIST OF FIGURES (continued)}

Figure

Page

17 The effect of temperature and steam/nitrogen partial pressure on Wyodak CO

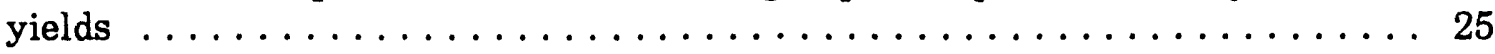

18 The effect of steam/reactive gas atmosphere on Wyodak char yields . . . . . 26

19 The effect of steam/reartive gas atmosphere on Wyodak char volatile content 27

20 The effect of steam/reactive gas atmosphere on Wyodak condensable yields . . 28

21 The effect of steam/reactive gas atmosphere on Wyodak water yields . . . . . 29

22 The effect of steam/reactive gas atmosphere on Wyodak gas yields . . . . . . 30

23 The effect of steam $/ \mathrm{CO}_{2}$ partial pressure on Wyodak product yields ..... 31

24 The effect of steam $/ \mathrm{CO}_{2}$ partial pressure on Wyodak char

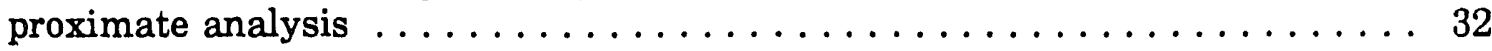

25 The effect of steam $/ \mathrm{CO}_{2}$ partial pressure on Wyodak product gas component yields $\ldots \ldots \ldots \ldots \ldots \ldots \ldots \ldots \ldots \ldots \ldots \ldots \ldots \ldots \ldots$

26 Indiana No. 3 coal agglomerate $(\mathrm{cm}) . \ldots \ldots \ldots \ldots \ldots \ldots \ldots$

27 Close-up of Indiana No. 3 char agglomerate (100 mag.) . . . . . . . . . . . 37

28 Close-up of Indiana No. 3 char agglomerate $(360$ mag.). . . . . . . . . . . . 38

29 Unconverted coal in Indiana No. 3 agglomerate $(360$ mag.). . . . . . . . . . 38

$30 \quad$ Organic bridges in Indiana No. 3 char agglomerate (1000 mag.). . . . . . . 38

31 Sulfur-coated bridge in Indiana No. 3 char agglomerate (1000 mag.). . . . . . 38

32 Sulfur-coated bridge in Indiana No. 3 char agglomerate (3000 mag.). . . . . . 39

33 The effect of temperature and steam/nitrogen partial pressure on Indiana

No. 3 char yields . . . . . . . . . . . . . . . . . . . . . . 42

34 The effect of temperature and steam/nitrogen partial pressure on Indiana

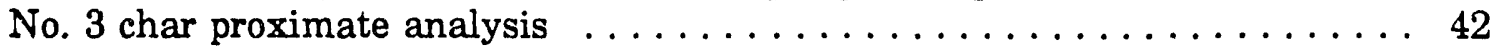

35 The effect of temperature and steam/nitrogen partial pressure on Indiana

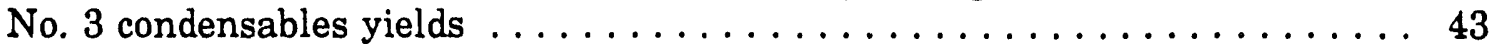

36 Indiana No. 3 condensable boiling point distributions $\ldots \ldots \ldots \ldots \ldots$ 


\section{LIST OF FIGURES (continued)}

Figure

Page

37 The effect of temperature and steam/nitrogen partial pressure on Indiana

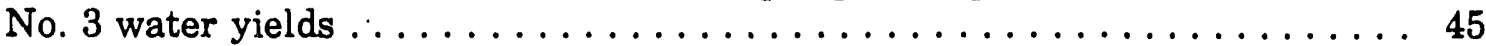

38 The effect of temperature and steam/nitrogen partial pressure on Indiana

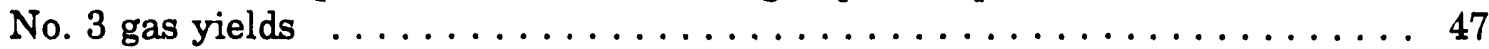

39 The effect of temperature and steam/nitrogen partial pressure on Indiana

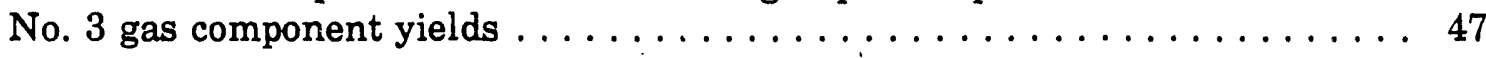

$40 \quad$ Bench-scale activated sludge system schematic $\ldots \ldots \ldots \ldots \ldots \ldots$

41 The effect of temperature on Cannelton product yields . . . . . . . . . 52

42 The effect of temperature on Cannelton char proximate analyses . . . . . . 53

43 The effect of temperature on Cannelton char ultimate analyses $\ldots \ldots \ldots \ldots$

44. Cannelton condensable simulated distillation curve $\ldots \ldots \ldots \ldots \ldots \ldots$

45 The effect of temperature on Wyodak proximate analyses (PRU) . . . . . . 58

46 Particle-size distribution analyses of $\mathrm{P} 010$ feed coal and char products . . . . 58

47 The effect of temperature on Indiana proximate analysis (PRU) . . . . . . 61

48 Particle-size distribution analyses of P011 feed coal and char products . . . . 61

49 Tar scrubber FID, sulfur, and hydrogen simulated distillation curves (P010) . 62

50 Sieve tower FID, sulfur, and hydrogen simulated distillation curves (P010) . . 62

51 Water scrubber FID, sulfur, and hydrogen simulated distillation curves (P010) 63

52 The effect of temperature on Indiana condensable yields (PRU) . . . . . 63

53 Fixed carbon and ash levels in tar scrubber liquids $\ldots \ldots \ldots \ldots 4$

54 Tar scrubber simulated boiling distribution range (P024, P025, P026, P027,

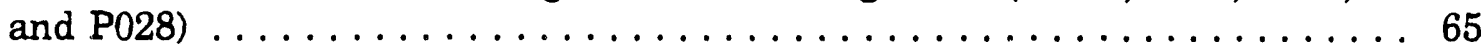

55 Tar scrubber operating temperature for PRU run. (P024, P025, P026, P027,

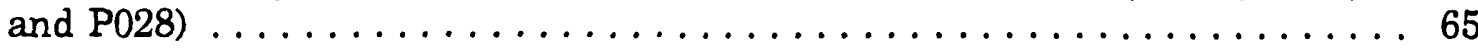

56 Sieve tower simulated boiling distribution range (P024, P025, P026,

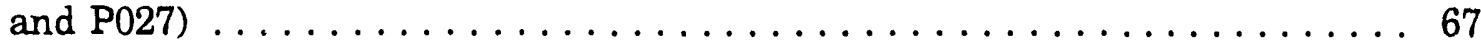




\section{LIST OF FIGURES (continued)}

Figure

57 Sieve tower operating temperature for PRU runs (P024, P025, P026, P027,

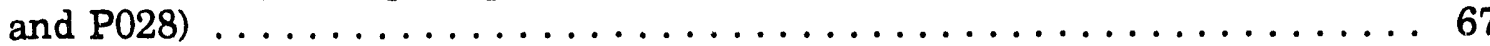

58 Water scrubber simulated boiling distribution ranges (P024, P025, P026, and P027)

59 Water scrubber operating temperature for PRU runs (P024, P025, P026, P027, and P028)

60 Sulfur content simulated distillation curves $(\mathrm{P} 011) \ldots \ldots \ldots \ldots$

61 Hydrogen content simulated distillation curves (P011) . . . . . . . 69

62 Tar scrubber tar FID, sulfur, and hydrogen simulated distillation curves (P011) ................................... 70

63 Water scrubber tar FID, sulfur, and hydrogen simulated distillation curves . 70

64 Mass balance for char upgrading unit operations $\ldots \ldots \ldots \ldots \ldots \ldots \ldots$

65 The effect of temperature and steam/nitrogen partial pressure on Wyodak

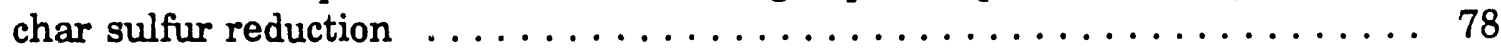

66 The effect of temperature and steam/nitrogen partial pressure on Wyodak

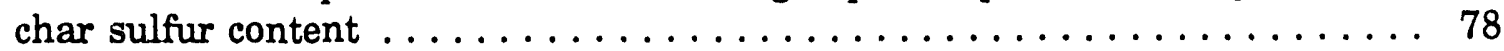

67 Sulfur/fixed carbon ratio versus temperature for chars prepared from Indiana No. 3 bituminous coal under reducing atmosphere ............. 84

68 Indiana No. 3 coal and agglomerate particle $(1000$ mag.) . . . . . . . . . il

69 Indiana No. 3 coal surface sulfur crystals (3600 mag.) . . . . . . . . . . 91

70 Indiana No. 3 char $\mathrm{SEM} /$ sulfur map, $660^{\circ} \mathrm{F} / 350^{\circ} \mathrm{C} \ldots \ldots \ldots \ldots 2$

71 Indiana No. 3 char SEM/sulfur map, $840^{\circ} \mathrm{F} / 450^{\circ} \mathrm{C} \ldots \ldots \ldots \ldots$

72 Indiana No. 3 char $\mathrm{SEM} /$ sulfur map, $1110^{\circ} \mathrm{F} / 600^{\circ} \mathrm{C} \ldots \ldots \ldots \ldots$

73 Indiana No. 3 char elemental map, $840^{\circ} \mathrm{F} / 450^{\circ} \mathrm{C} \ldots \ldots \ldots \ldots$

74 Indiana No. 3 char elemental map, $1110^{\circ} \mathrm{F} / 600^{\circ} \mathrm{C} \ldots \ldots \ldots \ldots$

75 Production of $930^{\circ} \mathrm{F}\left(500^{\circ} \mathrm{C}\right)$ char by stage heating under nitrogen $\ldots \ldots 104$

76 Production of $1290^{\circ} \mathrm{F}\left(700^{\circ} \mathrm{C}\right)$ char from $930^{\circ} \mathrm{F}\left(500^{\circ} \mathrm{C}\right)$ char under nitrogen . 105 


\section{LIST OF FIGURES (continued)}

Figure

77 Weight loss versus temperature for -270 -mesh dolomite $\ldots \ldots \ldots 106$

78 Weight loss versus temperature for -270 -mesh fraction of $660^{\circ} \mathrm{F}\left(350^{\circ} \mathrm{C}\right)$ char/dolomite product made under $90 \%$ hydrogen $10 \%$ nitrogen . . . . . . . 107

79 Weight loss versus temperature for -270 -mesh fraction of $1290^{\circ} \mathrm{F}\left(700^{\circ} \mathrm{C}\right)$ char/dolomite product made under $90 \%$ hydrogen $10 \%$ nitrogen . . . . . . . 108

80 Weight loss versus temperature for the -270 -mesh fraction of $1290^{\circ} \mathrm{F}\left(700^{\circ} \mathrm{C}\right)$ char/dolomite product made under nitrogen . . . . . . . . . . . . 109

81 Production of $1290^{\circ} \mathrm{F}\left(700^{\circ} \mathrm{C}\right)$ char from $930^{\circ} \mathrm{F}\left(500^{\circ} \mathrm{C}\right)$ char under hydrogen,

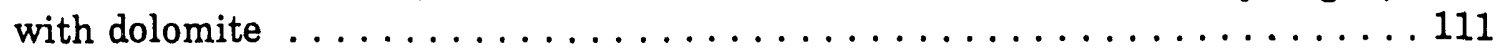

82 Weight loss of No. 20 pellets heated to $2700^{\circ} \mathrm{F}\left(1480^{\circ} \mathrm{C}\right) \ldots \ldots \ldots \ldots$

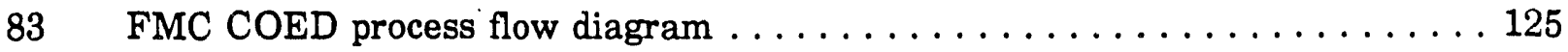

84 Low- and high-density Wyodak chars and Indiana reactor char and cyclone char . . . . . . . . . . . . . . . . . . 127

85 Wyodak and Indiana chars sized for tableting $\ldots \ldots \ldots \ldots \ldots$

86 Wyodak and Indiana chars sized for briquetting . . . . . . . . . . . 143

87 Briquette moisture content vs. air-curing time $\ldots \ldots \ldots \ldots \ldots \ldots \ldots$

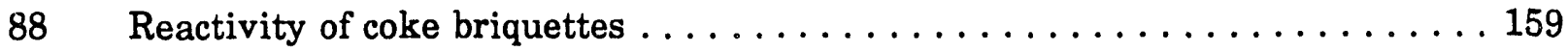




\section{LIST OF TABLES}

Table

1 Product Specifications for Metallurgical Coke Substitutes and Condensable Boiling Point Fractions . . . . . . . . . . . . . . . . . . . 2

2 Typical Composition/Characteristics of Feed Coal for Mild Gasification Project 5

3 Mild Gasification - Estimated Yields and Quality (wt\% mf Coal) . . . . . . . 6

4 Condensable Composition Quality Estimates (normalized area \% by pyrolysis

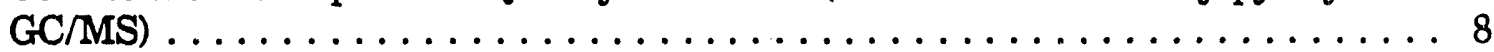

$5 \quad$ Test Matrix for Wyodak Coal $\ldots \ldots \ldots \ldots \ldots \ldots \ldots \ldots \ldots$

6 Proximate Analysis of Wyodak Coal and Char ............... 13

$7 \quad$ Wyodak Condensable Yields Breakdown . . . . . . . . . . . . . . . 20

8 Wyodak Condensable Elemental Composition ................. 21

$9 \quad$ Test Matrix for Indiana No. 3 Coal $\ldots \ldots \ldots \ldots \ldots \ldots \ldots \ldots$

10 Chemical Composition of Indiana No. 3 Agglomerate Produced at $1110^{\circ} \mathrm{F}$ in $75 \%$ Steam $25 \% \mathrm{CO}_{2}$ Fluidization Gas $\ldots \ldots \ldots \ldots \ldots \ldots$

11 TGA Agglomeration Test Results for Indiana No. 3 and Illinois No. 6 Coals . 40

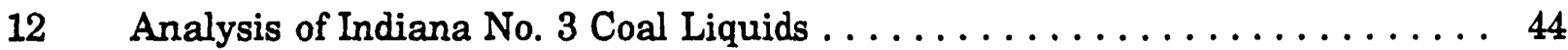

13 Simulated Distillation of Liquids from Staged Heating of Indiana No. 3 Coal 45

14 Raw Process Wastewater Characterization Data . . . . . . . . . . . . . 48

15 Operating Parameters for Activated Sludge Treatment of Indiana No. 3 Mild Gasification Process Wastewater ................... 50

16 Average Constituent Removals by Activated Sludge Treatment of Indiana No. 3 Mild Gasification Process Wastewater . . . . . . . . . . . . . . . 50

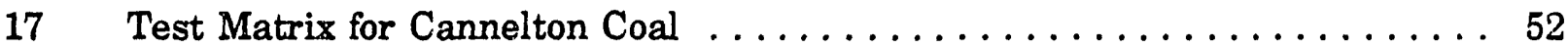

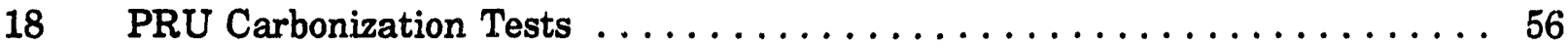

19 Carbonizer Product Char Proximate Analysis . . . . . . . . . . . . 57

20 Carbonizer Primary Cyclone Proximate Analysis . . . . . . . . . . . 57 


\section{LIST OF TABLES (iontinued)}

Table

21 Carbonizer Secondary Cyclone Proximate Analysis $\ldots \ldots \ldots \ldots \ldots$

22 Carbonizer Product Char Proximate Analysis . . . . . . . . . . . . 60

23 Carbonizer Primary Cyclone Proximate Analysis ............... 60

24 Carbonizer Secondary Cyclone Proximate Analysis . . . . . . . . . . 60

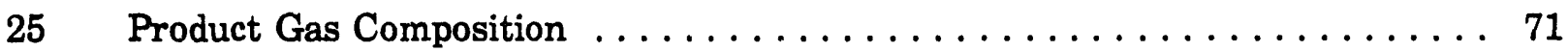

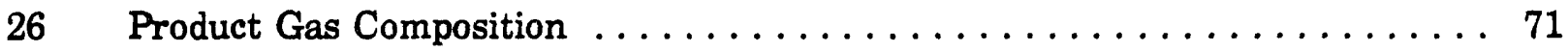

27 Wastewater Operational Parameters and Analytical Data . . . . . . . . 72

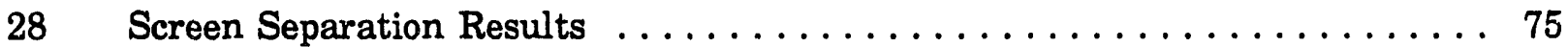

29 Results of Air Table Cleaning Test for Chinook Coal Sent to the EERC . . . . 76

30 Sulfur Content of Wyodak Mild Gasification Chars . . . . . . . . . . . . 79

31 Total Sulfur Content in Indiana No. 3 Coal ${ }^{a}$ Char Prepared under Staged Heating Conditions in Various Atmospheres $\ldots \ldots \ldots \ldots \ldots \ldots$

32 Indiana No. 3 Bituminous Coal Char (TGA) Total Sulfur Analyses $\ldots \ldots \ldots$

33 Indiana No. 3 Bituminous Coal Char (TGA) Pyritic Sulfur Analyses _. . . . 82

34 Indiana No. 3 Bituminous Coal Char (TGA) Organic Sulfur Analysis . . . . . 83

35 Sulfur in Indiana No. 3 Bituminous Char Prepared at Three Temperatures under Nitrogen . . . . . . . . . . . . . . . . . . . . 85

36 Binding Energies (eV) of Elements in Each of Three Indiana No. 3 Coal Chars Prepared under Inert Atmosphere in the TGA . . . . . . . . . . 86

37 Elemental $\%$ of Char Surfaces as Determined by ESCA . . . . . . . . . 86

38 Binding Energies (eV) of Elements in Indiana No. 3 Coal Chars Prepared under $\mathrm{H}_{2} / \mathrm{CO}$ Atmosphere at $660^{\circ} \mathrm{F}$ in the TGA $\ldots \ldots \ldots \ldots$

39 Total Sulfur Analysis of Indiana No. 3 Chars Prepared at Three Temperatures under $\mathrm{N}_{2}$ and under $\mathrm{H}_{2} / \mathrm{CO}^{a} \ldots \ldots \ldots \ldots \ldots \ldots$

40 The Effect of Process and Feedstock Variability on Indiana No. 3 Char Sulfur Content (values expressed in wt\%) $\ldots \ldots \ldots \ldots \ldots \ldots \ldots \ldots$ 


\section{LIST OF TABLES (continued)}

Table

41 The Effect of Steam and Three Temperature Stages $\left(840^{\circ} \mathrm{F} / 450^{\circ} \mathrm{C}\right)$ on Indiana No. 3 Char Sulfur Content (values expressed in wt\%) . . . . . . . . . 88

42 The Effect of Steam and Four Temperature Stages $\left(930^{\circ} \mathrm{F} / 500^{\circ} \mathrm{C}\right)$ on Indiana No. 3 Char Sulfur Content (values expressed in wt\%) . . . . . . . . 88

The Effect of Temperature in Single Stages on Indiana No. 3 Char Sulfur Content (values expressed in wt\%) $\ldots \ldots \ldots \ldots \ldots \ldots \ldots \ldots$

44 The Effect of Temperature in Multistages on Indiana No. 3 Char Sulfur Content (values expressed in wt\%) $\ldots \ldots \ldots \ldots \ldots \ldots \ldots \ldots$

45 The Effect of Long Residence Time on Indiana No. 3 Char Sulfur Content ... 90

46 Sulfur Analysis of Indiana No. 3 Mild Gasification Char (Sample M042-311-2

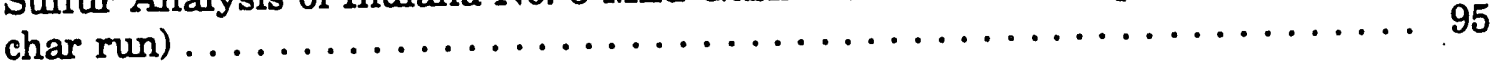

47 Analysis of $14 \times 100$ mesh Calcined Indiana No. 3 Coal Char . . . . . . . . 95

48 Analytical Results for Mild Gasification Chars . . . . . . . . . . . . . 98

49 Results of Magnetic Separation for P027 Char . . . . . . . . . . . . 98

$50 \quad$ Results of Magnetic Separation for P025 Char . . . . . . . . . . . . 98

51 Float/Sink Separation of Indiana No. 3 (P007 Char) . . . . . . . . . . 99

52 Sulfur Forms Analysis of CFBR Char/Dolomite Products . . . . . . . . . . . 101

53 XRF (Ash) Analysis of Reactants and Char/Dolomite Products . . . . . . . . 101

54 XRF (Ash) Analysis of Reactants and Char/Dolomite Products . . . . . . . . 102

55 Dolomite Concentration in Char/Dolomite Products . . . . . . . . . . 102

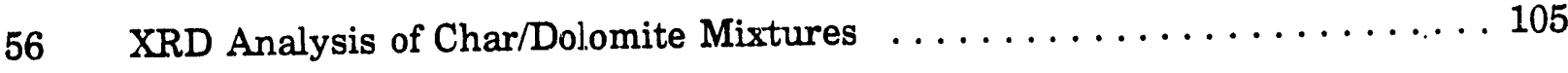

57 XRF (Ash) Analysis of Reactants and Char/Dolomite Products . . . . . . . . 110

58 Sulfur Content in Char/Dolomite Mix--Particle-Size Effects . . . . . . . 112

59 Calcining Test Parameters and Results $\ldots \ldots \ldots \ldots \ldots \ldots \ldots \ldots$

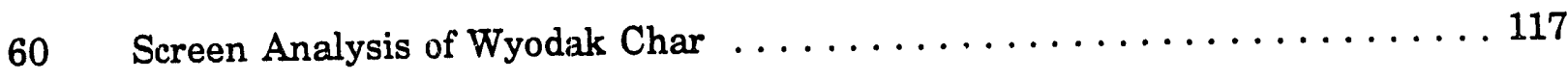

61 Chemical Analysis of Wyodak Char $\ldots \ldots \ldots \ldots \ldots \ldots \ldots \ldots$ 


\section{LIST OF TABLES (continued)}

Table

62 Physical Characteristics of Char Pellets Made From Coal Char of Various

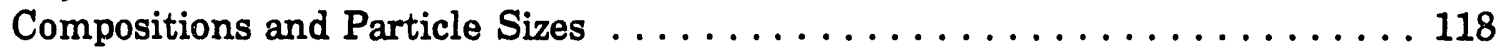

63 Tumble Test Results and Apparent Densities of Test No. 11 Coal Char Pellets

64 Chemical Analysis of Test No. 11 Coal Char Pellets (dry basis) . . . . . . . 119

65 Chemical and Screen Analyses of Empire Concentrate . . . . . . . . . . 120

66 Physical Characteristics of Carbon-Bearing Pellets Made at Various

Binder Levels . . . . . . . . . . . . . . . . . . . . . . . . 120

67 Tumble Test Results and Apparent Densities of Carbon-Bearing Iron Ore

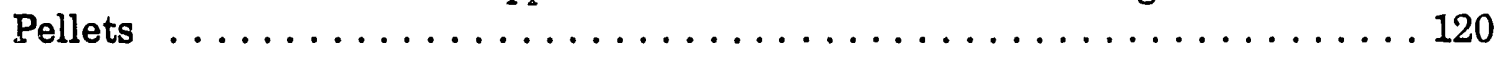

68 Chemical Analysis of Carbon-Bearing, Metallized Pellets and Reduced Iron . . 122

69 Results of Pellet Technology Corporation Char Pelletizing Tests Using

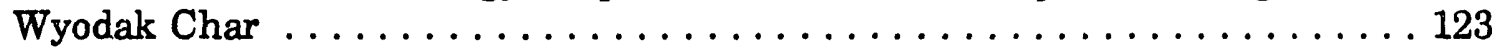

70 Results of Pellet Technology Corporation Char Pelletizing Tests Using

Indiana Char . . . . . . . . . . . . . . . . . . . . . . . . 124

71 Wyodak and Indiana Char Analysis . . . . . . . . . . . . . 127

72 Binders Used for Tableting and Briquetting Tests $\ldots \ldots \ldots \ldots \ldots$

73 Coal- and Petroleum-Derived Binder Analyses . . . . . . . . . . . . 132

74 Wyodak and Indiana Char Tableting Tests $\ldots \ldots \ldots \ldots \ldots$

75 Drop-Shatter, Compressive Load, and Density Testing: Air-Cured Wyodak

Char Tablets . . . . . . . . . . . . . . . . . . . . . . . . . . . 139

76 Weight-Loss, Compressive Load and Density Testing: Oven-Cured and

Coked Wyodak and Indiana Char Tablets . . . . . . . . . . . . . . . . 141

77 Testing of Wyodak and Indiana Char Briquettes . . . . . . . . . . 144

$78 \quad$ Results of Briquette Spray and Soak Testing $\ldots \ldots \ldots \ldots \ldots$

79 Indiana Char Briquette Analyses $\ldots \ldots \ldots \ldots \ldots \ldots$

80 Wyodak Char Briquette Analyses . . . . . . . . . . . . . 156 


\section{LIST OF TABLES (continued)}

Table

81 Briquette Weight Loss Due to Oven-Curing and Coking . . . . . . . . . 157

82 TGA Analyses and Reactivity in $\mathrm{CO}_{2}$ at $1650^{\circ} \mathrm{F}\left(900^{\circ} \mathrm{C}\right)$ : Formed Coke

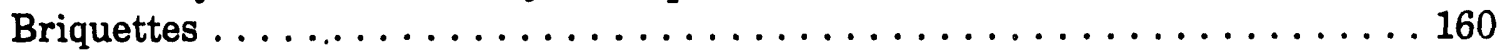

83 Pellet-Making Results . . . . . . . . . . . . . . . . 163

84 Wyodak Char Sieve Analysis $\ldots \ldots \ldots \ldots \ldots \ldots$

85 Wyodak Char Proximate Analysis (Dry Basis) $\ldots \ldots \ldots \ldots \ldots$

86 Calcium Oxide/Silica Ratios and Cure Treatments . . . . . . . . . . . . 164

87 Proximate Analysis Results $\ldots \ldots \ldots \ldots \ldots \ldots \ldots$

88 Conditions for Activated Carbon Production Runs . . . . . . . . . . . 165

89 TGA and Proximate Analysis Results $\ldots \ldots \ldots \ldots \ldots$

90 Characterization of EERC Char $\ldots \ldots \ldots \ldots \ldots$

$91 \quad$ Analytical Results for P027 Liquids $\ldots \ldots \ldots \ldots \ldots$

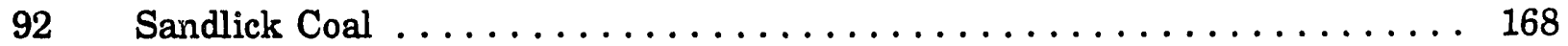

93 Cresylic Acid Distribution $\ldots \ldots \ldots \ldots \ldots \ldots$

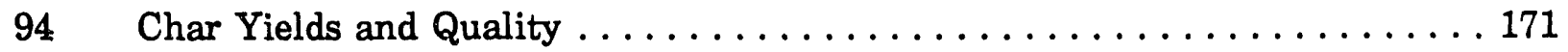

95 Condensable Yields and Quality $\ldots \ldots \ldots \ldots \ldots \ldots$

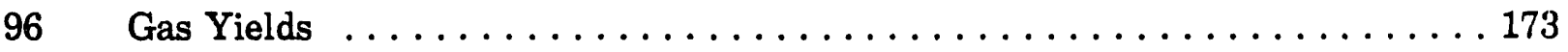

97 Comparison of Wyodak and Indiana No. 3 Condensable Boiling Point

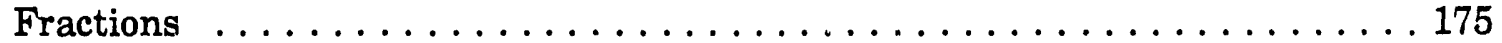

98 Summary of Inorganic and Organic Pelletizing Tests . . . . . . . . . . . 178 


\section{LIST OF APPENDICES}
A TASK 2 MILD GASIFICATION TEST PROGRAM
B MILD GASIFICATION - ANALYTICAL TEST PROCEDURES
C 1. TO 4-LB/HR CONTINUOUS FLUIDIZED-BED REACTOR (CFBR) SYSTEM DESCRIPTION
D MILD GASIFICATION PRU DESCRIPTION 


\section{EXECUTIVE SUMMARY}

The University of North Dakota Energy and Environmental Research Center (EERC) and the AMAX Research and Development Center are cooperating in the development of a Mild Gasification process that will rapidly devolatilize coals of all ranks at relatively low temperatures between $930^{\circ}$ and $1470^{\circ} \mathrm{F}\left(500^{\circ}\right.$ and $\left.800^{\circ} \mathrm{C}\right)$ and near atmospheric pressure to produce primary products that include a reactive char, a hydrocarbon condensate, and a low-Btu gas. These will be upgraded in a "coal refinery" system having the flexibility to optimize products based on market demand. End-use products may include metallurgical coke substitutes, activated carbons, electrode carbon, liquid fuels, and chemicals. The low-Btu gas produced will be used to cogenerate process heat and electric power. The fluidized-bed reactor system used represents a simplification and improvement of the previous COED process and other similar systems. One of the primary objectives of the project is to achieve successful operation on mildly caking coals of high sulfur content in support of the strategic goal of producing a metallurgical coke substitute for the Great Lakes steel industry from midwestern bituminous coal feedstocks.

Task 2 of the four-task development sequence primarily covered bench-scale testing on a 10-gram thermogravimetric analyzer (TGA) and a 1-to $4-\mathrm{lb} / \mathrm{hr}$ continuous fluidizedbed reactor (CFBR). Tests were performed to determine product yields and qualities for the two major test coals--one a high-sulfur bituminous coal from the Ilinois Basin (Indiana No. 3) and the other a low-sulfur subbituminous coal from the Powder River Basin (Wyodak). Results from Task 3, on product upgrading tests performed by AMAX Research and Development (R\&D), are also reported, based on quantities of product obtained from Tasks 2 and 4. Background information guiding this process development effort has been previously presented in two study reports addressing markets and processing technologies (January 1988).

Task 4 of the program included the construction, operation of a Process Research Unit (PRU), and the upgrading of the products. An economic evaluation of a commercial facility was made, based on the data produced in the PRU, CFBR, and the physical cleaning steps. End-use tests included pellets using inorganic binders (Pellet Technology Corporation process), briquettes using organic binders, activated carbon production, cresylic acid production, anode binder production, and diesel fuel additives.

Under a variety of operating conditions, the yields observed in the 1- to $4-1 \mathrm{~b} / \mathrm{hr}$ CFBR and PRU differed from estimates based on Fischer Assay correlations made during the Task 1 background study. The differences, however, do not materially change preliminary assessments on markets and processing conditions. The yield of hydrocarbon condensate from Indiana No. 3 bituminous coal, which reached a maximum of $18 \%$ of the moisture- and ash-free coal compared to the $29 \%$ predicted, increased along with the staging temperature up to $1110^{\circ} \mathrm{F}\left(600^{\circ} \mathrm{C}\right)$ and remained unchanged at $1470^{\circ} \mathrm{F}\left(800^{\circ} \mathrm{C}\right)$. For Wyodak subbituminous coal, the maximum of $11 \%$ was the same as predicted, and it occurred at the lower temperature of $930^{\circ} \mathrm{F}\left(500^{\circ} \mathrm{C}\right)$. The liquid yields from Wyodak coal increased along with the partial pressure of steam in reaction atmospheres otherwise containing $\mathrm{CO}_{2}, \mathrm{~N}_{2}$, or $\mathrm{N}_{2} / \mathrm{CO}_{2} / 2 \% \mathrm{O}_{2}$, representing flue gas with $12 \%$ excess air; char yields were correspondingly reduced. Tests were also conducted on Cannelton coal. Char yields (74\%) were considerably higher than the Indiana No. 3 and the Wyodak coal. Condensable yields (19\%) were similar to the Indiana, but the characteristics were slightly heavier and resembled diesel fuel. No consistent trend in yield was noted with changes in 
steam for Indiana No. 3 hituminous coal. The effect for subbituminous coal may be attributed to the adsorption of steam on the surface of the highly reactive char, which would otherwise promote condensation and retrograde polymerization of hydrocarbons. The most attractive markets identified for coal liquids were for blending with diesel at around $\$ 0.50 /$ gallon and as chemical feedstocks for producing benzene, phenol, and cresylic acids at $\$ 1$ to $\$ 2 /$ gallon.

Analysis indicated that the liquids were highly complex mixtures containing over 300 chromatographable compounds. Condensates from Indiana No. 3 bituminous and Wyodak subbituminous coals differed most prominently in their concentrations of heavy pitch boiling above $770^{\circ} \mathrm{F}\left(410^{\circ} \mathrm{C}\right)$, with very little produced from the Indiana No. 3 coal, but over $20 \%$ coming from the Wyodak coal. The concentrations of BTX (benzene, toluene, and xylene) and of phenolics (boiling beiow $430^{\circ} \mathrm{F}\left[220^{\circ} \mathrm{C}\right]$ ) were similar for the two coals, at about $4 \%$ and $35 \%$ to $40 \%$ of the liquid stream, respectively. The use of steam with Wyodak coal produced both a heavier liquid and a slightly higher liquid yield.

The targeted char specifications set by the project for metallurgical applications were $3 \%$ to $12 \%$ volatile matter and a maximum of $10 \%$ ash and $1 \%$ sulfur. The volatile matter content of Indiana No. 3 bituminous char $1470^{\circ} \mathrm{F}\left(800^{\circ} \mathrm{C}\right)$ was within specification at $9 \%$, but the corresponding levels of ash (16\%) and sulfur (2\% to $3 \%$ ) indicated a need for upgrading. Wyodak subbituminous char at $1110^{\circ} \mathrm{F}\left(600^{\circ} \mathrm{C}\right)$ contained $12 \%$ ash, $0.3 \%$ sulfur, and $12 \%$ volatile matter (coarse fraction). Char yields at these temperatures were about as predicted for Indiana No. 3 coal (61\%), but were lower than predicted for Wyodak (about $50 \%$ versus $70 \%$ ). The use of steam reduced Wyodak char yields by $4 \%$ to $10 \%$ of moisture- and ash-free (maf) coal, owing to gasification of the reactive char.

Progress was made in upgrading Indiana No. 3 char for sulfur and ash removal by a combination of gravity cleaning on the coal, in-process sulfur removal, and dry magnetic cleaning of the char. The amount of total sulfur removed in the mild gasification process generally increased along with temperature and was greatest in a reducing atmosphere. The remaining organic sulfur content was highest under reducing conditions and at high temperatures where the pyritic sulfur was low, suggesting retrograde conversion of sulfur from pyritic to organic form. The results of the sulfur studies indicate the need for a better fundamental understanding of the true chemical forms of sulfur and their conversion chemistry. The maximum reduction in sulfur content achieved in a 20 - to 30 -minute reaction time was about 50\%; e.g., from $4.9 \%$ in Indiana No. 3 coal to $2.6 \%$ in char, with a further reduction to $1.4 \%$ observed after 6 hours of reaction time. The reduction in sulfur and ash represents an economic trade-off between the cost of processing the char and the penalties of increased slag and higher sulfur content in pig iron.

Wastewater produced in the mild gasification process was successfully biotreated at full strength in an aerated activated sludge system that removed $96.9 \%$ of the biological oxygen demand (BOD), $92.7 \%$ of phenol, and $49.5 \%$ of total chemical oxygen demand (COD) at 2.9 days hydraulic retention time.

Wyodak and Indiana No. 3 char were tested for use in steelmaking by preparing cold-bonded pellets, with addition of $\mathrm{CaO}$ and $\mathrm{SiO}_{2}$ as binder, using the Pellet Technology Corporation (PTC) process. Both char and char-iron ore pellets of acceptable strength were produced. The char-iron ore pellets were reduced to iron metal at a rate five times 
greater than coke-iron ore pellets, owing to the very high reactivity of the Wyodak char. This property could have important applications in smelting slowly reacting ores, such as chrome oxides in the manufacture of ferrochrome steel. The addition of calcium and silica binder in the PTC process has the adverse effect of increasing the slag burden; however, the calcium may provide the offsetting benefit of retaining sulfur in slag-which warrants further study, but was beyond the scope of this project.

Wyodak and Indiana No. 3 char were also tested by the EERC by making a briquette using an organic binder. A considerable number of binders, including coalderived liquids, were used in the tests series, many of which provide acceptable briquette characteristics for use in blast furnaces. Unfortunately all coke substitutes produced from the Indiana No. 3 had a sulfur content greater than $1 \%$ and would not be acceptable on that basis. The Wyodak coke products were acceptable on a sulfur basis and were only slightly higher than the required $10 \%$ ash content. Activated carbon was also produced for the evaluation of $\mathrm{SO}_{2}$ adsorption.

The Wyodak liquids contained large quantities of cresylic acids while the Indiana condensables did not. These tests were conducted by the Merichem company. AMAX R\&D determined that Wyodak pitch exhibited marginally acceptable characteristics for electrode anode binder production. Liquids were evaluated for use as a diesel fuel additive under a separate DOE contract with Oak Ridge Laboratory, and the results were not available by the time this document went to press. 


\section{DEVELOPMENT OF AN ADVANCED, CONTINUOUS MILD GASIFICATION PROCESS FOR THE PRODUCTION OF CO-PRODUCTS}

\subsection{INTRODUCTION}

Coal is the largest indigenous energy resource in the United States. With the increasing consumption of petroleum products and electricity in this country, it is becoming increasingly important to develop processes that will allow the wider use of coal, including its use as a substitute for petroleum in energy and chemical markets. One approach is to develop a process that would be similar to that in a petroleum refinery in which several products are produced that meet the needs of different end users. Thus within the process boundaries, a high-value product could be maximized at the expense of a lower-value product. The capability to alter product distributions, either by changing feedstocks or process conditions, would permit timely response to the ever-changing market. AMAX Coal Company described the coal refinery concept at the Twelfth International Corference on Slurry Technology (1).

Under the mild gasification concept, for which research is sponsored by the Morgantown Energy Technology Center (METC) of the Department of Energy (DOE), a rapid devolatilization of coal under mild conditions of temperature and pressure would produce three products: a reactive char, a valuable hydrocarbon condensate, and a low-Btu gas. The proposed process under development at the EERC would produce metallurgical coke substitutes, diesel fuel additives, and chemical feedstocks.

The continuing objective of this program is to develop a continuous mild gasification process to produce a product mix that optimizes process economics and is acceptable to the marketplace. The Task 2 portion of the program focused on the use of Indiana No. 3 bituminous and Wyodak subbituminous coal for the purpose of optimizing product yields over a variety of reactor conditions. The data generated from this task were used to design, construct, and operate a 100-lb/hr Process Development Unit (PDU) under Task 4 of the program. Char was briquetted or pelletized to be evaluated as a metallurgical coke substitute while the liquids were evaluated as chemical feedstocks or diesel fuel additives. The information contained in this report complements the literature survey and market assessment reported previously in the staged development of a commercial process $(2,3)$. 


\subsection{TASK 2-OBJECTIVES}

The primary objective of Task 2 was to provide yield data for various operating conditions that would be used in the design of a 100-lb/hr PDU. Parameters included coal rank, temperature, solids residence time, and gaseous atmosphere. Secondary objectives included the production and analysis of the co-products to determine the upgrading necessary to meet market specifications. Table 1 shows the produrt specifications for using char as a metallurgical coke substitute and the boiling point distributions relating to various liquid products.

\section{TABLE 1}

Product Specifications for Metallurgical Coke Substitutes and Condensable Boiling Point Fractions

\begin{tabular}{lcc}
\hline & PTC Process & Form Coke \\
$\%$ Volatile Content & 12 & $3-6$ \\
$\%$ Ash & 10 & 10 \\
$\%$ Sulfur & $<1$ & $<1$ \\
& & \\
& & \\
ibp $-330^{\circ} \mathrm{F}$ & Condensable Boiling Point Fractions & \\
$330^{\circ}-430^{\circ} \mathrm{F}$ & Gasoline Octane Enhancer, Benzene & \\
$430^{\circ}-700^{\circ} \mathrm{F}$ & Cresylic Acids, Phenols & \\
$700^{\circ} \cdot 1020^{\circ} \mathrm{F}$ & Diesel Fuel Blends & \\
\hline
\end{tabular}




\subsection{TASK 2-EXPERIMENTAL TEST MATRIX}

The detailed test plan for Task 2 is found in Appendix A. The program included tests to study the effects of the following parameters:

1. Coal type (Indiana No. 3 and Illinois No. 6 bituminous, Wyodak subbituminous)

2. Temperature $\left(660^{\circ}\right.$ to $\left.1470^{\circ} \mathrm{F}\left[350^{\circ} .800^{\circ} \mathrm{C}\right]\right)$

3. Solids residence time (minutes)

4. Gaseous environment $\left(\mathrm{N}_{2}\right.$, steam, $\mathrm{CO}_{2}$, or simulated combustion flue gas with/without excess air)

These tests examined experimental conditions of particular importance for economic assessment, operability, and design of the PDU.

Each of the tests included the following analysis:

1. Char

a. Proximate

b. Ultimate

2. Condensables

a. Methylene chloride solubles (condensable/water yields)

b. Tetrahydrofuran solubles (fines in condensables)

c. Boiling point distributions analyses for selected samples

3. Gas: $\mathrm{GC}$ analysis for the following: $\mathrm{H}_{2}, \mathrm{CO}_{2}, \mathrm{C}_{3} \mathrm{H}_{8}, \mathrm{C}_{3} \mathrm{H}_{8}, i-\mathrm{C}_{4}, \mathrm{COS}, n-\mathrm{C}_{4}, \mathrm{H}_{2} \mathrm{~S}$, 1-Bu, $t-2-\mathrm{Bu}, i-\mathrm{C}_{5}, \mathrm{C}-2-\mathrm{Bu}, n-\mathrm{C}_{6}, \mathrm{C}_{2} \cdot \mathrm{H}_{4}, \mathrm{C}_{2} \mathrm{H}_{8}, \mathrm{O}_{2}, \mathrm{~N}_{2}, \mathrm{CH}_{4}, \mathrm{CO}, \mathrm{NH}_{3}$.

A detailed description of the analyticial techniques is found in Appendix B. 


\subsection{SUMMARY OF FEED COALS AND PRELIMINARY YIELD DETERMINATIONS}

\subsection{Feed Coal Analysis}

The EERC completed a preliminary screening of product yields using TGA and pyrolysis/GC/MS for two of the three coals selected by AMAX as candidates for a commercial mild gasification plant. The coals tested were Hlinois No. 6 (Delta mine) bituminous coal, Wyodak (Belle Ayr mine) subbituminous coal, and Indiana No. 3 obtained from the Pittsburgh Energy Technology Center (PETC). The purpose of the screening was to give a preliminary indication of the product yields and qualities and to develop improved analytical techniques to be used in support of the mild gasification program.

Average coal analysis data supplied by AMAX are presented in Table 2. Key differences are the high moisture and oxygen contents of the subbituminous coal and the high sulfur and ash contents of the bituminous coals.

Wyodak contains over $30 \mathrm{wt} \%$ moisture and has an as-received heating value of $8300 \mathrm{Btu} / \mathrm{lb}$. The sulfur content is low, at $0.35 \mathrm{wt} \%$. The ash content is also low, at $5 \mathrm{wt} \%$ on an as-received basis and 7 wt\% on a dry basis. Work performed at AMAX R\&D has indicated that the ash content can be brought down to $1.82 \mathrm{wt} \%$ on a dry basis by physical cleaning (4). The iron content of the ash is very low and its ASTM fusion temperature is relatively low. The high calcium content contributes to the retention of sulfur in the char.

Illinois No. 6 has the lowest moisture content, at 9 wt\%, and the highest heating value at $11,600 \mathrm{Btu} / \mathrm{lb}$. The sulfur content is high, at $2.85 \mathrm{wt} \%$, and is almost equally divided between organic and pyritic sulfur forms. The ash content is also relatively high, at 12.09 wt\% on a dry basis.

Indiana No. 3 is similar to Illinois No. 6 in ash content, but its moisture and volatile matter contents are somewhat higher, and the sulfur content is substantially higher. Thus mild gasification offers the challenge of processing this high-silfiur coal into more useful low-sulfur metallurgical coke and chemical products.

\subsection{Projected Yield and Characieristics of Mild Gasification Products}

The three coals were analyzed by TGA to determine the yield structures under mild gasification conditions, i.e., $1290^{\circ} \mathrm{F}\left(700^{\circ} \mathrm{C}\right)$ and at atmospheric pressure.

The major components of the volatile matter were determined and their quantities estimated by pyrolysis/GC/MS. The devolatilization and pyrolysis products were introduced into a split injector and cryogenically trapped at the head of a fused-silica capillary gas chromatographic column. The use of a relatively large sample, 2 to $4 \mathrm{mg}$, and a split injector allowed a representative sample to be collected on the capillary column. The sample was then separated and analyzed using standard GC/MS techniques. A more detailed description of the analytical technique can be found in Appendix B. 
TABLE 2

Typical Composition/Characteristics of Feed Coal for Mild Gasification Project

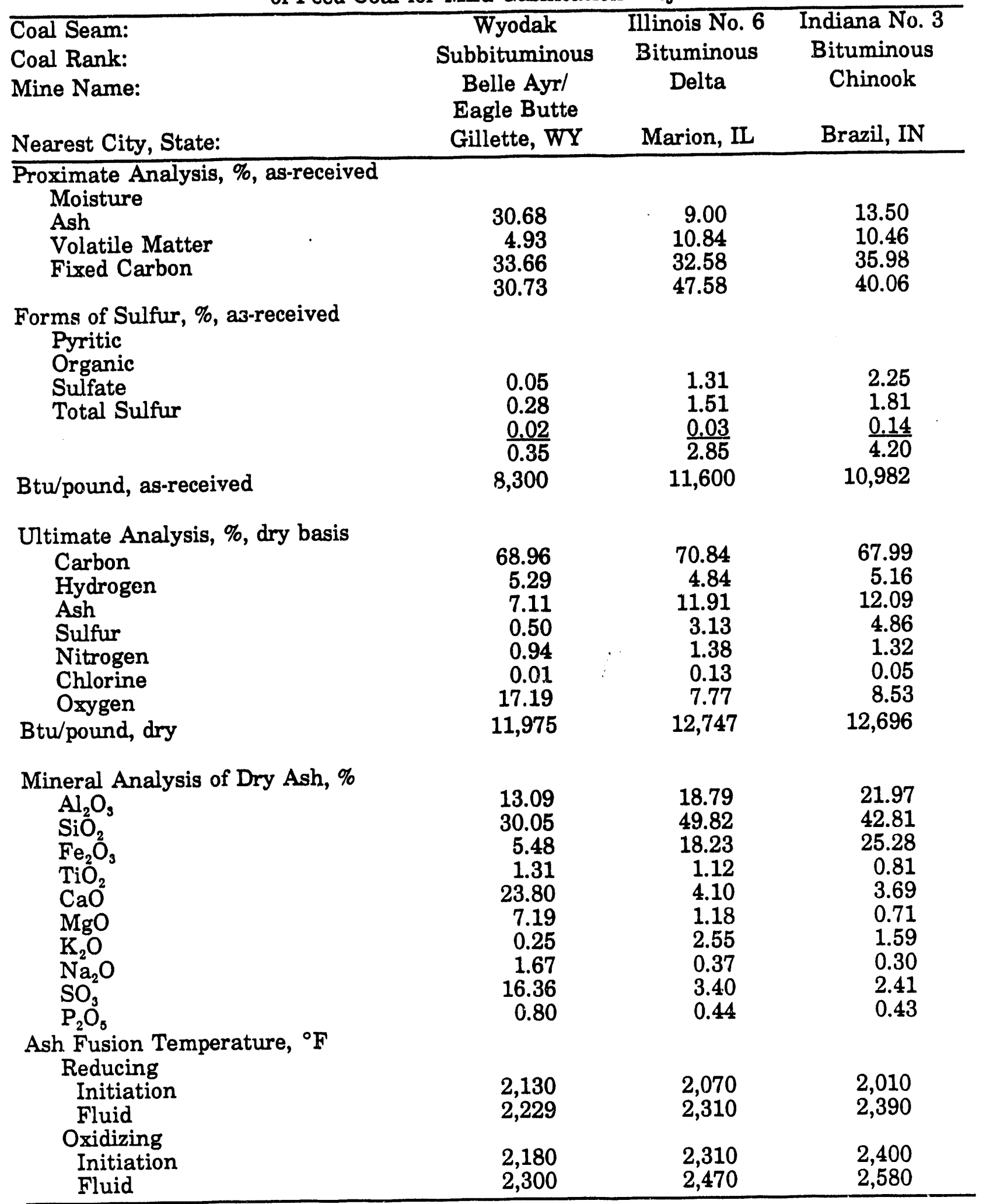


On heating the coal sample at $210^{\circ} \mathrm{F}\left(100^{\circ} \mathrm{C}\right)$ per minute to approximately $1290^{\circ} \mathrm{F}$ $\left(700^{\circ} \mathrm{C}\right.$ ), the yield of organic volatiles (condensable and gas) on a mf basis was nearly the same for the three coals, as seen by Figure 1, with a difference of only $1.53 \mathrm{wt} \%$ separating the highest and lowest. There was, however, a significant difference in the temperature of the inflection point, where the rate of devolatilization was greatest. The devolatilization of the subbituminous coal reached its maximum rate at the lowest temperature $\left(880^{\circ} \mathrm{F}\left[470^{\circ} \mathrm{C}\right]\right)$ of the three coals tested. This indicates the presence of more easily fragmented, lower boiling point organic components and a large quantity of decarboxylate that is evolved as carbon dioxide in the Wyodak coal. The bituminous coals exhibited similar inflection points $\left(950^{\circ} \mathrm{F}\left[510^{\circ} \mathrm{C}\right]\right.$ vs. $\left.960^{\circ} \mathrm{F}\left[515^{\circ} \mathrm{C}\right]\right)$, indicating similar composition and structure. At $1210^{\circ} \mathrm{F}\left(670^{\circ} \mathrm{C}\right)$, the devolatilization of the bituminous coals had slowed significantly, whereas the devolatilization of the subbituminous coal was continuing at a fairly rapid rate.

Product yield and proximate analysis estimates for chars of the three coals based on TGA results and Fischer Assay correlations are presented in Table 3. For the subbituminous coal, the sulfur concentration is shown to increase slightly in the char compared to the raw coal, but in the cases of the bituminous coals, the sulfur concentration decreases in the char. The co-product yield estimates were made using Bureau of Mines correlations developed to predict Fischer Assay yields for bituminous coals (5). This correlation provides a conservation estimate for condensable yields, which can be enhanced by as much as $50 \%$ through rapid heating (6). This correlation, however, predicts too high a liquid yield for lower-rank coals; therefore, value correction was made for the high yield of carbon dioxide $(6,7)$. The $11 \mathrm{wt} \%$ condensate yield shown in Table 3 is consistent with review data on mild gasification of Wyodak coals $(6,7)$.

\section{TABLE 3}

Mild Gasification - Estimated Yields and Quality (wt\% $\mathrm{mf}$ Coal)

\begin{tabular}{lccc}
\hline Coal Seam: & Wyodak & Illinois No. 6 & Indiana No. 3 \\
Coal Mine: & Belle Ayr & Delta & Composite \\
\hline Char Yield & 70.0 & 66.0 & 61.0 \\
Condensable Yield & 10.0 & 21.0 & 29.0 \\
$\mathrm{H}_{2}$ O Yield & 10.0 & 6.0 & 3.0 \\
Gas Yield & 10.0 & 7.0 & 7.0 \\
Char Proximate Analysis (dry) & & & \\
$\quad$ Volatile Matter & 13.0 & 9.0 & 12.0 \\
$\quad$ Fixed Carbon & 80.0 & 79.0 & 76.0 \\
$\quad$ Ash & 7.0 & 12.0 & 12.0 \\
$\quad$ Char Sulfur & 0.4 & 2.6 & 1.7 \\
Product Gas (Btu scf) & 450.0 & 600.0 & 600.0 \\
\hline
\end{tabular}



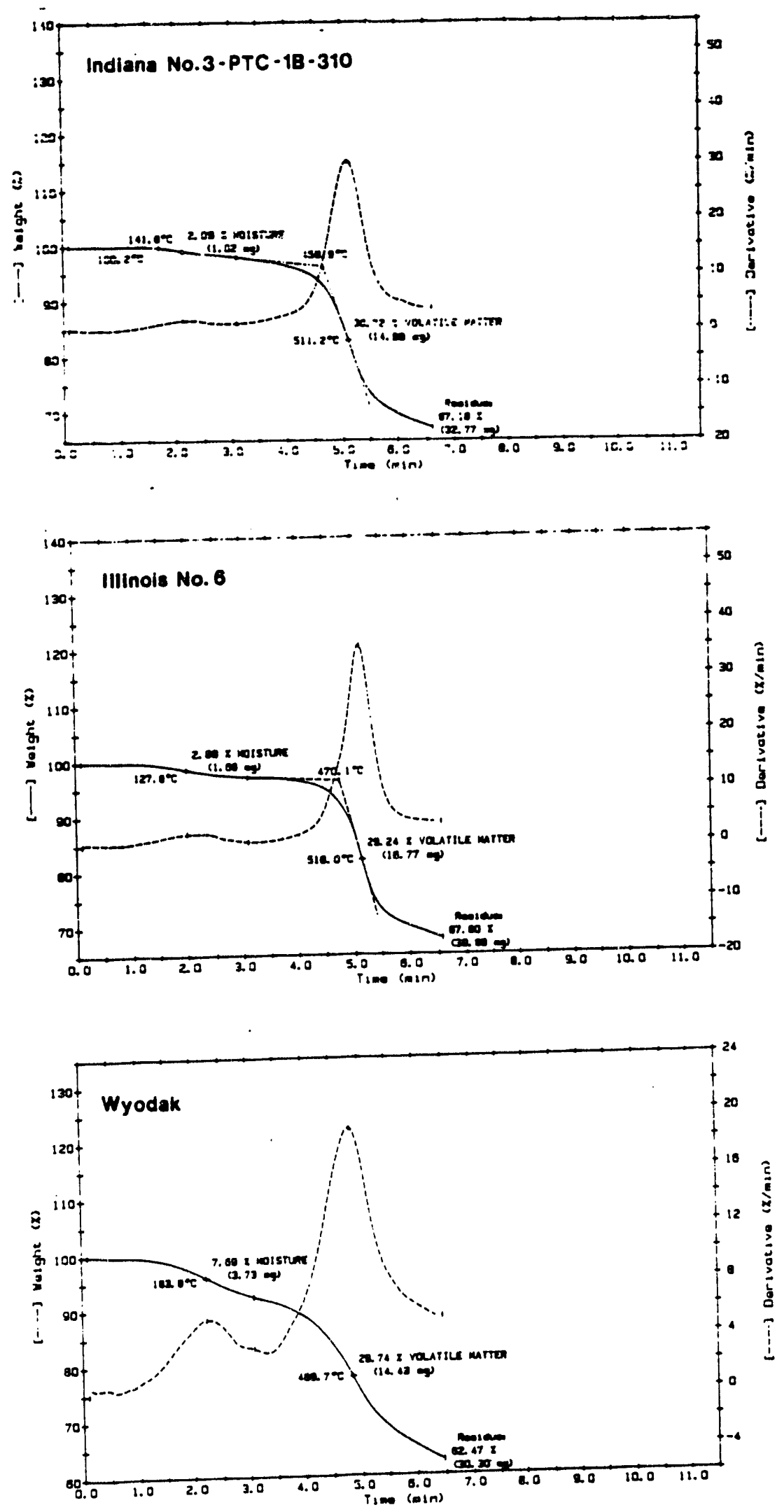

Figure 1. Thermograms of Indiana No. 3, Illinois No. 6, and Wyodak Coals (heating rate $210^{\circ} \mathrm{F}\left(100^{\circ} \mathrm{C}\right)$, min., $1290^{\circ} \mathrm{F}\left(700^{\circ} \mathrm{C}\right)$, max.). 
The calibrated GC/MS area percentages of the major organic compounds observed in the total ion chromatogram of products from TGA gasification of the three test coals are listed in Table 4. Comparison of the three coals shows a marked difference in the composition of their condensates. The concentrations of benzene and C1- and C3-benzenes are similar for the three coals, with the Wyodak coal having the highest concentration of benzene. The concentrations of phenol from the Wyodak coal is double that found in the condensables of the two bituminous coals. The concentrations of C1-phenols, catechols, and C1-catechols are approximately the same for all three coals. The Wyodak coal had only one-half of the concentration of C2-phenols observed for the two bituminous coals.

The compound distributions determined by GC/MS analysis for the pyrolysis products from the three coals were used to calculate the simulated distillation curves shown in Figure 2. The distillation curves integrate product yield as determined by the corrected area percent in the GC chromatogram versus temperature, using the boiling points of normal alkanes and their known position on the chromatogram to define temperatures along the chromatogram. Experience has shown that this procedure closely approximates the experimental ASTM distillation curve.

\section{TABLE 4}

Condensable Composition Quality Estimates (normalized area \% by pyrolysis GC/MS)

\begin{tabular}{lccc}
\hline Peak ID & Wyodak & $\begin{array}{c}\text { Delta } \\
\text { Illinois No. 6 }\end{array}$ & $\begin{array}{c}\text { Composite }^{a} \\
\text { Indiana No. 3 }\end{array}$ \\
\hline 1. Benzene & 8.6 & 5.4 & 6.9 \\
2. Toluene & 5.3 & 6.4 & 6.5 \\
3. Xylene & 3.9 & 3.8 & 5.3 \\
4. C3-Benzene & 2.2 & 2.5 & 3.1 \\
5. Phenol & 30.5 & 15.4 & 14.5 \\
6. Cresol & 24.2 & 27.2 & 28.3 \\
7. Xylenol & 9.7 & 18.9 & 19.7 \\
8. Catechol & 10.2 & 11.1 & 7.8 \\
9. C1-Catechol & 5.4 & 9.3 & 7.6 \\
\hline
\end{tabular}

a Sample from PETC. 


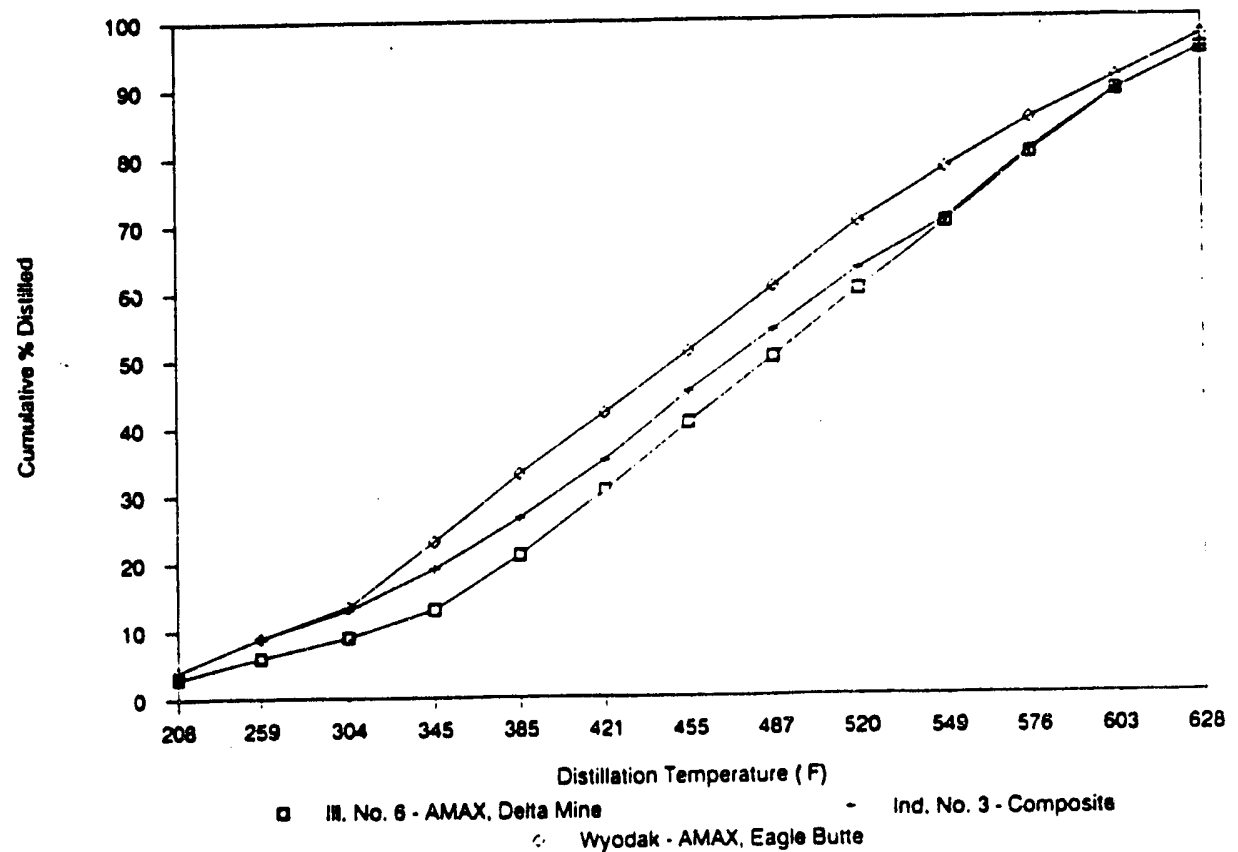

Figure 2. Simulated distillation of condensables (based on normal alkanes from pyrolysis/GS/MS unit). 


\subsection{RESULTS OF TESTS ON WYODAK COAL}

The 23 test conditions investigated on the Wyodak coal are shown in Table 5 . Three temperatures were evaluated $\left(930^{\circ}, 1020^{\circ}\right.$, and $1110^{\circ} \mathrm{F}\left[500^{\circ}, 550^{\circ}\right.$, and $\left.\left.600^{\circ} \mathrm{C}\right]\right)$ at various partial pressures of steam ranging from $0 \%$ to $100 \%$. Several gases were used in conjunction with the steam, including nitrogen, carbon dioxide, and simulated flue gases. The flue gases $\left(90 \% \mathrm{~N}_{2} / 10 \% \mathrm{CO}_{2}\right.$ or $89 \% \mathrm{~N}_{2} / 9 \% \mathrm{CO}_{2} / 2 \% \mathrm{O}_{2}$ ) represent the products of combustion of carbon with either stoichiometric or $12 \%$ excess air. The commercial plant would use an atmospheric fluidized-bed combustor to provide process heat via hot flue gas. Material balances, product yields, and analyses of the product slate for the entire matrix of points are shown in Appendix D. The procedures used in determining normalized material balance closures are detailed in Appendix $\mathrm{E}$.

\section{TABLE 5}

Test Matrix for Wyodak Coal

\begin{tabular}{|c|c|c|c|c|c|}
\hline \multirow[b]{2}{*}{ Temp. } & \multirow[b]{2}{*}{ Gas } & \multicolumn{4}{|c|}{$\%$ Steam } \\
\hline & & $0-29$ & $30-59$ & $60-89$ & $90-100$ \\
\hline $930^{\circ} \mathrm{F}$ & $\begin{array}{l}\mathrm{N}_{2} / \mathrm{CO}_{2}{ }^{\mathrm{b}} \\
\mathrm{N}_{2}^{\mathrm{d}} \\
\mathrm{CO}_{2}{ }^{\circ}\end{array}$ & $\begin{array}{c}1,2^{c} \\
- \\
11\end{array}$ & $\begin{array}{c}3 \\
- \\
12\end{array}$ & $\begin{array}{c}4 \\
- \\
13\end{array}$ & $\begin{array}{l}\ddot{.} \\
\ddot{14}\end{array}$ \\
\hline $1020^{\circ} \mathrm{F}$ & $\begin{array}{l}\mathrm{N}_{2} / \mathrm{CO}_{2} \\
\mathrm{~N}_{2} \\
\mathrm{CO}_{2}\end{array}$ & $\begin{array}{c}. . \\
15,16 \\
. .\end{array}$ & $\begin{array}{l}\ddot{17} \\
. .\end{array}$ & $\begin{array}{l}-. \\
-. \\
-\end{array}$ & $\begin{array}{l}.- \\
-. \\
-\end{array}$ \\
\hline $1110^{\circ} \mathrm{F}$ & $\begin{array}{l}\mathrm{N}_{2} / \mathrm{CO}_{2} \\
\mathrm{~N}_{2} \\
\mathrm{CO}_{2} \\
\mathrm{~N}_{2} / \mathrm{CO}_{2} / \mathrm{O}_{2}{ }^{\mathrm{f}}\end{array}$ & $\begin{array}{c}321,322 \\
21 \\
25 \\
\end{array}$ & $\begin{array}{c}-. \\
323 \\
22 \\
26 \\
\end{array}$ & $\begin{array}{c}-. \\
324 \\
23 \\
27 \\
\end{array}$ & $\begin{array}{c}-. \\
24, \\
200 \\
.- \\
\end{array}$ \\
\hline
\end{tabular}

- \% steam in fluidization gas.

b Remainder of fluidization gas is $90 \% \mathrm{~N}_{2} / 10 \% \mathrm{CO}_{2}$, which is a simulated flue gas that represents stoichiometric combustion of a carbon source.

- Matrix test number.

d Remainder of fluidization gas is $\mathrm{N}_{2}$.

- Remainder of fluidization gas is $\mathrm{Cr}_{2}$.

f Remainder of fluidization gas is $89 \% \mathrm{~N}_{2} / 9 \% \mathrm{CO}_{2} / 2 \% \mathrm{O}_{2}$, which is a simulated flue gas that represents stoichiometric combustion of a carbon source with $12 \%$ excess air. 


\subsection{The Effect of Temperature and Steam/Nitrogen Partial Pressure on Wyodak Char Production}

The highest char yield $(60.5 \%)$ occurred at $930^{\circ} \mathrm{F}\left(500^{\circ} \mathrm{C}\right)$ with $0 \%$ steam $(100 \%$ flue gas). Char production decreased slightly with increasing temperature at steam partial pressure less than 50\%, as shown in Figure 3. Increasing the steam partial pressure also decreased the char yields by approximately $4 \%$ to $10 \%$ over the range of temperatures studied. Two methods for determining char yields were used. The first method utilized an ash balance between the feed coal and the product char; the second method was based on the maf char yield normalized to $100 \%$ material balance closures. The maf char yield included char fines that were collected with the condensables. Results from both methods were similar, indicating an accurate measurement of the char yield.

The largest reduction in char volatile content was observed at the highest steam level and temperature, $1110^{\circ} \mathrm{F}\left(600^{\circ} \mathrm{C}\right)$, as shown in Figure 4. The decrease in volatile content with increasing steam is relatively consistent (approximately $3.7 \%$ to $5.6 \%$ ) between $930^{\circ}$ and $1110^{\circ} \mathrm{F}\left(500^{\circ}\right.$ and $\left.600^{\circ} \mathrm{C}\right)$. Similarly, a relatively consistent decrease in char volatiles of $6.3 \%$ to $9.6 \%$ was observed with increasing temperature at various levels of steam partial pressure.

The char volatile content was observed to be higher for the smaller particle-size fraction because this material was entrained from the bed faster than the larger size fraction. The proximate analysis for two char particle-size fractions as compared to the coal feed data is given in Table 6. After processing, the maf volatile content was reduced from $46.4 \%$ to $11.9 \%$ and $13.6 \%$ for the two respectively smaller char size fractions. Char yield and volatile content was also affected by transients in bed heights, with only a $30 \%$ char yield being observed during some one-hour test periods when the char level in the bed was still increasing. Also, steam gasification accounted for some reduction in char yields at the higher temperatures and steam levels.

The char moisture content, shown in Figure 5, varied randomly between $0.5 \%$ and $3.6 \%$, with a possible trend toward higher values at the higher steam levels. Ash content, shown in Figure 6, varied inversely with char yields since the ash constituents were relatively unaffected by changes in process conditions. The fixed-carbon content, which was determined by difference from the moisture, ash, and volatile contents, increased with temperature and steam partial pressure, reflecting the loss of volatile matter (shown in Figure 7).

\subsection{The Effect of Temperature and Steam/Nitrogen/Carbon Dioxide Partial Pressure on Wyodak Condensable Production}

High condensable yields, nearly $10 \%$ of the maf coal, were observed in a nitrogen/carbon dioxide atmosphere both at $930^{\circ} \mathrm{F}\left(500^{\circ} \mathrm{C}\right)$ and low steam and at $1110^{\circ} \mathrm{F}$ $\left(600^{\circ} \mathrm{C}\right)$ and high steam. Figure 8 shows the condensable yields minus the solid fines that were collected with the liquids. The trends in Figure 8 indicate that the steam substantially improved the condensable yield at $1110^{\circ} \mathrm{F}\left(600^{\circ} \mathrm{C}\right)$, but not at $930^{\circ}$ or $1020^{\circ} \mathrm{F}\left(500^{\circ}\right.$ or $\left.550^{\circ} \mathrm{C}\right)$. The benefit of steam at $1110^{\circ} \mathrm{F}\left(600^{\circ} \mathrm{C}\right)$ is further borne out by the results for carbon dioxide/steam and nitrogen/carbon dioxide/oxygen/steam atmospheres presented later in this report. At low levels of steam, an increase in temperature between $930^{\circ}$ and $1110^{\circ} \mathrm{F}\left(500^{\circ}\right.$ and $\left.600^{\circ} \mathrm{C}\right)$ substantially reduced liquid 
yield in the nitrogen/carbon dioxide gas atmosphere (Figure 8), although the very low level of only $0.23 \%$ of maf coal observed at $1110^{\circ} \mathrm{F}\left(600^{\circ} \mathrm{C}\right)$ and $20.6 \%$ steam may be subject to question since it is not consistent with later results for a nitrogen/carbon dioxide/oxygen atmosphere.

The amount of fines carryover in Figure 9 varied inversely with temperature because of the decrease in particle separation efficiency occurring along with a reduction in temperature and gas velocity. On the average, the fines accounted for $84 \%$ of the material in the condensable heavy residue category (bp $\left.>1800^{\circ} \mathrm{F}\left[980^{\circ} \mathrm{C}\right]\right)$. The fines were separated by THF (tetrahydrofuran) extraction and analyzed for particle size to give the distributions shown in Figures 10a-f. For the six cases shown, the mean particle size decreased as temperature and steam level were increased. The variance in the distributions remained similar on the log scale shown in Figures 10a-f, meaning that it increased in terms of actual size as the mean size increased. One bimodal distribution was observed, possibly due to an upset condition.

Condensates from no-steam and high-steam tests at $1100^{\circ} \mathrm{F}\left(600^{\circ} \mathrm{C}\right)$ were analyzed in detail to determine differences due to processing conditions. The condensates contained at least 347 individual compounds as determined by GC/MS. However, 64 identified compounds constituted 55 to $60 \mathrm{wt} \%$ of the total condensate. Phenolics were most prevalent, accounting for 28 and $42 \mathrm{wt} \%$ of the no- and high-steam condensates, respectively. Normal alkanes and normal alkenes with an olefin group, with carbon numbers of $\mathrm{C} 7$ to $\mathrm{C} 30$, were observed in substantial amounts of 23 and $15 \mathrm{wt} \%$, respectively. Unidentified components, mainly substituted phenolics and aromatics, made up the remaining 283 chromatographic peaks.

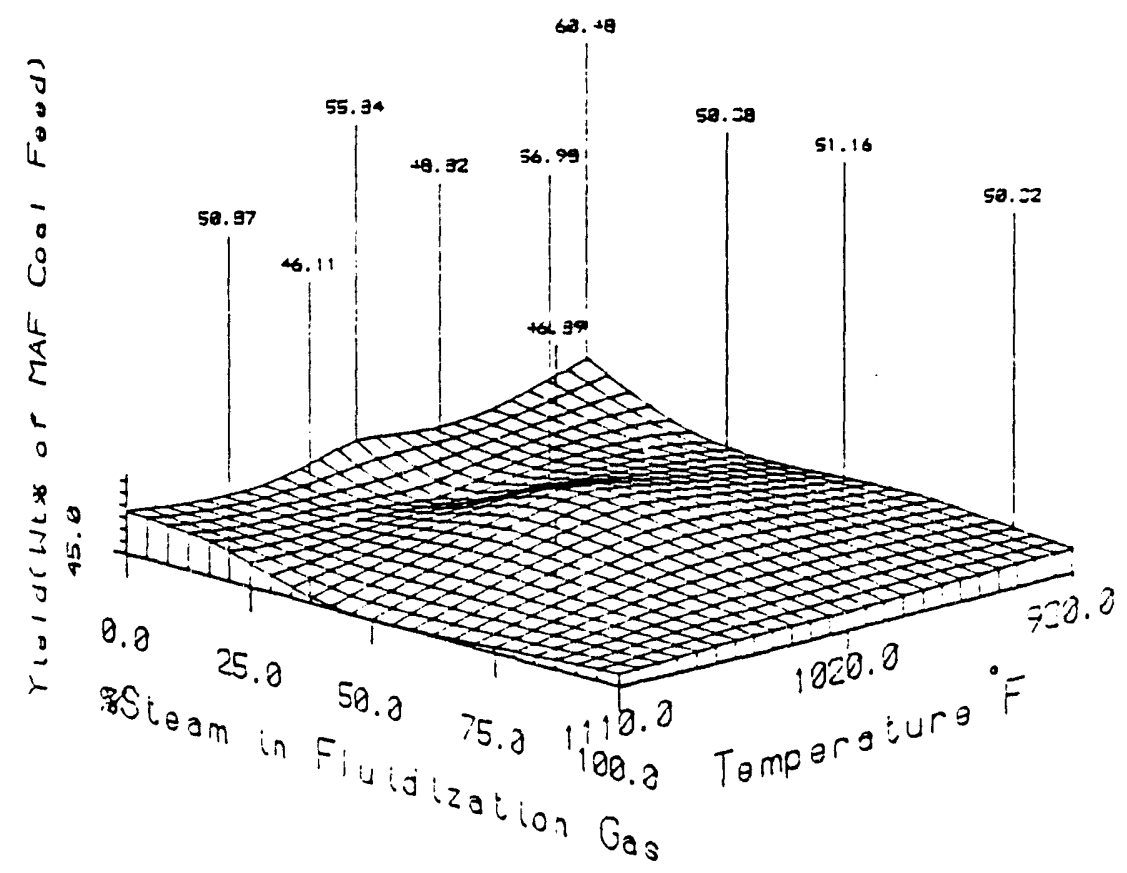

Figure 3. The effect of temperature and steam/nitrogen partial pressure on Wyodak char yields. 


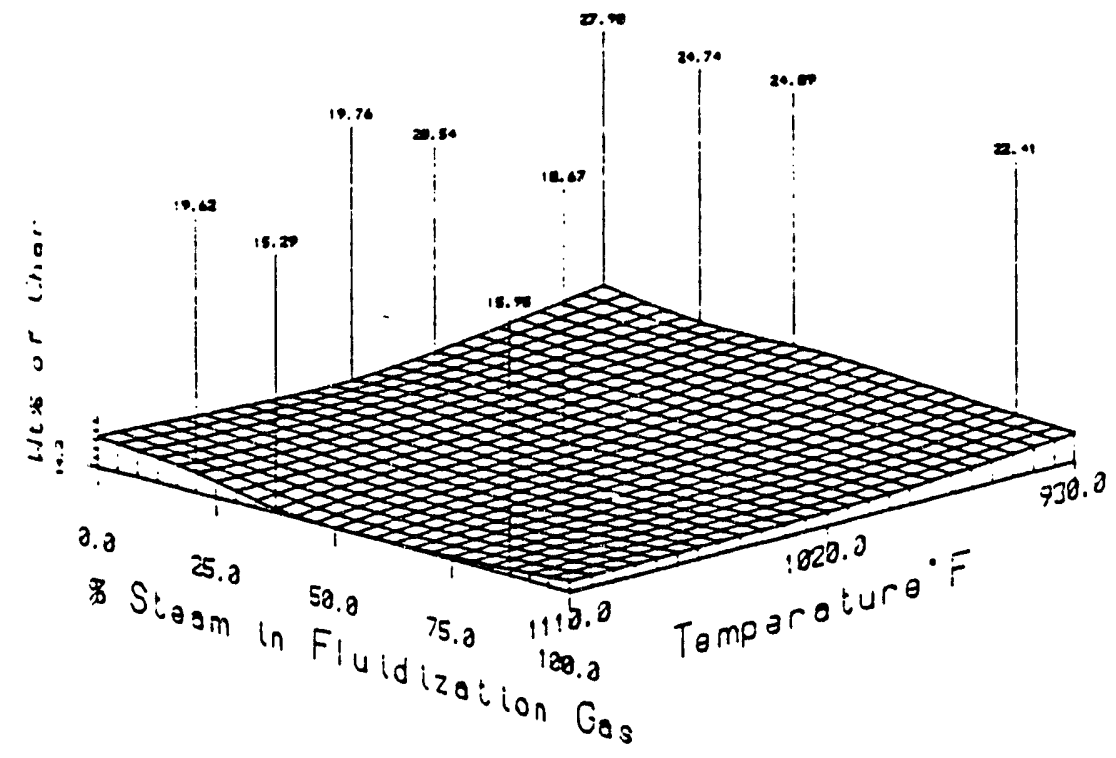

Figure 4. The effect of temperature and steam/nitrogen partial pressure on Wyodak char volatile content.

\section{TABLE 6}

Proximate Analysis of Wyodak Coal and Char

\begin{tabular}{|c|c|c|c|c|c|c|c|}
\hline \multirow[b]{2}{*}{ Wyodak Coal } & \multicolumn{3}{|c|}{ Coal } & \multicolumn{2}{|c|}{$\begin{array}{c}\text { Char } \\
8,12,20,25 \text { momh }\end{array}$} & \multicolumn{2}{|c|}{$\begin{array}{c}\text { Cher } \\
26,60,-60 \text { Mosh }\end{array}$} \\
\hline & $\begin{array}{l}\text { As-Mined } \\
\text { (9) }\end{array}$ & $\begin{array}{l}\text { Air.Dried } \\
(\%)\end{array}$ & $\begin{array}{l}\text { Moist Ash } \\
\text { Froe }(\%)\end{array}$ & AtDet. (\%) & $\begin{array}{l}\text { Moist Aab } \\
\text { Frow (\$s) }\end{array}$ & As-Det. $(\tilde{f})$ & $\begin{array}{c}\text { Moist Ash } \\
\text { Free (T) }\end{array}$ \\
\hline \multicolumn{8}{|c|}{ Proximate Analysis } \\
\hline Moisture & 30.68 & 22.10 & N/A & $12.28^{\circ}$ & $N / A$ & 7.89 & NiA \\
\hline Volatile Matter & 33.66 & 34.06 & 46.40 & 9.60 & 11.93 & 11.34 & 13.66 \\
\hline $\begin{array}{l}\text { Fixod Carbon } \\
\text { (IND) }\end{array}$ & 30.73 & 39.32 & 63.60 & 70.13 & 88.06 & 72.27 & 86.43 \\
\hline Ash & 4.93 & 4.61 & $\mathbf{N} / \mathrm{A}$ & 8.07 & N/A & 8.48 & N/A \\
\hline
\end{tabular}

- Early torts gave abnormally high moisture contents. 


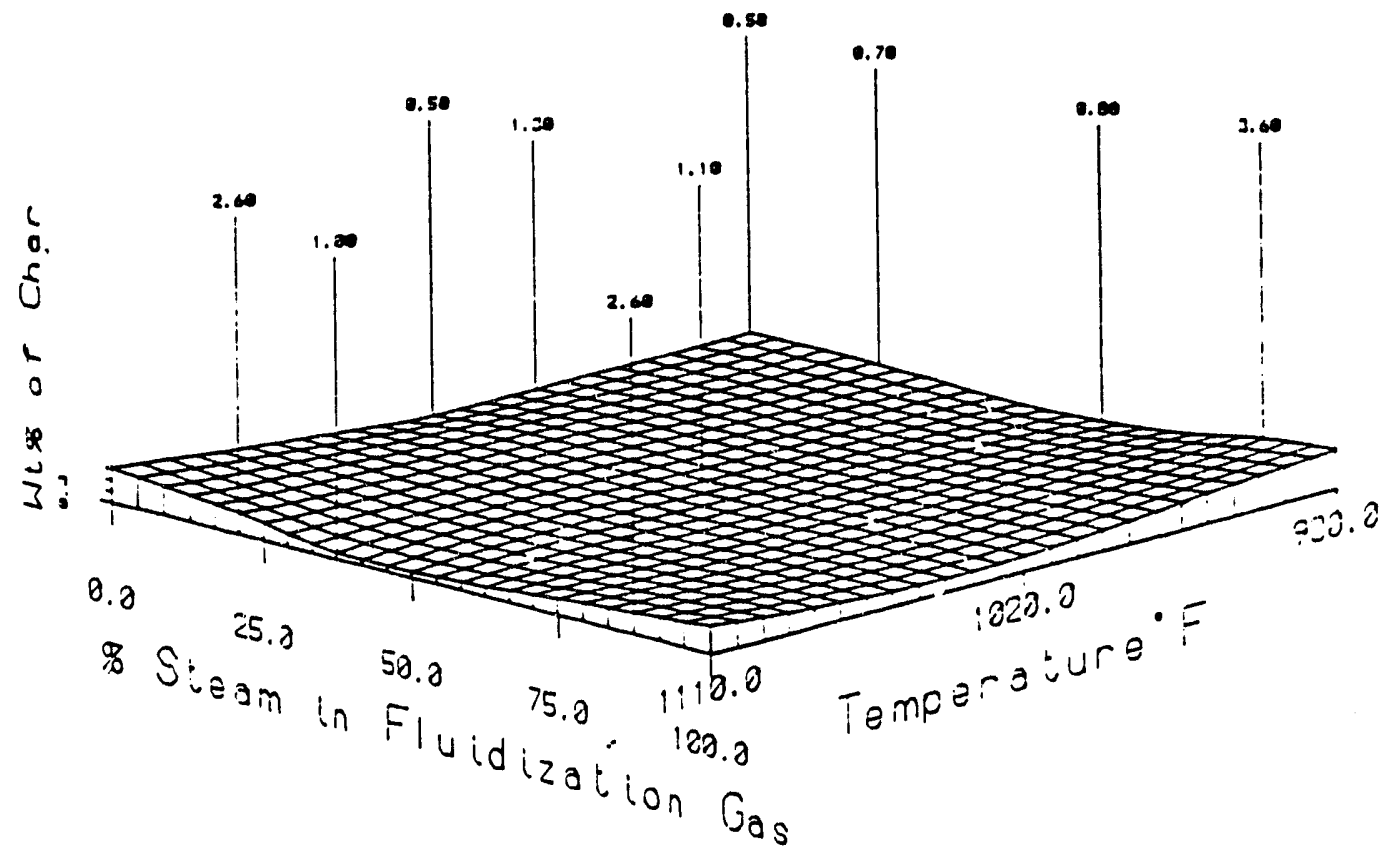

Figure 5. The effect of temperature and steam/nitrogen partial pressure on Wyodak char moisture content.

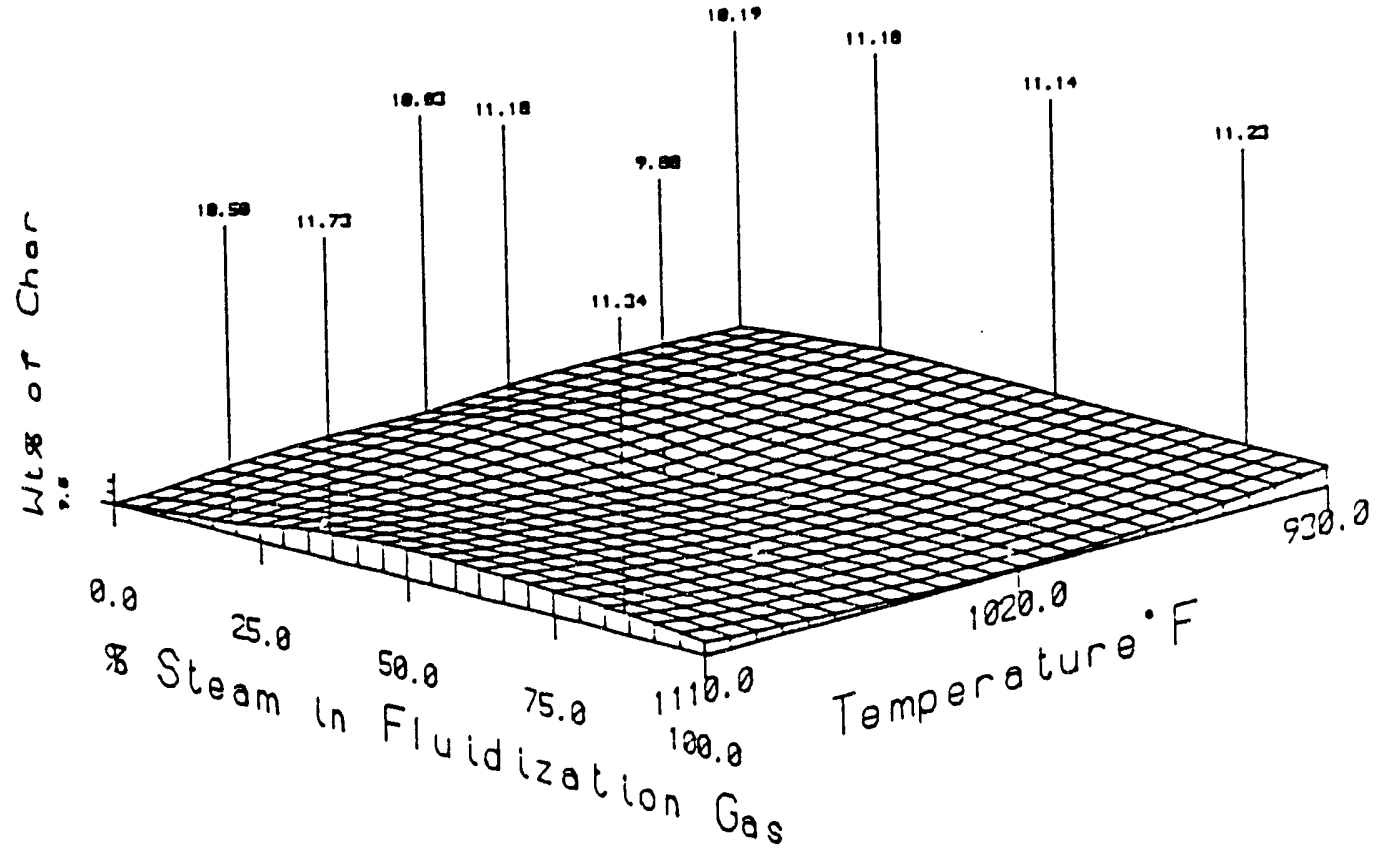

Figure 6. The effect of temperature and steam/nitrogen partial pressure on Wyodak char ash content. 


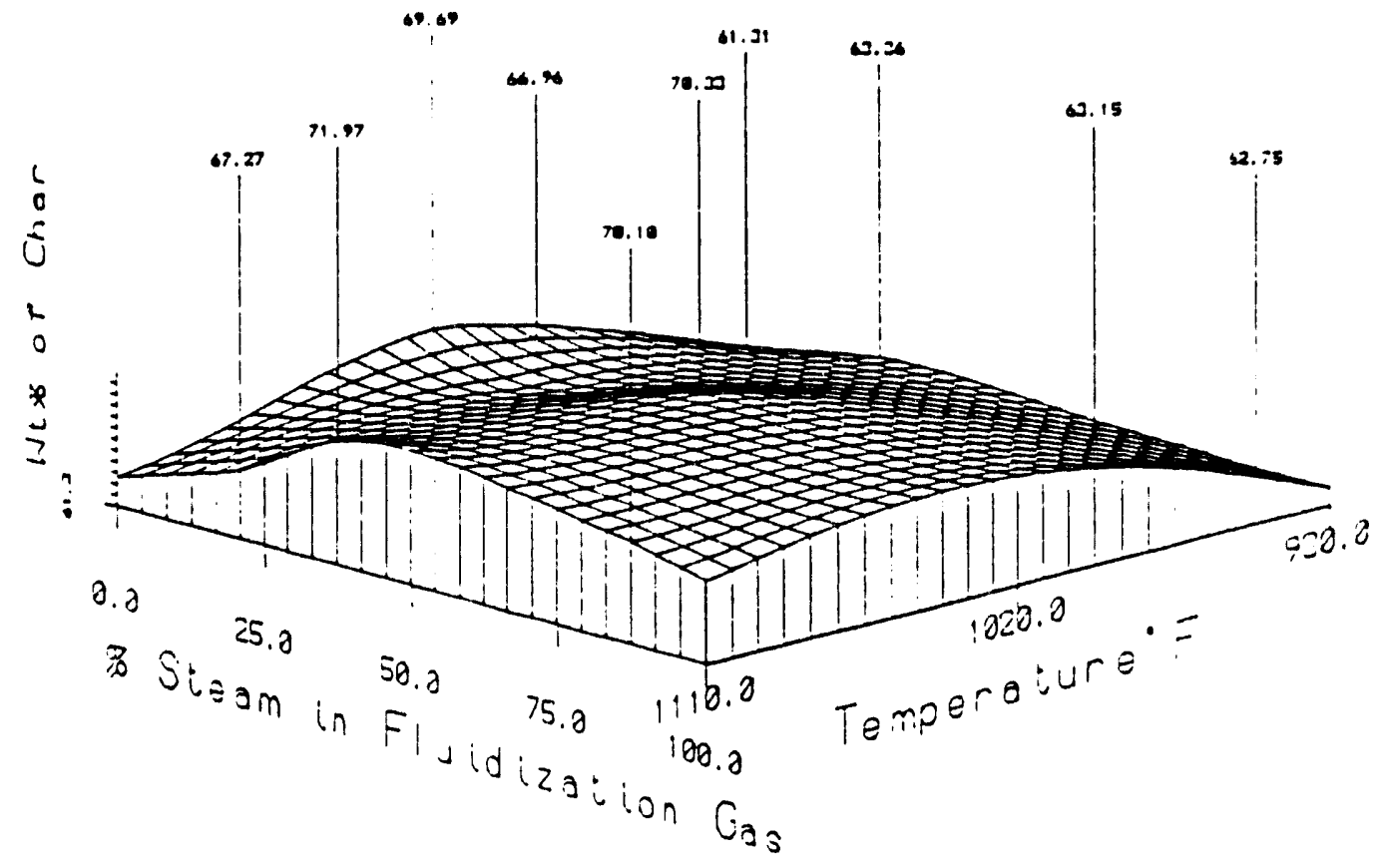

Figure 7. The effect of temperature and steam/nitrogen partial pressure on Wyodak char fixed-carbon content.

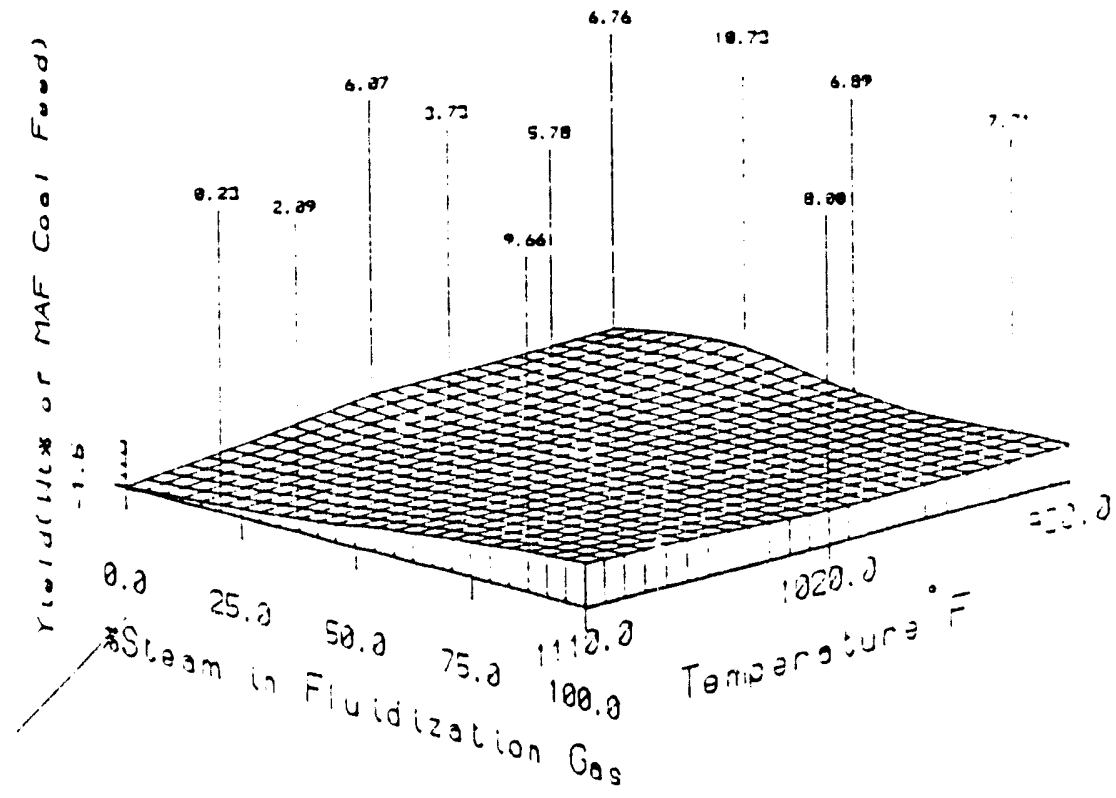

Figure 8. The effect of temperature and steam/nitrogen partial pressure on Wyodak condensable yields. 
Steam increased the total yield of condensables from $1.29 \%$ to $9.54 \%$ and shifted the boiling point distribution slightly toward the heavier compounds (Table 7). The amount of phenols and cresols increased by four- to sixfold. The NMR spectra for the distillate produced in the high-steam case (Figure 11) indicates a complex mixture of compounds. The broadening of the aromatic proton region at 6.5 to $8.5 \mathrm{ppm}$ indicates the presence of large aromatic ring systems. The greater complexity between 2.3 and $3.0 \mathrm{ppm}$ indicates that the aliphatic alkyl side chains ars more complex. The elemental data in Table 8 reflects the low hydrogen content of the $W$ yodak distillate and indicates high aromaticity.

The characterization of condensables as small amounts of numerous ccmpounds indicates the need for upgrading in order to produce marketable products. Additional reaction time in a hydrogen-containing atmosphere, either during mild gasification or during subsequent processing at temperatures over $900^{\circ} \mathrm{F}\left(480^{\circ} \mathrm{C}\right)$, is required to dealkylate aromatics, thereby yielding higher concentrations of the more stable species of benzene, phenol, and naphthalene. The extra processing would also tend to decompose alkanes towards methane gas, consuming hydrogen, and could possibly cause polymerization.

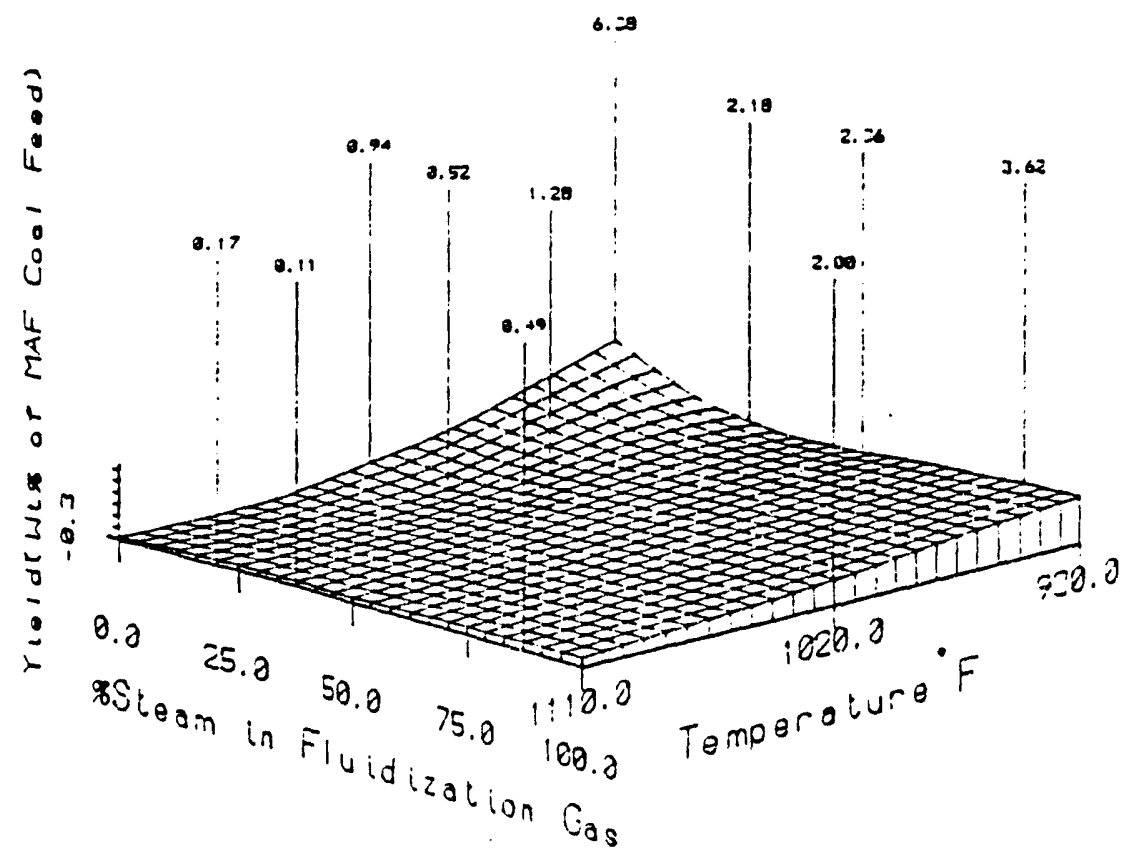

Figure 9. The effect of temperature and steam/nitrogen partial pressure on Wyodak condensable fines yields. 


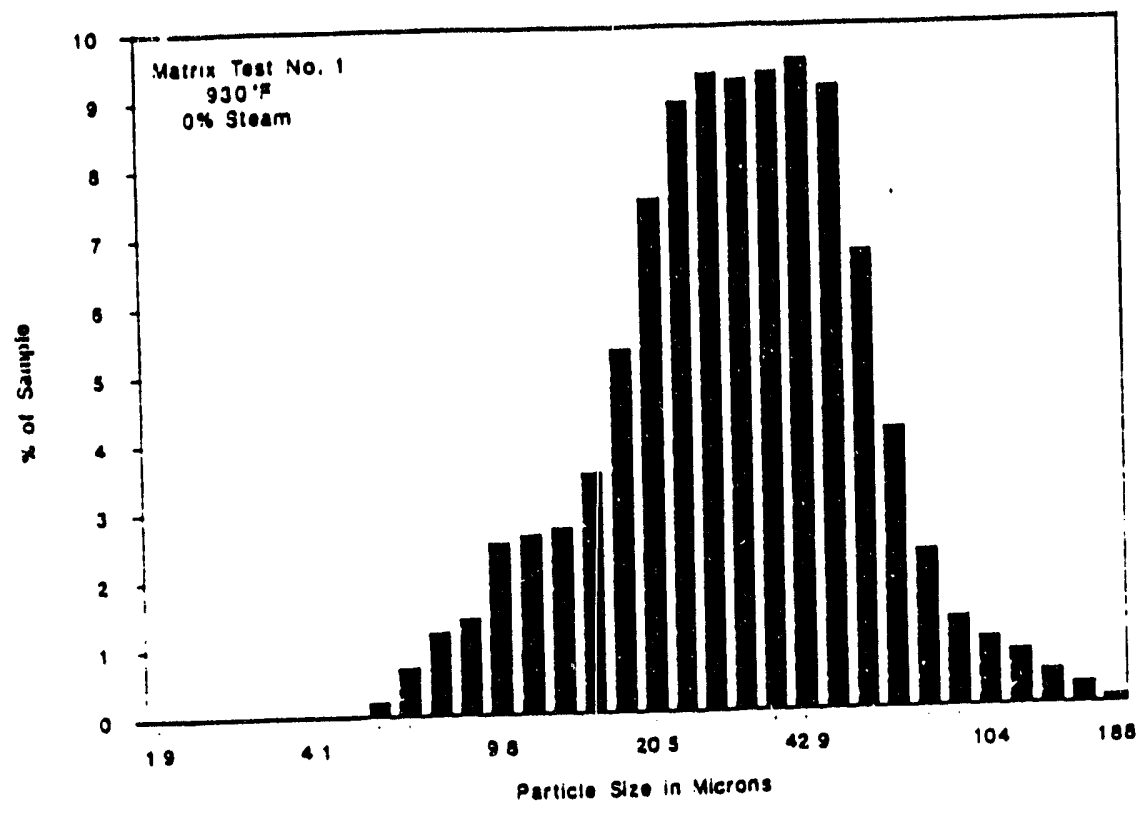

(a)

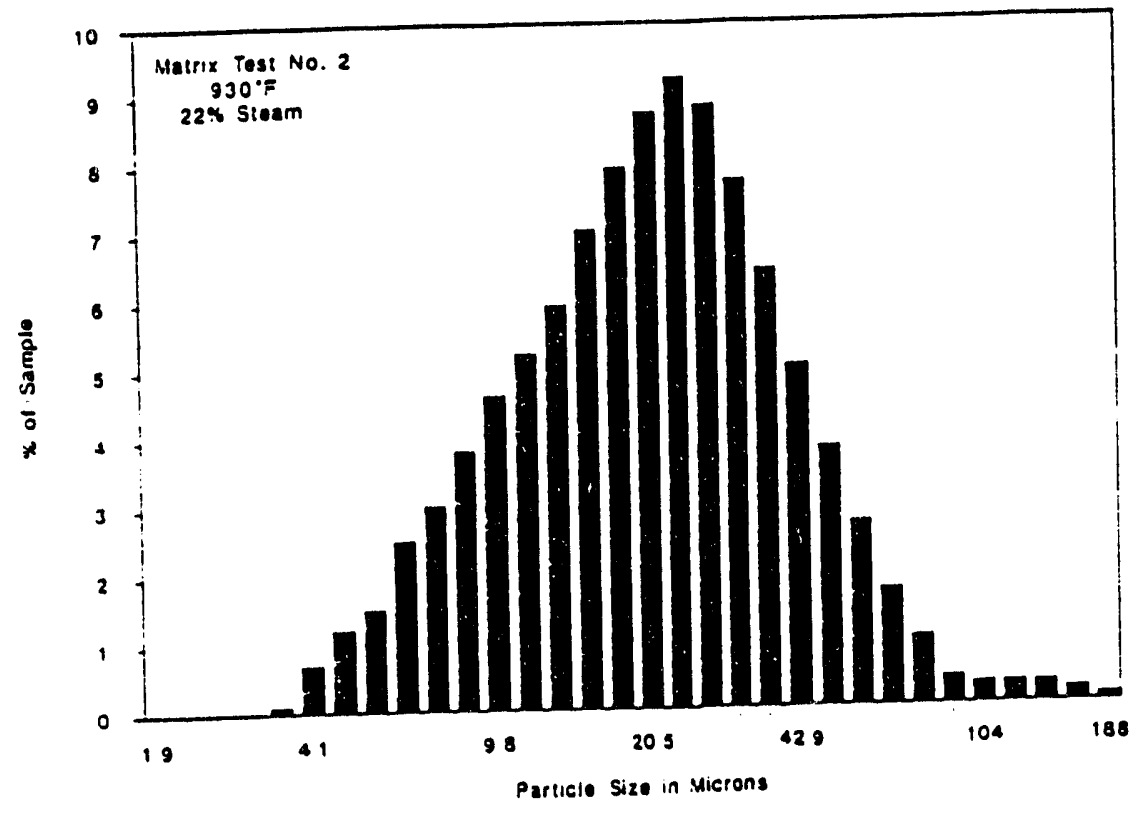

(b)

Figure 10. Wyodak char fines particle-size distribution. 


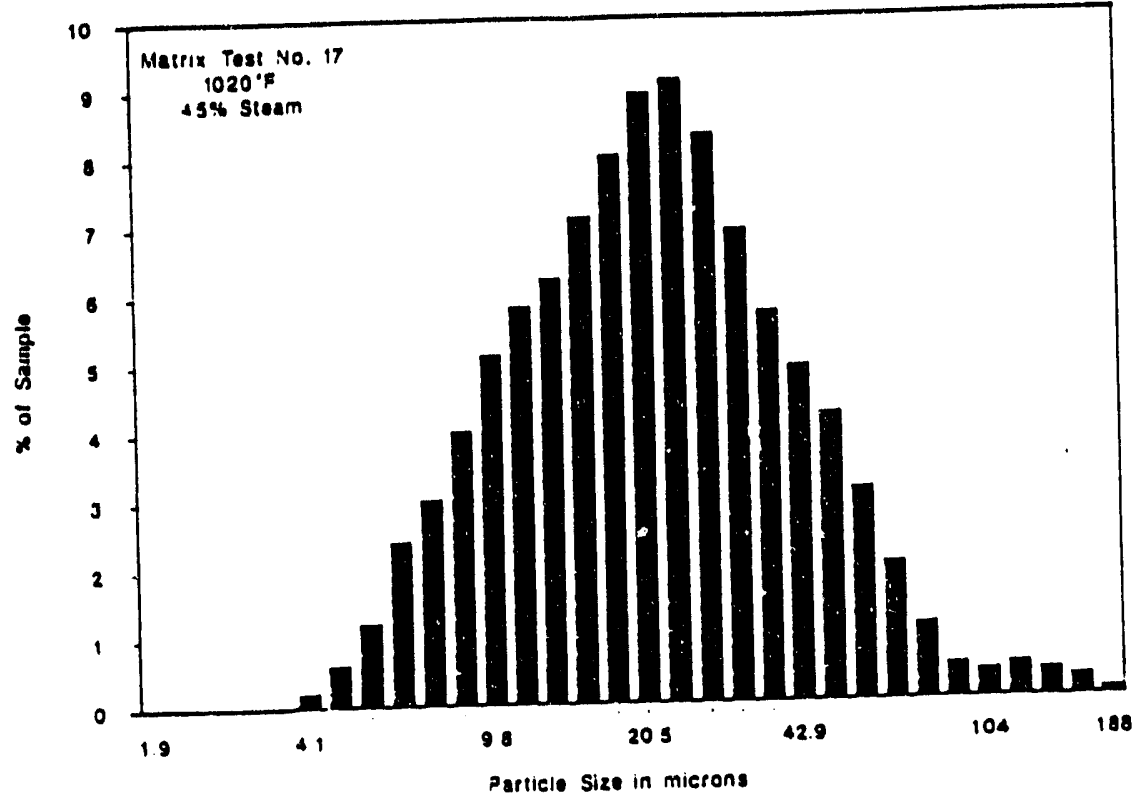

(c)

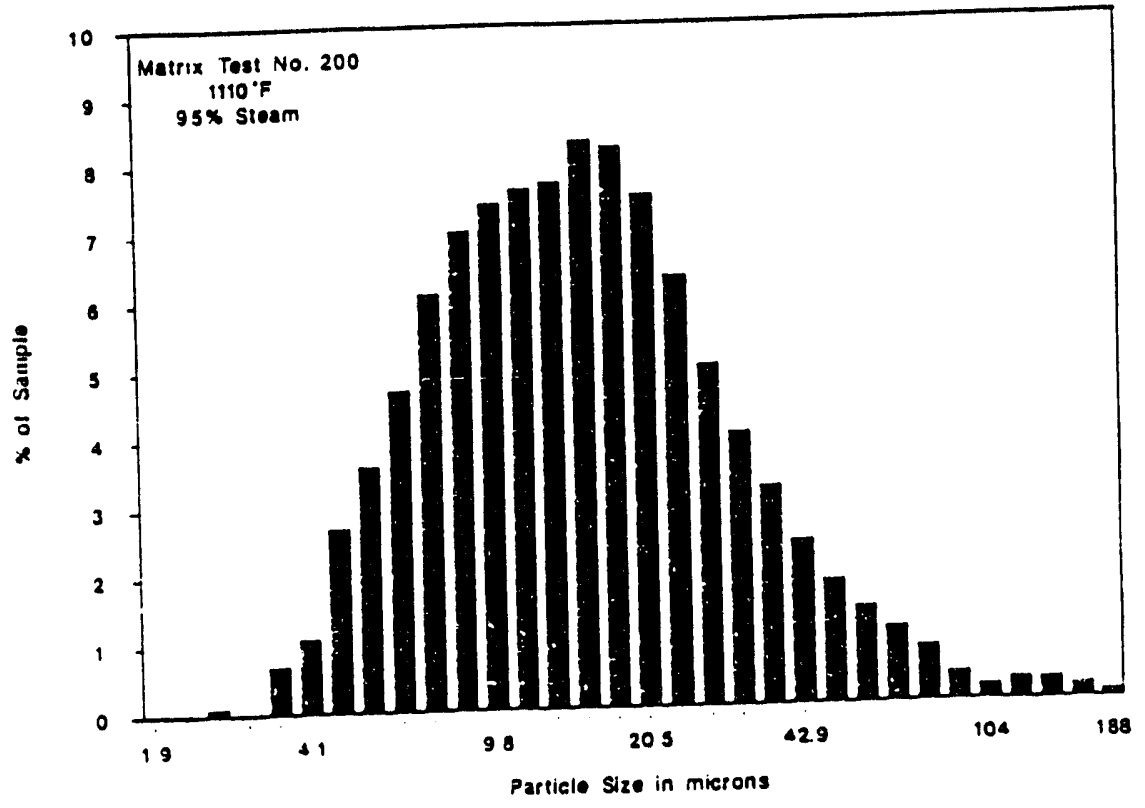

(d)

Figure 10. Wyodak char fines particle-size distribution. 


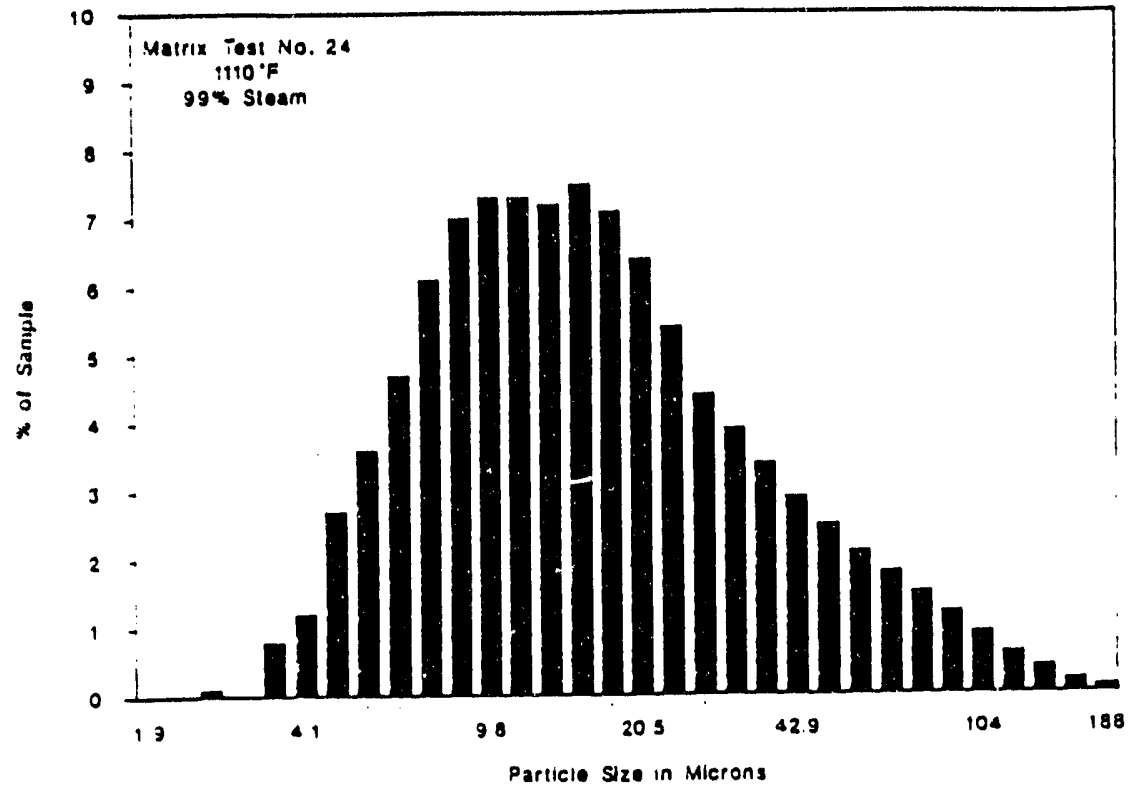

(e)

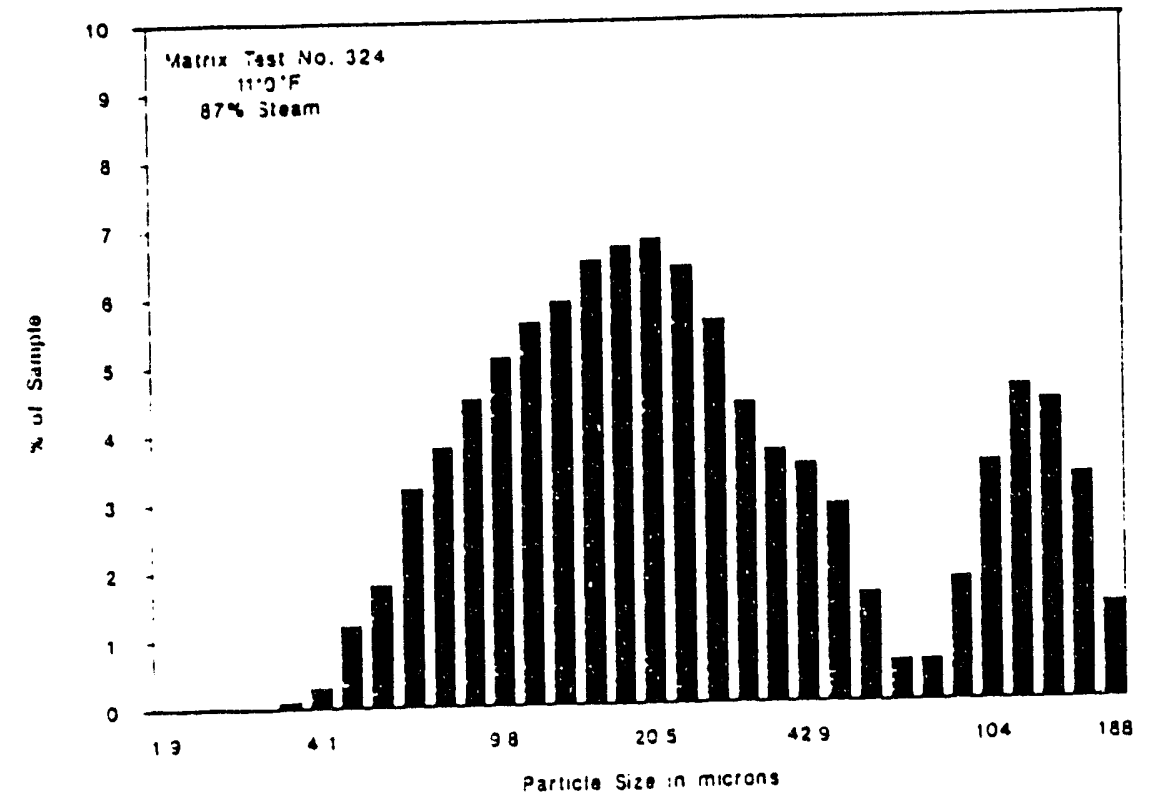

(f)

Figure 10. Wyodak char fines particle-size distribution. 
TABLE 7

Wyodak Condensable Yields Breakdown

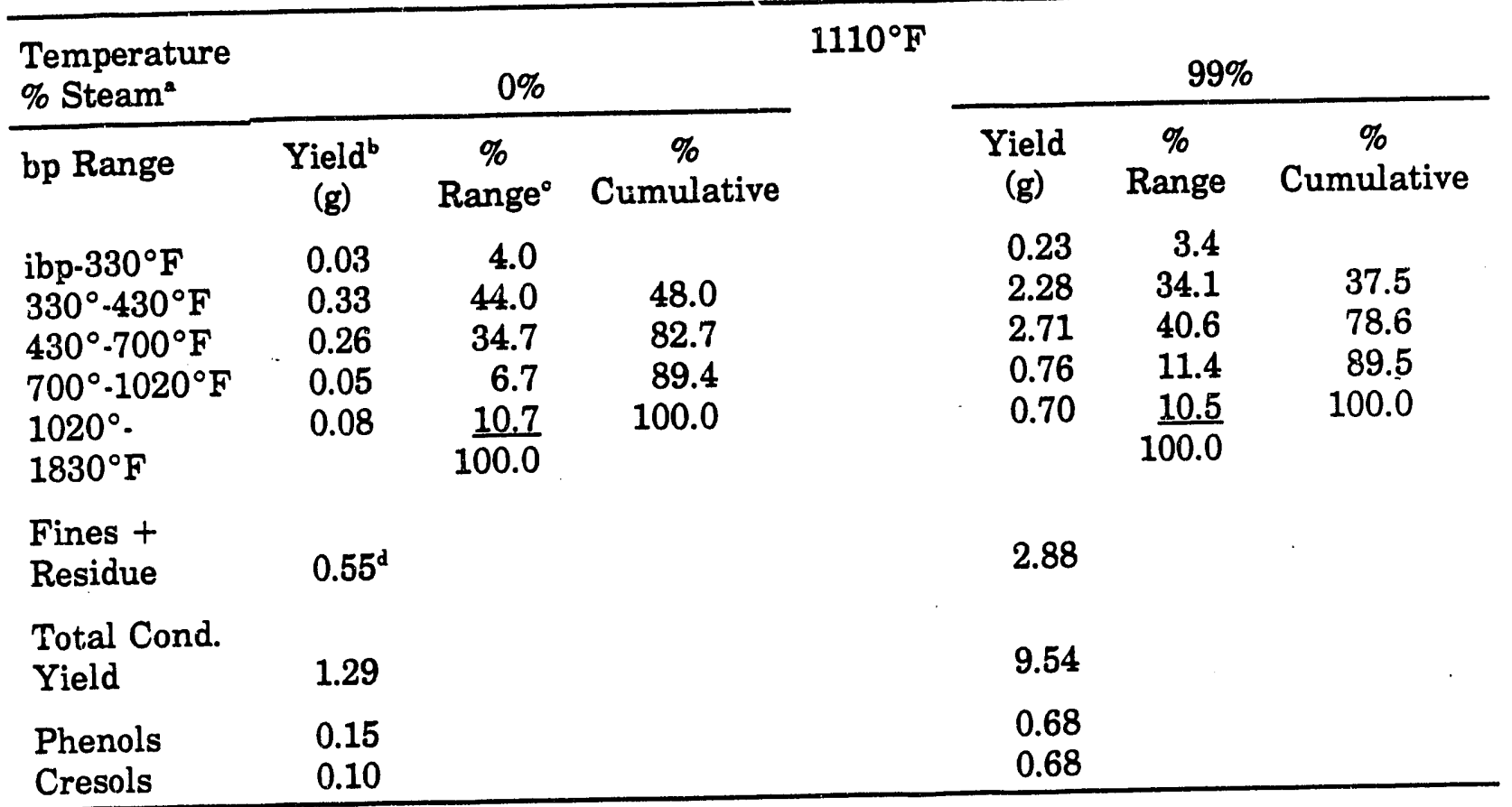

- Remainder of fluidization gas is $\mathrm{CO}_{2}$.

b Percent of total liquids.

- Percent of condensable yield in boiling point range.

d Yield estimates based on THF insoluble tests done on points at similar run conditions.

\subsection{The Effect of Temperature and Steam/Nitrogen Partial Pressure on Wyodak Water Yields}

Water yields were negligible over the range of conditions tested (Figure 12). One point (11.2\%) appeared to be an anomaly.

\subsection{The Effect of Temperature and Steam/Nitrogen Partial Pressure on Wyodak Gas Production}

The effects of temperature and steam partial pressure on total gas production in the range of $30.7 \%$ to $51.2 \%$ of maf coal are shown in Figure 13. The highest gas production was observed at $1110^{\circ} \mathrm{F}\left(600^{\circ} \mathrm{C}\right)$ at low to intermediate steam partial pressures. The effect of steam partial pressure varied with temperature: at $930^{\circ} \mathrm{F}\left(500^{\circ} \mathrm{C}\right)$, high steam partial pressures increased gas production, while at $1110^{\circ} \mathrm{F}\left(600^{\circ} \mathrm{C}\right)$, high steam pressures decreased the gas production slightly. An increase in temperature increased gas production over the entire range of steam partial pressures. These trends are the inverse of those observed for condensables. 


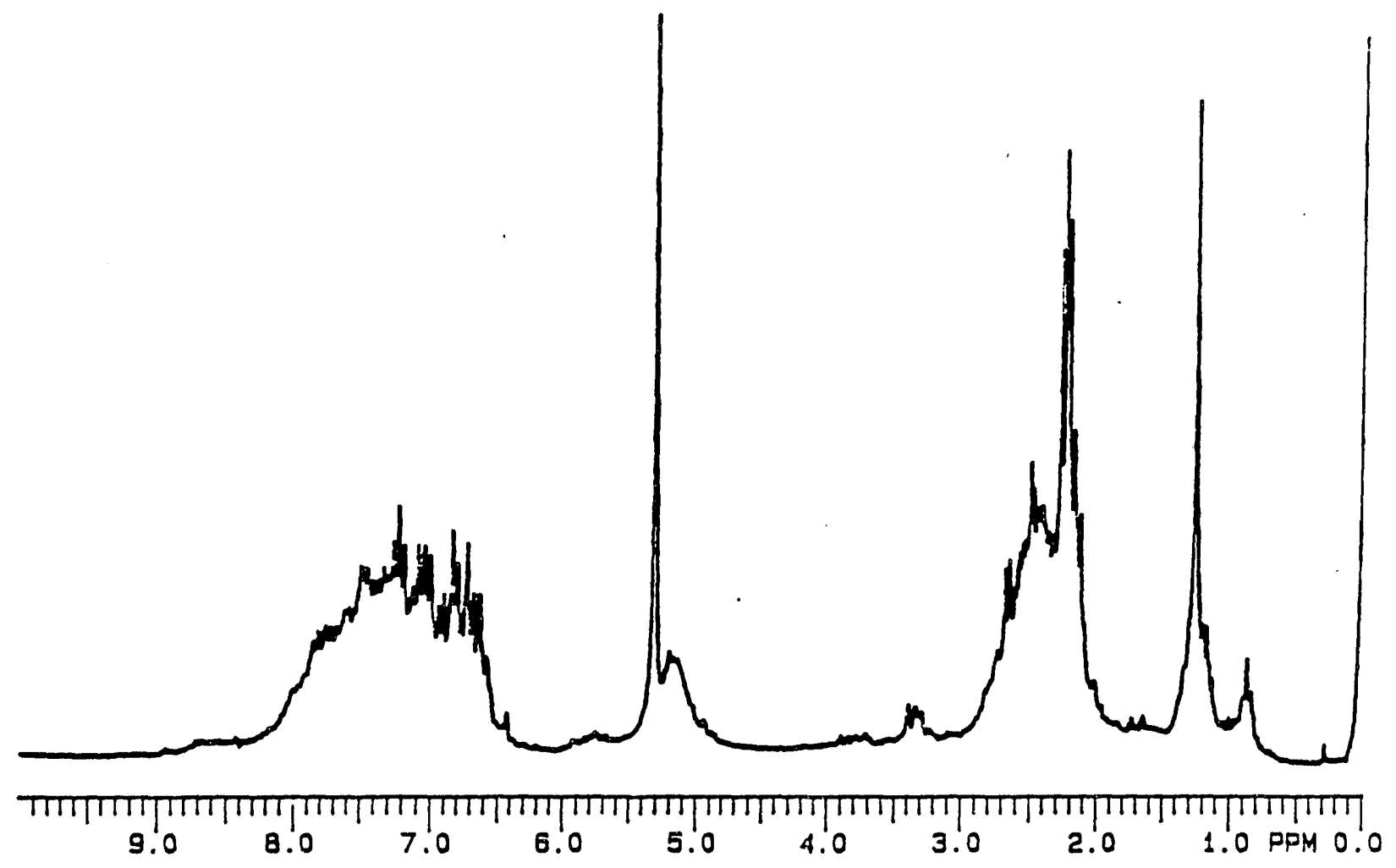

Figure 11. Proton NMR spectrum of condensables from Wyodak coal.

TABLE 8

Wyodak Condensable Elemental Composition (wt\%)

\begin{tabular}{lr}
\hline Carbon & 79.93 \\
Hydrogen & 6.87 \\
Nitrogen & 0.57 \\
Sulfur & 0.54 \\
Other diff. & 11.54 \\
Ash (by TGA) & 0.64 \\
\hline
\end{tabular}




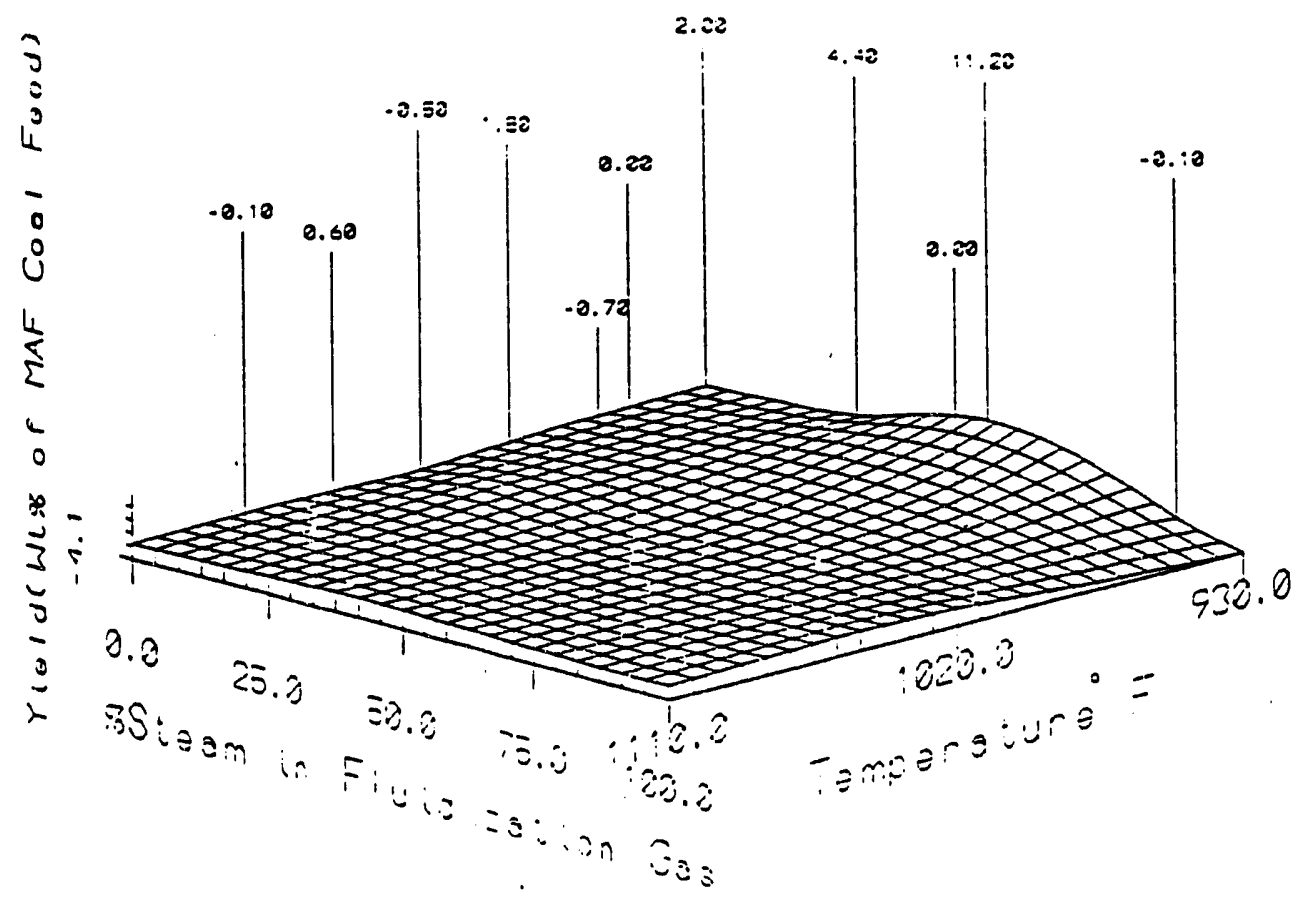

Figure 12. The effect of temperature and steam/nitrogen partial pressure on Wyodak water yields.

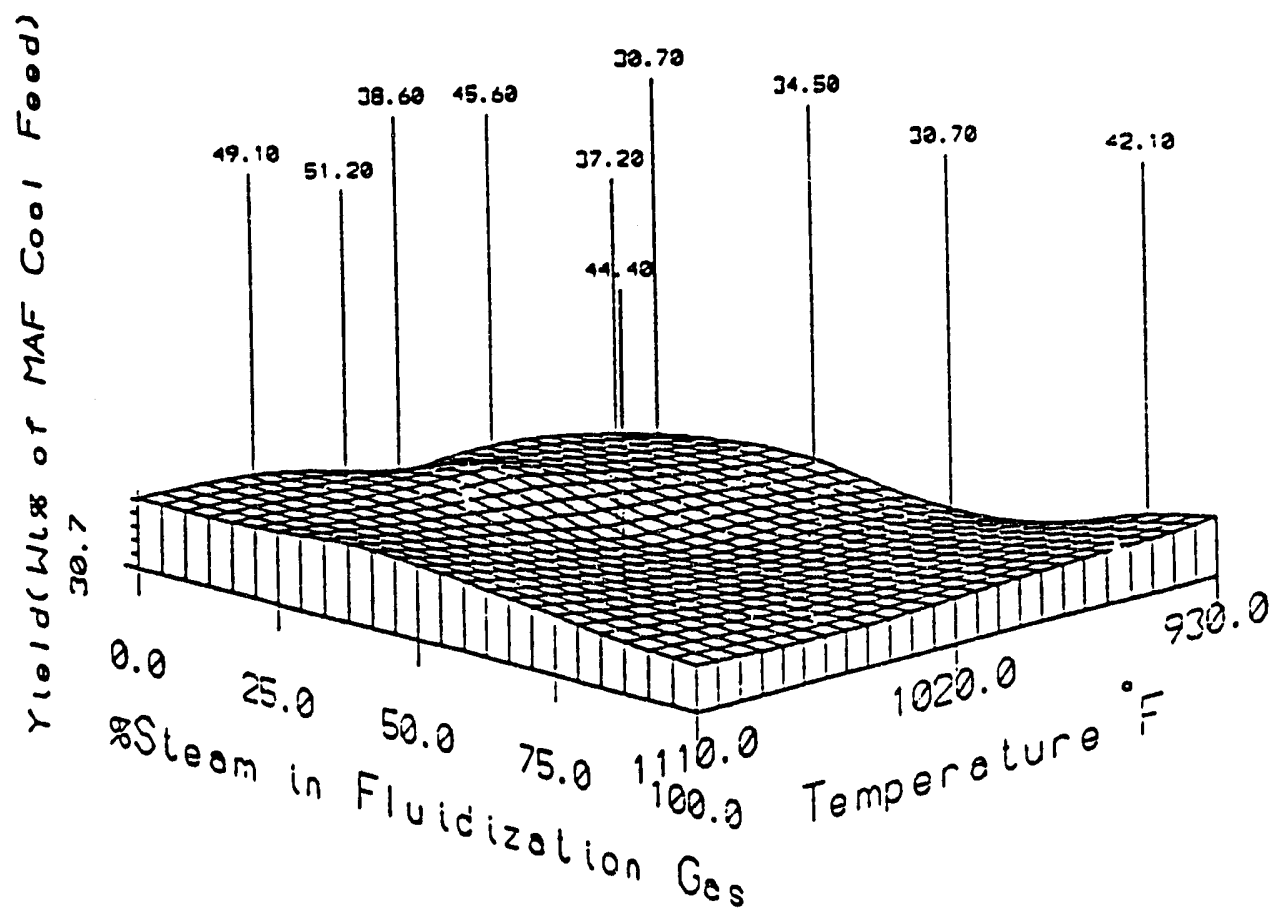

Figure 13. The effect of temperature and steam/nitrogen partial pressure on Wyodak gas yields. 
As seen in Figure 14, the major constituent of the gas was $\mathrm{CO}_{2}$, ranging from $29.5 \%$ to $43.8 \%$ of the maf coal. $\mathrm{H}_{2}$ production, in the range of $0 \%$ to $1.3 \%$, increased along with temperature and the partial pressures of steam (Figure 15) due to the increase in steam gasification and the shift reaction. $\mathrm{CH}_{4}$ production of $1.0 \%$ to $3.4 \%$ varied somewhat randomly over the test conditions (Figure 16 ) as did $\mathrm{CO}$, between $1.5 \%$ and $3.0 \%$

(Figure 17). $\mathrm{H}_{2} \mathrm{~S}$ was detected in only two samples and was near the lower detection limit of the gas chromatograph.

\subsection{The Effect of Steam in Three Gas Atmospheres on Wyodak Product Yields at $1110^{\circ} \mathrm{F}\left(600^{\circ} \mathrm{C}\right)$}

The effects of steam and three gas atmospheres on char yields are shown in Figure 18. $\mathrm{N}_{2}, \mathrm{CO}_{2}$, and $89 \% \mathrm{~N}_{2} / 9 \% \mathrm{CO}_{2} / 2 \% \mathrm{O}_{2}$ were the gases tested. The $89 \% \mathrm{~N}_{2} / 9 \%$ $\mathrm{CO}_{2} / 2 \% \mathrm{O}_{2}$ gas was used to represent flue gas that would be produced by the combustion of carbon with $12 \%$ excess air. The yields observed were relatively constant, with the standard deviation of only $2 \%$ representing essentially random error. There was a slight difference in the volatile content of the chars, with the higher volatile content being observed in $\mathrm{N}_{2}$ (Figure 19).

At $1110^{\circ} \mathrm{F}\left(600^{\circ} \mathrm{C}\right)$, condensable yields increased with steam partial pressure for each of the three gas atmospheres (Figure 20). At lower temperatures of $1020^{\circ}$ and $930^{\circ} \mathrm{F}$ $\left(550^{\circ}\right.$ and $500^{\circ} \mathrm{C}$ ) in $\mathrm{N}_{2} / \mathrm{CO}_{2}$, there was no discernable trend, as shown previously in Figure 9. Water yields, shown in Figure 21, varied randomly over the range of steam partial pressures, and the variation between the three gas atmospheres is not believed to be significant.

The total gas yield declined slightly as the partial pressure of stem increased, as indicated in Figure 22. Once again, the largest component of the gas was $\mathrm{CO}_{2}$. Gas yields were higher in either $\mathrm{N}_{2}$ or $\mathrm{CO}_{2}$ than in the simulated flue gas with excess air.

\subsection{The Effect of Temperature and Steam/Carbon Dioxide Partial Pressure on Wyodak Product Yields}

There was not a definite trend for char production at the various steam partial pressures. Yields varied from $44.9 \%$ to $50.1 \%$, as shown in Figure 23 . There was a slight change in char volatile content with increasing steam partial pressure, as shown in Figure 24. These ranged from $13 \%$ to $16 \%$ at $1110^{\circ} \mathrm{F}\left(600^{\circ} \mathrm{C}\right)$. Char moisture contents, ash contents, and fixed carbon all followed similar trends to those produced with $\mathrm{N}_{2} /$ steam (Figure 24).

Total condensable yields (Figure 23) increased with steam partial pressure. Similar trends were seen under the $\mathrm{N}_{2}$ atmosphere at $1110^{\circ} \mathrm{F}\left(600^{\circ} \mathrm{C}\right)$. It is not apparent whether $\mathrm{CO}_{2}$ or $\mathrm{N}_{2}$ has an effect on condensable production due to the scatter of the data.

Water yields (Figure 23) were unaffected by steam partial pressure, while the gas yields (Figure 23) decreased slightly with steam partial pressure. Similar trends were seen for $\mathrm{CO}_{2}$ production (Figure 25) which is the majority of the product gas. $\mathrm{H}_{2}, \mathrm{CH}_{4}$, $\mathrm{CO}$, and $\mathrm{H}_{2} \mathrm{~S}$ production were all stable for the various conditions observed. These ranges were all similar to those observed for the $\mathrm{N}_{2}$ /steam atmosphere. 


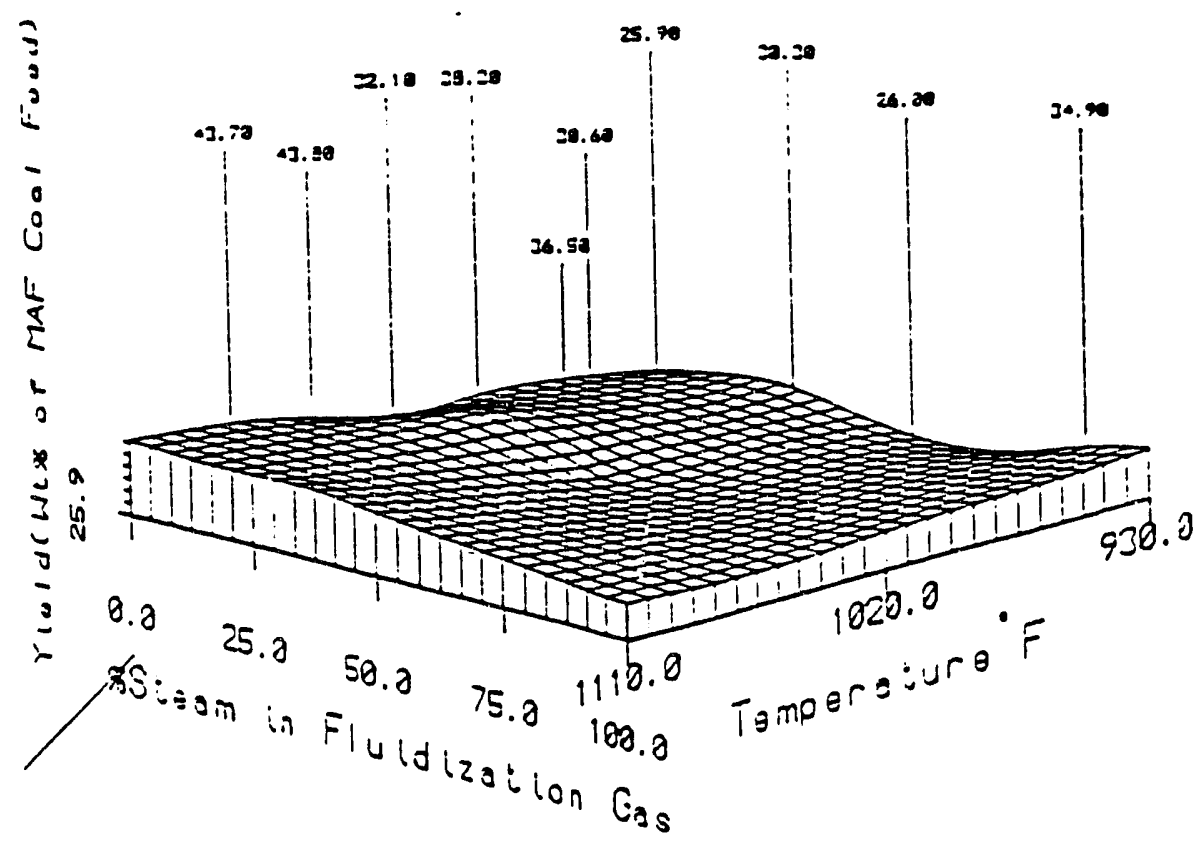

Figure 14. The effect of temperature and steam/nitrogen partial pressure on Wyodak $\mathrm{CO}_{2}$ yields.

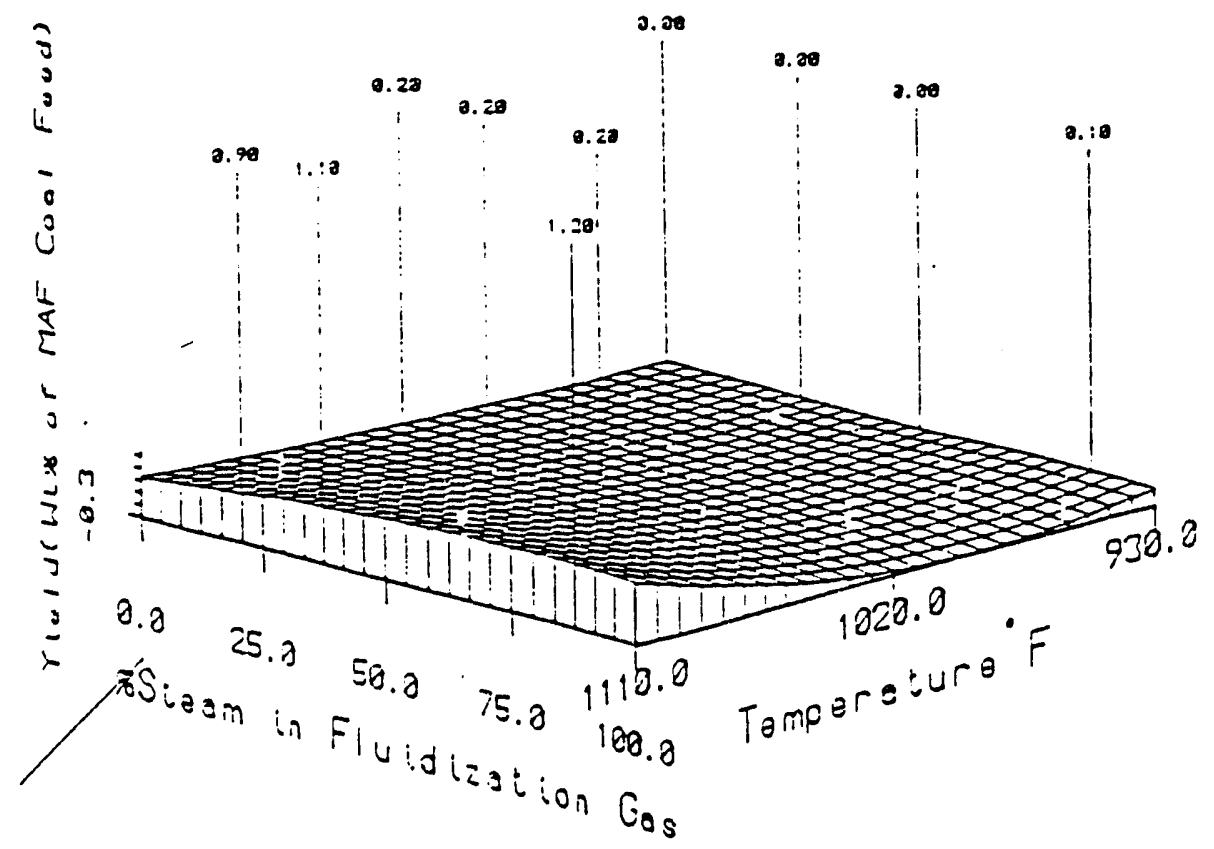

Figure 15. The effect of temperature and steam/nitrogen partial pressure on Wyodak $\mathrm{H}_{2}$ yields. 


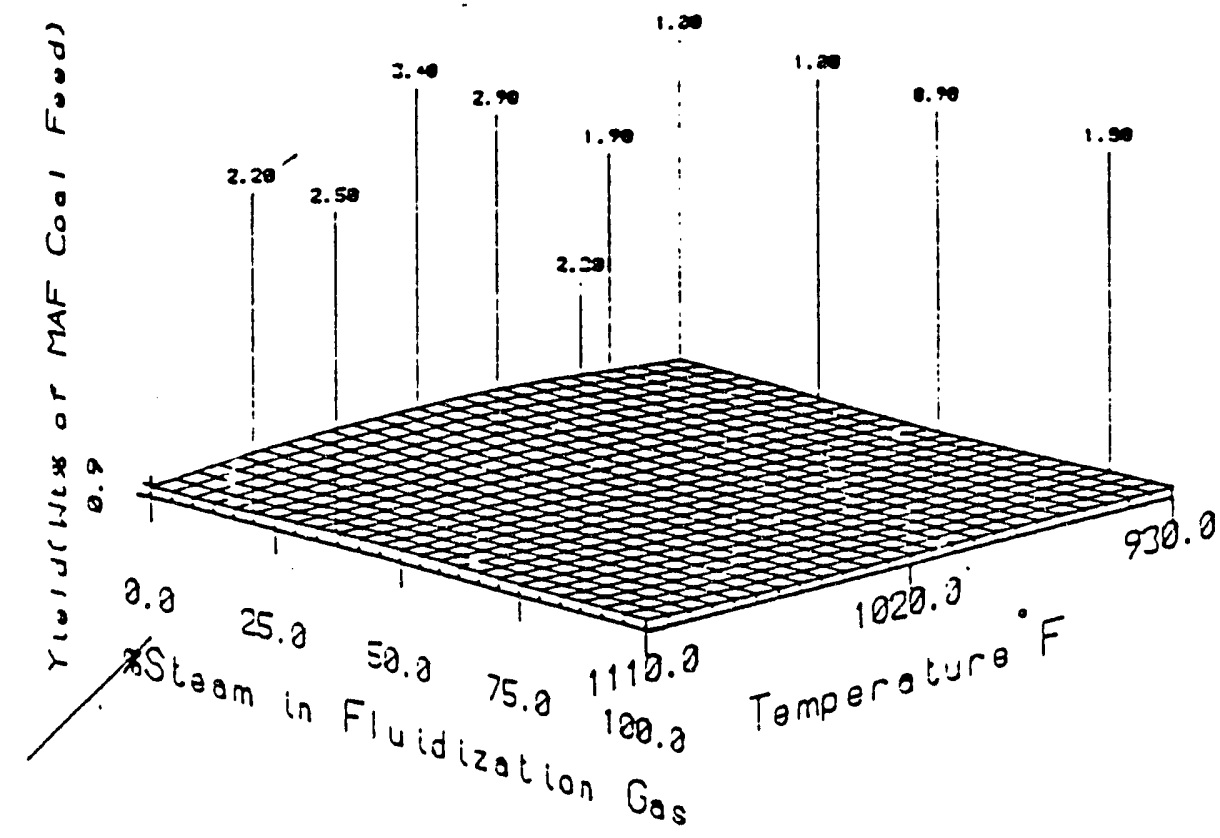

Figure 16. The effect of temperature and steam/nitrogen partial pressure on Wyodak $\mathrm{CH}_{4}$ yields.

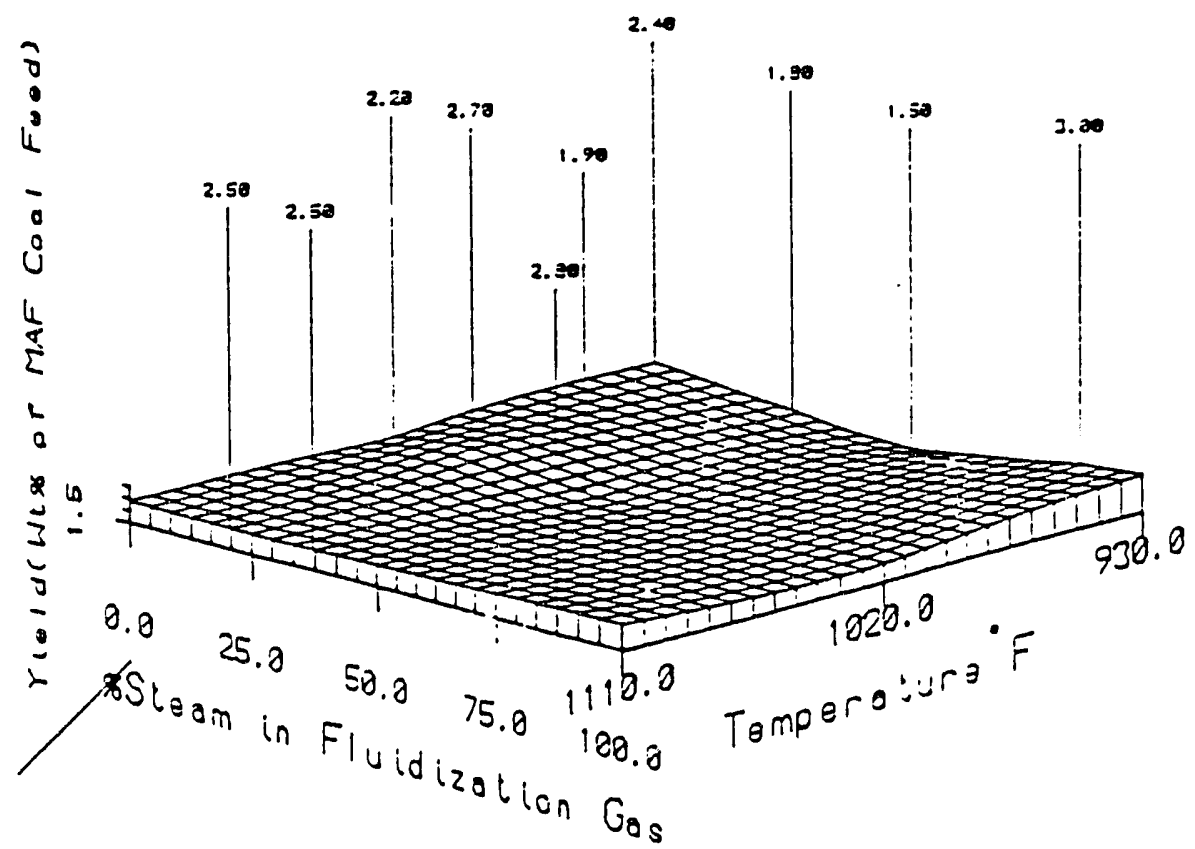

Figure 17. The effect of temperature and steam/nitrogen partial pressure on Wyodak $\mathrm{CO}$ yields. 


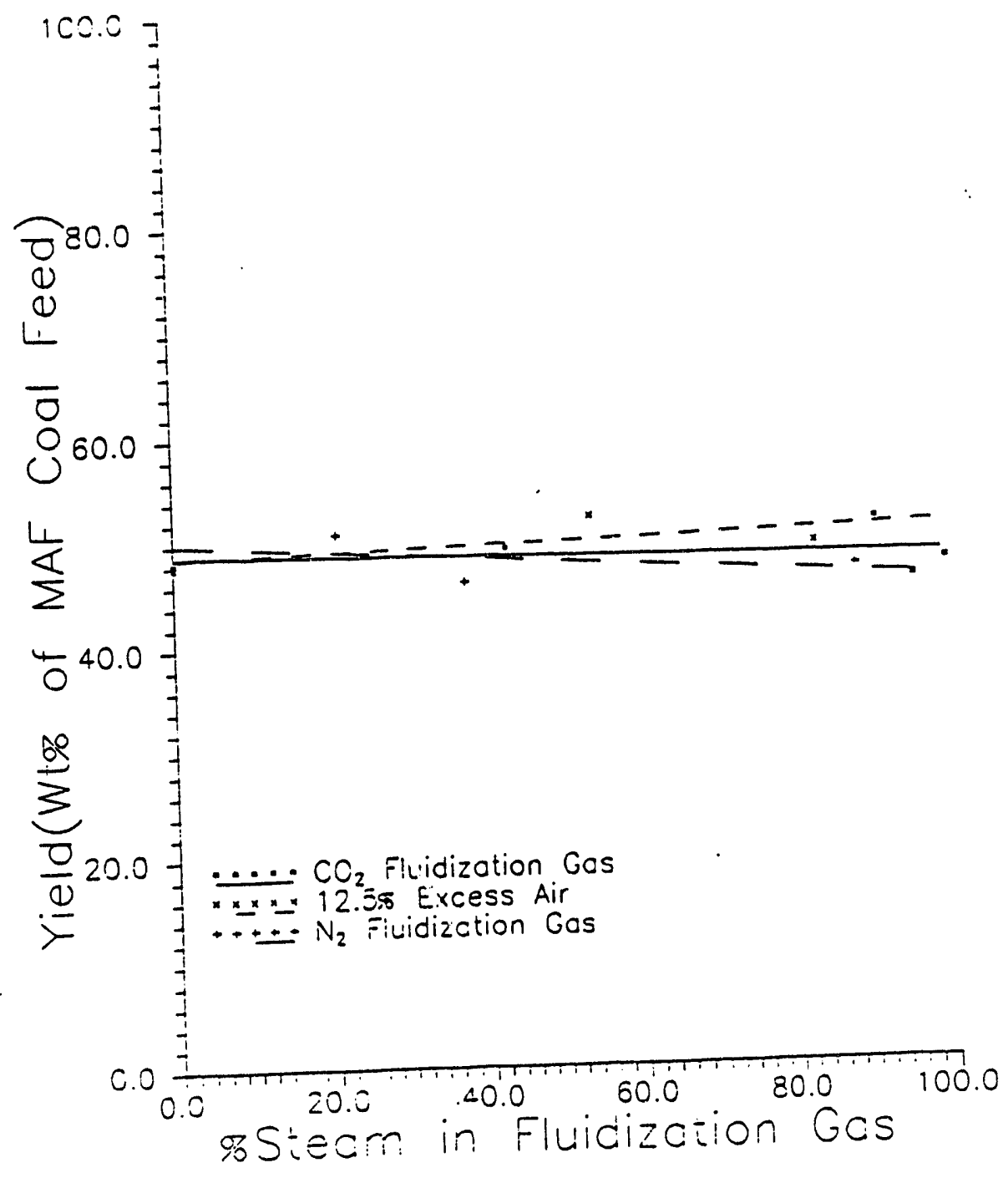

Figure 18. The effect of steam/reactive gas atmosphere on Wyodak char yields. 


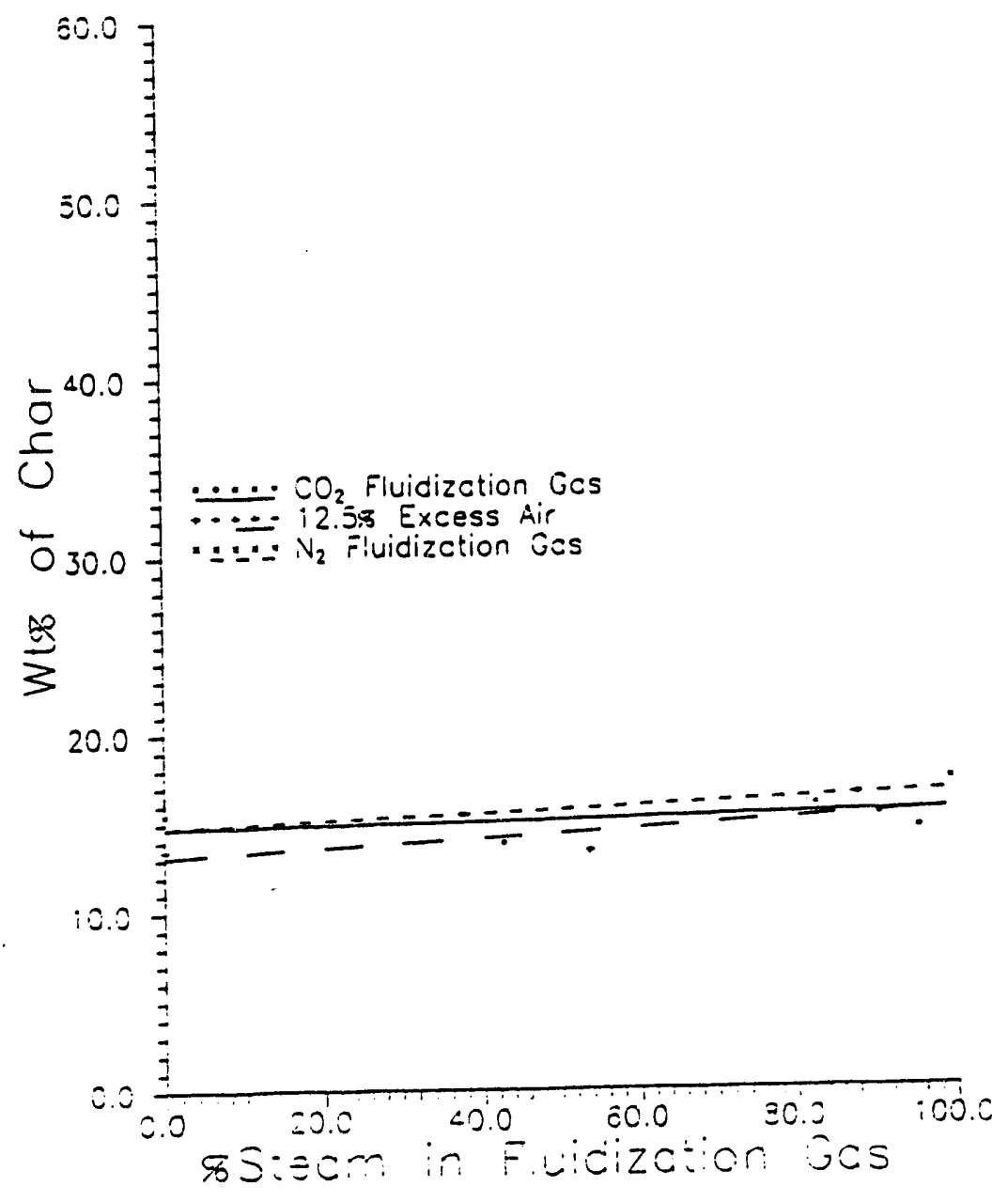

Figure 19. The effect of steam/reactive gas atmosphere on Wyodak char volatile content. 


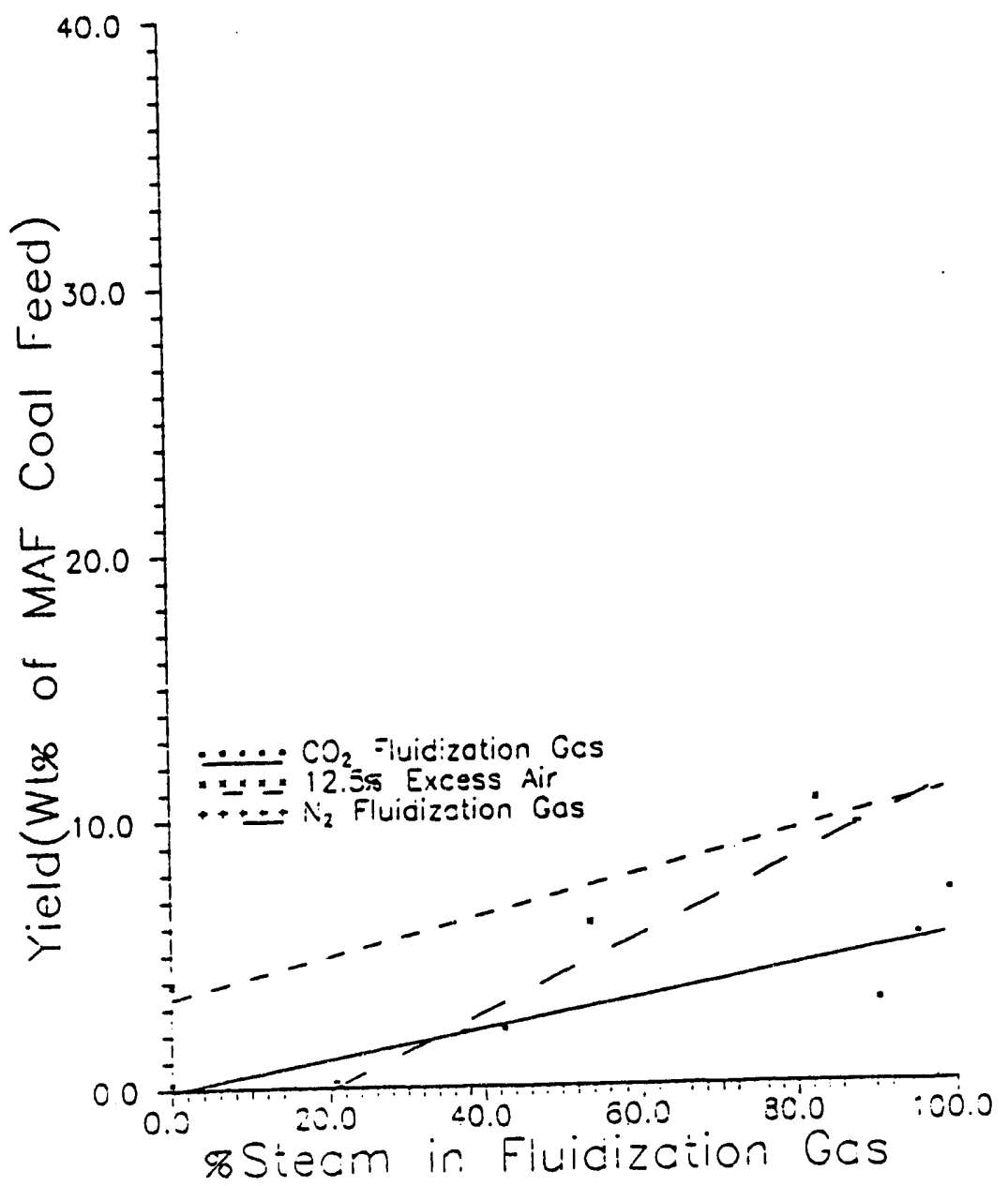

Figure 20. The effect of steam/reactive gas atmosphere on Wyodak condensable yields. 


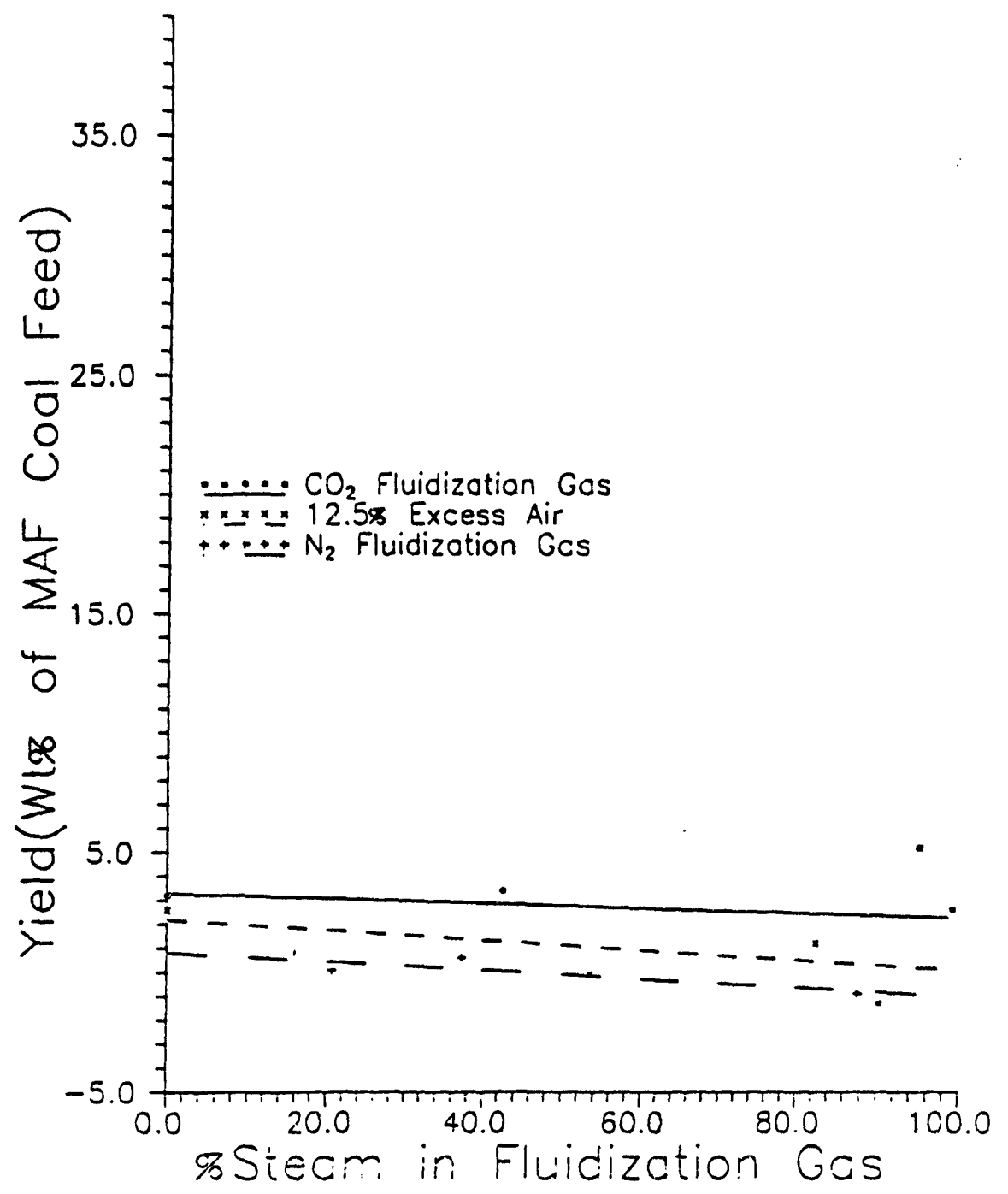

Figure 21. The effect of steam/reactive gas atmosphere on Wyodak water yields. 


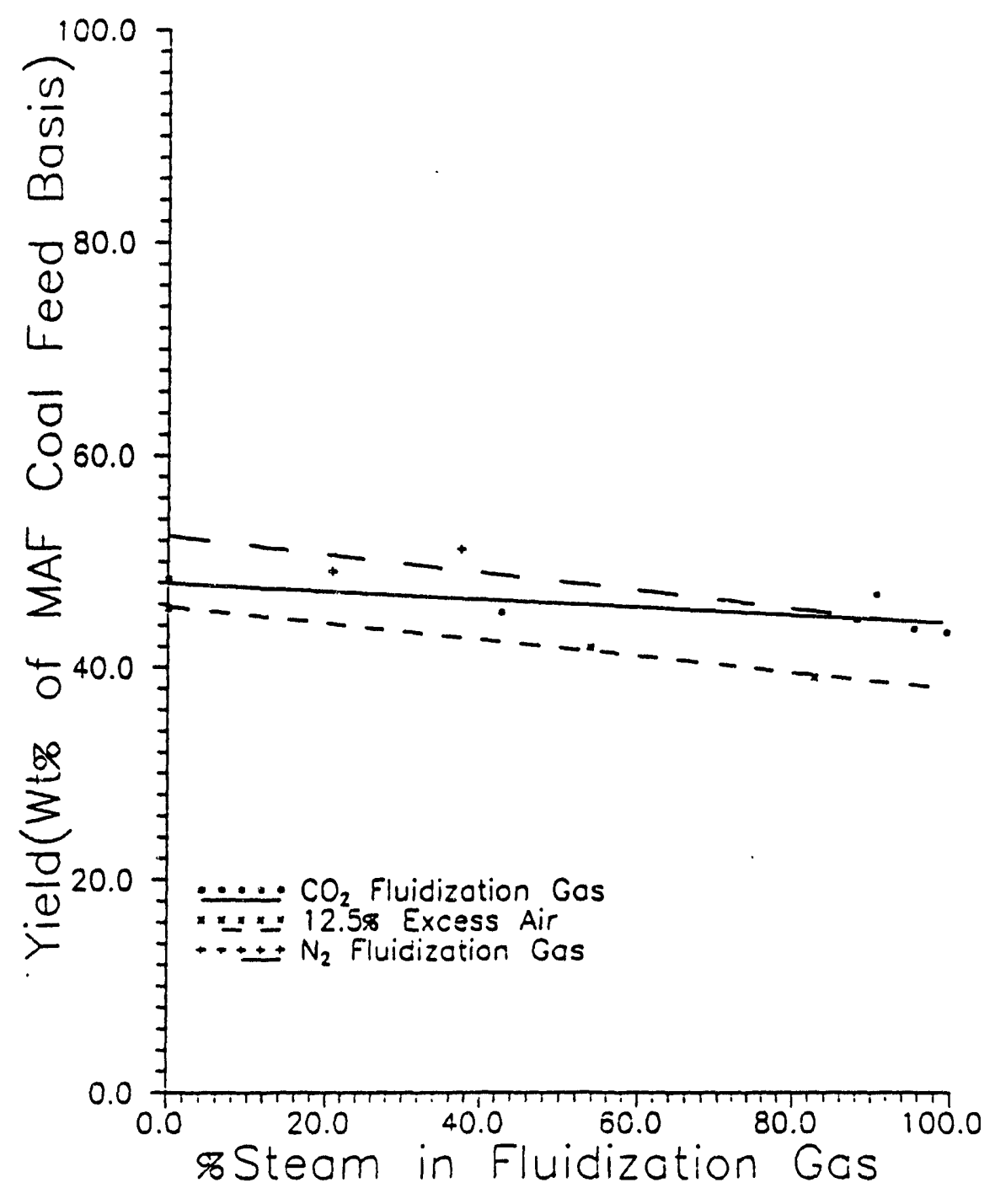

Figure 22. The effect of steam/reactive gas atmosphere on Wyodak gas yields. 


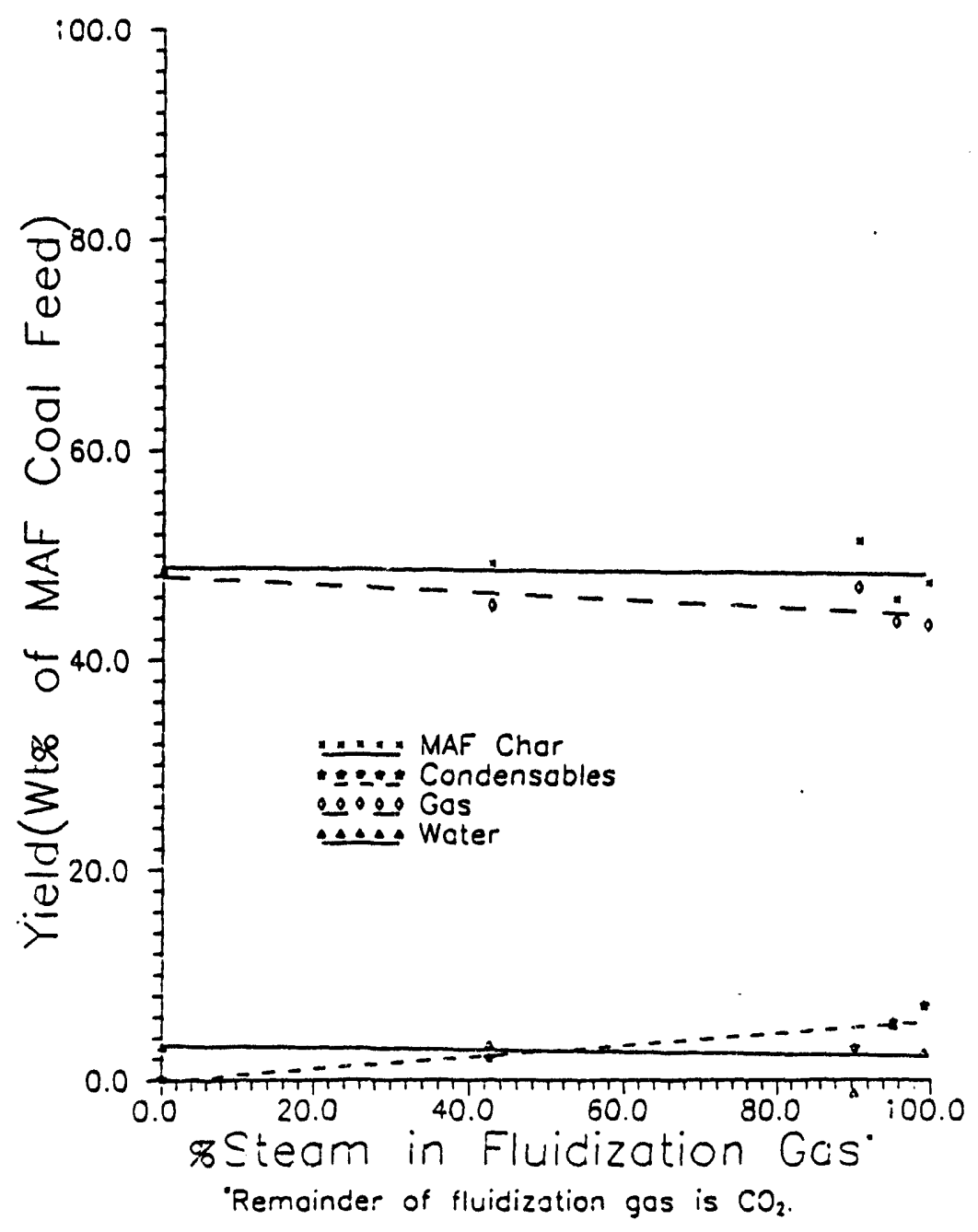

Figure 23. The effect of steam $/ \mathrm{CO}_{2}$ partial pressure on Wyodak product yields. 


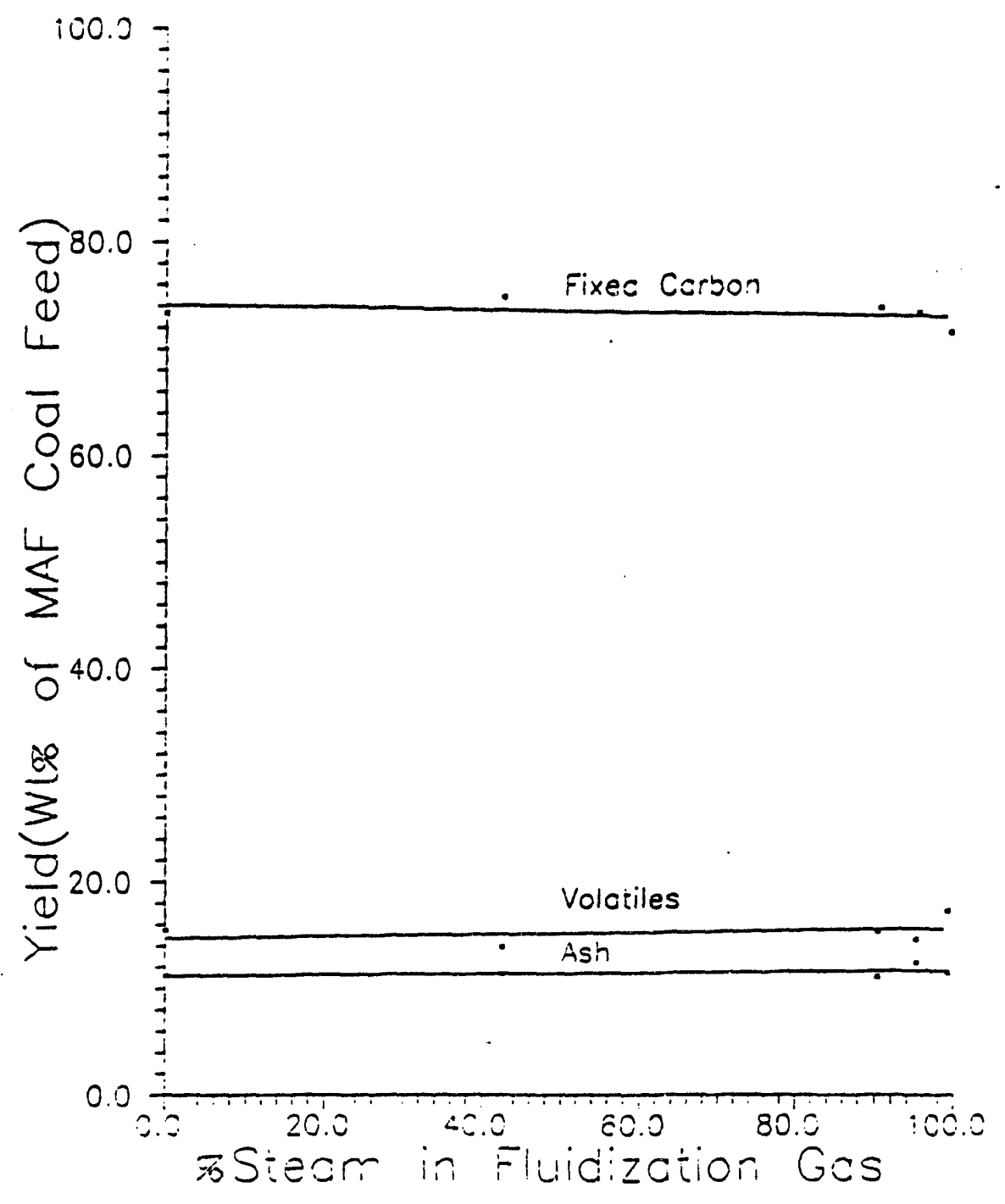

Figure 24. The effect of steam $/ \mathrm{CO}_{2}$ partial pressure on Wyodak char proximate analysis. 


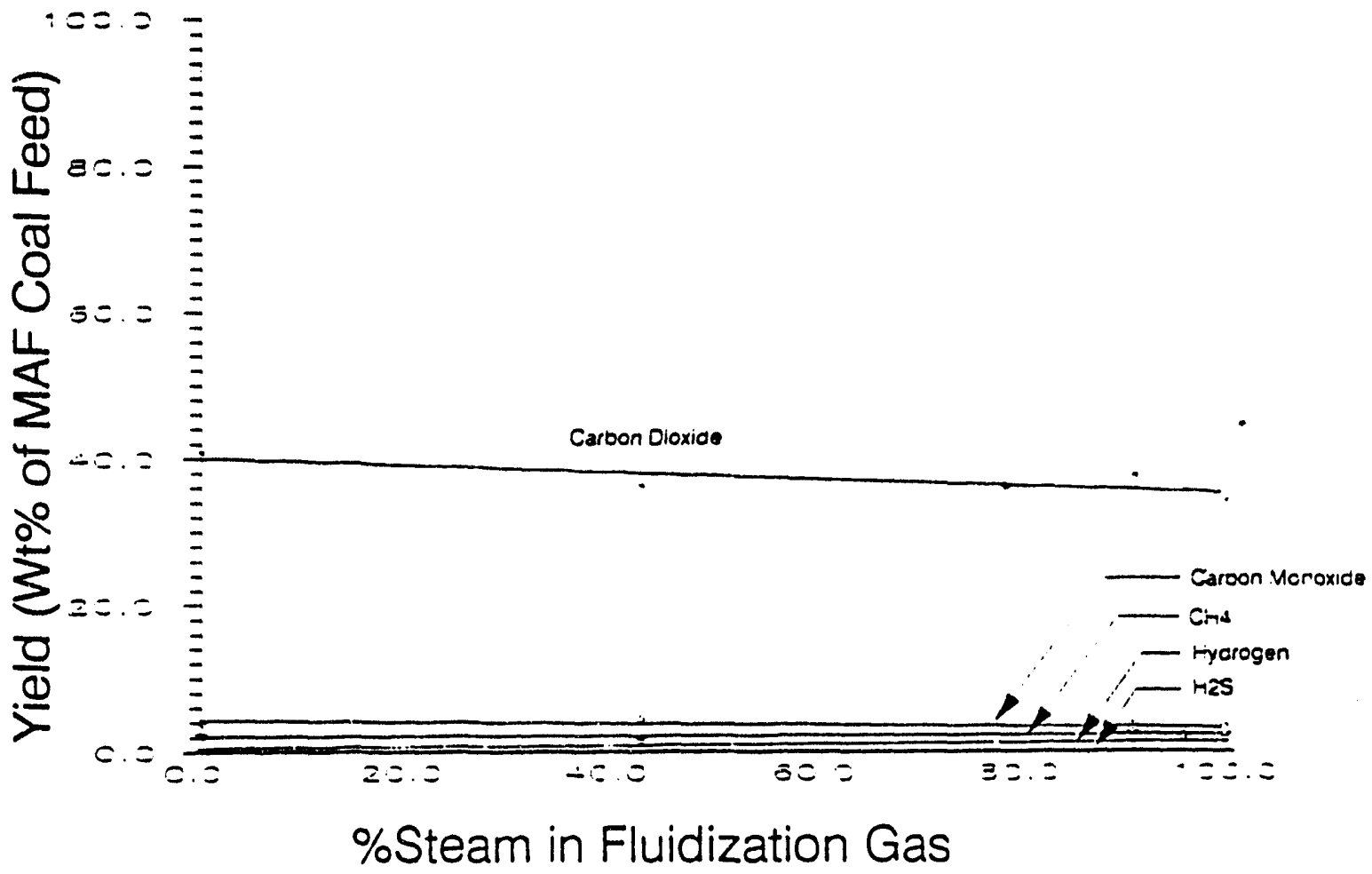

Figure 25. The effect of steam/ $/ \mathrm{CO}_{2}$ partial pressure on Wyodak product gas component yields. 


\subsection{RESULTS OF TESTS COMPLETED ON ILLINOIS NO. 6 COAL}

One test was conducted during equipment shakedown on Illinois No. 6 coal. Due to the operability problems with Indiana No. 3 coals, the test matrix for Illinois No. 6 coal was not completed in favor of an expanded matrix for the Indiana No. 3 coal. 


\subsection{RESULTS FROM TESTS ON INDIANA NO. 3 COAL}

The test matrix for the Indiana No. 3 test series is shown in Table 9. The matrix is divided into four areas representing different methods for testing agglomeration: 1) feed coal injection into char bed, 2) preoxidation of coal feed, 3) oxidation within the reactor bed, and 4) staged heating of the coal. These options were based on suggested methods as discussed in the literature survey "Development of an Advanced, Continuous Mild Gasification Process for the Production of Co-Products" (2). All four methods showed limited success, but only the staged heating allowed for extended periods of operation. The large size of the coal feed $(-1 / 4 \times 10$ mesh) and the small reactor diameter ( 3 " ID) made the agglomeration far more difficult to control than in a larger reactor.

The experimental conditions evaluated for Indiana No. 3 coal covered a range of temperatures from $660^{\circ}$ to $1470^{\circ} \mathrm{F}\left(350^{\circ}\right.$ to $\left.800^{\circ} \mathrm{C}\right)$ at various percentages of steam in $\mathrm{N}_{2}$ or in $\mathrm{N}_{2} / \mathrm{CO}_{2}$.

\subsection{Direct Injection of Indiana No. 3 Coal into a Char Bed}

In trial tests at $1110^{\circ} \mathrm{F}\left(600^{\circ} \mathrm{C}\right)$ using steam and $\mathrm{CO}_{2}$ as the fluidization gas, Wyodak coal was first fed to the reactor, and then Indiana No. 3 coal was fed into the system only after the char bed had fully developed. Agglomeration of the bed occurred within ten minutes after the Indiana No. 3 coal was fed. Figure 26 shows a part of the agglomerate removed from the reactor, representing one-third of the total plug. The remainder of the agglomerate crumbled when it was removed. Figures 27 and 28, under 100 and 360 power magnification, respectively, show the high porosity of the agglomerate caused by passage of gas through the semifluid coal at $1110^{\circ} \mathrm{F}\left(600^{\circ} \mathrm{C}\right)$.

A cross section of the agglomerated material magnified 360 times, in Figure 29, shows unconverted coal surrounded by the porous char deposited in a semifluid state. Inorganic mineral matter is clearly visible in the unconverted coal, but is less so in the semifluid material. Because of the importance of reducing the sulfur content in the char by in situ methods, special attention was given to the sulfur and ash contents of the Indiana No. 3 chars. Based on discussions with the Illinois State Geological Survey, it is believed that sulfur may be reacting with the carbon in the agglomerate (8). Figure 30 shows several bridges between particles (1000 power magnification). Elemental and chemical oxide surface analyses were performed on a char at five different points, shown in Figure 31. The results are reported in Table 10. It should be noted that sulfur crystals were not present in the photomicrograph. However, there was a small amount of sulfur present on the bridges (Points $\# 1$, \#3, and \#5), indicating that sulfur exists at the carbon surface, which was true of all points analyzed. The bridges were mostly organic, with little inorganic material present. The sharp edges of the minerals (Point \#2 and \#4) suggest that these particular minerals were not affected by heating to $1110^{\circ} \mathrm{F}\left(600^{\circ} \mathrm{C}\right)$ and did not play a role in the agglomeration. Figures 31 and 32 show a cross section of a bridge that was analyzed for sulfur content. Sulfur was detected over the entire surface of the bridge, but the depth, exact concentration, and form of the sulfur were not determined. 
TABLE 9

Test Matrix for Indiana No. 3 Coal

\begin{tabular}{|c|c|c|c|c|c|}
\hline \multirow[b]{2}{*}{ Temperature } & \multirow[b]{2}{*}{ Gas } & \multicolumn{4}{|c|}{$\%$ Steam } \\
\hline & & 0.29 & 30.59 & $60-89$ & $90-100$ \\
\hline $\begin{array}{l}\text { Coal Injection into } \\
\text { Char Bed, } 1020^{\circ} \mathrm{F}\end{array}$ & $\mathrm{N}_{2}$ & & 106 & & \\
\hline $\begin{array}{l}\text { Preoxidation, } \\
1020^{\circ} \mathrm{F}\end{array}$ & $\mathbf{N}_{2}$ & & & & \\
\hline $\begin{array}{l}\text { Internal Oxidation, } \\
1020^{\circ} \mathrm{F}\end{array}$ & $\mathbf{N}_{2}$ & & & & \\
\hline \multicolumn{6}{|l|}{ Staged } \\
\hline $660^{\circ} \mathrm{F}$ & $\begin{array}{c}\mathrm{N}_{2}-\mathrm{CO}_{2}^{b} \\
\mathrm{~N}_{2}^{\mathrm{d}}\end{array}$ & $303,304^{\circ}$ & $\begin{array}{c}305 \\
325,308,309\end{array}$ & 307 & $\begin{array}{l}301 \\
306\end{array}$ \\
\hline $700^{\circ} \mathrm{F}$ & $\mathrm{N}_{2}-\mathrm{CO}_{2}$ & & & & 300-A, 300-B \\
\hline $750^{\circ} \mathrm{F}$ & $\mathbf{N}_{2}$ & 221 & 220,222 & & \\
\hline $780^{\circ} \mathrm{F}$ & $\mathbf{N}_{2}$ & & 302 & & \\
\hline $840^{\circ} \mathrm{F}$ & $\mathrm{N}_{2}$ & 330,337 & $\begin{array}{c}336,315,338 \\
223,331\end{array}$ & 339,332 & 302 \\
\hline $930^{\circ} \mathrm{F}$ & $\mathbf{N}_{2}$ & 224 & 225,227 & 226 & \\
\hline $1020^{\circ} \mathrm{F}$ & $\mathrm{N}_{2} \cdot \mathrm{CO}_{2}$ & & & & $311-A, 311-B$ \\
\hline $1470^{\circ} \mathrm{F}$ & $\mathbf{N}_{2}$ & 402,404 & 403,405 & & \\
\hline
\end{tabular}

- \% steam in fluidization gas.

b Remainder of fluidization gas is $90 \% \mathrm{~N}_{2} / 10 \% \mathrm{CO}_{2}$, which is a simulated flue gas that represents stoichiometric combustion of carbon.

- Matrix test number.

d Remainder of fluidization gas is $\mathrm{N}_{2}$.

\subsection{Preoxidation of Indiana No. 3 Feed Coal}

Tests were performed in a thermogravimetric analyzer (TGA) on Indiana No. 3 coal that was pulverized to $100 \%-60$ mesh. The results from these tests are shown in

Table 11. In each of the tests, the coal was heated to $1110^{\circ} \mathrm{F}\left(600^{\circ} \mathrm{C}\right)$ or higher in a TGA for ten minutes. Agglomeration was measured as the percent of the material taken from the TGA that was retained on a 60-mesh screen. Untreated coal was used in the basecase tests; limestone was added in the second set of tests; and preoxidation by drying the coal in air at $300^{\circ} \mathrm{F}\left(150^{\circ} \mathrm{C}\right)$ for six hours was tried in the third set of tests. Limestone was tested because it is a potential bed material that could be used for sulfur capture. For the untreated Indiana No. 3 coal, $69 \%$ of the char agglomerated and would not pass the 60 -mesh screen. With limestone addition, $13 \%$ to $60 \%$ of the char agglomerated, depending on the percentage of limestone and the temperature, and with preoxidation $2 \%$ to $4 \%$ agglomerated. Based on the favorable results with preoxidation, several pounds of 


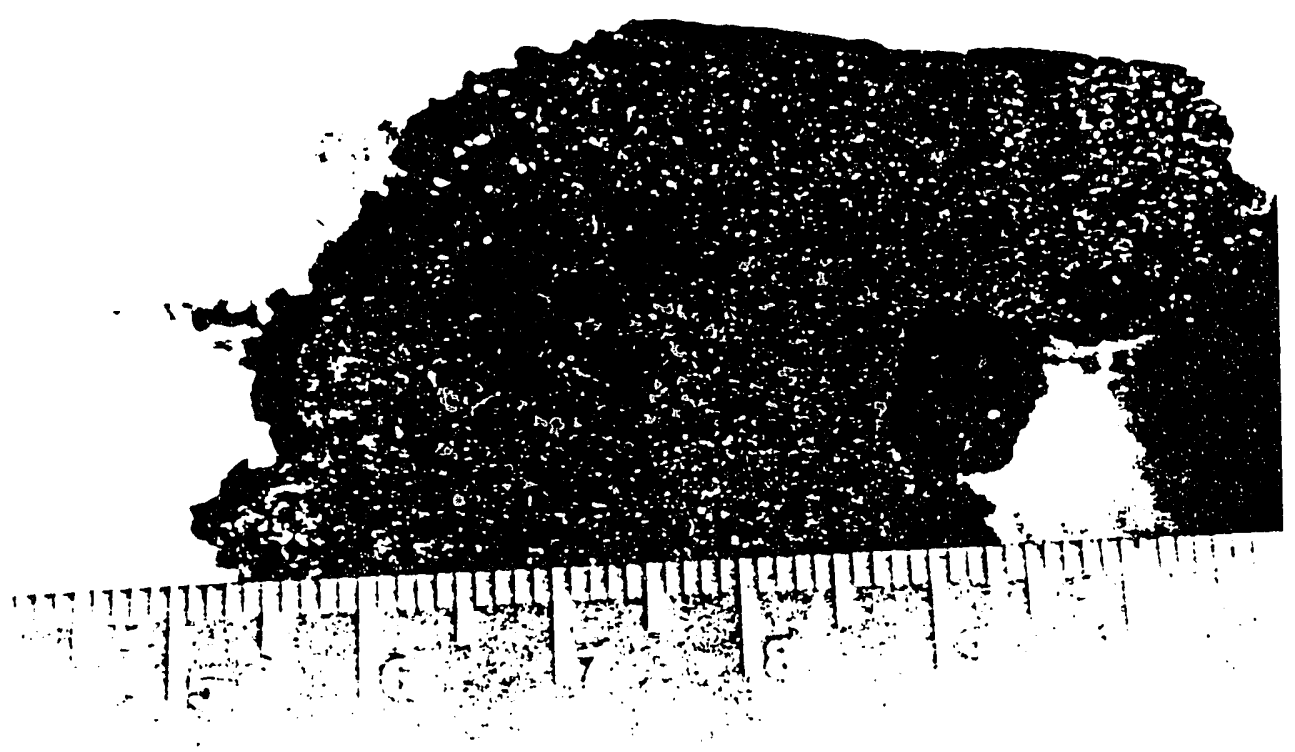

Figure 26. Indiana No. 3 coal agglomerate (cm).

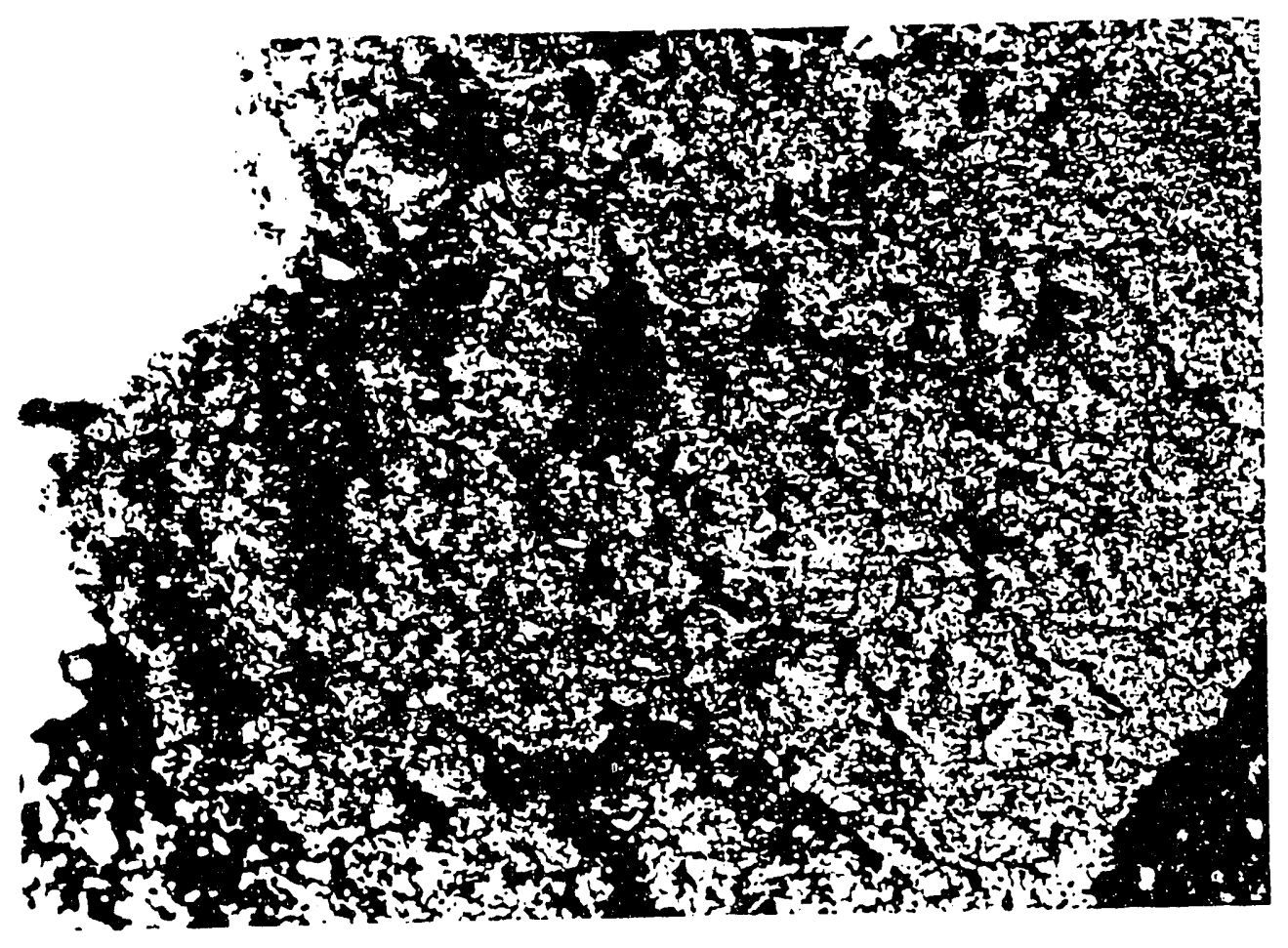

Figure 27. Close-up of Indiana No. 3 char agglomerate (100 mag.). 


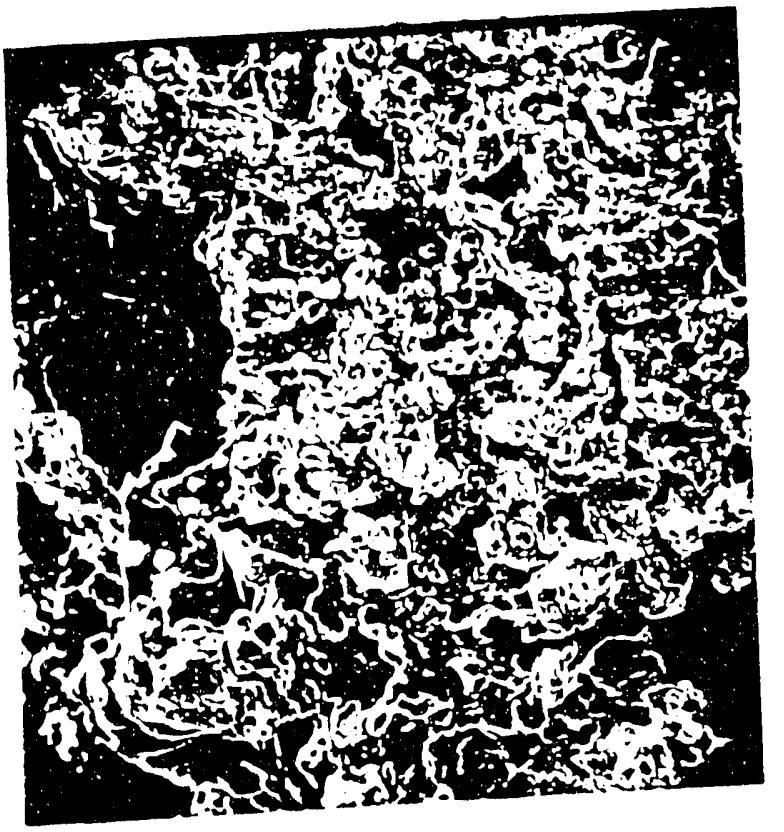

Firure 2s. Cose-up of Indiana

$\therefore$ i). 3 char gomerate

300 mate.

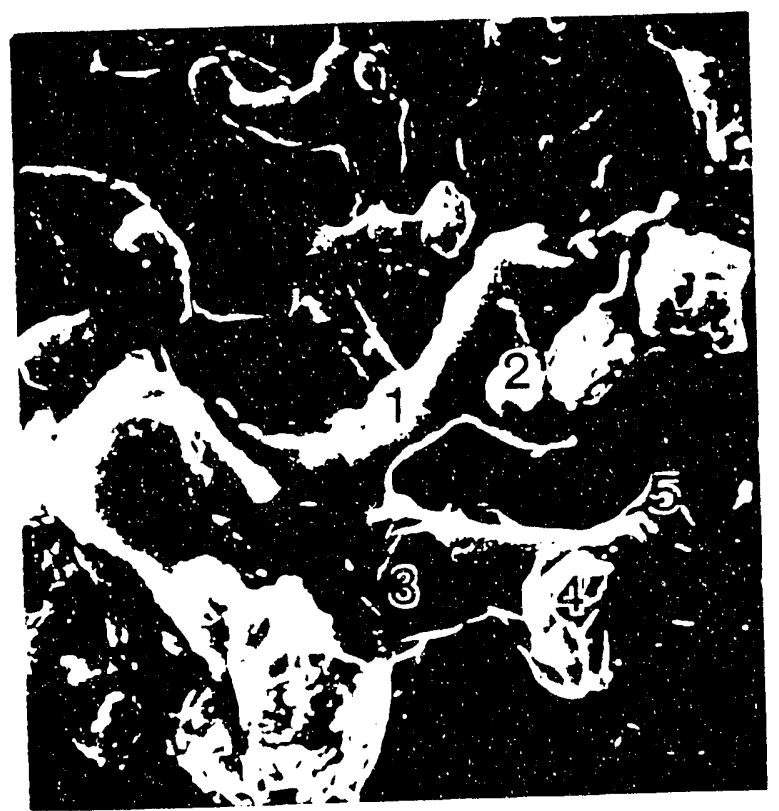

Finure 30 orrance brices an

Indiana No. Buter

a-riomerate lon: arag.

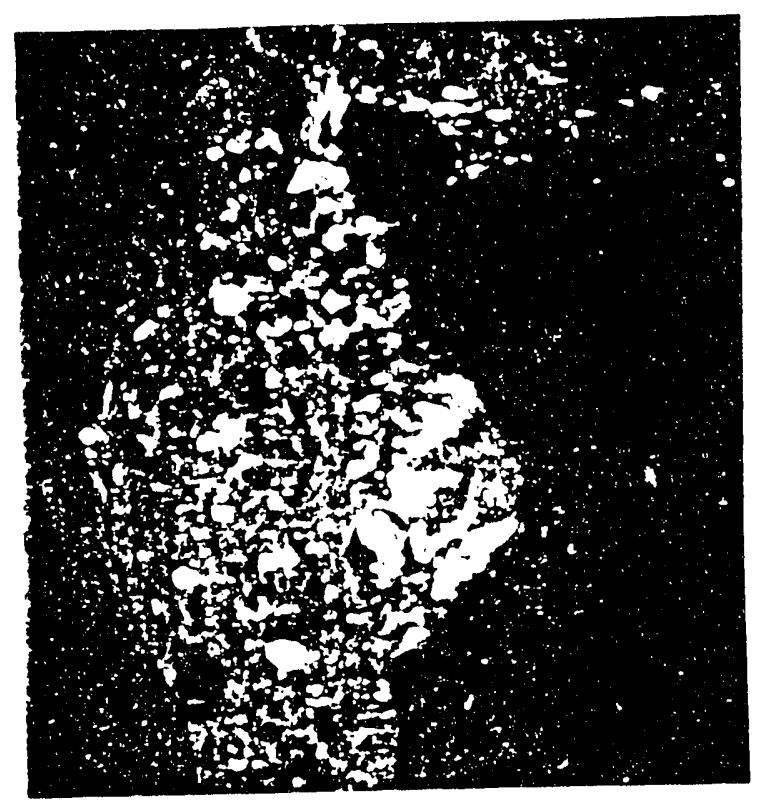

Figure 29 Cononverted colia an

Indiana Vio. 3 agsomerate (36i) mats.

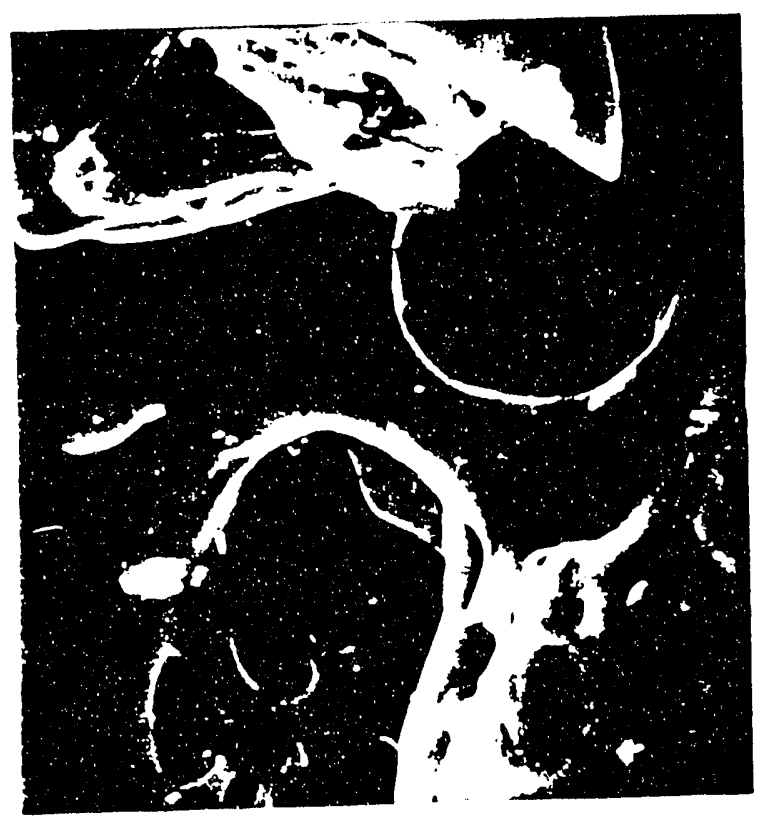

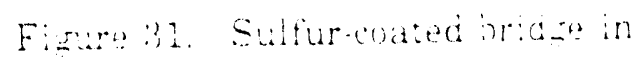

Indiana Do.? Con

arromerate : $1: 11$ mats 
T.ABLE 10

Chemical Composition of Indiana No. 3 Agglomerate Produced at $111 i^{\circ} \mathrm{F}$ in $75^{\circ}{ }_{c}$ Steam $25^{\circ} \mathrm{CO}_{2}$ Fluidization Gas

\begin{tabular}{|c|c|c|c|c|c|c|c|c|c|c|c|c|}
\hline & \multirow[b]{2}{*}{$\begin{array}{c}\text { Points in } \\
\text { Fig. } 32\end{array}$} & \multicolumn{11}{|c|}{ Surface Analysis, wt \% } \\
\hline & & $\therefore a$ & $\because$ & $A 1$ & $\mathrm{si}$ & $P$ & $s$ & $\mathrm{Cl}$ & $\mathrm{K}$ & $\mathrm{Ca}$ & $\mathrm{Ti}$ & $\mathrm{Fe}$ \\
\hline $\mathrm{M} 025-104$ & $¥ 1$ & $0 . \because$ & $\therefore$ & 0.9 & 1.2 & 0.0 & 1.1 & 0.0 & 0.0 & 0.4 & 0.4 & 0.39 \\
\hline M025.104 & $\neq 2$ & 0.0 & $\dot{0}$ & 2.8 & 2.7 & 0.9 & 0.9 & 0.0 & 0.1 & 0.6 & 0.0 & 1.13 \\
\hline. $\mathrm{M} 025 \cdot 104$ & $\neq 3$ & 0.2 & $\therefore$ & 1). .3 & 1.2 & 1.0 & 1.1 & 0.0 & 0.0 & 1.9 & 0.0 & 0.83 \\
\hline .11025 .104 & +4 & $0.1)$ & $\therefore$ & 0.0 & $33 .:$ & $0.1 j$ & 0.0 & 0.0 & 0.0 & 0.0 & 0.0 & 0.00 \\
\hline \multirow[t]{2}{*}{$\mathrm{M} 025.104$} & $\$ 5$ & 0.0 &.$i$ & 0.3 & $i j .6$ & 0.0 & D. 8 & 0.0 & 0.0 & 0.2 & 0.0 & 0.38 \\
\hline & & \multicolumn{11}{|c|}{ Average Jurface Analysis } \\
\hline \multicolumn{2}{|l|}{ Elem., wt $\tau_{c}$} & 0.0 & $\therefore$ & 0.8 & $i . i$ & $0.1)$ & 0.8 & 0.0 & 0.0 & 0.6 & 0.1 & 0.50 \\
\hline \multicolumn{2}{|c|}{ Oxide, wt?c } & 0.0 & 3 & 1.6 & $16 . \overline{3}$ & 0.0 & 1.9 & 0.0 & 0.0 & 0.9 & 0.1 & 0.78 \\
\hline \multicolumn{2}{|c|}{ Norm. Oxide. wt\% } & 0.2 & $\therefore 2$ & 7.2 & 74.5 & 0.0 & 8.7 & 0.0 & 0.1 & 4.1 & 0.6 & 3.50 \\
\hline
\end{tabular}

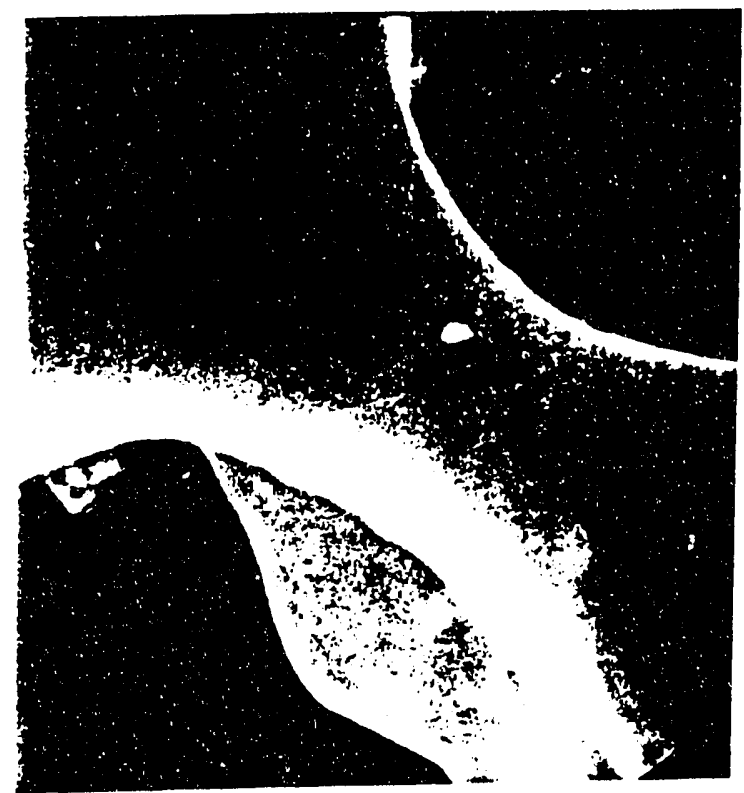

Figure 32. Sulfur-coated sridge in Indiana No. 3 char agglomerate (3000 mag.).

the Indiana No. 3 feed coa. sized to -1. in $\times 10$ mesh, were preoxidized and tested in the $1-1 \mathrm{~b} / \mathrm{hr}$ CFBR at $1110=\mathrm{F}\left(6 ; 0^{\circ} \mathrm{C}\right)$ in an $\div$ : gas atmosphere. The bed quickly agglomerated, but the run was successfu: $\because$ continued for a period of two hours using a very low coal feed rate, approximately 1200 the normal rate. Repeating the TGA tests on the

$-1 / 4 \times 10$-mesh feed materiai used in the CFBR verified that agglomeration of the larger coal size occurred under $a:$. preoxidation conditions. It was concluded that the amount of oxidation needed to suppr $\leq s$ agglomeration could not be achieved without the high surface area available wit: ise fine i-6i-mesh! coal. Based on these results, further testing of preoxidized coai in the CFBR uas suspended. 
TABLE 11

TGA Agglomeration Test Results for Indiana No. 3 and Illinois No. 6 Coals

\begin{tabular}{|c|c|c|c|c|c|c|c|}
\hline Sample & $\begin{array}{c}\text { TGA } \\
\text { Temp; }{ }^{\circ} \mathrm{F}\end{array}$ & Pretreatment & $\begin{array}{l}\text { Test } \\
\text { Atm. }\end{array}$ & Aggl." & $\begin{array}{c}\text { Sample wt, } \\
\text { g }\end{array}$ & Fines $^{\mathrm{b}}, a_{0}$ & Aggl.,$\%$ \\
\hline $\begin{array}{l}\text { Illinois No. } 6 \\
\text { Indiana No. } 3\end{array}$ & $\begin{array}{l}1380 \\
1380\end{array}$ & $\begin{array}{l}\text { None } \\
\text { None }\end{array}$ & $\begin{array}{l}\text { Argon } \\
\text { Argon }\end{array}$ & $\begin{array}{l}\text { Large, Hard } \\
\text { Large, Hard }\end{array}$ & $\begin{array}{l}2.89 \\
2.31\end{array}$ & $\begin{array}{l}34.68 \\
31.17\end{array}$ & $\begin{array}{l}65.32 \\
68.83\end{array}$ \\
\hline $\begin{array}{l}\text { Indiana No. } 3 \\
\text { Indiana No. } 3 \\
\text { Indiana No. } 3\end{array}$ & $\begin{array}{l}1110 \\
1200 \\
1290\end{array}$ & $\begin{array}{l}10 \% \text { Limestone } \\
10 \% \text { Limestone } \\
10 \% \text { Limestone }\end{array}$ & $\begin{array}{l}\text { Argon } \\
\text { Argon } \\
\text { Argon }\end{array}$ & $\begin{array}{l}\text { Large, Hard } \\
\text { Large, Hard } \\
\text { Large, Hard }\end{array}$ & $\begin{array}{l}2.09 \\
2.46 \\
2.63\end{array}$ & $\begin{array}{l}52.63 \\
39.84 \\
50.57\end{array}$ & $\begin{array}{l}47.37 \\
60.16 \\
49.43\end{array}$ \\
\hline $\begin{array}{l}\text { Indiana No. } 3 \\
\text { Indiana No. } 3 \\
\text { Indiana No. } 3\end{array}$ & $\begin{array}{l}1110 \\
1200 \\
1290\end{array}$ & $\begin{array}{l}20 \% \text { Limestone } \\
20 \% \text { Limestone } \\
20 \% \text { Limestone }\end{array}$ & $\begin{array}{l}\text { Argon } \\
\text { Argon } \\
\text { Argon }\end{array}$ & $\begin{array}{l}\text { Large, Hard } \\
\text { Large, Hard } \\
\text { Large, Hard }\end{array}$ & $\begin{array}{l}2.67 \\
2.87 \\
2.96\end{array}$ & $\begin{array}{l}80.15 \\
86.76 \\
63.18\end{array}$ & $\begin{array}{l}19.85 \\
13.24 \\
36.82\end{array}$ \\
\hline $\begin{array}{l}\text { Indiana No. } 3 \\
\text { Indiana No. } 3 \\
\text { Indiana No. } 3\end{array}$ & $\begin{array}{l}1110 \\
1200 \\
1290\end{array}$ & $\begin{array}{l}\text { Ox. at } 300^{\circ} \mathrm{F} \\
\text { Ox. at } 300^{\circ} \mathrm{F} \\
\text { Ox. at } 300^{\circ} \mathrm{F}\end{array}$ & $\begin{array}{l}\text { Argon } \\
\text { Argon } \\
\text { Argon }\end{array}$ & $\begin{array}{l}\text { None } \\
\text { None } \\
\text { None }\end{array}$ & $\begin{array}{l}3.15 \\
2.78 \\
3.37\end{array}$ & $\begin{array}{l}98.09 \\
97.20 \\
96.44\end{array}$ & $\begin{array}{l}1.91 \\
2.80 \\
3.56\end{array}$ \\
\hline $\begin{array}{l}\text { Indiana No. } 3 \\
\text { Indiana No. } 3 \\
\text { Indiana No. } 3\end{array}$ & $\begin{array}{l}1110 \\
1200 \\
1290\end{array}$ & $\begin{array}{l}\text { Ox. at } 300^{\circ} \mathrm{F} \\
\mathrm{Ox} \text {. at } 300^{\circ} \mathrm{F} \\
\mathrm{Ox} \text {. at } 300^{\circ} \mathrm{F}\end{array}$ & $\begin{array}{l}\text { Ar/Steam } \\
\text { Ar/Steam } \\
\text { Ar/Steam }\end{array}$ & $\begin{array}{l}\text { None } \\
\text { None } \\
\text { None }\end{array}$ & $\begin{array}{l}3.49 \\
2.97 \\
2.86 \\
\end{array}$ & $\begin{array}{l}98.28 \\
97.64 \\
97.55\end{array}$ & $\begin{array}{l}1.72 \\
2.36 \\
2.45\end{array}$ \\
\hline
\end{tabular}

- Agglomerate description.

b Material passed through a 60 -mesh screen.

c Material did not pass through a 60-mesh screen.

\subsection{In-Bed Oxidation of Indiana No. 3 Coal}

Tests were performed at $1110^{\circ} \mathrm{F}\left(600^{\circ} \mathrm{C}\right)$ using a simulated flue gas containing $89 \% \mathrm{~N}_{2} / 9 \% \mathrm{CO}_{2} / 2 \% \mathrm{O}_{2}$, to represent gas produced by combustion of a carbon source such as methane or coal with $12 \%$ excess air. These tests showed only marginal improvement in bed agglomeration compared to the base case, and testing had to be terminated shortly after the introduction of the Indiana No. 3 coal because of plugging. These test conditions had been used successfully on caking coals by Boley and Fegley in a $400-\mathrm{lb} / \mathrm{hr}$ fast fluidbed system (9). However, the combined oxidation, mechanical attrition, and internal recycling of char that was successful in preventing agglomeration in the large system was not effective in the small reactor.

\subsection{Staged Heating of Indiana No. 3 Coal}

The tests on staged heating for control of agglomeration was based on previous work done by FMC (7), where coal was heated in a series of fluidized-bed reactors to progressively higher temperatures. The devolatilization that occurred at each stage allowed the resultant char to be heated to a higher temperature in the next stage without agglomeration.

In the current test series using the single CFBR reactor, char produced at $660^{\circ} \mathrm{F}$ $\left(350^{\circ} \mathrm{C}\right)$ was collected and subsequently fed at $840^{\circ} \mathrm{F}\left(450^{\circ} \mathrm{C}\right)$; the char produced at $840^{\circ} \mathrm{C}$ $\left(450^{\circ} \mathrm{C}\right)$ was fed at $1020^{\circ} \mathrm{F}\left(550^{\circ} \mathrm{C}\right)$. This system of heating proved to be very effective in reducing the plugging of the reactor, as the agglomerates that formed were very small and did not stick together. These temperature differences between stages cannot be scaled to the $100-\mathrm{lb} / \mathrm{hr}$ design because of the difference in the internal mixing of the two units. As the internal recycle of char increases, the tendency for agglomeration can be better tolerated without plugging the reactor. In this test series, the effect of steam 
partial pressure was evaluated at each staging temperature, and the bulk of the char was processed under a $30 \%$ steam $/ 0 \% \mathrm{~N}_{2}$ mixture for use in tests at the next higher temperature.

\subsubsection{The Effect of Temperature and Steam/Nitrogen Partial Pressure on Indiana No. 3 Char Yields}

Char yields decreased from 97.14 wt\% at $660^{\circ} \mathrm{F}\left(350^{\circ} \mathrm{C}\right)$ to $63.46 \mathrm{wt} \%$ at $1470^{\circ} \mathrm{F}$ $\left(800^{\circ} \mathrm{C}\right)$, with the major drop occurring between the temperatures of $780^{\circ} \mathrm{F}$ and $840^{\circ} \mathrm{F}$ $\left(420^{\circ}\right.$ and $\left.450^{\circ} \mathrm{C}\right)$ as shown in Figure 33. The arrows on the graph indicate the effect of steam on the char yield. For example, an arrow pointing upward indicates that char yield increased with increasing steam partial pressure. The hooked arrows indicate a reversal in the yield trend with progressively increasing steam. Because of the close proximity of some data points, the reversals may not represent actual effects. Overall, char yields appear to increase along with steam partial pressure.

The volatile content of the char decreased from $35 \%$ to $8.6 \%$ over the range of temperatures studied, Figure 34. Related trends are seen for the fixed carbon (53.7\% to $72.6 \%)$ and ash contents (11\% to $18.8 \%)$.

\subsubsection{The Effect of Temperature and Steam/Nitrogen Partial Pressure on Indiana No. 3 Condensable Yields}

Condensable yields from staged testing increased monotonically from $0.33 \%$ at $660^{\circ} \mathrm{F}\left(350^{\circ} \mathrm{C}\right)$ to $18 \%$ at $1470^{\circ} \mathrm{F}\left(800^{\circ} \mathrm{C}\right)$, Figure 35 . The intermediate yield for each staged test was calculated by totaling the yields for the test condition plus all temperature stages prior to it. No tests were performed at temperatures between $1020^{\circ}$ and $1470^{\circ} \mathrm{F}\left(550^{\circ}\right.$ and $\left.800^{\circ} \mathrm{C}\right)$, and a higher yield might have occurred at an intermediate temperature if it had been run.

The effect of steam was to increase the yield of condensables in the case of nine related data points and to reduce it in the case of two. Because the increase in condensable yields was within the experimental error of yield determination, no conclusion can be reached in regards to the effect of steam.

Condensate samples from staged testing up to $660^{\circ}, 750^{\circ}, 840^{\circ}$, and $930^{\circ} \mathrm{F}\left(350^{\circ}\right.$, $400^{\circ}, 450^{\circ}$, and $500^{\circ} \mathrm{C}$ ) were collected and analyzed to determine boiling point distribution and molecular composition by GC/FID/MS methods. The boiling point distribution in Figure 36 based on data from the D85 GC column is a good approximation of the ASTM distillation curve, although aromatic compounds tend to elute at higher temperatures than their actual boiling points when normal alkanes are used as indices of temperature.

The GC analysis detected approximately 300 compounds in each sample. A summary of the identifiable compounds is presented in Table 12 and includes peaks for benzene, toluene, and >1-ring aromatics (3.9 wt\% in the composite analysis), 12 peaks for phenolic compounds (34.2 wt\%), and 19 peaks for normal alkanes (6.0 wt\%), for a total of $44.1 \mathrm{wt} \%$ identifiable in the composite analysis. The approximately 270 remaining peaks averaged about 0.2 wt\% each and were not individually identifiable. Elution position did, however, provide some indication of compound types. 


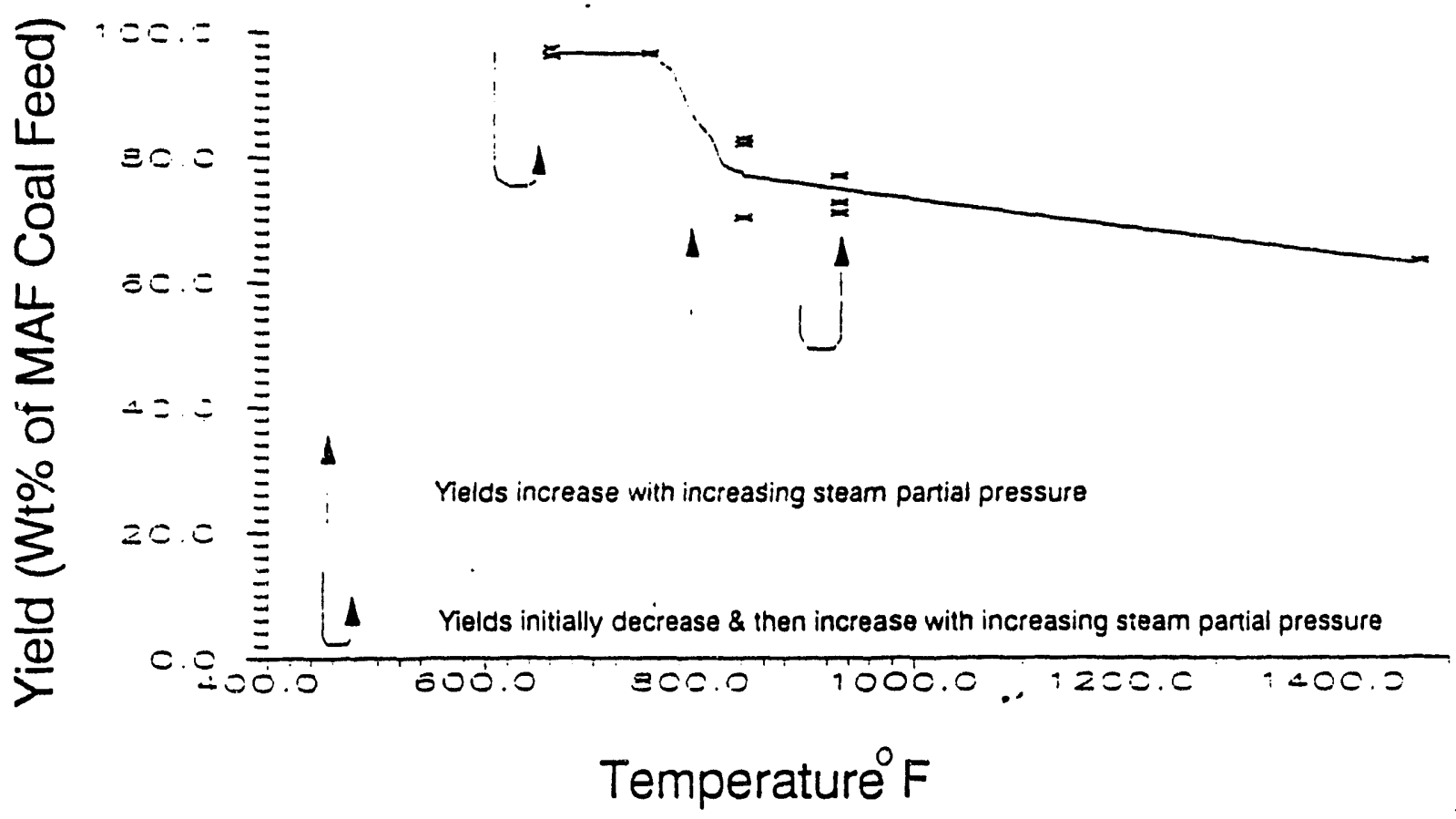

Figure 33. The effect of temperature and steam/nitrogen partial pressure on Indiana No. 3 char yields.

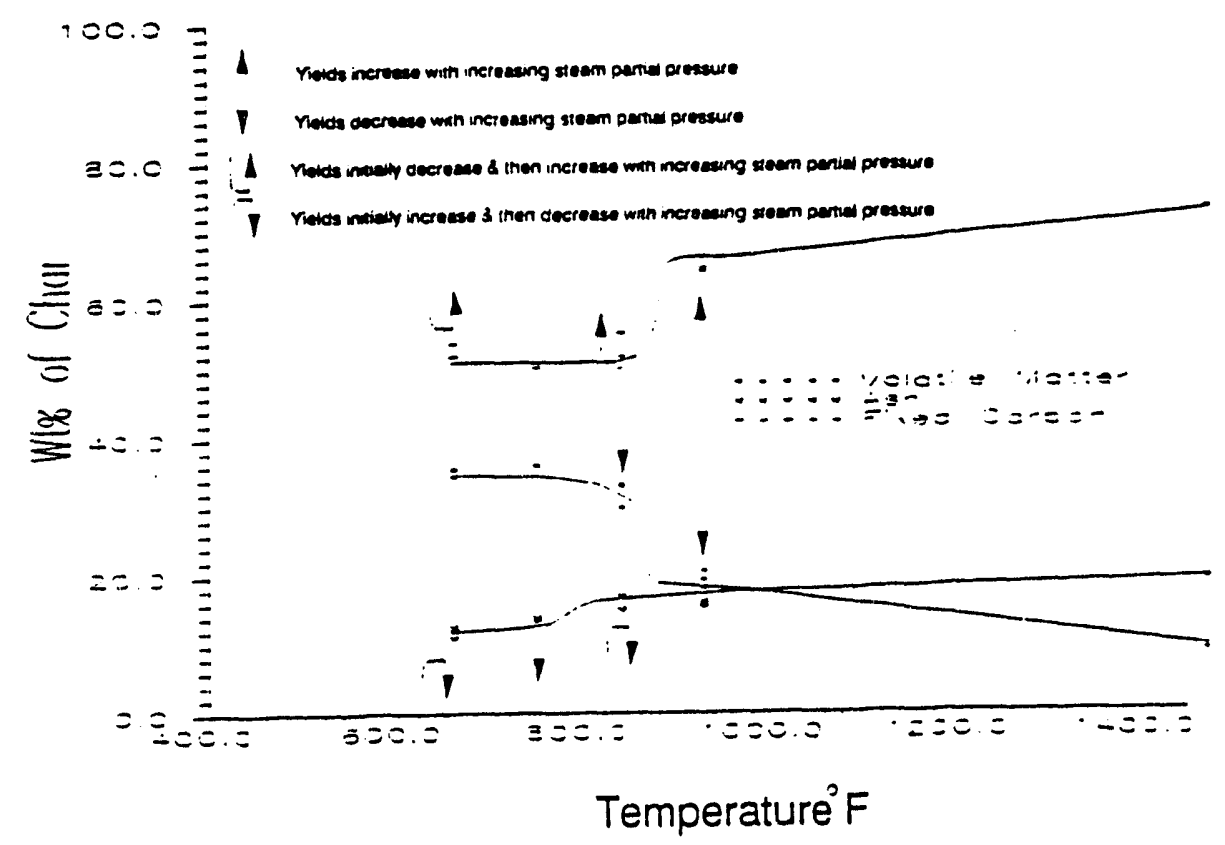

Figure 34. The effect of temperature and steam/nitrogen partial pressure on Indiana No. 3 char proximate analysis. 


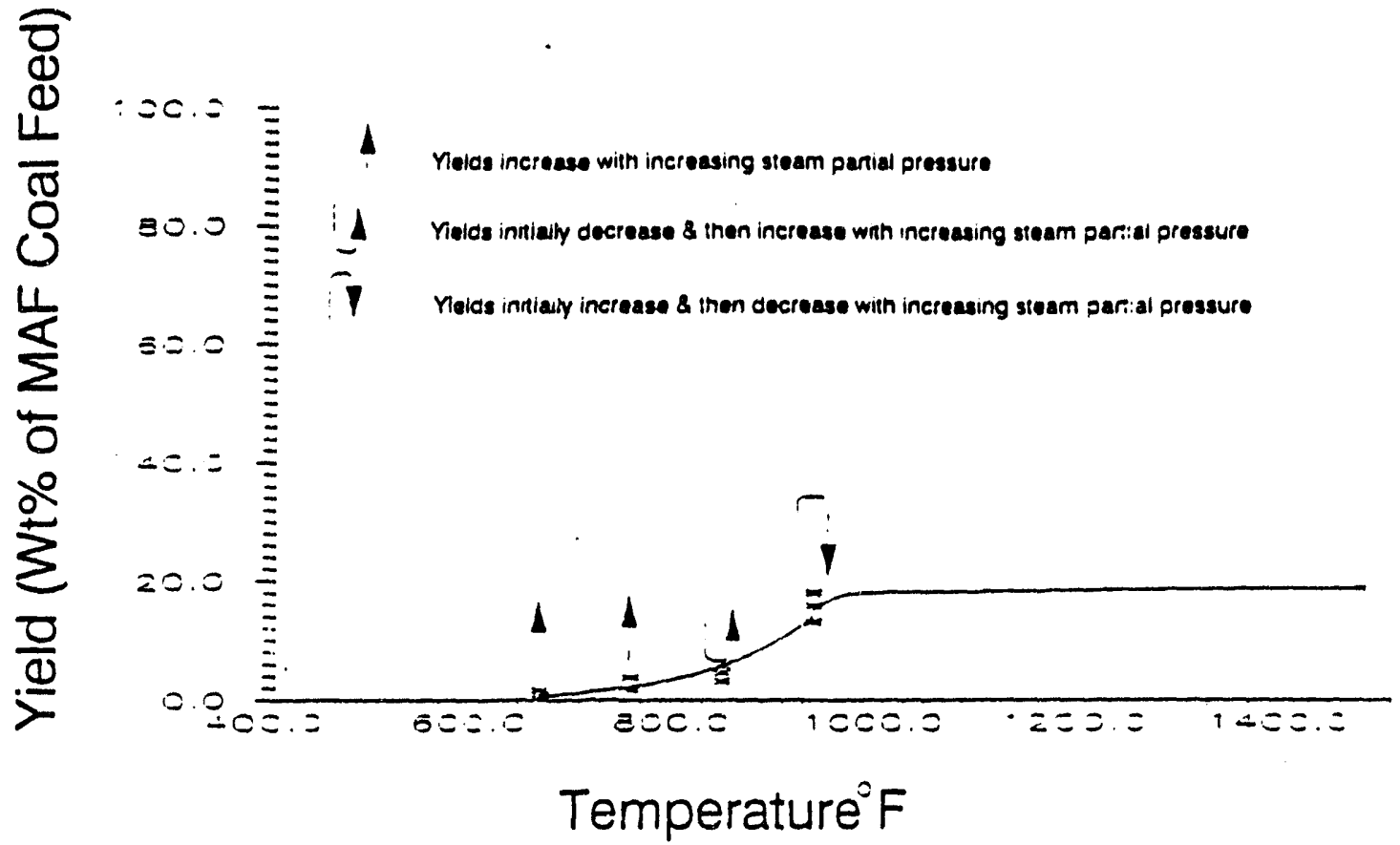

Figure 35. The effect of temperature and steam/nitrogen partial pressure on Indiana No. 3 condensables yields.

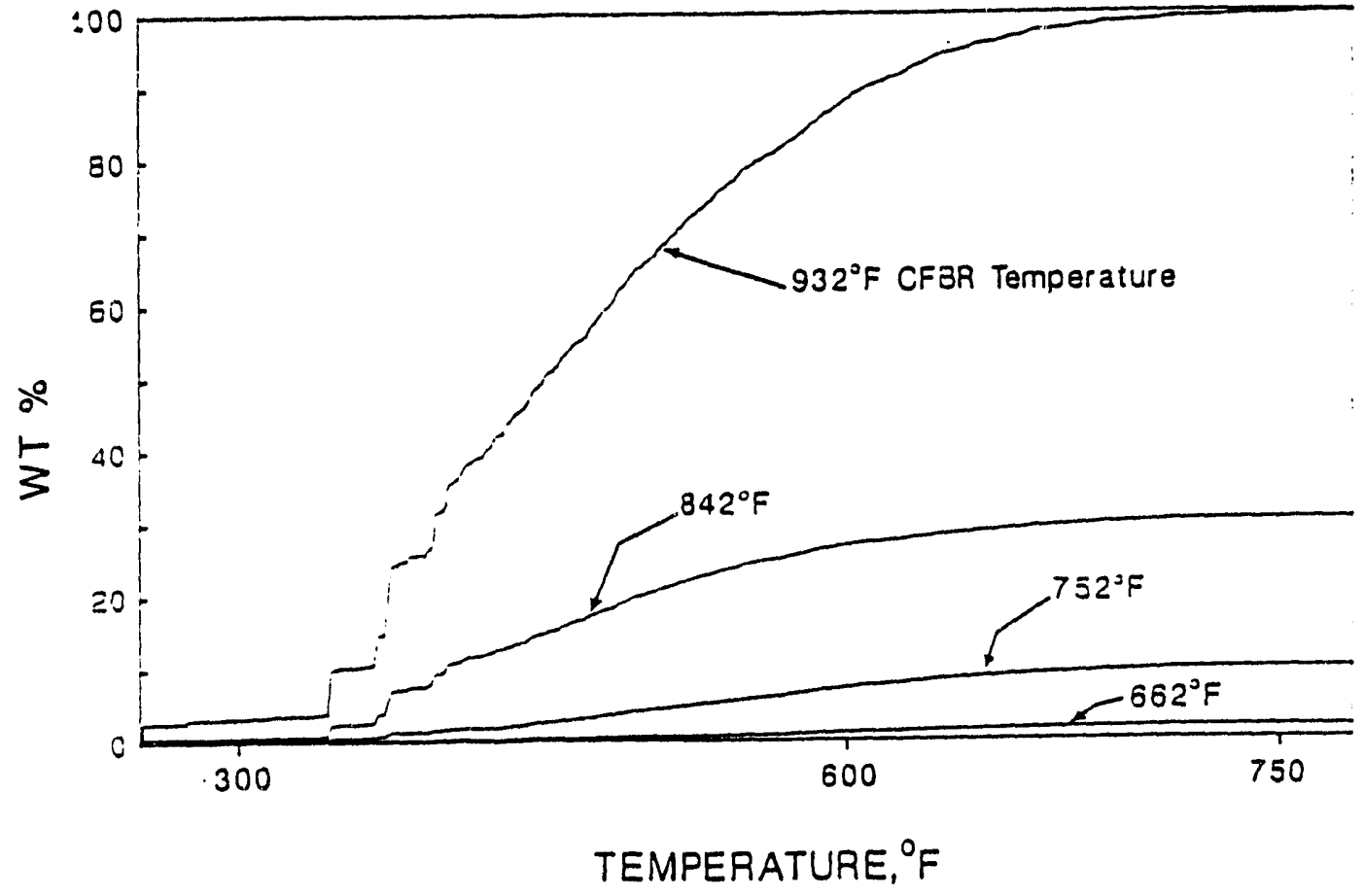

Figure 36. Indiana No. 3 condensable boiling point distributions. 
Analysis of Indiana No. 3 Coal Liquids

\begin{tabular}{lrr}
\hline & Totals \\
Benzene and Toluene & 2.75 & \\
>1-ring Aromatics & 1.18 & 3.93 \\
$\quad$ Total Aromatics & & \\
Phenol & 6.11 & \\
Cresols & 13.36 & \\
Xylenols & 11.13 & \\
C3-Phenols & 3.55 & 34.15 \\
$\quad$ Total POH & & \\
Normal Alkanes & & \\
C6-9 & & \\
ibp to $330^{\circ} \mathrm{F}$ & 0.02 & \\
C10-12 & & \\
$330^{\circ}$ to $430^{\circ} \mathrm{F}$ & 0.61 & \\
C12-22 & & \\
$430^{\circ}$ to $710^{\circ} \mathrm{F}$ & 5.00 & \\
C23-25 & & \\
$710^{\circ} \mathrm{F}$ plus & 0.37 & 44.08 \\
Total Alkanes & & \\
Total Identified & 44.08 & \\
\hline
\end{tabular}

The simulated distillation data shown in Figure 37 and Table 13 indicate that greater amounts of low-boiling material were produced at the higher staging temperatures of $840^{\circ}$ and $930^{\circ} \mathrm{F}\left(450^{\circ}\right.$ and $\left.500^{\circ} \mathrm{C}\right)$. Classification of the data into the four boiling point ranges shown in Tables 12 and 13 leads to the following observations:

ibp to $330^{\circ} \mathrm{F}$ (ibp to $165^{\circ} \mathrm{C}$ ) - This $3.6 \mathrm{wt} \%$ fraction consists mainly of lower alkanes, benzene, and toluene, and would be suitable as a gasoline octane enhancer.

Alternatively, it could be processed using the Dynaphen process to produce benzene.

$330^{\circ}$ to $430^{\circ} \mathrm{F}\left(165^{\circ}\right.$ to $\left.220^{\circ} \mathrm{C}\right)$. This fraction representing $35 \mathrm{wt} \%$ of the total condensate is $86 \%$ phenol, cresol, and zylenol, and the remaining $14 \%$ is alkylated benzenes and aliphatics. It could be used to produce mixed cresylic acids or be processed by the Dynaphen process to produce pure benzene and phenol.

$430^{\circ}$ to $710^{\circ} \mathrm{F}\left(220^{\circ}\right.$ to $\left.375^{\circ} \mathrm{C}\right)$ - This faction represents $60 \mathrm{wt} \%$ of the condensate and is highly diverse, containing mixed aliphatics, alkylated phenolics, and 2- and 3ring aromatics. Its phenolic content of 6 wt\% is based only on the identification of the trimethylphenols, and additional small peaks could add 3 to $5 \mathrm{wt} \%$ to the polar material content. Part of this fraction could be used with the higher boiling pitch fraction directly as a binder in making briquettes. Extraction of the phenolics could potentially yield a phenolic fraction that could be processed in the Dynaphen process. The separated aliphatic-aromatic fraction may be usable in diesel fuel blends. 


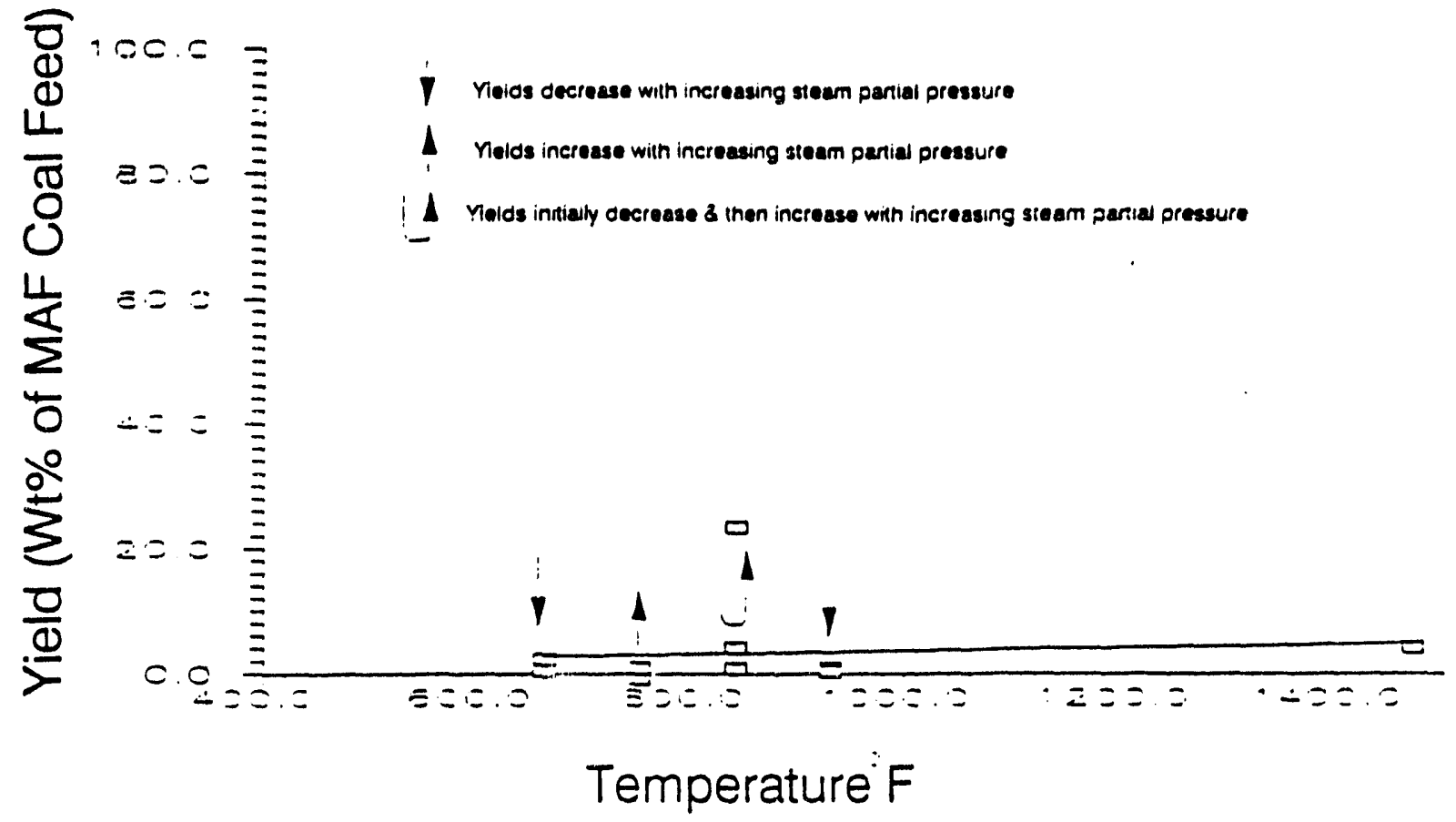

Figure 37. The effect of temperature and steam/nitrogen partial pressure on Indiana No. 3 water yields.

TABLE 13

Simulated Distillation of Liquids from Staged Heating of Indiana No. 3 Coal

\begin{tabular}{|c|c|c|c|c|c|c|c|c|}
\hline \multirow{3}{*}{$\begin{array}{l}\text { Staging Temperature, }{ }^{\circ} \mathrm{F} \\
\text { wt\% maf yield at staging } \\
\text { temperature }\end{array}$} & \multicolumn{5}{|r|}{$\begin{array}{c}\text { Composite } \\
\text { Total }\end{array}$} & \multicolumn{3}{|c|}{$\begin{array}{l}\text { Compound Type } \\
\text { Distribution }\end{array}$} \\
\hline & 660 & 750 & 840 & 930 & & & & \\
\hline & 0.30 & 1.44 & 3.63 & 12.47 & 17.84 & & & \\
\hline & \multicolumn{5}{|c|}{ Condensates, wt\% } & Aliphatic & Phenolic & Aromatic \\
\hline ibp to $330^{\circ} \mathrm{F}$ & 0.38 & 1.62 & 2.54 & 4.23 & 3.61 & 0.02 & & 3.59 \\
\hline $330^{\circ}$ to $430^{\circ} \mathrm{F}$ & 13.67 & 18.58 & 46.01 & 34.72 & 35.36 & 0.61 & 30.60 & 4.15 \\
\hline $430^{\circ}$ to $710^{\circ} \mathrm{F}$ & 78.60 & 76.19 & 51.35 & 59.65 & 59.61 & 5.00 & 3.55 & 51.07 \\
\hline plus $710^{\circ} \mathrm{F}$ & 7.35 & 3.61 & 0.10 & 1.40 & 1.41 & 0.37 & & 1.04 \\
\hline Total & 100.00 & 100.00 & 100.00 & 100.00 & 100.00 & 6.00 & 34.12 & 59.85 \\
\hline
\end{tabular}


plus $-710^{\circ} \mathrm{F}$ (plus $\cdot 375^{\circ} \mathrm{C}$ ) - This pitch fraction represents $1.4 \mathrm{wt} \%$ of the condensate. This material, along with a portion of the previous fraction, can be used as a binder in briquetting and possibly to produce needle coke, anode carbon, etc. Removal of nitrogen-based compounds (expected to be present) would be needed to make this material a suitable carbon fiber feedstock (10).

\subsubsection{The Effect of Temperature and Steam/Nitrogen Partial Pressure on Indiana No, 3 Water Yields}

Water yields on average increased slightly from $0.5 \%$ to $4.4 \%$ with increasing temperature between $660^{\circ}$ and $1470^{\circ} \mathrm{F}\left(350^{\circ}\right.$ and $\left.800^{\circ} \mathrm{C}\right)$, Figure 37. Steam did not have any consistent effect on water yields.

\subsubsection{The Effect of Temperature and Steam/Nitrogen Partial Pressure on Indiana No. 3 Gas Yields}

Gas yields increased linearly with temperatures from $3 \%$ to $21 \%$ (Figure 38 ). $\mathrm{CO}_{2}$, $\mathrm{H}_{2}, \mathrm{CO}, \mathrm{CH}_{4}$, and $\mathrm{H}_{2} \mathrm{~S}$ all increased with temperature (Figure 39). Steam partial pressure did not have a consistent effect on the gas yield between $660^{\circ}$ and $1470^{\circ} \mathrm{F}\left(350^{\circ}\right.$ and $\left.800^{\circ} \mathrm{C}\right)$.

\subsection{Results of Bench-Scale Indiana No. 3 Wastewater Tests}

Mild gasification produces a contaminated process condensate stream that must be treated prior to reuse or discharge to the environment. Biological treatment removes biodegradable organics, such as $\mathrm{BOD}_{5}$ and phenol, from wastewater. Ammonia oxidation (nitrification) will also occur if favorable conditions are maintained for the development of nitrifying bacteria. The goal of this study was to verify the treatability of mild gasification process condensates by the activated sludge process, without pretreatment for process data for PDU design.

\subsubsection{Wastewater Characteristics}

A sample of Indiana No. 3 coal mild gasification process condensate was chemically characterized for the parameters given in Table 14. This wastewater was found to contain relatively low concentrations of organic constituents, compared to other gasification wastewaters. Heavy metals concentrations, e.g., barium, chromium, lead, and silver, were all below drinking water standards.

\subsubsection{Equipment Description}

A schematic diagram of the bench-scale activated sludge system is shown in Figure 40. The mixed liquor aeration basin consisted of a 10-liter plexiglass tank with an operating volume of six liters. Biological solids within the aeration basin were maintained in suspension by mechanical mixing. Oxygen was supplied to the system as filtered, humidified, and compressed air, through a coarse bubble diffuser. Wastewater was fed to the aeration basin by a peristaltic pump. Mixed liquor flowed by gravity to a secondary clarifier with an operating volume of approximately 650 milliliters. Biological solids that settled to the bottom of the secondary clarifier were recycled back to the aeration basin three times each hour. Supernatant and nonsettleable solids overflowed a central weir and were collected in an effluent storage tank. 


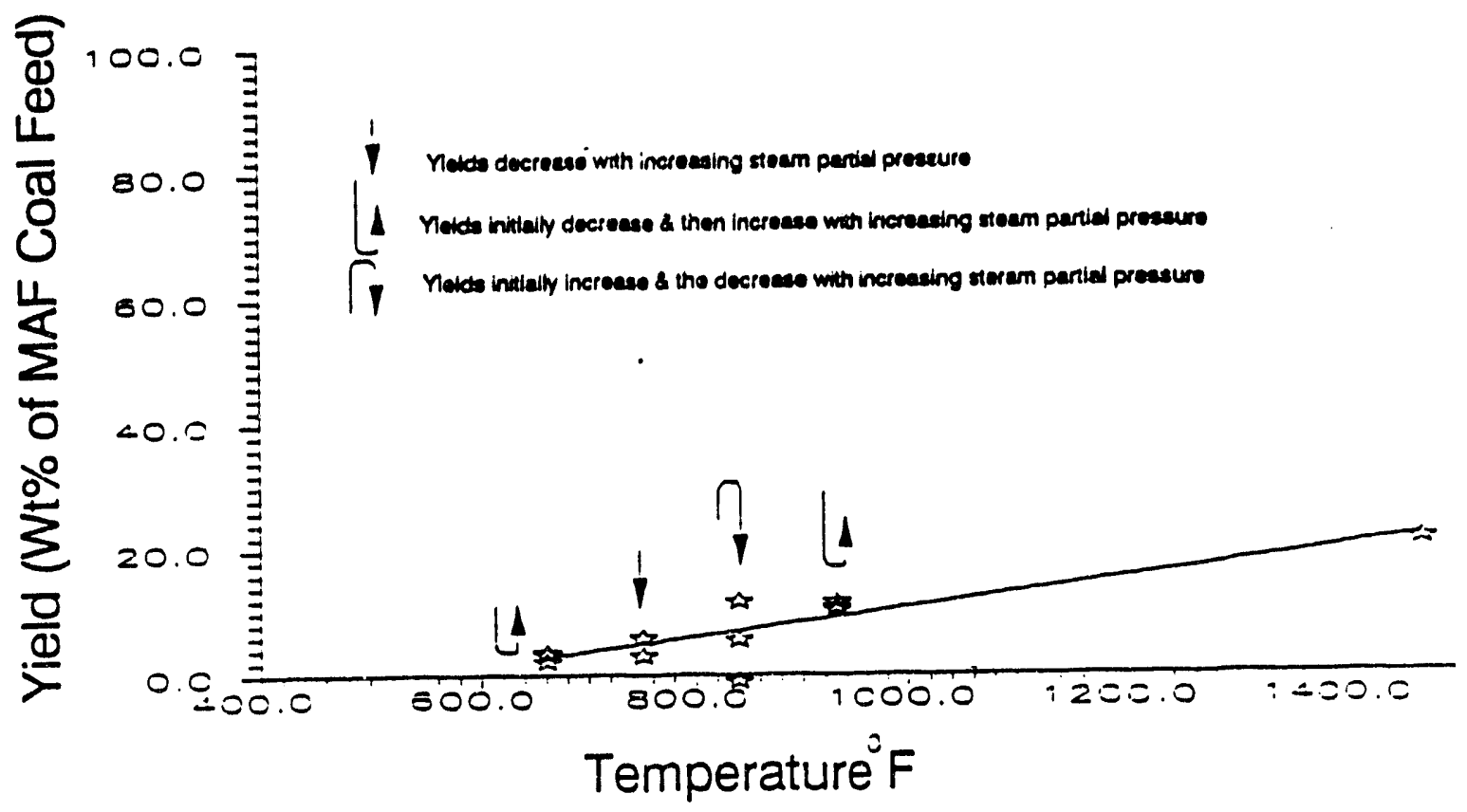

Figure 38. The effect of temperature and steam/nitrogen partial pressure on Indiana No. 3 gas yields.

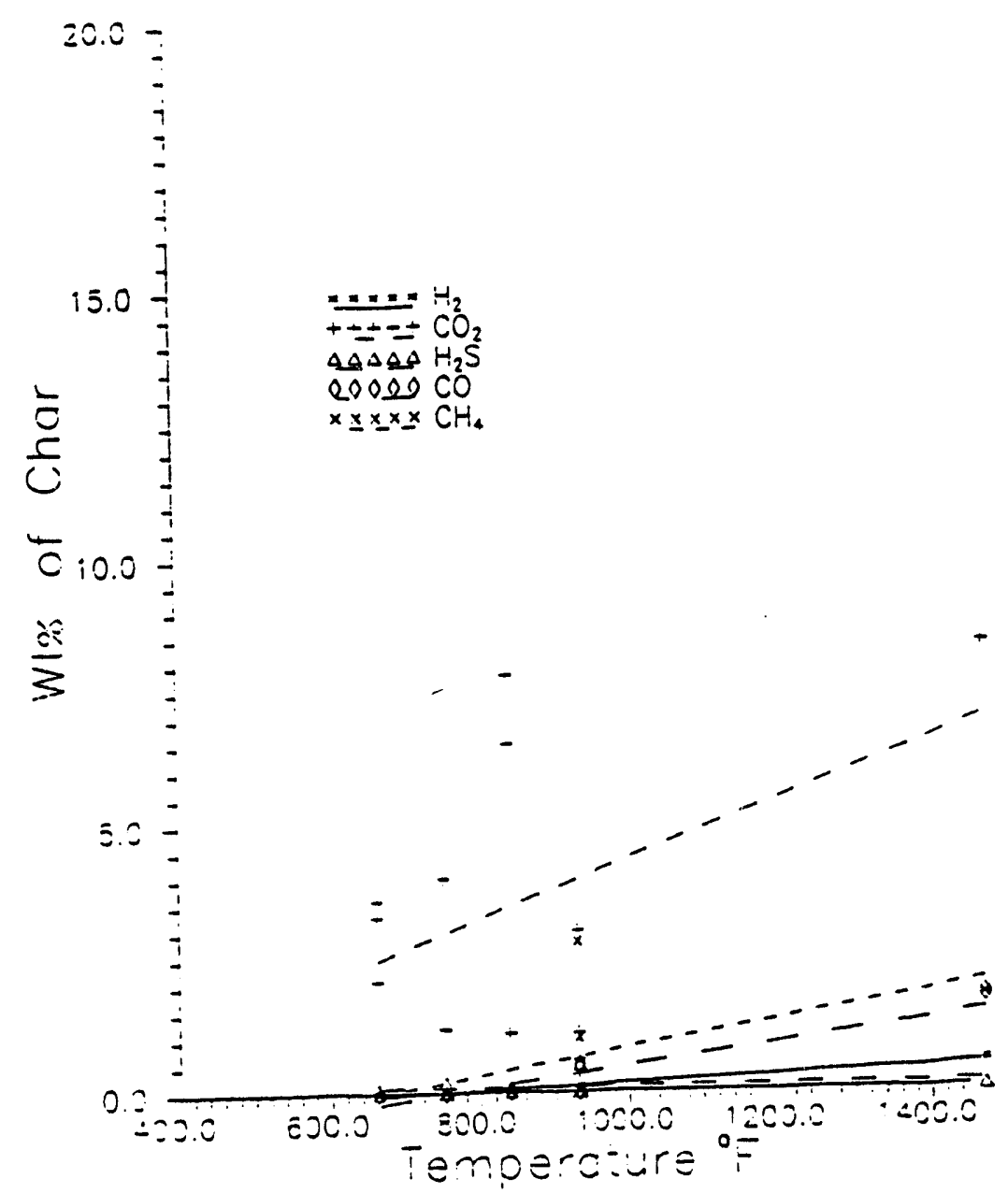

Figure 39. The effect of temperature and steam/nitrogen partial pressure on Indiana No. 3 gas component yields. 


\section{TABLE 14}

Raw Process Wastewater Characterization Data

\begin{tabular}{lc}
\hline \multicolumn{1}{c}{ Parameter/Constituent } & $\begin{array}{c}\text { Indiana No. } 3 \text { Mild Gasification } \\
\text { Process }\end{array}$ \\
\hline pH & 4.09 \\
Ammonia, total & $75.0^{\circ}$ \\
Ammonia, steam-strippable & 31.0 \\
Cyanide, total & 1.3 \\
Sulfide & $<5.0$ \\
Thiocyanate & 0.8 \\
Thiosulfate & 3.0 \\
Chemical Oxygen Demand & 4590.0 \\
Biochemical Oxygen Demand & 2040.0 \\
Phenol (4AAP) & 365.0 \\
Arsenic, $\mu \mathrm{m} / \mathrm{L}$ & $<50.0$ \\
Barium & $<0.2$ \\
Cadmium & $<0.02$ \\
Chromium & $<0.02$ \\
Lead & $<0.6$ \\
Mercury, $\mu \mathrm{m} / \mathrm{L}$ & $<3.0$ \\
Sele $i$ ium, $\mu \mathrm{m} / \mathrm{L}$ & 6.1 \\
Silver, $\mu \mathrm{m} / \mathrm{L}$ & $<1.0$ \\
\hline
\end{tabular}

- All values in $\mathrm{mg} / \mathrm{L}$, unless otherwise designated.

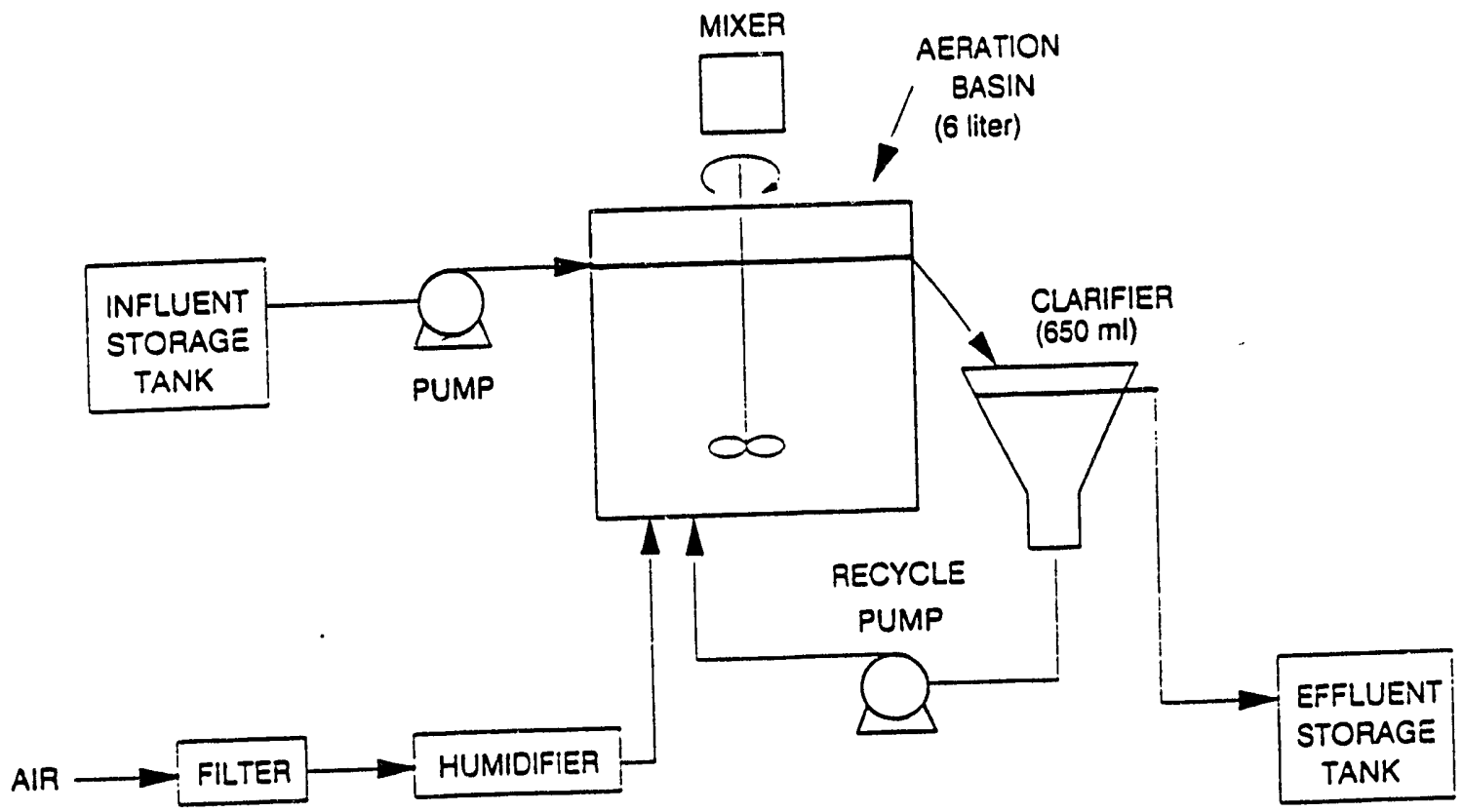

Figure 40. Bench-scale activated sludge system schematic. 


\subsubsection{Operation}

The bench-scale activated system was seeded with mixed liquor from another activated sludge reactor treating liquor from the Great Plains Gasification Plant. The test reactor was fed mild gasification wastewater diluted with pretreated Lurgi wastewater, with decreasing dilutions over the period of approximately one week. The high $\mathrm{pH}$ of the influent stream required adjustment to 7.0 using dilute sulfuric acid prior to being fed to the reactor. The reactor was operated on undiluted mild gasification wastewater for an additional week for acclimation and stabilization. Sampling and analysis for the evaluation of treatability performance was conducted during the third week of operation. The sampling period was short due to the limited amount of Indiana No. 3 mild gasification wastewater that was available.

Activated sludge parameters calculated for monitoring system operation included the solids retention time (SRT), the hydraulic retention time (HRT), the mixed liquor suspended solids (MLSS) concentration, and the food-to-microorganism (F/M) ratio. Among these, the two that were used to control the bench-scale activated sludge system were the HRT and SRT. The HRT was regulated by adjusting the influent feed rate. The SRT was controlled through volumetric wasting of mixed liquor. Routine testing procedures included measuring flow rates, $\mathrm{pH}$, temperature, mixed liquor dissolved oxygen concentration, mixed liquor solids settleability, and mixed liquor dissolved oxygen uptake rate.

\subsubsection{Results and Discussion}

Table 15 summarizes average operating parameters and conditions of the treatability study.

Organic parameters used to evaluate treatability included $\mathrm{BOD}_{5}, \mathrm{COD}$, and phenol. Activated sludge treatment at a 10 -day solids retention time resulted in a $97 \% \mathrm{BOD}_{5}$ removal, from an average of $1715 \mathrm{mg} / \mathrm{L}$ influent concentration to $54 \mathrm{mg} / \mathrm{L}$ in the effluent. COD was reduced from $4590 \mathrm{mg} / \mathrm{L}$ to $2320 \mathrm{mg} / \mathrm{L}$, a $50 \%$ removal efficiency. A $93 \%$ phenol reduction was achieved, with influent and effluent concentrations of $315 \mathrm{~m}, \mathrm{~L}$ and $23 \mathrm{mg} / \mathrm{L}$, respectively. Ammonia was reduced from $181 \mathrm{mg} / \mathrm{L}$ to $165 \mathrm{mg} / \mathrm{L}$. The slight ammonia removal that occurred can be attributed entirely to air-stripping and biological nitrogen requirements. Table 16 summarizes average constituent removals during treatability testing.

Although high removal efficiencies were achieved during the abbreviated testing period, a considerable amount of organics (54 $\mathrm{mg} \mathrm{BOD} / \mathrm{siter}$ ) remained in the effluent. With a longer period of operation for acclimation and stabilization, a higher effluent quality would be expected, as no apparent inhibition was observed during treatment. Approximately 50\% of the chemical oxygen demand was accounted for in the effluent. Removal of these biorefractory organics would require tertiary treatment. These effluent polishing steps might include ozonation, activated carbon adsorption, or chemical coagulation and precipitation. Stringent discharge criteria may require further reduction of effluent ammonia. This may be accomplished through ion-exchange using clinoptilolite, a naturally occurring zeolite. 
TABLE 15

Operating Parameters for Activated Sludge Treatment of Indiana No. 3 Mild Gasification Process Wastewater

\begin{tabular}{lcc}
\hline \multicolumn{1}{c}{ Parameter } & Units & Value \\
\hline HRT & days & 2.9 \\
SRT & days & 10.2 \\
F/M & $\mathrm{g} \mathrm{BOD}_{\mathrm{s}}$ removed/ & 0.45 \\
& $\mathrm{~g} \mathrm{MLVSS/day}$ & \\
MLVSS & $\mathrm{mg} / \mathrm{L}$ & 1290.0 \\
MLSS & $\mathrm{mg} / \mathrm{L}$ & 1390.0 \\
Solids Settleability & $\mathrm{mL} / \mathrm{L}$ & 67.0 \\
Sludge Volume Index & $\mathrm{mL} / \mathrm{g}$ & 48.2 \\
Oxygen Uptake Rate & $\mathrm{mg} / \mathrm{L} / \mathrm{min}$ & 0.17 \\
& $\mathrm{mg} / \mathrm{g} / \mathrm{hour}$ & 7.8 \\
\hline
\end{tabular}

TABLE 16

Average Constituent Removals by Activated Sludge Treatment of Indiana No. 3 Mild Gasification Process Wastewater

\begin{tabular}{lccc}
\hline \multicolumn{1}{c}{ Parameter } & Influent, $\mathrm{mg} / \mathrm{L}$ & Effluent, $\mathrm{mg} / \mathrm{L}$ & Removal, \% \\
\hline BOD $_{5}$ & 1720 & 54 & 96.9 \\
COD & 4590 & 2320 & 49.5 \\
Phenol (4AAP) & 315 & 23 & 92.7 \\
Ammonia & 181 & 165 & 8.8 \\
\hline
\end{tabular}

\subsubsection{Conclusions of Wastewater Treatment Study}

The conclusions from the brief treatability testing program on Indiana No. 3 mild gasification process wastewater are:

- Pretreatment was not required to provide effective biological treatment, but could be considered to enhance removal efficiencies of arsenic and selenium.

- Although high $\mathrm{BOD}_{5}$ and phenol removal efficiencies were achieved, better removals can be anticipated with a longer operating period for acclimation and stabilization.

- Depending upon effluent discharge regulations, further effluent polishing steps may be required to reduce refractory COD and ammonia concentrations.

- A complete bench-scale treatability testing program should be performed to determine the relative treatment efficiencies under various operating conditions and to determine the degree of effluent polishing necessary to meet assumed effluent discharge criteria. 


\subsection{RESULTS OF TESTS ON CANNELTON COAL}

The test matrix for the Cannelton test series is shown in Table 17. Due to the higher swelling index, 6, of the Cannelton compared to the 4.5 index of Indiana No. 3 testing proceeded directly to the staged heating tests. The experimental conditions evaluated for the Cannelton ranged from $660^{\circ} \mathrm{F}\left(350^{\circ} \mathrm{C}\right)$ to $1290^{\circ} \mathrm{F}\left(700^{\circ} \mathrm{C}\right)$. Steam was not used in any of the tests. In the test series using a single reactor, char produced at $660^{\circ} \mathrm{F}\left(350^{\circ} \mathrm{C}\right)$ was collected and subsequently fed back into the reactor at $730^{\circ} \mathrm{F}\left(390^{\circ} \mathrm{C}\right)$. Char was again collected and the process was repeated until the final temperature, $1290^{\circ} \mathrm{F}\left(700^{\circ} \mathrm{C}\right)$, was achieved. The temperature ramp was somewhat different than that used for the Indiana No. 3 tests because the higher swelling index forced the used of more temperature stages.

\subsection{The Effect of Temperature on Cannelton Char Yields}

Char yields ranged from $99.5 \mathrm{wt} \%$ at $660^{\circ} \mathrm{F}\left(350^{\circ} \mathrm{C}\right)$ to $74 \mathrm{wt} \%$ at $1290^{\circ} \mathrm{F}\left(700^{\circ} \mathrm{C}\right)$. The largest drop occurred between $790^{\circ} \mathrm{F}\left(420^{\circ} \mathrm{C}\right)$ to $930^{\circ} \mathrm{F}\left(500^{\circ} \mathrm{C}\right)$ as shown in Figure 41. The volatile content of the char decreased from 33 to $7 \mathrm{wt} \%$ over the range of temperatures studied, Figure 42. Related trends are seen for the fixed carbon (54 to 73 wt\%) and ash contents (12.6 to $19.7 \mathrm{wt} \%)$. The Cannelton coal produced char in slightly higher levels than the Indiana No. 3. $\left(74\right.$ wt\% at $1290^{\circ} \mathrm{F}$ to 63 wt\% at $1470^{\circ} \mathrm{F}$, respectively). While the Indiana No. 3 was operated at $180^{\circ} \mathrm{F}$ higher than the Cannelton, the temperature would not account for $11 \mathrm{wt} \%$ difference in char yields.

Figure 43 shows the changes in the ultimate analysis. It should be noted the carbon content remains fairly constant with oxygen and hydrogen contents decreasing with increasing processing temperature.

\subsection{The Effect of Temperature on Cannelton Condensable Yields}

Condensable yields increased from $0.9 \mathrm{wt} \%$ at $730^{\circ} \mathrm{F}\left(390^{\circ} \mathrm{C}\right)$ to $19 \mathrm{wt} \%$ at $1290^{\circ} \mathrm{F}$ $\left(700^{\circ} \mathrm{C}\right)$, as shown in Figure 41 . The intermediate yields were accumulations from each stage plus the previous stages. These yields are very comparable to the Indiana No. 3 yields. This is to be expected as the volatile contents of the two coals were very similar.

Condensable boiling point distribution is shown in Figure 44. Each processing stage produced lighter material. The total combined material had a boiling point distribution between \#2 diesel and the decant which is equivalent to a $\# 5$ or $\# 6$ diesel. This is a good. quality liquid without any separation and might prove to be a very useful feedstock for chemicals, diesel fuel additives, or anode-binders.

\subsection{The Effect of Temperature on Cannelton Gas Yields}

Gas yields were low, ranging from $0.3 \mathrm{wt} \%$ at $660^{\circ} \mathrm{F}\left(350^{\circ} \mathrm{C}\right)$ to $8.5 \mathrm{wt} \%$ at $1290^{\circ} \mathrm{F}$ $\left(700^{\circ} \mathrm{C}\right)$. Gas was not readily produced until $930^{\circ} \mathrm{F}\left(500^{\circ} \mathrm{C}\right)$. Figure 41 shows the product gas yields. 
TABLE 17

Test Matrix for Cannelton Coal

\begin{tabular}{cccc}
\hline Run No. & Temperature, ${ }^{\circ} \mathrm{F} /{ }^{\circ} \mathrm{C}$ & Press & Gas \\
\hline M247 & $660 / 350$ & 10 & $\mathrm{~N}_{2}$ \\
M248 & $730 / 390$ & 10 & $\mathrm{~N}_{2}$ \\
M256 & $790 / 420$ & 10 & $\mathrm{~N}_{2}$ \\
M257 & $860 / 460$ & 10 & $\mathrm{~N}_{2}$ \\
M258 & $930 / 500$ & 10 & $\mathrm{~N}_{2}$ \\
M259 & $1290 / 700$ & 10 & $\mathrm{~N}_{2}$ \\
\hline
\end{tabular}

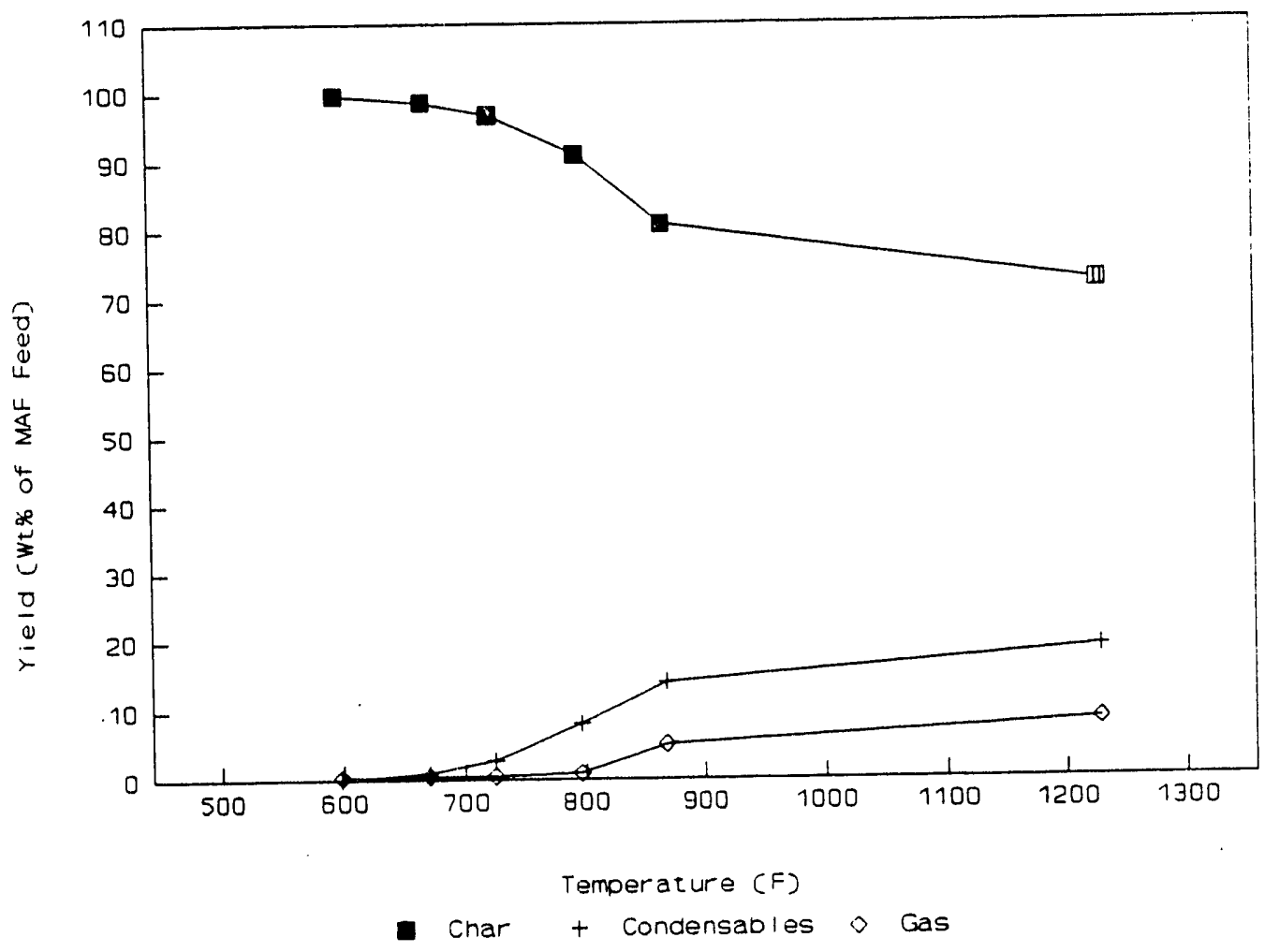

Figure 41. The effect of temperature on Cannelton product yields. 


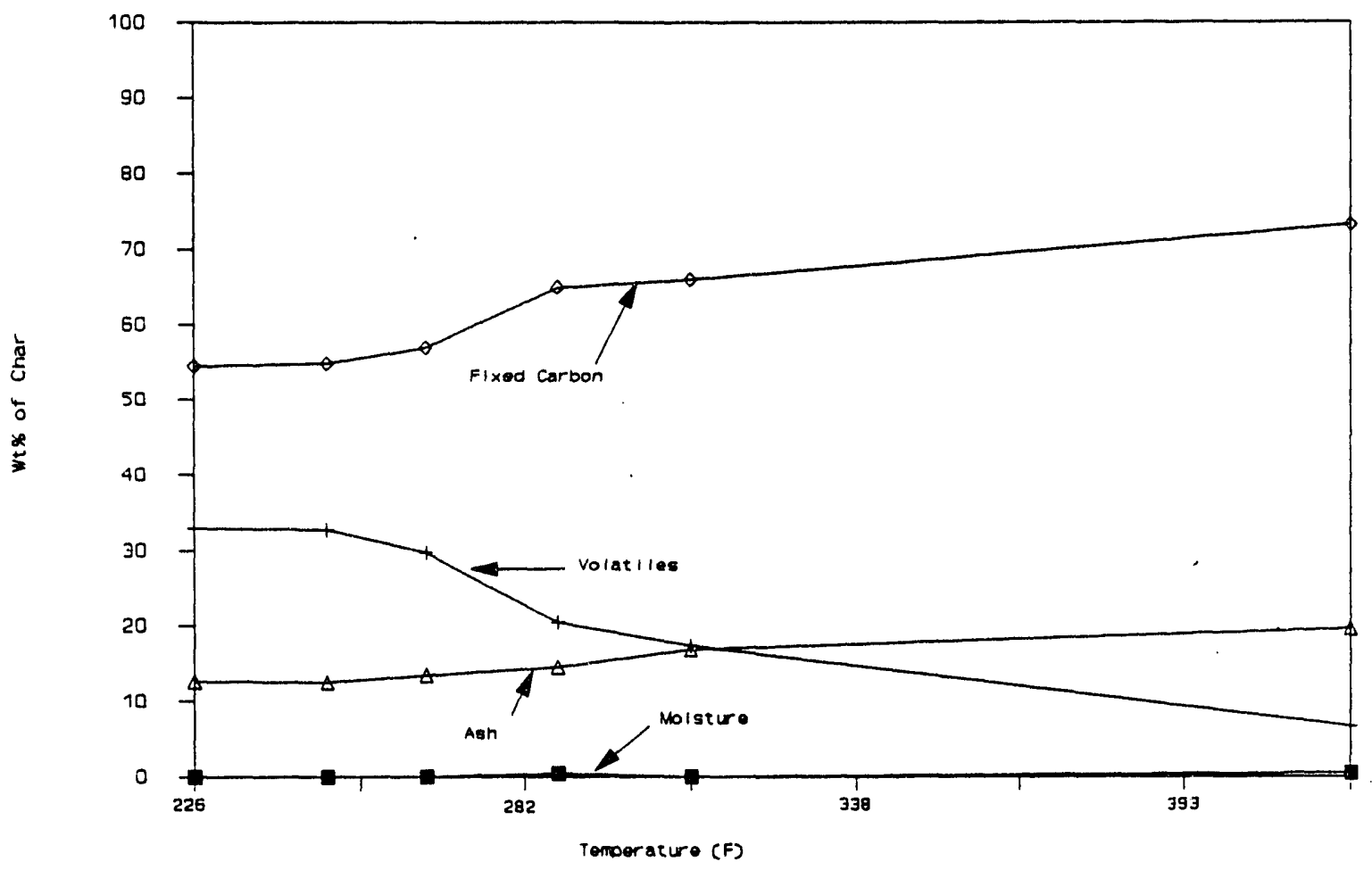

Figure 42. The effect of temperature on Cannelton char proximate analyses.

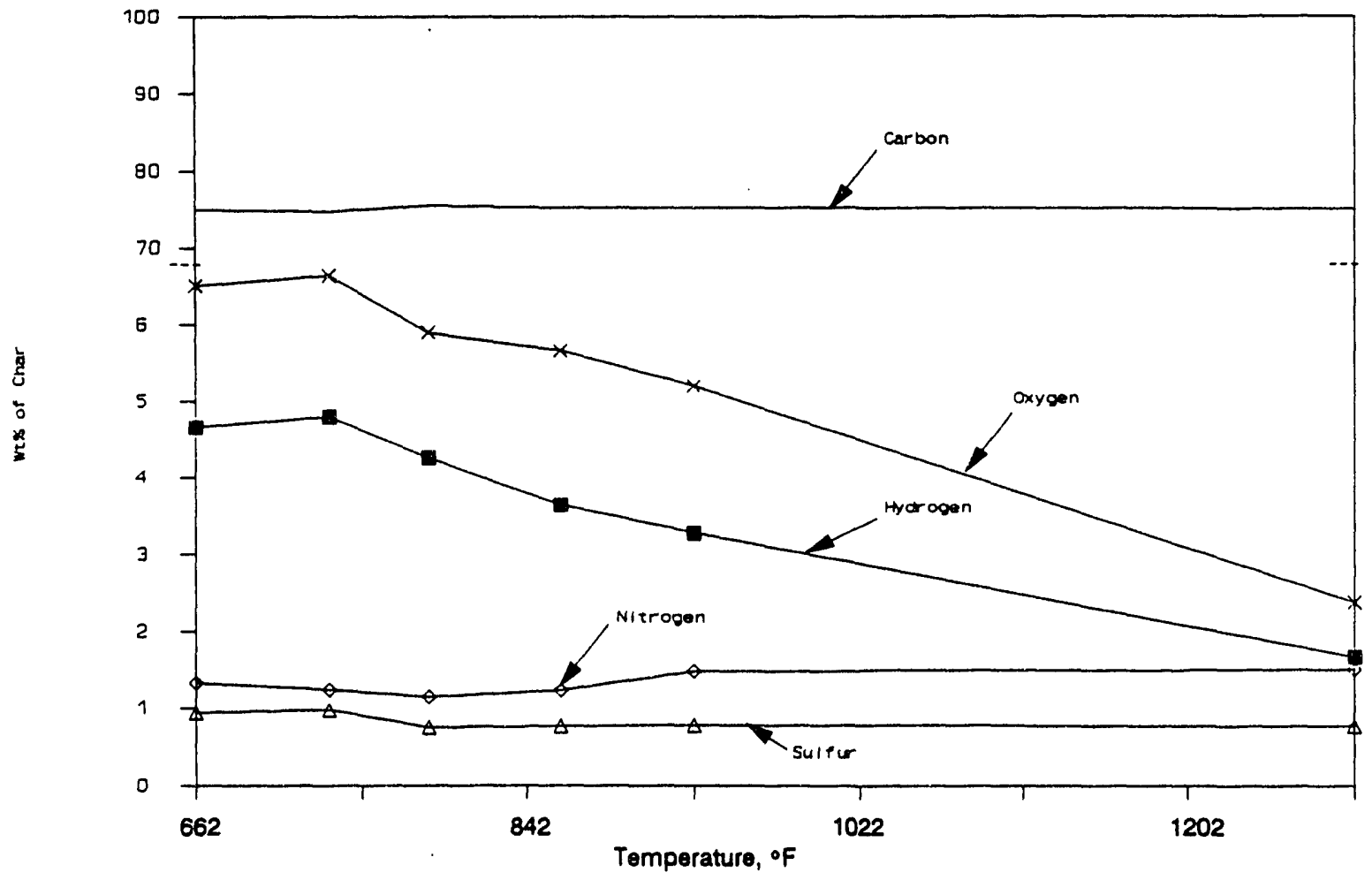

Figure 43. The effect of temperature on Cannelton char ultimate analyses. 


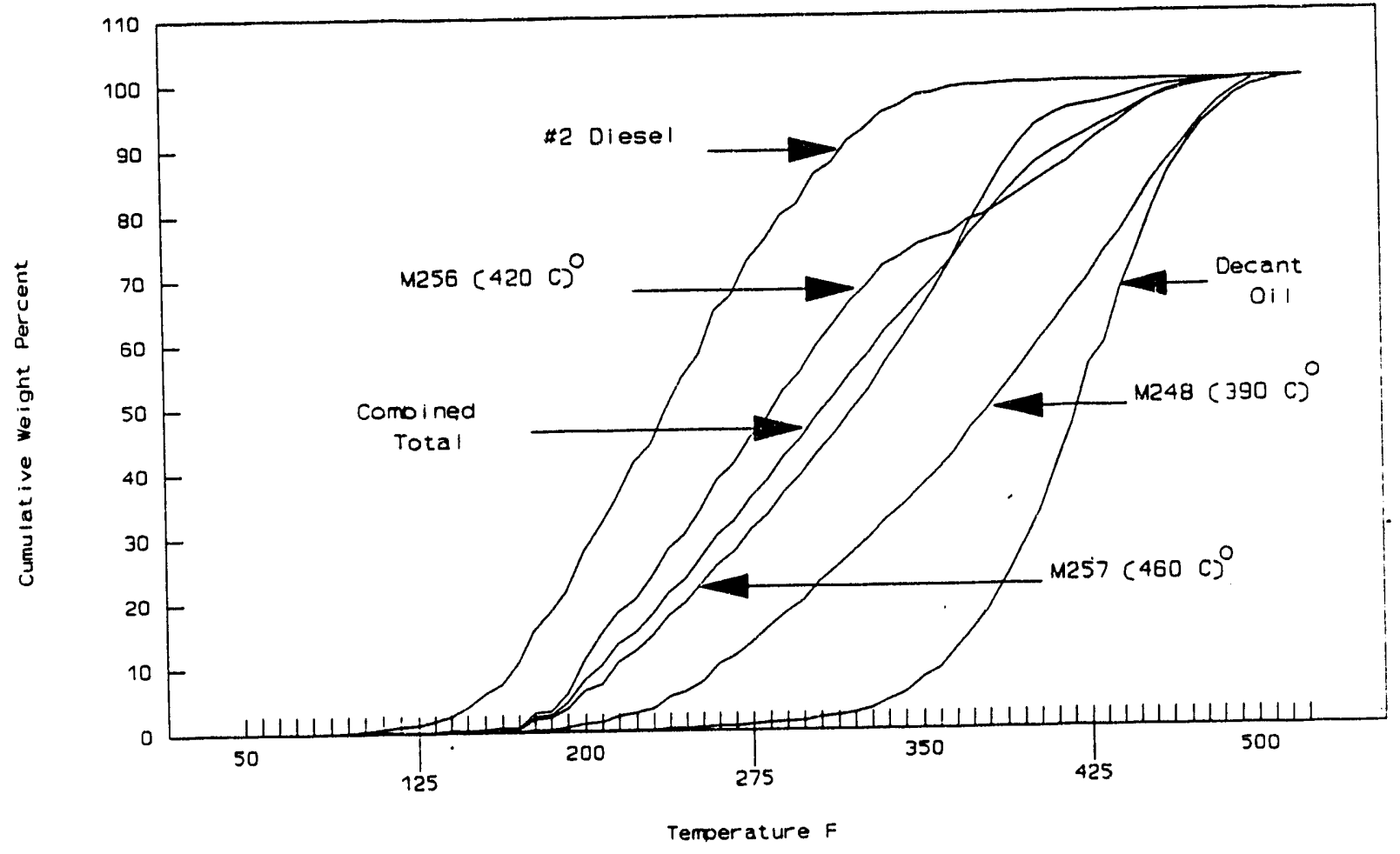

Figure 44. Cannelton condensable simulated distillation curve. 


\subsection{TASK 4 OBJECTIVES}

The primary objective of Task 4 was to provide products for end-use testing for the production of metallurgical coke substitutes, char upgrading for sulfur removal, chemical feedstocks and diesel fuel additives. Operability data were gathered for the carbonizer and condensation train. The data generated from the test program were then used to perform an economic assessment of a commercial mild gasification plant. 


\subsection{RESULTS FROM TESTS ON THE PROCESS RESEARCH UNIT (PRU)}

The 16 tests run on Wyodak and Indiana No. 3 coal are shown in Table 18. Wyodak coal was used in all shakedown activities and was used in the startup of the PRU to produce a char bed prior to the feeding of the Indiana coal. The water quench was used for the first tests but plugged very quickly with tar due to the low temperature of the system. It became evident that this approach would be useful only when operating the carbonizer at such conditions that would suppress condensable production such as in a gasifier or high-temperature carbonizer.

\section{TABLE 18}

PRU Carbonization Tests

\begin{tabular}{|c|c|c|c|c|c|c|c|}
\hline $\begin{array}{c}\text { Run } \\
\text { Number }\end{array}$ & Coal & $\begin{array}{c}\text { Temperature, } \\
{ }^{\circ} \mathrm{F} /{ }^{\circ} \mathrm{C}\end{array}$ & $\begin{array}{l}\text { Quench } \\
\text { System }\end{array}$ & Test Parameter & $\begin{array}{l}\text { Char } \\
\text { Yield }\end{array}$ & $\begin{array}{l}\text { Cond. } \\
\text { Yield }\end{array}$ & $\begin{array}{l}\text { Gas } \\
\text { Yield }\end{array}$ \\
\hline P001 & Refractory Cure & $2200 / 1200$ & Water & Shakedown Gas System & & & \\
\hline $\mathrm{P} 002$ & Petroleum Coke & $1100 / 600$ & Water & Shakedown Solids Handling & & & \\
\hline P003 & Wyodak & $1.100 / 600$ & Water & Shakedown Water Quench & & & \\
\hline P004 & Wyodak & $1100 / 600$ & Water & Early Shutdown & & & \\
\hline P005 & Wyodak & & Water & Early Shutdown & & & \\
\hline P006 & Wyodak & $1020 / 550$ & Tar/Oil & Shakedown Tar/Oil & & & \\
\hline $\mathrm{P} 007$ & Indiana & $1020 / 550$ & Tar/Oil & Shakedown Indiana Coal & & & \\
\hline P008 & Wyodak & $820 / 440$ & Tar/Oil & Quench Liquid Entrainment & & & \\
\hline P009 & Wyodak & $820 / 440$ & Tar/Oil & Quench Liquid Entrainment & & & \\
\hline P010 & Wyodak & $1100 / 600$ & Tar/Oil & Quench New Configuration & 49.0 & 9.0 & 42.0 \\
\hline P011 & Indiana & $1100 / 600$ & Tar/Oil & Quench New Configuration & & & \\
\hline P024 & Indiana & $1200 / 650$ & Tar/Oil & Production & 44.9 & 19.3 & 35.8 \\
\hline P025 & Indiana & $1100 / 600$ & Tar/Oil & Production & 51.6 & 12.5 & 35.9 \\
\hline P026 & Indiana & $1020 / 550$ & Tar/Oil & Production & 51.2 & 13.8 & 35.0 \\
\hline P027 & Indiana & $1020 / 550$ & Tar/Oil & Production & 55.5 & 9.4 & 35.2 \\
\hline P028 & Indiana & $1070 / 575$ & Tar/Oil & Production & 59.3 & 9.7 & 31.0 \\
\hline
\end{tabular}

\subsection{Product Characterization}

\subsubsection{Char Production}

\subsubsection{Wyodak Char Production}

Wyodak char yields varied from 49.0 to $44.9 \mathrm{wt} \%$ over a range of 1100 to $1200^{\circ} \mathrm{F}$ $\left(600\right.$ to $\left.650^{\circ} \mathrm{C}\right)$. This compares with $50.0 \mathrm{wt} \%$ at $1100^{\circ} \mathrm{F}\left(600^{\circ} \mathrm{C}\right)$ in the CFBR and 20 wt\% steam partial pressure. Tables 19,20, and 21 show the proximate analysis of the product char, primary cyclone char, and secondary char for the varying temperatures. Figure 45 shows a plot of the proximate analysis versus temperature. These comparisons are also very similar to the CFBR test series. (see Section 5.1). The range of values is associated with the range of variability in the duplicate tests. Figure 16 shows a typical particle-size distribution of the feed coal, char, and fines. The Addendum contains all the particle-size distributions for the Wyodak tests. 
TABLE 19

Carbonizer Product Char Proximate Analysis

\begin{tabular}{|c|c|c|c|c|c|}
\hline & \multirow{3}{*}{ Feed Coal } & P005 & P006 & P009 & \multirow{3}{*}{$\begin{array}{c}\mathrm{P} 010 \\
1100^{\circ} \mathrm{F} \\
\left(600^{\circ} \mathrm{C}\right)\end{array}$} \\
\hline & & \multicolumn{3}{|c|}{ | } & \\
\hline & & $\begin{array}{l}1100^{\circ} \mathrm{F} \\
\left(600^{\circ} \mathrm{C}\right)\end{array}$ & $\begin{array}{l}1020^{\circ} \mathrm{F} \\
\left(550^{\circ} \mathrm{C}\right)\end{array}$ & $\begin{array}{c}820^{\circ} \mathrm{F} \\
\left(440^{\circ} \mathrm{C}\right)\end{array}$ & \\
\hline Moisture & 23.9 & 1.5 & 1.39 & 1.36 & 0.3 \\
\hline Vol. Matter & 33.8 & 15.7 & 23.79 & 30.16 & 18.5 \\
\hline Fixed Carbon & 37.9 & 73.9 & 66.62 & 60.73 & 69.9 \\
\hline Ash & 4.4 & 72.1 & 8.21 & 7.76 & 11.7 \\
\hline Sulfur & & 3.0 & 0.27 & 0.4 & 0.7 \\
\hline
\end{tabular}

TABLE 20

Carbonizer Primary Cyclone Proximate Analysis

\begin{tabular}{|c|c|c|c|c|}
\hline & \multirow[t]{2}{*}{ P005 } & P006 & P009 & \multirow{2}{*}{$\begin{array}{l}P 010 \\
\ldots 1\end{array}$} \\
\hline & & \multicolumn{2}{|c|}{ |-..............-Primary Cyclone Char.................... } & \\
\hline & $\begin{array}{l}1100^{\circ} \mathrm{F} \\
\left(600^{\circ} \mathrm{C}\right)\end{array}$ & $\begin{array}{l}1020^{\circ} \mathrm{F} \\
\left(550^{\circ} \mathrm{C}\right)\end{array}$ & $\begin{array}{c}820^{\circ} \mathrm{F} \\
\left(440^{\circ} \mathrm{C}\right)\end{array}$ & $\begin{array}{l}1100^{\circ} \mathrm{F} \\
\left(600^{\circ} \mathrm{C}\right)\end{array}$ \\
\hline Moisture & 2.5 & 1.39 & 12.1 & 3.7 \\
\hline Vol. Matter & 15.0 & 23.79 & 28.06 & 18.5 \\
\hline Fixed Carbon & 69.2 & 66.62 & 59.24 & 66.8 \\
\hline Ash & 8.9 & 8.21 & 10.59 & 11.0 \\
\hline Sulfur & & 0.27 & 30.71 & 0.5 \\
\hline
\end{tabular}

TABLE 21

Carbonizer Secondary Cyclone Proximate Analysis

\begin{tabular}{|c|c|c|}
\hline & P005 & P006 \\
\hline & \multicolumn{2}{|c|}{ 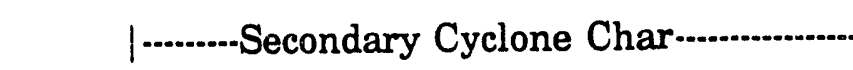 } \\
\hline & $\begin{array}{l}1100^{\circ} \mathrm{F} \\
\left(600^{\circ} \mathrm{C}\right) \\
\end{array}$ & $\begin{array}{l}1020^{\circ} \mathrm{F} \\
\left(550^{\circ} \mathrm{C}\right)\end{array}$ \\
\hline Moisture & 4.2 & 6.11 \\
\hline Vol. Matter & 16.0 & 18.80 \\
\hline Fixed Carbon & 65.5 & 62.22 \\
\hline Ash & 14.4 & 12.85 \\
\hline Sulfur & & 0.51 \\
\hline
\end{tabular}




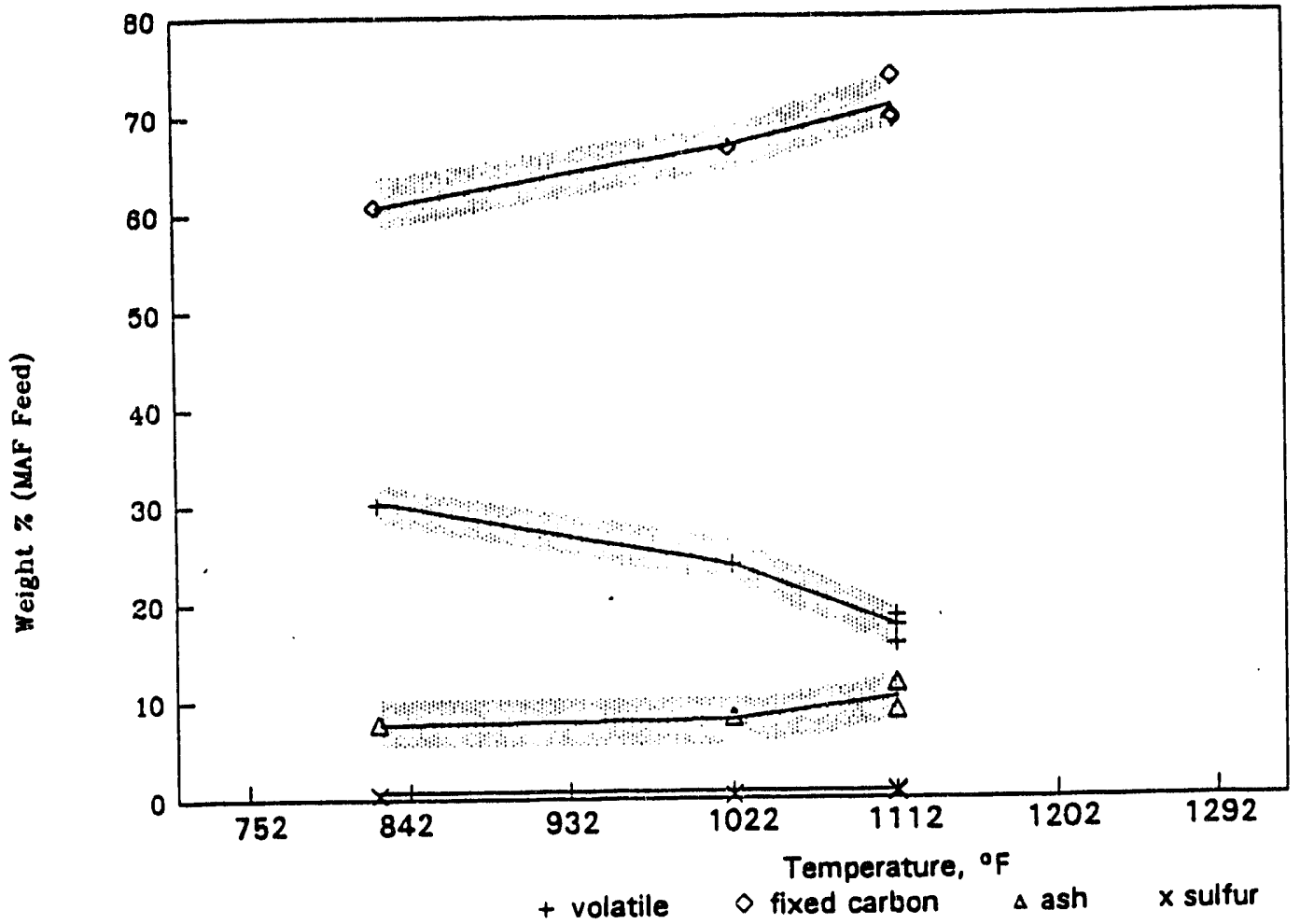

Figure 45. The effect of temperature on Wyodak proximate analyses (PRU).

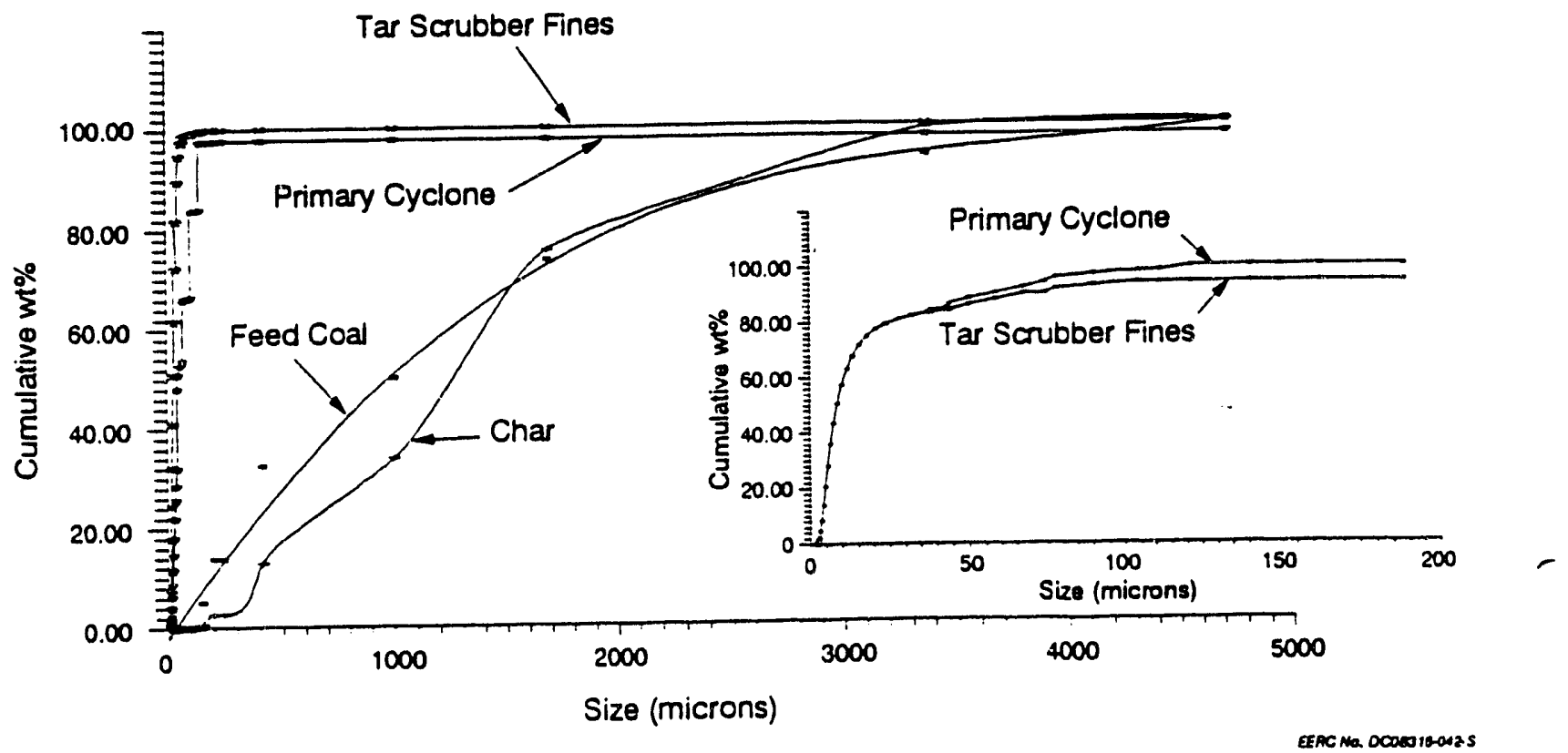

Figure 46. Particle-size distribution analyses of P010 feed coal and char products. 


\subsubsection{Indiana No. 3 Char Production}

Indiana char production ranged from 59.3 to $51.2 \mathrm{wt \%}$ over a temperature range of $1020^{\circ}$ to $1100^{\circ} \mathrm{F}\left(550^{\circ}\right.$ to $\left.600^{\circ} \mathrm{C}\right)$. The CFBR tests indicated yields would be approximately $70 \%$. The reason for the difference in the case of the PRU was a limited amount of internal combustion during the PRU testing to restrict the amount of char agglomeration due to swelling. This would reduce the char produced in the PRU and increase the amount of $\mathrm{CO}_{2}$ production. Tables 22, 23, and 24 show the product char, primary cyclone fines, and the secondary cyclones fines for each of the tests. Figure 47 shows the proximate analysis over the narrow range of temperatures investigated. These values are also similar to the data reported for the CFBR (see Section 7.4.1). Figure 48 shows a typical particle-size distribution for the feed coal, char, and fines. Complete distributions are shown in the Addendum.

\subsubsection{Condensable Production}

\subsubsection{Wyodak Condensable Production}

Condensable production from the PRU was $9 \%$ at $1100^{\circ} \mathrm{F}\left(600^{\circ} \mathrm{C}\right)$ for the one point where yield was determined. In the CFBR, condensable yields ranged from $0.2 \%$ to $9.7 \%$ at $1100^{\circ} \mathrm{F}\left(600^{\circ} \mathrm{C}\right)$ over several steam partial pressures.

Figures 49,50, and 51 show the sulfur and hydrogen simulated distillation curves in relation to the FID curve, which represents the boiling point distribution curve. While the sulfur is not concentrated in any particular boiling point range, there is not a significant amount of sulfur in the lower 10 and $40 \mathrm{wt} \%$ boiling point fractions for the sieve tower and waier scrubber, respectively.

\subsubsection{Indiana Condensable Production}

The Indiana condensable production ranged from $9.4 \%$ to $19.3 \%$ at temperatures from $1020^{\circ}$ to $1100^{\circ} \mathrm{F}\left(550^{\circ}\right.$ to $\left.600^{\circ} \mathrm{C}\right)$. The stage CFBR yields produced a yield of $18 \%$. Figure 52 shows the yields versus temperature. The shaded area indicates process variability determined by duplicate points.

The tar scrubber was the major source of operational difficulty in the PRU. The liquid in the recycle loop would become viscous to the point that the material would not recirculate and would become solid. Early tests indicated the problem may be caused by the accumulation of solids in the recirculating tar. Figure 53 shows the relationship of solids in the tar stream. It was believed that the liquid was being entrained out of the cyclone at a rate equivalent to the amount of liquid being condensed. Thus the net "make" of liquids was zero, which resulted in no liquids being removed from the tar scrubber. Over time, the solids concentration gradually rose until the liquid was unpumpable.

During the modeling effort completed by Xytel-Bechtel inc. for the economic assessment, it was apparent that the problem associated with the tar scrubber may not be due as much to liquid entrainment as to distillation of the decant oil and subsequent condensation of a very limited high boiling point coal liquid. This is due to the very dilute amount of condensables in the gas stream of a spouting bed reactor which requires 
TABLE 22

Carbonizer Product Char Proximate Analysis

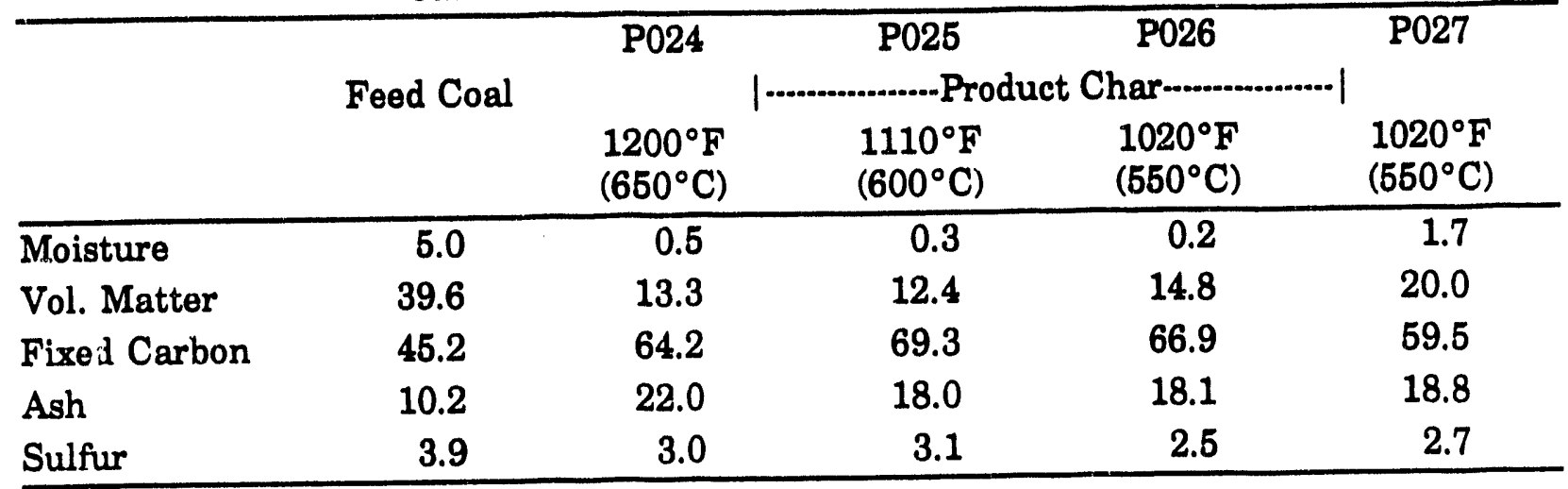

TABLE 23

Carbonizer Primary Cyclone Proximate Analysis

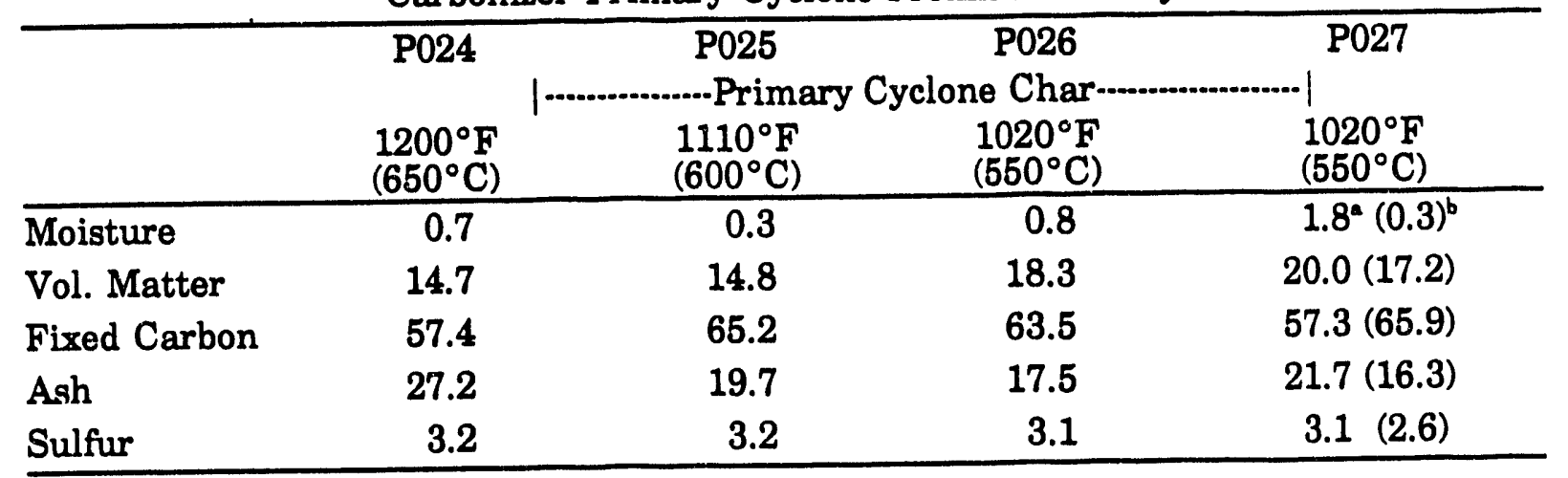

- Average sample composition.

b Typical sample composition.

TABLE 24

Carbonizer Secondary Cyclone Proximate Analysis

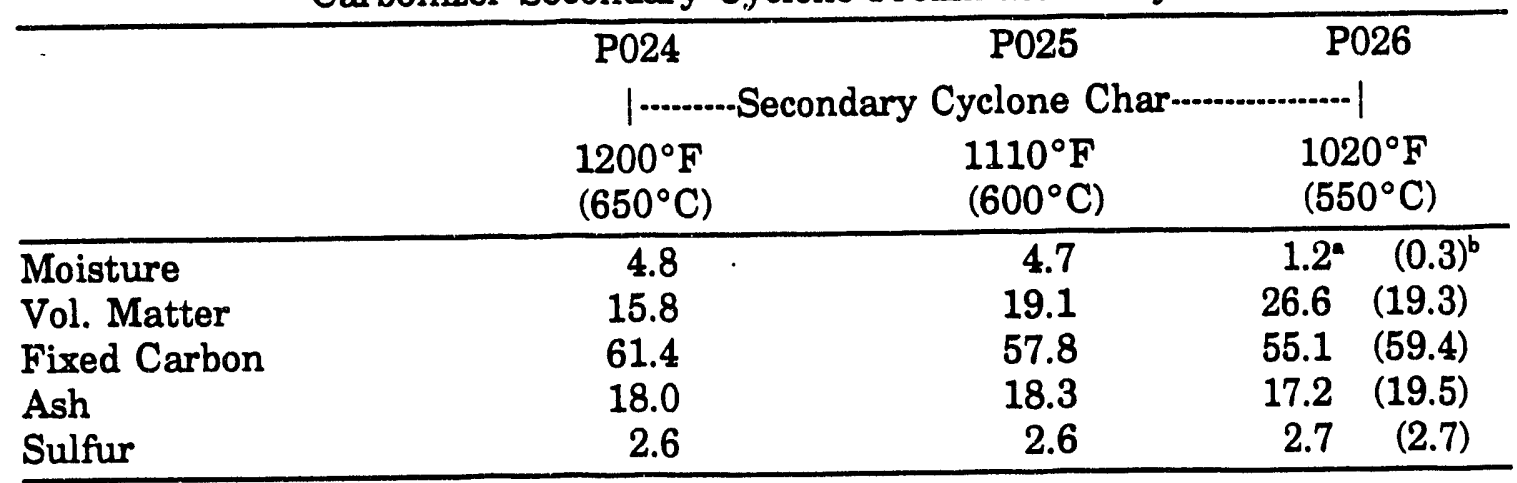

- Average sample composition.

b Typical sample composition. 


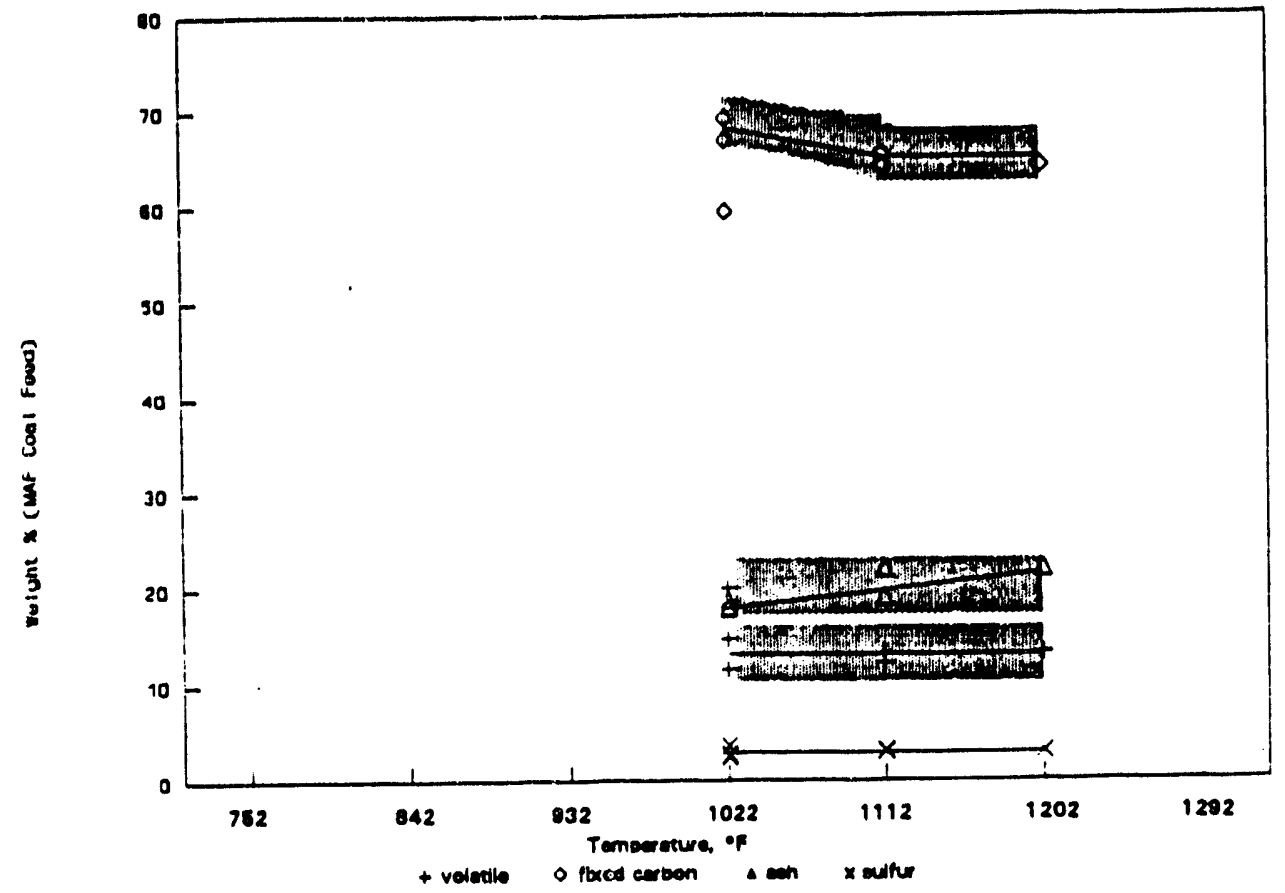

Figure 47. The effect of temperature on Indiana proximate analysis (PRU).

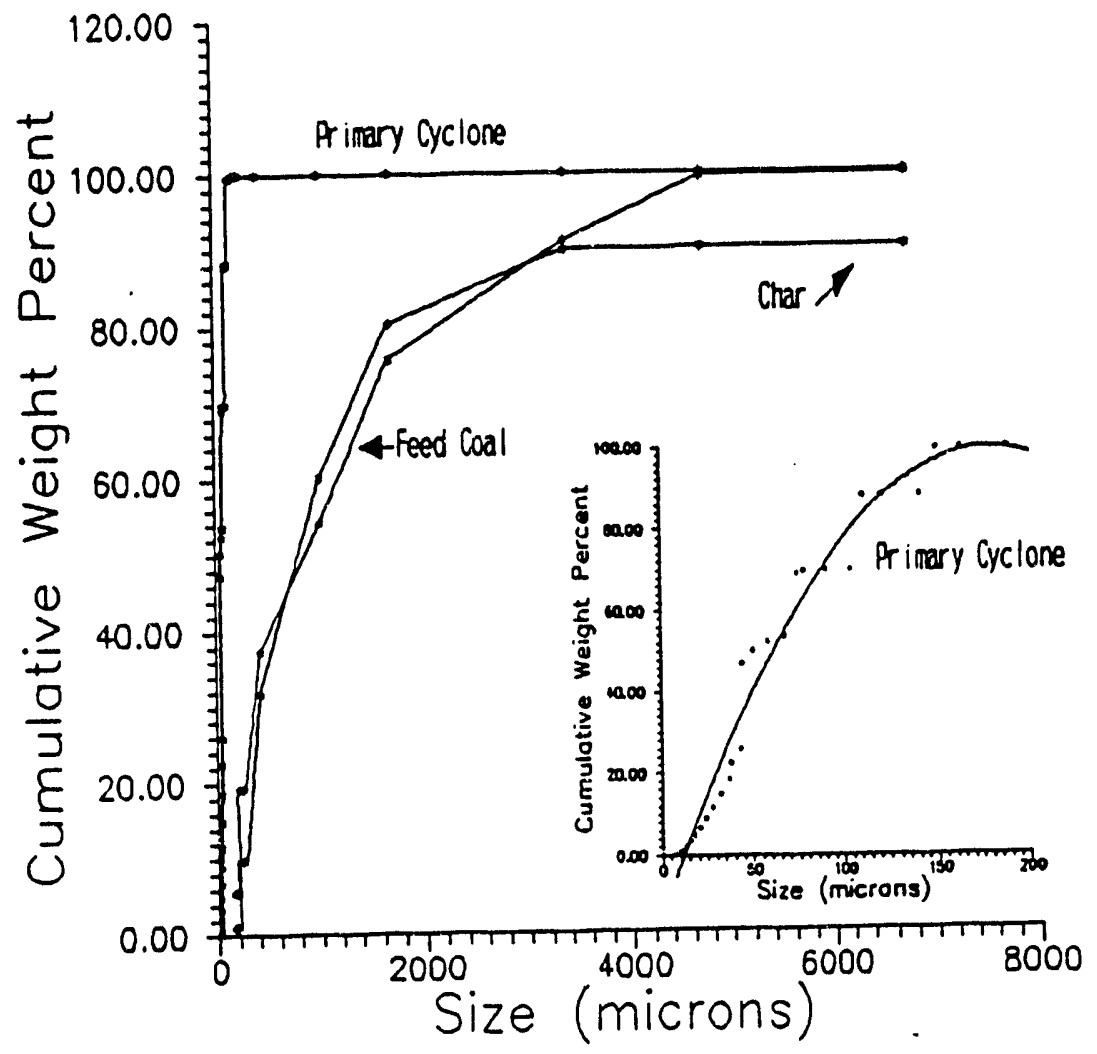

Figure 48. Particle-size distribution analyses of P011 feed coal and char products. 


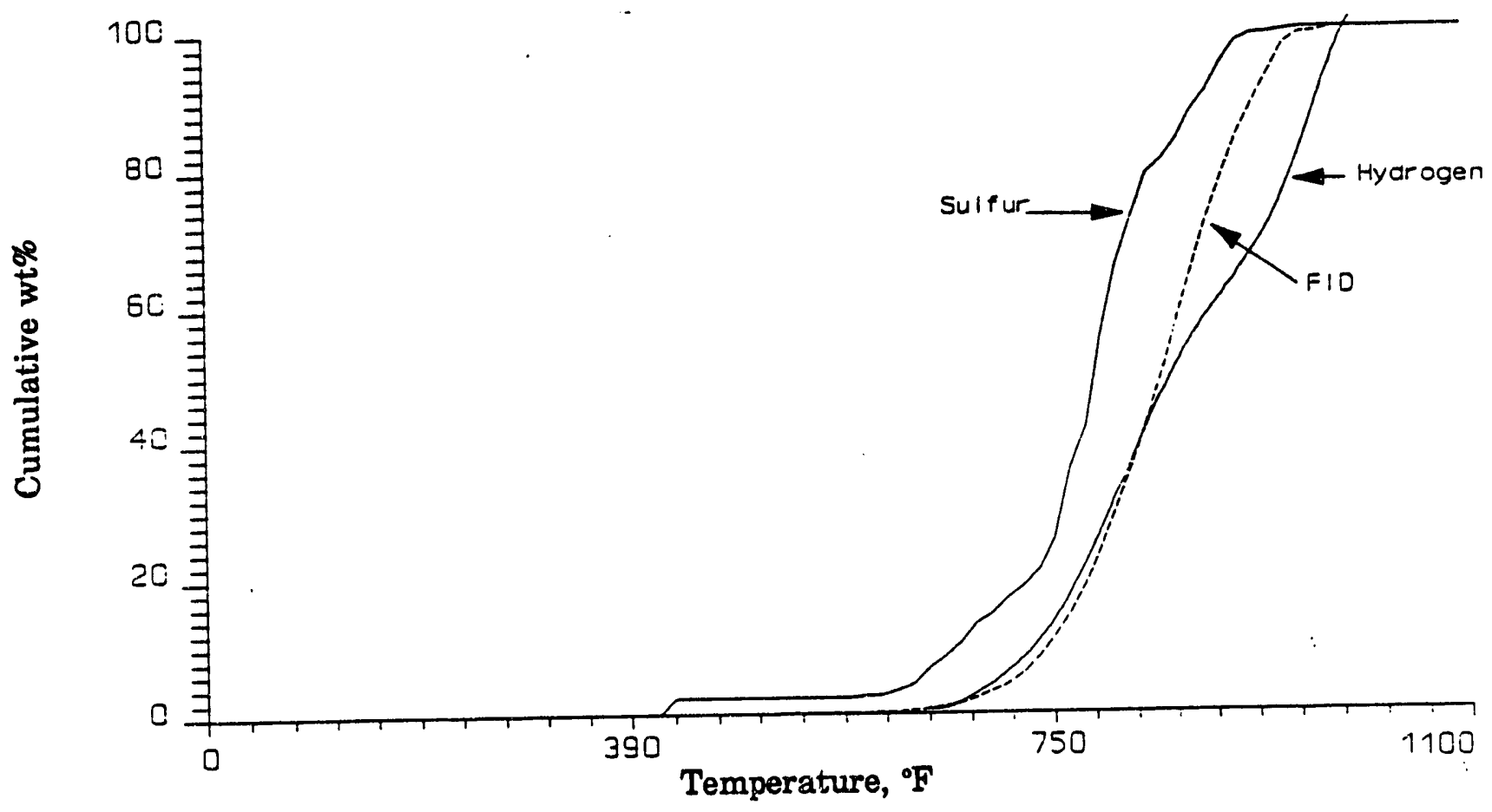

Figure 49. Tar scrubber FID, sulfur, and hydrogen simulated distillation curves (P010).

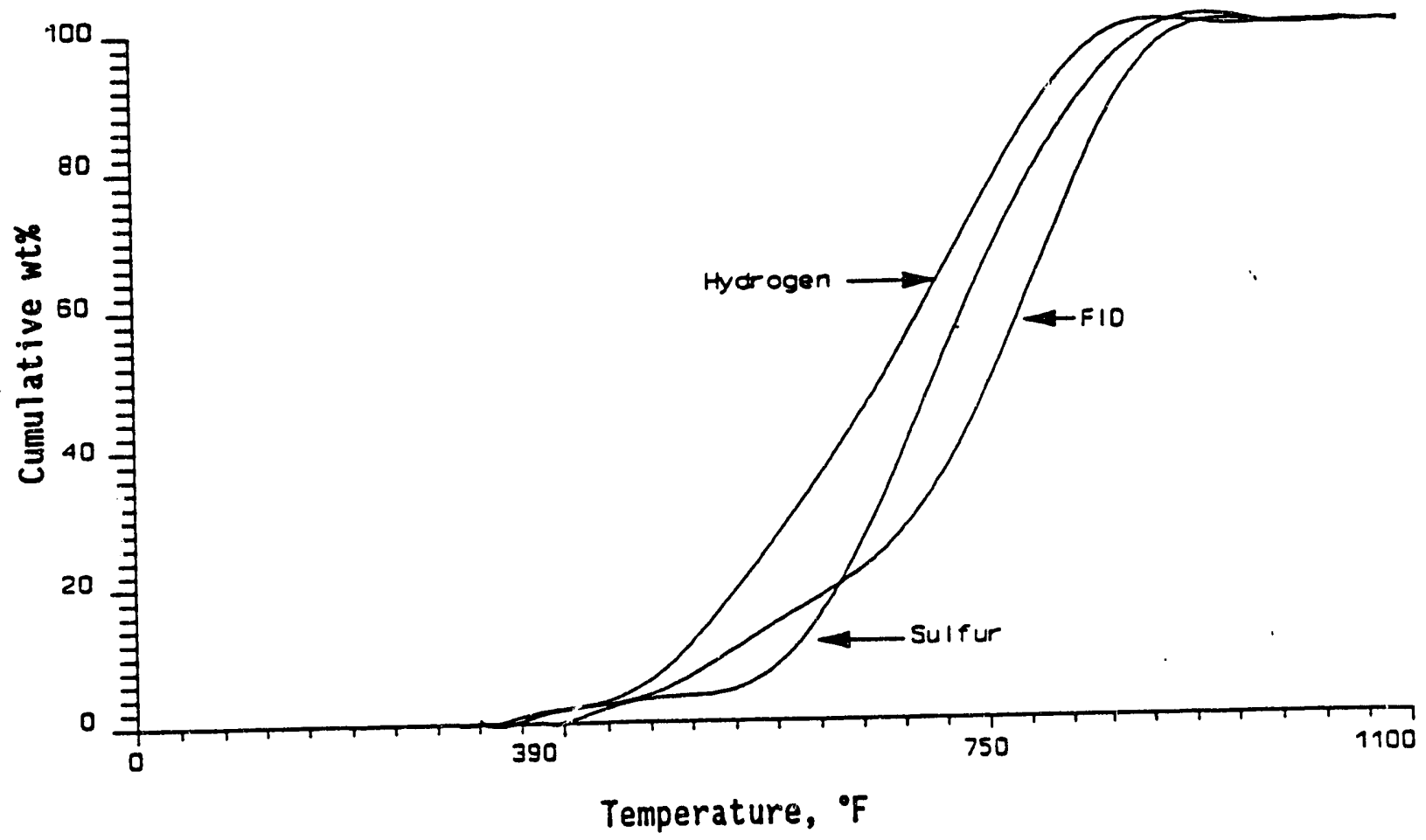

Figure 50. Sieve tower FID, sulfur, and hydrogen simulated distillation curves (P010). 


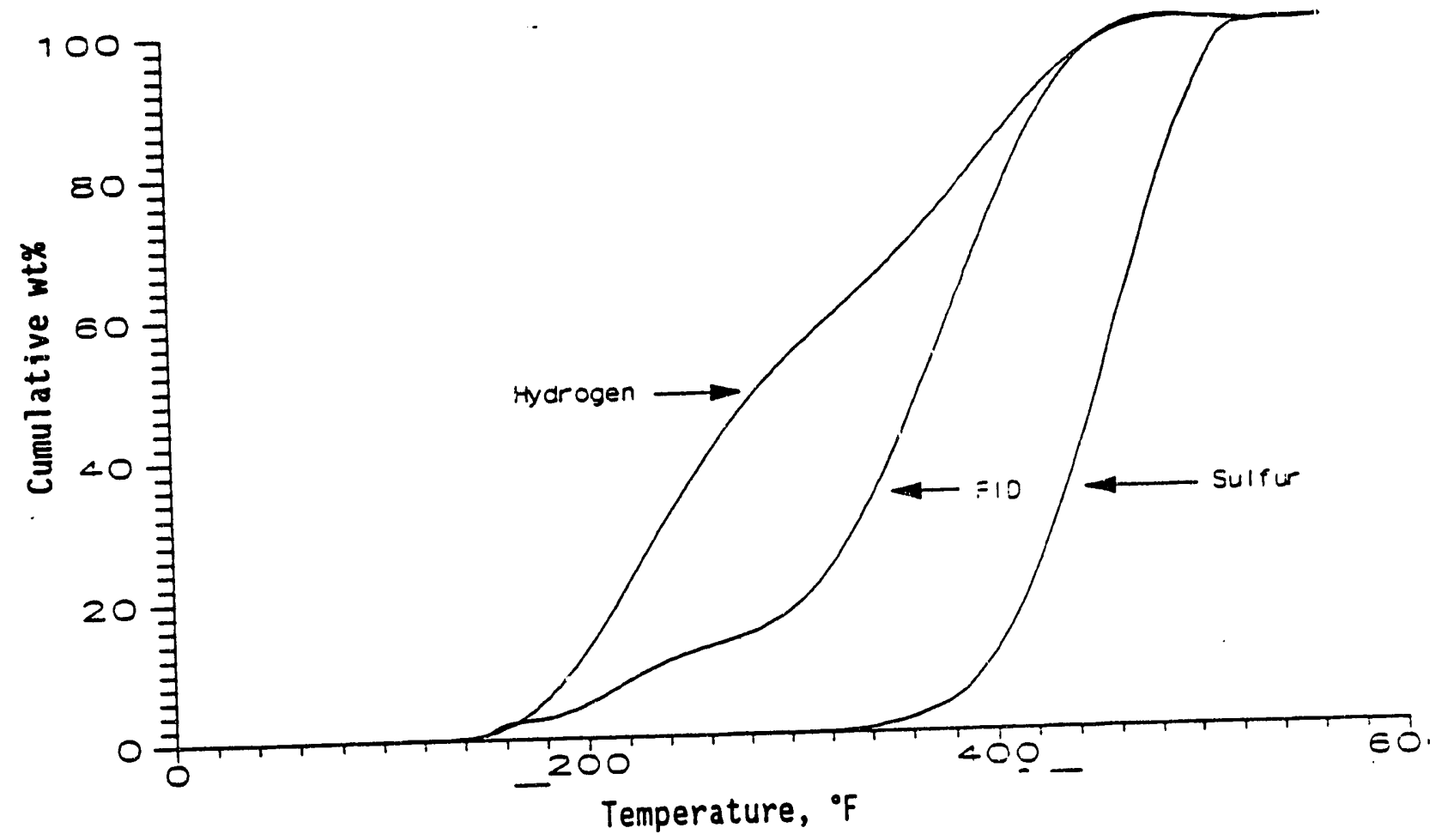

Figure 51. Water scrubber FID, sulfur, and hydrogen simulated distillation curves (P010).

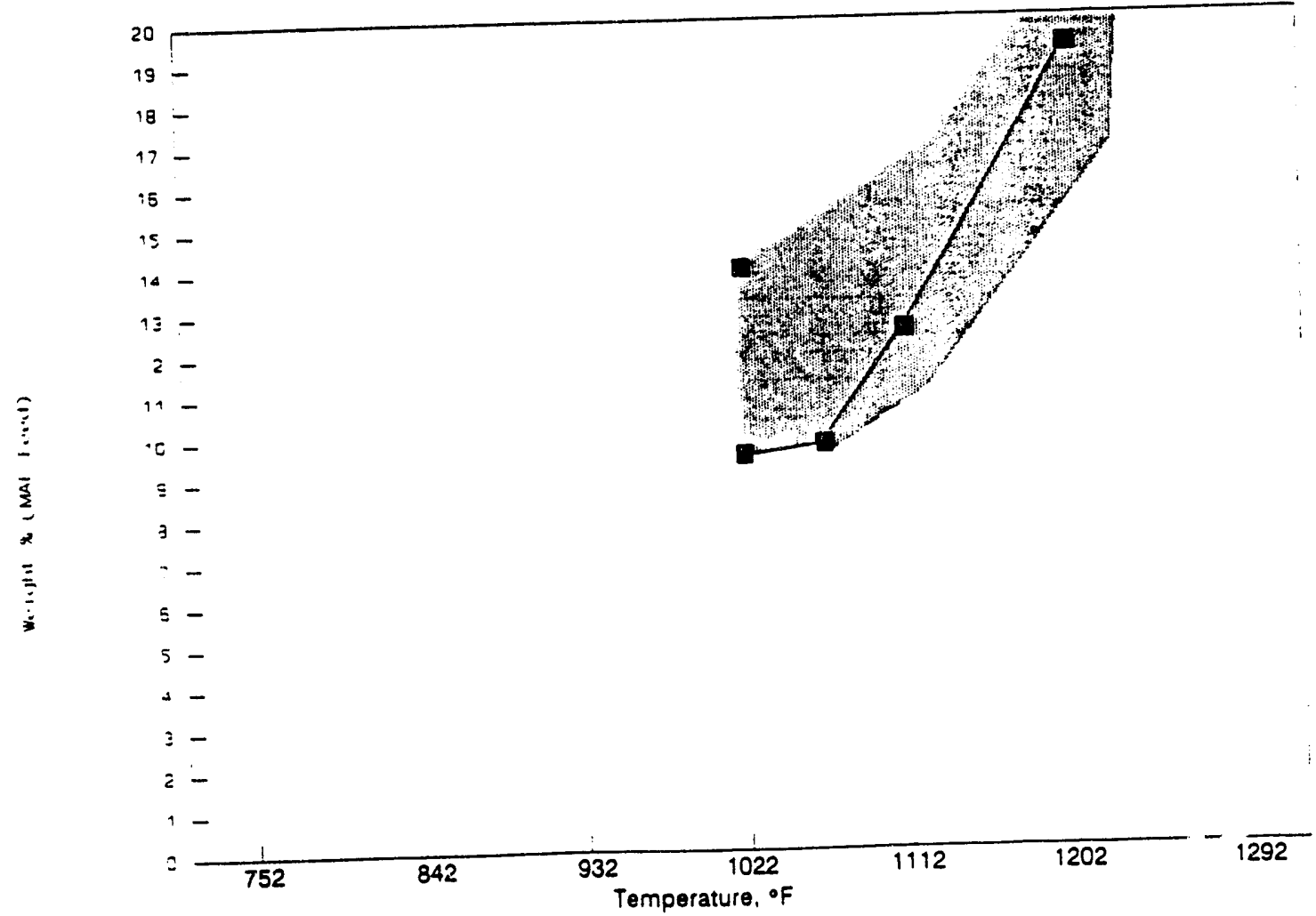

Figure 52. The effect of temperature on Indiana condensable yields (PRU). 


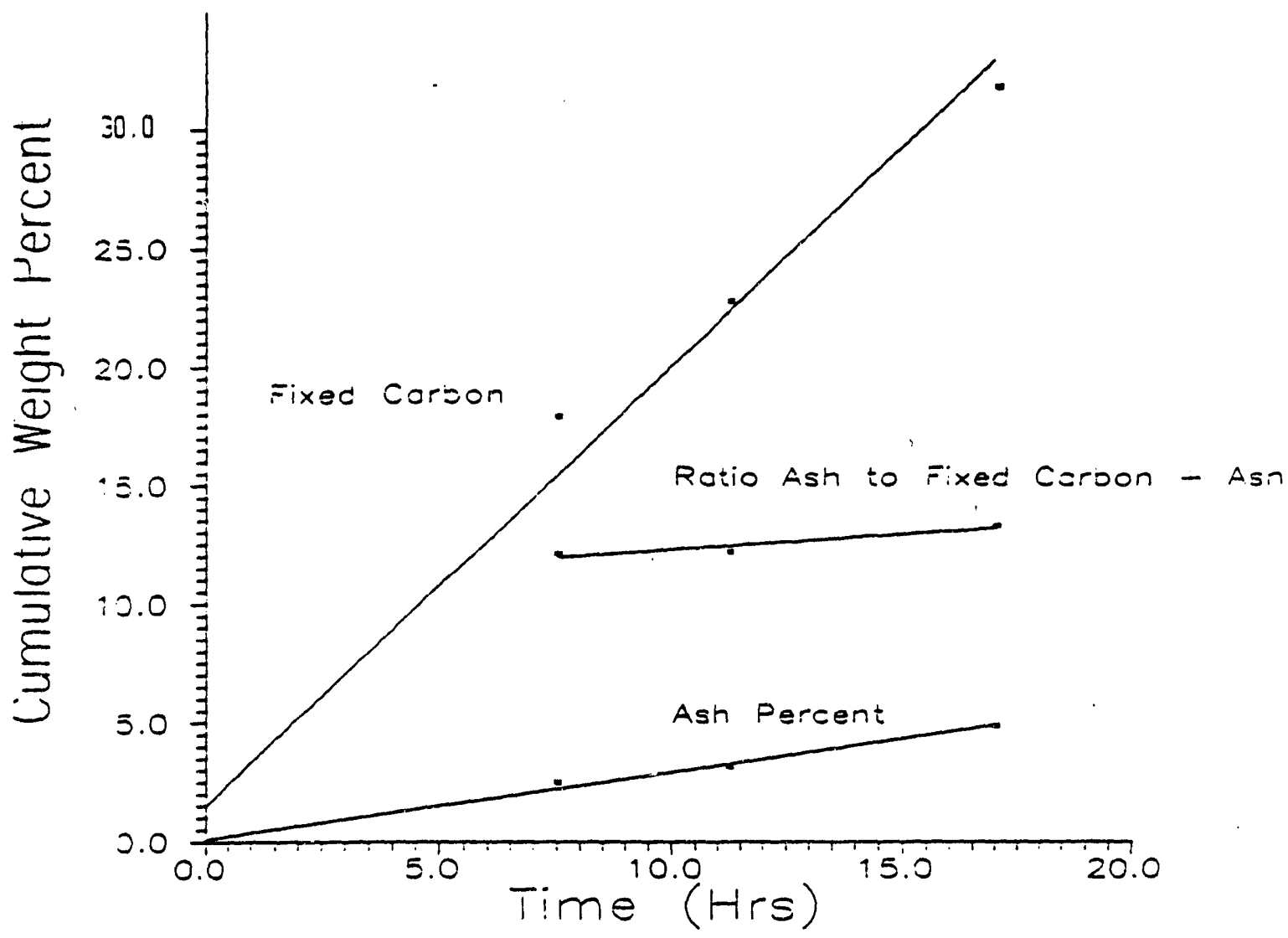

Figure 53. Fixed carbon and ash levels in tar scrubber liquids.

a very low gas temperature in order to reach the condensation temperature of the coal liquids. Figure 54 shows the boiling point distribution curve of the decant oil used for startup and the tar scrubber liquids for runs P024, P025, and P026. Number 2 diesel fuel was used for runs P027 and P028. Figure 55 shows the gas outlet temperatures for the tar scrubber.

A net "make" of condensables was not achieved until the gas outlet temperature was reduced to $275^{\circ} \mathrm{F}\left(135^{\circ} \mathrm{C}\right.$ ). At this temperature, the tar scrubber would periodically drain tar from the recycle loop. The start-up liquid for runs P027 and P028 was changed to $\angle$ diesel fuel. While this material is considerably lighter than condensed material, it acted as a good solvent during start-up to keep the recycle loop from solidifying.

After the test program, it was evident that the outlet gas temperature should be further reduced by 18 to 36 Fahrenheit degrees ( 10 to 20 Celsius degrees) to increase the amount of condensables that are being removed from the tar scrubber. This would reduce the fines loading in the system and also increase the amount of light material that would reduce the tar viscosity. This would involve increasing the cooling capacity of the tar heat exchanger and was not completed due to the completion of the PRU test phase of the project. 


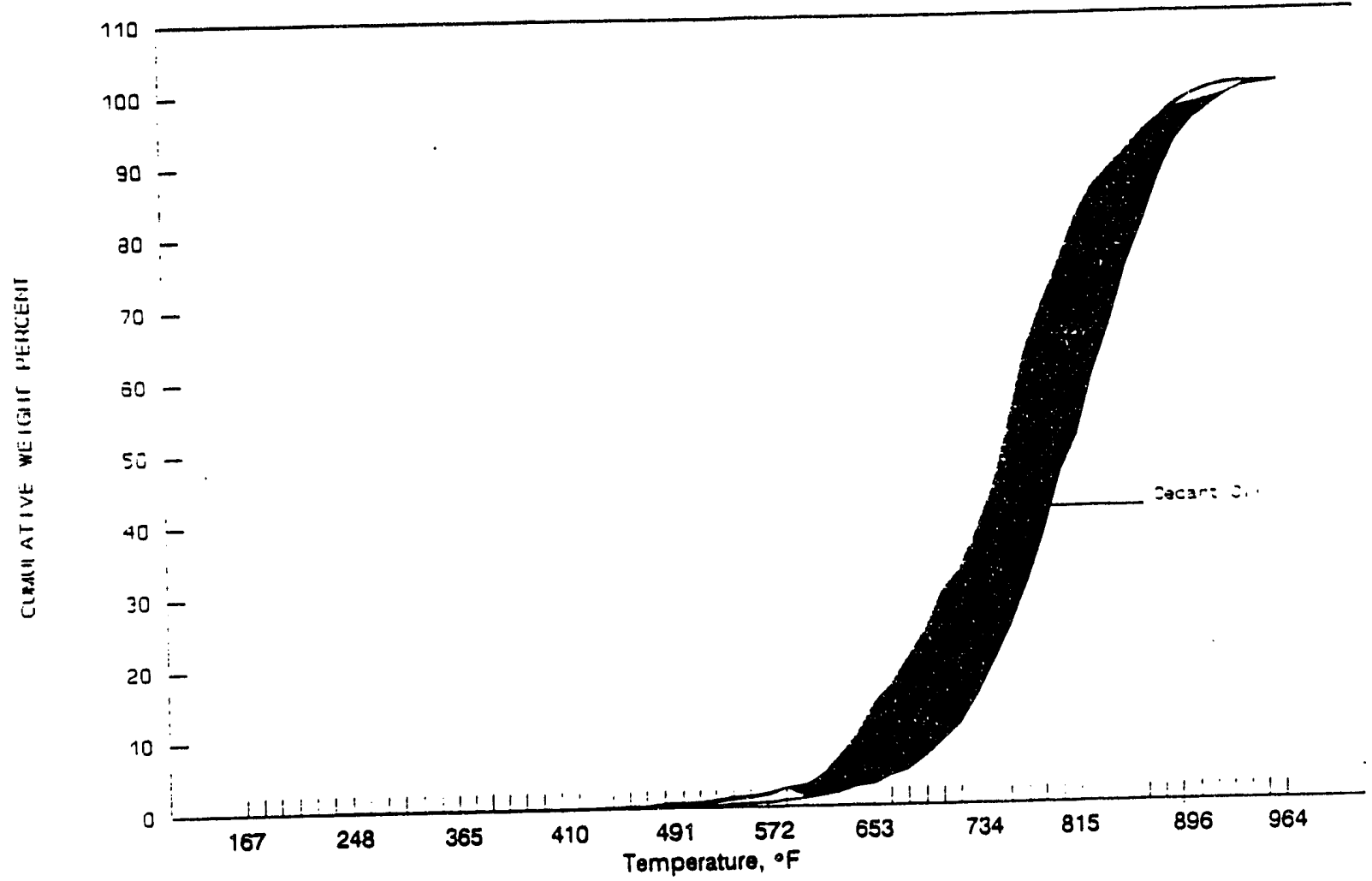

Figure 54. Tar scrubber simulated boiling distribution range (P024, P025, P026, P027, and P028).

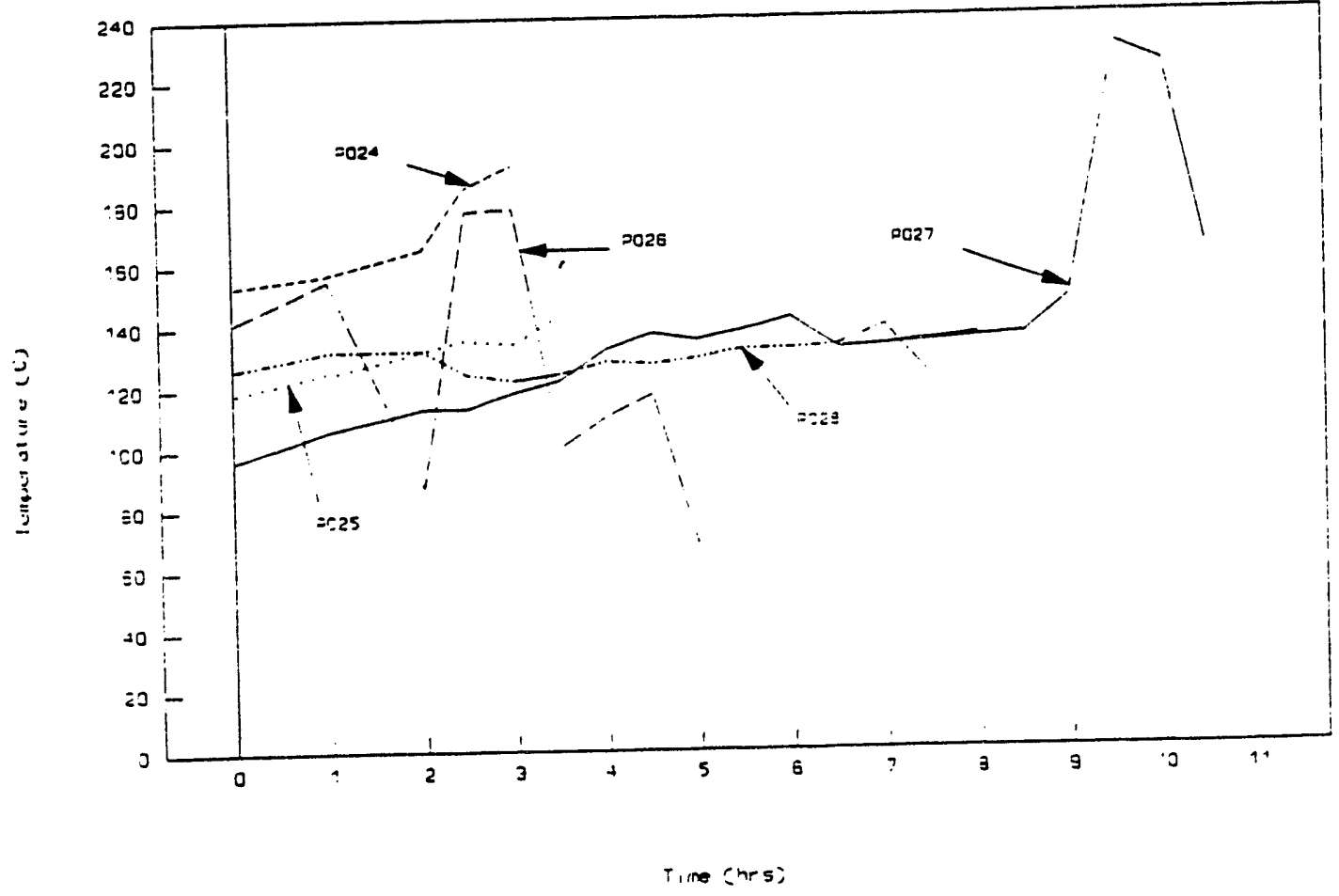

Figure 55. Tar scrubber operating temperature for PRU runs (P024, P025, P026, P027, and P028). 
Figures 56 and 57 show the sieve tower condensables boiling point distributions and gas outlet temperatures, respectively. The effect of outlet temperature greatly affects the boiling point distribution as shown in the two figures. The outlet temperature of $68^{\circ}$ to $86^{\circ} \mathrm{F}\left(20^{\circ}\right.$ to $30^{\circ} \mathrm{C}$ ) produced a material of which $75 \%$ boiled between $380^{\circ}$ and $640^{\circ} \mathrm{F}$ $\left(195^{\circ}\right.$ and $\left.338^{\circ} \mathrm{C}\right)$. This boiling point distribution covers the range associated with cresylic acids, phenols, and diesel fuel blends.

Figures 58 and 59 show the water scrubber condensable boiling point distributions and gas outlet temperatures, respectively. The boiling point distributions are slightly lighter than those seen in the sieve tower. This would lead one to believe that most of the organic material that is collected is entrained from the sieve tower. The operating temperatures are approximately 36 Fahrenheit degrees (20 Celsius degrees) lower than the sieve tower.

Figures $60,61,62$, and 63 show the sulfur and hydrogen contents of various condensable streams. Weight for each of the heteroatoms is evenly distributed throughout the samples.

\subsubsection{Gas Production}

\subsubsection{Wyodak Gas Production}

Table 25 shows the product gas composition for run P024. The results show the raw gas analysis on a nitrogen-free basis. The actual commercial nitrogen composition was less than the raw gas analysis because of the large amount of nitrogen used in the pressure tap purge and the coal feed transport gas.

\subsubsection{Indiana No. 3 Gas Production}

Table 26 shows the product gas composition for runs P025, P026, P027, and P028. The differences in compositions are within experimental and sampling error over the temperature ranges for which the carbonizer operated. Nitrogen balances ranged from $94 \%$ to $106 \%$.

\subsubsection{Wastewater Treatment}

The commercial plant flow sheet was designed so the entire process gas stream temperature did not decrease below the dew point of water, thereby avoiding the need for a commercial wastewater treatment plant and the associated capital cost. However, in the CFBR and PRU, water was condensed for analysis of organic components and for mass balance purposes. This water had to be treated and analyzed prior to discharge as per North Dakota state and Grand Forks city permit requirements (15). The following is a summary of the data generated to meet these requirements.

The wastewater was treated with an activated sludge biotreatment system prior to discharge to the Grand Forks sanitary wastewater treatment plant. This unit was operated not to derive commercially scaleable wastewater treatment data, but rather to treat the condensate water prior to discharge. Since the treatment took place in an existing unit that has a much greater capacity than was needed, the hydraulic retention time (HRT) and the solids retention time (SRT) are not typical of commercial activated 


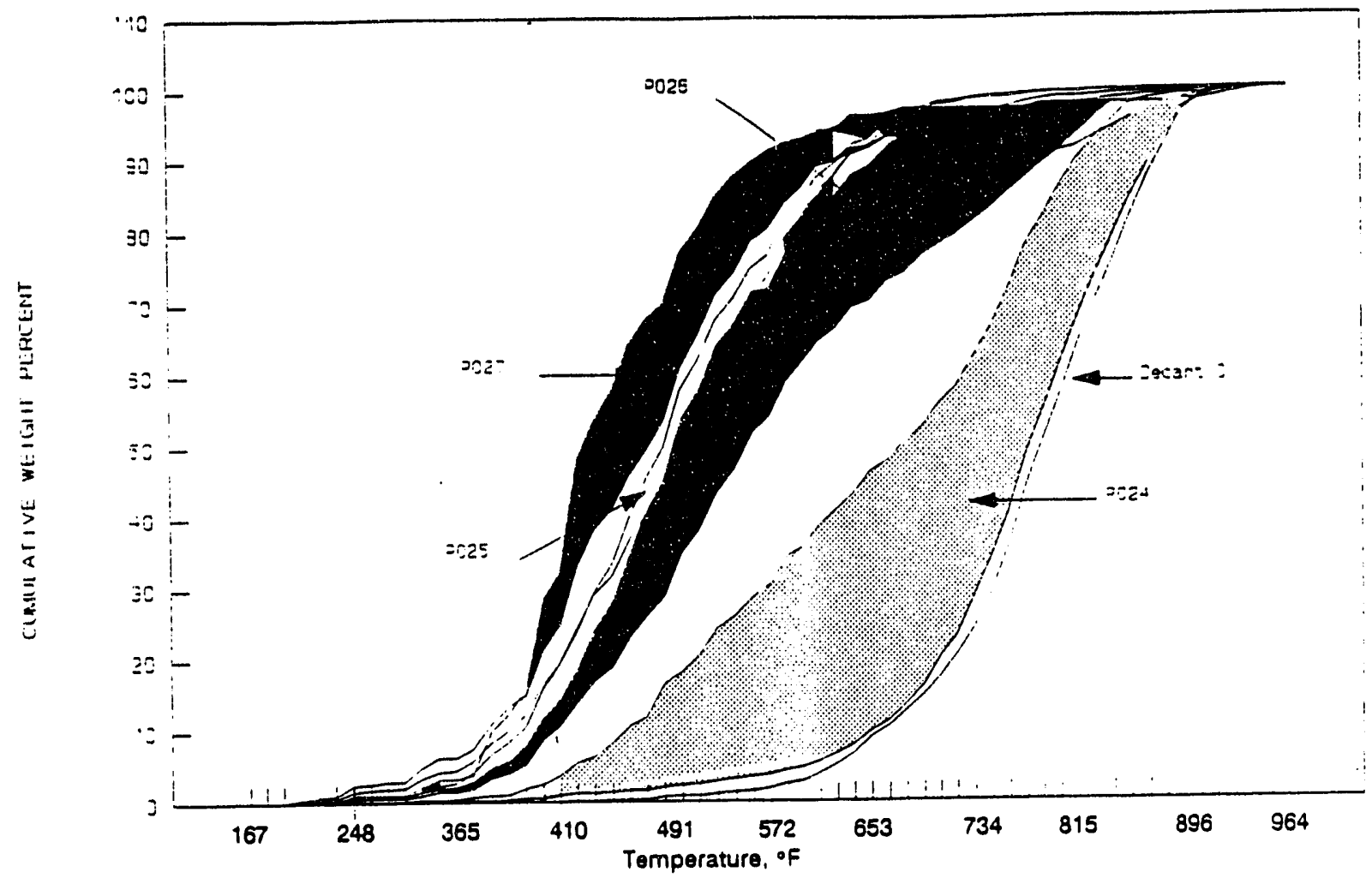

Figure 56. Sieve tower simulated boiling distribution range (P024, P025, P026, and P027).

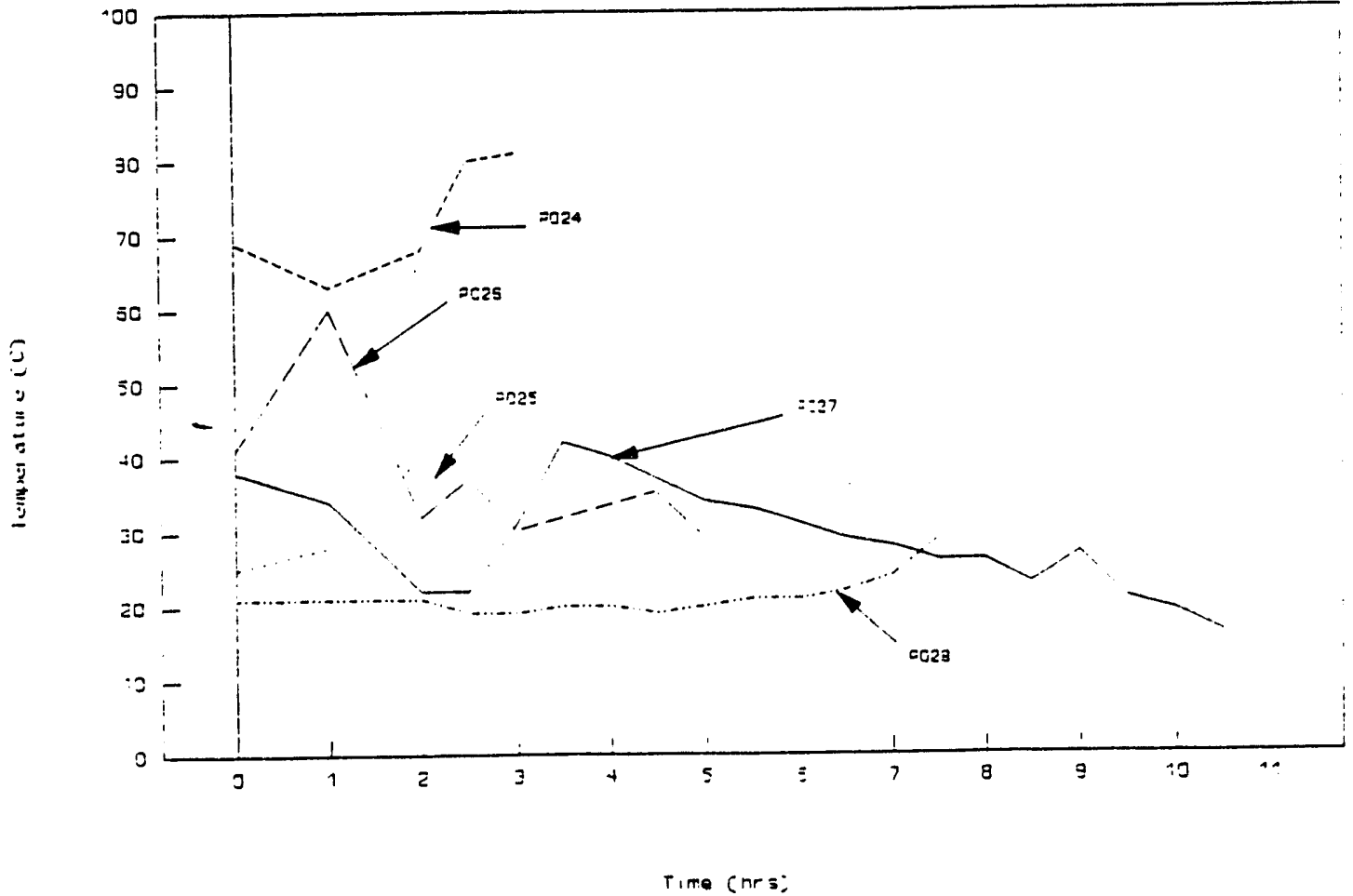

Figure 57. Sieve tower operating temperature for PRU runs (P024, P025, P026, P027, and P028). 


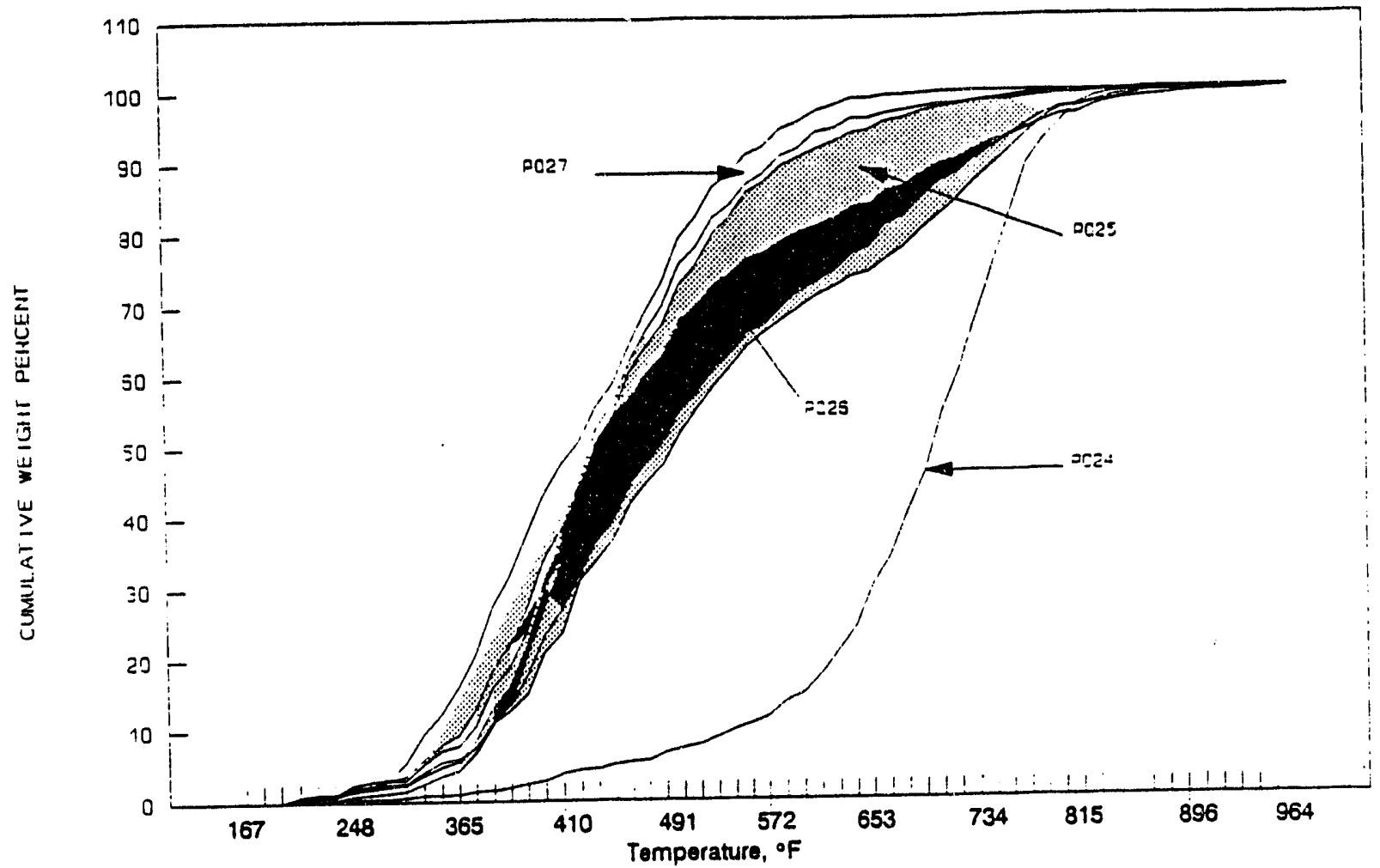

Figure 58. Water scrubber simulated boiling distribution ranges (P024, P025, P026, and P027).

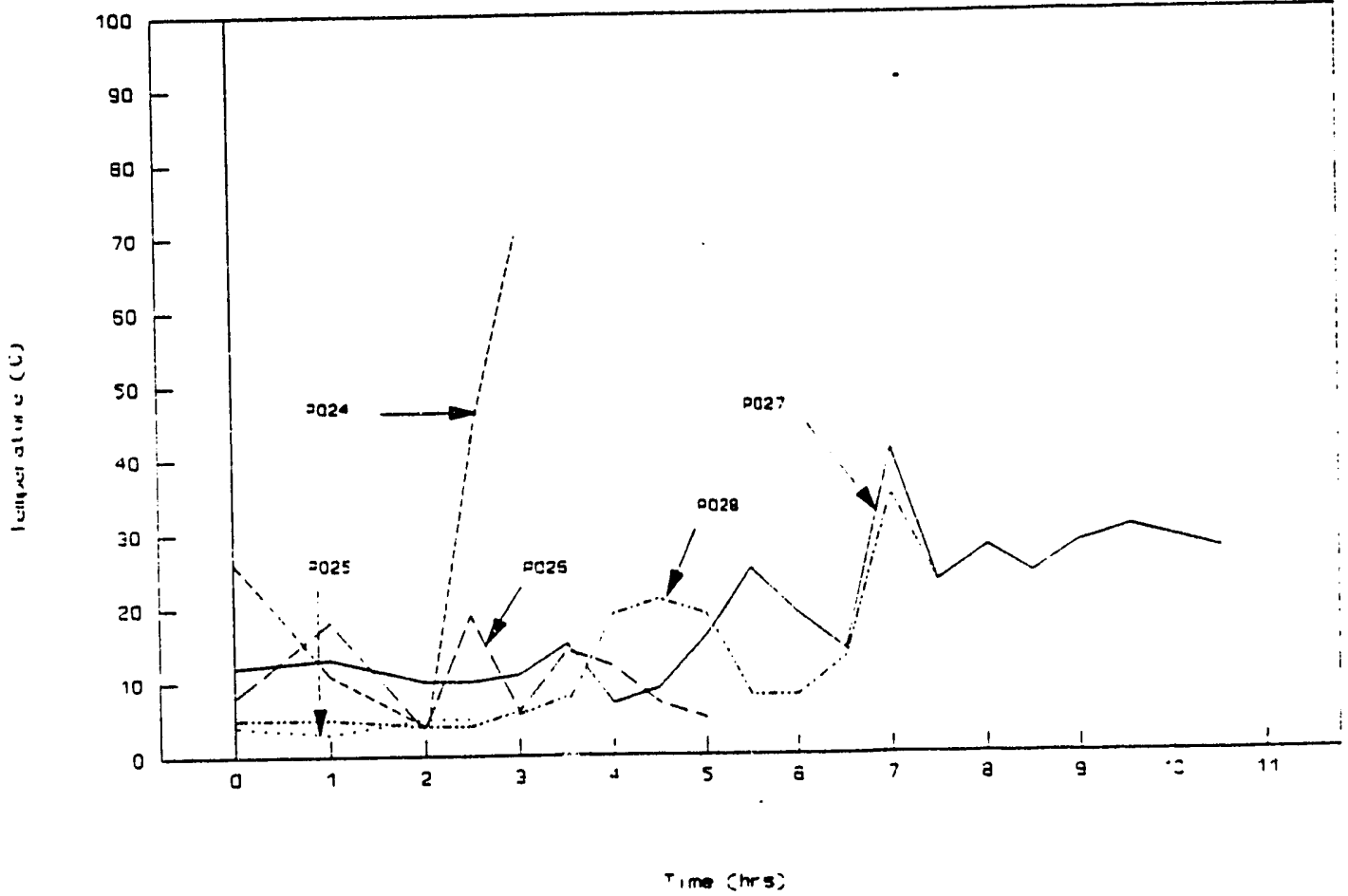

Figure 59. Water scrubber operating temperature for PRU runs (P024, P025, P026, $\mathrm{P} 027$, and P028). 


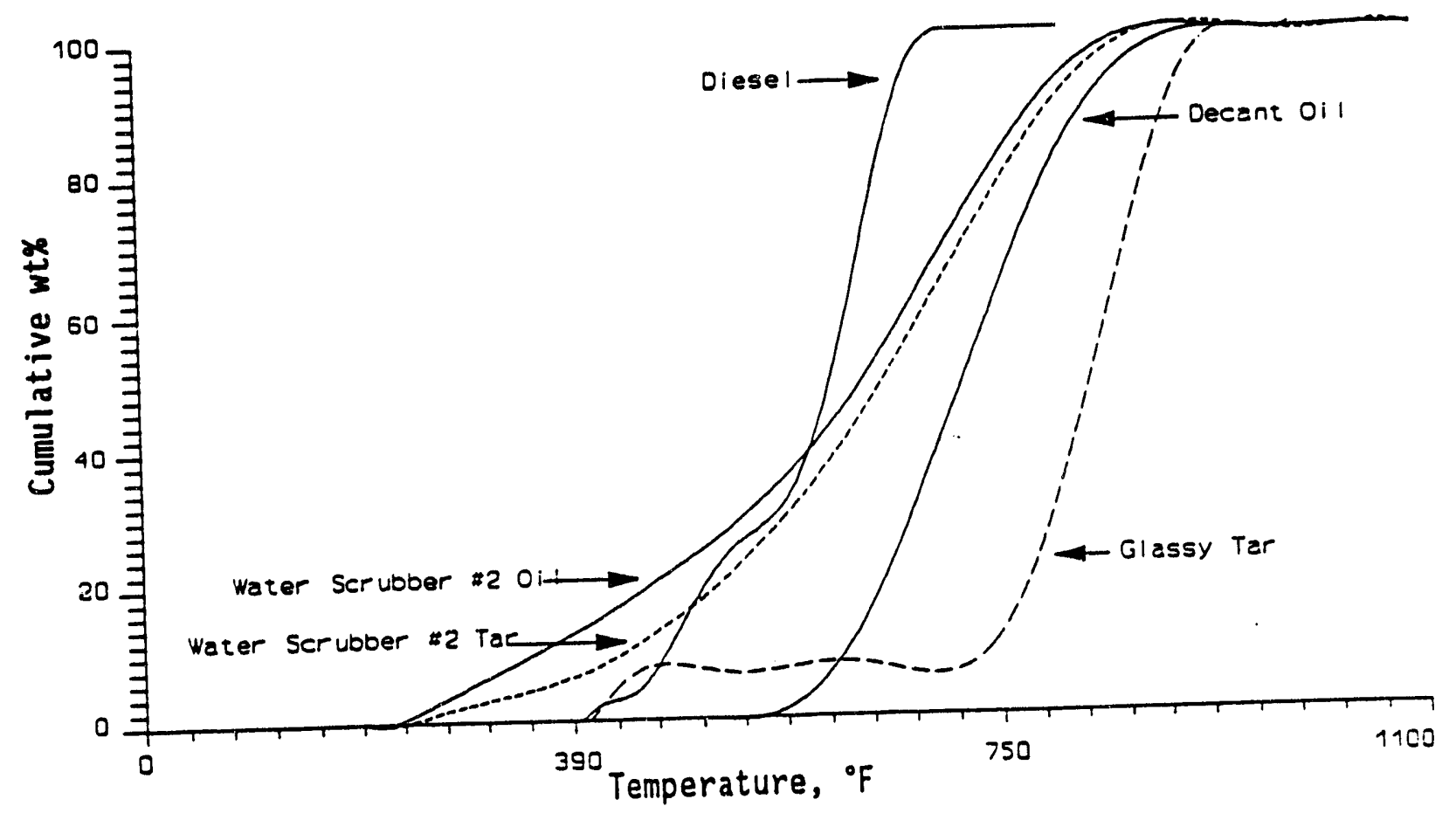

Figure 60. Sulfur content simulated distillation curves (P011).

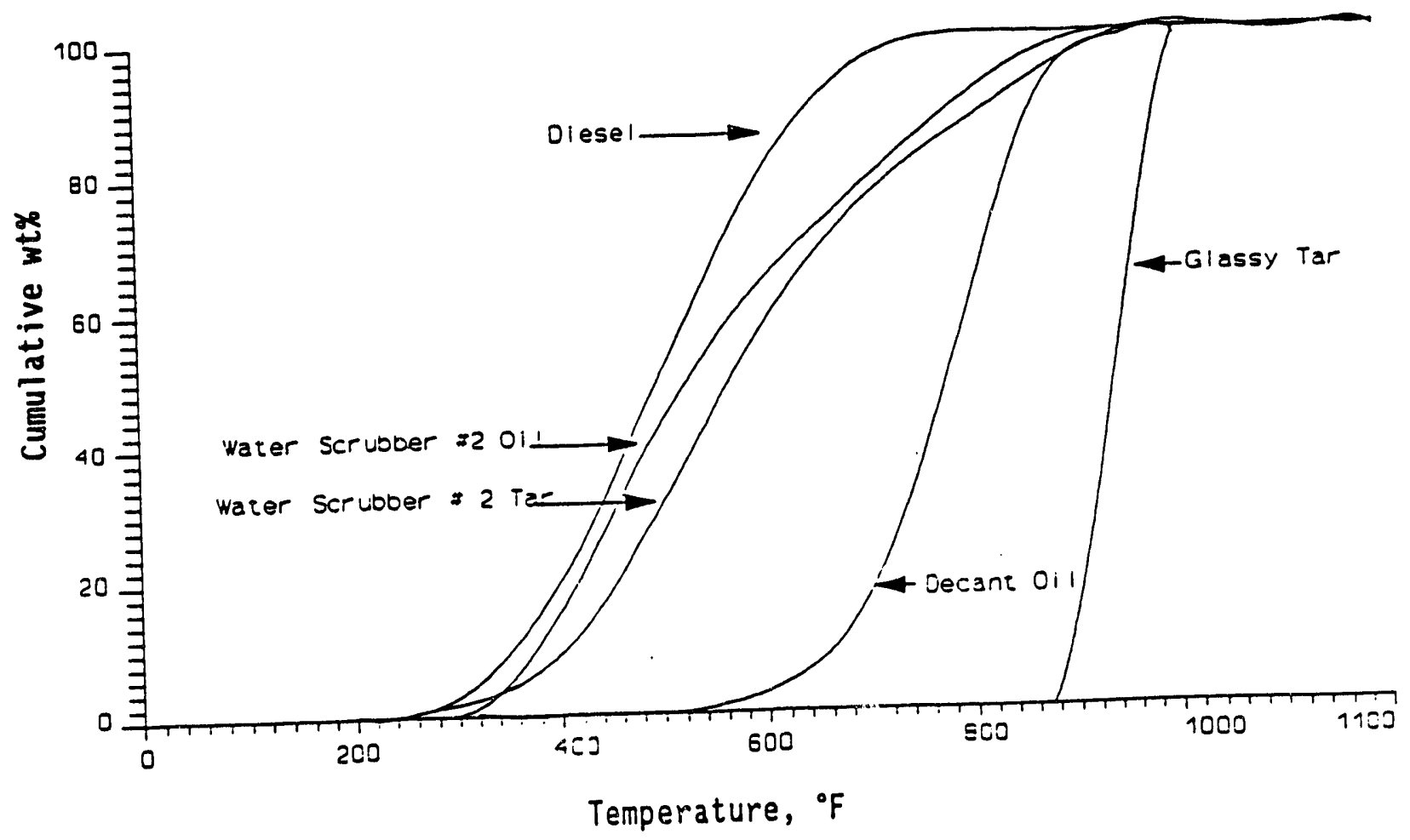

Figure 61. Hydrogen content simulated distillation curves (P011). 


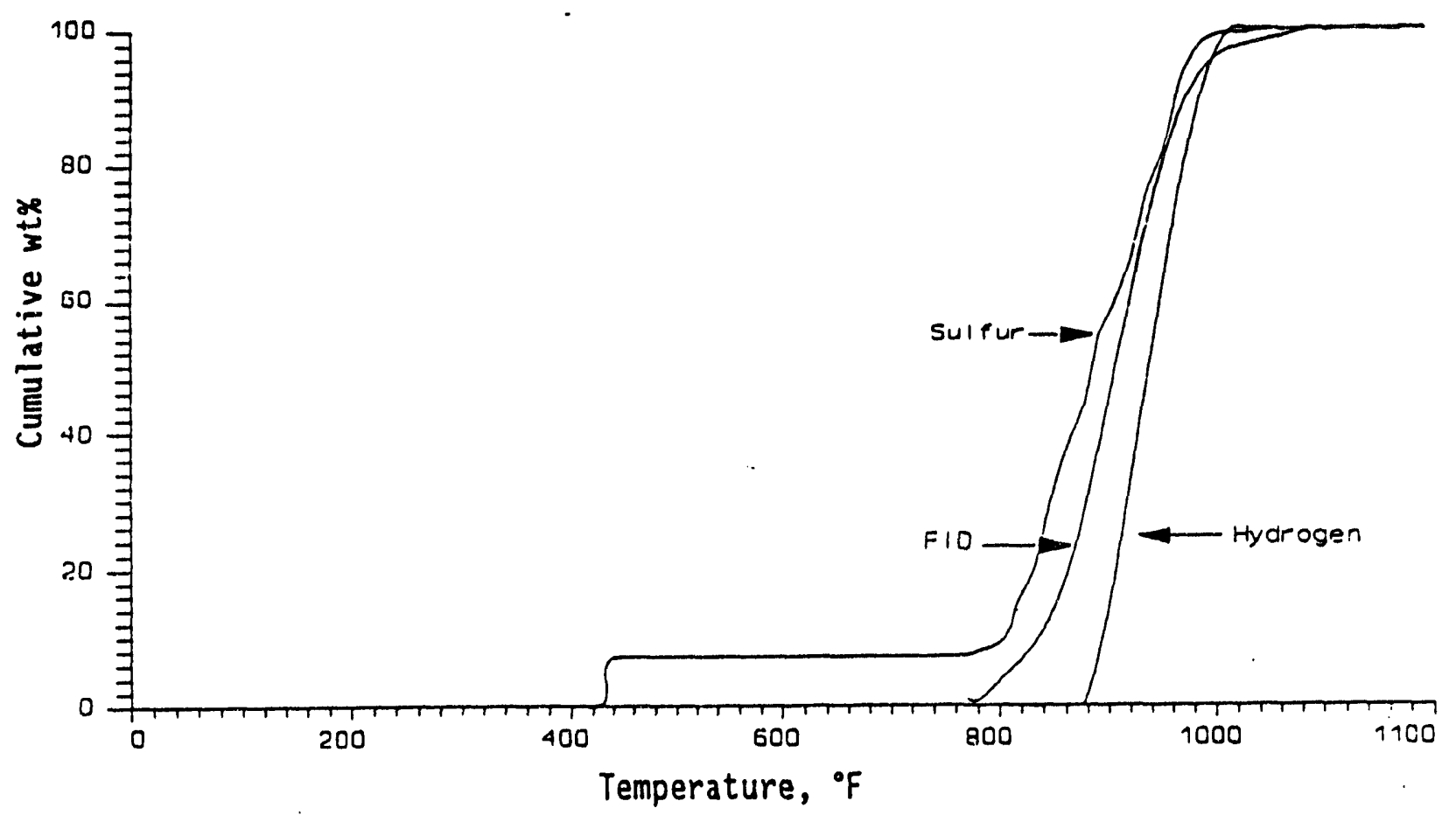

Figure 62. Tar scrubber tar FID, sulfur, and hydrogen simulated distillation curves (P011).

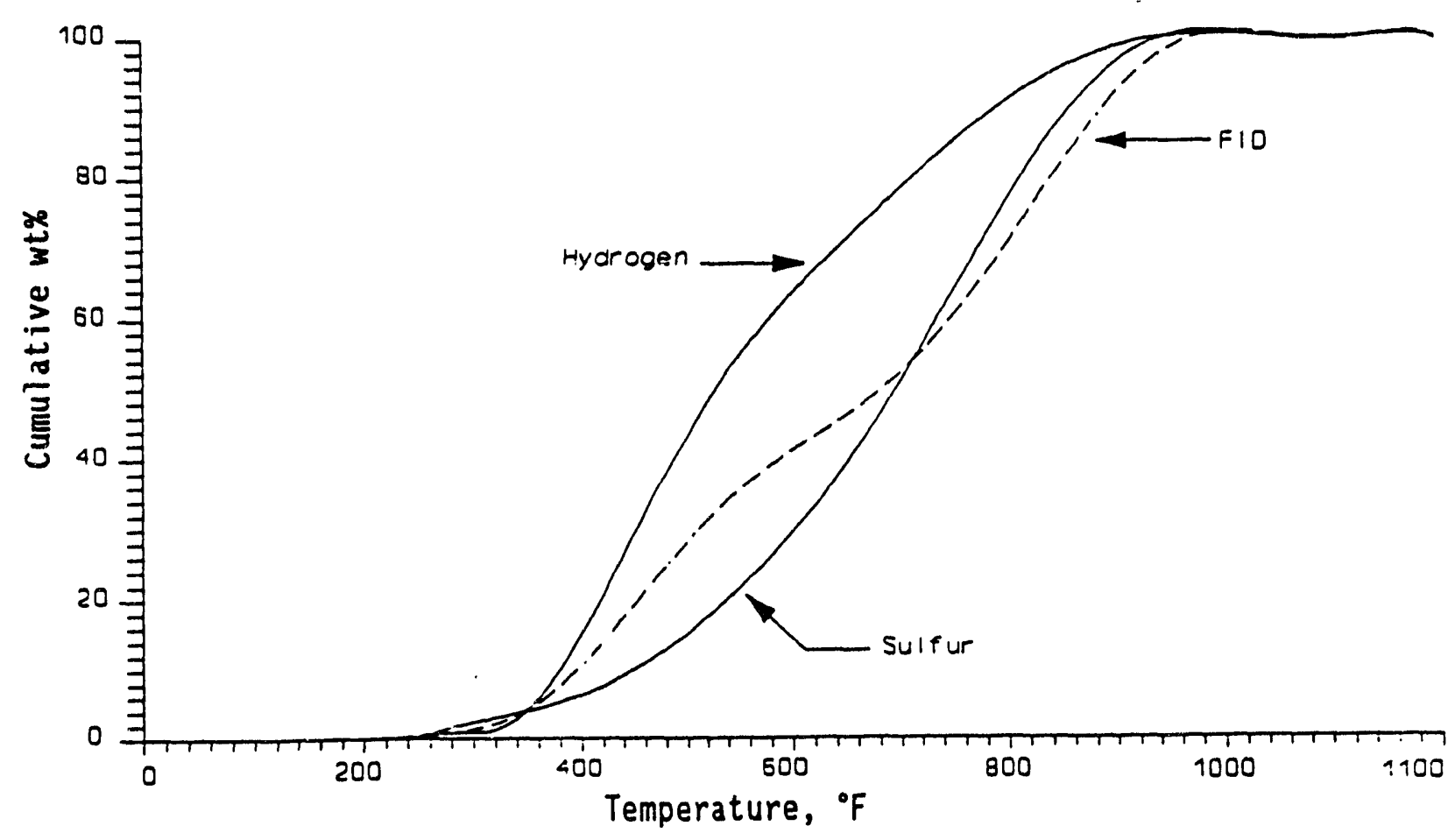

Figure 63. Water scrubber tar FID, sulfur, and hydrogen simulated distillation curves. 
TABLE 25

Product Gas Composition"

\begin{tabular}{lr}
\hline Gas Analysis & \multicolumn{1}{c}{ P024 } \\
\hline $\mathrm{H}_{2}$ & $5.6(30.6)$ \\
$\mathrm{CO}_{2}$ & $7.2(39.5)$ \\
$\mathrm{Propane}$ & $0.1(0.3)$ \\
Propylene & $0.1(0.4)$ \\
i-Butene & $0.0(0.0)$ \\
COS & $0.0(0.0)$ \\
$\mathrm{H}_{2} \mathrm{~S}$ & $0.1(0.8)$ \\
I-Butene & $0.0(0.0)$ \\
t-2-Butene & $0.0(0.0)$ \\
i-Pentane & $0.0(0.0)$ \\
c-2-Butane & $0.0(0.0)$ \\
n-Pentane & $0.0(0.0)$ \\
Ethylene & $0.0(0.2)$ \\
Ethene & $0.2(0.9)$ \\
$\mathrm{O}_{2}$ Ar & $0.0(0.0)$ \\
$\mathrm{N}_{2}$ & $81.7(0.0)$ \\
CH & $2.0(10.7)$ \\
CO & $3.0(16.5)$ \\
& $100.0(99.9)$ \\
\hline
\end{tabular}

- Values in parentheses represent gas analysis on a nitrogen-free basis.

TABLE 26

Product Gas Composition ${ }^{2}$

\begin{tabular}{|c|c|c|c|c|c|c|c|c|}
\hline \multirow{2}{*}{$\begin{array}{l}\text { Gas Analysis } \\
\mathrm{H}_{2}\end{array}$} & \multicolumn{2}{|c|}{$\mathrm{P} 025$} & \multicolumn{2}{|c|}{ P026 } & \multicolumn{2}{|c|}{ P027 } & \multicolumn{2}{|c|}{ P028 } \\
\hline & 4.4 & (24.5) & 2.8 & $(20.5)$ & 3.9 & $(24.9)$ & 3.6 & (25.4) \\
\hline $\mathrm{CO}_{2}$ & 8.4 & $(46.7)$ & 6.8 & $(50.4)$ & 7.5 & (48.6) & 6.7 & $(47.8)$ \\
\hline Propane & 0.1 & $(0.3)$ & 0.1 & $(0.5)$ & 0.0 & $(0.0)$ & 0.1 & $(0.4)$ \\
\hline Propylene & 0.0 & $(0.5)$ & 0.0 & $(0.3)$ & 0.0 & $(0.3)$ & 0.0 & $(0.3)$ \\
\hline i-Butene & 0.0 & $(0.0)$ & 0.0 & $(0.0)$ & 0.0 & $(0.0)$ & 0.0 & $(0.0)$ \\
\hline $\cos$ & 0.0 & $(0.0)$ & 0.0 & $(0.0)$ & 0.0 & $(0.0)$ & 0.0 & $(0.0)$ \\
\hline $\mathrm{H}_{2} \mathrm{~S}$ & 0.4 & (2.3) & 0.3 & $(2.0)$ & 0.0 & $(0.0)$ & 0.3 & $(2.0)$ \\
\hline 1-Butene & 0.0 & $(0.0)$ & 0.0 & $(0.0)$ & 0.0 & $(0.0)$ & 0.0 & $(0.0)$ \\
\hline t-2-Butene & 0.0 & $(0.0)$ & 0.0 & $(0.0)$ & 0.0 & $(0.0)$ & 0.0 & $(0.0)$ \\
\hline i-Pentane & 0.0 & $(0.0)$ & 0.0 & $(0.0)$ & 0.0 & $(0.0)$ & 0.0 & $(0.0)$ \\
\hline c-2-Butane & 0.0 & $(0.0)$ & 0.0 & $(0.0)$ & 0.0 & $(0.0)$ & 0.0 & $(0.0)$ \\
\hline n-Pentane & 0.0 & $(0.0)$ & 0.0 & $(0.0)$ & 0.0 & $(0.0)$ & 0.0 & $(0.0)$ \\
\hline Ethylene & 0.2 & (1.0) & 0.0 & $(0.0)$ & 0.1 & $(0.7)$ & 0.1 & $(0.6)$ \\
\hline Ethene & 0.2 & (1.2) & 0.1 & $(0.6)$ & 0.1 & $(0.9)$ & 0.1 & $(0.9)$ \\
\hline $\mathrm{O}_{2} / \mathrm{Ar}$ & 0.0 & $(0.0)$ & 0.0 & $(0.0)$ & 0.0 & $(0.0)$ & 0.0 & $(0.0)$ \\
\hline $\mathrm{N}_{2}$ & 82.0 & $(0.0)$ & 86.6 & $(0.0)$ & 84.5 & $(0.0)$ & 85.9 & $(0.0)$ \\
\hline $\mathrm{CH}_{4}$ & 2.2 & (12.4) & 1.3 & (10.0) & 1.7 & (10.7) & 1.3 & (9.5) \\
\hline $\mathrm{CO}$ & 2.0 & (11.0) & 2.1 & $(15.5)$ & 2.2 & (13.9) & 1.9 & $(13.1)$ \\
\hline & 100.0 & $(100.0)$ & 100.0 & (100.0) & 100.0 & $(100.0)$ & 100.0 & $(100.0)$ \\
\hline
\end{tabular}

- Values in parentheses represent gas analysis on a nitrogen-free basis. 
sludge systems where the HRT and SRT are 1 to 2 days and 3 to 6 days, respectively. The effluent analytical results, shown in Table 27, were obtained from the stirred effluent storage tank which holds approximately $\mathbf{5 0 0}$ gallons. The effluent was not sampled as it left the clarifier. Therefore, the wastewater was exposed to biotreatment for upwards of 200 days prior to discharge. Table 27 also contains data from the Great Plains Gasification Plant and an EERC hydrogen production gasifier for comparison purposes. The very high removal rates for $\mathrm{BOD}_{5}, \mathrm{COD}$, and phenol are apparently due to the very long HRT and SRT.

TABLE 27

Wastewater Operational Parameters and Analytical Data

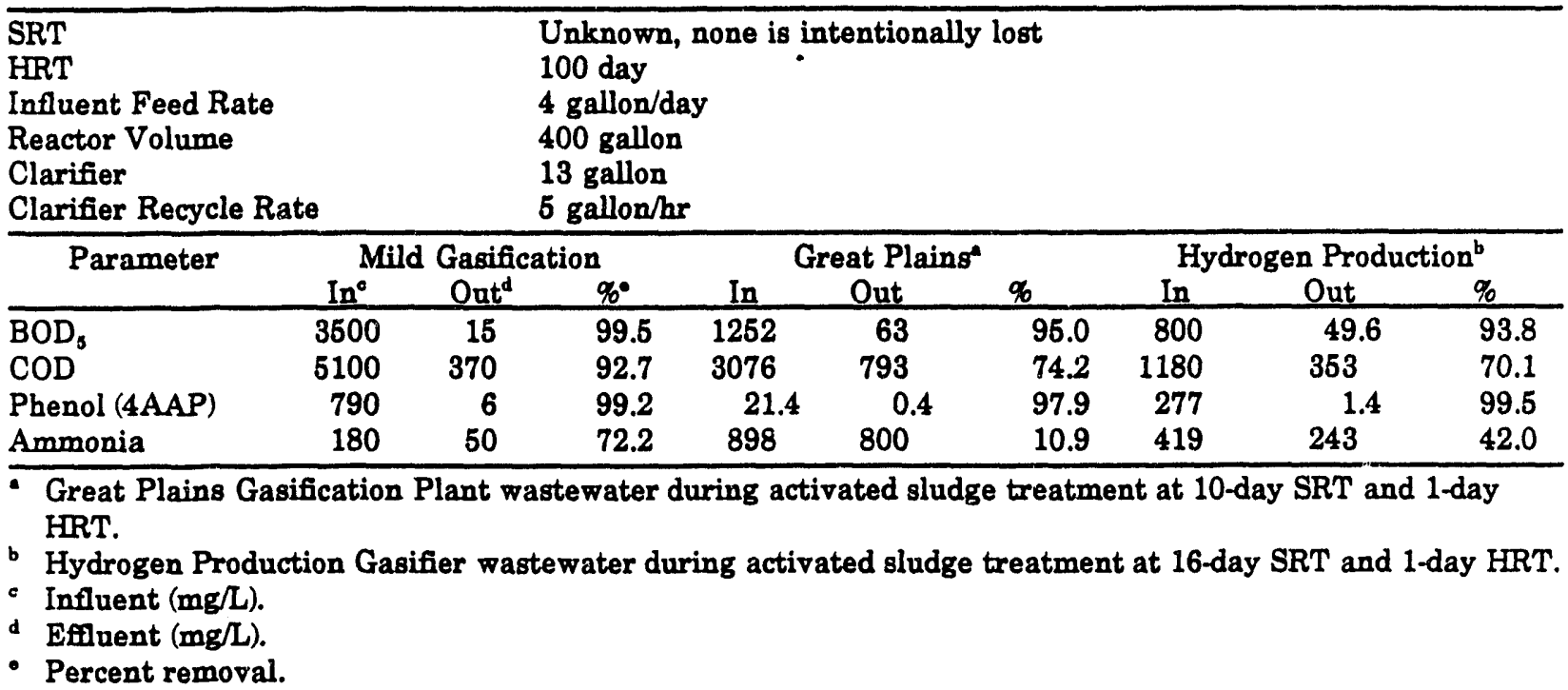




\section{$11.0^{\circ}$ SULFUR AND ASH REDUCTION VIA IN SITU AND PHYSICAL SEPARATION FOR CHAR UPGRADING}

The sulfur content of char must be $1 \%$ or lower if it is to be used as a substitute for petroleum coke in the PTC bonded-pellet process, and below about $1 \%$ sulfur to be used in making a specification-grade metallurgical form coke acceptable to the steel industry. Sulfur content is not expected to be a problem when using low-sulfur Wyodak subbituminous coal, but it will be for Indiana No. 3 bituminous coal-particularly if the goal of $1 \%$ sulfur is to be met. Dry physical separations are preferred for char upgrading because of compatibility with the mild gasification processing scheme, which produces a dry char product. Physical separations are also generally lower in cost than chemical or thermal treatments. Initial char upgrading activities have therefore centered on evaluation of physical upgrading techniques such as magnetic and gravity separations for removal of sulfur and ash compounds. Other upgrading methods are to be investigated as needed to achieve target char specifications. Sulfur forms analyses were performed according to ASTM D2492 procedures developed for coal. Pyritic sulfur is determined on the basis of nitric acid-soluble iron.

There were four proposed operations for removing sulfur, of which two operations also reduce ash:

- gravity separation

- carbonization

- magnetic separation

- high-temperature calcination with in situ sorbent

Figure 64 shows the four unit operations with the estimated removal efficiencies based on bench-scale testing and the actual results from PRU tests.

\subsection{Dry Gravity Separation of the Indiana No. 3 Feed Coal}

AMAX supplied the EERC with 25 tons of Indiana No. 3 that had been cleaned to lower the sulfur and ash content prior to PRU tests. An air table was purchased from Oliver Manufacturing in Rocky Fork, Colorado, for use in the separation process.

Approximately 45 tons of coal was crushed to $-1 / 4$ inch. The coal had to be air dried prior to cleaning because of the extremely wet conditions under which the coal had been mined and shipped.

Dried coal in the amount of 8.5 tons was screened into three size ranges in preparation for cleaning on the air table. The coal, with an initial top size of $1 / 4$ inch, was separated on 10- and 24-mesh screens. This resulted in the desired three screen fractions, plus some fugitive dust that was collected, weighed, and discarded. Results of the screen separations are shown in Table 28.

Samples of the different screen fractions were submitted for Btu content, proximate, ultimate, and sulfur analysis, including total sulfur, pyritic, and sulfate sulfur. (Organic sulfur is determined by difference.) Results of these tests are shown in Table 29. 


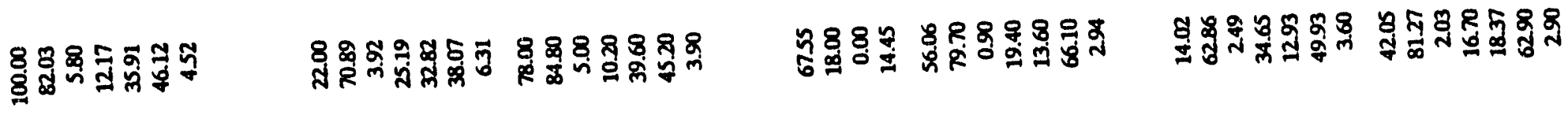

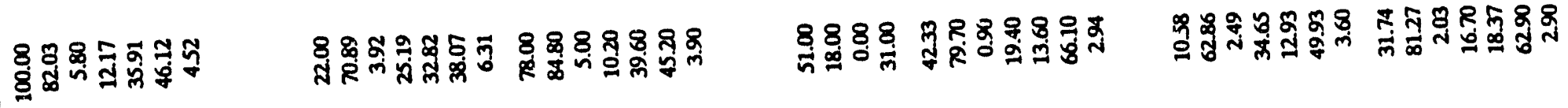

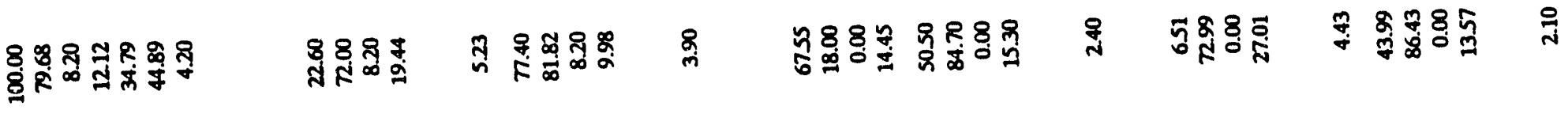

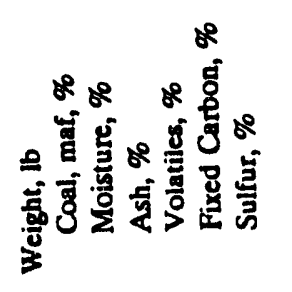

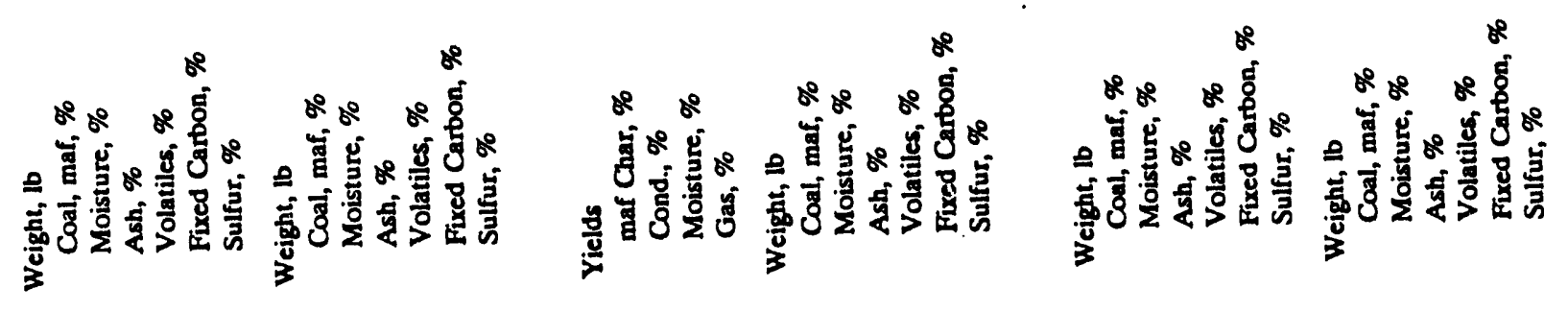

喜

$\frac{5}{2}$

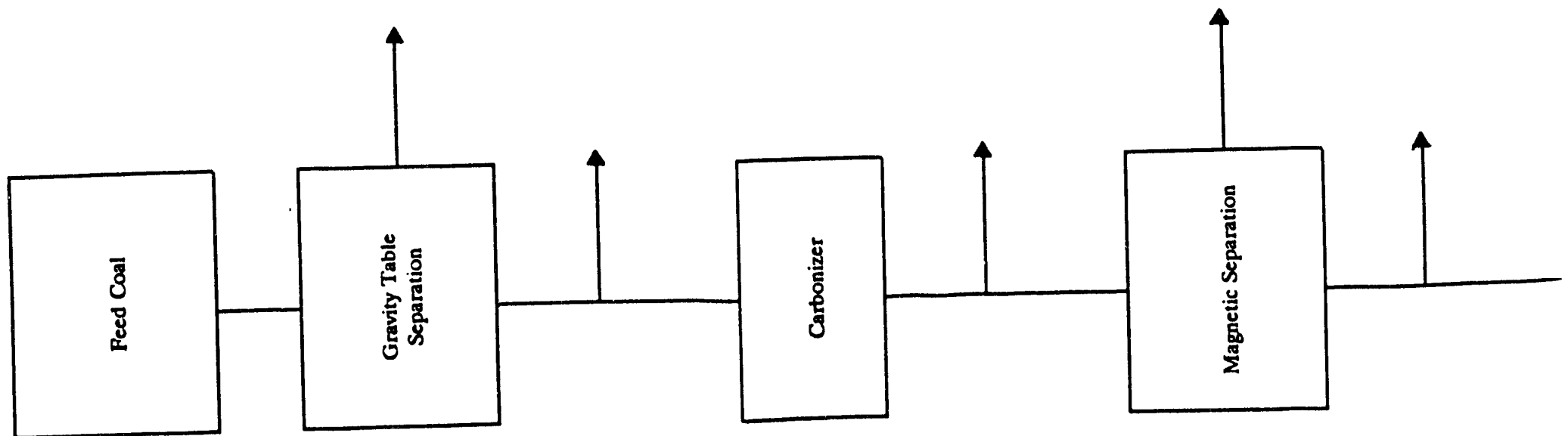




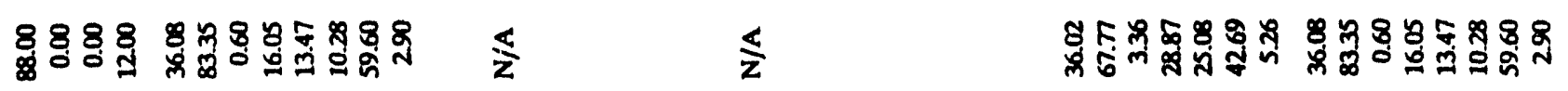

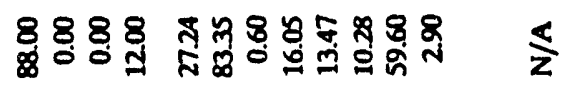
$\frac{5}{z}$

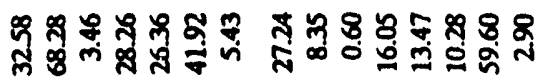

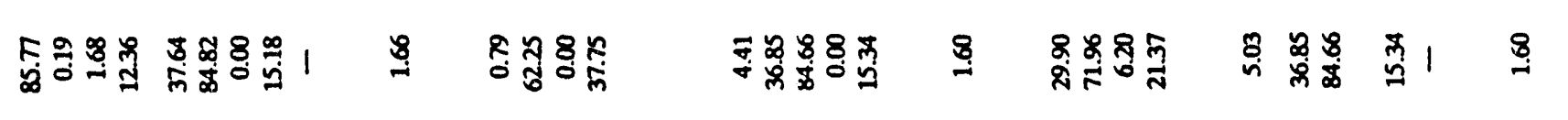

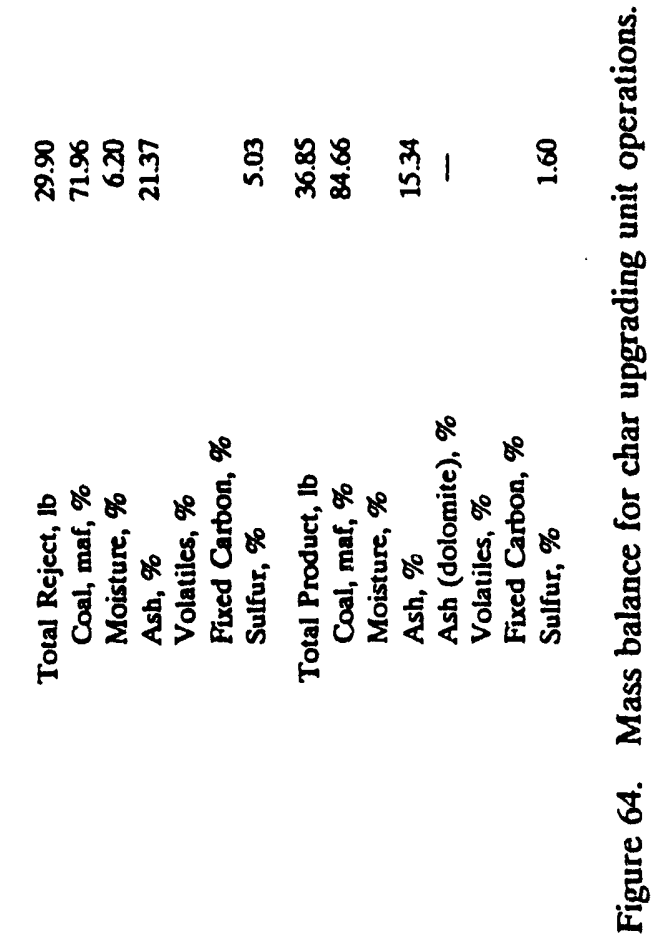

$\frac{1}{1}$

I

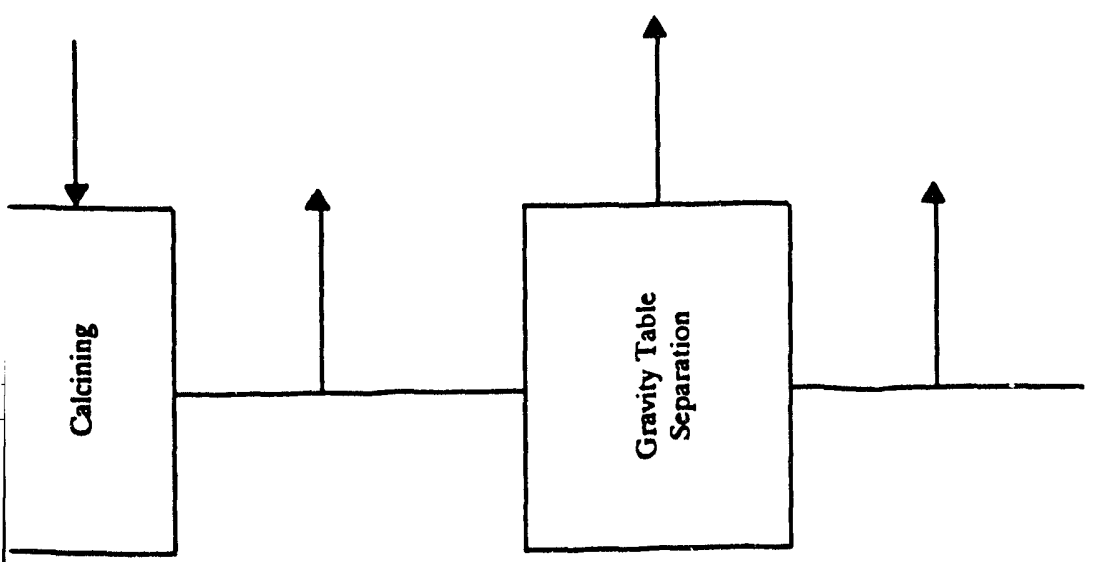

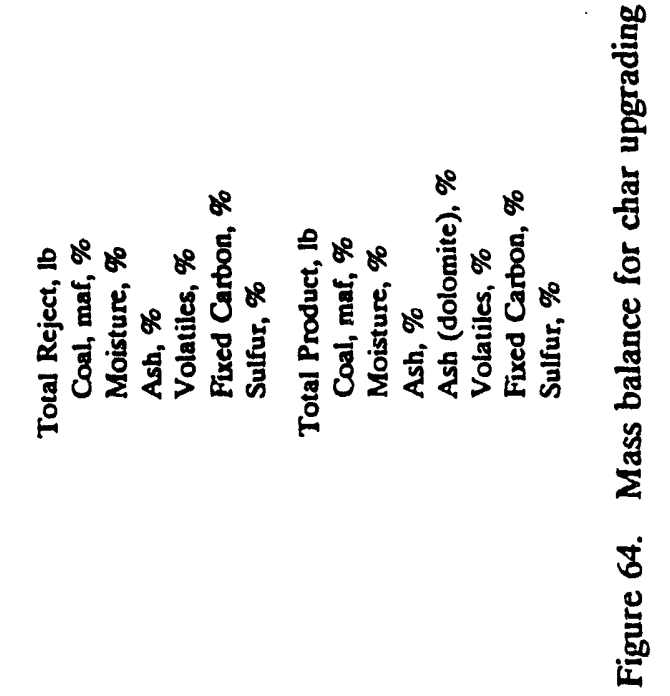

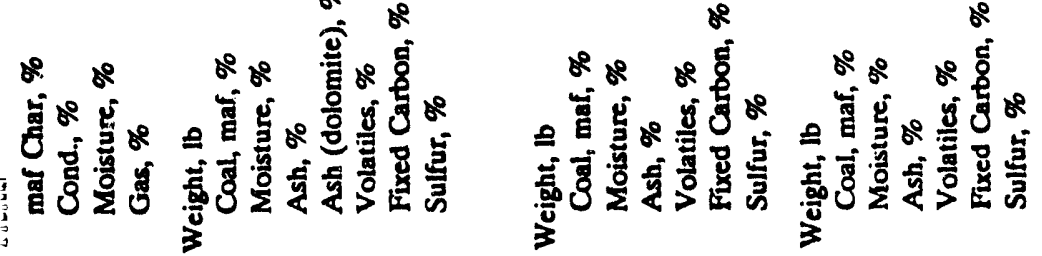



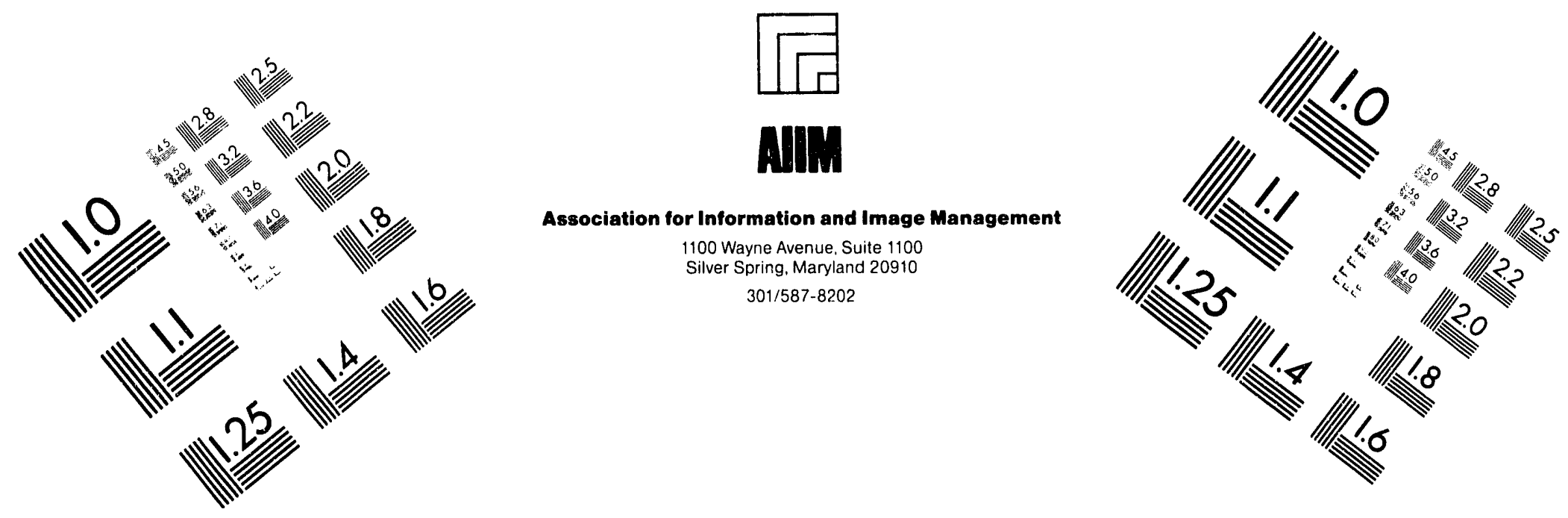

Centimeter

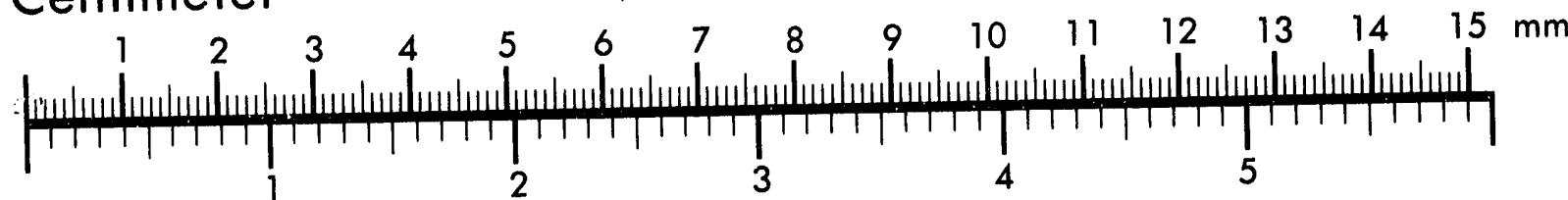
Inches
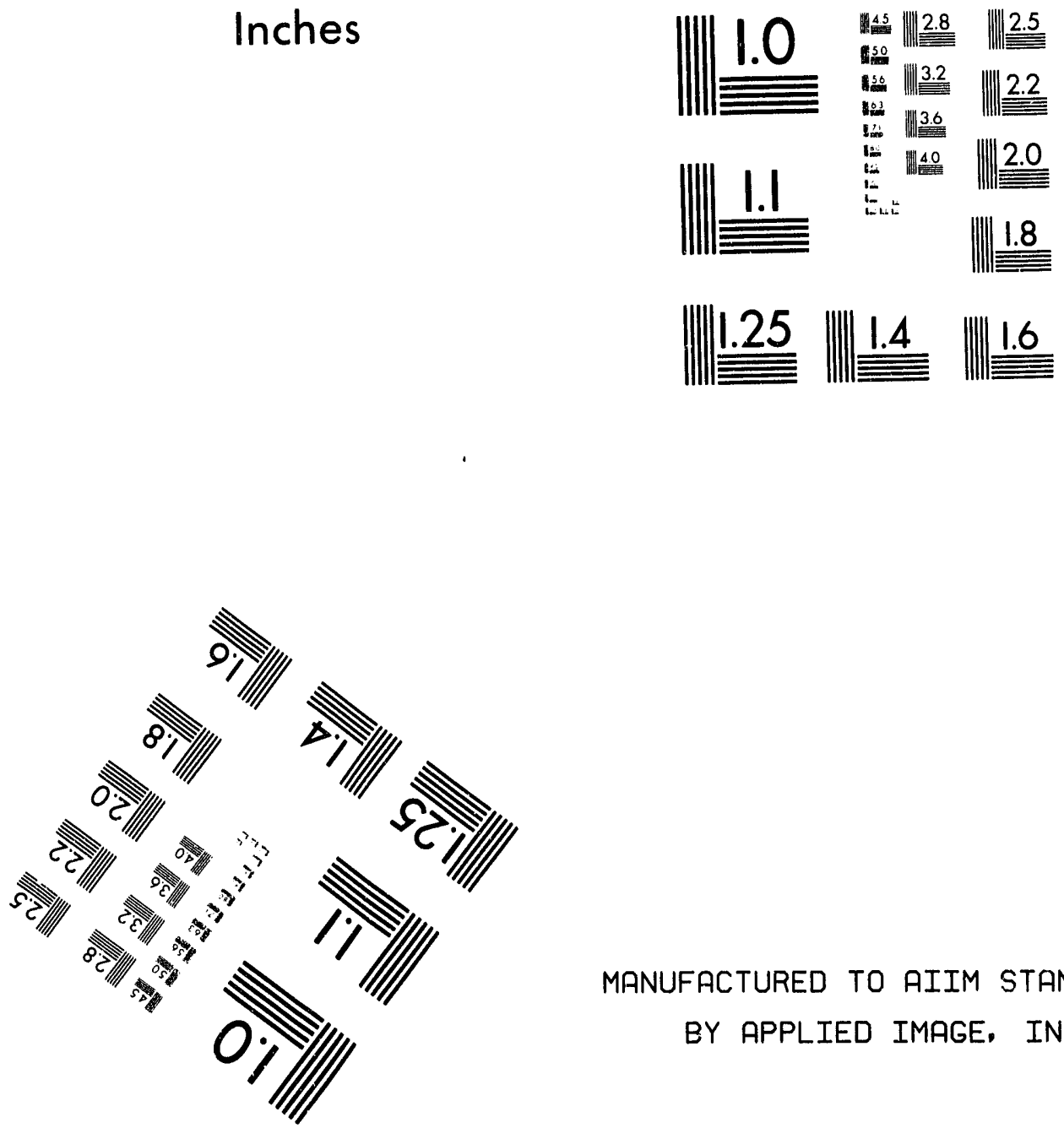

MANUFACTURED TO AIIM STANDARDS

BY APPLIED IMAGE, INC.

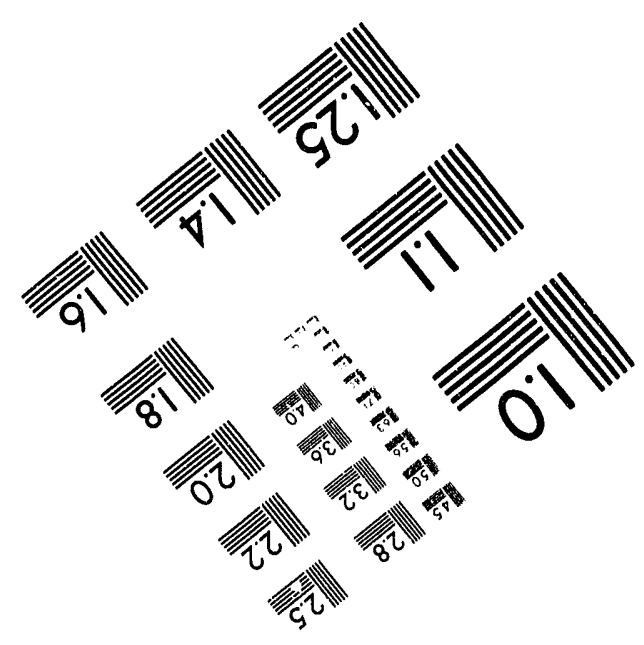



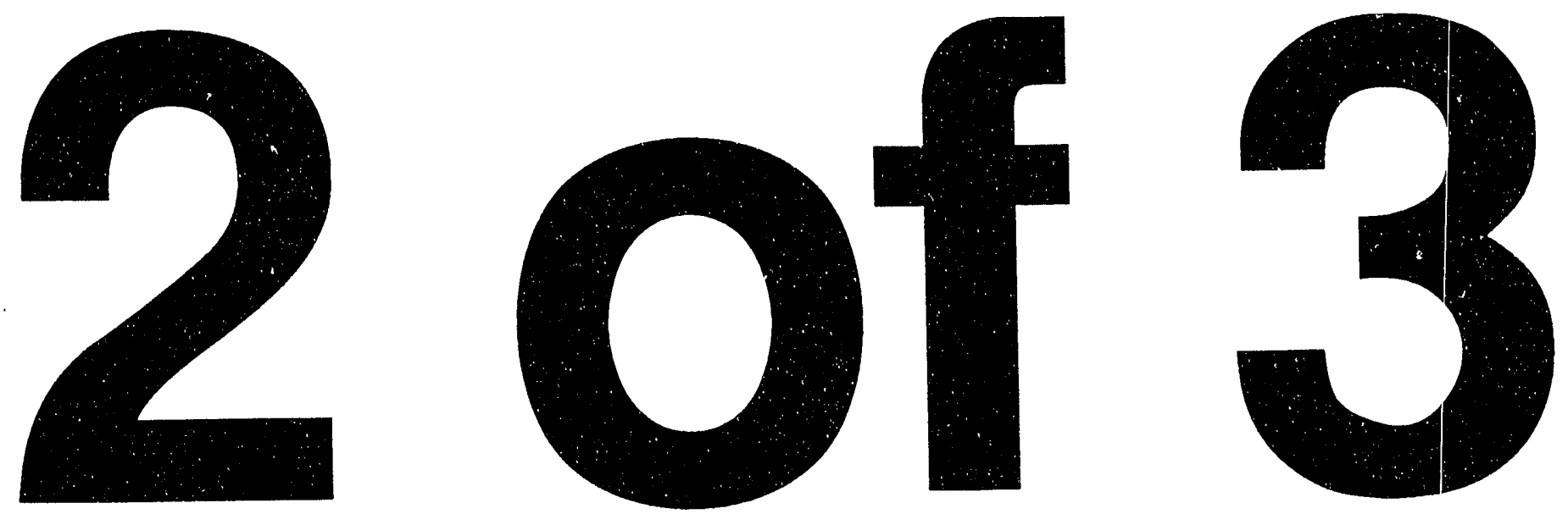
TABLE 28

Screen Separation Results

\begin{tabular}{lcr}
\hline & Weight & \\
Size Range & Collected, lb & Feed, \% \\
\hline$-3 / 4$ inch $\times 10$ mesh & 7,070 & 41.14 \\
$-10 \times+24$ mesh & 5,695 & 33.14 \\
-24 mesh & 4,133 & 24.05 \\
Fugitive Dust & 286 & 1.66 \\
Total & 17,184 & 99.99 \\
\hline
\end{tabular}

Initial cleaning tests were begun on the air table, and the operator recycled material back through the cleaning step until some measure of reproducibility was achieved. At that time, the actual processing of the coal was begun, one size range at a time. After cleaning, the light fraction from each size range was combined and blended prior to shipment to the EERC.

On a weight basis, $77.6 \%$ of the coal was recovered in the cleaned product. Ash rejection was fair with only $63.9 \%$ of the ash in the feed reporting in the product. These results are typical of those obtained with preliminary bench-scale testing that also indicated the sulfur is uniformly distributed throughout the coal, making sulfur removal by this technique very difficult at acceptable recovery rates.

Analysis of the data on the cleaned coal shows the distribution of ash and sulfur as follows:

- The feed stream was 17,184 pounds at $5.81 \%$ moisture, $12.12 \%$ ash, and $4.52 \%$ sulfur.

- The cleaned product was 13,329 pounds at $4.12 \%$ moisture, $9.99 \%$ ash, and $4.28 \%$ sulfur.

- The reject streams, including dust, weighed 3,855 pounds at $19.48 \%$ ash, and $5.25 \%$ sulfur.

Compared to the $22 \%$ weight loss from the starting material, about $38 \%$ of the ash and $34 \%$ of the sulfur was rejected during the cleaning operation. Btu rejection was less at $17 \%$, which shows that the cleaning step was effective in improving the coal quality. Final cleaned product quality on an as-received basis was $4.57 \%$ moisture, $3.88 \%$ sulfur, $9.84 \%$ ash, and Btu content of $12,474 \mathrm{Btu} / \mathrm{lb}$. This compares to the respective head assay values of $5.80 \%$ moisture, $4.52 \%$ sulfur, $12.17 \%$ ash, and $11,570 \mathrm{Btu} / \mathrm{lb}$. The resultant 6.5 tons of clean coal was shipped for processing in the PRU carbonizer.

\subsection{Lab, CFBR, Bench, and PRU Carbonizer Sulfur Reduction Tests}

The most critical unit operation in terms of sulfur reduction is the carbonization step. The coal temperature is raised above the vaporization temperature of elemental sulfur, tar is vaporizing, inorganic sulfides are being reduced, and molecular bonds are 


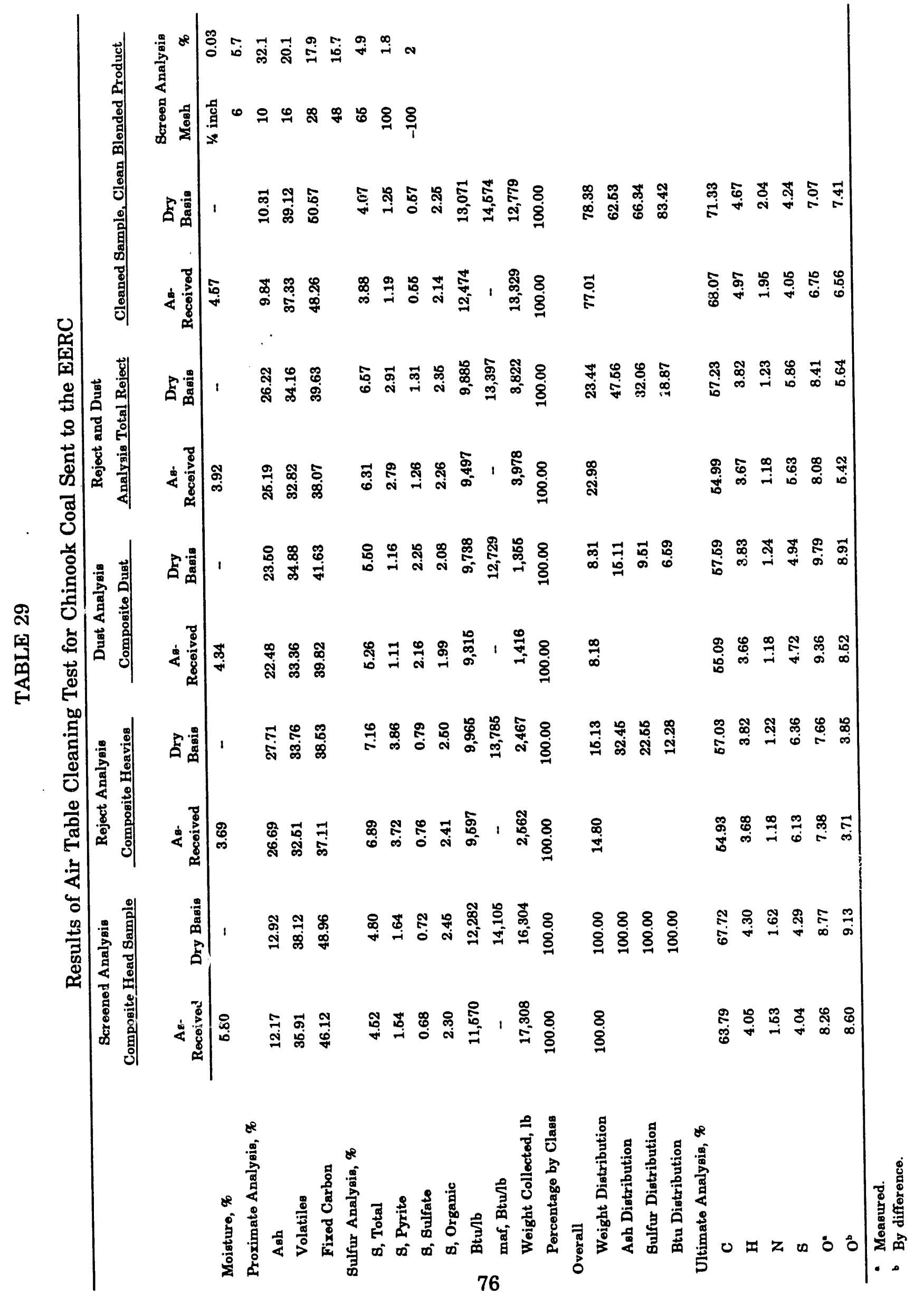


being cleaved. All these processes provide the sulfur an opportunity to become incorporated into the organic matrix. If this occurs, the potential for sulfur removal is very remote. Because of the critical importance of this step, an expanded program for investigating the process options for carbonization was undertaken.

Several studies were conducted using a TGA to determine the effect of reactive atmosphere on sulfur removal. This was done on noncleaned Indiana No. 3 coal prior to the gravity table separation testing. After the TGA testing, selected conditions were investigated in the CFBR using noncleaned coal. Based on these results, the cleaned coal was processed in the PRU. Limited data are available on the Wyodak coal because it was included in the CFBR and PRU test series.

\subsubsection{In Situ Sulfur Reduction Techniques}

\subsubsection{The Effect of Temperature and Steam/Nitrogen Partial Pressure on the Sulfur Content in Wyodak Char}

For Wyodak subbituminous coal, the maximum percentage reduction in sulfur content between feed coal and char was 33\% (Figure 65). The actual sulfur contents of the chars shown in Figure 66 fall well below 1\% sulfur. Total sulfur content was progressively reduced along with increasing temperature up to $1020^{\circ} \mathrm{F}\left(550^{\circ} \mathrm{C}\right)$ and to a lesser extent along with increasing steam partial pressure. Sulfur form analyses for selected samples are presented in Table 30. Pyritic sulfur tended to decrease with increasing temperature and steam partial pressure. Sulfate sulfur increased slightly above the level in the feed coal. The difference between the amount of total sulfur and the amount of pyritic and sulfate sulfur, normally called "organic" sulfur, made up the largest. fraction of sulfur in the char. Increasing temperature caused only a slight decrease in this component, but an increase in steam partial pressure had a greater effect. Because the sulfur contents of the Wyodak chars were well below that required for metallurgical coke substitutes, further studies were not conducted.

\subsubsection{The Effect of Reaction Conditions on the Sulfur Content of Indiana No. 3 Char Produced in a TGA}

Preliminary TGA experiments were performed on washed $1 / 4$ inch $\mathrm{x}-10$ mesh Indiana No. 3 bituminous coal having a maf sulfur content of $3.56 \%$. The coal was heated in one to four stages to a final temperature of either $1020^{\circ}$ or $1470^{\circ} \mathrm{F}\left(550^{\circ}\right.$ or $\left.800^{\circ} \mathrm{C}\right)$, using several different gas atmospheres by stage. The gases used, ranked in order of reducing to oxidizing, were $\mathrm{CO} / \mathrm{H}_{2}$ syngas, $\mathrm{CO}$, steam, $\mathrm{N}_{2}$, and air. The range of reduction in char sulfur content was from $20 \%$ to $35 \%$, with the order of effectiveness as shown in Table 31. The observations that can be made based on these results are:

- A temperature higher than the mild gas carbonization temperature of $1020^{\circ} \mathrm{F}$ $\left(550^{\circ} \mathrm{C}\right)$ was needed in these tests to achieve optimum sulfur removal.

- Staged heating with hold time at intermediate temperatures, to allow time for reaction and removal of coal sulfur, was more effective than heating directly to a high temperature. 


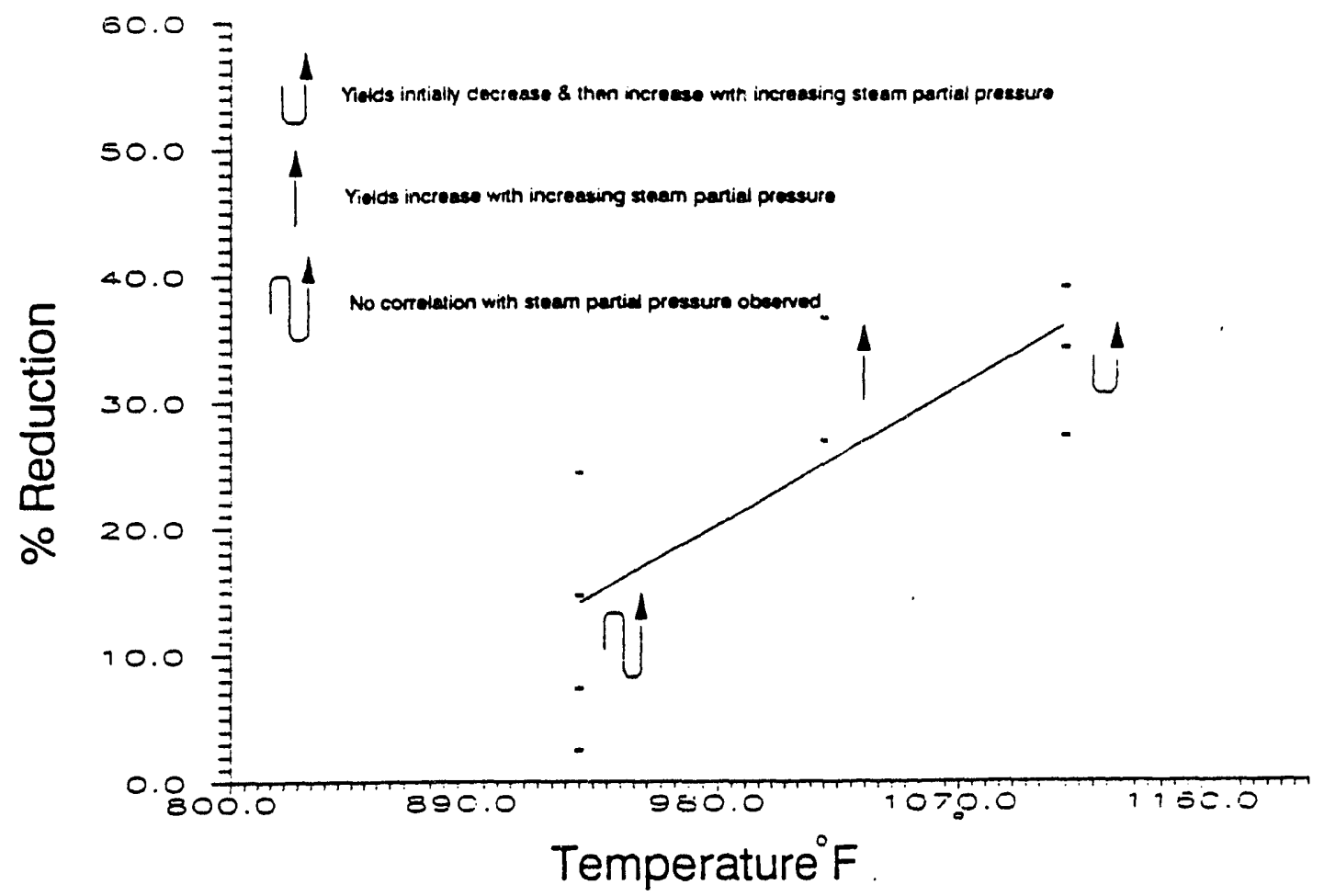

Figure 65. The effect of temperature and steam/nitrogen partial pressure on Wyodak char sulfur reduction.

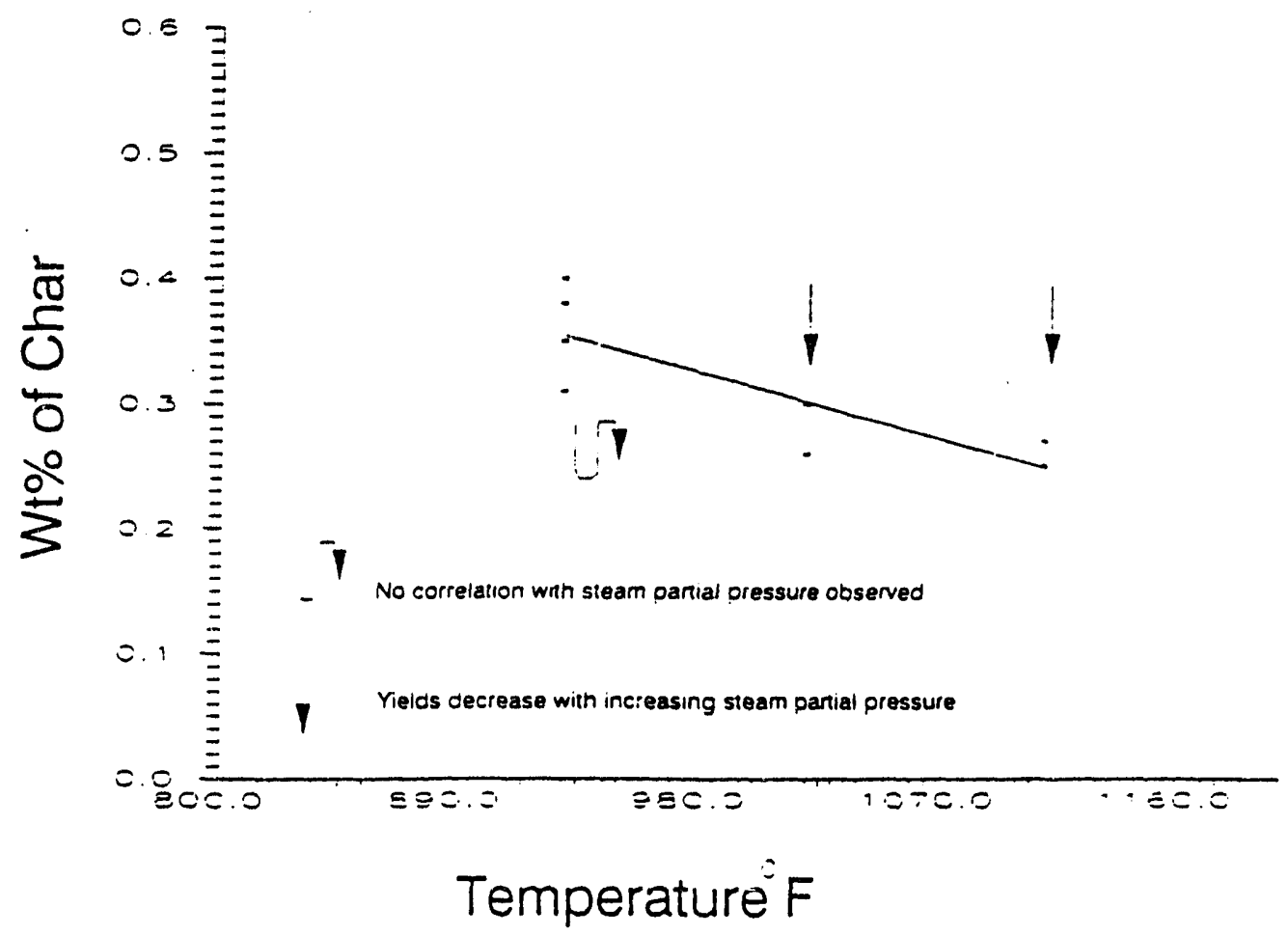

Figure 66. The effect of temperature and steam/nitrogen partial pressure on Wyodak char sulfur content. 
TABLE 30

Sulfur Content of Wyodak Mild Gasification Chars

\begin{tabular}{ccccccc}
\hline \multirow{2}{*}{$\begin{array}{c}\text { Test } \\
\text { Matrix } \\
\text { Number }\end{array}$} & Temperature, & \multirow{2}{*}{$\begin{array}{c}\text { Steam } \\
\text { Ratio, } \\
\%_{\%^{a}}{ }^{\circ} \text { C }\end{array}$} & & \multicolumn{5}{c}{ Sulfur, wt\%; dry basis } \\
\cline { 5 - 7 } & & & Total & Pyritic & Sulfate & $\begin{array}{c}\text { Organic or } \\
\text { Elemental }\end{array}$ \\
\hline Feed Coal & & & 0.38 & 0.054 & 0.022 & 0.30 \\
11 & $1020 / 550$ & 0 & 0.30 & 0.033 & 0.037 & 0.23 \\
12 & $1020 / 550$ & 10 & 0.28 & & & \\
13 & $1020 / 550$ & 50 & 0.19 & & & \\
14 & $1020 / 550$ & 100 & 0.22 & 0.014 & 0.030 & 0.18 \\
21 & $1110 / 600$ & 0 & 0.32 & 0.011 & 0.026 & 0.28 \\
22 & $1110 / 600$ & 10 & 0.25 & & & \\
23 & $1110 / 600$ & 50 & 0.23 & & & \\
24 & $1110 / 600$ & 100 & 0.25 & 0.026 & 0.026 & 0.20 \\
\hline
\end{tabular}

a Remainder is $\mathrm{CO}_{2}$.

- Similar levels of sulfur removal were achieved in three high-temperature $\left(1470^{\circ} \mathrm{F} / 800^{\circ} \mathrm{C}\right)$ atmospheres, with only slight improvement in the order of $\mathrm{N}_{2}$, air, and syngas.

- At the lower staging temperatures up to $1020^{\circ} \mathrm{F}\left(550^{\circ} \mathrm{C}\right), \mathrm{N}_{2}$ appeared to be as effective as $\mathrm{CO}_{2}$, although a direct comparison was not provided by the test conditions.

A second set of TGA experiments was performed on mine-washed Indiana No. 3 bituminous coal containing $5 \%$ sulfur to determine more exactly the effects of temperature staging, residence time, and reactor atmosphere. Experimental conditions and results are presented in Table 32 . Coal samples were heated directly to $660^{\circ}, 840^{\circ}, 930^{\circ}$, or $1470^{\circ} \mathrm{F}$ $\left(350^{\circ}, 450^{\circ}, 500^{\circ}\right.$, or $\left.800^{\circ} \mathrm{C}\right)$ for comparison with those staged at $660^{\circ}$ and $840^{\circ} \mathrm{F}\left(350^{\circ}\right.$ and $\left.450^{\circ} \mathrm{C}\right), 660^{\circ}, 840^{\circ}$, and $930^{\circ} \mathrm{F}\left(350^{\circ}, 450^{\circ}\right.$, and $\left.500^{\circ} \mathrm{C}\right)$, and $660^{\circ}, 840^{\circ}, 930^{\circ}$, and $1470^{\circ} \mathrm{F}\left(350^{\circ}, 450^{\circ}, 500^{\circ}\right.$, and $\left.800^{\circ} \mathrm{C}\right)$. The effect of staging atmosphere was determined using three combinations of gases. Gas A consisted of $90: 10 \mathrm{v}: \mathrm{v}_{2}: \mathrm{CO}_{2}$. Gas B consisted of a $50: 50$ v:v $\mathrm{H}_{2}: \mathrm{CO}$. Gas $A B$ was a 50:50 v:v $A: B$. Staging residence times were 10 or 30 minutes at temperature, not counting the heating times required to reach the target temperatures, which were 12,6 , and 5 minutes to reach $660^{\circ}, 840^{\circ}$, and $930^{\circ} \mathrm{F}\left(350^{\circ}\right.$, $450^{\circ} \mathrm{C}$, and $500^{\circ} \mathrm{C}$ ), respectively. Analyses for total sulfur and sulfur forms were performed by AMAX R\&D in Golden, Colorado.

Table 32 presents results in the order of decreasing sulfur content in char. In general, the total sulfur content decreased as total residence time and temperature increased. However, the effect of temperature is not clearly defined by these tests since staged heating to a moderate final temperature of $1020^{\circ} \mathrm{F}\left(550^{\circ} \mathrm{C}\right)$ produced several of the lower sulfur contents. The char with the lowest total sulfur content $(2.59 \mathrm{wt} \%)$ was produced using staged heating to temperatures of $660^{\circ}, 840^{\circ}$, and $1020^{\circ} \mathrm{F}\left(350^{\circ}, 450^{\circ}\right.$, and $500^{\circ} \mathrm{C}$ ), at residence times of 30,20 , and 120 minutes, in a reducing atmosphere consisting of $45 \% \mathrm{~N}_{2}, 25 \% \mathrm{H}_{2}, 25 \% \mathrm{CO}$, and $5 \% \mathrm{CO}_{2}$. The results in Table 32 generally show that the sulfur content was lower in a reducing gas than in an unreactive gas $(90 \%$ $\mathrm{N}_{2} / 10 \% \mathrm{CO}_{2}$ ). 


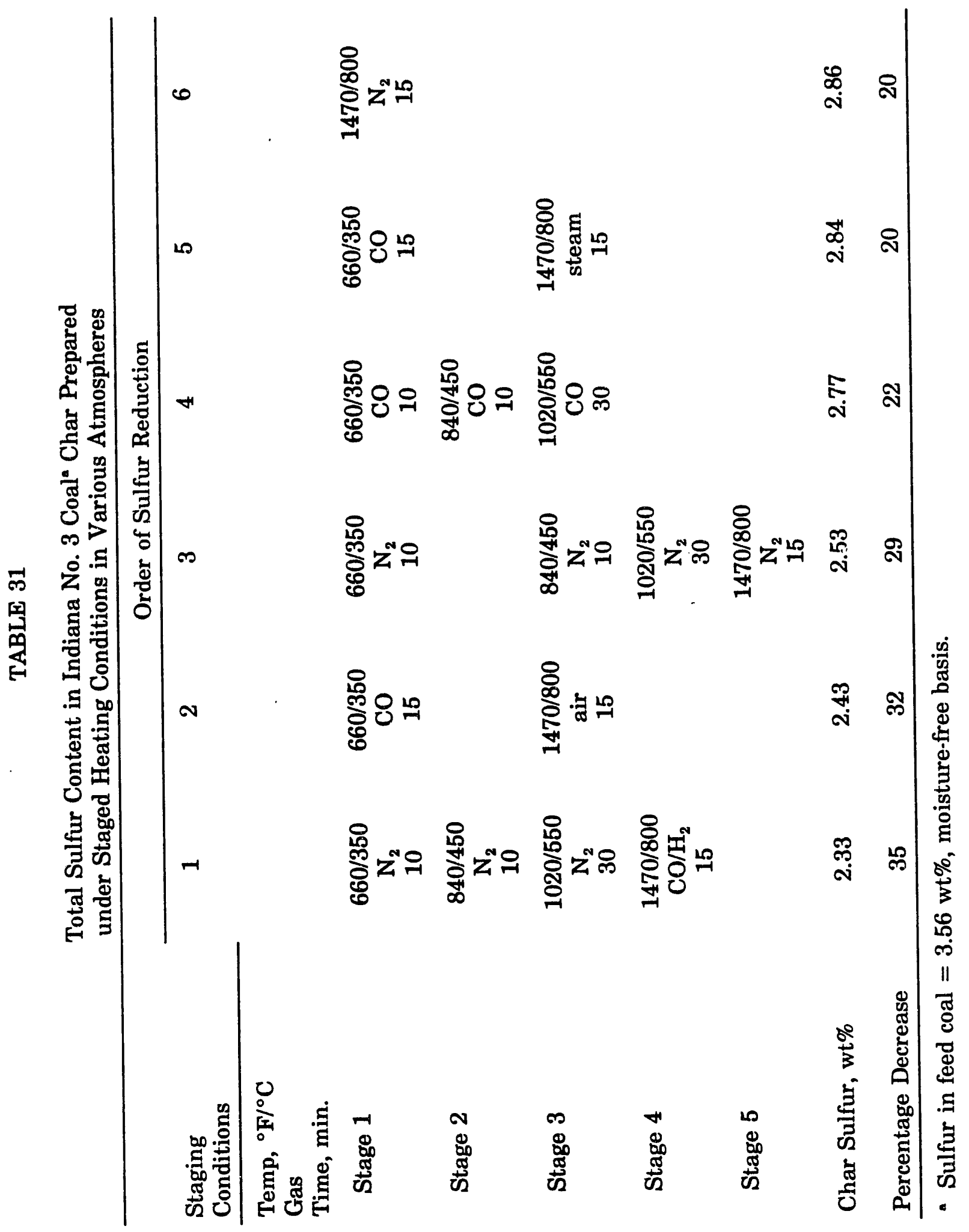


TABLE 32

Indiana No. 3 Bituminous Coal Char (TGA) Total Sulfur Analyses

\begin{tabular}{|c|c|c|c|c|c|c|c|}
\hline Run No. & Temp., ${ }^{\circ} \mathrm{F}$ & Gas & Time, min & $\begin{array}{c}\text { Total S, } \\
\text { wt\% }\end{array}$ & Ash & Vol & FC \\
\hline \multicolumn{4}{|c|}{$\begin{array}{l}\text { Indiana Coal } \\
\text { Standard }\end{array}$} & $\begin{array}{l}4.89 \\
5.20\end{array}$ & 11.43 & 40.34 & 48.23 \\
\hline 27 & 660 & $\mathrm{AB}$ & 30 & 5.01 & 13.45 & 39.32 & 47.23 \\
\hline 32 & 660 & $A B$ & 10 & 4.69 & 12.35 & 41.00 & 46.65 \\
\hline 17 & 660 & A & 30 & 4.68 & 12.17 & 39.96 & 47.87 \\
\hline 22 & 660 & A & 10 & 4.67 & 11.92 & 41.17 & 46.91 \\
\hline 59 & $660 / 840 / 930$ & $\mathrm{AB} / \mathrm{AB} / \mathrm{AB}$ & $30 / 30 / 30$ & 4.61 & & & \\
\hline 26 & 930 & A & 10 & 4.26 & 18.54 & 17.33 & 64.13 \\
\hline 52 & 1470 & $\mathrm{AB}$ & 30 & 4.24 & & & \\
\hline 38 & $660 / 840$ & $\mathrm{~A} / \mathrm{A}$ & $10 / 30$ & 4.19 & 18.80 & 17.17 & 64.03 \\
\hline 43 & $660 / 840$ & $\mathrm{~A} / \mathrm{A}$ & $30 / 10$ & 4.18 & 17.53 & 19.26 & 63.21 \\
\hline 21 & 930 & A & 30 & 4.18 & 17.40 & 15.02 & 67.58 \\
\hline 25 & $660 / 840 / 930$ & $\mathrm{~A} / \mathrm{A} / \mathrm{A}$ & $10 / 10 / 10$ & 4.17 & 18.28 & 17.32 & 64.40 \\
\hline 20 & $660 / 840 / 930$ & A/A/A & $30 / 30 / 30$ & 4.16 & 17.82 & 16.28 & 65.90 \\
\hline 19 & 840 & A & 30 & 4.11 & 17.80 & 18.76 & 63.44 \\
\hline 18 & 840 & A & $30 / 30$ & 4.11 & 17.38 & 18.16 & 64.46 \\
\hline 23 & $660 / 840$ & A/A & $10 / 10$ & 4.04 & 17.41 & 21.80 & 60.79 \\
\hline 29 & 840 & $\mathrm{AB}$ & 30 & 4.00 & 15.07 & 22.59 & 62.34 \\
\hline 24 & 840 & A & 10 & 3.99 & 14.67 & 27.39 & 57.94 \\
\hline 53 & 1560 & $\mathrm{AB}$ & 30 & 3.99 & & & \\
\hline 60 & $660 / 840 / 930$ & $\mathrm{AB} / \mathrm{AB} / \mathrm{AB}$ & $30 / 30 / 30$ & 3.98 & & & \\
\hline 55 & $660 / 840 / 930$ & $\mathrm{AB} / \mathrm{AB} / \mathrm{AB}$ & $30 / 30 / 16$ & 3.97 & & & \\
\hline 40 & $660 / 840 / 930$ & $\mathrm{AB} / \mathrm{AB} / \mathrm{AB}$ & $30 / 30 / 10$ & 3.73 & 18.00 & 14.87 & 67.13 \\
\hline 33 & $660 / 840$ & $\mathrm{AB} / \mathrm{AB}$ & $10 / 10$ & 3.69 & 17.98 & 22.66 & 59.36 \\
\hline 48 & $660 / 840 / 930 / 1470$ & $\mathrm{AB} / \mathrm{AB} / \mathrm{AB} / \mathrm{H}_{2} \mathrm{O}$ & $30 / 30 / 30 / 30$ & 3.59 & 21.16 & 5.51 & 73.33 \\
\hline 35 & $660 / 840 / 930$ & $\mathrm{AB} / \mathrm{AB} / \mathrm{AB}$ & $10 / 10 / 10$ & 3.56 & 18.54 & 16.32 & 65.14 \\
\hline 31 & 930 & $\mathrm{AB}$ & 30 & 3.51 & 19.11 & 15.00 & 65.86 \\
\hline 28 & $660 / 840$ & $\overrightarrow{A B} / \mathrm{AB}$ & $30 / 30$ & 3.51 & 16.60 & 20.96 & 62.44 \\
\hline 58 & $660 / 840 / 930$ & $\mathrm{AB} / \mathrm{AB} / \mathrm{AB}$ & $30 / 30 / 30$ & 3.47 & & & \\
\hline 49 & $660 / 840 / 930 / 1470$ & $\mathrm{AB} / \mathrm{AB} / \mathrm{AB} / \mathrm{AB}$ & $30 / 30 / 30 / 30$ & 3.40 & 27.50 & 3.78 & 68.72 \\
\hline 56 & $660 / 840 / 930$ & $\mathrm{AB} / \mathrm{AB} / \mathrm{AB}$ & $30 / 30 / 20$ & 3.30 & & & \\
\hline 47 & $660 / 840 / 930 / 1470$ & $\mathrm{AB} / \mathrm{AB} / \mathrm{AB} / \mathrm{A}$ & $30 / 30 / 30 / 30$ & 3.30 & 26.78 & 5.39 & 67.83 \\
\hline 57 & $660 / 840 / 930$ & $\mathrm{AB} / \mathrm{AB} / \mathrm{AB}$ & $30 / 30 / 30$ & 3.24 & & & \\
\hline 45 & $660 / 840 / 930$ & $\mathrm{AB} / \mathrm{AB} / \mathrm{A}$ & $30 / 30 / 30$ & 3.24 & 17.23 & 12.87 & 69.90 \\
\hline 30 & $660 / 840 / 930$ & $\mathrm{AB} / \mathrm{AB} / \mathrm{AB}$ & $30 / 30 / 30$ & 3.19 & 16.75 & 14.30 & 68.94 \\
\hline 62 & $660 / 840 / 930$ & $\mathrm{AB} / \mathrm{AB} / \mathrm{AB}$ & $30 / 30 / 120$ & 2.77 & & & \\
\hline 61 & $660 / 840 / 930$ & $\mathrm{AB} / \mathrm{AB} / \mathrm{AB}$ & $30 / 30 / 120$ & 2.59 & & & \\
\hline
\end{tabular}

$\mathrm{A}=90: 10 \quad \mathrm{~N}_{2}: \mathrm{CO}_{2} \quad \mathrm{v}: \mathrm{v}$

$B=50: 50 \quad \mathrm{H}_{2}: \mathrm{CO} \quad \mathrm{v}: \mathrm{v}$

$\mathrm{AB}=50: 50 \quad A: B \quad v: v$

Table 33 reorders the above TGA data in the order of decreasing pyritic sulfur content. Generally, pyritic sulfur content decreases as total residence time and temperature increase. The chars made in a reducing atmosphere had lower pyritic sulfur contents than those made in an inert atmosphere. These results indicate that pyritic sulfur content is affected by temperature, residence time, and atmosphere in much the same way as total sulfur content. 
TABLE 33

Indiana No. 3 Bituminous Coal Char (TGA) Pyritic Sulfur Analyses

\begin{tabular}{clllc}
\hline Run No. & Temp., ${ }^{\circ} \mathrm{F}$ & Time, $\min$ & Gas & $\begin{array}{c}\text { Pyritic } \\
\text { Sulfur, wt\% }\end{array}$ \\
\hline Indiana Coal & & & & \\
20 & $660 / 840 / 930$ & $30 / 30 / 30$ & $\mathrm{~A} / \mathrm{A} / \mathrm{A}$ & 2.37 \\
32 & 660 & 10 & $\mathrm{AB}$ & 2.12 \\
22 & 660 & 10 & $\mathrm{~A}$ & 2.06 \\
26 & 930 & 10 & $\mathrm{~A}$ & 1.99 \\
43 & $660 / 840$ & $30 / 10$ & $\mathrm{~A} / \mathrm{A}$ & 1.99 \\
38 & $660 / 840$ & $10 / 30$ & $\mathrm{~A} / \mathrm{A}$ & 1.96 \\
19 & 840 & 30 & $\mathrm{~A}$ & 1.96 \\
18 & $660 / 840$ & $30 / 30$ & $\mathrm{~A} / \mathrm{A}$ & 1.94 \\
27 & 660 & 30 & $\mathrm{AB}$ & 1.89 \\
23 & $660 / 840$ & $10 / 10$ & $\mathrm{~A} / \mathrm{A}$ & 1.88 \\
24 & 840 & 10 & $\mathrm{~A}$ & 1.79 \\
25 & $660 / 840 / 930$ & $10 / 10 / 10$ & $\mathrm{~A} / \mathrm{A} / \mathrm{A}$ & 1.72 \\
17 & 660 & 30 & $\mathrm{~A}$ & 1.68 \\
21 & 930 & 30 & $\mathrm{~A}$ & 1.68 \\
33 & $660 / 840$ & $10 / 10$ & $\mathrm{AB} / \mathrm{AB}$ & 1.55 \\
29 & 840 & 30 & $\mathrm{AB}$ & 1.29 \\
28 & $660 / 840$ & $30 / 30$ & $\mathrm{AB} / \mathrm{AB}$ & 1.12 \\
35 & $660 / 840 / 930$ & $10 / 10 / 10$ & $\mathrm{AB} / \mathrm{AB} / \mathrm{AB}$ & 1.02 \\
31 & 930 & 30 & $\mathrm{AB}$ & 0.65 \\
40 & $660 / 840 / 930$ & $30 / 30 / 10$ & $\mathrm{AB} / \mathrm{AB} / \mathrm{AB}$ & 0.41 \\
48 & $660 / 840 / 930 / 1470$ & $30 / 30 / 30 / 30$ & $\mathrm{AB} / \mathrm{AB} / \mathrm{AB} / \mathrm{H}_{2} \mathrm{O}$ & 0.31 \\
30 & $660 / 840 / 930$ & $30 / 30 / 30$ & $\mathrm{AB} / \mathrm{AB} / \mathrm{AB}$ & 0.29 \\
49 & $660 / 840 / 930 / 1470$ & $30 / 30 / 30 / 30$ & $\mathrm{AB} / \mathrm{AB} / \mathrm{AB} / \mathrm{AB}$ & 0.18 \\
47 & $660 / 840 / 930 / 1470$ & $30 / 30 / 30 / 30$ & $\mathrm{AB} / \mathrm{AB} / \mathrm{AB} / \mathrm{A}$ & 0.17 \\
45 & $660 / 840 / 930$ & $30 / 30 / 30$ & $\mathrm{AB} / \mathrm{AB} / \mathrm{A}$ & 0.16 \\
\hline
\end{tabular}

Table 34 again reorders the above TGA data, next in decreasing order of organic sulfur content. In contrast to pyritic sulfur, the organic sulfur content did not decrease as total residence time and temperature increased. The seven lowest organic sulfur contents were observed for chars that were heated to final temperatures of $840^{\circ}$ or $930^{\circ} \mathrm{F}\left(450^{\circ}\right.$ or $\left.500^{\circ} \mathrm{C}\right)$ in an inert atmosphere $\left(90 \% \mathrm{~N}_{2} / 10 \% \mathrm{CO}_{2}\right)$ for a total residence time of 10 to 90 minutes. Several of the higher organic sulfur contents were observed for chars that were stage-heated to $1470^{\circ} \mathrm{F}\left(800^{\circ} \mathrm{C}\right)$ in a reducing atmosphere for up to 120 minutes. The relative decrease in pyritic and increase in organic sulfur contents with increasing time and temperature suggest that the sulfur disassociated from pyrite at the higher temperatures (e.g., $\mathrm{H}_{2} \mathrm{~S}$ ) may be immediately reacting with the organic matrix of the char, thereby becoming reincorporated into the char as "organic sulfur." To determine whether this had occurred, organic sulfur was rationed to fixed carbon for chars produced under a reducing atmosphere (Figure 67). Also shown are the ratios of total and pyritic sulfur 
TABLE 34

Indiana No. 3 Bituminous Coal Char (TGA) Organic Sulfur Analysis

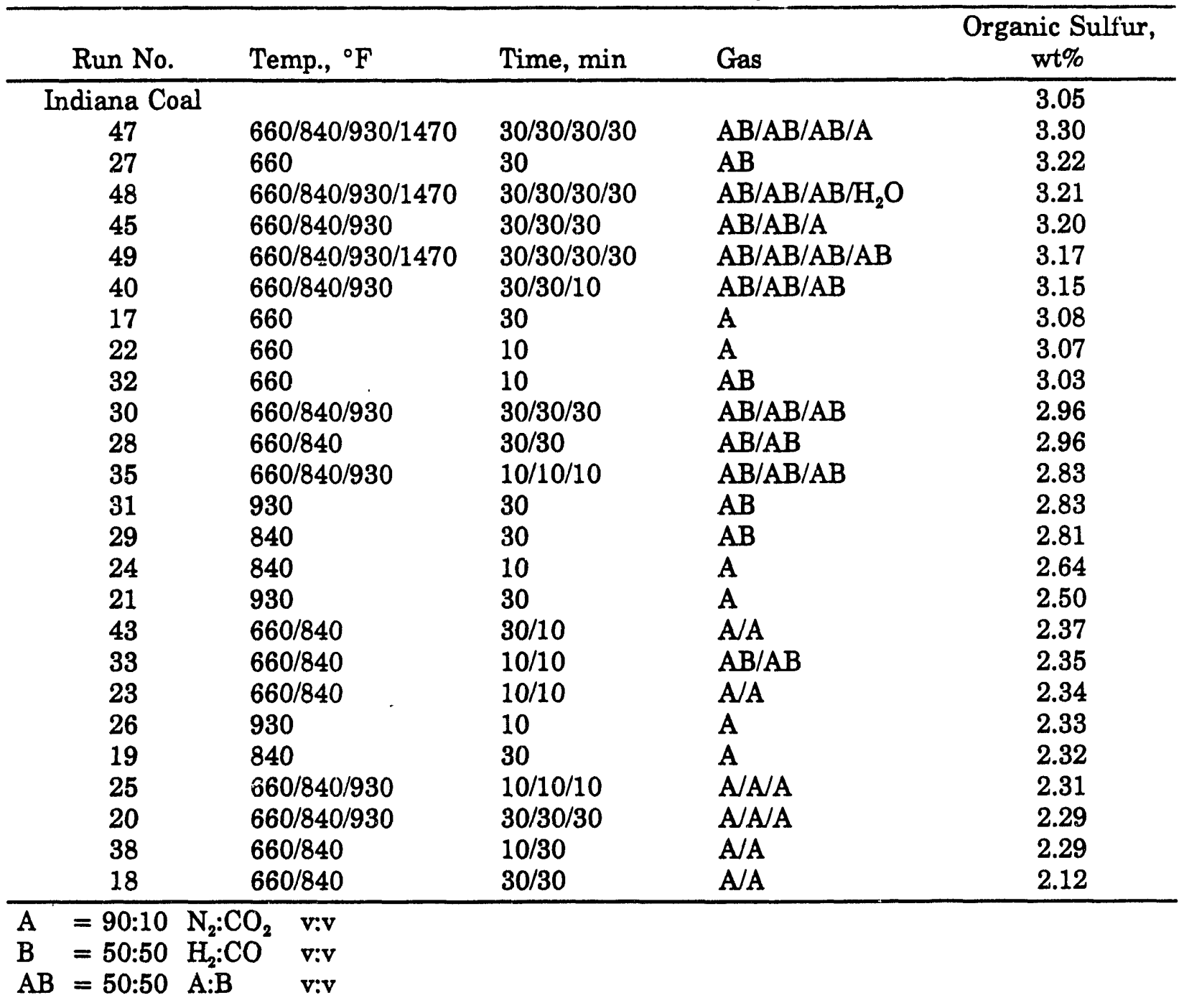

contents to fixed carbon. Since the ratio for organic sulfur decreased slightly with increasing temperature, no net increase in organic sulfur could be substantiated. However, the absence of a net increase in organic sulfur does not rule out reaction mechanisms that transfer or transform sulfur to a more stable and refractory form in the char.

Overall, the TGA tests showed that heating directly to $1470^{\circ} \mathrm{F}\left(800^{\circ} \mathrm{C}\right)$ in a reducing atmosphere yielded chars with higher sulfur contents than expected. The two chars having the lowest sulfur contents (2.59 and $2.77 \mathrm{wt} \%)$ resulted from staged heating in a reducing atmosphere, to a final temperature of $930^{\circ} \mathrm{F}\left(500^{\circ} \mathrm{C}\right)$ over a total residence time at staging temperatures of 120 minutes. Reaction at lower temperatures is indicated to be necessary to permit sulfur to escape without being trapped in the char by hightemperature retrograde reactions. The results of the TGA tests indicate the importance of gaining a fundamental understanding of the true chemical forms of sulfur in coal and char, and of the reactions of these compounds during char formation. 


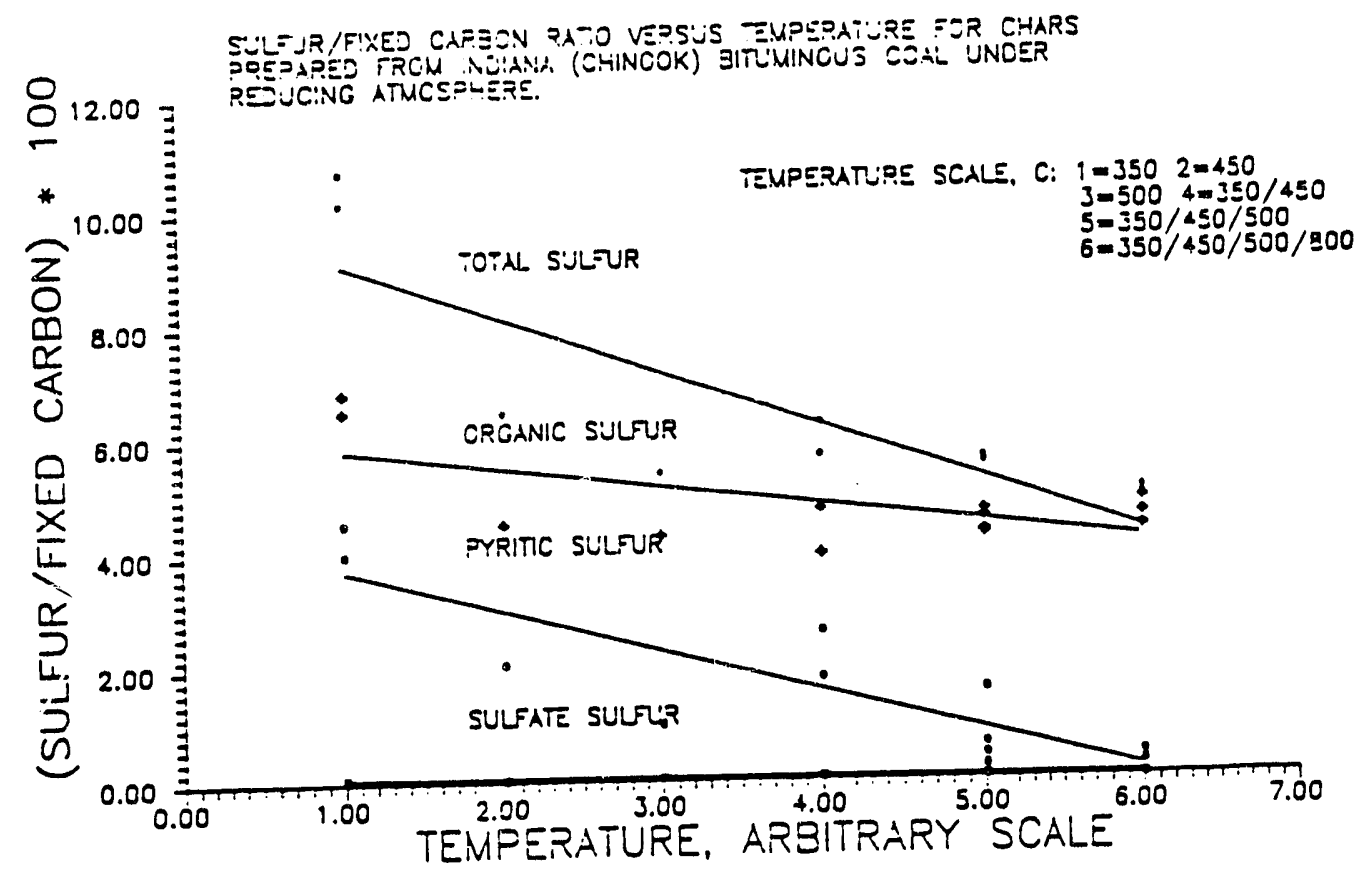

Figure 67. Sulfur/fixed carbon ratio versus temperature for chars prepared from Indiana No. 3 bituminous coal under reducing atmosphere.

\subsection{Detailed Analyses of the Chemical and Physical Forms of Sulfur in Indiana No. 3 Coal Char Prepared by TGA}

Samples of Indiana No. 3 char prepared in the TGA at $660^{\circ}, 840^{\circ}$, and $1110^{\circ}\left(350^{\circ}\right.$, $450^{\circ}$, and $600^{\circ}$ ) under $\mathrm{N}_{2}$ were analyzed by scanning electron microscopy/energy dispersive spectroscopy (SEM/EDS). Crystals of various minerals, including aluminosilicates, calcium sulfate, and calcium carbonate, were observed. Elemental analysis maps of the surface indicated that sulfur was distributed over the entire surface of the char, in some cases on the mineral material as well as on the carbon matrix. Calcium and iron, very often mineralogically associated with sulfur, were coincident with the sulfur in only a few isolated spots on the map. ASTM sulfur analyses for samples investigated by SEM/EDS are given in Table 35.

Chars were also prepared in the TGA from washed Indiana No. 3 bituminous coal (ground to pass $1 / 4$ inch $\times 0$ ) at $660^{\circ}, 840^{\circ}$, and $1020^{\circ} \mathrm{F}\left(350^{\circ}, 450^{\circ}\right.$, and $\left.550^{\circ} \mathrm{C}\right)$ in both $\mathrm{N}_{2}$ and $\mathrm{H}_{2} / \mathrm{CO} / \mathrm{N}_{2}$. The partial pressures of the three gases in the latter atmosphere were approximately equal. The residence time at maximum temperature was approximately equal. The residence time at maximum temperature was approximately 30 minutes. Analysis of these chars by SEM/EDS and electron spectroscopy for chemical analis sis (ESCA) again detected sulfur deposits on the char surfaces. Some of the sulfur was coincident with iron and/or calcium, but a significant quantity appeared to be unassociated. Crystals of $\mathrm{CaCO}_{3}, \mathrm{CaSO}_{4}$, and aluminosilicates were observed in the chars prepared in $\mathrm{N}_{2}$. Relatively fewer pyrite or pyrrhotite crystals were observed in the chars prepared in $\mathrm{N}_{2}$ compared to chars prepared in reducing gas. 
TABLE 35

Sulfur in Indiana No. 3 Bituminous Char Prepared at Three

Temperatures under Nitrogen

\begin{tabular}{cc}
\hline Char Temperature, ${ }^{\circ} \mathrm{F}$ & Sulfur, wt\% \\
\hline 660 & 3.59 \\
840 & 4.67 \\
1110 & 3.14 \\
Moisture-/Volatile-Free Coal & 6.52 \\
\hline
\end{tabular}

Elemental sulfur (bp $=830^{\circ} \mathrm{F} / 440^{\circ} \mathrm{C}$ ) crystals were detected by SEM/EDS in a sample of Indiana No. 3 char prepared at $840^{\circ} \mathrm{F}\left(450^{\circ} \mathrm{C}\right)$ in the $1 \cdot \mathrm{lb} / \mathrm{hr}$ CFBR. Elemental sulfur was also detected by ESCA in an Indiana No. 3 char that had been prepared in inert gas at $350^{\circ} \mathrm{F}\left(450^{\circ} \mathrm{C}\right)$ in the TGA. The ESCA analysis, which identifies bonded atoms through a measure of their electron binding energies, showed the presence of sulfur-sulfur bonds, but no carbon-sulfur or metal-sulfur bonds for the TGA char sample (Table 36). The binding energies of the sulfur electrons were those of $S_{n}$ and/or $S_{8}$, corroborating the finding of elemental sulfur in the sample prepared in the CFBR. The oxygen spectrum indicated that sulfur was bonded to $\mathrm{O}_{2}$ in the form of $-\mathrm{SO}_{2},-\mathrm{SO}_{3}$, or $-\mathrm{SO}_{4}$.

Additional TGA chars were prepared from Indiana No. 3 coal in $\mathrm{N}_{2}$ at $660^{\circ}, 840^{\circ}$, and $1020^{\circ} \mathrm{F}\left(350^{\circ}, 450^{\circ}\right.$, and $\left.550^{\circ} \mathrm{C}\right)$ to determine types of sulfur bonds. Tables 36,37 , and 38 summarize the ESCA results. Analysis again showed sulfur distributed over the surface. SEM/EDS showed more calcium and iron coincident with sulfur in the $660^{\circ} \mathrm{F}$ $\left(350^{\circ} \mathrm{C}\right)$ char than in the $1020^{\circ} \mathrm{F}\left(550^{\circ} \mathrm{C}\right)$ sample. The ESCA analysis indicated elemental sulfur evidenced by sulfur-sulfur bonds, but no positive evidence of sulfur bonded to metals or carbon. The ESCA oxygen spectra for both the $840^{\circ}$ and $1020^{\circ} \mathrm{F}\left(450^{\circ} \mathrm{C}\right.$ and $550^{\circ} \mathrm{C}$ ) samples indicated the presence of ether bonds. $\mathrm{O}_{2}$ bonded as $-\mathrm{SO}_{\mathbf{z}} \cdot$ was detected in all three samples.

Indiana No. 3 char prepared at $660^{\circ} \mathrm{F}\left(350^{\circ} \mathrm{C}\right)$ in $\mathrm{H}_{2} / \mathrm{CO} / \mathrm{N}_{2}$ was also analyzed by ESCA (Table 37). The atom percent sulfur on the surface of this char was significantly lower than it had been on the surface of char prepared in $\mathrm{N}_{2}$. The $\mathrm{C} / \mathrm{S}$ ratio was also significantly higher, indicating that sulfur had been removed from the char in the reducing atmosphere. This char also evidenced more $\mathrm{O}_{2}$ at the surface, as shown in Table 37. The reactions shown below have been observed to occur under reducing conditions near this carbonization temperature, and may account for the decrease in surface sulfur (11).

$$
\mathrm{FeS}_{2}+\mathrm{CO} \ldots-\cdots \mathrm{FeS}+\mathrm{COS}
$$

which may be followed by:

$$
\mathrm{COS}+\mathrm{H}_{2} \mathrm{O} \cdots-\cdots \mathrm{CO}_{2}+\mathrm{H}_{2} \mathrm{~S}
$$

Another reaction that removes sulfur from coal during pyrolysis at $660^{\circ} \mathrm{F}\left(350^{\circ} \mathrm{C}\right)$ in a reducing atmosphere is reaction with $\mathrm{H}_{2}$ to form $\mathrm{H}_{2} \mathrm{~S}$. However, there is an associated problem. The production of char results in the formation of carbon sites that are reactive toward $\mathrm{H}_{2} \mathrm{~S}$. Thus, as the gas is formed in pores and diffuses through the char, chemisorption of a portion of the gas on the active sites is likely to occur. This redeposited chemically bound sulfur could be a major contributor to the sulfur that is 
difficult to remove. Tak ie 39 compares chars prepared in $\mathrm{N}_{2}$ and $\mathrm{H}_{2} / \mathrm{CO}$ reducing gas at $660^{\circ}, 840^{\circ}$, and $1020^{\circ} \mathrm{F}\left(350^{\circ}, 450^{\circ}\right.$, and $\left.550^{\circ} \mathrm{C}\right)$. The decrease in total sulfur content was greater in $\mathrm{N}_{2}$ than in the reducing atmosphere where $\mathrm{H}_{2} \mathrm{~S}$ was formed, possibly due to chemisorption of $\mathrm{H}_{2} \mathrm{~S}$.

\section{TABLE 36}

Binding Energies (eV) of Elements in Each of Three Indiana No. 3 Coal Chars Prepared under Inert Atmosphere in the TGA

\begin{tabular}{lccccc}
\hline Element & Bond & $660^{\circ} \mathrm{F}$ & $840^{\circ} \mathrm{F}$ & $1020^{\circ} \mathrm{F}$ & Literature \\
\hline Carbon & $\mathrm{C}-\mathrm{C}$ & 284.6 & 284.6 & 284.6 & 284.6 \\
& & & 285.4 & & \\
Oxygen & ether & ND & ND & 286.0 & $\sim 286.0$ \\
& $-\mathrm{SO}_{\mathbf{x}}$ & 531.9 & 532.0 & 532.0 & \\
& ether & $\mathrm{ND}$ & 533.5 & 533.6 & $\sim 533.5$ \\
Sulfur & $\mathrm{S}_{\mathrm{n}}$ or $\mathrm{S}_{8}$ & 163.8 & 163.8 & 163.8 & $\sim 163.8$ \\
& or disulfide & & & & \\
\hline
\end{tabular}

ND - not detected.

TABLE 37

Elemental \% of Char Surfaces as Determined by ESCA

\begin{tabular}{lrrrrrr}
\hline Atmosphere: & \multicolumn{3}{c}{$\mathrm{N}_{2}$} & & \multicolumn{2}{c}{$\mathrm{H}_{2} / \mathrm{CO} / \mathrm{N}_{2}$} \\
\cline { 2 - 3 } \cline { 6 - 7 } Element & $660^{\circ} \mathrm{F}$ & $840^{\circ} \mathrm{F}$ & $1020^{\circ} \mathrm{F}$ & & $660^{\circ} \mathrm{F}$ & $660^{\circ} \mathrm{F}$ \\
\hline Carbon & 76.1 & 91.1 & 90.8 & & 73.5 & 67.3 \\
Oxygen & 15.0 & 6.8 & 6.4 & & 18.8 & 22.9 \\
Sulfur & 1.0 & 0.7 & 1.1 & & 0.4 & 0.4 \\
Iron & 0.1 & $\mathrm{ND}$ & $\mathrm{ND}$ & & 0.5 & 0.4 \\
Calcium & $\mathrm{ND}$ & $\mathrm{ND}$ & 0.1 & & 0.2 & $\mathrm{ND}$ \\
Other & 6.7 & 1.4 & 1.6 & & 6.2 & 8.7 \\
C/O & 4.9 & 13.4 & 14.2 & & 3.9 & 2.9 \\
C/S & 77.0 & 130.0 & 82.5 & & 184.0 & 168.0 \\
\hline
\end{tabular}

ND - not detected.

TABLE 38

Binding Energies (eV) of Elements in Indiana No. 3 Coal

Chars Prepared under $\mathrm{H}_{2} / \mathrm{CO}$ Atmosphere at $660^{\circ} \mathrm{F}$ in the TGA

\begin{tabular}{lccc}
\hline Element & Bond & Binding Energy & Literature \\
\hline Carbon & $\mathrm{C}-\mathrm{C}$ & 284.6 & 284.6 \\
Oxygen & $-\mathrm{SO}_{z^{-}}$ & 532.4 & $\sim 532.0$ \\
Sulfur & $\mathrm{S}_{\mathrm{n}}$ or Thiophenic & 164.0 & $\sim 163.8$ \\
Iron & $\mathrm{Fe}_{2} \mathrm{O}_{3}$ & 710.7 & -711.0 \\
\hline
\end{tabular}


Total Sulfur Analysis of Indiana No. 3 Chars Prepared at Three Temperatures under $\mathrm{N}_{2}$ and under $\mathrm{H}_{2} / \mathrm{CO}^{*}$

\begin{tabular}{lcccccc}
\hline Temp., ${ }^{\circ} \mathrm{F}$ & 660 & 840 & 1020 & 660 & 840 & 1020 \\
atm. & $\mathrm{N}_{2}$ & $\mathrm{~N}_{2}$ & $\mathrm{~N}_{2}$ & $\mathrm{H}_{2} / \mathrm{CO}$ & $\mathrm{H}_{2} / \mathrm{CO}$ & $\mathrm{H}_{2} / \mathrm{CO}$ \\
$\mathrm{S}$, wt\% & 2.46 & 1.76 & 1.76 & 2.11 & 1.93 & 1.93 \\
\hline
\end{tabular}

- $\mathrm{H}_{2} / \mathrm{CO}$ and $\mathrm{N}_{2}$ at approximately equal partial pressures.

\subsection{The Effect of Process Conditions on the Sulfur Content of Indiana No. 3 Char Produced in the 1-lb/hr CFBR}

Sulfur removal was studied in the $1-1 \mathrm{~b} / \mathrm{hr}$ reactor using a shipment of mine-washed Indiana No.3 bituminous coal containing $3.94 \%$ total sulfur. The primary objective of the tests was to determine the effects of steam and temperature-staging on the extent of sulfur removal during char production. The chars produced were sent to AMAX in Golden, Colorado, for determining the total sulfur and sulfur form values reported in the following tables.

Table 40 shows the effects of process and feedstock variability. The three tests referred to in the table were performed at $660^{\circ} \mathrm{F}\left(350^{\circ} \mathrm{C}\right)$ with no temperature staging, under an atmosphere of $70 \% \mathrm{~N}_{2} / 30 \%$ steam. Residence times for the tests were about 20 to 30 minutes. Essentially no sulfur removal occurred at $660^{\circ} \mathrm{F}\left(350^{\circ} \mathrm{C}\right)$. The one high char sulfur content reported is believed to be the result of analyzing a nonrepresentative char sample that resulted from irregular mixing or residence time in the reactor.

Tables 41 and 42 show the effect of steam on sulfur removal at final staging temperatures of $840^{\circ}$ and $930^{\circ} \mathrm{F}\left(450^{\circ}\right.$ and $\left.500^{\circ} \mathrm{C}\right)$, respectively. The percent steam in the fluidization gas did not affect the amount of sulfur removed. However, it should be noted that in these staged tests the fluidization gas contained the same $30 \%$ steam level at all temperatures except the final temperature. At a final temperature of $840^{\circ} \mathrm{F}$ $\left(450^{\circ} \mathrm{C}\right)$, only an insignificant reduction in sulfur content was observed. At $930^{\circ} \mathrm{F}$ $\left(500^{\circ} \mathrm{C}\right)$, a signirifieant quantity of sulfur was removed, but the amount of steam used in the final stage did not affect the extent of the removal. The total sulfur content of 2.87 wt\% observed at $930^{\circ} \mathrm{F}\left(500^{\circ} \mathrm{C}\right)$ for both $10 \%$ and $90 \%$ steam was within experimental error of the lowest sulfur content produced in the $1-1 \mathrm{~b} / \mathrm{hr}$ reactor, which was $2.83 \mathrm{wt} \%$, produced using four-stage heating to a final temperature of $1470^{\circ} \mathrm{F}\left(800^{\circ} \mathrm{C}\right)$ under $\mathrm{N}_{2}$ with no steam.

Table 43 shows the effect of temperature on sulfur removal in successive stages of heating. Significant sulfur removal occurred between $840^{\circ}$ and $930^{\circ} \mathrm{F}\left(450^{\circ}\right.$ and $\left.500^{\circ} \mathrm{C}\right)$, but very little occurred below $840^{\circ} \mathrm{F}\left(450^{\circ}\right)$. It is important to note that the average char yield at $930^{\circ} \mathrm{F}\left(500^{\circ} \mathrm{C}\right)$ is about $77 \mathrm{wt} \%$ of the maf coal, which means that the total amount of sulfur removed is proportionately greater than the reported reduction in percentage sulfur content owing to the inverse relationship to char yield. 
TABLE 40

The Effect of Process and Feedstock Variability on Indiana No. 3 Char Sulfur Content

(values expressed in wt\%)

\begin{tabular}{ccccc}
\hline Run No. & $\mathrm{S}$, total & $\mathrm{SO}_{2}$ & Pyritic & Organic \\
\hline Feed Coal & 3.94 & 0.24 & 1.70 & 2.00 \\
M061,308 & 3.99 & 0.06 & 1.87 & 2.06 \\
M051,325 & 4.62 & 0.09 & 1.86 & 2.67 \\
M060,308 & 3.81 & 0.04 & 1.58 & 2.19 \\
$660^{\circ} \mathrm{F}$ (no temperature staging); about 20-30 minutes residence time; 30\% steam, $70 \% \mathrm{~N}_{2}$. \\
\hline
\end{tabular}

\section{TABLE 41}

The Effect of Steam and Three Temperature Stages $\left(840^{\circ} \mathrm{F} / 450^{\circ} \mathrm{C}\right)$ on Indiana No. 3 Char Sulfur Content (values expressed in wt\%)

\begin{tabular}{cccccc}
\hline Run No. & Steam, \% & S, total & SO $_{4}$ & Pyritic & Organic \\
\hline Feed Coal & & 3.94 & 0.24 & 1.70 & 2.00 \\
M058,337 & 10 & 3.84 & 0.00 & 1.95 & 1.89 \\
M068,223 & 30 & 3.73 & 0.05 & 2.40 & 1.28 \\
M058,338 & 50 & 3.75 & 0.00 & 1.85 & 1.90 \\
M058,339 & 90 & 3.75 & 0.08 & 1.70 & 1.97
\end{tabular}

Three-stage runs $\left(660^{\circ}, 750^{\circ}, 840^{\circ} \mathrm{F}\left[350^{\circ}, 400^{\circ}, 450^{\circ} \mathrm{C}\right]\right.$ ); fluidization gas for first two stages was $30 \%$, steam $/ 70 \% \mathrm{~N}_{2}$; steam level for final stage is shown in column 2-remainder is $\mathrm{N}_{2}$.

\section{TABLE 42}

The Effect of Steam and Four Temperature Stages $\left(930^{\circ} \mathrm{F} / 500^{\circ} \mathrm{C}\right)$ on Indiana No. 3 Char Sulfur Content

(values expressed in wt\%)

\begin{tabular}{cccccc}
\hline Run No. & Steam, \% & S, total & $\mathrm{SO}_{4}$ & Pyritic & Organic \\
\hline Feed Coal & & 3.94 & 0.24 & 1.70 & 2.00 \\
M070,224 & 10 & 2.87 & 0.03 & 1.05 & 1.79 \\
M070,225 & 50 & 2.96 & 0.03 & 0.92 & 2.01 \\
M070,226 & 90 & 2.87 & 0.05 & 1.34 & 1.49
\end{tabular}

Four-stage runs $\left(660^{\circ}, 750^{\circ}, 840^{\circ}, 930^{\circ} \mathrm{F}\left[350^{\circ}, 400^{\circ}, 450^{\circ}, 500^{\circ} \mathrm{C}\right]\right.$ ); fluidization gas for the first three stages was $30 \%$ steam $/ 70 \% \mathrm{~N}_{2}$; steam level for fourth stage is shown in column 2-remainder is $\mathrm{N}_{2}$. 
The Effect of Temperature in Single Stages

on Indiana No. 3 Char Sulfur Content

(values expressed in wt\%)

\begin{tabular}{ccccccc}
\hline Run No. & Stage & Temp., $^{\circ} \mathrm{F}$ & $\mathrm{S}$, total & $\mathrm{SO}_{4}$ & Pyritic & Organic \\
\hline Feed Coal & & & 3.94 & 0.24 & 1.70 & 2.00 \\
M064,220 & 2 & 750 & 4.06 & 0.08 & 2.08 & 1.90 \\
M058,338 & 3 & 840 & 3.75 & 0.00 & 1.85 & 1.90 \\
M070,225 & 4 & 930 & 2.96 & 0.03 & 0.92 & 2.01
\end{tabular}

Stage 1 temperature was $660^{\circ} \mathrm{F}$ for all runs; fluidization gas for all final stages was $50 \%$ steam $/ 50 \% \mathrm{~N}_{2} ; 30 \%$ steam $/ 70 \% \mathrm{~N}_{2}$ for all preceding stages.

Table 44 compares sulfur removals for chars heated to $840^{\circ}\left(450^{\circ} \mathrm{C}\right)$ in two stages and three stages, respectively. For the test conditions shown, the extra stage had no effect on the extent of sulfirr removal.

Table 45 shows that the sulfur contents of three chars produced in the larger 30-1b/hr fluidized-bed reactor normally used for the EERC Hydrogen Production Project were reduced to half of the lowest levels achieved in the small reactor (12). The factor that probably contributed most to the lower total sulfur contents was the approximately 6 hour residence time at final temperature in the large reactor compared to the 20 to 30 minutes in the small $1-\mathrm{lb} / \mathrm{hr}$ reactor. Residence time in the large reactor operated at a lower gas velocity was not limited by reaction conditions, whereas residence time in the small reactor was limited to about 30 minutes at the gas velocity and coal feed rates used to represent a "fast fluid-bed" reactor.

\subsection{Detailed Chemical and Physical Analyses of Indiana No. 3 Coal Char Prepared in the 1- to 4-lb/hr CFBR}

The initial stages of testing on Indiana No. 3 coal in the 1- to $4-\mathrm{lb} / \mathrm{hr}$ CFBR were conducted at $660^{\circ}$ to $720^{\circ} \mathrm{F}\left(350^{\circ}\right.$ to $\left.380^{\circ} \mathrm{C}\right)$, with successive tests feeding the product chars at progressively higher temperatures. Any fluctuation in temperature above $720^{\circ} \mathrm{F}$ $\left(380^{\circ} \mathrm{C}\right)$ in the initial stage of heating caused agglomeration to occur. The photomicrograph in Figure 68 shows an agglomerate starting to form. The bottom portion of the photograph shows the original coal, which is dotted with sulfur crystals, while the upper portion shows where swelling has started. A large sulfur-containing crystal with a high sulfur concentration is shown in the lower right of the figure. The crystalline structure of the sulfur is more apparent in Figure 69. Preliminary mapping of the crystals indicated low levels of iron in combination with the sulfur. However, it did not appear that there was sufficient iron in these crystals to stoichiometrically represent pyrite, $\mathrm{FeS}_{2}$. At about $930^{\circ} \mathrm{F}\left(500^{\circ} \mathrm{C}\right)$ pyrite would be converted to a form of pyrrhotite, $\mathrm{FeS}$, having a stoichiometry close to $\mathrm{FeS}$, which, depending on its exact stoichiometry and crystal structure, might be magnetically separable. 


\section{TABLE 44}

The Effect of Temperature in Multistages

on Indiana No. 3 Char Sulfur Content

(values expressed in wt\%)

\begin{tabular}{|c|c|c|c|c|c|}
\hline Run No. & Stages & S, total & $\mathrm{SO}_{4}$ & Pyritic & Organic \\
\hline Feed Coal & & 3.94 & 0.24 & 1.70 & 2.00 \\
\hline M054,331 & 2 & 3.71 & 0.01 & 1.85 & 1.85 \\
\hline M058,337 & 3 & 3.84 & 0.00 & 1.95 & 1.89 \\
\hline M059,337 & 3 & 3.72 & 0.00 & 1.84 & 1.88 \\
\hline \multicolumn{6}{|c|}{$\begin{array}{l}\text { Final temperature for all runs was } 840^{\circ} \mathrm{F} \text {; Stage } 1 \text { was } 660^{\circ} \mathrm{F} \text { for all runs; Stage } 2 \text { for } \\
\text { Runs M058,337 and } \mathrm{M} 059,337 \text { was } 750^{\circ} \mathrm{F} \text {; fluidization gas was } 10 \% \text { steam } / 90 \% \mathrm{~N}_{2} \text { for the } \\
\text { final stage; } 30 \% \text { steam } / 70 \% \mathrm{~N}_{2} \text { for the preceding stages. }\end{array}$} \\
\hline
\end{tabular}

TABLE 45

The Effect of Long Residence Time on Indiana No. 3 Char Sulfur Content

\begin{tabular}{cccccc}
\hline Run No. & Steam, \% & S, total & SO, & Pyritic & Organic \\
\hline Feed Coal & & 3.94 & 1.70 & 0.24 & 2.00 \\
M072,403 & 30 & 1.25 & 0.04 & 0.04 & 1.17 \\
M073,404 & 0 & 1.39 & 0.04 & 0.04 & 1.31 \\
M073,405 & 30 & 1.43 & 0.02 & 0.04 & 1.37 \\
Final temperature for all runs was 1470 F; Stages 1, 2, and 3 were 660, $750^{\circ}$, and \\
$840^{\circ} \mathrm{F}$, respectively; residence time at final temperature was about 6 hours.
\end{tabular}

It should be noted that sulfur crystals were not present in the portion of the sample that had softened and swelled. However, upon further analysis, sulfur was detected in low concentrations uniformly over the surface of, and possibly throughout, the swelled material. It is not known if the transformation of sulfur from crystalline form to apparently amorphous is dependent on temperature per se, or is part of the swelling process. It is also not known if the sulfur is chemically bonded to the organic material in the semifluid regions.

Scanning electron microscopy with energy dispersive spectroscopy for elemental mapping (SEM/EDS) and electron spectroscopy for chemical analysis (ESCA) were used to characterize forms of sulfur in Indiana No. 3 chars produced at $660^{\circ}, 840^{\circ}$, and $1110^{\circ} \mathrm{F}$ $\left(350^{\circ}, 450^{\circ}\right.$, and $\left.600^{\circ} \mathrm{C}\right)$ in an $\mathrm{N}_{2}$ atmosphere. In Figure 70 the right portion is the SEM photomicrograph of the surface, while the left portion is the corresponding sulfur map. The sulfur map shows a substantial amount of sulfur over the entire surface of the char. 


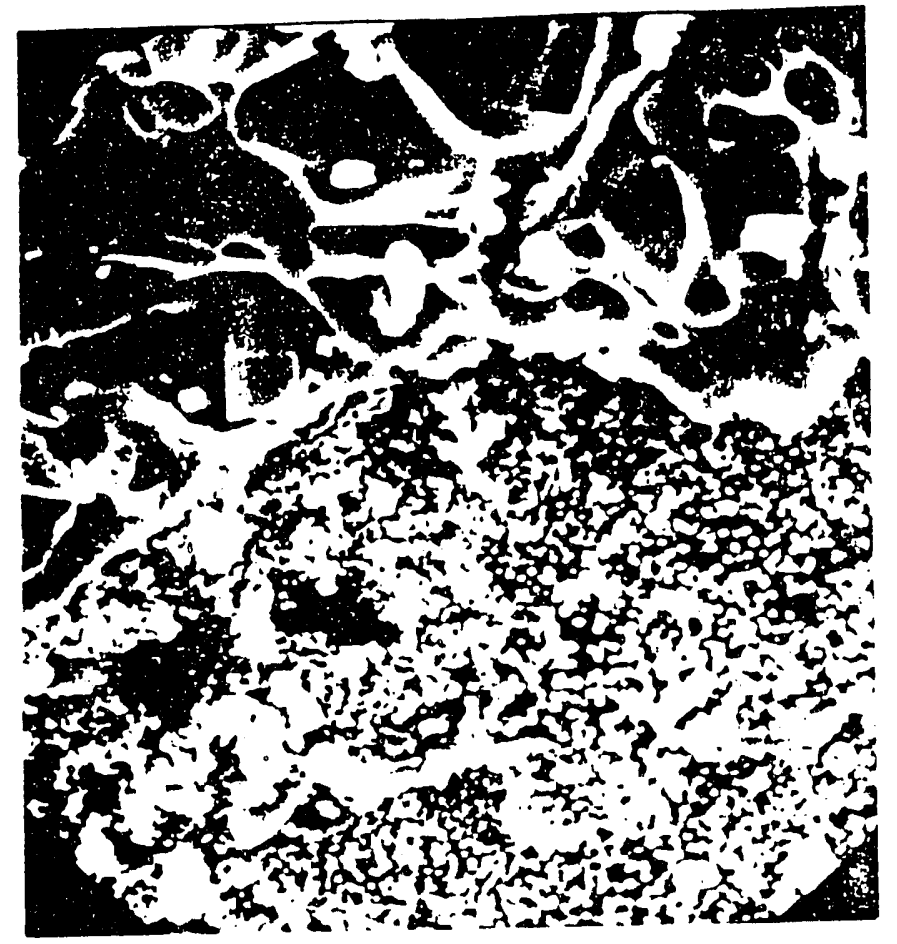

Figure 68. Indiand No. $3 \mathrm{coal}$ and agglomerate particle (1000 mag.).

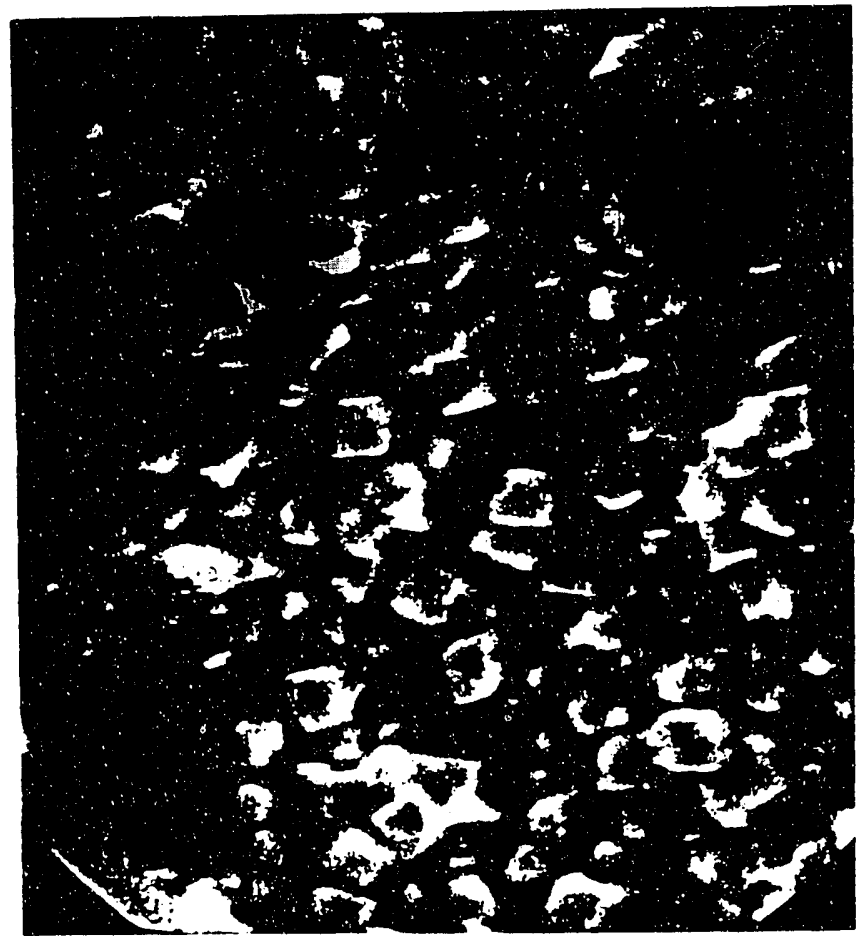

Figure 69. Indiana No. 3 coal surface su.tur crystas 3600 mag.). 


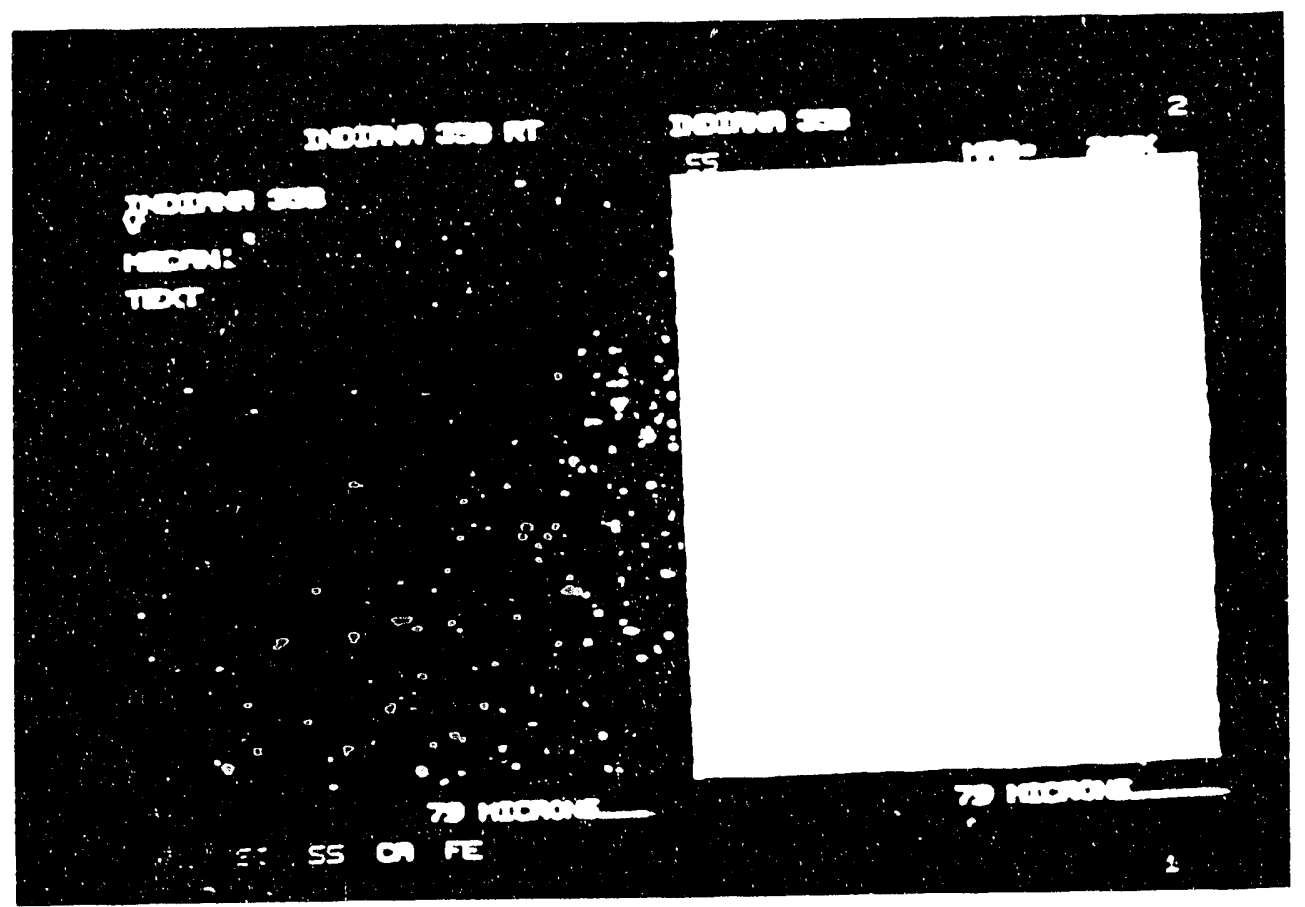

Figure 70. Indiana No. 3 char SEMisulfur map, $660^{\circ} \mathrm{F} / 350^{\circ} \mathrm{C}$.

All colors on the map indicate sulfur; the variations are believed to be various concentrations of sulfur, but this was not verified. Figure 71 shows the char and sulfur map at $840^{\circ} \mathrm{F}\left(450^{\circ} \mathrm{C}\right)$. This char was heated directly to $840^{\circ} \mathrm{F}\left(450^{\circ} \mathrm{C}\right)$ without staged heating. The agglomeration and the sulfur on the surface are again clearly seen. Similar results are observed for a char that was heated directly to $1110 \% \mathrm{~F}\left(600^{\circ} \mathrm{C}\right.$ ) (Figure 72 ).

Elemental maps of additional elements were determined on selected char samples to study the possible relationships of $\mathrm{Al}, \mathrm{Si}, \mathrm{Ca}$, and $\mathrm{Fe}$ to sulfur, Figures $\mathrm{i} 3$ and 74 . Color intensities shown are a measure of elemental location, but not necessarily of concentration. Some association of $\mathrm{Ca}$ and $\mathrm{Fe}$ with sulfur can be seen in the selected areas. Several bright spots representing Fe appear to coincide with bright spots in the sulfur map. It should be noted, however, that sulfur is observed over the entire surface and is not just in the areas of concentrated inorganic materials.

Analyses for ASTM sulfur forms are given in Tables 46 and 47 for :wo Indiana No. 3 chars produced by successive heatings, furst to $1020^{\circ} \mathrm{F}\left(500^{\circ} \mathrm{C}\right)$ in $95 \mathrm{c}$ steam $5^{\circ} \mathrm{N}$. followed by further heating to $1290^{\circ} \mathrm{F}\left(700^{\circ} \mathrm{C}\right)$ in $\mathrm{N}_{2}$. Table 46 shows that the prritic sulfur was somewhat concentrated in the finer size fractions, whereas the organic sulfur was not. It should be mainly noted in Table 47 that the percent organic sulfur (determined by difference) increased as the pyritic sulfur was reduced to near zero between $1020^{\circ}$ and $1290^{\circ} \mathrm{F}\left(550^{\circ}\right.$ and $\left.700^{\circ} \mathrm{C}\right)$. In this case, the increase in percent organic sulfur was more than the concentrating effect of a loss in char vield, meaning that a net gain in the quantity of organic sulfur had occurred. 


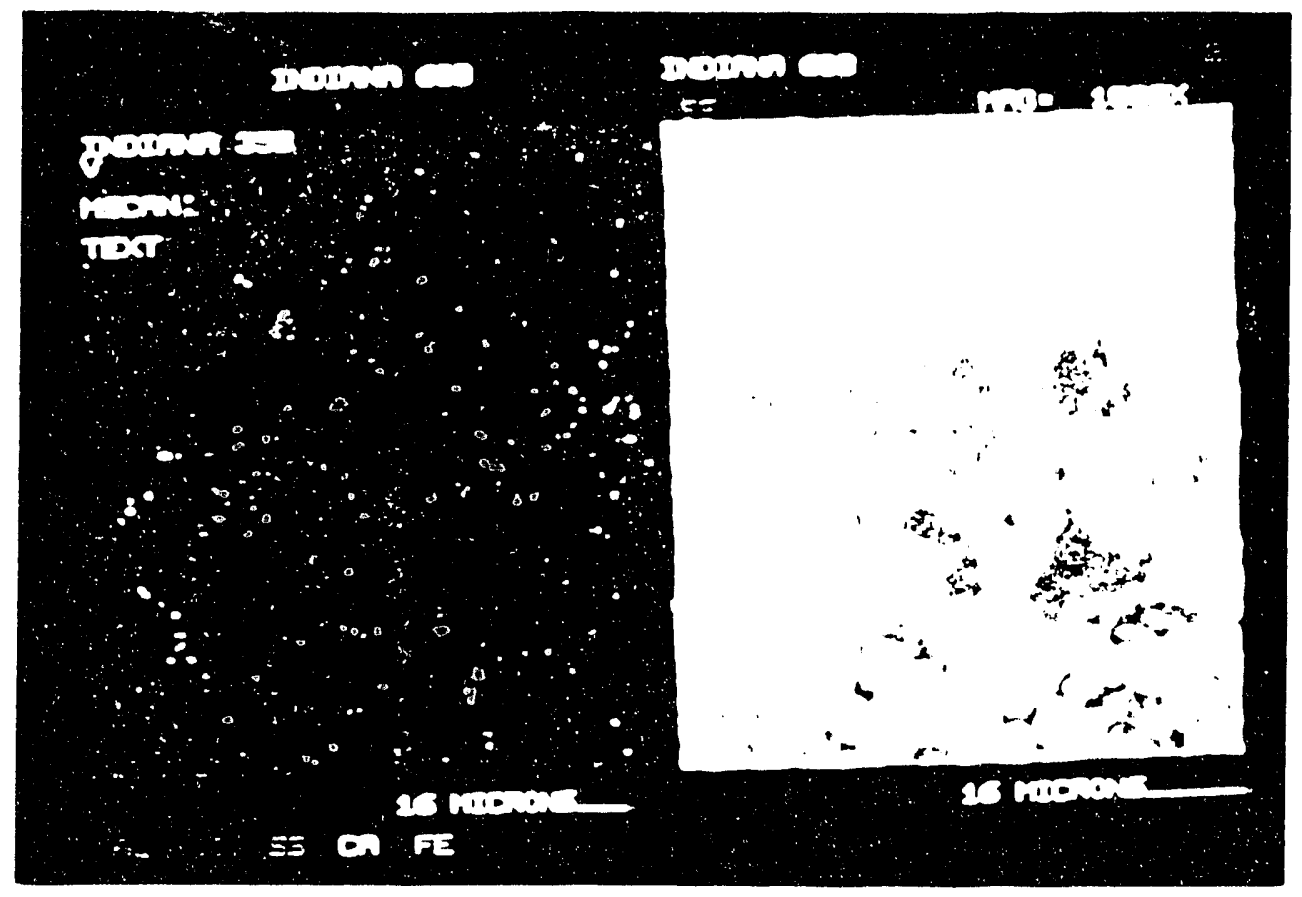

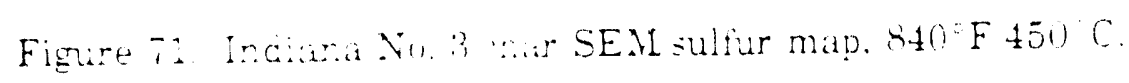

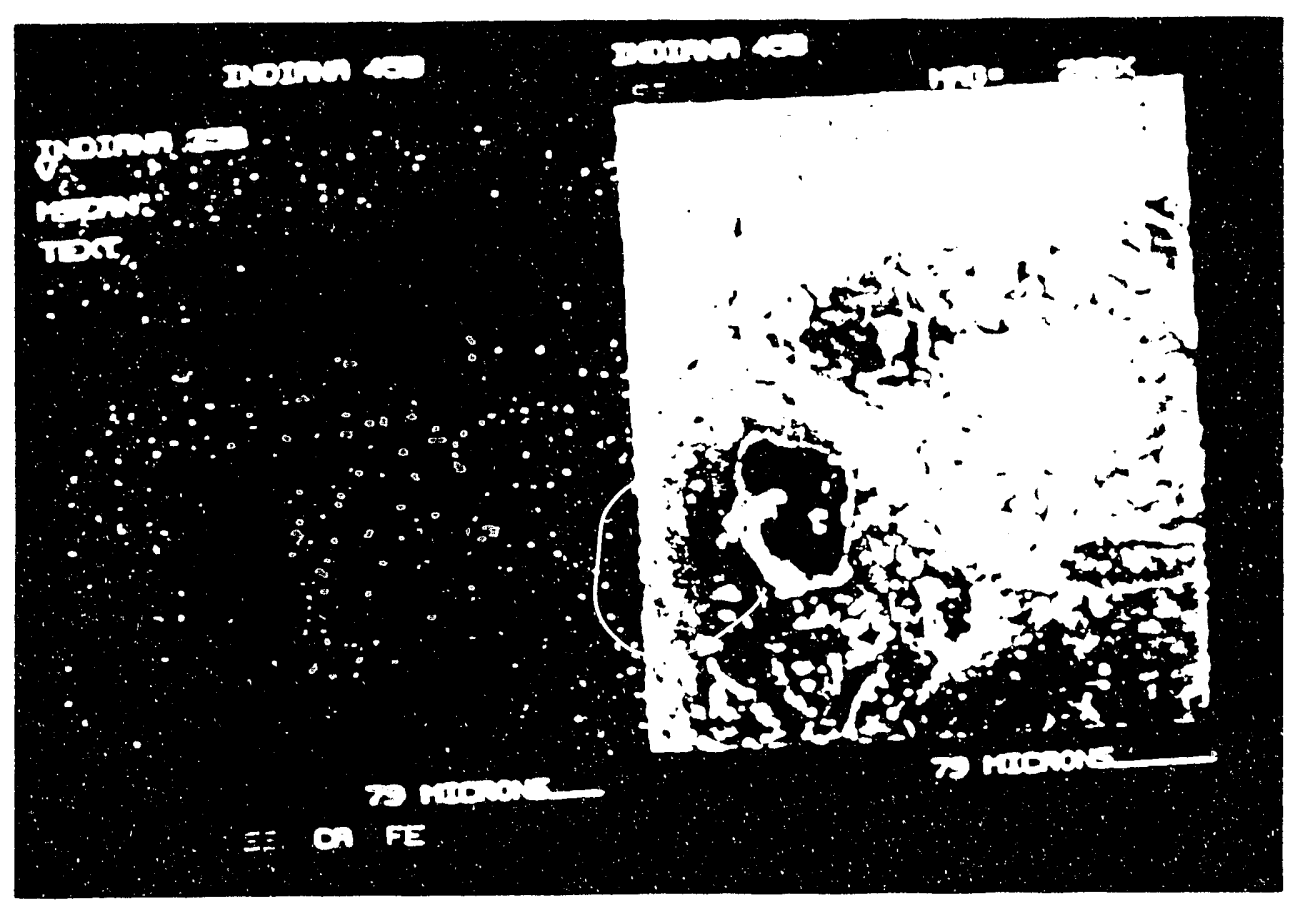

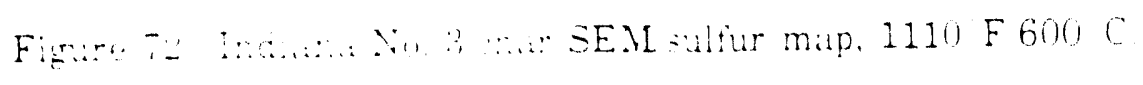




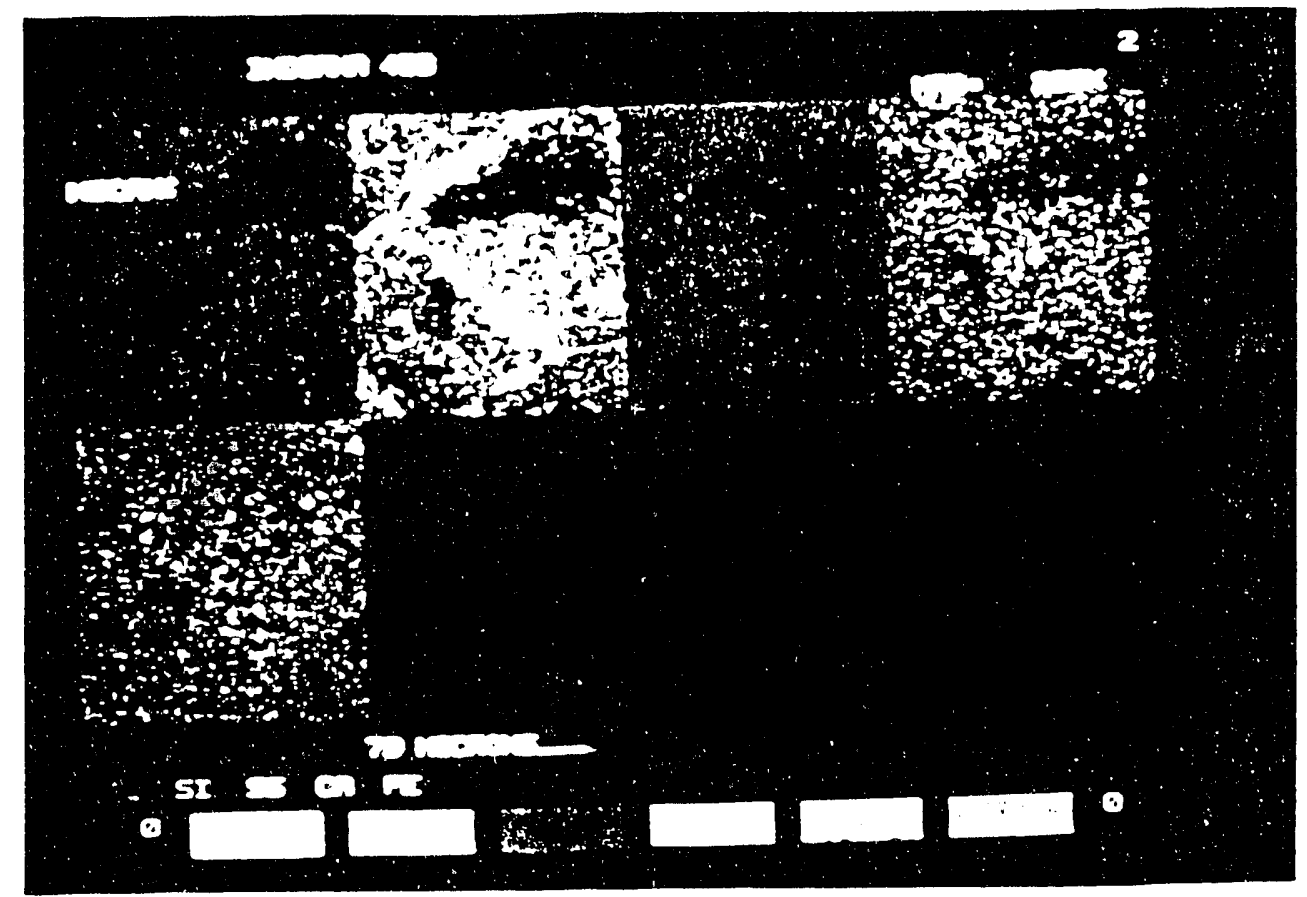

Figure 73. Indiana No. 3 char elemental map. $840: 450 C$.

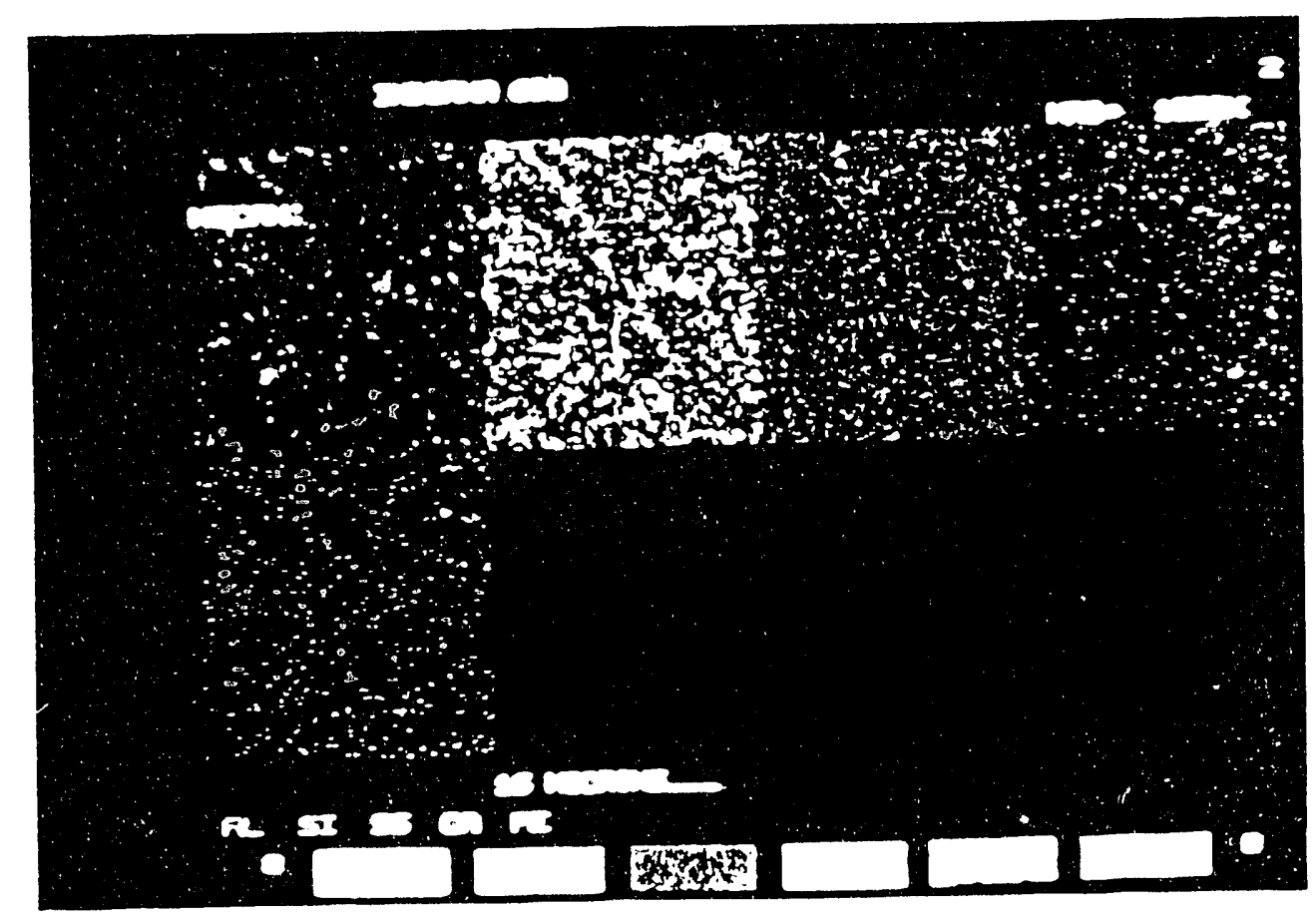

Figure 74. Indiana So. 3 char elemental mo. 1110 F fill C 


\section{TABLE 46}

Sulfur Analysis of Indiana No. 3

Mild Gasification Char (Sample M042-311-2 char run)

\begin{tabular}{lccccc}
\hline & & \multicolumn{4}{c}{ Analysis, \%, dry basis } \\
\cline { 3 - 6 } & Weight & S, total & S, SO, & S, pyritic & S, organic $^{\mathrm{a}}$ \\
\cline { 2 - 6 } Feed Coal &.. & 4.20 & 0.140 & 2.25 & 1.81 \\
Sample & & & & & \\
$\quad$ +14 mesh & 37.3 & 2.83 & 0.056 & 0.68 & 2.09 \\
-14 x 100 mesh & 48.5 & 3.04 & 0.097 & 1.12 & 1.82 \\
-100 mesh & 14.2 & 3.52 & 0.199 & 1.42 & 1.90 \\
Total & 100.0 & 3.03 & 0.096 & 1.00 & 1.93 \\
\hline
\end{tabular}

- Calculated by difference.

\section{TABLE 47}

Analysis of $14 \times 100$ mesh

Calcined Indiana No. 3 Coal Char

\begin{tabular}{|c|c|c|c|c|c|c|c|}
\hline & \multicolumn{7}{|c|}{ Analysis, $\%$, dry basis } \\
\hline & Volatiles & Ash & Fixed C & S, total & $\mathrm{S}, \mathrm{SO}_{4}$ & S, pyritic & $S$, organic ${ }^{a}$ \\
\hline $\begin{array}{l}1020^{\circ} \mathrm{F} / 550^{\circ} \mathrm{C} \\
\text { Char }\end{array}$ & 18.54 & 15.24 & 66.22 & 3.04 & 0.097 & 1.12 & 1.82 \\
\hline $\begin{array}{l}1290^{\circ} \mathrm{F} / 700^{\circ} \mathrm{C} \\
\text { Char }\end{array}$ & 6.89 & 18.86 & 74.25 & 2.80 & 0.036 & 0.04 & 2.72 \\
\hline
\end{tabular}

- Calculated by difference.

Conversion of sulfur from one form to another during pyrolysis has been widely reported in the literature. Reactions of sulfur with either coal, carbon, or inorganic mineral matter can cause fixation of sulfur in the char. Conversion of pyrite to pyrrhotite takes place with the concurrent release of sulfur that can react with available $\mathrm{H}_{2}$ or $\mathrm{CH}_{4}$ to produce $\mathrm{H}_{2} \mathrm{~S}$ gas. Organic sulfur compounds are known to be transformed in the presence of reducing gases to form other organic compounds, hydrogen sulfide, and/or other sulfur-containing gases. The presence of mineral matter, particularly iron and calcium compounds, have been shown to prevent the release of sulfur into the gas phase (13). Also, some of the sulfur released from pyrite can combine with the carbon in the coal to produce organic sulfur. Concentrations dropped in mineral-free sections of the samples, while organic sulfur increased in regions containing pyrite particles. These results again suggest that some of the sulfur released from pyrite reacts with the char to produce organic sulfur bound to the char. 
A summary of the current findings on in-process sulfur removal, based on data from all of the testing on Indiana No. 3 coal in the TGA, the $1 \cdot \mathrm{lb} / \mathrm{hr}$ CFBR, and the $30-\mathrm{lb} / \mathrm{hr}$ fluidized-bed reactor, includes the following points:

- Pyritic sulfur was effectively reduced to low levels, but organic sulfur as defined by ASTM analytical methods was not.

- Essentially no loss of sulfur occurred in the first stage of heating to $660^{\circ} \mathrm{F}$ $\left(350^{\circ} \mathrm{C}\right)$ that was used to control agglomeration.

- The extent of pyritic sulfur removal was determined mainly by temperature, with the loss due to conversion of pyrite to pyrrhotite $\left(\mathrm{FeS}_{2}\right.$ to $\left.\mathrm{FeS}\right)$ occurring at or below carbonization temperature of $840^{\circ}$ and $930^{\circ} \mathrm{F}\left(450^{\circ}\right.$ and $\left.500^{\circ} \mathrm{C}\right)$, and the remainder being lost at char calcining temperatures of $1290^{\circ}$ to $1470^{\circ} \mathrm{F}\left(700^{\circ}\right.$ to $\left.800^{\circ} \mathrm{C}\right)$.

- Reaction time had an important influence on the amount of pyritic and total sulfur removed. The effect extended beyond the 20- to 30-minute residence time at staging temperatures in the TGA and CFBR, since the largest reduction in total sulfur content (from $3.9 \%$ to $1.2 \%$ ) was observed after six hours of residence time in the $30 \cdot \mathrm{lb} / \mathrm{hr}$ fluidized-bed reactor.

- Gas atmosphere had some effect on sulfur removal, but it was not the primary controlling factor. The largest reductions in total sulfur content in TGA tests were in reducing ( $\mathrm{CO}$ or $\mathrm{H}_{2} / \mathrm{CO}$ ) or oxidizing atmospheres rather than in $\mathrm{N}_{2}$. The use of steam in the $1-\mathrm{lb} / \mathrm{hr}$ CFBR did not increase the extent of sulfur removal.

- The percent organic sulfur, determined by difference in the ASTM procedure, was not systematically reduced by increasing either temperature or reaction time under most of the conditions studied, although the level was significantly reduced after the six hours of residence time noted above. The decrease observed in TGA tests was greater in an $\mathrm{N}_{2}$ atmosphere rather than in a reducing atmosphere.

- The true chemical forms of sulfur in char were found to be more complex and diverse than the pyritic, sulfitic, and organic forms defined by the ASTM procedure. Analyses of char surfaces using SEM/EDS and ESC $A_{\Delta}$ indicated that important changes in the physical and chemical form of sulfur occurred at $720^{\circ}$ to $840^{\circ} \mathrm{F}\left(380^{\circ}\right.$ to $\left.450^{\circ} \mathrm{C}\right)$ coincident with the onset of coal agglomeration and with the loss of sulfur from pyrite $\left(\mathrm{FeS}_{2}\right.$ to $\left.\mathrm{FeS}\right)$. The principal change observed was that discrete crystals containing sulfur (possibly pyrite) present at $660^{\circ} \mathrm{F}\left(350^{\circ} \mathrm{C}\right)$ had disappeared at $840^{\circ} \mathrm{F}\left(450^{\circ} \mathrm{C}\right)$ and were replaced by a low concentration of sulfur detected over the entire char surface. ESCA analysis of bond types at the higher temperature identified $\mathrm{S}-\mathrm{S},-\mathrm{SO}_{2},-\mathrm{SO}_{3}$, and $-\mathrm{SO}_{4}$ bonds, but no $\mathrm{S}-\mathrm{C}$ bonds. SEM mappings of elements indicated some coincidence in the location of sulfur with $\mathrm{Fe}$ and $\mathrm{Ca}$.

- The evidence in this and other studies suggests that coal sulfur undergoes transformations during carbonization by a variety of reactions, but that in the end it is either removed in the gas or left in the char in a stable form. After heating to calcining temperatures, most of the remaining sulfur is in the ASTM 
organic form. No combination of time, temperature, and gas atmosphere investigated in this study was successful in systematically removing this stable form of "organic sulfur."

\subsection{Magnetic Upgrading of Carbonizer Char}

Analytical results from P025 and P027 are shown in Table 48. These data suggest that much of the pyritic sulfur was converted to organic sulfur during the carbonization stage. Some improvement is indicated in the P027 char, which was produced at a lower temperature, and this may also account for this char's higher oxygen content. However, any sulfur as sulfide, as in pyrrhotite, would be counted as organic sulfur in the ASTM. sulfur forms procedure.

The product char is cleaned using a continuous roll magnet system. The variables in this system are feed rate and roll rpm. Roll rpm determines the thickness of the char layer which passes over the magnet. Table 49 shows the results of magnetic separation tests using the P027 char. In Test 2, a cut blade was used to force some of the nominally nonmagnetic product to report to the magnetic fraction. A run under the same conditions without the blade is reported in Test 3. These results indicate that somewhat bettercleaned char can be obtained from the P027 char (2.5 wt\% sulfur versus $2.7 \mathrm{wt} \%$ for P025). However, these values are still well above the target of $1 \mathrm{wt} \%$ sulfur. Table 50 shows the results from the P025 char.

A significant improvement in throughput was achieved by making minor modifications to the magnetic separator feed system. These modifications allowed feed rates of $80 \mathrm{lb} / \mathrm{hr}$ to be achieved.

\subsection{Heavy Liquids Gravity Separation Feasibility Studies}

The feasibility of using heavy liquid separation of the ash and char was investigated on P007 char. It should be noted that the P007 char was produced from a noncleaned Indiana No. 3 that was $11.9 \%$ ash and $5.1 \%$ sulfur. The char was separated into the same screen sizes used for magnetic separations. As expected, the lowest ash values were found in the lightest specific gravity (sg) fraction (1.3 sink) as shown in Table 51. The lowest ash content produced during the tests was $15 \%$, which was contained in the $14 \times 100$ mesh $1.3 \mathrm{sg}$ float fraction.

The lowest total sulfur values were found in the $4.1 \mathrm{sg}$ float $/ 1.3 \mathrm{sg}$ sink fraction. Total sulfur values of about $2.5 \%$ were found in this gravity fraction of both the 1/4-in $\times 14$-mesh and the $14 \times 100$-mesh size fractions of char. The heaviest specific gravity fraction (1.9 sg sink) contained the greatest concentrations of ash and all sulfur forms.

About $3 \%$ of the total char weight reported as the $1.0 \mathrm{sg}$ sink fraction. Contained in this fraction were about $10 \%$ of all of the ash and about $8 \%$ of the total sulfur in the char. Removal of this fraction, along with the $<100$-mesh fines, would result in a decrease in char ash content from about $19.2 \%$ to $17.9 \%$. Total sulfur content would be reduced from about $3.4 \%$ to $3.2 \%$. 
TABLE 48

Analytical Results for Mild Gasification Chars

\begin{tabular}{lrc}
\hline & P025 & P027 \\
\hline Mild Gasification Temperature, ${ }^{\circ} \mathrm{F} /{ }^{\circ} \mathrm{C}$ & $1110 / 600$ & $1020 / 550$ \\
Proximate Analysis, wt\% & & \\
Ash & 19.11 & 19.59 \\
Volatile Matter & 9.11 & 16.15 \\
Fixed Carbon & 71.78 & 64.26 \\
Moisture & 0.86 & 0.93 \\
Sulfur Forms, wt\% & & \\
Total Sulfur & 3.10 & 2.94 \\
Pyritic Sulfur & 0.24 & 0.67 \\
Sulfate & 0.09 & 0.31 \\
Organic Sulfur, by diff. & 2.77 & 1.96 \\
Ultimate Analysis, wt\% & & \\
Carbon & 74.41 & 68.24 \\
Hydrogen & 2.10 & 2.63 \\
Nitrogen & 1.71 & 1.61 \\
Oxygen & 2.37 & 6.98 \\
\hline
\end{tabular}

TABLE 49

Results of Magnetic Separation for P027 Char

\begin{tabular}{ccccccccc}
\hline & Feed Rate, & Roll, & \multicolumn{2}{c}{$\mid$ |---Magnetic, wt\%.-.--| } & \multicolumn{3}{c}{ |---Nonmagnetic, wt\%---| } \\
Test & lb/hr & rpm & Recovery & Sulfur & Ash & Recovery & Sulfur & Ash \\
\hline 1 & 21.8 & 40 & 43.2 & 3.69 & 21.2 & 55.9 & 2.52 & 16.3 \\
2 & 33.0 & 40 & 50.8 & 3.66 & 19.8 & 49.5 & 2.61 & 15.5 \\
3 & 33.0 & 40 & 41.5 & 4.01 & 22.7 & 58.4 & 2.49 & 16.1 \\
4 & 80.0 & 40 & 47.6 & 4.19 & 22.0 & 52.8 & 2.50 & 15.7 \\
5 & 80.5 & 50 & 25.1 & 4.34 & 25.5 & 74.9 & 2.66 & 16.7 \\
\hline
\end{tabular}

\section{TABLE 50}

Results of Magnetic Separation for P025 Char

\begin{tabular}{ccccccccc}
\hline & Feed Rate, & Roll, & \multicolumn{3}{c}{$\mid----$ Magnetic, wt\%----| } & \multicolumn{3}{c}{ |---Nonmagnetic, wt\%-.-| } \\
Test & $\mathrm{lb} / \mathrm{hr}$ & $\mathrm{rpm}$ & Recovery & Sulfur & Ash & Recovery & Sulfur & Ash \\
\hline 1 & 5.9 & 20 & 47.6 & 3.67 & 19.2 & 52.2 & 2.41 & 15.9 \\
2 & 5.9 & 40 & 23.6 & 3.94 & 22.1 & 76.3 & 2.69 & 16.4 \\
3 & 5.9 & 50 & 7.7 & 4.97 & 23.8 & 91.7 & 2.98 & 18.1 \\
4 & 22.6 & 40 & 23.8 & 4.28 & 22.1 & 78.5 & 2.71 & 16.8 \\
5 & 22.6 & 50 & 11.6 & 4.98 & 24.2 & 91.1 & 2.84 & 21.1 \\
\hline
\end{tabular}




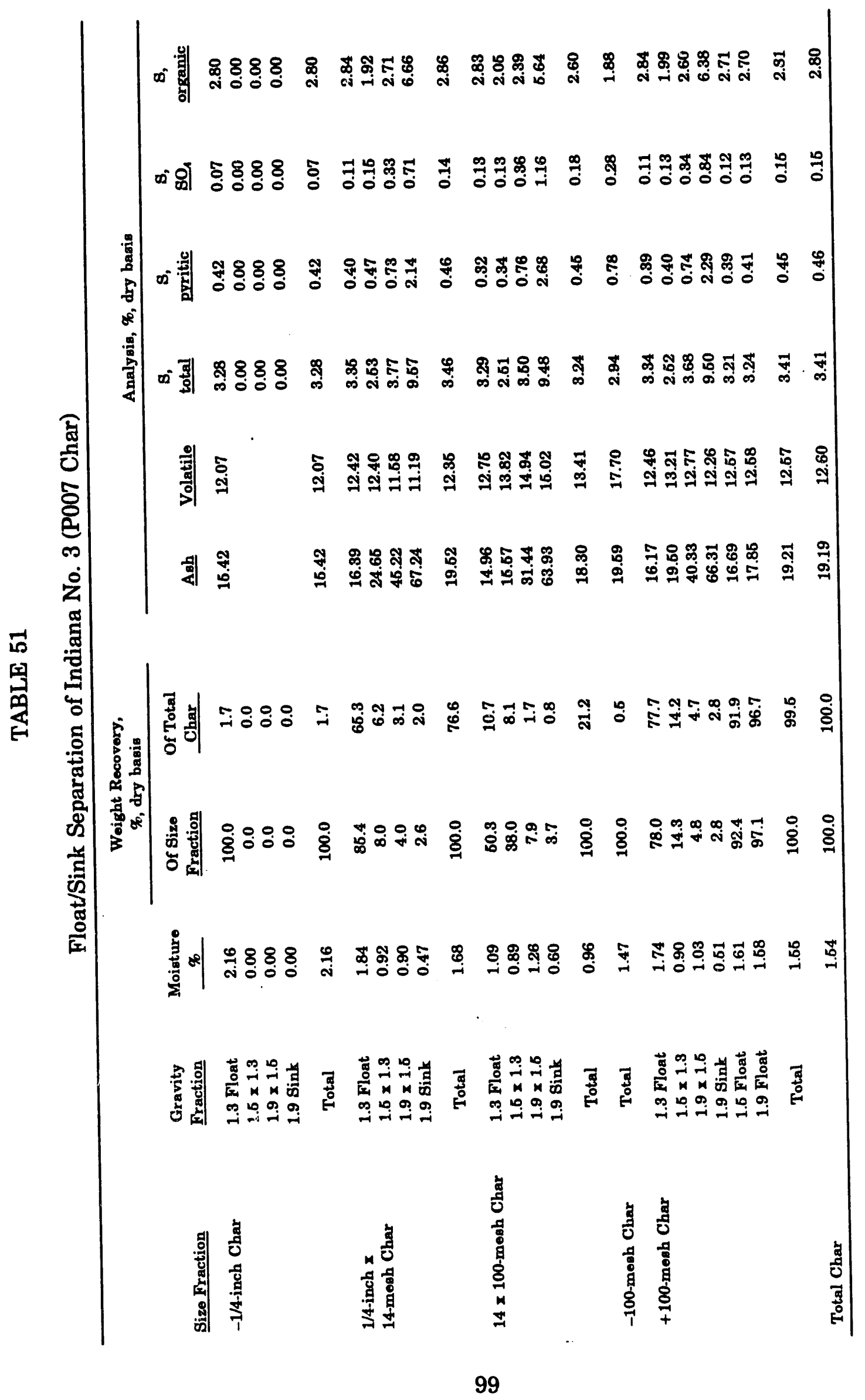


About $20 \%$ and $13 \%$ of all ash and sulfur, respectively, would be removed with $8 \%$ of the char weight contained in the combined $<100$-mesh fraction and all $1.5 \mathrm{sg}$ sink material. A product char containing $16.7 \%$ ash and $3.2 \%$ sulfur would result. Due to the poor separation of the sulfur-containing ash, further heavy liquid separation was not continued.

\subsection{High-Temperature Calcination of Char for Sulfur Reduction}

\subsubsection{Preliminary Calcining Tests for Sulfur Capture using Staged Heating in the CFBR}

Four chars were made with $-60 \mathrm{x}+200$-mesh Indiana coal and dolomite in the 1-lb/hr CFBR. The first two were produced from a mixture of coal and dolomite (the dolomite was added in an amount equivalent to $15 \%$ of the weight of the coal).

Approximately half of the mixture was heated to $660^{\circ} \mathrm{F}\left(350^{\circ} \mathrm{C}\right)$ under nitrogen to make the first char, and the other half was heated to $660^{\circ} \mathrm{F}\left(350^{\circ} \mathrm{C}\right)$ under a mixture of about $90 \%$ hydrogen $10 \%$ nitrogen to make the second char. Residence times at $660^{\circ} \mathrm{F}\left(350^{\circ} \mathrm{C}\right)$ for both tests were about 25 minutes. The third and fourth chars were produced from a mixture of stage-heated (at $660^{\circ}$ and $840^{\circ} \mathrm{F}$ [ $350^{\circ}$ and $450^{\circ} \mathrm{C}$ ]) $1020^{\circ} \mathrm{F}\left(550^{\circ} \mathrm{C}\right.$ ) char and dolomite (the dolomite was added in an amount equivalent to $20 \%$ of the weight of the char). Half of the mixture was heated to $1290^{\circ} \mathrm{F}\left(700^{\circ} \mathrm{C}\right)$ under nitrogen to make the third char, and the other half was heated to $1290^{\circ} \mathrm{F}\left(700^{\circ} \mathrm{C}\right)$ under a mixture of about $90 \%$ hydrogen $10 \%$ nitrogen to make the fourth char. Residence times were about 25 minutes.

To provide a possible means of separating the reacted dolomite from the char following gasification, the dolomite was pulverized to a -270-mesh particle size before being added to the coal/char feed. The -270-mesh size was selected because particle-size distribution analysis of $1290^{\circ} \mathrm{F}\left(700^{\circ} \mathrm{C}\right)$ char (made under nitrogen) showed that only about $5 \%$ of the char particles were -270 mesh in size; hence, it was thought that the smaller dolomite particles might be separable from the char particles using physical separation methods. A second reason for using a small dolomite particle size is because the density of dolumite is two or three times greater than the density of a $1290^{\circ} \mathrm{F}\left(700^{\circ} \mathrm{C}\right)$ char particle. Since it was desired to fluidize the dolomite along with the coal/char, rather than have it fall away from the coal/char soon after entering the reactor, less massive dolomite particles were needed. A third reason is that smaller particles provide more surface area for more reactivity and better mixing.

Sulfur analysis of the feed dolomite using a Leco sulfur analyzer determined that it contained no sulfur. Sulfur forms analyses of the four char/dolomite product mixtures are shown in Table 52. Also shown in Table 52, for comparison, are data for several chars made under nitrogen without dolomite. The $930^{\circ} \mathrm{F}\left(500^{\circ} \mathrm{C}\right)$ char shown in the table is the char that was mixed with dolomite to produce the $1290^{\circ} \mathrm{F}\left(700^{\circ} \mathrm{C}\right)$ char/dolomite products. Residence times for all chars were approximately 25 minutes.

To calculate the amount of dolomite recovered from the four tests, $x$-ray fluorescence (XRF) analysis was performed on ash samples made from the char/dolomite mixtures obtained from each test, the feed coal, the $930^{\circ} \mathrm{F}\left(500^{\circ} \mathrm{C}\right)$ feed char, and the dolomite. The results of the XRF analyses are shown in Tables 53 and 54 . The values in the tables are element concentrations in the ash made from each of the reactants and products. All calculations were made on an oxygen-free ash basis. 
TABLE 52

Sulfur Forms Analysis of CFBR Char/Dolomite Products

\begin{tabular}{|c|c|c|c|c|c|}
\hline & & \multicolumn{4}{|c|}{ Sulfur, moisture-free, wt\% } \\
\hline & & \multirow{2}{*}{ Total Sulfur } & \multicolumn{3}{|c|}{ Sulfur Forms } \\
\hline & & & Pyr. & $\mathrm{SO}_{4}$. & Org ${ }^{2}$ \\
\hline \multirow{2}{*}{\multicolumn{2}{|c|}{$\begin{array}{l}\text { Feed Coal } \\
660^{\circ} \mathrm{F}\left(350^{\circ} \mathrm{C}\right), 100 \% \mathrm{~N}_{2} \text {, dolomite }{ }^{1} \\
660^{\circ} \mathrm{F}, 90 \% \mathrm{H}_{2} / 10 \% \mathrm{~N}_{2} \text {, dolomite } \\
1290^{\circ} \mathrm{F}\left(700^{\circ} \mathrm{C}\right), 100 \% \mathrm{~N}_{2} \text {, dolomite } \\
1290^{\circ} \mathrm{F}, 90 \% \mathrm{H}_{2} / 10 \% \mathrm{~N}_{2} \text {, dolomite }\end{array}$}} & 5.26 & 2.20 & 0.32 & 2.73 \\
\hline & & $\begin{array}{l}4.47 \\
4.20 \\
3.46 \\
3.59\end{array}$ & $\begin{array}{l}1.93 \\
1.30 \\
0.56 \\
0.51\end{array}$ & $\begin{array}{l}0.28 \\
0.26 \\
0.06 \\
0.05\end{array}$ & $\begin{array}{l}2.27 \\
2.64 \\
2.85 \\
3.03\end{array}$ \\
\hline \multicolumn{2}{|c|}{$\begin{array}{l}660^{\circ} \mathrm{F}\left(350^{\circ} \mathrm{C}\right) \text {, no dolomite } \\
840^{\circ} \mathrm{F}\left(450^{\circ} \mathrm{C}\right) \text {, no dolomite } \\
930^{\circ} \mathrm{F}\left(500^{\circ} \mathrm{C} \text {, no dolomite }\right. \\
1290^{\circ} \mathrm{F}\left(700^{\circ} \mathrm{C}\right) \text {, no dolomite } \\
\end{array}$} & $\begin{array}{l}5.62 \\
5.03 \\
4.83 \\
4.25 \\
\end{array}$ & $\begin{array}{l}2.45 \\
2.16 \\
1.84 \\
0.54 \\
\end{array}$ & $\begin{array}{l}0.29 \\
0.15 \\
0.12 \\
0.06 \\
\end{array}$ & $\begin{array}{l}2.88 \\
2.72 \\
2.87 \\
3.65 \\
\end{array}$ \\
\hline \multicolumn{6}{|c|}{$\begin{array}{l}\text { Dolomite was added in an amount that was } 16 \text { to } 26 \text { wt\% of the moisture-free coal/char } \\
\text { feed. } \\
\text { With the use of the ASTM analysis, "Forms of Sulfur in Coal," sulfur contained in } \\
\text { calcium sulfide (the product of the reaction of dolomite with sulfur) is quantitated as } \\
\text { organic sulfur. }\end{array}$} \\
\hline \multicolumn{6}{|c|}{ TABLE 53} \\
\hline \multicolumn{6}{|c|}{ XRF (Ash) Analysis of Reactants and Char/Dolomite Products } \\
\hline & Feed Coal & Dolomite & $\begin{array}{r}660^{\circ} \mathrm{F}(35 \\
\text { Char/Dolc } \\
\mathrm{N}_{2} \\
\end{array}$ & $\begin{array}{ll} & \\
\text { te } \quad \mathrm{Cl} \\
& 90 \\
\end{array}$ & $\begin{array}{c}660^{\circ} \mathrm{F} \\
\text { har/Dolomite } \\
0 \% \mathrm{H}_{2} / 10 \% \mathrm{~N}_{2} \\
\end{array}$ \\
\hline Silicon & 35.8 & 0.8 & 20.9 & & 21.5 \\
\hline Aluminum & 19.3 & 0.0 & 10.7 & & 10.8 \\
\hline Iron & 33.4 & 0.0 & 16.7 & & 17.9 \\
\hline Calcium & 4.1 & 58.2 & 20.4 & & 19.7 \\
\hline Magnesium & 1.1 & 40.0 & 9.8 & & 9.4 \\
\hline Potassium & 2.5 & 0.0 & 1.5 & & 1.5 \\
\hline Sulfur & 2.5 & 0.0 & 17.7 & & 17.6 \\
\hline Other & 1.3 & 1.0 & 2.3 & & 1.6 \\
\hline
\end{tabular}

The dolomite concentration in each product mixture was calculated using the equation:

$$
C_{c} x+C_{d}(1-x)=C_{e d} \text { where }
$$

$x=$ char concentration in the product mixture

$1-x=$ dolomite concentration in the product mixture

$C_{c}=$ element concentration in feed coal or feed char

$C_{d}=$ element concentration in dolomite

$C_{c d}=$ element concentration in char/dolomite product mixture 
TABLE 54

XRF (Ash) Analysis of Reactants and Char/Dolomite Products

\begin{tabular}{lcccc}
\hline & & & $1290^{\circ} \mathrm{F}\left(700^{\circ} \mathrm{C}\right)$ \\
& $\begin{array}{c}1290^{\circ} \mathrm{F}\left(500^{\circ} \mathrm{C}\right) \\
\text { Char }\end{array}$ & $\begin{array}{c}1290^{\circ} \mathrm{F} \\
\text { Char } / \text { Dolomite } \\
\mathrm{N}_{2}\end{array}$ & $\begin{array}{c}\text { Char/Dolomite } \\
90 \% \mathrm{H}_{2} / 10 \% \mathrm{~N}_{2} \\
\text { Sample 1 }\end{array}$ & $\begin{array}{c}\text { Char/Dolomite } \\
90 \% \mathrm{H}_{2} / 10 \% \mathrm{~N}_{2} \\
\text { Sample 2 }\end{array}$ \\
\hline Silicon & 34.4 & 23.8 & 22.3 & 27.7 \\
Aluminum & 18.3 & 13.1 & 12.5 & 15.9 \\
Iron & 35.6 & 21.8 & 18.2 & 20.7 \\
Calcium & 4.4 & 15.4 & 19.1 & 14.8 \\
Magnesium & 0.9 & 7.5 & 8.5 & 5.1 \\
Potassium & 2.5 & 1.6 & 1.4 & 1.8 \\
Sulfur & 2.7 & 13.9 & 16.6 & 12.5 \\
Other & 1.2 & 2.9 & 1.4 & 1.5 \\
\hline
\end{tabular}

For each char/dolomite product, XRF data for four elements (silicon, aluminum, calcium, and magnesium) were entered into the above equation to calculate four values for dolomite concentration. The four values were averaged and are reported in Table 55 . Table 55 shows that the char/dolomite products made at $660^{\circ} \mathrm{F}\left(350^{\circ} \mathrm{C}\right)$ underwent a greater increase in dolomite concentration than the $1290^{\circ} \mathrm{F}\left(700^{\circ} \mathrm{C}\right)$ products. A partial explanation for this may involve the composition and moisture content of the dolomite used in the reactions. The dolomite used for the $660^{\circ} \mathrm{F}\left(350^{\circ} \mathrm{C}\right)$ reactions was dry, nonhydrated, reagent-grade material purchased from a chemical supply company, while the dolomite used for the $1290^{\circ} \mathrm{F}\left(700^{\circ} \mathrm{C}\right)$ reactions was chipped from a block of dolomite that had been exposed to the air for an extended period of time and, therefore, containecl a significant quantity of water -. as moisture and as water of hydration. The presence of this water (which would be driven off during char production) would cause the weight of the reactant dolomite to be higher than the product dolomite, even with $100 \%$ recovery.

\section{TABLE 55}

Dolomite Concentration in Char/Dolomite Products

\begin{tabular}{lccc}
\hline \multicolumn{1}{c}{ Reaction Conditions } & $\begin{array}{c}\text { Reactant } \\
\text { Dolomite Content, } \\
\text { wt\%, moisture-free }\end{array}$ & $\begin{array}{c}\text { Product } \\
\text { Dolomite Content }{ }^{2},\end{array}$ & $\begin{array}{c}\text { Product, wt\% } \\
\text { wt\%oisture-free }\end{array}$ \\
\hline $\mathrm{H}_{2} / \mathrm{N}_{2}, 660^{\circ} \mathrm{F}\left(350^{\circ} \mathrm{C}\right)$ & 14 & 26 & 7 \\
$\mathrm{~N}_{2}, 660^{\circ} \mathrm{F}$ & 14 & 23 & 22 \\
$\mathrm{H}_{2} / \mathrm{N}_{2}, 1290^{\circ} \mathrm{F}$ (Sample 2) & 18 & 16 & 22 \\
$\mathrm{~N}_{2}, 1290^{\circ} \mathrm{F}$ & 18 & 21 & 22 \\
\hline 1 Includes dolomite and dolomite-derived products (calcium sulfide and magnesium \\
oxide).
\end{tabular}


Another reason for the greater increase in dolomite concentration in the $660^{\circ} \mathrm{F}$ $\left(350^{\circ} \mathrm{C}\right)$ products is shown by Figures 75 and 76 , which list total char and sulfur recoveries obtained during stage-heating char production. The figures show that a greater proportion of reactant material is lost when feed coal is heated to $660^{\circ} \mathrm{F}\left(350^{\circ} \mathrm{C}\right)$, than when $930^{\circ} \mathrm{F}\left(500^{\circ} \mathrm{C}\right)$ char is heated to $1290^{\circ} \mathrm{F}\left(700^{\circ} \mathrm{C}\right)$. A possible explanation for the low dolomite content of the $1290^{\circ} \mathrm{F}\left(700^{\circ} \mathrm{C}\right)$ hydrogen-atmosphere product may involve settling of the relatively dense (compared to char) dolomite to the bottom of the feed hopper. This would result in higher dolomite recoveries in earlier product samples and lower recoveries in later product samples; the sample analyzed for Table 55 was obtained near the end of the run.

In an attempt to separate the dolomite from the char made in the $1 \cdot \mathrm{lb} / \mathrm{hr}$ CFBR, each of the four char/dolomite product mixtures was sieved to yield a -270-mesh fraction (containing primarily dolomite, along with some calcium sulfide and magnesium oxide) and a +270-mesh fraction (containing primarily char with a reduced sulfur content). For three of the four chars, the -270-mesh fraction comprised about $22 \mathrm{wt} \%$ of the char/dolomite product mixture (see Table 55). The one test that did not yield a -270-mesh fraction comprising about $22 \mathrm{wt} \%$ of the dolomite/char product mixture was the test conducted with coal and dolomite heated to $660^{\circ} \mathrm{F}\left(350^{\circ} \mathrm{C}\right)$ under the $90 \%$ hydrogen $10 \%$ nitrogen atmosphere. For this test, the -270-mesh fraction comprised only about 7 wt\% of the product mixture. This suggests that the presence of hydrogen may have an agglomerating effect at $660^{\circ} \mathrm{F}\left(350^{\circ} \mathrm{C}\right)$, since the only difference in the two $660^{\circ} \mathrm{F}\left(350^{\circ} \mathrm{C}\right)$ tests was that one was run under nitrogen and one was run under an atmosphere of $90 \%$ hydrogen/10\% nitrogen.

To investigate what happened to the dolomite during the gasification tests, $x$-ray diffraction (XRD) analysis was performed on a sample of -60 -mesh Indiana coal and the -270-mesh fraction of three of the char/dolomite mixtures. The results of the analyses (Table 56) show that 1) the -270-mesh fraction of all three products contains a substantial amount of dolomite, 2) pyrite $\left(\mathrm{FeS}_{2}\right)$ reacts (in the presence of dolomite) to form pyrrhotite $\left(\mathrm{FeS}_{1 . \mathrm{x}}\right)$ under both hydrogen and nitrogen, 3 ) dolomite is more reactive with sulfur at $1290^{\circ} \mathrm{F}\left(700^{\circ} \mathrm{C}\right)$ than at $660^{\circ} \mathrm{F}\left(350^{\circ} \mathrm{C}\right)$, and 4) the presence of hydrogen appears to enhance the formation of calcium sulfide.

TGA tests were performed on the -270-mesh fractions of three of the char/dolomite product mixtures and a sample of the raw -270-mesh dolomite, to provide a rough indication of whether these fractions contain primarily dolomite. Figure 77 is a plot of the weight loss of a dolomite sample as it is heated. The sample was heated under argon to $230^{\circ} \mathrm{F}\left(110^{\circ} \mathrm{C}\right)$ at a rate of $36^{\circ}\left(20^{\circ} \mathrm{C}\right) /$ minute and held at $230^{\circ} \mathrm{F}\left(110^{\circ} \mathrm{C}\right)$ for 5 minutes. The sample was then heated at a rate of $180^{\circ} \mathrm{F}\left(100^{\circ} \mathrm{C}\right) /$ minute to $1650^{\circ} \mathrm{F}\left(900^{\circ} \mathrm{C}\right)$ and held at $1650^{\circ} \mathrm{F}\left(900^{\circ} \mathrm{C}\right)$ for 35 minutes. After 9 minutes at $1650^{\circ} \mathrm{F}\left(900^{\circ} \mathrm{C}\right)$, the argon was shut off, and air was introduced into the sample chamber to oxidize any material not yet fully oxidized. Figure 77 shows that the ash content of the dolomite is about 53\%. The 47\% loss is probably essentially all carbon dioxide. Figures 78 to 80 are similar plots made with samples of the -270-mesh fractions of the three char/dolomite samples. In these figures, the point at which air is introduced into the sample chamber can be noted by the rapid drop in sample weight, initiated about 33 minutes into the test. Previous to the introduction of air, the plot of weight versus time (actually, temperature) is almost flat, indicating that all volatiles have been removed from the sample. The rapid weight loss upon air introduction is due to the rapid oxidation of carbon from the char. By contrast, 


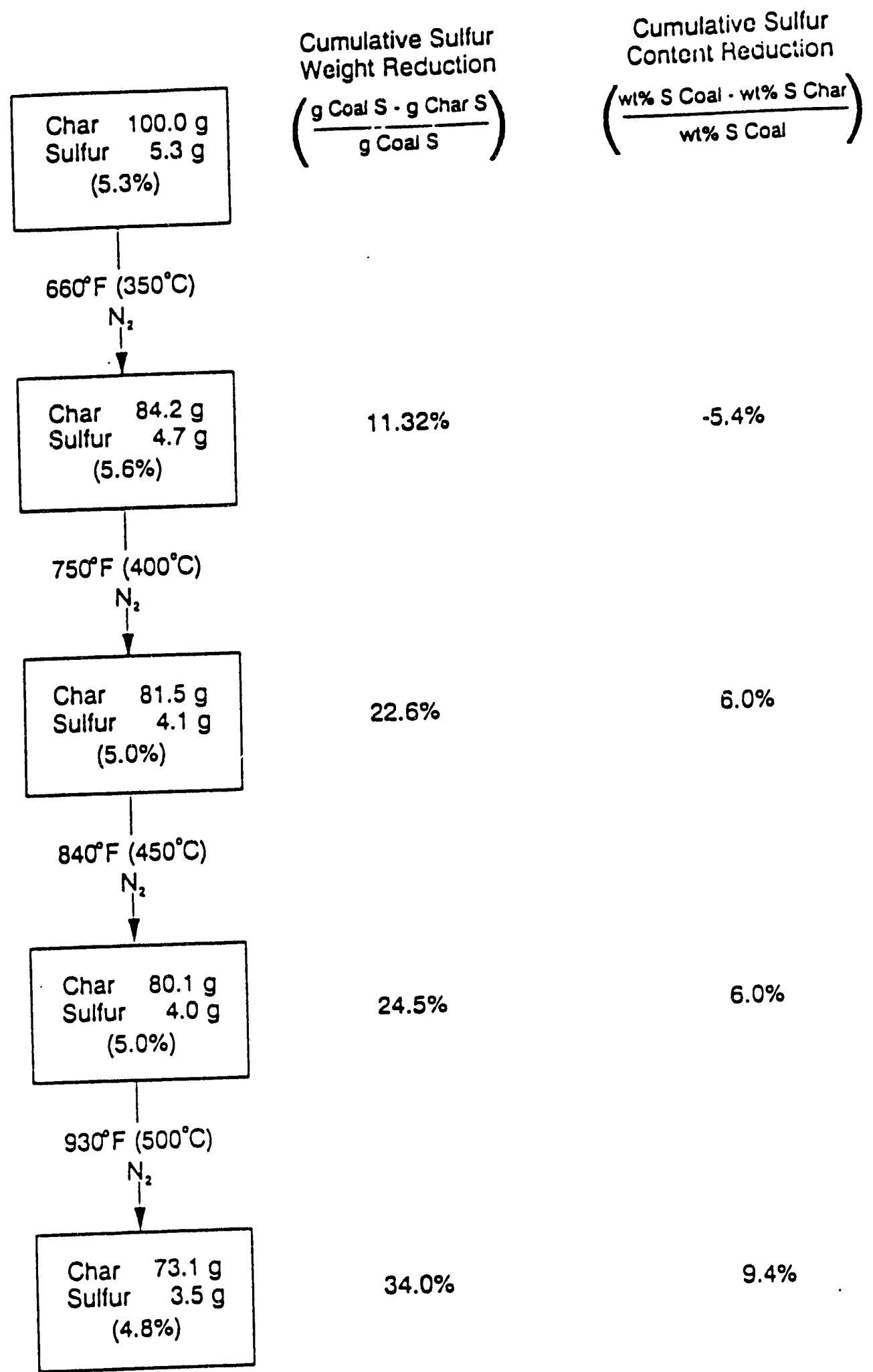

Figure 75. Production of $930^{\circ} \mathrm{F}\left(500^{\circ} \mathrm{C}\right)$ char by stage heating under nitrogen. 
Cumulative Sullur

Weight Reduction

$\left(\frac{g \text { Coal } S \cdot g \text { Char S }}{g \text { Codl S }}\right)$
Cumulative Sulfur

Content Fieduction

$\left(\frac{w i \% \text { S Coii - wro: S Char }}{w 1 \% \text { S Coal }}\right)$

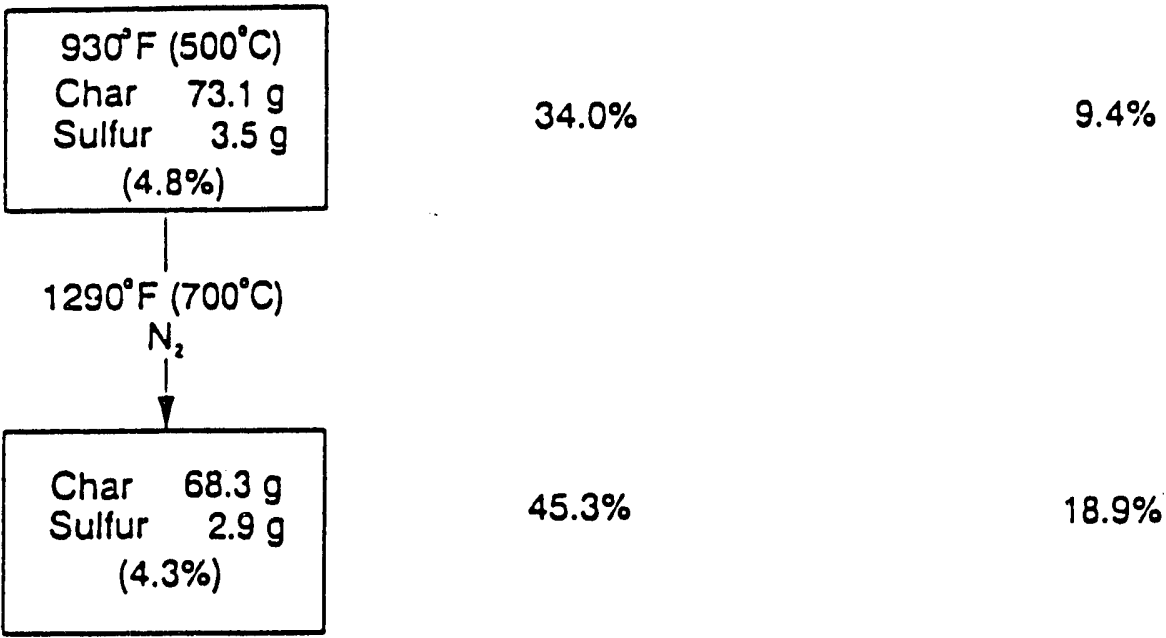

Figure 76. Production of $1290^{\circ} \mathrm{F}\left(700^{\circ} \mathrm{C}\right) \mathrm{char}$ from $930^{\circ} \mathrm{F}\left(500^{\circ} \mathrm{C}\right)$ char under nitrogen.

TABLE 56

XRD Analysis of Char/Dolomite Mixtures

Sample

Major Components (in order of decreasing concentration)

-60-mesh Indiana Coal

Quartz, Pyrite, Kaolinite -270-mesh Char/Dolomite $\left(\mathrm{H}_{2}, 660^{\circ} \mathrm{F} / 350^{\circ} \mathrm{C}\right) \quad \begin{aligned} & \text { Dolomite, Quartz, Pyrite, Kaolinite, } \\ & \text { Pyrrhotite }\end{aligned}$

-270-mesh Char/Dolomite $\left(\mathrm{N}_{2}, 1290^{\circ} \mathrm{F} / 700^{\circ} \mathrm{C}\right)$

Dolomite, Quartz, Calcium Sulfide,

Pyrrhotite, Magnesium Oxide

-270-mesh Char/Dolomite $\left(\mathrm{H}_{2}, 1290^{\circ} \mathrm{F} / 700^{\circ} \mathrm{C}\right)$ Dolomite, Calcium Sulfide, Quartz, Pyrrhotite, Magnesium Oxide

the plot in Figure 77 is smooth throughout the heating program and does not plunge steeply when air is introduced, because the rate of decarboxylation of the magnesium and calcium in dolomite is not affected by the presence of ambient-pressure air. Comparison of the "residue" fractions labeled in Figures 77 to 80 showed that, of the three products tested, the -270 -mesh fraction of the $1290^{\circ} \mathrm{F}\left(700^{\circ} \mathrm{C}\right)$ char produced under hydrogen contained the highest concentration of dolomite, followed by the $1290^{\circ} \mathrm{F}\left(700^{\circ} \mathrm{C}\right)$ nitrogen char, and finally, the $660^{\circ} \mathrm{F}\left(350^{\circ} \mathrm{C}\right)$ hydrogen char. 


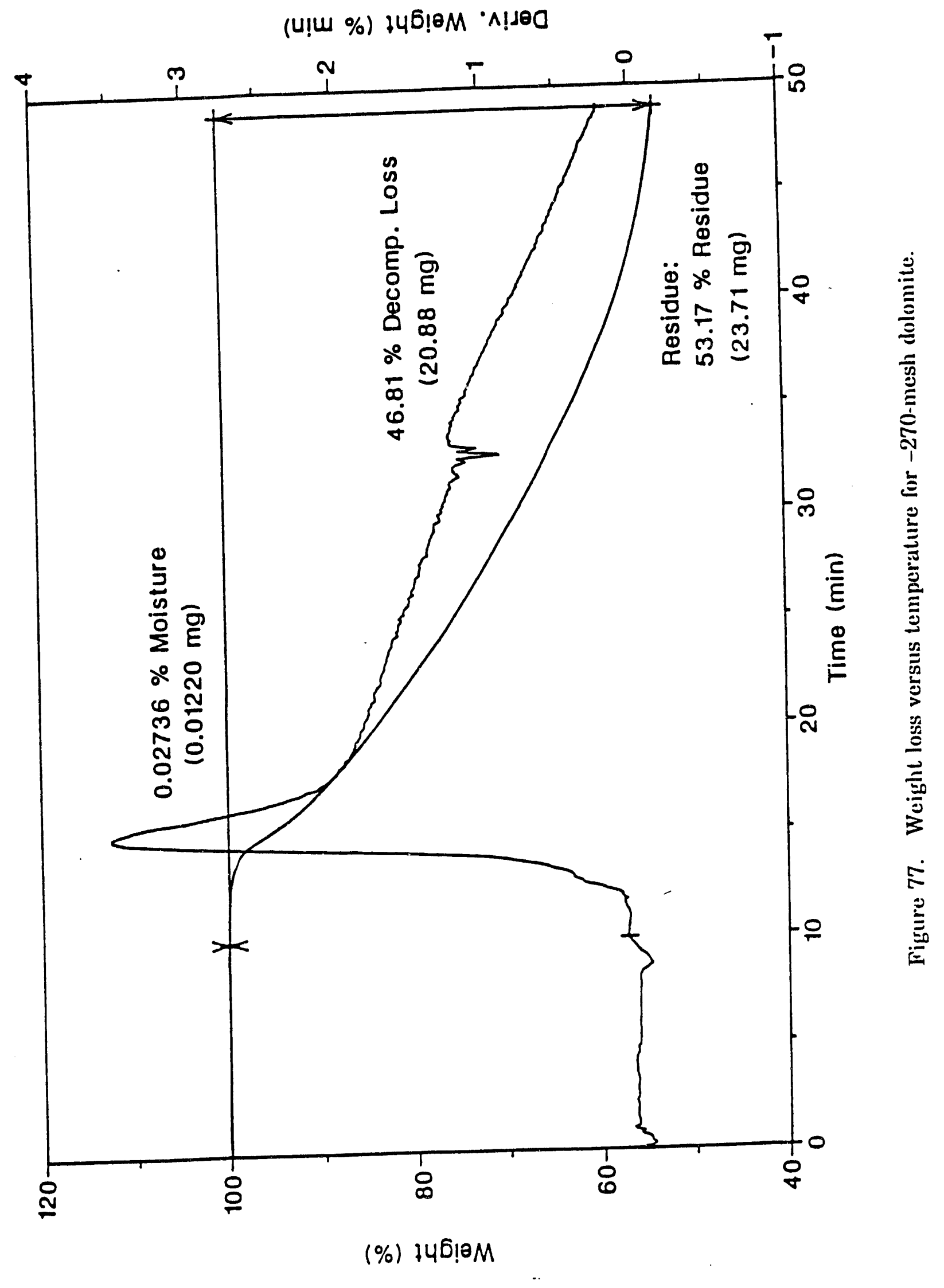




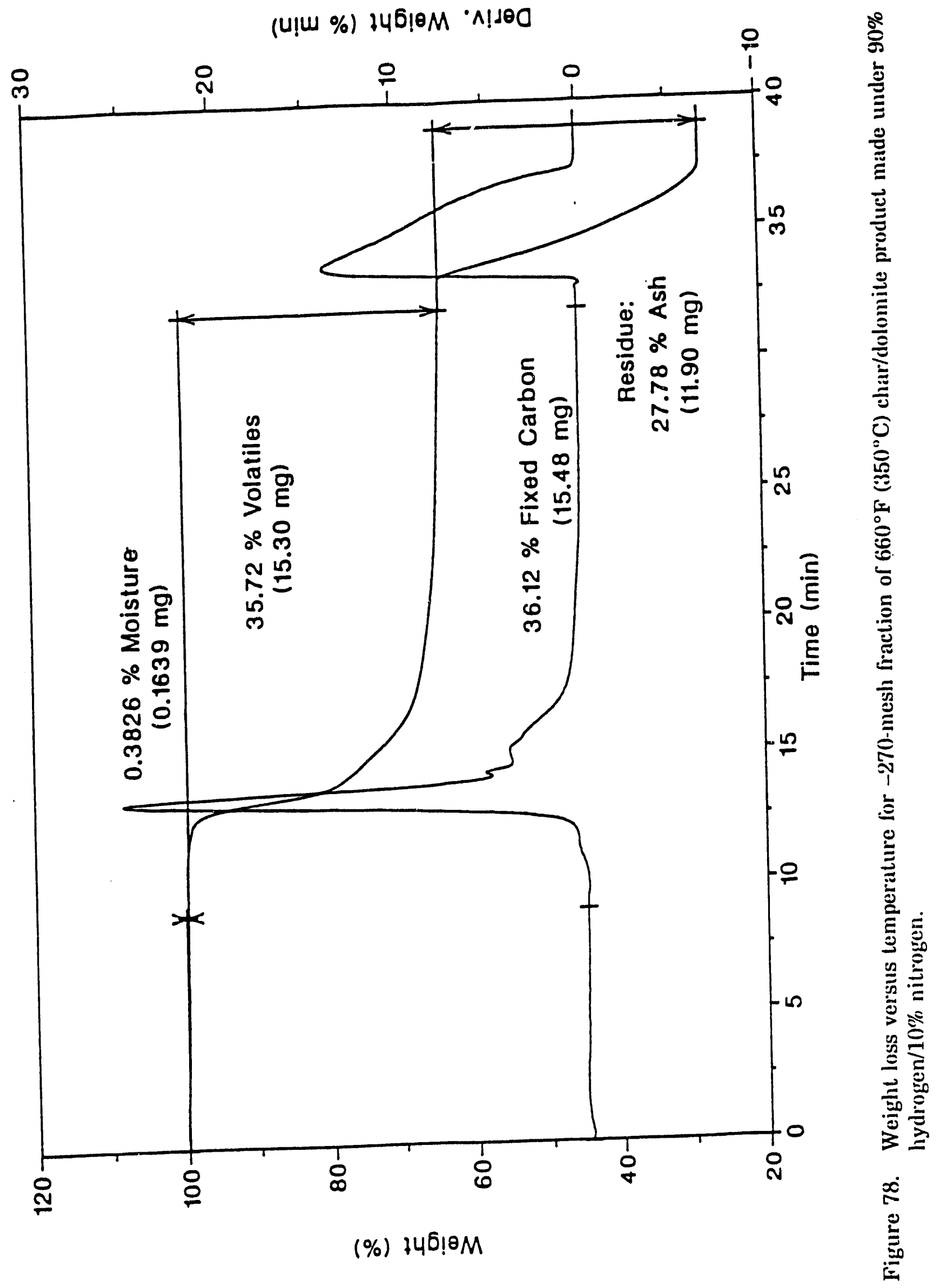




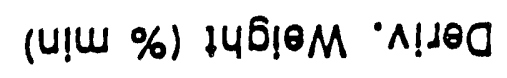

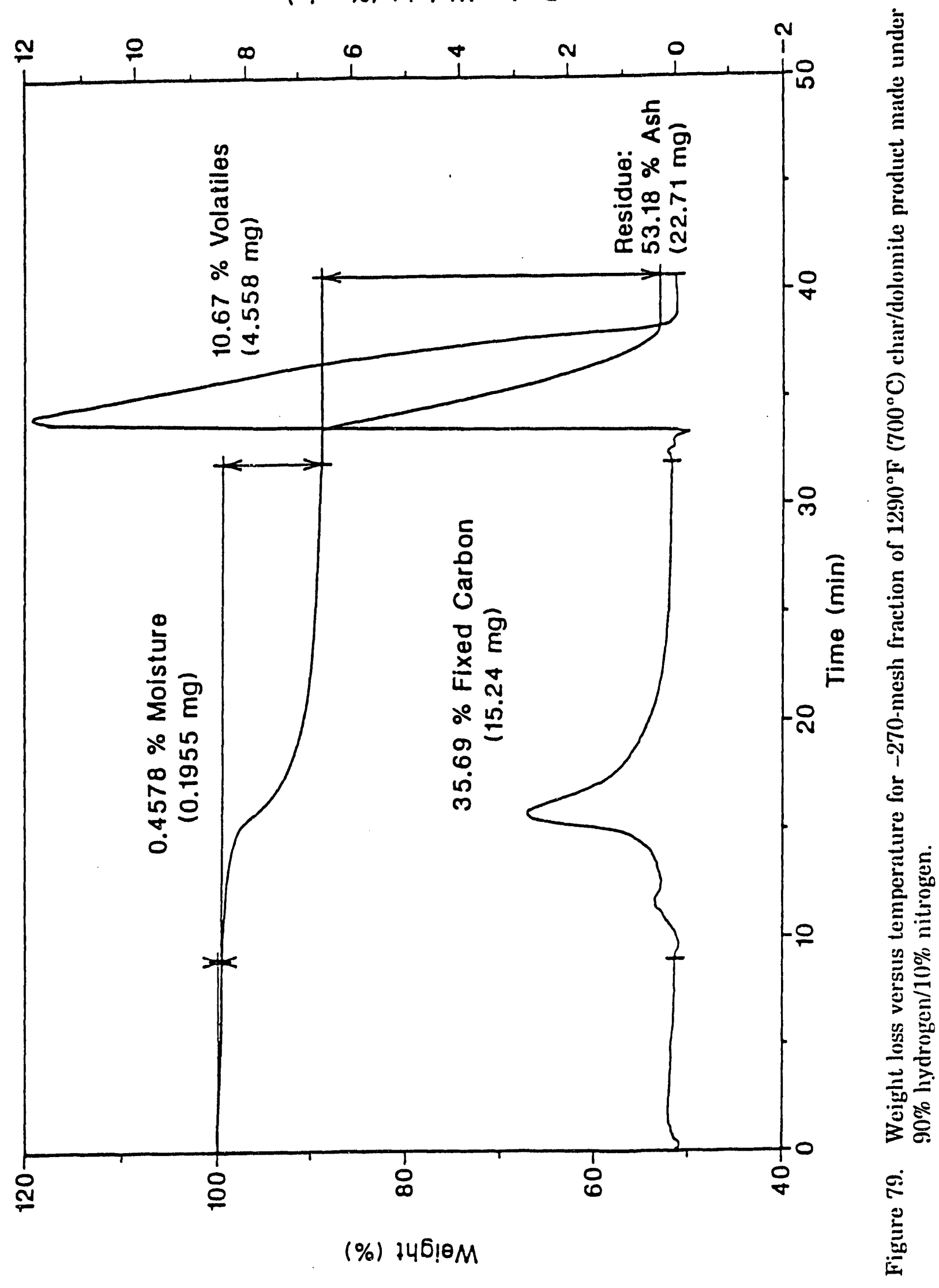




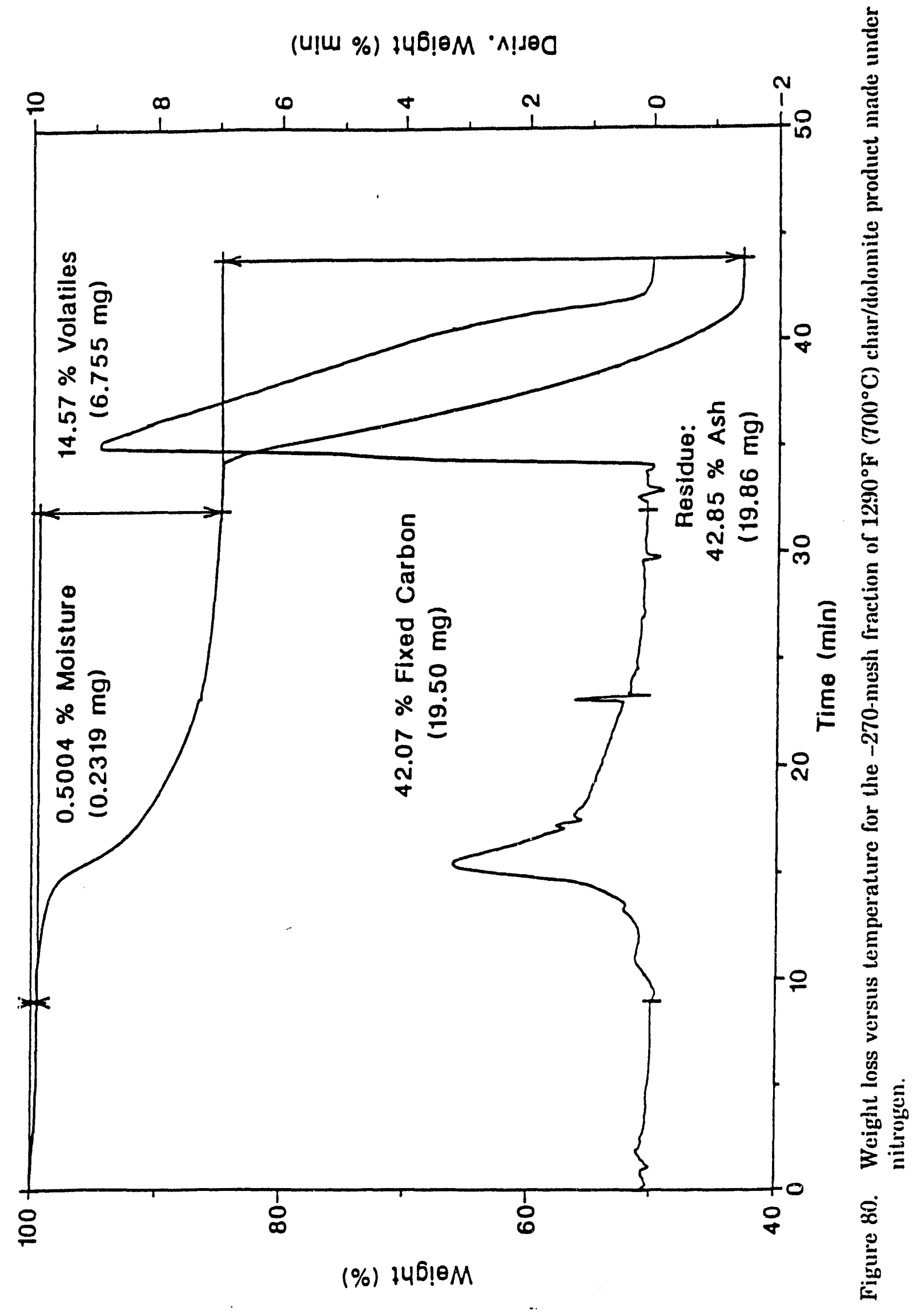


To calculate the amount of dolomite recovered in the -270-mesh fraction of the char/dolomite mixture produced from the $1290^{\circ} \mathrm{F}\left(700^{\circ} \mathrm{C}\right)$ hydrogen test, x-ray fluorescence (XRF) analysis was performed on ash samples made from the $930^{\circ} \mathrm{F}\left(500^{\circ} \mathrm{C}\right)$ feed char, the dolomite, the char/dolomite product, and the two size fractions $(+270$ mesh and -270 mesh) of the char/dolcmite product. As noted above, the +270-mesh fraction accounted for $78 \mathrm{wt} \%$ of the sample, and the -270 -mesh fraction accounted for $22 \mathrm{wt} \%$. Table 57 shows the results of the XRF analyses. Also included in the table is the XRF analysis of the $-60 \mathrm{x}+200$-mesh feed coal from which the $930^{\circ} \mathrm{F}\left(500^{\circ} \mathrm{C}\right)$ char was made. The values in the table are element concentrations in the ash (calculated on an oxygen-free ash basis) made from each of the five samples. For comparison of analytical techniques, Table 57 shows weight percent sulfur contents for the raw char/dolomite product and its two size fractions. The values in parentheses were calculated by multiplying the XRF sulfur values by ash content values obtained using the ASTM ashing method. Comparison of the XRF sulfur values with the Leco values shows that the two techniques give identical sulfur contents for the raw product, but significantly different values for the two size fractions. The most probable cause of the difference is the high-temperature ashing procedure used to prepare the ash samples for XRF analysis. The ashing technique will cause varying sulfur losses as vapor, depending on how the sulfur is associated.

The percentage of dolomite in the -270-mesh fraction was determined by first determining the percentage of char in this fraction. This was accomplished by calculating the percentage of the total aluminum content present in the -270 -mesh fraction. Aluminum content ratios can be used to indirectly calculate char content because the dolomite contains no aluminum. By performing an aluminum balance calculation, it was found that the composition of the -270 -mesh fraction was $73 \%$ dolomite and $27 \%$ char. These numbers support the idea of char/dolomite separation on the basis of particle size, since $73 \%$ of the $22 \%-270$-mesh fraction (which, on a 100 -gram basis, equates to about 16 grams) accounts for essentially all of the dolomite supplied to the reaction. Figure 81 summarizes char and sulfur recoveries for the $1290^{\circ} \mathrm{F}\left(700^{\circ} \mathrm{C}\right)$ dolomite test.

TABLE 57

XRF (Ash) Analysis of Reactants and Char/Dolomite Products

\begin{tabular}{|c|c|c|c|c|c|c|c|c|}
\hline & \multirow[b]{2}{*}{ Feed Coal } & \multirow[b]{2}{*}{$\begin{array}{c}1290^{\circ} \mathrm{F}\left(500^{\circ} \mathrm{C}\right) \\
\mathrm{Char}\end{array}$} & \multirow[b]{2}{*}{ Dolomite } & \multicolumn{5}{|c|}{$\begin{array}{c}\text { Char/Dolomite } \\
1290^{\circ} \mathrm{F}\left(700^{\circ} \mathrm{C}\right), \mathrm{H}_{2} \text {, Sample } 1\end{array}$} \\
\hline & & & & $\begin{array}{l}\text { Raw, } \\
100 \%\end{array}$ & $\begin{array}{c}+270-\text { mesh } \\
78 x\end{array}$ & & $\begin{array}{c}-270-\text { mesh } \\
22 \%\end{array}$ & \\
\hline Silicon & 35.8 & 34.4 & 0.8 & 27.7 & 34.2 & & 8.8 & \\
\hline Aluminum & 19.3 & 18.3 & 0.0 & 15.9 & 18.8 & & 5.0 & \\
\hline Iron & 33.4 & 35.6 & 0.0 & 20.7 & 28.5 & & 9.1 & \\
\hline Calcium & 4.1 & 4.4 & 58.2 & 14.8 & 6.2 & & 34.4 & \\
\hline Magnesium & 1.1 & 0.9 & 40.0 & 5.1 & 2.6 & & 16.8 & \\
\hline Potassium & 2.5 & 2.5 & 0.0 & 1.8 & 2.6 & & 0.2 & \\
\hline Sulfur & 2.5 & 2.7 & 0.0 & $12.5(3.6)^{1}$ & 5.6 & $(1.12)^{1}$ & 22.5 & $(11.7)^{1}$ \\
\hline Other & 1.3 & 1.2 & 1.0 & 1.5 & 1.5 & & 3.2 & \\
\hline
\end{tabular}

1 The values in parentheses are weight percent sulfur contents in the moisture-free raw char/dolomite product, its +270-mesh fraction, and its -270-mesh fraction, respectively, calculated based on the ASTM ash contents of the three samples. Leco sulfur numbers for the three samples are 3.6, 2.6, and $6.2 \mathrm{wt} \%$, respectively. 
Cumulative Sulfur

Weight Reduction

$\left(\frac{g \text { Coal S - g Char S }}{g \text { Coal S }}\right)$
Cumulative Sulfur Content Reduction

$\left(\frac{w \% \text { S Coal } \cdot m \% \text { s Char }}{w 1 \% \text { s Coal }}\right)$ $930^{\circ} \mathrm{F}\left(500^{\circ} \mathrm{C}\right)$

Char $73.1 \mathrm{~g}$

Sulfur $3.5 \mathrm{~g}$

(4.8\%)

$13.0 \mathrm{~g}$ Dolomite

$1290^{\circ} \mathrm{F}\left(700^{\circ} \mathrm{C}\right)$

$90 \% \mathrm{H}_{2} / 10 \% \mathrm{~N}_{2}$

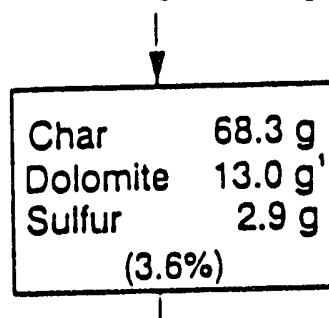

Size Separation

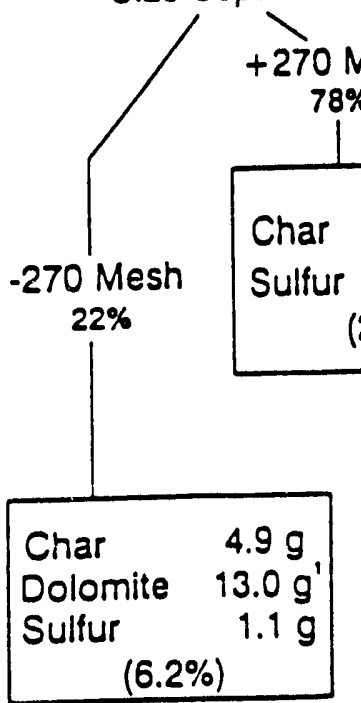

34.0

$9.4 \%$

$45.3 \%$

$32.1 \%$

$47.2 \%$

(2.8\%)
$66.0 \%$

$63.4 \mathrm{~g}$

$1.8 \mathrm{~g}$

$66.0 \%$

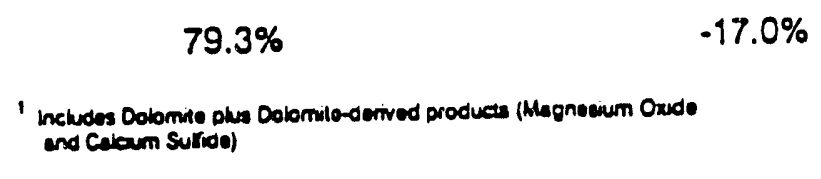

Figure 81. Production of $1290^{\circ} \mathrm{F}\left(700^{\circ} \mathrm{C}\right)$ char from $930^{\circ} \mathrm{F}\left(500^{\circ} \mathrm{C}\right)$ char under hydrogen, with dolomite. 
The +270-mesh char/dolomite products from the two $1290^{\circ} \mathrm{F}\left(700^{\circ} \mathrm{C}\right)$ tests (one performed under hydrogen and the other under nitrogen) were further separated into four equally weighted size fractions to determine if a low-organic-sulfur-content size fraction could be obtained. The results of the size separations and subsequent sulfur forms analyses are shown in Table 58. Table 58 also lists the sulfur forms data for the two size fractions (+270 and $-270-\mathrm{mesh})$ obtained from both $660^{\circ} \mathrm{F}\left(350^{\circ} \mathrm{C}\right)$ products.

\section{TABLE 58}

Sulfur Content in Char/Dolomite Mix--Particle-Size Effects

\begin{tabular}{|c|c|c|c|c|c|}
\hline & & Sulf & noisture & , wt\% & \\
\hline & & Total Sulfur & & dlfur Fo & \\
\hline & & & Pyr. & $\mathrm{SO}_{4}$ & Org. \\
\hline Feed Coal & & 5.26 & 2.20 & 0.32 & 2.73 \\
\hline $\begin{array}{l}\text { Chars } \\
\quad 660^{\circ} \mathrm{F}\left(350^{\circ} \mathrm{C}\right)\end{array}$ & · & & & & \\
\hline $\begin{array}{l}\text { Nitrogen } \\
+270 \text { mesh } \\
-270 \text { mesh }\end{array}$ & & $\begin{array}{ll}4.47 & (6.77)^{1} \\
4.37 & \\
4.50 & \end{array}$ & $\begin{array}{l}1.93 \\
1.85 \\
2.74\end{array}$ & $\begin{array}{l}0.28 \\
0.23 \\
0.52\end{array}$ & $\begin{array}{l}2.27 \\
2.29 \\
1.24\end{array}$ \\
\hline $\begin{array}{l}\text { Hydrogen } \\
\quad+270 \text { mesh } \\
-270 \text { mesh }\end{array}$ & & $\begin{array}{ll}4.20 & (6.46) \\
3.80 & \\
4.64 & \end{array}$ & $\begin{array}{l}1.30 \\
1.19 \\
2.22\end{array}$ & $\begin{array}{l}0.26 \\
0.23 \\
0.50\end{array}$ & $\begin{array}{l}2.64 \\
2.39 \\
1.91\end{array}$ \\
\hline $\begin{array}{l}\text { Nitrogen, no dolomite } \\
1290^{\circ} \mathrm{F}\left(700^{\circ} \mathrm{C}\right)\end{array}$ & & 5.62 & 2.45 & 0.29 & 2.88 \\
\hline $\begin{array}{lr}\text { Nitrogen } & (100 \%) \\
+70 \text { mesh } & (20 \%) \\
-70+120 \text { mesh } & (20 \%) \\
-120+170 \text { mesh }(18 \%) \\
-170+270 \text { mesh }(20 \%) \\
-270 \text { mesh }\end{array}$ & & $\begin{array}{l}3.46 \\
3.31 \\
2.94 \\
3.02 \\
3.06 \\
4.26\end{array}$ & $\begin{array}{l}0.56 \\
0.41 \\
0.39 \\
0.38 \\
0.41 \\
0.43\end{array}$ & $\begin{array}{l}0.06 \\
0.05 \\
0.05 \\
0.06 \\
0.07 \\
0.10\end{array}$ & $\begin{array}{l}2.85 \\
2.84 \\
2.51 \\
2.59 \\
2.58 \\
3.74\end{array}$ \\
\hline $\begin{array}{l}\text { Hydrogen } \\
+70 \text { mesh } \\
\begin{array}{l}(100 \%) \\
-70+100 \text { mesh } \\
-100+140 \text { mesh }(18 \%) \\
-140+270 \text { mesh }(23 \%) \\
-270 \text { mesh }\end{array}\end{array}$ & & $\begin{array}{l}3.59 \\
2.60 \\
2.40 \\
2.63 \\
2.77 \\
6.20\end{array}$ & $\begin{array}{l}0.51 \\
0.44 \\
0.42 \\
0.41 \\
0.38 \\
0.32\end{array}$ & $\begin{array}{l}0.05 \\
0.04 \\
0.04 \\
0.04 \\
0.05 \\
0.10\end{array}$ & $\begin{array}{l}3.03 \\
2.12 \\
1.95 \\
2.17 \\
2.34 \\
5.77\end{array}$ \\
\hline Nitrogen, no dolomite & & 4.25 & 0.54 & 0.06 & 3.65 \\
\hline
\end{tabular}

1 Dolomite-free basis .. values in this column were calculated using the dolomite contents listed in Table 55. 
The data in Table 58 show that:

1. At $660^{\circ} \mathrm{F}\left(350^{\circ} \mathrm{C}\right)$, some sulfur is adsorbed onto the dolomite, as shown by the high dolomite-free sulfur contents of the chars. However, at this temperature, very little dolomite reacts with su'fur to form calcium sulfide. This is evidenced by the low organic-sulfur content (isalcium sulfide is counted as organic sulfur using the ASTM sulfur forms anaiysis) of the $660^{\circ} \mathrm{F}\left(350^{\circ} \mathrm{C}\right)$ chars, especially the -270 -mesh fractions, which should contain any calcium sulfide formed during the reaction.

2. At $1290^{\circ} \mathrm{F}\left(700^{\circ} \mathrm{C}\right)$, dolomite appears to react with sulfur to form calcium sulfide. Evidence of this is the high organic-sulfur content of the -270-mesh fraction of both dolomite/char products, especially the char produced under hydrogen.

3. Although the pyritic and organic sulfur contents of the $1290^{\circ} \mathrm{F}\left(700^{\circ} \mathrm{C}\right)$ dolomite chars are similar (when dilution of sulfur by dolomite is considered) to those of the $1290^{\circ} \mathrm{F}\left(700^{\circ} \mathrm{C}\right)$ char made without dolomite, the fact that XRF analysis shows the presence of calcium sulfide means that, in the dolomite chars, pyritic sulfur is converted to calcium sulfide and, in the nondolomite char, pyritic sulfur is converted to species classified by ASTM analysis as "organic" sulfur.

4. The presence of hydrogen appears to enhance the reaction of calcium with sulfur.

\subsubsection{Final Calcining Tests using PRU Cleaned Char in the CFBR}

The CFBR was used to perform the calcining tests due to the limited amount of char produced in the carbonization tests. Dolomite was added to the char to act as a "sulfur getter" in a 1.5 calcium-to-sulfur ratio. Three temperatures were then tested with the majority of char production taking place at $1470^{\circ} \mathrm{F}\left(800^{\circ} \mathrm{C}\right)$. The test parameters and results are shown in Table 59. The dolomite was sized to -30 mesh, so a physical separation should separate the dolomite from the Indiana No. 3 char.

Due to the limited sulfur reduction achieved with the tests, further upgrading or analytical tests were not performed. The results were very similar to those achieved using the stage heating with the CFBR and did not achieve the $1 \%$ sulfur level that the metallurgical coke substitute requires. 
TABLE 59

Calcining Test Parameters and Results

\begin{tabular}{cccc}
\hline Run No. & Temp., $\left({ }^{\circ} \mathrm{F} /{ }^{\circ} \mathrm{C}\right)$ & Sample & Sulfur Content \\
\hline Feed & & & 2.44 \\
M249 & $1290 / 700$ & Char & 2.56 \\
M249 & $1290 / 700$ & Cyclone Fines & 2.51 \\
M250 & $1380 / 750$ & Char & 2.80 \\
M250 & $1380 / 750$ & Cyclone Fines & 2.56 \\
M251 & $1470 / 800$ & Char & 3.32 \\
M251 & $1470 / 800$ & Cyclone Fines & 2.72 \\
\hline
\end{tabular}

M251 Char sulfur analysis by sieve size

\begin{tabular}{cccccc} 
Mesh & Coal, wt\% & Ash, \% & Sulfur, \% & Sulfur, g & Sulfur in Fraction, \% \\
\hline+30 & 36.32 & 20.34 & 2.66 & 0.97 & 33.26 \\
-30 & 63.68 & 34.60 & 3.03 & 1.94 & 66.74 \\
+40 & 47.74 & 20.35 & 2.65 & 1.27 & 43.60 \\
-40 & 52.26 & 37.70 & 3.12 & 1.63 & 56.11 \\
+60 & 70.57 & 23.39 & 2.78 & 1.96 & 67.57 \\
-60 & 29.43 & 43.80 & 3.17 & 0.93 & 32.13 \\
+120 & 91.79 & 27.81 & 2.95 & 2.71 & 93.29 \\
-120 & 8.21 & 47.06 & 2.30 & 0.19 & 6.50 \\
\hline
\end{tabular}

Gas Analysis

\begin{tabular}{|c|c|c|c|}
\hline & M249 & M250 & M251 \\
\hline Hydrogen & $2.40(40.96)^{a}$ & 2.32 (48.43) & $\begin{array}{l}3.85(53.77) \\
06(12.01)\end{array}$ \\
\hline Carbon Dioxide & 0.69 (11.77) & 0.54 (11.27) & $\begin{array}{ll}0.86 & (12.01) \\
0.00 & (0.00)\end{array}$ \\
\hline Propylene & $0.05 \quad(0.85)$ & $0.00 \quad(0.00)$ & $\begin{array}{ll}0.00 & (0.00) \\
0.00 & (0.00)\end{array}$ \\
\hline Hydrogen Sulfide & $0.06 \quad(1.02)$ & $(0.00)$ & $(0.00)$ \\
\hline Ethylene & $0.09 \quad(1.54)$ & $0.22 \quad(4.59)$ & $(1.26)$ \\
\hline Ethane & $0.09 \quad(1.54)$ & $0.00 \quad(0.00)$ & $(0.00)$ \\
\hline Nitrogen & $94.14 \quad(.)$. & $95.21 \quad(-)$. & 92.84 \\
\hline Methane & $1.58(26.96)$ & 0.62 (12.94) & $0.71 \quad(9.92)$ \\
\hline Carbon Monoxide & $0.90(15.36)$ & $0.94(19.62)$ & $1.58(22.07)$ \\
\hline
\end{tabular}

a Nitrogen-free. 


\subsection{METALLURGICAL COKE SUBSTITUTE TEST RESULTS}

\subsection{Pelletixing of Char using Inorganic Binders (PTC Process)}

A new process being developed by Pellet Technology Corporation (PTC) produces pellets containing both iron oxide and carbon by a low-temperature, cold-bonded method. The PTC process can produce molten metal from the carbon-bearing, iron oxide pellets in a hot-blast cupola without the need for a blast furnace. The process is based on a program started in 1966 at Michigan. Technology University's Institute of Mineral Research (MTU) in Houghton, Michigan.

The pellets can be made from a variety of iron oxides including the waste oxides from iron and steel-making operations. These wastes have increasingly high disposal costs. In making the pellets, calcium oxide and silica are added, and a reaction between the these two components creates a strong, cement-like bond. Numerous tests established that the pellets are strong enough for the transportation and handling associated with use as charge material for blast furnaces, rotary kilns, and cupolas. By the inclusion of carbon fines and burnt lime, a pellet is formed that is a complete iron reduction system with its own reductant and flux. Because oxidation does not occur at the low hardening temperature of $400^{\circ} \mathrm{F}\left(205^{\circ} \mathrm{C}\right)$, carbon can be added to the cold-bonded pellet. Carbon cannot be added to conventional indurated iron ore pellets because it oxidizes at the high process temperatures used.

Potential PTC technologies for commercial use based on the cold-bonded pellet process include production of iron oxide and carbon-bearing pellets for blast furnace burden material, production of hot metal in a hot-blast cupola using carbon-bearing pellets, production of direct-reduced iron in rotary kilns using carbon-bearing pellets, recycle of steel-making waste oxides with by-product recovery of lead and zinc, and production of carbon agglomerates to replace coke.

The extremely fast reduction rate of cold-bonded, carbon-bearing pellets is applicable to the production of DRI (direct-reduced iron). The production of hot metal from carbonbearing pellets melted in a hot-blast cupola is referred to as the PTC hot-metal process. Tests in production hot-blast cupolas have demonstrated that cold-bonded, carbon-bearing pellets are an excellent charge material and produced various grades of iron, including ductile iron, gray iron, and conventional pig iron. It is important to note that the pellets provide a source of clean iron units for cupolas which mostly smelt scrap iron. Another benefit of using carbon-bearing pellets in the cupolas is the ability to control the sulfur content of the product by adjusting the carbon content and basicity of the pellet.

The overall process is shown in Figure 25. A PTC autoclave is operated at approximately $390^{\circ} \mathrm{F}\left(199^{\circ} \mathrm{C}\right)$ compared to $2400^{\circ} \mathrm{F}\left(1315^{\circ} \mathrm{C}\right)$ for a conventional iron pellet kiln. Because of the lower temperature of the autoclaving process, the MTU pellets can keep the iron ore in the form of magnetite, instead of converting it to hematite as happens in a conventional pelletizing operation. This phase phenomenon creates a pellet that has more iron per unit volume and requires less energy to reduce.

The pellets can be used in at least three different ways: +as feed to a conventional blast furnace to produce hot metal; as feed to a rotary kiln to produce DRI; and, most importantly, to a hot-blast cupola where hot metal equivalent to that from a blast furnace can be produced. 
The special attraction of the PTC process with respect to mild gasification is that it can use a low-temperature char rather than requiring a low-volatile metallurgical coke. This is possible because the chemical bond created in making the pellets (calcium oxide + silicon $=$ calcium silicate) is stable at temperatures up to the melting point of calcium silicate, about $2800^{\circ} \mathrm{F}\left(1538^{\circ} \mathrm{C}\right)$. The pellets can therefore be used at temperatures up to $2400^{\circ} \mathrm{F}\left(1315^{\circ} \mathrm{C}\right)$. By contrast, conventional iron ore pellets cannot be used above about $1800^{\circ} \mathrm{F}\left(980^{\circ} \mathrm{C}\right)$ without having metallurgical coke present to provide stability to the burden in the blast furnace.

Although volatile content in the carbon source can be counteracted to a certain extent by the use of more lime and silica, practical considerations eliminate the use of raw coal. A crucial advantage of the PTC process is that the intimate mixing of carbon and iron ore within the pellets makes possible a much faster reaction time. The reduction of iron ore in a blast furnace is a diffusion-controlled process. Retention times in the furnace are 10 to 16 hours. As a result, blast furnaces rnust be very large to be . economical--with outputs of two million tons per year or more. By contrast, reduction of PTC pellets can be completed with a furnace residence time of only 30 minutes. This means that hot metal, or pig iron, can be produced from iron ore in a hot-blast cupola instead of requiring a large and expensive blast furnace.

Hot-blast cupolas are normally used at foundries to remelt scrap metal. They are much smaller than blast furnaces, 80 feet tall versus 270 feet. The capital cost per ton of hot metal may be only $1 / 4$ to $1 / 3$ that of a blast furnace. Hundreds of hot-blast cupolas are in existence around the United States. These cupolas can now become primary hot-metal producers for an extremely low capital investment. The existence of a large number of small-scale, low-cost and flexible operations for producing primary hot metal from iron ore could reshape the steel industry in exactly the same way that the electric furnace and the minimill have done already.

\subsubsection{Pelletizing of Wyodak Char with Limestone Addition}

Laboratory tests were performed at PTC research laboratory in Houghton, Michigan, on one Wyodak coal char. The primary objectives were:

1. To investigate the "agglomeration"1 characteristics of the coal char for the production of carbon agglomerates.

2. To investigate utilization of the same char as a source of internal carbon in char-iron ore pellets that could be used in the production of hot metal in a cupola.

Approximately 20 pounds of Wyodak test char were prepared by operating the 30-lb/hr hydrogen production gasifier in a fast fluid-bed gasification mode using steam. Temperatures in the gasifier approached $1380^{\circ} \mathrm{F}\left(750^{\circ} \mathrm{C}\right)$. The product char was collected as fines from the primary cyclone. Limestone was used to provide a high-density bed to retain the char in the bed for a longer period of time. This method was not representative

1 Agglomeration in this section refers to the PTC cold-bonding process for forming char pellets that could be used as a metallurgical coke substitute, not the agglomeration that occurs in a reactor when using caking coal. 
of the planned mild gasification process, and it was used only to produce the quantity of char needed by PTC for a preliminary evaluation of pellet production. The sieve, proximate, and chemical analyses of the char are shown in Tables 60 and 61 . The very high ash content, from limestone attrition of the bed, is not characteristic of the Wyodak char that would be produced in the mild gasification process.

TABLE 60

Screen Analysis of Wyodak Char

\begin{tabular}{ccc}
\hline Tyler Mesh & Ind. wt\% & Cum. wt\% \\
\hline+20 & 0.01 & 0.01 \\
+28 & 0.14 & 0.15 \\
+35 & 2.89 & 3.04 \\
+48 & 20.60 & 23.64 \\
+65 & 18.29 & 41.93 \\
+100 & 14.99 & 56.92 \\
+150 & 10.94 & 67.86 \\
+200 & 7.20 & 75.06 \\
+270 & 3.90 & 78.96 \\
+325 & 2.58 & 81.54 \\
-325 & 18.46 & 100.00 \\
\hline
\end{tabular}

TABLE 61

Chemical Analysis of Wyodak Char

\begin{tabular}{lr}
\hline Analysis & wt\% \\
\hline Proximate Analysis & 3.20 \\
Moisture & 11.60 \\
Volatiles & 61.00 \\
Fixed Carbon & 27.20 \\
Ash & \\
Ultimate Analysis & 1.05 \\
Hydrogen & 64.34 \\
Carbon & 0.89 \\
Nitrogen & 0.84 \\
Sulfur & 4.67 \\
Oxygen & 28.18 \\
Ash & \\
$\mathrm{Ash} \mathrm{Analysis}_{\mathrm{AaO}}$ & 22.10 \\
$\mathrm{CaO}_{\mathrm{MgO}}$ & 5.06 \\
$\mathrm{SiO}_{2}$ & 25.90 \\
$\mathrm{Al}_{2} \mathrm{O}$ & 12.40 \\
$\mathrm{FeO}_{\mathrm{MnO}}$ & 3.28 \\
$\mathrm{Na}_{2} \mathrm{O}$ & 0.07 \\
$\mathrm{~K}_{2} \mathrm{O}$ & 0.68 \\
$\mathrm{TiO}_{2}$ & 0.40 \\
& 0.84 \\
\hline
\end{tabular}




\subsubsection{Agglomeration Tests - Carbon Agglomerates}

Oval-shaped briquettes were made manually in a steel mold after adding $7 \% \mathrm{CaO}$, $3 \% \mathrm{SiO}_{2}$, and $20 \%$ water to the char. The size of the briquettes was $43 \mathrm{~mm}$ long, $30 \mathrm{~mm}$ wide and $20 \mathrm{~mm}$ high. The briquettes were formed at various pressures from 5,000 to $15,000 \mathrm{psi}$. All briquettes from this test expanded and broke after forming. Similar tests were repeated in a $19-\mathrm{mm}$-diameter semispherical mold without success. Due to unsuccessful results, the briquetting tests were terminated.

Pelletizing tests were performed on the same Wyodak char in a laboratory size pelletizer at the various binder levels and char sizes presented in Table 62. Pellets of oneinch diameter were produced successfully and hardened in an autoclave in 300-psig saturated steam for one and two hours. Tests run on the green, dry, and hardened pellets included compressive strengths and impact resistances measured by dropping pellets from 18 inches on a $1 / 2$-inch steel plate. Apparent density was measured only on the hardened pellets by mercury submersion. Tumble tests were run on the hardened pellets in a special tumbler in place of the ASTM tumbler that requires a 25-pound sample. Five hundred grams of pellets were tumbled for 200 revolutions and then screened on 3- and 14-mesh screens.

Results in Table 63 show that the pellets having the highest density and best abrasion resistance were produced from char using $7 \% \mathrm{CaO}$ and $3 \% \mathrm{SiO}_{2}$. Similar pellets made with $3.5 \% \mathrm{CaO}$ and $1.5 \% \mathrm{SiO}_{2}$ had lower density and strength; further testing of this binder level was omitted. The chemical analysis of Test No. 11 pellets is presented in Table 64.

\subsubsection{Agglomeration Tests - Carbon-Bearing Iron Ore Pellets}

Carbon-bearing iron ore pellets offer the potential of very high rates of reduction to hot metal by intimately mixing the ore and reductant in the same pellet. Two pellet batches were prepared at a number of different binder levels. The Wyodak char was ground to -325 mesh to improve its reduction characteristics. Chemical and screen analyses of the Empire iron ore concentrate are presented in Table 65. The calculated amounts of iron ore concentrate, $\mathrm{CaO}, \mathrm{SiO}_{2}$, and char fines, were mixed with water in a roller mixer for 5 minutes. The mixture was then introduced to the pelletizer, and 1-inch-diameter pellets were produced. Separate batches of pellets were hardened in an autoclave in 300-psig saturated steam for periods of 1 and 3 hours. Compressive strengths

\section{TABLE 62}

Physical Characteristics of Char Pellets Made From Coal Char of Various Compositions and Particle Sizes

\begin{tabular}{|c|c|c|c|c|c|c|c|c|c|c|c|}
\hline \multirow{3}{*}{$\begin{array}{l}\text { Teat } \\
\text { No. }\end{array}$} & \multirow{3}{*}{$\begin{array}{l}\text { Char } \\
\text { Sizo }\end{array}$} & \multicolumn{2}{|c|}{ Amounts of Binder } & \multicolumn{2}{|c|}{ Groen Polloks } & \multicolumn{2}{|c|}{ Driod Pollots } & \multicolumn{4}{|c|}{ Hardened Pellots } \\
\hline & & \multirow{2}{*}{$\begin{array}{l}\mathrm{CaO} \\
w t \%\end{array}$} & \multirow{2}{*}{$\begin{array}{l}\mathrm{SiO}_{2} \\
\text { wt\% }\end{array}$} & \multirow{2}{*}{$\begin{array}{l}\text { Comp. Str., } \\
\text { lb. }\end{array}$} & \multirow{2}{*}{$\begin{array}{l}\text { Impact } \\
\text { No., 18" }\end{array}$} & \multirow{2}{*}{$\begin{array}{c}\text { Comp. Str., } \\
\text { Ib }\end{array}$} & \multirow{2}{*}{$\begin{array}{l}\text { Impact } \\
\text { No., 18" }\end{array}$} & \multicolumn{2}{|c|}{ Comp. Str. lb } & \multicolumn{2}{|c|}{ Impact No., $18^{n}$} \\
\hline & & & & & & & & $1 \mathrm{hr}$ & $2 \mathrm{hr}$ & $1 \mathrm{hr}$ & $2 \mathrm{hr}$ \\
\hline 10 & As-is & 7.00 & 3.00 & 28.4 & $100+$ & 48.2 & 14.6 & 36.6 & 46.6 & 9.0 & ND \\
\hline 11 & $95 \%,-100$ meah & 7.00 & 3.00 & 36.6 & $100+$ & 63.3 & 16.7 & 60.0 & 60.0 & 13.0 & ND \\
\hline 12 & $98 \%,-200$ mesh & 7.00 & 3.00 & 26.3 & $100+$ & 62.2 & 12.7 & 66.2 & 58.4 & 14.0 & ND \\
\hline 13 & $96 \%,-100$ meen & 3.60 & 1.60 & 34.8 & $60+$ & 43.0 & 9.9 & 23.0 & 20.6 & 2.0 & ND \\
\hline
\end{tabular}


TABLE 63

Tumble Test Results and Apparent Densities of Test No. 11 Coal Char Pellets

\begin{tabular}{|c|c|c|c|c|}
\hline \multirow{2}{*}{$\begin{array}{l}\text { Test } \\
\text { No. }\end{array}$} & \multicolumn{3}{|c|}{ Abrasion Index, wt\% } & \multirow{2}{*}{$\begin{array}{c}\text { Apparent } \\
\text { Densities } \\
\mathrm{g} / \mathrm{cm}^{3}\end{array}$} \\
\hline & +3 mesh & $-3+14$ mesh & -14 mesh & \\
\hline 10 & 85.15 & 0.40 & 14.46 & 0.93 \\
\hline 11 & 95.00 & 0.20 & 4.80 & 0.95 \\
\hline 12 & 91.97 & 0.20 & 7.83 & 0.92 \\
\hline 13 & 45.91 & 4.59 & 49.50 & 0.88 \\
\hline
\end{tabular}

TABILE 64

\begin{tabular}{lc} 
Chemical Analysis of Test No. 11 Coal Char Pellets (dry basis) \\
\hline Analysis & wt\% \\
\hline Fixed Carbon & 58.60 \\
Volatiles, $1380^{\circ} \mathrm{F}\left(750^{\circ} \mathrm{C}\right)$ & 8.60 \\
Sulfur & 0.704 \\
Ash, $1380^{\circ} \mathrm{F}\left(750^{\circ} \mathrm{C}\right)$ & 32.80 \\
$\mathrm{Ash} \mathrm{Analysis}$ & \\
$\mathrm{CaO}$ & 37.40 \\
$\mathrm{MgO}$ & 3.04 \\
$\mathrm{SiO}$ & 30.40 \\
$\mathrm{Al}_{2} \mathrm{O}$ & 9.96 \\
$\mathrm{FeO}$ & 6.71 \\
$\mathrm{MnO}$ & 0.07 \\
$\mathrm{~K}_{2} \mathrm{O}$ & 0.18 \\
$\mathrm{Na}_{2} \mathrm{O}$ & 0.98 \\
$\mathrm{TiO}_{2}$ & 0.58 \\
$\mathrm{Moisture}$ & 0.20 \\
\hline
\end{tabular}

and impact resistance numbers of the green, dry, and hardened pellets were determined in the same manner as for the char pellets. The results are presented in Table 66. Tumble test results and pellet densities shown in Table 67 are similar to those from the char pellets.

The reduction behavior of iron ore pellets was investigated in a Leco tube furnace. For each test, pellets were placed in a ceramic boat and slowly pushed from the entrance of the tube to the hot zone in approximately two minutes, where it was heated at $2700^{\circ}$, $2500^{\circ}$, or $2300^{\circ} \mathrm{F}\left(1480^{\circ}, 1370^{\circ}\right.$, or $\left.1260^{\circ} \mathrm{C}\right)$ for 5,15 , and 30 minutes under $\mathrm{N}_{2}$ gas at a flow rate of 0.5 liter/minute. At $2300^{\circ} \mathrm{F}\left(1260^{\circ} \mathrm{C}\right)$, the reduced and sintered pellets were found not to crack, chip, or swell, but remained strong. Signs of melting were observed after heating only five minutes at $2700^{\circ} \mathrm{F}\left(1480^{\circ} \mathrm{C}\right)$, and complete melting took place after 15 minutes. The slag was easily separated from the metal. The weight loss, shown in Figure 82 is proportional to the degree of reduction or metallization. Metallized pellets 


\section{TABLE 65}

Chemical and Screen Analyses of Empire Concentrate

\begin{tabular}{ccc}
\hline Chemical Analysis & wt\% & \\
& 67.00 & \\
$\mathrm{Fe}_{\text {sot }}$ & 18.00 & \\
$\mathrm{Fe}^{++}$ & 6.43 & \\
$\mathrm{SiO}_{2}$ & 0.10 & \\
$\mathrm{CaO}_{\mathrm{MgO}}$ & 0.17 & \\
$\mathrm{Al}_{2} \mathrm{O}_{\mathrm{s}}$ & 0.29 & \\
$\mathrm{P}$ & 0.009 & \\
$\mathrm{~S}$ & 0.004 & \\
$\mathrm{MnO}$ & 0.05 & \\
$\mathrm{LOI}$ & +1.91 & \\
$\mathrm{Moisture}$ & 10.60 & \\
Screen Analysis & & \\
Tyler Mesh & $\mathrm{wt} \%$ & 0.140 \\
+65 & 0.140 & 0.350 \\
+100 & 0.010 & 0.555 \\
+150 & 0.205 & 0.810 \\
+200 & 0.200 & 1.285 \\
+270 & 0.255 & 100.000 \\
+325 & 0.475 & \\
-325 & 98.715 & \\
\hline
\end{tabular}

TABLE 66

Physical Characteristics of Carbon-Bearing Pellets Made at Various Binder Levels

\begin{tabular}{|c|c|c|c|c|c|c|c|c|c|c|c|}
\hline \multirow{3}{*}{$\begin{array}{l}\text { Test } \\
\text { No. }\end{array}$} & \multirow{3}{*}{$\begin{array}{l}\text { Char } \\
\text { Size }\end{array}$} & \multicolumn{2}{|c|}{ Amounts of Binder } & \multicolumn{2}{|c|}{ Green Pellets } & \multicolumn{2}{|c|}{ Dried Pellets } & \multicolumn{4}{|c|}{ Hardened Pellets } \\
\hline & & $\mathrm{CaO}$, & $\mathrm{SiO}_{2}$ & Comp. & Impact & Comp. & Impact & Comp. & $\mathrm{c}, \mathrm{lb}$ & Impact & $0.18 "$ \\
\hline & & wt\% & wt\% & Str., lb & No., 18" & Str.,lb & No., 18" & $1 \mathrm{hr}$ & $2 \mathrm{hr}$ & $1 \mathrm{hr}$ & $2 \mathrm{hr}$ \\
\hline 20 & $98 \%,-325$ mesh & 7.00 & 3.00 & 30.6 & 45.4 & 1.5 & 1.5 & 340 & 517 & $100+$ & ND \\
\hline 21 & $98 \%,-325$ mesh & 5.00 & 2.00 & 42.0 & 51.0 & 1.5 & 1.5 & 201 & 165 & 37.4 & ND \\
\hline
\end{tabular}

ND - not determined.

TABLE 67

Tumble Test Results and Apparent Densities of Carbon-Bearing Iron Ore Pellets

Apparent

\begin{tabular}{ccccc} 
Test & \multicolumn{3}{c}{ Abrasion Index, wt\% } & $\begin{array}{c}\text { Densities, } \\
\mathrm{g} / \mathrm{cm}^{3}\end{array}$ \\
No. & +3 mesh & $-3+14$ mesh & -14 mesh & 2.07 \\
\hline 20 & 98.22 & 0.00 & 1.78 & 2.10 \\
21 & 95.57 & 0.81 & 3.62 &
\end{tabular}




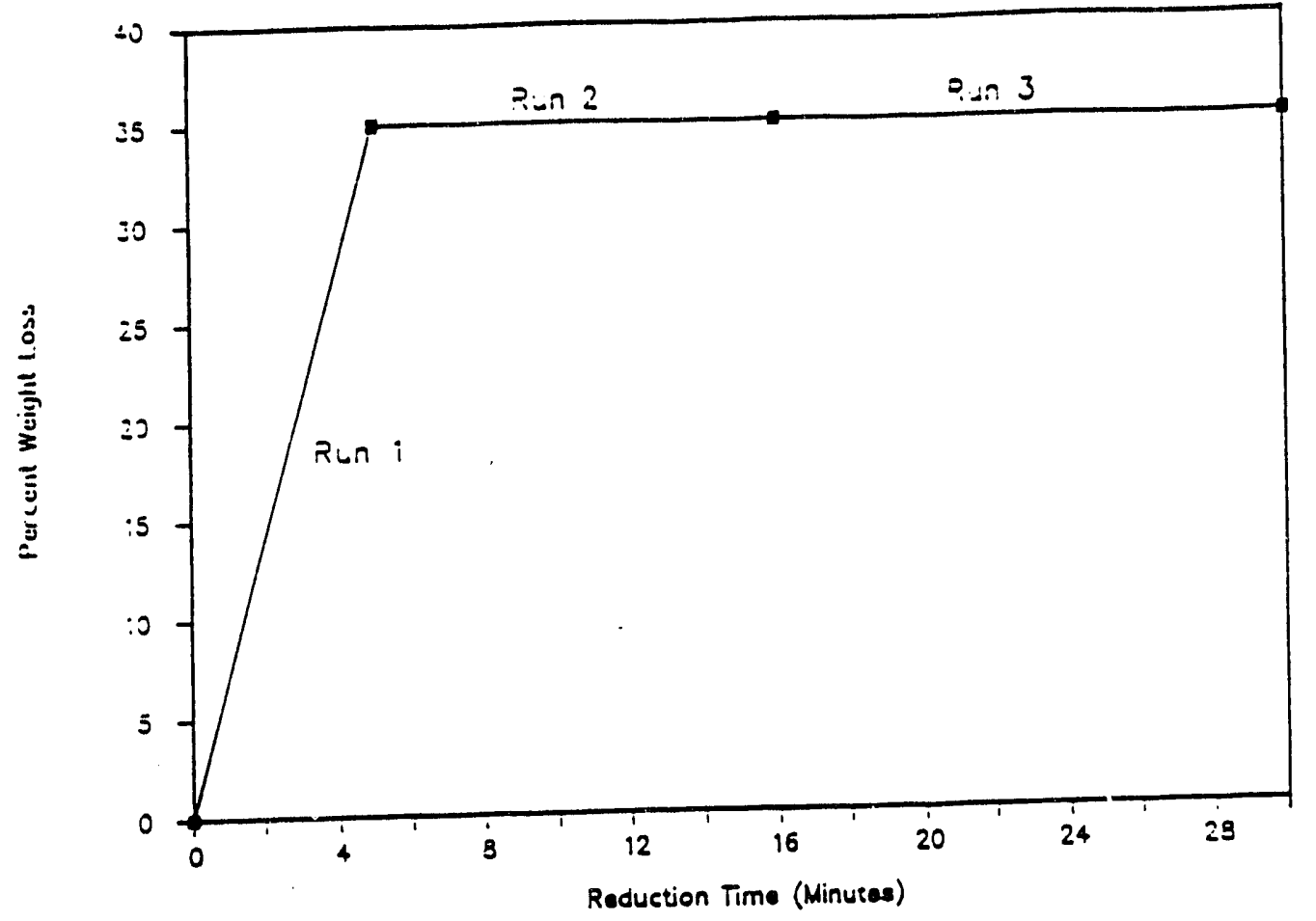

Figure 82. Weight loss of No. 20 pellets heated to $2700^{\circ} \mathrm{F}\left(1480^{\circ} \mathrm{C}\right)$.

heated to $2500^{\circ} \mathrm{F}\left(1370^{\circ} \mathrm{C}\right)$ for 15 minutes were analyzed and the degree of reduction was calculated to be $94.28 \%$. To obtain a larger quantity of metal, melting tests were repeated numerous times at $2700^{\circ} \mathrm{F}\left(1480^{\circ} \mathrm{C}\right)$ and 15 minutes. Metal nuggets were separated from the slag and analyzed. Results from the tests are shown in Table 68. Similar tests performed at a lower $5 \%$ binder level $\left(3.5 \% \mathrm{CaO}, 1.5 \% \mathrm{SiO}_{2}\right)$ produced weak pellets, and further tests were not conducted.

The test results indicate that $7 \% \mathrm{CaO} \cdot 3 \% \mathrm{SiO}_{2}$ bonded-carbon pellets and carbon-iron ore pellets can be successfully produced from Wyodak mild gasification char. Briquetting was not successful due to the swelling behavior of the Wyodak char. Better pellet strengths were obtained after grinding the char to -100 mesh or finer. Grinding to -200 mesh increased the compressive strength of the pellets from 36.5 pounds to 66.2 pounds after one hour of hardening in the autoclave. The tumble index improved from $85.1 \%$ to $95 \%$ by grinding the char to -100 mesh. The densities were also slightly higher for the ground char pellets.

The compressive strength and tumbling index of pellets containing $5 \%$ binder $(3.5 \%$ $\mathrm{CaO}, 1.5 \% \mathrm{SiO}_{2}$ ) were very low, possibly due to the uncharacteristically high ash content of the char. Since this is not a normal ash content, the poor results may not be characteristic of the process as a whole.

Reduction tests run on carbon-iron ore pellets showed very rapid reduction to metal due to the high reactivity of the Wyodak char. The 5-minute reduction time observed is much faster than can be obtained with ordinary coke. This property may be very important to some slow reducing ores, such as chrome oxides, and should be investigated further. 
TABLE 68

Chemical Analysis of Carbon-Bearing, Metallized Pellets and Reduced Iron

\begin{tabular}{lccc}
\hline Substances & $\begin{array}{c}\text { Hardened Pellets, } \\
\text { wt\% }\end{array}$ & $\begin{array}{c}\text { Metallized Pellets, } \\
\text { wt\% }\end{array}$ & $\begin{array}{c}\text { Reduced Iron, } \\
\text { wt\% }\end{array}$ \\
\hline $\mathrm{Fe}_{\text {TOTAL }}$ & 44.80 & 69.90 &.- \\
$\mathrm{Fe}^{++}$ & 13.76 & 3.18 &.. \\
$\mathrm{Fe}^{\circ}$ &.- & 65.90 &.. \\
$\mathrm{Fe}^{* * *}$ & 31.04 & 0.82 &.- \\
$\mathrm{CaO}$ & 8.73 & 13.80 &.. \\
$\mathrm{MgO}$ & 0.40 & 0.63 &.. \\
$\mathrm{SiO}$ & & 13.60 & $0.28(\mathrm{Si})$ \\
$\mathrm{Al}_{2} \mathrm{O}_{3}$ & 8.74 & 1.53 &.- \\
$\mathrm{MnO}_{\mathrm{S}}$ & 0.94 & 0.08 & $0.03(\mathrm{Mn})$ \\
$\mathrm{P}$ & 0.05 & 0.295 & 0.228 \\
$\mathrm{C}$ & 0.74 & 0.027 & 0.024 \\
Degree of Metallization, \% & 0.01 & 0.476 & 0.85 \\
Metal/Slag Ratio & 13.40 & 94.28 &.- \\
\hline
\end{tabular}

\subsubsection{Pelletizing of Wyodak Char Without Limestone Addition}

Table 69 shows the results from the Wyodak char tests. The hardened pellets exhibit compressive strengths similar to the results with the Wyodak char with the limestone addition. Abrasion tests and apparent densities are also similar.

\subsubsection{Pelletizing of Indiana No. 3 Char}

Table 70 shows the results from the Indiana char tests. The hardened pellets for test No. 28 show a very high compressive strength, while the carbon pellets were not as strong as the Wyodak chars.

\subsection{Briquetting of Char Using Organic Binders}

The manufacture of an "artificial" coke, or form coke, from low-cost noncoking coals, has received considerable development attention in the past. At least nine different form coke processes have been developed to some stage of demonstration. FMC Corporation, in a joint venture with U.S. Steel Corporation (now USX), built a small form coke plant at Kemmerer, Wyoming, in the 1960s. The demonstration unit was upgraded from 1969 to 1972 into a 120,000-tpy production unit. Since 1965, when FMC bought U.S. Steel's interest in the operation, the plant has produced coke for testing by a number of major domestic and foreign steel companies. A 20,000-ton test was carried out at Inland Steel's Harbor Works in Indiana. 
TABLE 69

Results of Pellet Technology Corporation Char

Pelletizing Tests Using Wyodak Char

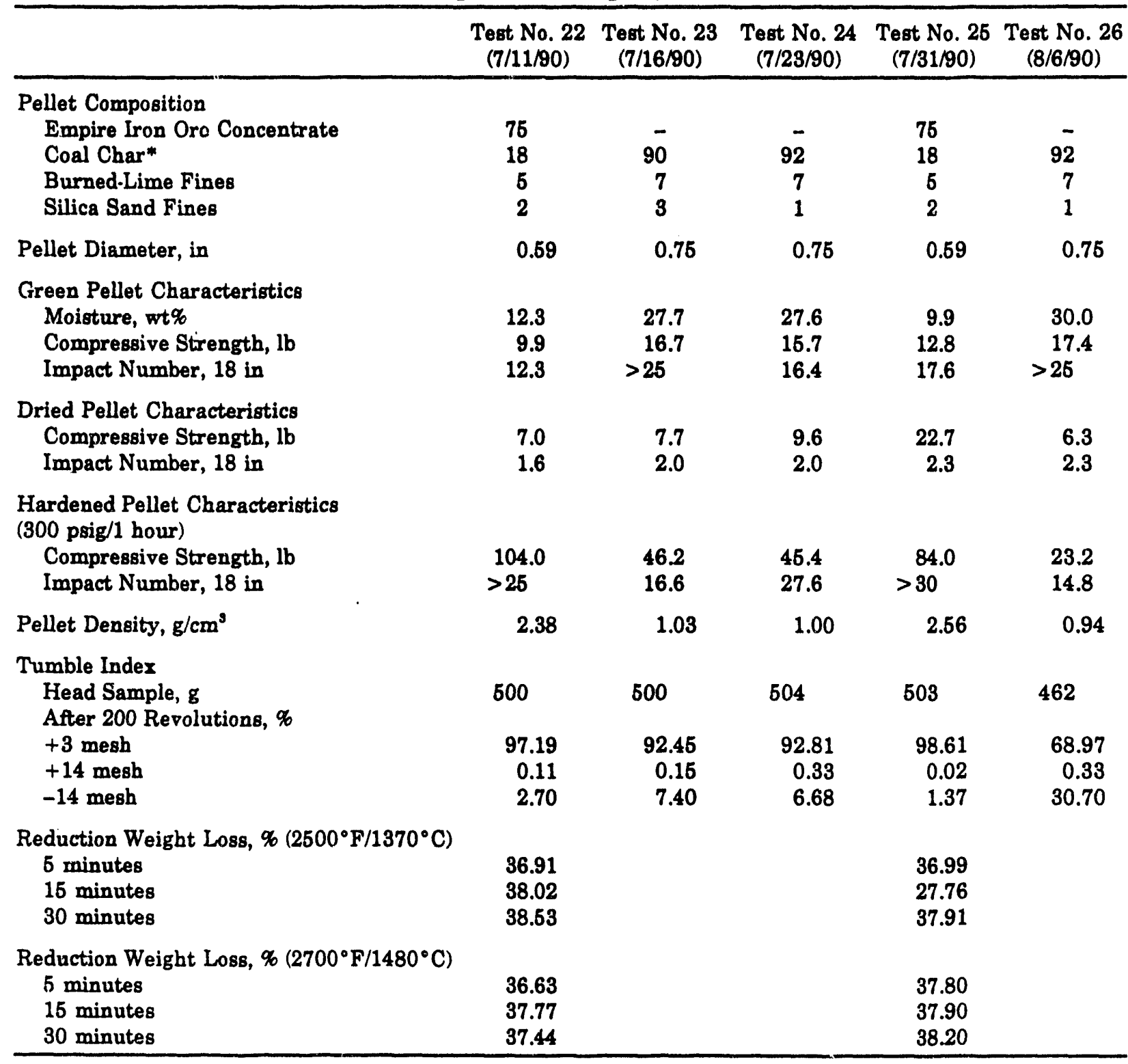

* Char No. M149-190 used for Tests 22-24. 78\% M149-190/22\% M149 tops used for Tests 25 and 26.

High-quality metallurgical coke is made from noncoking coal by using mild gasification technology as the first step to produce a low-volatile char and a pitch or tar binder. After further processing, these two intermediate products are blended and formed into briquettes, which are further processed into coke. The process is outlined in Figure 83.

The tar recovery section cools, condenses, and collects tar vapors formed during the carbonization of coal and processes the recovered raw carbonizer and kiln tar into a kinder for the briquetting operation. 
TABLE 70

Results of Pellet Technology Corporation Char Pelletizing Tests Using Indiana Char

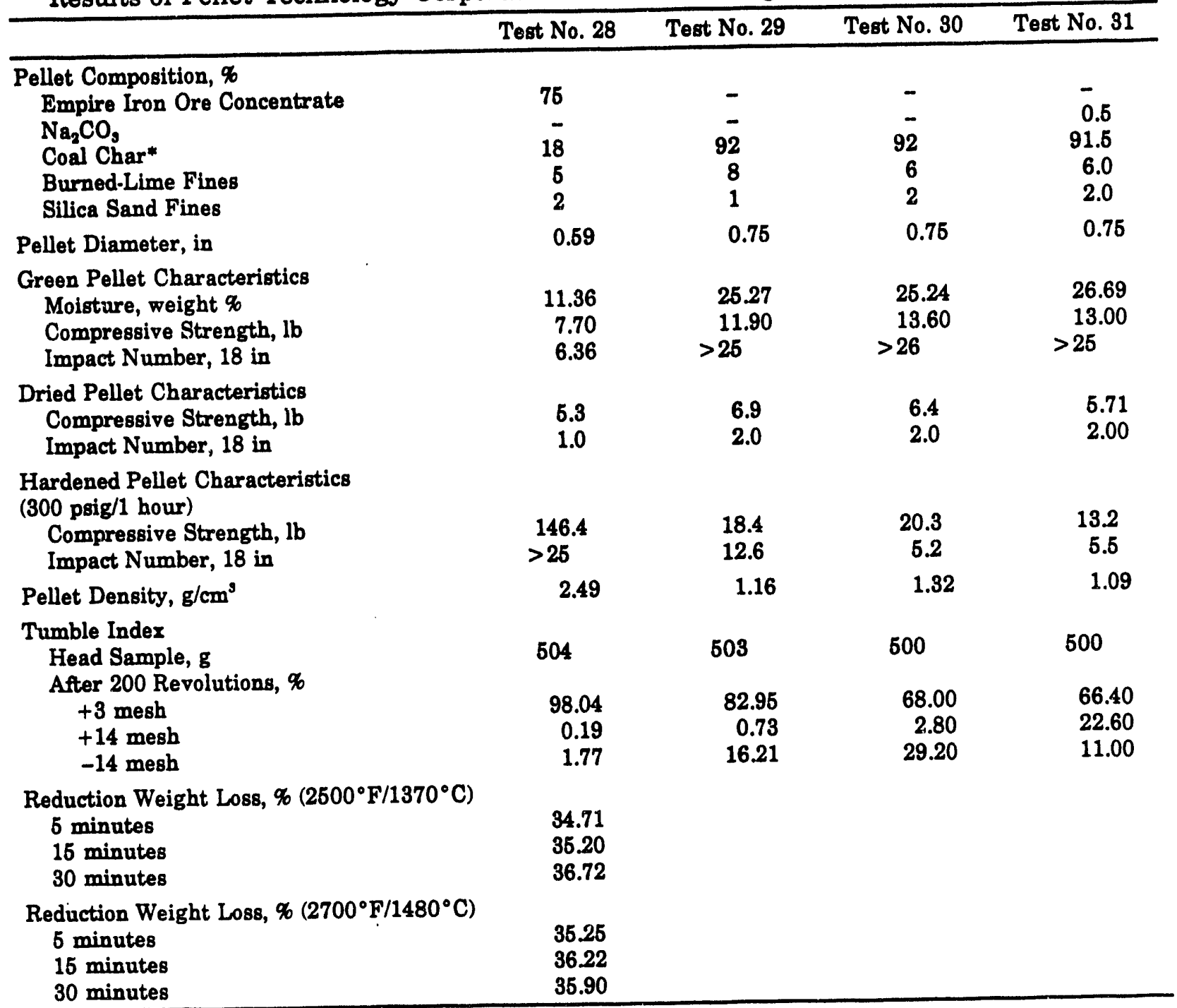

* Char No. P007 used for Test 28. Char No. P008 used for Tests 29-31.

The char and binder are mixed together and compressed to form pillow-shaped briquettes. The newly formed briquettes are "green," or uncured, and must be cured to harden them so they will hold their shape during handling and coking. The green briquettes are cured in a traveling-grate oven where a high oxygen content causes partial polymerization of the binder and results in a "cured" briquette that has approximately $50 \%$ of the final coke strength.

The final step is coking. Cured briquettes are transferred to the coking kiln, a square refractory-lined vessel about 25 feet tall. Fed into the top of the kiln through an air lock, the briquettes gradually travel down through the kiln and are discharged through a second air lock. As they travel down through the kiln, they are first heated to $1600^{\circ} \mathrm{F}\left(870^{\circ} \mathrm{C}\right)$ to complete the coking process. They are then cooled to $400^{\circ} \mathrm{F}\left(205^{\circ} \mathrm{C}\right)$ to prevent combustion when they are discharged to the outside air. 


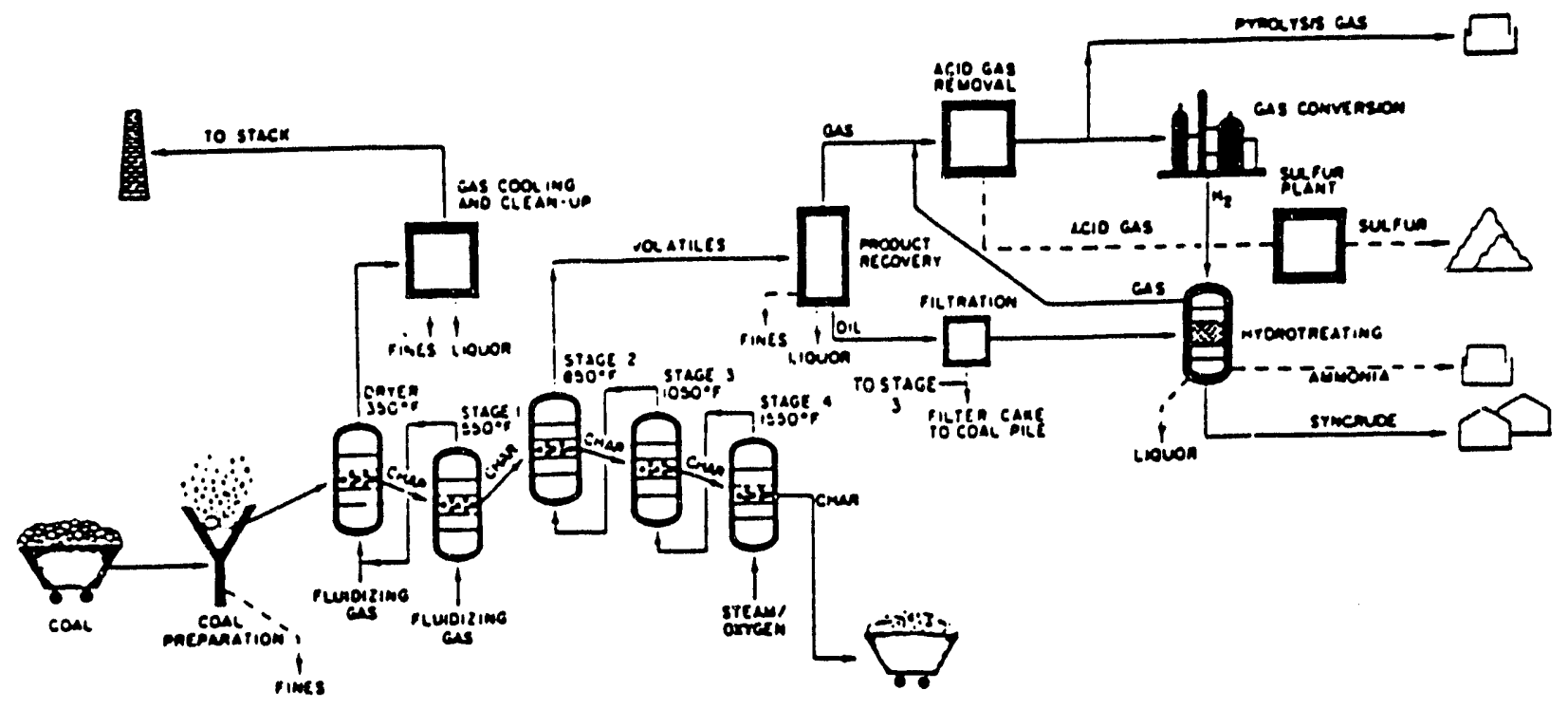

Figure 83. FMC COED process flow diagram

The process is used in FMC's elemental phosphorus plant and has been successfully demonstrated in a blast furnace to make iron.

Tests have successfully demonstrated that chars produced from the mild gasification of Wyodak subbituminous and Indiana bituminous coals can be tableted and briquetted. The range of char/binder combinations studied include those potentially suited as lowvolatile cooking and/or heating fuels or as formed coke for blast furnace fuel.

A number of binders were investigated including molasses, molasses/hydrated lime, pregelatinized and cooked corn/potato starches, petroleum asphalt emulsions, petroleum vacuum distillation resids, coal tars and coal tar pitches, liquefaction resids, polyvinyl alcohol, and acrylic and vinyl acetate-ethylene copolymers.

The development of briquette strength was investigated as a function of air-curing time, and oven-curing and coking were investigated as posttreatment techniques for increasing the strength of air-cured and green briquettes.

Strong and reactive briquettes, suitable for use in a blast furnace, were prepared from Indiana and Wyodak chars using coal-and petroleum-derived binders. At concentrations up to $15 \mathrm{wt} \%$, an EERC mild gasification tar produced formed coke with strength and durability approaching that of an FMC formcoke ${ }^{\star}$. These briquettes were also resistant to moisture absorption under simulated conditions of water soaking and showering. 
The pregelatinized and cooked potato and corn starches were determined to be the most suitable binders for producing strong, abrasion-resistant tablets/briquettes without posttreatment from Wyodak chars. At concentrations of approximately $4 \mathrm{wt} \%$, the strength and durability of briquettes made with these binders exceeded those of commercial barbecue briquettes. Exceptionally strong briquettes with almost negligible shatter and abrasion degradation were formulated using up to $7 \mathrm{wt} \%$ pregelatinized potato starch. These briquettes were made resistant to water absorption by adding up to 5 wt\% of a coal p olysis tar or petroleum distillation resid.

\subsubsection{Background}

The utilization of char produced during coal pyrolysis or mild gasification for fuel applications (blast furnace, heating, etc.) requires size reconstitution into a strong and durable agglomerate with uniform properties. Several cost-effective and widely used methods exist in the chemical and resource-based industries for size reconstitution, including briquetting, pelletizing, and extrusion. Compared to other compaction processes, briquetting with double-roll presses offers several advantages such as high material throughput, minor insensitivity to feed material variations, and relatively low energy consumption and equipment maintenance.

The achievement of coal or char cohesion to produce well-formed, strong, and durable briquettes depends on feed material properties such as composition, structure, particle-size distribution, mineral matter size and content, moisture content, hardness, and surface characteristics. Other equally important influences are the binder type, feed material mixing procedure, and briquetting processing conditions.

The selection of feed material properties, binder type, processing conditions, etc., depend on the utilization and cost of the product. Binder choice is critical to producing a cost-effective briquette with acceptable strength and durability. Additional factors influencing binder choice include benign nature and supply. The range of binders previously and currently used in coal briquetting is extensive. Common binders include molasses/hydrated lime, starch, polyvinyl alcohol, lignosulfonates, clay, asphalt (bitumen), coal tars and pitches, resins; and metal stearates. The imparted strength and durability when using any binder depend, to some degree, on the properties of the coal/char with which the binder is mixed.

\subsubsection{Experimental}

\subsubsection{Char Characterization}

The as-received Wyodak chars and Indiana coarse and fines chars were analyzed for proximate and ultimate composition, heating value, true density, and bulk density, and the results of the analyses are presented in Table 71. The particle-size distributions of the as-received coarse chars and char fines are illustrated in Figure 84.

The Wyodak chars from the EERC $100-1 \mathrm{~b} / \mathrm{hr}$ mild gasification system were produced in five tests designated P024, P025, P026, P027, and P028 during start-up prior to Indiana No. 3 tests. The bulk densities of the chars differed from test to test, sometimes significantly. This was possibly a result of differing particle-size distributions. Chars from Runs P026 and P027 had a lower bulk density than the chars from Runs P024, P025, 
TABLE 71

Wyodak and Indiana Char Analysis (as-received)

\begin{tabular}{|c|c|c|c|c|}
\hline Char Type & $\begin{array}{c}\text { Wyodak } \\
\text { Low-Density }\end{array}$ & $\begin{array}{c}\text { Wyodak } \\
\text { High-Density }\end{array}$ & $\begin{array}{c}\text { Indiana } \\
\text { Reactor Char }\end{array}$ & $\begin{array}{c}\text { Indiana } \\
\text { Cyclone } \\
\text { Char }\end{array}$ \\
\hline $\begin{array}{l}\text { Proximate, wt\% } \\
\text { Moisture } \\
\text { Volatile Matter } \\
\text { Fixed Carbon } \\
\text { Ash }\end{array}$ & $\begin{array}{r}2.10 \\
14.74 \\
66.72 \\
16.42\end{array}$ & $\begin{array}{r}3.70 \\
13.77 \\
64.13 \\
18.38\end{array}$ & $\begin{array}{r}0.60 \\
10.28 \\
60.18 \\
28.93\end{array}$ & $\begin{array}{r}0.60 \\
17.43 \\
53.96 \\
28.00\end{array}$ \\
\hline $\begin{array}{l}\text { Ultimate, wt\% } \\
\text { Hydrogen } \\
\text { Carbon } \\
\text { Nitrogen } \\
\text { Sulfur } \\
\text { Oxygen (difference) } \\
\text { Ash }\end{array}$ & $\begin{array}{r}2.55 \\
71.54 \\
1.41 \\
2.54 \\
5.53 \\
16.42\end{array}$ & $\begin{array}{r}2.28 \\
69.30 \\
1.32 \\
2.53 \\
6.18 \\
18.38\end{array}$ & $\begin{array}{c}0.98 \\
68.12 \\
1.26 \\
2.71 \\
(2.00)^{*} \\
28.93\end{array}$ & $\begin{array}{r}1.67 \\
64.99 \\
1.44 \\
2.42 \\
1.47 \\
28.00\end{array}$ \\
\hline Heating Value, Btu/b & 11,600 & 11,100 & 10,590 & 10,200 \\
\hline True Density, $\mathrm{g} / \mathrm{cm}^{\mathrm{s}}$ & 1.632 & 1.655 & 1.951 & 1.812 \\
\hline Bulk Density, $\mathrm{g} / \mathrm{cm}^{3}$ & 0.209 & 0.321 & 0.455 & 0.589 \\
\hline
\end{tabular}

* Denotes negative value.

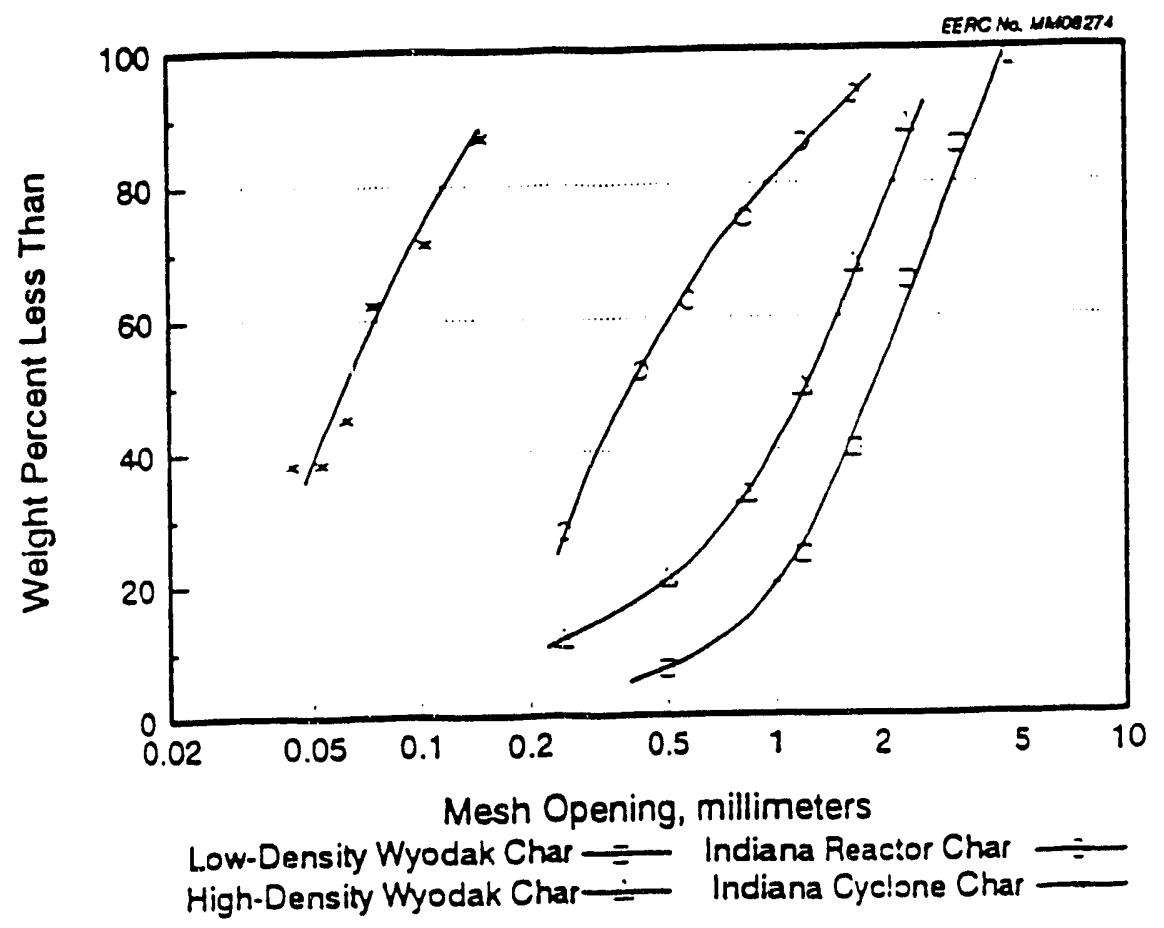

Figure 84. Low. and high-density Wyodak chars and Indiana reactor char and cyclone char. 
and P028. Bulk densities, determined from the weight of char occupying a known volume, were 0.224 and $0.204 \mathrm{~g} / \mathrm{cm}^{3}$ for Runs P026 and P027, respectively, and 0.343 , 0.320 , and $0.299 \mathrm{~g} / \mathrm{cm}^{3}$ for Runs P024, P025, and P028, respectively. To reduce the effect of variable char density (or particle-size distribution) on tablet and briquette properties, chars from Runs P026 and P027 and chars from Runs P024, P025, and P028 were combined to form two distinct composites. The former composite was thereafter called low-density char, and the latter composite was called high-density char.

Compositional variations among the low- and high-density Wyodak chars were essentially limited to slight differences in ash, carbon, and fixed carbon contents. Multivolume pycnometry indicated that the true densities of the char particles were essentially equivalent, $1.63 \mathrm{vs} .1 .66 \mathrm{~g} / \mathrm{cm}^{3}$ for low- and high-density chars. Thus the true particle density had a negligible influence on the char bulk density. Particle-size distributions, determined by dry sieve techniques, indicated that both char types were largely under 4-mesh (4.76 mm by U.S. Bureau Standards or $4.7 \mathrm{~mm}$ Tyler) top size. However, the mass mean diameters of the low- and high-density chars, $\sim 2.0$ and $\sim 1.2 \mathrm{~mm}$, respectively, were considerably different. The differences in PSDs and, possibly, differences in the shapes of the chars were presumably the cause of the different bulk densities.

The Indiana chars for tableting and briquetting were produced in a series of carbonization, cleaning, and calcination tests. The carbonized chars were produced in the $100-\mathrm{lb} / \mathrm{hr}$ PRU at $930^{\circ} \mathrm{F}\left(500^{\circ} \mathrm{C}\right)$. The carbonized chars were magnetically cleaned by AMAX to reduce the ash content. The cleaned char was then calcined in the CFBR at $1470^{\circ} \mathrm{F}\left(800^{\circ} \mathrm{C}\right)$ in a test designated M251. The products from the fluid-bed reactor of the gasification system were a coarse char withdrawn from the bed and elutriated char fines recovered by a cyclone. The coarse char and char fines were collected separately, and weights were determined for each fraction. The coarse char comprised $64.7 \mathrm{wt} \%$ of the total char product, and the balance, $35.3 \mathrm{wt} \%$, was cyclone char fines. These proportions were maintain ed during subsequent tableting and briquetting tests by mixing the coarse char with the fine char.

The Indiana coarse char and cyclone char fines differed significantly in volatile matter content, presumably because of insufficient residence time for devolatilization of the fines. The high ash contents of the coarse and fine chars was due to the dolomite $\left([\mathrm{Ca}, \mathrm{Mg}] \mathrm{CO}_{3}\right)$ which was intended to facilitate in-bed sulfur capture during calcination. Dolomite was blended with the carbonized, magnetically cleaned coal at a concrntration of $12 \mathrm{wt} \%$, but could not be separated from the calcined char. The true particle densities of the coarse char and cyclone char fines were also slightly different, quite possibly due to variations in volatile matter contents. The mass mean particle size of the coarse Indiana char, at $\sim 0.4 \mathrm{~mm}$, was significantly smaller than the low- or high-density Wyodak chars. This may be due to differences in coal friabilities during mild gasification as well as the additional processing (magnetic separation and calcination) of the Indiana char.

The top size of the cyclone char fines was approximately between 0.15 and $0.2 \mathrm{~mm}$, as indicated by the PSDs, and the mass mean particle size was between 0.05 and $0.06 \mathrm{~mm}$. 


\subsubsection{Binder Characterization}

The binders used in the production of tablets and briquettes are listed in Table 72. The binders included molasses, molasses/hydrated lime, potato and corn starches, tars and oils derived from coal liquefaction and coal pyrolysis, heavy resids from petroleum refining, emulsions formulated from petroleum asphalts, and synthetically derived polymeric materials.

The molasses, a by-product of sugarbeet processing, is a dark, highly viscous fluid at room temperaiure with a solids content of approximately $88 \mathrm{wt} \%$. The ROSE ${ }^{\oplus}$ resid, Reilly and FMC coal ta* pitches, and EERC coal tars and resids were solids at room temperature. The EERC coal tars and resids included a P028 tar scrubber tar, a P028 tar heat exchanger residue, a P027 tar cyclone residue, and a P027 tar scrubber tar distillation residue. The ROSE ${ }^{\star}$ resid, Reilly and FMC pitches, and P027 tar cyclone residue are brittle and easily broken solids. The P028 tar scrubber and P027 tar scrubber tar distillation residue are nonbrittle, somewhat pliable solids. The V1074, P028 tar heat exchanger residue, and low- and high-sulfur resids are easily deformable solids at room temperature and could be classified as extremely high-viscosity fluids. The AO4, acrylic emulsions, and asphalt emulsions are low-viscosity fluids at room temperature. The starches and VAE copolymer are dry, flake powders, whereas the PVA is a dry powder with spherically shaped particles.

In the case of the solid tars, pitches, and resids used as binders for formed coke production, a nonstandard procedure was employed for achieving their complete fluidity. The fluid points for the ROSE ${ }^{\star}$ resid, V1074, Reilly pitch, FMC pitch, P028 scrubber tar, P027 distillation resid, and low-sulfur petroleum resid were $\sim 250^{\circ}, 160^{\circ}, 330^{\circ}, 250^{\circ}$, $185^{\circ}, 160^{\circ}$, and $150^{\circ} \mathrm{F}\left(120^{\circ}, 70^{\circ}, 165^{\circ}, 120^{\circ}, 85^{\circ}, 70^{\circ}\right.$, and $\left.65^{\circ} \mathrm{C}\right)$, respectively.

The coal-derived binders which were tested for formed coke production were analyzed to determine CHN, and a carbon/hydrogen ratio was determined from these analyses. The moisture contents of the coal-derived binders and the low-sulfur petroleum resid were assumed to be negligible and did not greatly contribute to the $\mathrm{H}$ content. The asphalt emulsions were analyzed by Karl Fischer analysis to determine moisture content, and then the CHN content was normalized to a moisture-free basis. Therefore, the $\mathrm{H}$ content and $\mathrm{C} / \mathrm{H}$ ratio was based on the asphalt in the emulsion and did not include $\mathrm{H}$ contributed by the moisture. The results are presented in Table 73 on an as-determined basis for the coal-derived and petroleum resid binders and on a moisture-free basis for the asphalt emulsion binders.

\subsubsection{Tableting Procedure}

Tableting tests were performed principally to determine suitable binders for subsequent briquetting tests, to evaluate methods of char/binder blending, and to evaluate posttreatment techniques for the tablets and briquettes, such as oven-curing and coking.

Tablets were produced with a hand-operated hydraulic press, designed to prepare acrylic-mounted analytical specimens. The press is configured with a cylindrical mold and threaded closure and is capable of pressures up to $8200 \mathrm{psig}(57 \mathrm{MPa})$. The internal diameter of the mold is $1 \frac{1}{4}$ " $(31.8 \mathrm{~mm})$ with a piston displacement length of $2 \frac{1}{2} 2$ $(63.5 \mathrm{~mm})$. 


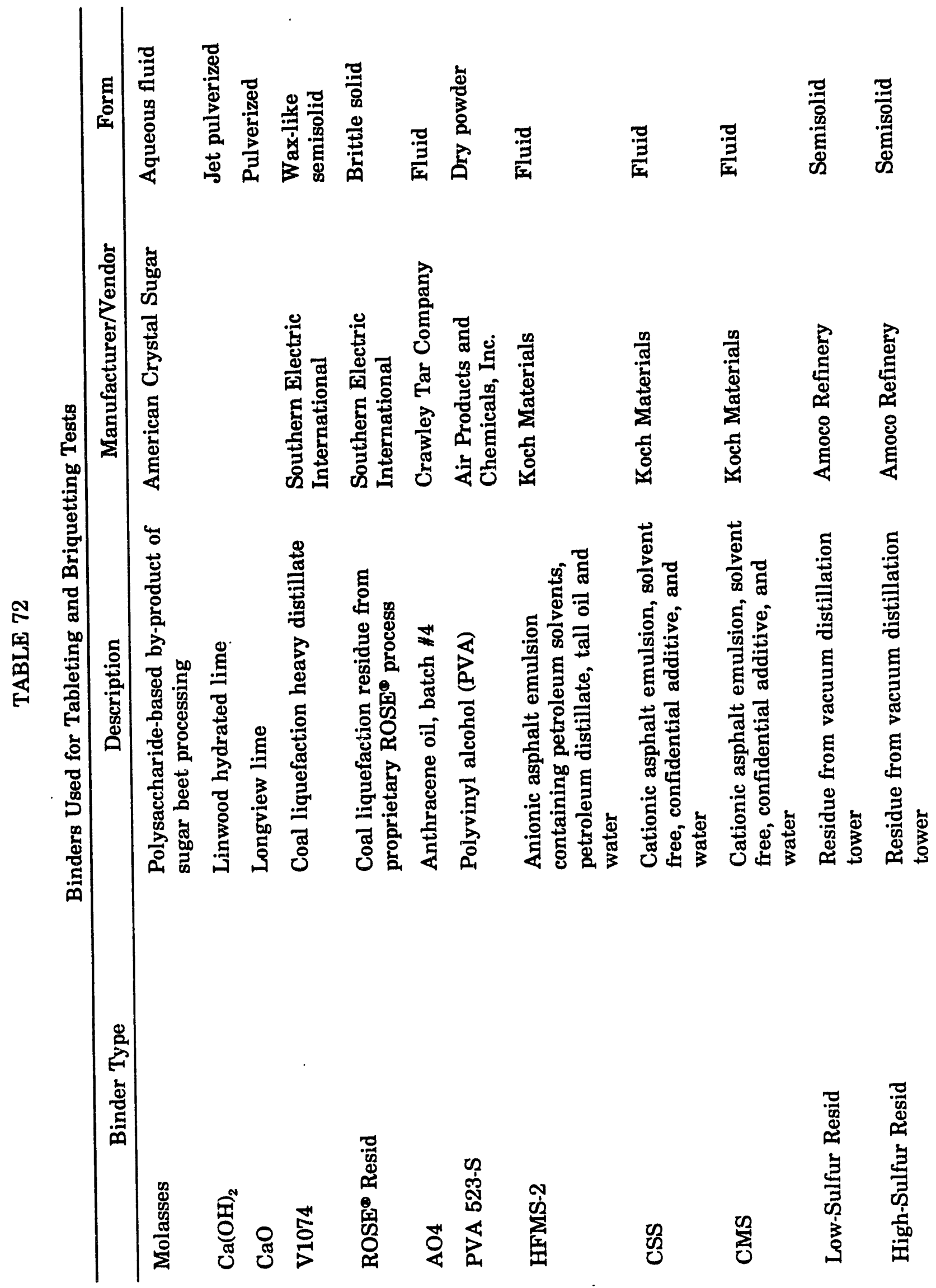




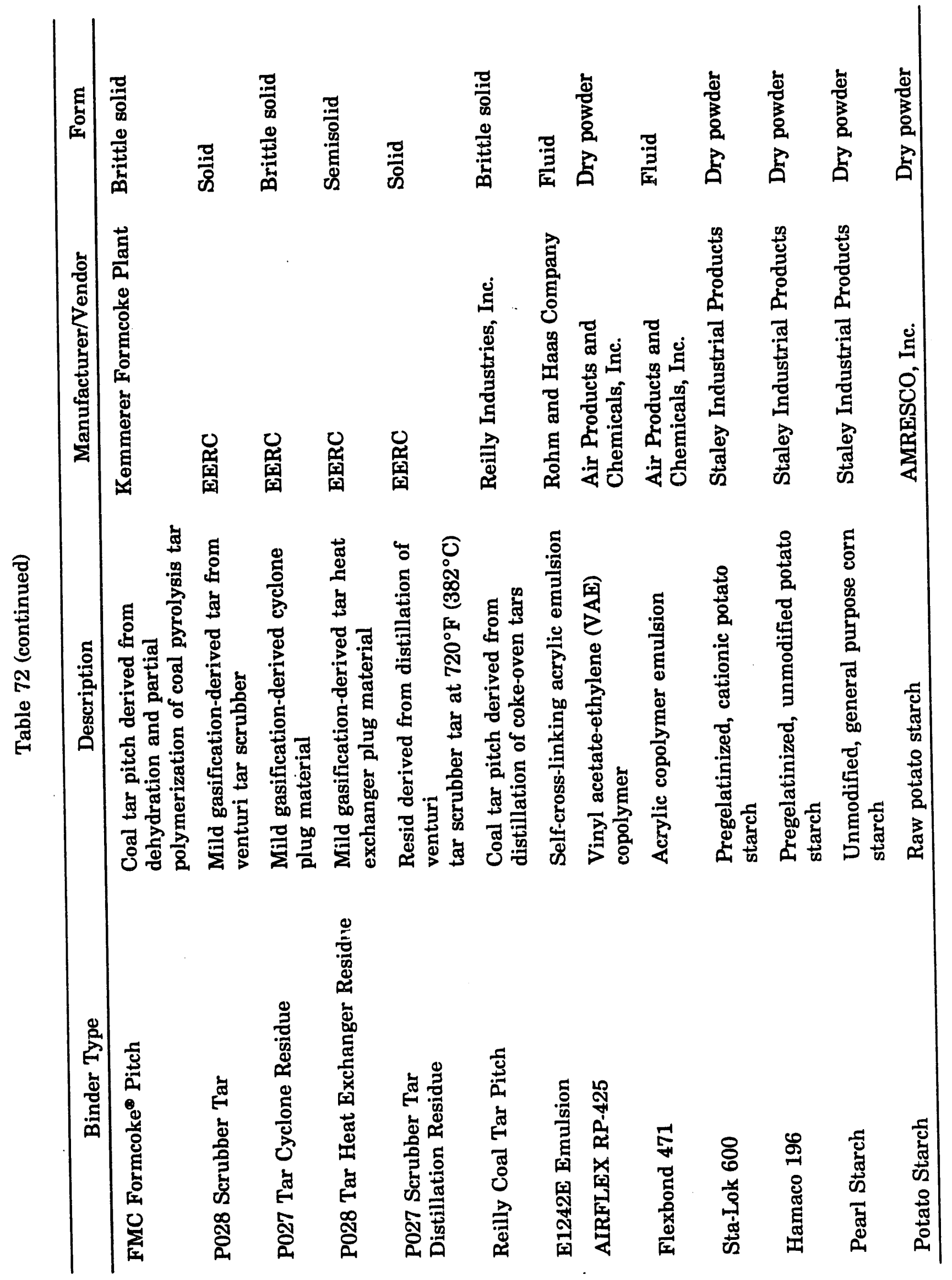


Coal- and Petroleum-Derived Binder Analyses (as-received wt\%)

\begin{tabular}{|c|c|c|c|c|}
\hline Binder & Carbon & Hydrogen & Nitrogen & $\mathrm{C} / \mathrm{H}$ \\
\hline P028 Scrubber Tar & 81.62 & 6.36 & 1.21 & 12.8 \\
\hline $\begin{array}{l}\text { P027 Scrubber Tar } \\
\text { Distillation Residue }\end{array}$ & 87.09 & 8.35 & 1.06 & 10.4 \\
\hline CSS Asphalt Emulsion ${ }^{1}$ & 86.70 & 9.87 & 1.11 & 8.78 \\
\hline HFMS-2 Asphalt Emulsion ${ }^{2}$ & 81.69 & 10.22 & 0.89 & 7.99 \\
\hline Low-Sulfur Petroleum Resid & 86.34 & 11.07 & 0.85 & 7.80 \\
\hline FMC Formcoke Pitch & 78.99 & 5.98 & 1.31 & 13.2 \\
\hline Reilly Coal Tar Pitch & 92.12 & 4.00 & 1.24 & 23.0 \\
\hline
\end{tabular}

Typically 150 to 200 grams of char/binder mixture were prepared for each tableting test, and blending the char and binder(s) was accomplished with a handheld kitchen type mixer. The binders were added as dry solids, aqueous solutions, or liquids to a premoistened or dry char. The pregelatinized starches and VAE copolymer were used as dry flakes or powders, whereas the raw or pearl starches were gelatinized in boiling water and then added as thick pastes to the char. Moistening the char was necessary when using the dry starches to aid in adhesion with the char. The petroleum asphalt emulsions, anthracene oil, and acrylic emulsions were added as fluids at room temperature to the char. Molasses was heated to approximately $105^{\circ} \mathrm{F}\left(40^{\circ} \mathrm{C}\right)$ to reduce its viscosity prior to blending with the char. The hydrated lime, when used with molasses, was added as a micronized powder to the char/molasses mixture. Polyvinyl alcohol was solubilized in hot water and then added as an aqueous solution to the char. The heavy distillates and resids were added first when used in combination with starch.

Several char preheating techniques were investigated when the coal- and petroleumderived heavy distillates and resids were blended with the chars. Preheating the char was done to prevent rapid setting or lumping of the binders. The initial technique involved indirectly heating moist char in a metal container which was partially submerged in boiling water. The char was kept moist by periodically adding boiling water, and the char temperature was maintained between $200^{\circ} \mathrm{F}\left(93^{\circ} \mathrm{C}\right)$ and $212^{\circ} \mathrm{F}$ $\left(100^{\circ} \mathrm{C}\right)$. The hot, fluid binder was then added to the hot, moist char. The second technique involved heating $\frac{d r y}{c h a r}$ in a heat-traced metal container. The char was heated to approximately $50^{\circ} \mathrm{F}\left(10^{\circ} \mathrm{C}\right)$ above the fluid point of the binder prior to adding the hot, fluid binder. The binders used in the first two techniques were heated to $50^{\circ} \mathrm{F}$ $\left(10^{\circ} \mathrm{C}\right)$ abcie their fluid points using either a heat-traced metal container or a metal container heated by a hot plate. The third technique involved comixing solid binders and 
dry char at room temperature to maximize the homogeneous dispersion of the binder. The char/binder mixture was then heated to approximately $50^{\circ} \mathrm{F}\left(10^{\circ} \mathrm{C}\right)$ above the fluid point of the binder to facilitate wetting of the char surface.

Tableting was performed either at room temperature or with the press mold preheated. The press mold could be heated to the temperature of the char/binder mixture by two electrical band heaters. The desired temperature was maintained by a controller. A preheated press was used when hot, dry char/binder mixtures were tableted.

Approximately 12 to 15 tablets were produced per test, and a press pressure of 6500 psi was used for all tableting tests. The compaction time at pressure was typically about 1 second for tablets that were to be air-cured and 3 seconds for tablets that were to be oven-cured and coked. The green tablets were either air-cured for several days prior to evaluation of integrity or were cured in an oven prior to coking.

\subsubsection{Briquetting Procedure}

Briquetting tests were performed using a Komarek-Greaves continuous double-roll press with a throughput up to $10,000 \mathrm{lb} / \mathrm{hr}(4540 \mathrm{~kg} / \mathrm{hr})$. The briquetter, with $10^{\prime \prime}$ (254-mm) diameter by 4" (102-mm) wide rolls, was configured to produce $1 \frac{14}{\prime \prime} \times 1 \frac{1}{4}$ " $\times 7 / 8$ " (32-mm $\times 32-\mathrm{mm} \times 22-\mathrm{mm})$ pillow-shaped briquettes. The system has a maximum hydraulic pressure rating of $3000 \mathrm{psi}(20.7 \mathrm{MPa})$ and variable speed control for the roll drive, vertic.l feeder and feed tank augers. It is noted that the pressure applied at the roll pockets is appreciably higher than $3000 \mathrm{psi}(20.7 \mathrm{MPa})$.

Char and binder mixtures were prepared in a procedure similar to that used during tableting tests. Typically $20-\mathrm{lb}(9.1-\mathrm{kg})$ to $30-\mathrm{lb}(13.6-\mathrm{kg})$ batches of char $/$ binder were prepared for each briquetting test. Blending the char and binders was performed using a batch, planetary change-can mixer with $\sim 30$-gallon (111-liter) capacity. Agitation was provided by a hook-type aitachment which moved in a planetary (rotational and orbital) path through the char/binder mixture. A scrapper blade was used to continuously dislodge char/binder from the bowl wall.

Two briquetting techniques were investigated: 1) briquetting moist char/binder mixtures at room temperature, and 2) briquetting hot, dry char/binder mixtures. The first technique involved wetting the char to achieve approximately 25 wt\% total moisture. Hot, fluid binders such as the petroleum resid and scrubber tar were added without prior heating of the moist char. The second technique involved adding a fluid binder to the preheated char. A steam coil, fastened to the interior of the planetary mixing bowl, was used to preheat char and to maintain temperature after addition of the binder. The binders, if necessary, were heated to $\sim 50^{\circ} \mathrm{F}\left(10^{\circ} \mathrm{C}\right)$ above their fluid points and were then added in several aliquouts to the preheated char. The char/binder mixture was continuously heated during blending to assure homogeneous wetting of the char by the binder. The rolls on the briquetter were heated with an acetylene torch to between $200^{\circ} \mathrm{F}$ $\left(93^{\circ} \mathrm{C}\right)$ and $250^{\circ} \mathrm{F}\left(121^{\circ} \mathrm{C}\right)$ to minimize cooling and binder hardening before compaction of the mixture.

The char/binder mixture was then added to the briquetter feed tank and compacted at a hydraulic pressure of $2800 \mathrm{psig}$. The roll drive was maintained at its lowest speed, $10 \mathrm{rpm}$, due to the small quantities of char/binder mixture used in each test. The vertical 
feeder was used to control the char/binder feed rate to the press rolls. The feeder motor speed was adjusted to maximize predensification without overloading and stopping the rolls. Poorly formed or unfirm green briquettes plus unbriquetted material were recycled to the feeder, as necessary, to produce sufficient quantities of good briquettes for testing.

The green briquettes were either air-cured prior to evaluation of their strength or were oven-cured for subsequent coking.

\subsubsection{Oven-Curing and Coking}

Curing green tablets and briquettes in a heated, oxygen-containing environment was investigated for developing sufficient strength in the tablets and briquettes. Ovencuring was used to reduce the curing time for starch and molasses/hydrated lime-based binders or was used to cause polymerization of coal-or petroleum-derived binders subsequent to coking. Curing was performed in an electrically heated oven which was continuously purged with a air/nitrogen stream. Briquettes made with starch and molasses $/$ ime binders were cured between $300^{\circ} \mathrm{F}\left(149^{\circ} \mathrm{C}\right)$ to $400^{\circ} \mathrm{F}\left(204^{\circ} \mathrm{C}\right)$ at an oxygen level of 10 vol\% and a total gas rate of $8 \mathrm{scth}(227$ liters $/ \mathrm{hr})$. Tablets and briquettes made with coal-and petroleum-derived binders were cured between $400^{\circ} \mathrm{F}\left(204^{\circ} \mathrm{C}\right)$ to $450^{\circ} \mathrm{F}$ $\left(232^{\circ} \mathrm{C}\right.$ ) at an oxygen level of 14 to 15 vol\% and a total gas rate of 6 to 9 scfh (170 to 255 liters/hr). The tablets and briquettes were weighed before and after curing to determine weight loss. Selected samples of the oven-cured tablets and briquettes were evaluated for strength or were coked.

Coking was investigated as a method to 1 ) reduce char volatile matter content, 2) reduce the binder into a carbon or a coke "skeleton," and 3) develop additional aggregate strength. Tablets and briquettes were typically coked in an electric tube furnace equipped with a high-temperature Vycor tube. The tablets and briquettes were coked between $1500^{\circ} \mathrm{F}\left(816^{\circ} \mathrm{C}\right)$ to $1600^{\circ} \mathrm{F}\left(871^{\circ} \mathrm{C}\right)$ for 20 to 30 minutes at a nitrogen flow rate of 1.5 to 3 $\mathrm{scfh}$ (42 to 85 liters/hr). The inert gas purge functioned to prevent undesired combustion and to sweep the volatiles (tar/oil) and noncondensable gases from the furnace tube.

A single coking test was performed in which the CFBR was operated in a batch mode. This system was intended to simulate the operation of a vertical retort coking system.

Tablets and briquettes were weighed before and after coking to determine weight loss. Coked tablets and briquettes were evaluated for strength and stability. Select samples were analyzed for proximate and ultimate composition as well as reactivity towards $\mathrm{CO}_{2}$ (as measured by rate of mass loss).

\subsubsection{Strength and Stability Testing}

Strength and stability tests were performed on briquettes nominally 4 and 7 days after air-curing or 1 day after oven-curing or coking. The strength tests included drop and tumble resistance and compressive load resistance, and the stability tests included resistance to moisture reabsorption during soaking and spraying.

The drop test measured the impact or shatter resistance of 24 to 30 briquettes dropped from a height of 6 feet onto a concrete floor. The weight percentage of material 
passing a 4-mesh (0.187") opening was then determined, and the drop testing was repeated nine more times on the plus 4-mesh material, the final cumulative weight being determined.

The tumble test measured the abrasion resistance of approximately 200 grams of briquettes tumbled at $40 \mathrm{rpm}$ in a $77 / 8$ " $(200-\mathrm{mm})$ diameter cylindrical vessel. The briquettes were tumbled for 200,500 , and 1000 revolutions in between which the material was screened to determine the weight percentage passing a 4-mesh (0.187") opening.

The compressive strength test determined the force load required to cause complete failure on a plane passing vertically through the briquette. The force is normalized to a pressure in $\mathrm{lb} / \mathrm{in}^{2}$ based on the cross-sectional area of the failure plane. The crosssectional area of the tablets was variable, depending on the thickness. Twelve briquettes were tested, the high and low values rejected, and an average was determined from the ten remaining values.

The soak and spray tests determined the resistance toward water absorption and the effect on briquette strength. Seven to thirteen briquettes were immersed in water for thirty minutes, and the condition of the briquettes was noted at intervals of 10 minutes. Compressive testing was performed on six to twelve briquettes, and the remaining briquette was submitted for moisture analysis. In the spray test, seven to thirteen briquettes were placed under a $2 \mathrm{~g} / \mathrm{hr}(7.3 \mathrm{liter} / \mathrm{hr})$ shower for 1 hour during which the condition of the briquettes were periodically noted. The briquettes were allowed to air-dry for two hours and then sprayed for fifteen more minutes. Compressive testing was performed on six to twelve of the briquettes, and the remaining briquettes were submitted for moisture analysis.

Tablet density was determined from the measured mass and the volume calculated from the tablet diameter and thickness. Briquette density was determined from the measured mass and volume determined by displacement in a graduated cylinder filled with water. A representative mass and volume for each briquette type were determined from an average of 10 to 12 well-formed briquettes.

The reactivity of coked briquettes was determined by measuring weight loss as a function of time during reaction under an atmosphere of $100 \% \mathrm{CO}_{2}$. The briquette was crushed to $<60$ mesh and approximately $50 \mathrm{mg}$ of $-60 . \times 100$-mesh sample was heated in a thermogravimetric analyzer at $10^{\circ} \mathrm{C} / \mathrm{min}$ under an inert atmosphere. At $1650^{\circ} \mathrm{F}\left(900^{\circ} \mathrm{C}\right)$, the inert flow was suspended, and $100 \mathrm{~cm} / \mathrm{min}$ of $\mathrm{CO}_{2}$ was initiated. The weight loss via the Boudouard reaction, $\mathrm{C}+\mathrm{CO}_{2} \rightleftharpoons 2 \mathrm{CO}$, was measured over time until the weight loss was negligible. The reaction order and reactivity were determined by fitting the appropriate kinetics equations to the curves of fixed carbon remaining versus time. Gas samples were also taken during the weight loss period to check for the presence of oxygen (air) which would cause erroneous weight loss due to combustion.

\subsubsection{Results}

\subsubsection{Tableting Formulation}

The conditions are presented in Table 74 for the 57 tableting formulation tests performed with the Wyodak and Indiana chars. The majority, 53 of 57 , were performed 


\section{TABLE 74}

Wyodak and Indiana Char Tableting Tests

\begin{tabular}{|c|c|c|}
\hline Test \# & Char/Binder Type(s) & $\begin{array}{l}\text { Binder Concentration } \\
\text { (wt\%) }\end{array}$ \\
\hline \multicolumn{3}{|c|}{ Coarse, High-Density Wyodak Char } \\
\hline $1,2,3$ & Molasses/hydrated lime (2/1) & $12,9,6$ \\
\hline $4,5,6$ & V1074 & $10,7,4$ \\
\hline $\begin{array}{l}7 \\
8\end{array}$ & ROSE・ Resid & 12 \\
\hline $\begin{array}{l}8 \\
9\end{array}$ & $\begin{array}{l}\text { AO4 } \\
\text { Hydrated lime/523-S PVA (2.4/1) }\end{array}$ & $\begin{array}{l}12 \\
3.4\end{array}$ \\
\hline & & \\
\hline 11 & 523-S PVA/Sta-Lok 600 (0.5/6.5) & 7.0 \\
\hline 12 & $\begin{array}{l}\text { HFMS-2 } \\
\text { CMS }\end{array}$ & 10 \\
\hline 13 & $\begin{array}{l}\text { CMS } \\
\text { CSS }\end{array}$ & 10 \\
\hline 14 & $\begin{array}{l}\text { CSS } \\
\text { P028 Heat Exchanger Residue }\end{array}$ & 10 \\
\hline & P028 Heat Exchanger Residue & 10 \\
\hline $\begin{array}{l}15 \\
16\end{array}$ & P028 Tar Scrubber Tar & 10 \\
\hline 17 & $\begin{array}{l}\text { P027 Tar Cyclone Residue } \\
\text { FMC Formcoke }{ }^{\bullet} \text { Pitch }\end{array}$ & 10 \\
\hline 18 & $\begin{array}{l}\text { FMC Formcoke }{ }^{\bullet} \text { Pitch } \\
\text { High-Sulfur Petroleum Resid }\end{array}$ & 10 \\
\hline 19 & $\begin{array}{l}\text { High-Sulfur Petroleum Resid } \\
\text { Low-Sulfur Petroleum Resid }\end{array}$ & $\begin{array}{l}10 \\
10\end{array}$ \\
\hline & Low-Sulfur Petroleum Resid & \\
\hline $21,22,23$ & Raw Potato Starch & 10 \\
\hline $\begin{array}{l}21,22,20 \\
24\end{array}$ & E1242E Emulsion & $12,9,6$ \\
\hline 25 & Raw Potato Starch/Molasses (1/1) & 10 \\
\hline 26 & Sta-Lok 600 & 10 \\
\hline & Molasses & 10 \\
\hline 27 & Hamaco 196 & 10 \\
\hline 28 & Sta-Lok 600/Molasses (1/1) & 10 \\
\hline 29 & Airflex RP425/Hamaco 196 (1/1) & 10 \\
\hline $\begin{array}{l}30,31,32 \\
33,34,35\end{array}$ & Sta-Lok 600/P028 Scrubber Tar (1/1) & $10,7,4$ \\
\hline \multirow{6}{*}{$\begin{array}{c}36,37,38 \\
39,40,41 \\
42,43 \\
44,45,46\end{array}$} & Hamaco 196/P028 Scrubber Tar (1/1) & $10,7,4$ \\
\hline & Cooked Pearl Starch & $10,7,4$ \\
\hline & Cooked Potato Starch & $10,7,4$ \\
\hline & PVA 523-S/Lime (1.0/2.5) & $3.5,7.0$ \\
\hline & FLEXBOND 471 & $2,4,6$ \\
\hline & \multicolumn{2}{|l|}{ Crushed High.Density Wyodak Char } \\
\hline 47 & Reilly Coal Tar Pitch & 15 \\
\hline 48 & FMC Formcoke ${ }^{\circ}$ Pitch & 15 \\
\hline 49 & P028 Tar Scrubber Tar & 15 \\
\hline 50 & HFMS-2 Asphalt Emulsion & 21 \\
\hline 51 & Low-Sulfur Petroleum Resid & 16 \\
\hline 52 & P028 Tar Scrubber Tar & 16 \\
\hline \multirow[t]{2}{*}{53} & FMC Formcoke ${ }^{\bullet}$ Pitch & 16 \\
\hline & Crushed Indiana Char & \\
\hline 54 & P028 Tar Scrubber Tar & 15 \\
\hline 55 & FMC Formcoke ${ }^{\bullet}$ Pitch & 15 \\
\hline 56 & Low-Sulfur Petroleum Resid & 15 \\
\hline 57 & P027 Scrubber Tar Distillation Resid & 15 \\
\hline
\end{tabular}


with Wyodak char; the first 46 with coarse, high.density char and the last seven with crushed high-density char. The four In. iana char tablet tests used a blend of crushed coarse char (64.7 wt\%) and cyclone char fines (35.3 wt\%). The tableting tests presented in Table 74 are arranged from the earliest to the latest.

The overall aim of the tableting tests was the development of char/binder blending procedures, tableting procedures, and curing procedures as a function of binder type and tablet end use. The first 46 tableting tests with coarse Wyodak char investigated moistchar/binder blending procedures and air-curing for producing strong tablets. The final seven tableting tests with crushed Wyodak char and the four Indiana char tableting tests investigated hot char/binder blending techniques and oven-curing and coking for producing strong tablets.

The small quantities of char used in the final seven Wyodak char and four Indiana char tableting tests necessitated the use of a nonstandard method for reducing the size of the coarse char. The coarse chars were placed in sealed bags to prevent fugitive dust emissions and then crushed using a rubber mallet. Samples of the crushed chars were saved, and the particle-size distributions are presented in Figure 85. The particle-size distribution for the Indiana char does not include the cyclone char fines.

\subsection{Evaluation of Green Tablets}

All green tablets produced with Wyodak and Indiana chars were well formed with sharp edges, and the char size (coarse vs. ground) did not appear to affect green tablet formation. The condition of the char/binder mixture, moist vs. dry or room temperature vs. hot, did not affect the appearance of the tablets. Tablet formation with a moist char

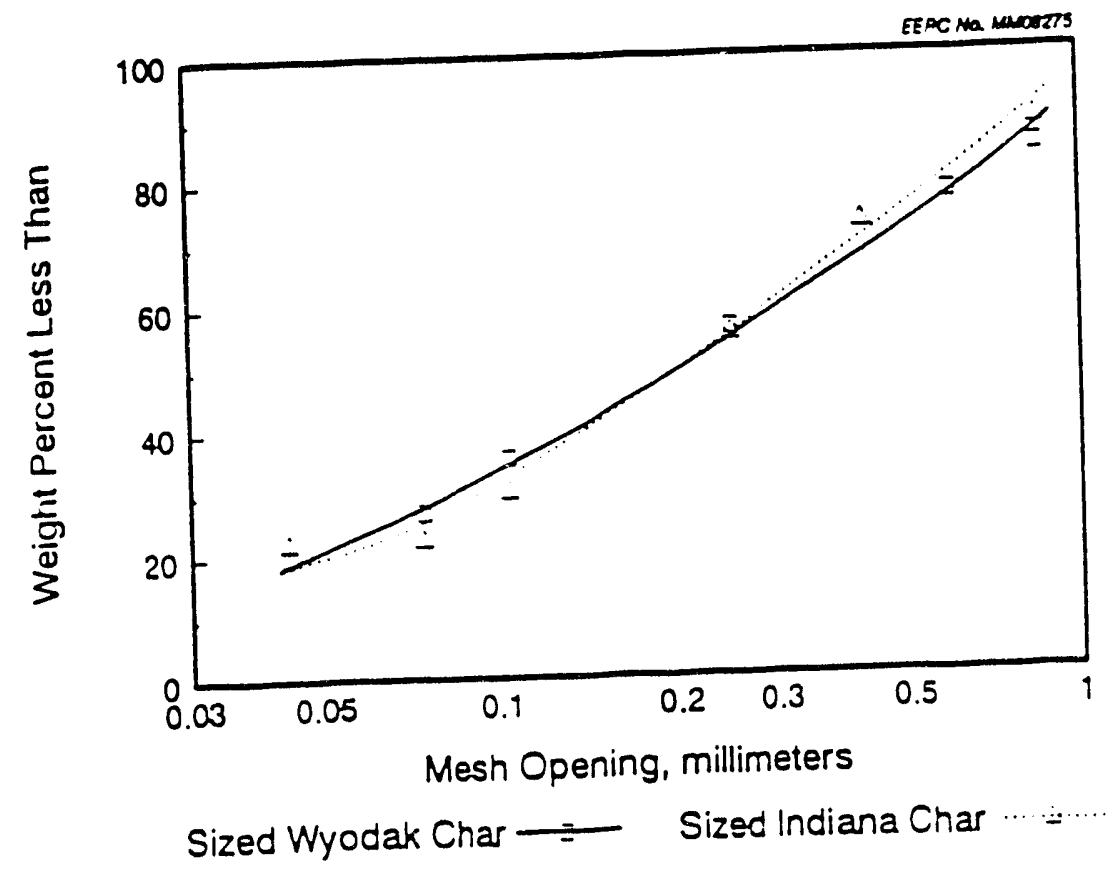

Figure 85. Wyodak and Indiana chars sized for tableting. 
was determined to work ideally when the moisture content was between 25 to 27 wt\% based on the total char/binder/water mixture. Although a moistened char was necessary to initiate bonding when using dry starches, for example, the water was hypothesized to function as an adhesive to maintain green tablet integrity until the binder had set or cured. Water is a well-known binder for various powders.

Strength testing was not performed on the green tablets, but a qualitative evaluation was performed by applying slight finger pressure to the top surface of each tablet type. All green tablets produced in the last sever Wyodak char tests and all four Indiana char tests were exceptionally firm, as were ta.blets made with the starches, molasses, molasses/hydrated lime, acrylic copolymers, asphalt emulsions, P028 scrubber tar, petroleum resids and combinations of starch, PVA, VAE, and P028 scrubber tar. The V0174, ROSE ${ }^{\oplus}$ resid, AO4, $\mathrm{P} 028$ heat exchanger residue, $\mathrm{P} 027$ tar cyclone residue, and FMC pitch binders appeared to be less than ideal candidates for blending with a moist char, as tablets made with these coal-derived binders suffered varying degrees of decrepitation. Examination of these tablets, however, did not reveal ariy distinct lumps of binder which would be indicative of poor char/binder blending.

\subsection{Evaluation of Air-Cured Tablets}

The green tablets produced in the first 46 tests with coarse Wyodak char were allowed to air-cure (air-dry) within the test laboratory at prevailing conditions of temperature and humidity. The tablets suffered varying degrees of decrepitation (material loss) and dustiness during air-curing, handling and storage. Material loss and dustiness were generally characteristics of the green tablets which tended to decreptitate under slight finger pressure. Also, the P028 scrubber tar tablets and low- and high-sulfur petroleum resid tablets experienced relatively minor dustiness and material loss. All other tablet types were dust free and retained their sharp edges after air-curing. Aircured tablets were also qualitatively evaluated to determine the extent of strength development or binder setting by performing limited drop-shatter testing. Approximately four of each tablet type were dropped $6 \mathrm{ft}(183 \mathrm{~cm})$ onto a concrete floor to determine the extent of breakage, with tablets graded on a pass/fail basis. Tablets which either remained whole or only fractured in half were considered acceptable, and those which fractured in many pieces or disintegrated into tine char were rejected. The tablet types which were considered acceptable are listed in the upper half of Table 75, and the unacceptable tablet types are listed in the lower half. Further distinctions were made among the acceptable tablets to reflect the relative degree of hardness as indicated by the sound the tablets made when impacting the concrete floor. The hardest tablets sounded similar to a piece of wood and tended to bounce off the floor, while the least hard tablets made a duller sound and tended not to bounce. Some tablets were intermediate in hardness and bounce. The degree of bounce is probably related to the rigidity between the char and binder where the more rigidly bound material cannot absorb the impact energy; consequently, the energy is released by bouncing.

Compressive strength testing was also performed on the air-cured tablets produced in the first 46 tests, and the results are presented in Table 75. Average compressive strengths were determined based on four tablets without rejecting low or high values. The trend of compressive strengths tended to agree generally well with the grouping of tablets by drop-shatter results, and the compressive strengths tended to be higher for the hardest sounding tablets. The results indicate that the pregelatinized and cooked starches 


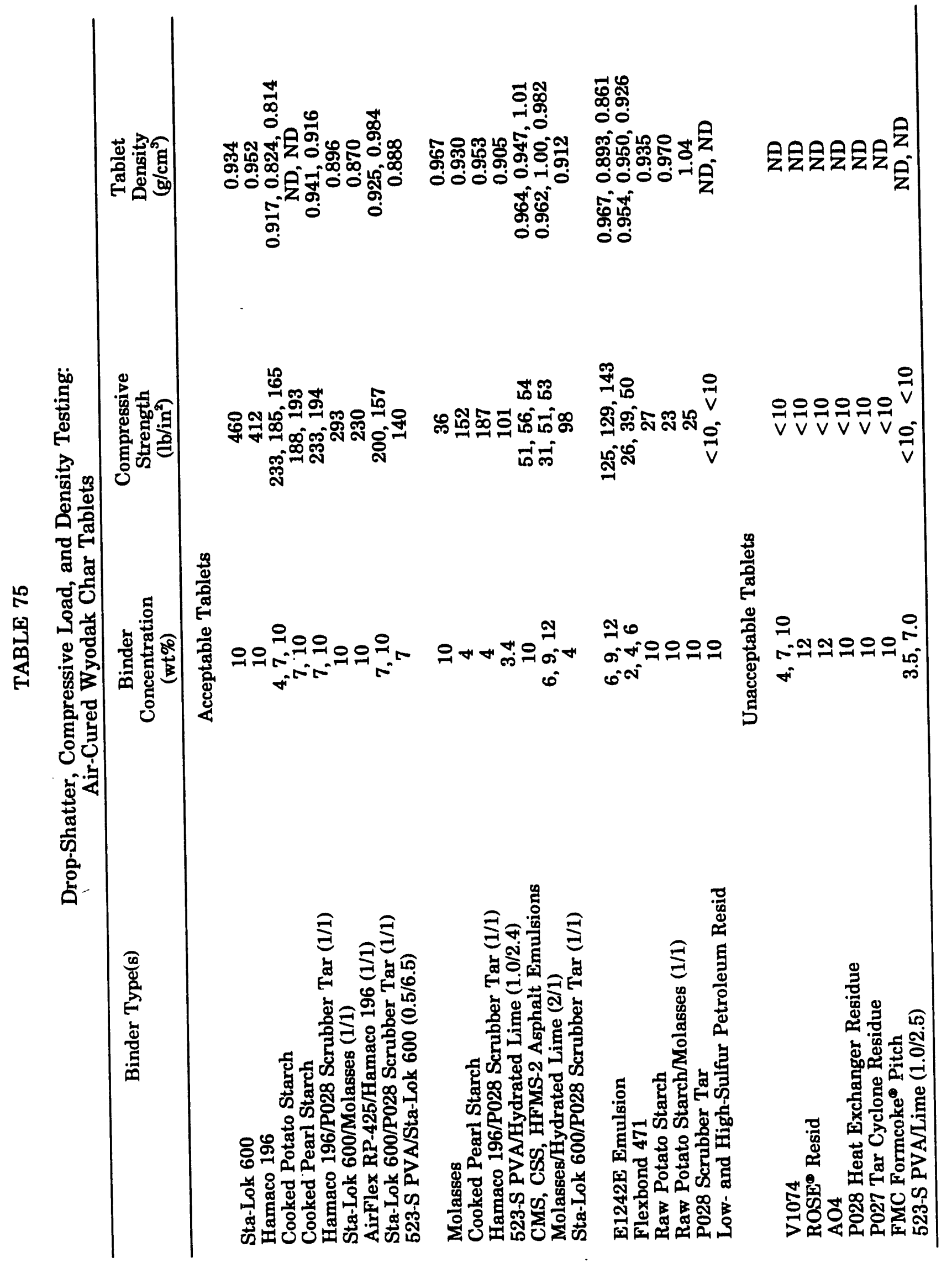


are superior to the acrylic copolymers, VAE copolymer, molasses/hydrated lime, raw starches, asphalt emulsions, P028 scrubber tar, and petroleum resids at comparable concentrations. The PVA/hydrated lime blend may be suitable at higher concentrations as the compressive strength was significant reiative to the low concentration evaluated during tableting.

The air-cured tablet densities, presented in Table 75 for each test, ranged from 0.81 to $1.01 \mathrm{~g} / \mathrm{cm}^{3}$ and typically between 0.90 and $1.01 \mathrm{~g} / \mathrm{cm}^{3}$. Based on a bulk char density of 0.321 and a maximum density of $1.66 \mathrm{~g} / \mathrm{cm}^{3}$ (true particle density), the air-cured tablet densities were approximately $43 \%$ to $50 \%$ of the maximum achievable density. The effect of tablet density on compressive strength or hardness is not clear from the data; presumably it may be expected that denser tablets would have higher compressive strength. This relationship, however, is confounded by the different binder properties such as density and the degree of strength development during air-curing. Comparison of tablets made with the same binder but at different concentrations shows that in some instances a higher density (greater compaction) may more than compensate for lower concentration. This result is seen for instance with the cooked potato starch, Hamaco 196/P028 scrubber tar, and E1242E emulsion tablets. With other binders, however, this comparison does not hold; consequently, the relationship between density and strength should be investigated further.

\subsection{Evaluation of Oven-Cured and Coked Tablets}

The green tablets produced in the last seven Wyodak char and all four Indiana char tablet tests were oven-cured, and selected samples were then coked. Oven-curing and coking were also performed on samples of previously air-cured tablets, including those made with $10 \%$ V1074, $12 \%$ ROSE $^{\circ}$ resid, $12 \%$ A04, $10 \%$ HFMS, $10 \%$ CMS, $10 \%$ CSS, and $10 \%$ molasses (Tests $4,7,8,11-13$, and 26). Compressive testing was performed on the oven-cured and coked tablets, and these results plus tablet densities are presented in Table 76. The compressive strengths of the air-cured tablets, shown in parentheses, are included for comparison. The results indicate that oven-curing produced a significant increase in tablet strength. The extent of strength development during oven-curing compared to air-curing is most easily distinguished in the tablets produced with the coarse Wyodak char (see Table 75). The strengths for tablets prepared with the asphalt emulsions ranged from only 51 to $56 \mathrm{psi}$ (352 to $386 \mathrm{KPa})$ after air-curing, whereas ovencuring increased the strengths to between 261 to $553 \mathrm{psi}$ (1800 to $3810 \mathrm{KPa}$ ). Oven curing also caused a significant increase in the strength of the $10 \%$ V1074 tablets, although oven-curing was minimally effective with the $12 \% \mathrm{ROSE}^{\otimes}$ resid and completely ineffective with the $12 \% \mathrm{AO} 4$ and $10 \%$ molasses. The effect of air-curing on strength development was not investigated for tablets made with the ground Wyodak and Indiana chars. These tests were designed for formed coke production, and the initial tests indicated that aircuring was ineffectual when using coal- and petroleum-derived binders.

The results of coking indicated that the type of char may affect the strength during the coking process. Coking the oven-cured Wyodak char tablets generally resulted in a decrease in tablet strength regardless of char size (coarse vs. ground). A significant increase in strength was observed when using the low-sulfur petroleum resid although the coked tablet strength was inferior to that of tablets made with an equivalent concentration of coal-derived binder. A different phenomenon was observed with the ground Indiana char where the strength increased significantly due to coking. The 


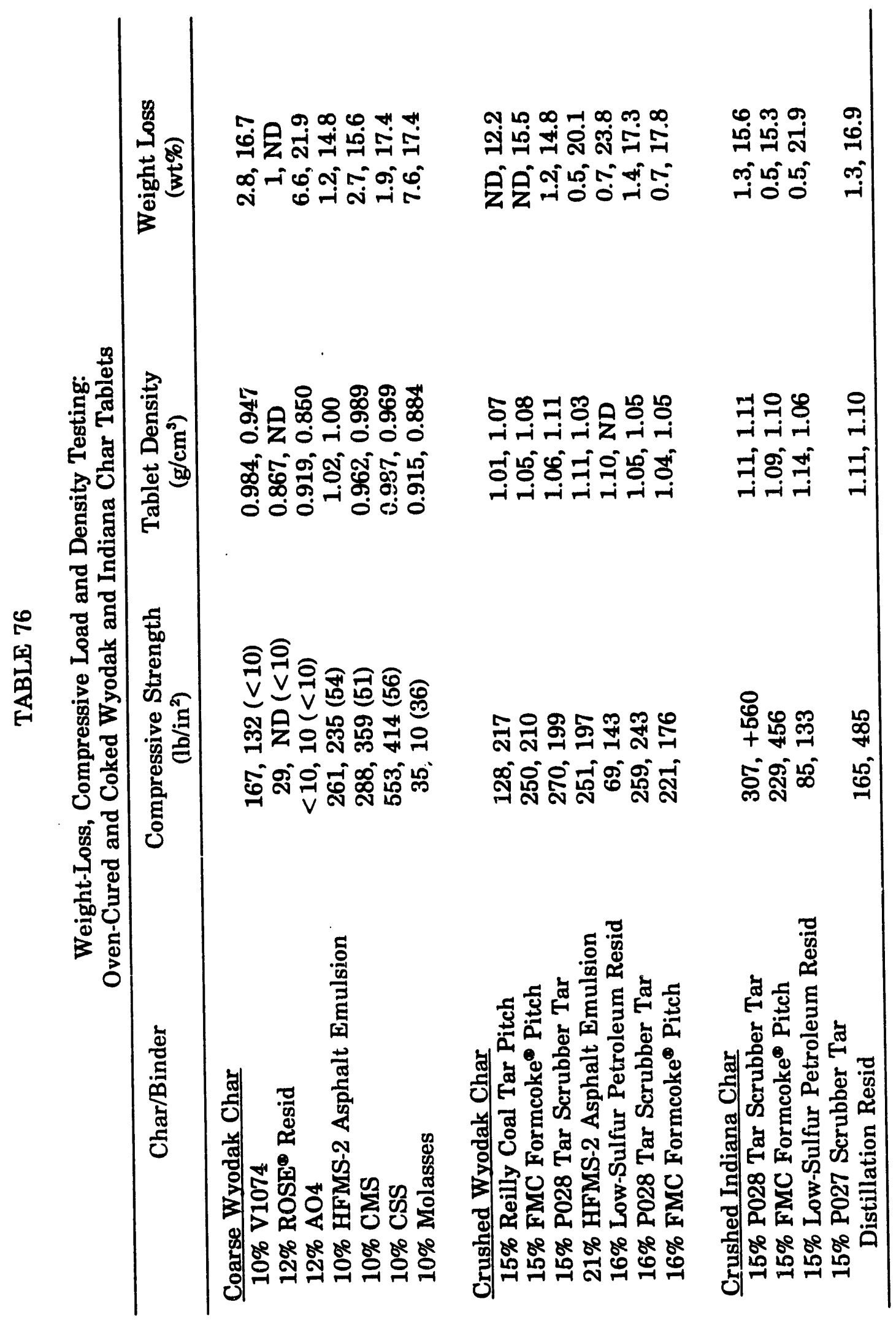


strength of coked Indiana char tablets was approximately twine that of the coked Wyodak char tablets made from equivalent concentrations of coal-derived binders. The increase in strength with the Indiana char may be due to its higher caking nature compared to the Wyodak char. No explanation is offered for the decrease in strength due to coking Wyodak char tablets.

Among the coal-derived binders and the low-sulfur petroleum resid, the former class of binders appears to be more suitable for formed coke production. Also, the coal tars produced at the EERC, namely, the P028 scrubber tar and P027 scrubber tar distillation resid, are at least equivalent to the FMC and Reilly coal tar pitches based on the limited number of tests.

The results of oven-curing and coking indicate that the two methods of binder addition were roughly equivalent hased on the limited amount of testing. Tests 48 and 49 with the ground Wyodak char and FMC pitch and P028 scrubber tar were performed by adding solid binder to a cold char after which the char/binder was heated to cause wetting of the char by the binder. Although probably impractical from a economic and technical standpoint, this method was intended to assure homogeneous blending of the char and binder. Tests 52 and 53 with ground Wyodak char and the same two binders were performed by adding hot, fluid binder to a hot char. The similarity in compressive strengths, for all practical purposes, indicates nearly equivalent distribution of the binder.

The weight loss during oven-curing and coking was also determined for each tablet test, and the results are shown in Table 76. The mass loss during oven-curing was relatively minor for tablets made with the mild gasification-derived tars, the Reilly and FMC pitch, low-sulfur petroleum resid, and the petroleum asphalt emulsions. The constituents removed during oven-curing were not collected or analyzed, but may be comprised of water and light, binder-derived fractions. The tablets made with the mild gasification-derived tars had a slightly higher mass loss compared to those made with the FMC and Reilly pitches, the low-sulfur petroleum resid, and the petroleum asphalt emulsion. The mass loss during coking appeared to depend upon the type of binder. The tablets made with the coal-derived tars and pitches had the lowest mass loss, typically ranging from 15 to $17 \mathrm{wt} \%$ when $15 \mathrm{wt} \%$ binder was used. Increasing the binder concentration in the last two ground Wyodak char tests (52 and 53) had the effect of increasing the coking mass loss by up to $1 \mathrm{wt} \%$. The highest mass loss occurred with the petroleum-derived low-sulfur resid and asphalt emulsion binders, presumably as a result of higher volatile matter content and fewer coke-forming species. Conversely, the lower mass loss with the Reilly coal tar pitch may be due to a lower volatile matter content and more coke-forming species.

The densities of the oven-cured and coked tablets were determined, and the results are presented in Table 76. The tablet densities appear to be fairly consistent and appear to be slightly higher for those made with the petroleum-derived binders and Indiana char. The latter effect is a result of the higher particle density of the Indiana char compared to that of the Wyodak char. Based on the limited testing, the effect of oven-curing and coking on tablet density appears to be variable in magnitude and effect (i.e., increase/decrease). Oven-curing the tablets made with asphalt emulsion tablets and coarse Wyodak char produces negligible effect with the HFMS-2 and CMS emulsions and about a $5 \%$ increase in density with the CSS tablets. Similarly, the change in tablet density during coking ranged from $+6.0 \%$ (increase) to $-7.2 \%$ (decrease) with no distinct trend with binder type. 


\subsubsection{Briquetting Formulation}

The briquetting formulation tests and results, including binder type/concentration, are presented in Table 77 for Wyodak and Indiana char briquettes. The tests are presented in chronological order. The majority of the tests were conducted with binders or binder combinations found to be suitable during tablet testing. The binders included molasses/hydrated lime, pregelatinized and cooked starches, combinations of the pregelatinized and cooked starches with mild gasification tars and petroleum resids, petroieum asphalt emulsions, molasses/starch, PVA/starch, PVAlime, PVA/hydrated lime, and mild gasification tars.

The first 30 briquetting tests were performed with low- and high-density Wyodak chars whose particle-size distributions are shown in Figure 84. Similar to the tableting tests, the first 30 tests used a moist char/binder blending technique followed by green briquette air-curing to develop strength. The last six briquetting tests, performed with crushed Wyodak and Indiana chars, investigated hot char/binder blending and ovencuring/coking to develop strong briquettes. The four tests with the Indiana char used a blend of $\sim 64.7$ wt $\%$ crushed reactor char and $\sim 35.3 w t \%$ cyclone char fines, and the two Wyodak tests used crushed low-density char. The particle-size distributions of the crushed chars, comminuted using a hammer mill, are presented in Figure 86. The particle-size distribution of the Indiana char does not include the cyclone char fines.

Briquettes were evaluated for strength; stability during water soaking and spraying; proximate, ultimate, and heating value analysis; and reactivity with $\mathrm{CO}_{2}$. Strength evaluations were also performed on FMC formcoke ${ }^{\star}$ and a commercial barbecue briquette for comparison to briquettes made at the EERC.

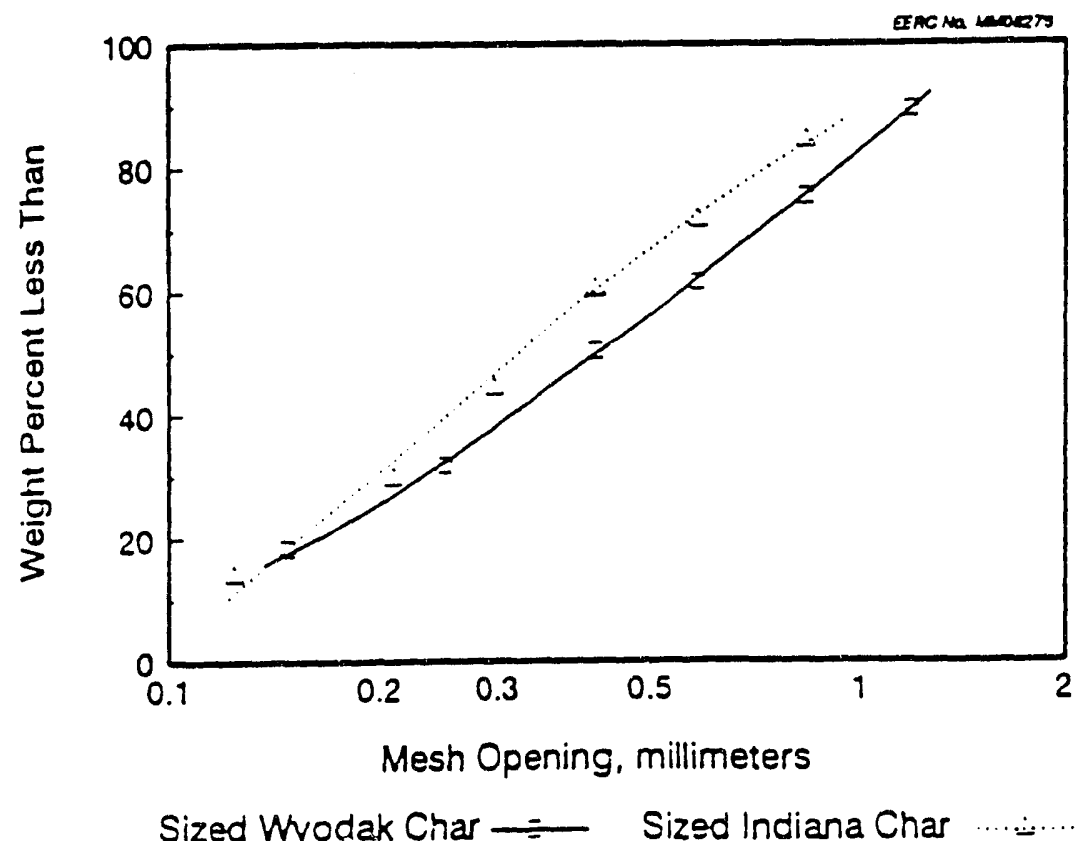

Figure 86. Wyodak and Indiana chars sized for briquetting. 


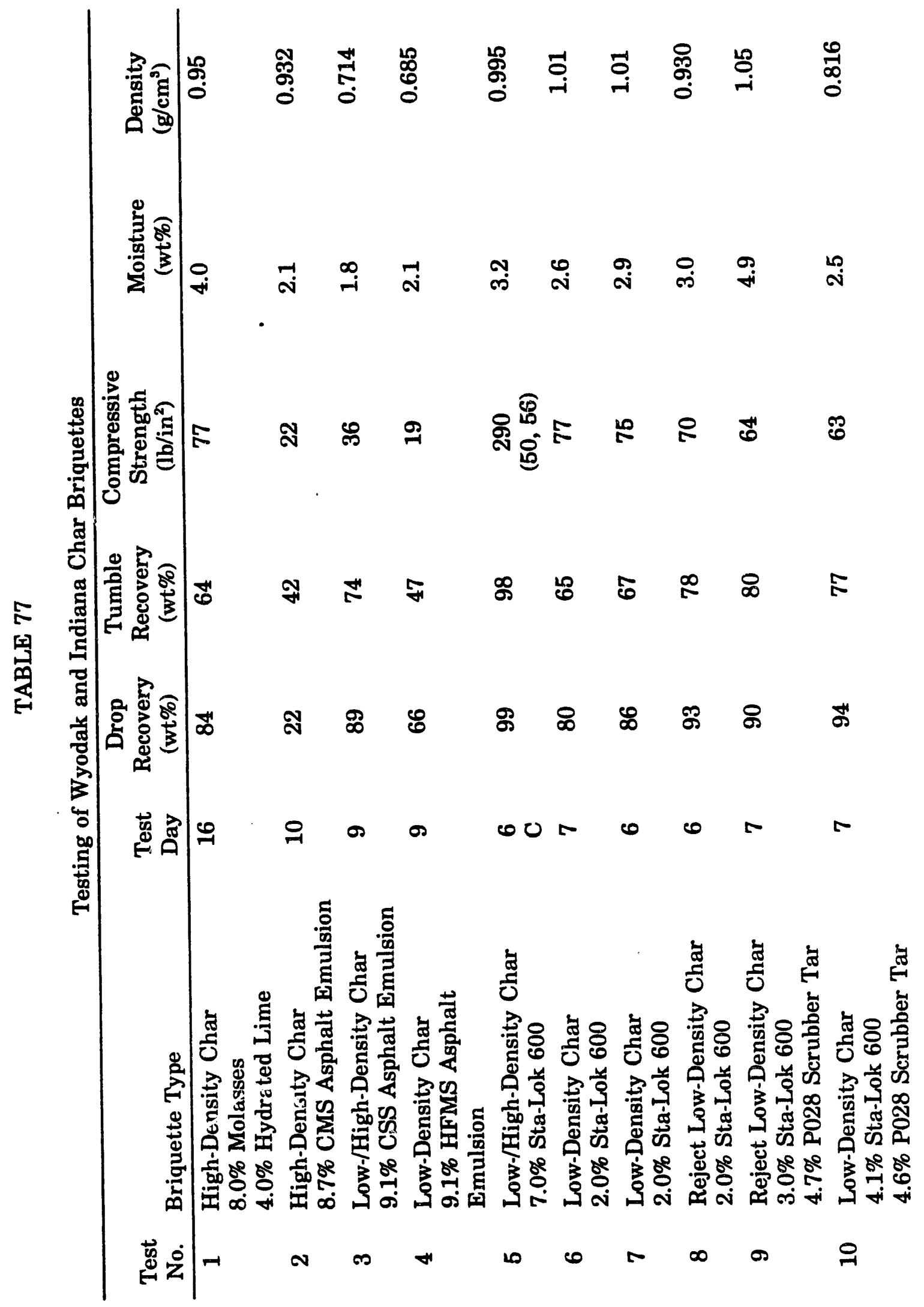




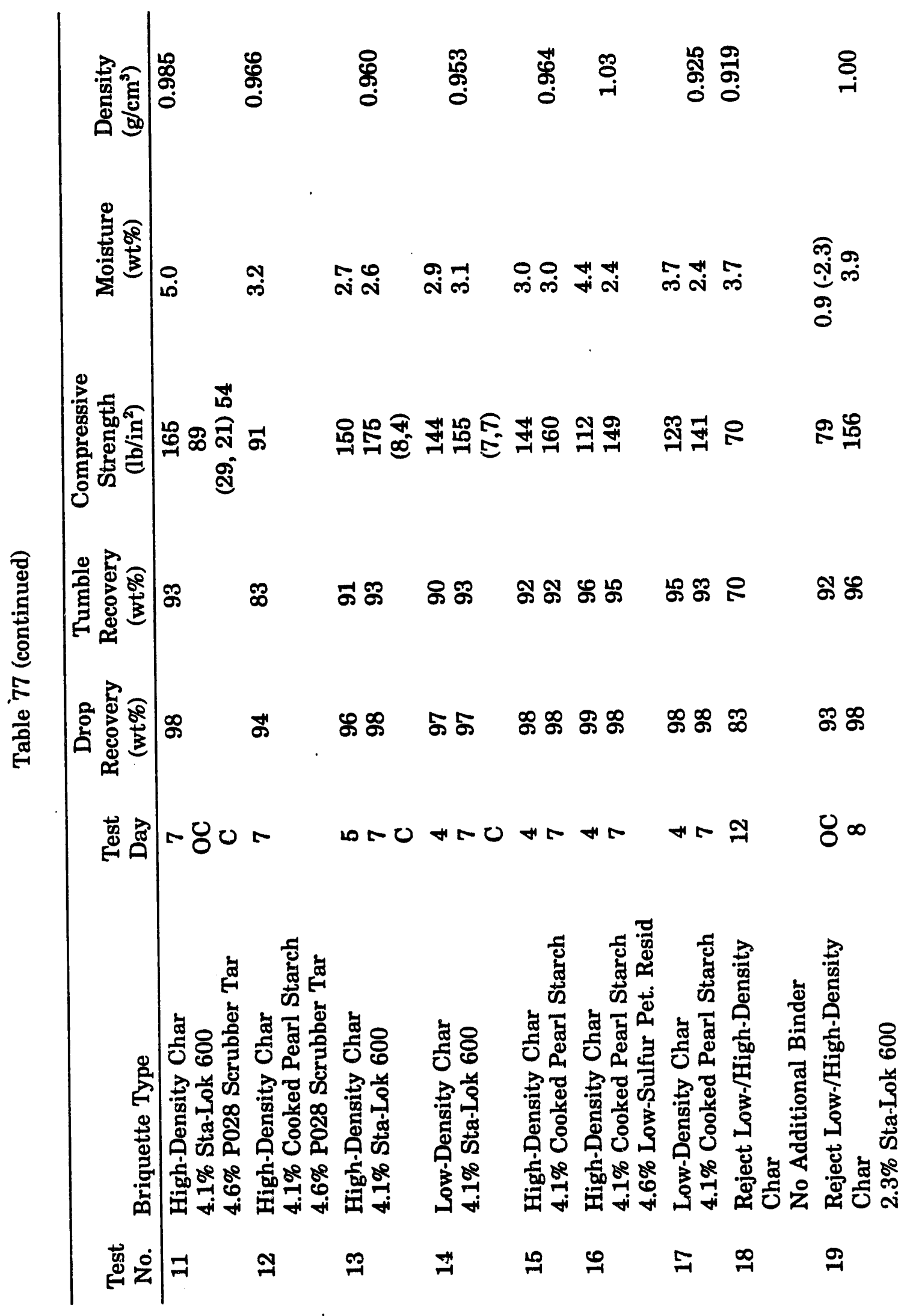




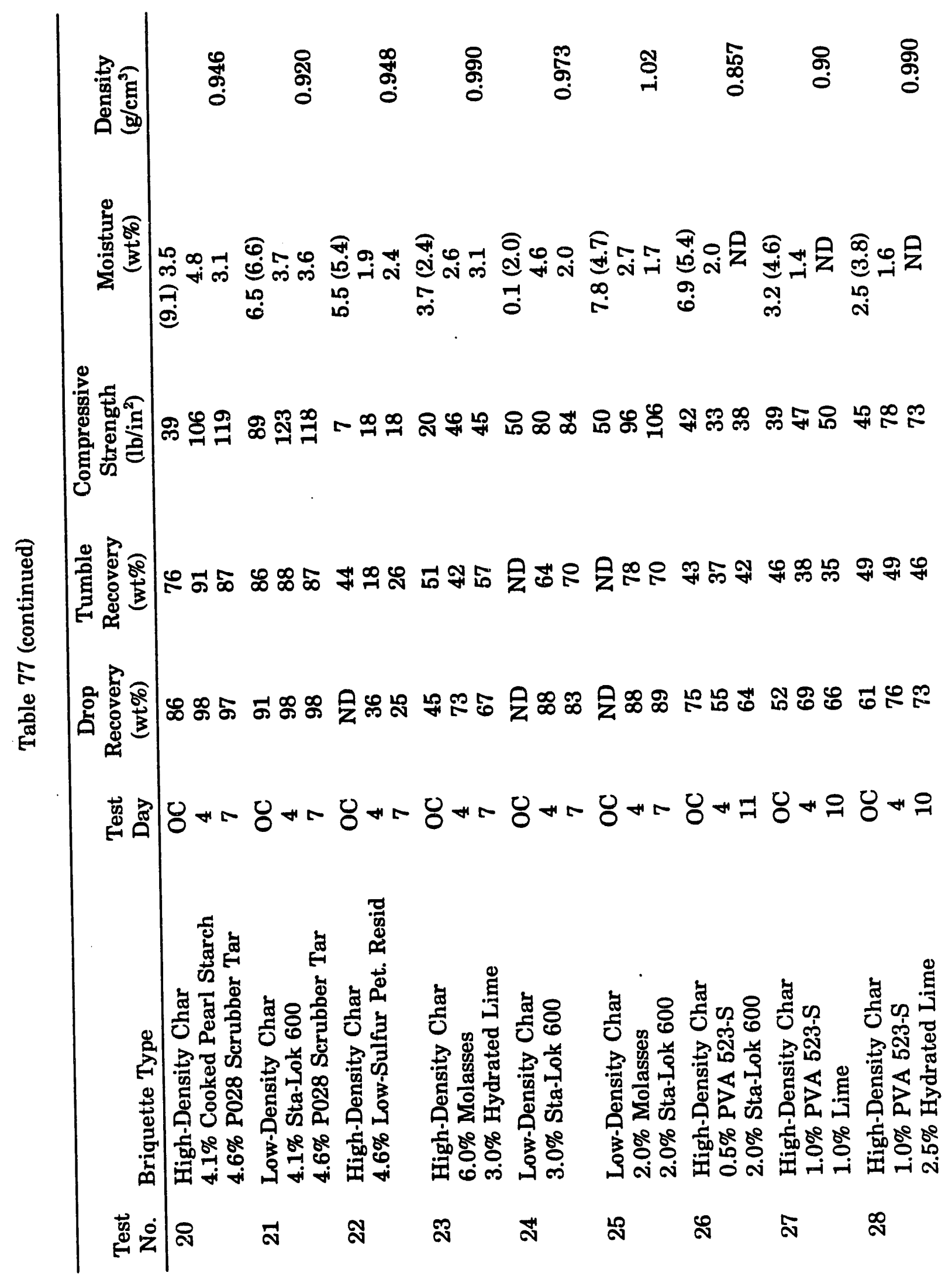




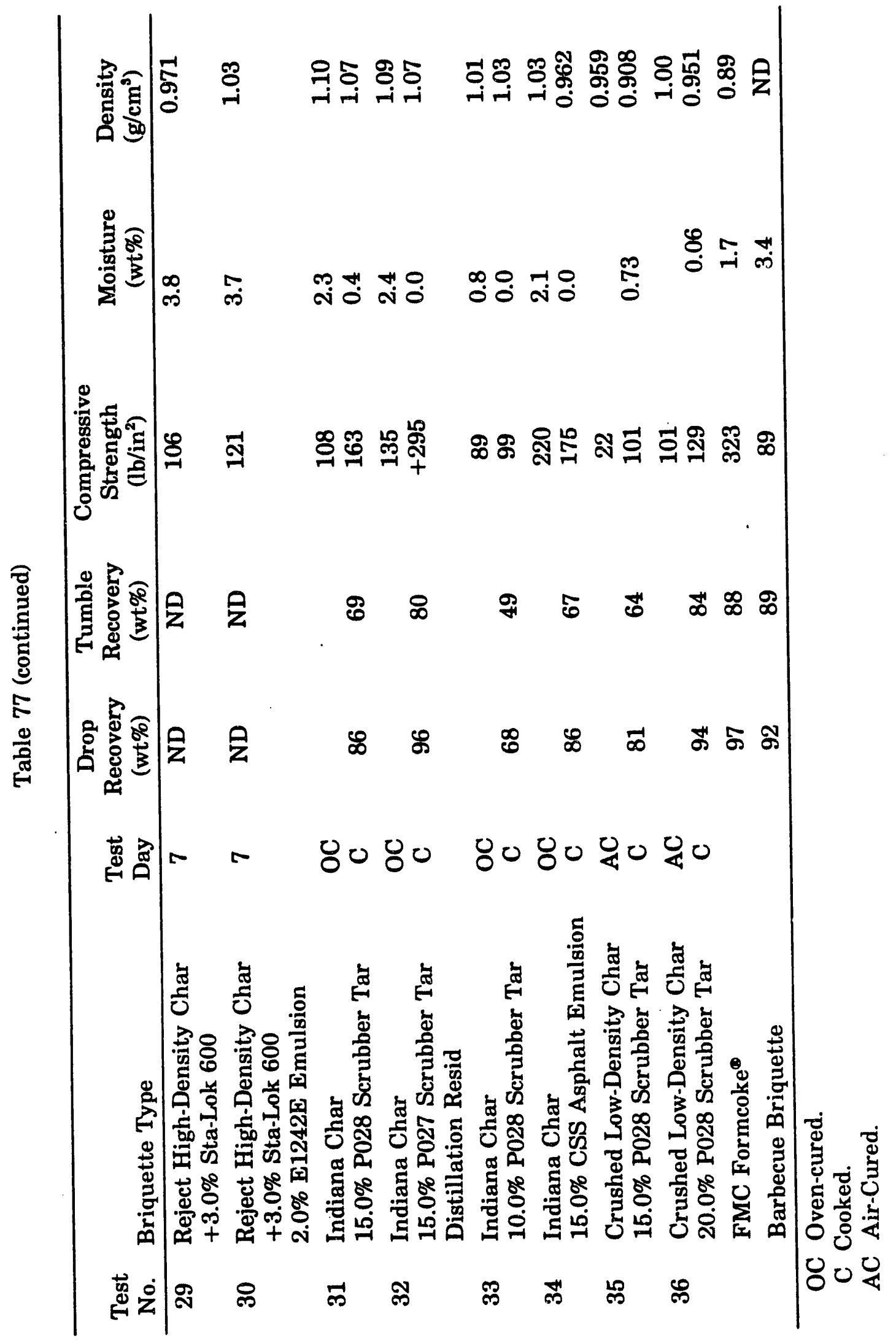




\subsection{Evaluation of Green Briquettes}

The production of well-formed green briquettes appeared to be related to a number of factors, including briquetter processing conditions, binder type, and, possibly, the type of char/binder preparation method. The effect of one briquetter operating condition, namely, feeder speed, was not discernible from the test matrix primarily because of the high briquetter through put compared to the mass of char/binder in each test. With char/binder batches of nominally 22 to $28 \mathrm{lb}(10$ to $22.71 \mathrm{~kg})$, the typical test lasted $\sim 35$ to 45 seconds, an insufficient time period to achieve steady-state operation. During this short time period, the feeder speed was usually continuously adjusted to maximize densification without stalling the rolls and drive motor. An artifact of briquetting, which complicated evaluation of processing conditions, was the unbriquetted material and poorly formed briquettes which were produced at start-up and at the end of feed. This artifact is a consequence of insufficient densification resulting from an underloaded nip region between the rolls. With the short duration tests, the production of both unbriquetted material and poorly formed briquettes was generally significant, estimated to be as much as $40 \%$. The non-steady-state operation of the briquetter also prevented evaluation of the effect of particle size (density) on briquette formation. As a consequence, comparisons of briquettes were made primarily on binder type and concentration and char/binder preparation method.

Overall, briquettes with smooth, nonporous surfaces, unbroken edges, and minimal "clam shelling" (splitting) and dusting were prepared using the pregelatinized/cooked starches with and without other binders. Similar well-formed briquettes for oven-curing and coking were prepared with specific concentrations and types of coal tars and asphalt emulsions. The minimum starch concentration for producing well-formed briquettes appeared to be between 2.0 and $3.0 \mathrm{wt} \%$, as those briquettes made in Tests 6 and 7 (2.0 wt\%) experienced only a slight loss of material around the edges and minor splitting. Adding $2.0 \mathrm{wt} \%$ molasses or $0.5 \mathrm{wt} \%$ PVA was sufficient to improve the appearance. Additionally, briquettes made with CMS asphalt emulsion (Test 2), low-sulfur petroleum resid (Test 22), and the PVA/hydrated lime (Test 28), although having unacceptable strength characteristics, were generally well formed with minor dustiness. The briquettes made with the CSS and HFMS asphalt emulsions (Tests 3,4 ) were more porous and crumbly, probably due to considerably lower densities $\left(0.714,0.685 \mathrm{~g} / \mathrm{cm}^{3}\right)$ compared to that of the CMS emulsion briquettes $\left(0.932 \mathrm{~g} / \mathrm{cm}^{3}\right)$. The briquettes made with the molasses/hydrated lime blend were less attractive in appearance compared to the starch briquettes and were characterized by higher porosity and poorly formed edges.

Apparently the starch has greater adhesive properties compared to the molasses when the briquettes are initially formed.

Moisture content did not appear to be a critical factor in the formation of the briquettes or the strength after air-curing. The moisture content of briquettes made in the first 30 tests ranged from 20 to $29 \mathrm{wt} \%$, with an average of $25 \mathrm{wt} \%$.

Briquettes prepared for eventual coking (Tests 30-36) appeared to require a specific minimum binder concentration or binder type to produce well-formed briquettes. The Indiana char briquettes, for example, were well formed when using $15 \mathrm{wt} \%$ CSS asphalt emulsion and experienced only moderate clam shelling with 15 wt\% P027 distillation resid (Tests 32,34). These binders may have wetted the char surface better than the 15 wt\% and 10 wt\% P028 scrubber tar (Tests 30,33 ) which produced dusty, poorly formed 
briquettes with considerable clam shelling. Similarly, for Wyodak briquettes for formed coke production, $20 \mathrm{wt} \%$ P028 scrubber tar produced very well-formed briquettes with no clam shelling whereas 15 wt\% P028 scrubber tar resulted in more clam shelling and dustiness.

\subsection{Evaluation of Briquettes after Air-Curing, Oven-Curing, and Coking}

\subsection{Briquette Volume, Weight, and Density}

Briquette volumes, weights, and, consequently, densities were determined after air. curing in the first 30 tests and after air-curing, oven-curing, and coking in the last six tests. The briquette volumes were generally very consistent from test to test. The average volume of the air-cured briquettes over the first 30 tests was $19.9 \mathrm{~cm}^{9}$, with a standard deviation of only $1.07 \mathrm{~cm}^{3}$. The only significant outliers were briquettes made in Tests 6 and 7 , which had volumes of 16.1 and $17.8 \mathrm{~cm}^{3}$, respectively. The average volumes of oven-cured and coked Indiana char briquettes were 20.8 and $18.4 \mathrm{~cm}^{3}$, with standard deviations of 0.189 and $0.096 \mathrm{~cm}^{3}$, respectively. The average weight of the aircured briquettes was 18.8 grams, with a range from 13.7 to 21.2 grams. The average weights of the oven-cured and coked Indiana char briquettes were 22.1 and 19.0 grams, respectively. The oven-cured briquettes ranged from 21.4 to 22.7 grams, and the coked briquettes ranged from 17.8 to 19.6 grams. The variation in densities from test to test was probably due to differences in feeder operation conditions. With the noticeable exceptions of briquettes from Tests 3,4 , and 10, the air-cured briquette densities ranged from 0.90 to $1.05 \mathrm{~g} / \mathrm{cm}^{3}$. The densities of the oven-cured Indiana char briquettes ranged from 1.01 to 1.10 , and the air-cured Wyodak char briquettes ranged from 0.959 to $1.00 \mathrm{~g} / \mathrm{cm}^{3}$. The overall effect of coking was a decrease in density for both Indiana and Wyodak char briquettes. The densities of the coked Indiana char briquettes ranged from 0.962 to $1.07 \mathrm{~g} / \mathrm{cm}^{3}$ and the coked Wyodak char briquettes ranged from 0.908 to $0.951 \mathrm{~g} / \mathrm{cm}^{3}$. The difference in densities between the coked Indiana and Wyodak char briquettes is due to the higher true particle density of the Indiana char.

\subsection{Mechanical Strength}

As with the tableting tests, the most suitable binders for producing strong briquettes were the pregelatinized (Sta-Lok 600) or cooked starches (pearl starch) and high concentrations of the mild gasification tars and asphalt emulsions. The starch binders developed complete strength after only 4 to 7 days of air-curing, whereas the coal-and petroleum-derived binders required an oven-curing and coking step to produce strong briquettes. The Sta-Lok 600 starch was tested with the low-density char over the range of 2.0 to $7.0 \mathrm{wt} \%$ (Tests $5.7,14$, and 24 ), with an effective concentration determined to be 4.1 $w t \%$. The criteria used were drop and tumble recoveries of $95 \mathrm{wt} \%$ and compressive strengths of $140 \mathrm{lb} / \mathrm{in}^{2}$. Although not meeting these criteria, briquettes made with starch concentrations of 2.0 and $3.0 \mathrm{wt} \%$ exhibited nearly equivalent strengths. Duplicate tests at $2.0 \mathrm{wt \%}$ Sta-Lok 600 (Tests 6 and 7) produced briquettes with reasonably comparable characteristics. Exceptionally strong briquettes were made with a combination of low. and high-density char (74\%/26\%) using a Sta-Lok 600 concentration of $7.0 \mathrm{wt} \%$. The drop and tumble recoveries exceeded $98 \mathrm{wt} \%$, and the average compressive strength was $290 \mathrm{lb} / \mathrm{in}^{2}(2000 \mathrm{kPa})$. The strength characteristics of a commercial barbecue briquette, in comparison, are drop and tumble recoveries of 92 and $89 \mathrm{wt} \%$, respectively, and an 
average compressive strength of $89 \mathrm{lb} / \mathrm{in}^{2}(614 \mathrm{kPa})$. The concentration of Sta-Lok 600 required to produce mild gasification char briquettes with equivalent strength to those of the barbecue briquettes appears to be between 3.0 and $4.1 \mathrm{wt} \%$.

Comparative tests made with low- and high-density chars at pregelatinized and cooked starch concentrations of $4.1 \mathrm{wt} \%$ (Tests 13 vs. 14,15 vs. 17 in Table 77) indicated that nearly equivalent briquettes were produced with only moderate differences in compressive strength. The low-density char briquettes had the lowest compressive strength. Additionally, briquettes made with the cooked pearl starch had slightly lower compressive strengths than briquettes made with the pregelatinized starches (Tests 13 vs. 15, 14 vs. 17). The Hamaco 196 pregelatinized starch and cooked AMRESCO potato starch, although not tested during briquette preparation, wculd presumably produce briquettes with similar strength characteristics to those made with the Sta-Lok 600 and cooked pearl starch.

The effect of blending a mild gasification tar or petroleum resid with the pregelatinized or cooked starches (Tests $9,10,11,12,16,20,21$ ) indicated a neutral to negative effect on air-cured briquette strength. The addition of the tar or resid at up to 4.6 wt\% with $4.1 \%$ pregelatinized or cooked starch (Tests 11 and 16) produced briquettes with comparable strengths to those made only with $4.1 \%$ starch. Conversely, the strengths of briquettes made in Tests 10 and 12 at $4.1 \%$ starch and $4.6 \%$ tar were inferior to starch-only briquettes, primarily in compressive strength and tumble recovery. Both tests were repeated, and improvements were achieved in all characteristics, including drop and tumble recovery and compressive strength. The improvement in briquette strength between Test 10 and repeat Test 21 , using low-density char, appears to be due to a significant increase in briquette density. This phenomenon was not observed with the high-density char where the briquette density actually decreased between Test 12 and the repeat Test 20.

The molasses/hydrated lime, asphalt emulsions, petroleum resid, and combinations of PVA with starch, lime, or hydrated lime produced air-cured briquettes with inferior strength characteristics at the binder concentrations studied. The combination of $2.0 \mathrm{wt} \%$ molasses $/ 2.0 \mathrm{wt} \%$ pregelatinized starch (Test 25) produced a briquette superior to that when using only 2.0 wt\% pregelatinized starch. Quite possibly, moderate increases in molasses and starch concentrations may produce briquettes meeting the aforementioned acceptable criteria (see page 28). The test with $0.5 \mathrm{wt} \%$ PVA/2.0 wt\% pregelatinized starch (Test 26) was designed to assess the increase in briquette strength due to PVA compared to when using only $2.0 \mathrm{wt} \%$ pregelatinized starch (Tests 6 and 7 ) or $2.0 \mathrm{wt} \%$ molasses/2.0 wt\% pregelatinized starch (Test 25). The comparison, however, was ineffectual, presumably due to a low briquette density in Test 26 with PVA. Similarly, a low briquette density in Test 27 appeared to obscure the effect of a $1.0 \mathrm{wt} \%$ PVA/1.0\% lime binder combination.

The moisture contents of briquettes produced in the first 30 briquetting tests were measured, typically daily, to determine the time period required to achieve constant moisture during air-curing. The moisture contents measured over a 7-day period are presented in Figure 87. The moisture contents determined on the days of strength testing are presented in Table 77 . The briquette moisture contents, which initially varied from 20 to $30 \mathrm{wt} \%$, were reduced to their final equilibrium moisture within 4 days and most typically within 3 days. Between Days 4 and 7 , the moisture contents remained relatively 


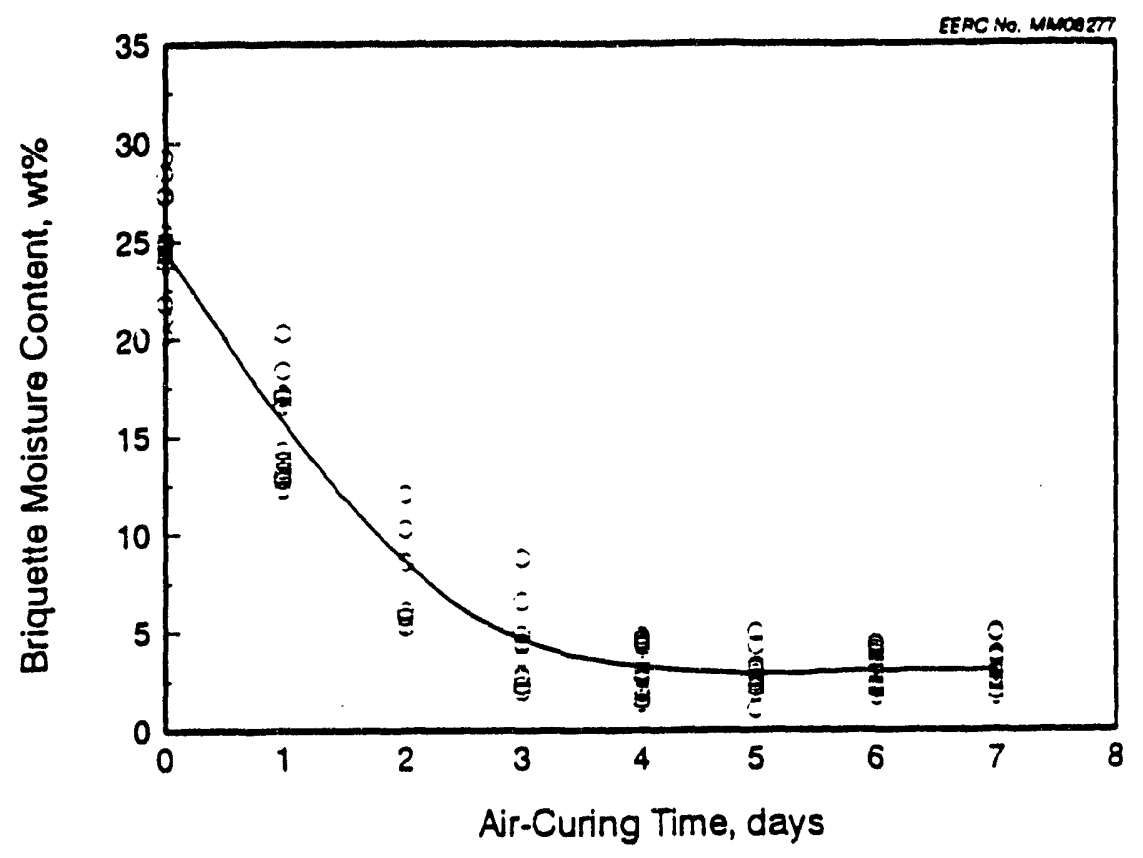

Figure 87. Briquette moisture content vs. air-curing time.

constant, and the range of equilibrium moisture contents ranged from $\sim 2$ to $5 \mathrm{wt} \%$, with an average moisture content of $3.1 \mathrm{wt} \%$. The effect of drying time on shatter and abrasion resistances and compressive strengths of the air-cured briquettes was determined by performing the analysis on Day 4 and repeating on Days 7 to 11 . The results for briquetting Tests 13-17 and 20-28 presented in Table 77 indicate that the abrasion and shatter resistance are usually fully developed after only 4 to 5 days of air-curing. However, the compressive strength tends to increase slightly over the additional 3 to 7 days of air-curing. The compressive tests also generally indicate that the briquettes with the lowest strengths tend to reach their maximum strength by Day 4 .

Oven-curing experiments were performed on green briquettes from Tests 19.28 to determine if the curing time and development of strength could be reduced to a few hours or less, instead of 4 days to a week required for air-curing. The results of the shatter and abrasion resistance and compressive testing are presented for these oven-cured briquettes in Table 77. In most tests, the abrasion resistance appeared to be almost completely developed after $\sim 1$ hour of oven curing. A number of oven-cured briquettes, noticeably those from Tests 19,21, and 26, had shatter resistances similar to results obtained after air-curing. Also, the oven-cured briquettes from Tests 26 and 27 had similar compressive strengths to those of the air-cured briquettes. More typically, however, the compressive strengths were quite deficient and the shatter resistances were moderately underdeveloped with oven-curing. The lack of sufficient drop resistance and compressive strength after oven-curing were attributed, to some degree, to nonuniform drying. Evidence for nonuniform drying was the difference in the measured briquette moisture contents and the calculated briquette moisture contents (in parentheses) shown in Table 77. The calculated final moisture content was determined based on initial briquette 
moisture content and the mass loss during oven-curing. Mass loss was assumed to be entirely moisture evaporation. The measured moisture content was determined from standard ASTM testing at $220^{\circ} \mathrm{F}\left(105^{\circ} \mathrm{C}\right)$ of two crushed briquettes. The moisture content of the two briquettes may not have accurately reflected the moisture content of the briquettes evaluated for strength.

Coking tests were performed on single air-cured briquettes produced in Tests $1,3,5$, 11-17, 21-22, and 25 using starch, molasses/hydrated lime, scrubber tab, and petroleum resid, or combinations of these binders. These air-cured briquettes were coked, without prior oven-curing, in the tube furnace coker at $1250^{\circ} \mathrm{F}\left(676^{\circ} \mathrm{C}\right)$ and $1500^{\circ} \mathrm{F}\left(816^{\circ} \mathrm{C}\right)$. The general outcome of the testing was that the coked briquettes tended to easily lose material or even crumble with minimal handling. Briquettes from Tests 3 and 16 actually disintegrated at both temperatures during the coking process, while the majority of the other briquettes had severe surface cracking or pitting. Compressive strength testing, performed on briquettes produced in Tests $5,11,13$, and 14, indicated a significant decrease from their air-cured compressive strengths. The air-cured briquettes produced in Test 16 retained a relatively smooth surface with only minor cracking during coking. These briquettes were chosen for further coke testing using the EERC $4-\mathrm{lb} / \mathrm{hr}$ mild gasification reactor. Twenty of these briquettes were coked at $1500^{\circ} \mathrm{F}\left(816^{\circ} \mathrm{C}\right)$ in a batch mode, and compressive strength testing was performed on 12 of the briquettes. The coked briquettes, similar in appearance to those produced in the tube furnace, were significantly diminished in strength, with an average compressive load value of only $15 \mathrm{lb} / \mathrm{in}^{2}$. To assess the effect of oven-curing, air-cured briquettes from Test 11 were ovencured at $400^{\circ} \mathrm{F}\left(204^{\circ} \mathrm{C}\right)$ and coked in the tube furnace at $1500^{\circ} \mathrm{F}\left(816^{\circ} \mathrm{C}\right)$ with compression testing performed on the oven-cured and coked briquettes. The results indicated that oven-curing contributed to higher briquette strength after coking. The compressive strength with oven-curing prior to coking was $54 \mathrm{lb} / \mathrm{in}^{2}(372 \mathrm{kPa})$ which compared to $21 \mathrm{lb} / \mathrm{in}^{2}(145 \mathrm{kPa})$ without incorporating the oven-curing step.

Briquettes in Tests 31 to 36 were prepared with a high concentration of coal- or petroleum-derived binders (10 to $20 \mathrm{wt} \%$ ) and the green briquettes were oven-cured prior to coking. This processing scheme produced the strongest formed coke briquettes, with one char/binder combination (Test 32) approaching the strength of FMC formcoke. The binder which appeared to be the most suitable for briquetting the Indiana char was the 15.0 wt\% P027 scrubber tar distillation resid. The shatter resistance and compressive strength of these coked briquettes were close to those of the FMC formcoke ${ }^{\star}$, whereas the abrasion resistance was somewhat lower. The coked 15.0 wt\% CSS asphalt emulsion briquettes were essentially equivalent to the coked $15.0 \%$ P028 scrubber tar briquettes. A binder concentration below $15 \mathrm{wt} \%$ appears to be entirely unsuitable for production of formed coke briquettes from Indiana char. The Wyodak char appeared to be less amenable to formed coke production at binder concentrations similar to those used for making Indiana char formed coke. The single test made with $15 \mathrm{wt} \%$ P028 scrubber tar indicated that the shatter and abrasion resistance and, more significantly, the compressive strength of Wyodak char formed coke were inferior relative to the Indiana char formed coke. Adding 5\% more binder increased the shatter and abrasion resistances significantly, although the compressive strength increased to a much lesser extent. This compressive value is presumed to be low and probably is similar to compressive values $\left(\sim 190 \mathrm{lb} / \mathrm{in}^{2}\right)$ measured during later water soak tests. The low value may be due to the small batches of briquettes produced and a nonrepresentative selection of briquettes for testing. 
The effect of coking on briquette compressive strength was assessed by comparing the strengths obtained by oven-curing (Tests 31-34) and by air-curing (Tests 35-36). The effect of coking on compressive strength was not consistent from test to test; i.e., the strength was increased in some briquettes and decreased in other briquettes. This phenomenon may also be an artifact of briquette batch size and selection of briquettes for testing.

\subsection{Water Resistance}

Several of the briquettes produced in the first 30 tests plus all of the briquettes produced in the last six tests were subjected to simulated weather-induced conditions which could be experienced during actual handling and transportation. The simulated iminersion (soak) and shower (spray) results are presented in Table 78. The air-cured briquettes made with only starch were compared against briquettes made with the same starch concentration plus an added binder with potential water-repellant properties. The strength of both the low- and high-density Wyodak chars briquetted with pregelatinized starch concentrations of 3.0 and 4.1 wt\% (Tests 29, 13, and 14) was almost completely dissipated after both soak and spray testing. The minimal strength remaining was probably due entirely to the adhesive force of the water. The soaked briquettes tended to crumble or flake, whereas the sprayed briquettes developed mushy surfaces with some bubbling. Additional evidence for the absorption of water during soak and spray testing was the high moisture content, typically 30 wt\% or higher. In comparison, the commercial barbecue briquettes fared no better than the starch-only briquettes, as the resulting compressive strengths were negligible. The char briquette made with $7.0 \mathrm{wt} \%$ pregelatinized starch retained significant strength after soak and spray testing, and this can be attributed to the high initial compressive strength. However, during testing with this briquette type, the surface appearance during soaking and spraying was not indicative of the extent of strength degradation. The soaked briquettes retained their smooth finish and did not flake or crumble, and, similarly, the sprayed briquettes did not bubble or crack. However, the sprayed briquettes were moist throughout, and the outer 3 to $4 \mathrm{~mm}$ of the soaked briquettes were moist.

The additional binders E1242E emulsion (Test 30), P028 scrubber tar (Tests 11, 21) and low-sulfur petroleum resid (Test 16) did show evidence of reducing water absorption and strength deterioration. The binders in ascending order of effectiveness appeared to be the E1242E emulsion, low-sulfur petroleum resid, and P028 scrubber tar. The results with the latter binder were conflicting, but the poor results with the low-density char (Test 21) may be due to improper densification. When the P028 scrubber tar was used with the high-density char (Test 11), there was essentially no degradation of briquette strength, and the slight increase in moisture content was mostly due to surface moisture. The water-soaked and sprayed briquettes from Tests 30,11 , and 16 showed no signs of flaking, crumbling, or bubbling, whereas in Test 21 the P028 scrubber tar only slowed the absorption of water and degradation of strength.

The briquettes which were oven-cured and coked were generally very resistant to moisture absorption during spray and soak testing. The anomalous data indicating an increase in strength during soaking for several briquette types (Tests 31 and 36) are presumed to be due solely to briquette sample selection. Moisture analysis of the soaked and sprayed briquettes indicated that water absorption could be significant even in the instances of minor compressive strength reduction. The strongest briquettes made with 15 wt\% P027 scrubber tar distillation resid exhibited resistance to water absorption similar to FMC formcoke ${ }^{\oplus}$ briquettes. 


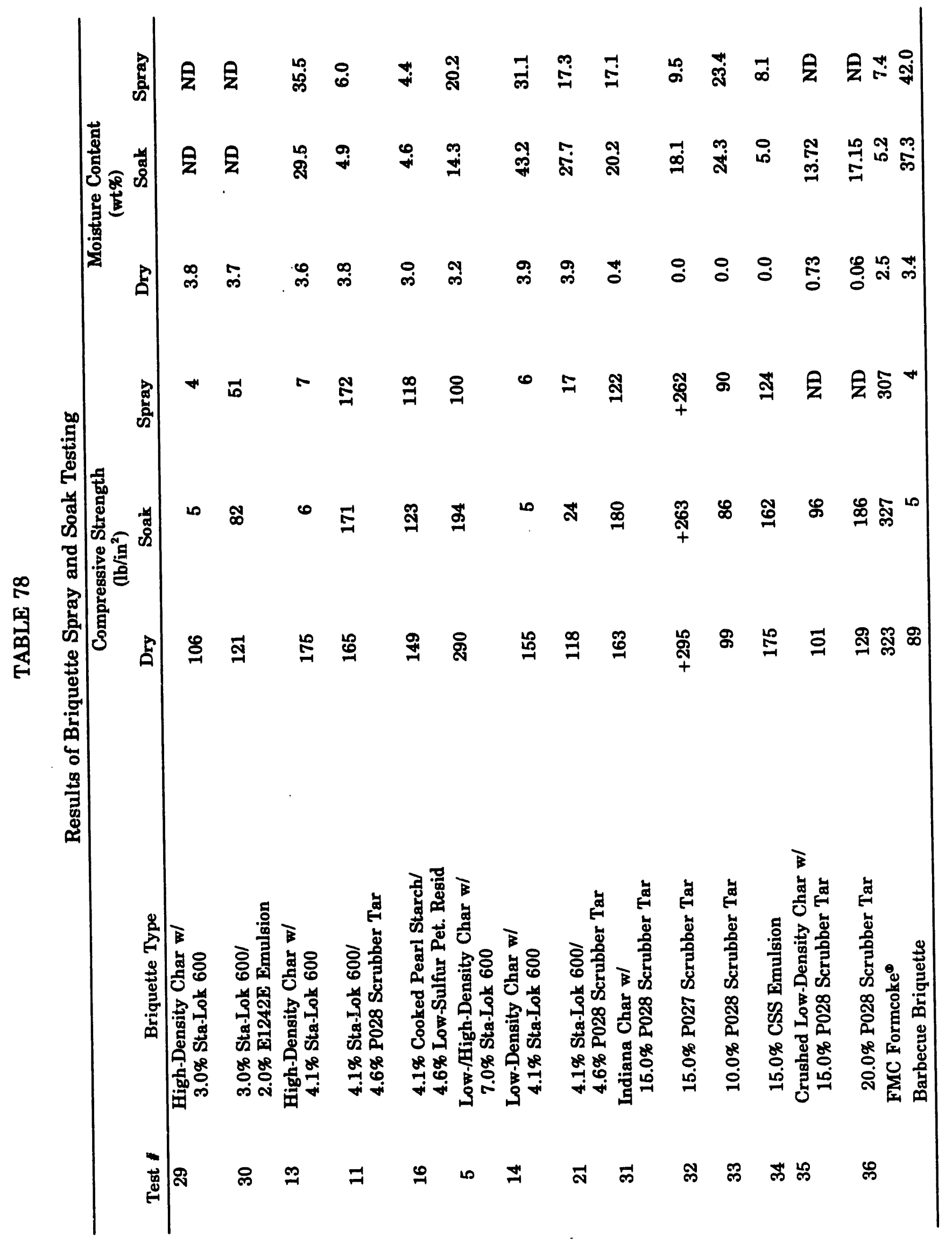




\subsection{Proximate and Ultimate Properties}

Several of the Indiana and Wyodak char briquettes were analyzed for proximate and ultimate composition plus heating value, and the results are presented in Tables 79 and 80. The Indiana char briquettes included formed coke briquettes made with 15 wt\% P028 scrubber tar (Test 31) and air-cured, oven-cured, and coked briquettes made with $15 \%$ P027 scrubber tar distillation resid (Test 32). The analysis indicated that the two Indiana formed coke briquettes had nearly equivalent compositions: volatile matter contents below $6 \mathrm{wt} \%$, carbon contents of 72 to $73 \mathrm{wt} \%$, and ash contents of approximately $27 \mathrm{wt} \%$. The calculated volatile matter, carbon, and ash contents of the composite Indiana reactor char and cyclone char fines were, in comparison, 12.8, 67.0, and 28.6 wt\%, respectively. The similar compositions of the coked briquettes contrast with the strengths which were determined to be superior with the P027 resid. Comparison of the proximate analysis of the air- and oven-cured briquettes made with the P027 tar indicated a reduction from 19.7 to $16.3 \mathrm{wt} \%$ in volatile matter, probably reflecting loss of low boiling binder components. The oven-cured char briquettes appeared to be moisture sensitive, resulting in reabsorption of moisture to a level near that of the air-cured briquettes. Subsequent coking of the oven-cured briquettes resulted in a significant reduction in volatile matter content and concentration of the fixed carbon and ash. An additional consequence of coking the Indiana char under an inert atmosphere was an apparent change in ash chemistry. This was hypothesized to have been the cause of the negative oxygen content values. Presumably during the coking step, certain mineral species were reac ' ${ }^{\circ}$, and during proximate analysis to determine ash content, the mineral species increasud in mass from oxidation. As a consequence, the sum of the weight fractions of the analytically determined species hydrogen, carbon, nitrogen, sulfur, and ash was greater than unity. Therefore, calculation of the oxygen content by difference resulted in a negative value. An additional consequence of coking was an increase in sulfur content, relative to the feed char.

Similar reductions in volatile matter and increases in carbon and ash content were observed after coking Wyodak char briquettes prepared with 15\% P028 scrubber tar (Test 35). The volatile matter, carbon, and ash contents of the coked briquettes were -5.5 , 76.3 , and 20.9 wt\%, respectively, which compare to $14.7,71.5$, and 16.4 wt\% for the lowdensity Wyodak char. As with the Indiana char briquettes, the calculated oxygen content was negative, although the phenomenon was less significant. The lower negative values of the oxygen contents for the Wyodak char formed coke briquettes are probably due to the lower ash content of the Wyodak char compared to that of the Indiana char. Also, differences in ash chemistry between the chars may affect the degree of reduction and oxidation. The increase in sulfur for the coked Wyodak briquettes, relative to the feed char, was more significant than with the Indiana briquettes.

In addition to the Wyodak formed coke briquettes, analyses were also performed on briquettes made with 4.1 wt\% pregelatinized starch (Test 13) and an equivalent concentration of starch blended with $4.6 \mathrm{wt} \%$ P028 scrubber tar (Test 11). The 4.1 wt\% starch concentration was previously determined to be near optimum for producing aircured briquettes with acceptable shatter/abrasion resistance and compressive strength. Presuming a sufficiently low volatile matter content, this binder concentration could produce an acceptable low-volatile cooking fuel briquette. The second briquette type was chosen because preliminary tests indicated that the scrubber tar may inhibit moisture absorption under severe conditions of water immersion or shower (rain). Quite possibly a 

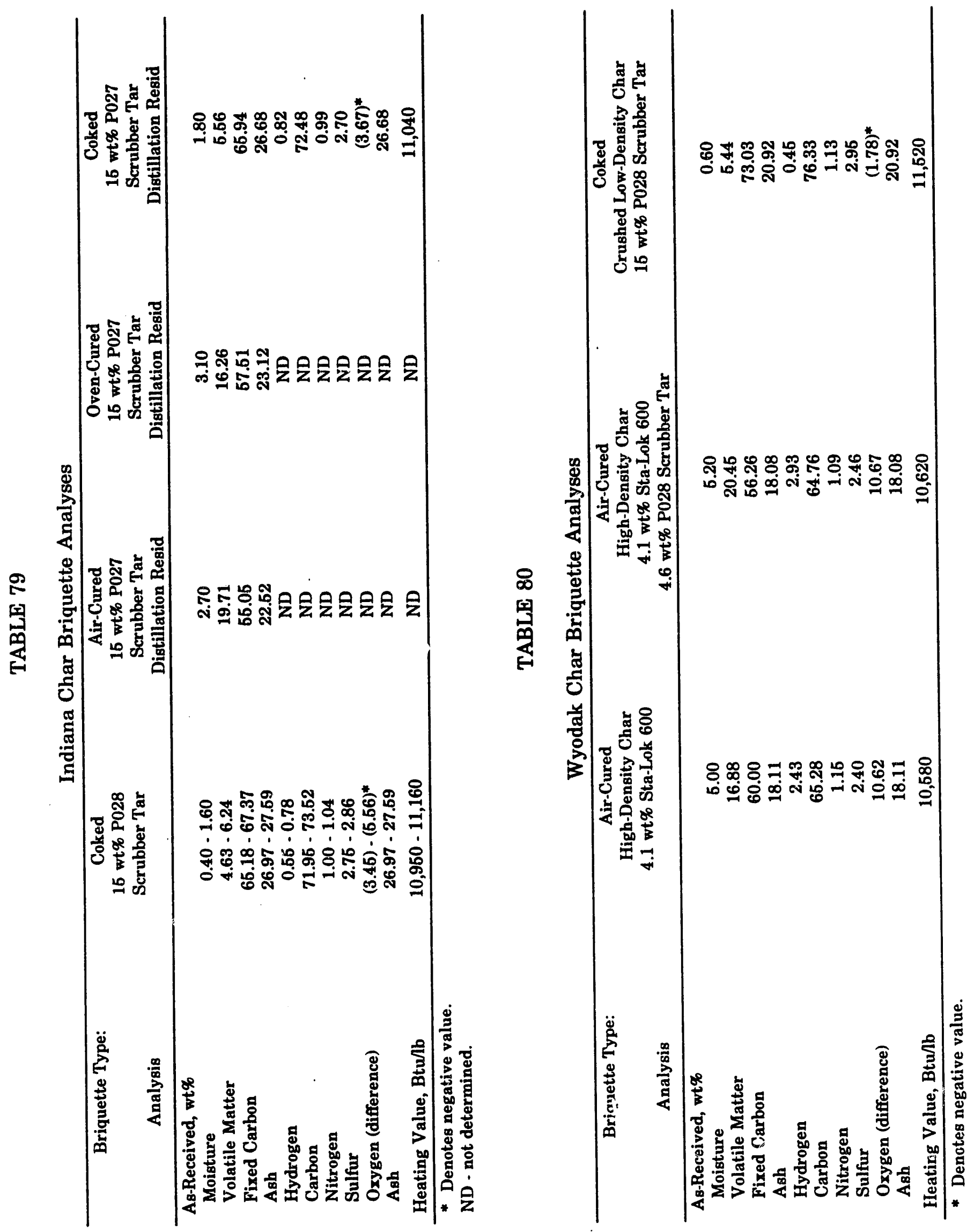
briquette with these water repulsion capabilities may be suitable as an industrial, utility, or residential heating fuel where outside, unprotected storage would warrant moisture resistance. The proximate, ultimate, and heating value analyses in Table 80 indicate that the addition of starch alone results in a volatile matter increase from 13.8 to $16.9 \mathrm{wt} \%$ and a heating value reduction from 11,600 to $10,580 \mathrm{Btu} / \mathrm{b}$. Blending the scrubber tar with the starch produced a further volatile matter increase from 16.9 to $20.5 \mathrm{wt} \%$, although the scrubber tar did contribute slightly to heating value.

\subsection{Weight Loss from Oven-Curing and Coking}

The weight loss from oven-curing and coking were determined for Wyodak and Indiana char formed coke briquettes produced in Tests 31 to 36 and for air-cured Wyodak char briquettes produced in Tests 11 and 20. The results are presented in Table 81 . The weight loss from oven-curing of Indiana and Wyodak formed coke briquettes ranged from about $2.5 \mathrm{wt} \%$ to $4.5 \mathrm{wt} \%$, although there was not a distinct relationship between the weight loss and the concentration of binder. The oven-curing weight loss was not determined for the Wyodak char made with 15 wt\% scrubber tar because of partial combustion of some of the briquettes. During all oven-curing tests with these briquettes, as many as $15 \mathrm{wt} \%$ developed charred edges similar to a barbecue briquette. This phenomenon was also observed with a single oven-cured batch of Indiana char made with 15 wt\% P028 scrubber tar. Subsequent batches of this type did not show this behavior

TABLE 81

Briquette Weight Loss Due to Oven-Curing and Coking

\begin{tabular}{lcc}
\hline Briquette Type & Oven-Curing Loss, wt\% & Coking Loss, wt\% \\
\hline $\begin{array}{l}\text { Indiana Char } \\
\text { 15\% P028 Scrubber Tar }\end{array}$ & 4.0 & 16.0 \\
$\begin{array}{l}\text { 15\% P027 Scrubber Tar } \\
\text { Distillation Resid }\end{array}$ & 4.0 & 17.7 \\
10\% P028 Scrubber Tar & 4.6 & 14.4 \\
$\begin{array}{l}\text { 15\% CSS Asphalt Emulsion } \\
\text { Wyodak Char }\end{array}$ & 2.7 & 16.7 \\
15\% P028 Scrubber Tar & & 18.0 \\
20\% P028 Scrubber Tar & ND & 20.2 \\
$\begin{array}{l}\text { 4.1\% Sta-Lok 600 } \\
\text { 4.6\% P028 Scrubber Tar }\end{array}$ & 2.6 & ND \\
$\begin{array}{l}\text { 4.1\% Cooked Pearl Starch } \\
4.6 \% \text { Low-Sulfur Pet. Resid }\end{array}$ & & \\
\hline ND - not determined & 9.5 & 19.7 \\
\hline
\end{tabular}

ND - not determined. 
during oven-curing. Partial combustion was not a problem at $10 \mathrm{wt} \%$ or $20 \mathrm{wt} \%$ P028 scrubber tar or with the other char/binder combinations. The problem was presumably a result of the operation of the curing oven and not due to an inherent binder property.

The mass loss during coking appeared to follow a more distinct trend based on char type and binder type/concentration. The coking mass losses were higher for the Wyodak char briquettes compared to the Indiana char briquettes and this is probably due to the higher volatile matter content of the subbituminous coal char. Comparison of the briquettes made with $15 \mathrm{wt} \%$ P028 scrubber tar indicated the difference in mass loss of the Wyodak and Indiana char briquettes was roughly equivalent to the difference in volatile matter content of the two feed chars. The mass loss of Wyodak char briquettes made with $15 \mathrm{wt} \%$ P027 resid was higher than that of briquettes made with an equivalent concentration of P028 scrubber tar. This result is presumed to be due to a lower $\mathrm{C} / \mathrm{H}$ ratio in the $\mathrm{P} 027$ resid which is indicative of lower coke- forming ability and higher volatile matter content relative to the scrubber tar. This lower coke-forming ability is contradictory to the briquette strength characteristics which indicate that the P027 resid may be superior compared to the P028 scrubber tar for formed coke production. A low $\mathrm{C} / \mathrm{H}$ ratio may also be the cause of the high mass loss during coking of briquettes made with 15 wt\% CSS asphalt emu'sion. Because the CSS asphalt emulsion is almost 40 wt\% water, the actual asphalt content of the briquettes was about $9.0 \mathrm{wt} \%$. The higher mass loss for briquettes made with $9 \mathrm{wt} \%$ asphalt compared to the $10 \mathrm{wt} \%$ scrubber tar briquettes would indicate higher volatile content for the asphalt.

\subsection{Carbon Dioxide Reactivity}

The reactivity of formed coke briquettes in an iron-producing blast furnace was simulated by heating several Wyodak and Indiana char formed coke briquettes in an atmosphere of $\mathrm{CO}_{2}$ at $900^{\circ} \mathrm{C}$. The Indiana char briquettes included the $15 \mathrm{wt} \%$ P028 scrubber tar (Test 31) and $15 \mathrm{wt} \%$ CSS asphalt emulsion (Test 34) and the Wyodak char briquettes produced with 15 wt\% P028 scrubber tar (Test 35). The reactivity of FMC formcoke briquettes was included for comparison. The reaction orders and reactivities plus TGA determined proximate analysis are presented in Table 82, and the reaction weight loss curves, on a moisture-, volatile-ash-free basis, are presented in Figure 88. The reaction order $(n)$ and reaction rate coefficient $(\mathrm{k})$ were determined from Equation 1:

$$
-\mathrm{dC} / \mathrm{dT}=\mathrm{k} \cdot \mathrm{C}^{\mathrm{n}}
$$

where $\mathrm{C}$ is the fixed carbon content as determined from TGA proximate analysis. The reaction order, with respect to carbon, is an indication of the extent to which carbon influences the rate of reaction. The reaction rate coefficient is a measure of the rate at which a unit quantity of carbon is consumed in the reaction. Reaction orders and rate coefficients were based on a $90 \%$ carbon conversion. The reactivity curves indicate that the consumption of fixed carbon proceeded at a faster rate, up to about $45 \%$ carbon remaining, for the Indiana and Wyodak formed coke briquettes relative to the FMC formcoke ${ }^{\oplus}$. After this cross-over point, the FMC formcoke ${ }^{\oplus}$ reacted at a much faster rate, and the time required to reach about $95 \%$ conversion was at least $33 \%$ lower for the FMC formcoke than for the Indiana char briquettes and almost half that for the Wyodak char briquettes. The lower reactivity of the Indiana and Wyodak formed coke briquettes is probably largely due to their higher ash content compared with the ash content of the FMC formcoke ${ }^{\otimes}$. 


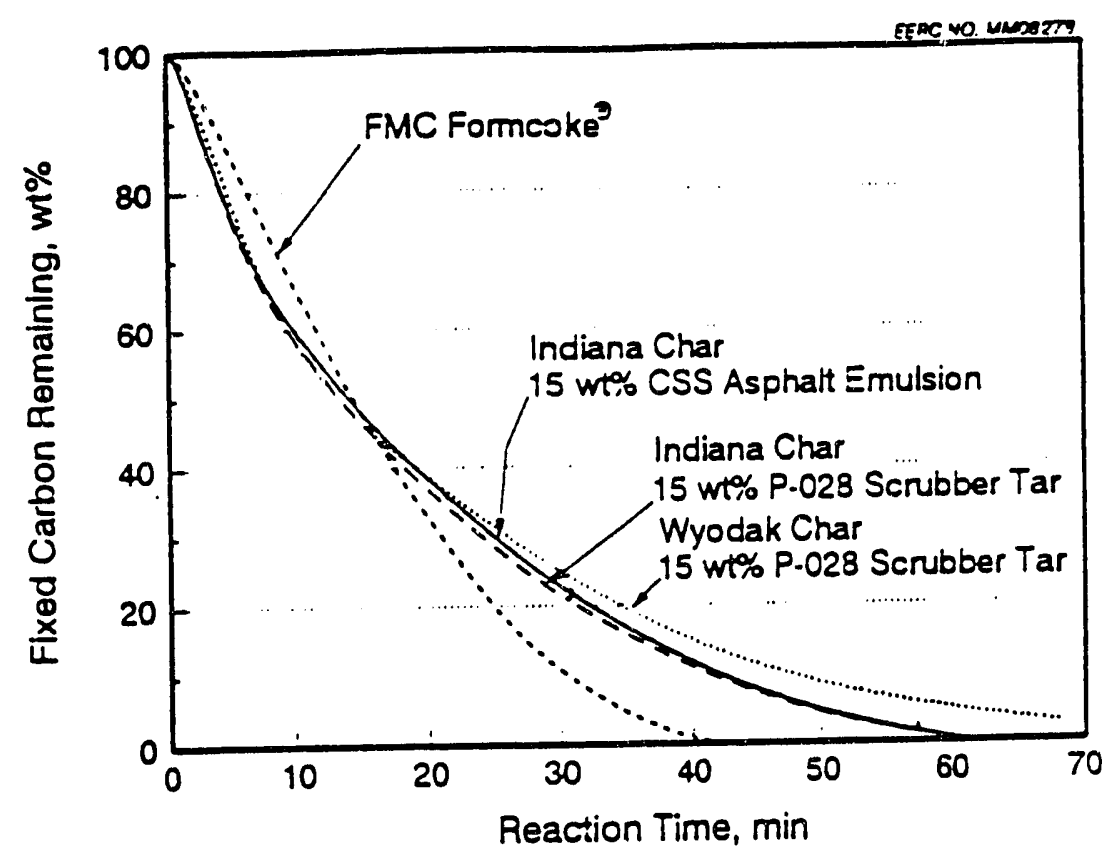

Figure 88. Reactivity of coke briquettes.

The lower reaction order for the FMC formcoke and Indiana formed coke briquettes relative to the Wyodak formed coke indicate that the rate of reaction of the Indiana formed coke and FMC formcoke briquettes are much less dependent upon the carbon concentration.

\subsubsection{Conclusions}

- The production of briquettes potentially suited for blast furnace fuel requires that Indiana and Wyodak char briquettes made with coal-derived tars/pitches and petroleum-derived asphalts and resids be oven-cured in an oxygen atmosphere to develop strength and be coked in an inert atmosphere to reduce volatile matter content.

- Indiana and Wyodak chars when mixed with the asphalt emulsions, FMC formcoke pitch, P028 scrubber tar, and P027 scrubber tar distillation resid as binders yielded durable oven-cured tablets with high compressive strengths.

- When the briquettes of Indiana char together with 15 wt\% P027 scrubber tar distillation resid and of Wyodak char and 20 wt\% P028 scrubber tar were coked, their strength approached that of FMC formcoke ${ }^{\infty}$. 


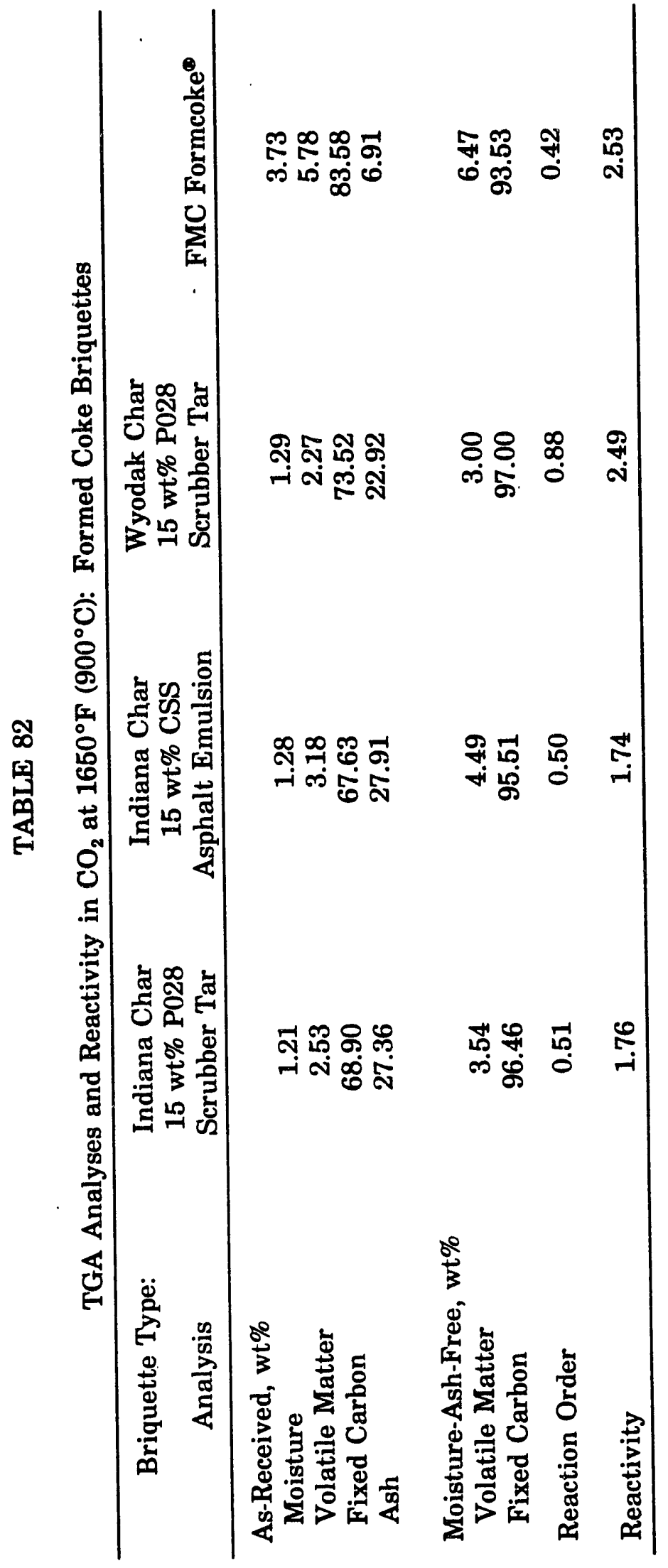


- Indiana char briquettes containing 15 wt\% or less P028 scrubber tar or 15 wt\% asphalt emulsion did not meet the strength criteria. Similarly, Wyodak char briquettes containing 15 wt\% P028 scrubber tar did not meet the strength criteria.

- Coked Indiana and Wyodak char briquettes were resistant to moisture absorption under simulated conditions of water soaking and rain showers.

- The reactivity towards carbon dioxide of the Indiana and Wyodak formed coke briquettes was somewhat lower than that of the FMC formcoke $e^{\oplus}$, but this is probably largely due to the higher ash content of the two tested char materials.

- Wyodak char briquettes, with strength and durability similar or superior to that of a commercial barbecue briquette, can be prepared using starch binders at concentrations of $\sim 4 \mathrm{wt} \%$. Exceedingly strong briquettes with almost complete shatter and abrasion resistance can be prepared with 7 wt\% starch.

- Briquettes made from Wyodak char combined with starch and scrubber tar or petroleum resid have the potential for an industrial, utility, or residential fuel, as they showed good strength, durability, ano resistance to moisture absorption.

- Briquettes produced with starch or combinations of starch and other binders develop complete strength and durability within 4 to 7 days of air-curing. The development of strength and durability can be shortened to hours rather than days using oven-curing.

\subsubsection{Recommendations}

- The amount of char/binder briquetted in future tests should be increased by approximately ten times based on the same throughput described herein to allow determination of proper conditions for steady-state operation.

- Formed coke testing should concentrate on the mild gasification-derived binder which shows considerable promise for producing an acceptable briquette, P027 scrubber tar distillation resid. The economics of the process could be enhanced if the $720^{\circ} \mathrm{F}\left(382^{\circ} \mathrm{C}\right)$ fraction can be sold to generate added revenue. The revenue could be used to purchase additional binders if the formed coke strength and durability prove inadequate.

- The strength and durability of formed coke briquettes should be investigated further as a function of char type (bituminous vs. subbituminous) and char properties (volatile matter content, ash content and particle-size distribution).

- The conditions (temperature, time, $\% \mathrm{O}_{2}$ ) for oven-curing to maximize strength and durability during formed coke production should be determined as a function of binder type and quantity. 


\subsection{ALTERNATIVE CHAR PRODUCTS}

\subsection{Pelletized Activated Carbon Production for the Capture of $\mathrm{SO}_{2}$}

Activated carbon has a wide variety of uses, mainly in water and air purification. These markets are well developed and would not be amenable to heavy penetration from a mild gasification process. New markets in $\mathrm{SO}_{2}$ and heavy metal adsorption, due to new clean air legislation, have been identified as having potential for expansion (see Sinor Addendum). Limited studies, due to budgetary constraints, were conducted on Wyodak coal to determine the feasibility of using the char for $\mathrm{SO}_{2}$ adsorption.

The char was initially activated with steam at $1380^{\circ} \mathrm{F}\left(750^{\circ} \mathrm{C}\right)$. The end product was then pelletized due to the amount of fine material produced, which would prove to be a handling problem in an adsorption column. The results from these tests are summarized below.

\subsubsection{Pellet Production Using the PTC Process}

Approximately 50 pounds of the char produced by Run M242 were pelletized to produce a solid activated carbon product which would perform well in a packed-bed style gas scrubber. From the $\mathrm{SO}_{2}$ adsorption data, the pelletizing appeared to have little effect on the ability of the carbon to trap $\mathrm{SO}_{2}$. The material handling characteristics were greatly increased by the pelletizing. The spherical pellets had a nominal diameter of 0.5 inches. Data on the physical characteristics of the pellets are listed in Table 83.

The pellets were produced using Wyodak char produced at $1380^{\circ} \mathrm{F}\left(750^{\circ} \mathrm{C}\right)$ with a $12 \%$ steam $/ \mathrm{N}^{2}$ atmosphere using PTC technology. These pellets and char were produced for the activated carbon study. Two different pelletizing procedures were employed: the standard 300-psig steaming procedure and a special low-pressure cure that has shown promise for carbon agglomeration.

The test matrix employed utilized two different grinds on the char: -10 mesh and -40 mesh. Table 84 shows the sieve analysis for the various grinds. Table 85 shows the proximate analysis of the char. The pellet production was difficult at -10 mesh, with a marked buildup of coarse char particles in the pellet disc, and the pellets appeared to become enriched in binder as compared to pellets made from -40 -mesh material. A minimum grind of -40 mesh would be appropriate on a commercial basis.

For the 300-psig steam process, three different calcium oxide/silica ratios of $2.4,4.3$, and 1.0 were used, as shown in Table 86. The proximate analyses for the green and hardened pellets are shown in Table 87. The best results were at the 2.6 ratio, which gave a crush strength of 31.7 pounds on a $3 / 4$-inch pellet and a drop strength of 13.6 drops. These pellets had a 3-mesh survival rate of $86.45 \mathrm{wt} \%$ on 200 revolutions in the abrasion test. These results are marginal for materials that will have to be used in bulk material handling systems.

For the special low-pressure curve, three binder levels were employed using a calcium/silica ratio of 2.6. Test DB-2 employed a -10 -mesh grind and $15 \mathrm{wt} \%$ total binder. The material was difficult to pelletize, as previously mentioned, but produced a pellet 
Table 83

Pellet-Making Results

\begin{tabular}{cccrrrr}
\hline & \multicolumn{2}{c}{ Green Pellets } & \multicolumn{2}{c}{ Dry Pellets } & \multicolumn{2}{c}{ Hardened Pellets } \\
Test & Crush & Drops & Crush & Drops & Crush & Drops \\
\hline DB-1 & 15.0 & +25 & 20.2 & 11.4 & 39.8 & 13.4 \\
DB-4 & 13.4 & +25 & 11.4 & 2.3 & 31.7 & 13.6 \\
DB-6 & 12.9 & +25 & 7.9 & 1.2 & 16.4 & 4.5 \\
DB-7 & 13.2 & +25 & 11.8 & 2.5 & 27.9 & 15.2 \\
DB-2 & 14.7 & +25 & 19.7 & 4.3 & 128.0 & +50 \\
DB-3 & 13.4 & +25 & 11.4 & 2.3 & 55.6 & +50 \\
DB-5 & 16.2 & +25 & 10.5 & 4.1 & 154.7 & +50 \\
\hline
\end{tabular}

Table 84

Wyodak Char Sieve Analysis

\begin{tabular}{|c|c|c|c|c|c|c|c|c|}
\hline \multirow[b]{2}{*}{ Mesh } & \multicolumn{2}{|c|}{--As-Received-- } & \multicolumn{3}{|c|}{-Ground to -10 Mesh-- } & \multicolumn{3}{|c|}{--Ground to -40 Mesh-- } \\
\hline & $\begin{array}{c}\% \\
\text { Retained }\end{array}$ & $\begin{array}{c}\% \\
\text { Cum. }\end{array}$ & Mesh & $\begin{array}{c}\% \\
\text { Retained }\end{array}$ & $\begin{array}{c}\% \\
\text { Cum. }\end{array}$ & Mesh & $\begin{array}{c}\% \\
\text { Retained }\end{array}$ & $\begin{array}{c}\% \\
\text { Cum. }\end{array}$ \\
\hline 4 & 0.3 & 0.3 & & & & & & \\
\hline 10 & 22.6 & 22.9 & 10 & 1.0 & 1.0 & & & \\
\hline 20 & 34.4 & 57.3 & 20 & 34.3 & 35.3 & & & \\
\hline 40 & 27.5 & 84.8 & 40 & 41.1 & 76.4 & 40 & 0.6 & 0.6 \\
\hline 70 & 12.8 & 97.6 & 70 & 20.6 & 97.0 & 70 & 5.6 & 6.2 \\
\hline 100 & 1.0 & 98.6 & 100 & 1.2 & 98.2 & 100 & 13.4 & 19.6 \\
\hline 140 & 0.6 & 99.2 & 140 & 0.6 & 98.8 & 140 & 16.5 & 36.1 \\
\hline-140 & 0.8 & 100.0 & .140 & 1.2 & 100.0 & 200 & 22.7 & 58.8 \\
\hline & & & & & 1.9. & -200 & 41.2 & 100.0 \\
\hline
\end{tabular}

Table 85

Wyodak Char Proximate Analysis (Dry Basis)

\begin{tabular}{lrr}
\hline & EERC & PTC \\
\hline Fixed Carbon & 80.97 & 81.92 \\
Volatiles & 5.63 & 4.98 \\
Ash & 13.40 & 13.10 \\
\hline
\end{tabular}


Table 86

Calcium Oxide/Silica Ratios and Cure Treatments

\begin{tabular}{ccrcc}
\hline Test & Grind & $\% \mathrm{CaO}$ & $\% \mathrm{SiO}_{2}$ & Cure Treatment \\
\hline DB-1 & -10 Mesh & 7.25 & 2.75 & $1 \mathrm{hr}$ of Steam \\
DB-4 & -40 Mesh & 7.25 & 2.75 & $1 \mathrm{hr}$ of Steam \\
DB-6 & -40 Mesh & 8.10 & 1.90 & $1 \mathrm{hr}$ of Steam \\
DB-7 & -40 Mesh & 5.10 & 4.90 & $1 \mathrm{hr}$ of Steam \\
DB-2 & -10 Mesh & 10.35 & 4.15 & Low Pres. Cure \\
DB-3 & -40 Mesh & 7.25 & 2.75 & Low Pres. Cure \\
DB-5 & -40 Mesh & 9.40 & 3.60 & Low Pres. Cure \\
\hline
\end{tabular}

Table 87

Proximate Analysis Results

\begin{tabular}{ccccc}
\hline & --Green Pellets-- & \multicolumn{3}{c}{.....-Hardened Pellets-...... } \\
Test & Moisture & \% FC & \% Vol. & \% Ash \\
\hline DB-1 & 30.0 & 69.27 & 5.99 & 24.74 \\
DB-4 & 32.7 & 72.18 & 6.25 & 21.57 \\
DB-6 & 33.5 & 72.03 & 6.34 & 21.63 \\
DB-7 & 34.0 & 71.36 & 5.96 & 22.68 \\
DB-2 & 26.6 & 65.91 & 6.17 & 27.92 \\
DB-3 & 32.7 & 72.18 & 6.25 & 21.57 \\
DB-5 & 31.3 & 70.61 & 5.85 & 23.54 \\
\hline
\end{tabular}

with good strength and abrasion resistance. It should be suitable for use in bulk material handling systems. The second test employed a total binder addition of $10 \mathrm{wt} \%$ at a -40 -mesh grind. These $\%$-inch pellets had a crush strength of 55.6 pounds with a +50 drop strength, as shown in Table 83. The abrasion index was $89.45 \mathrm{wt} \%$. The third test employed $13 \mathrm{wt} \%$ binder at a -40 -mesh grind. Crush strength was improved to 154.7 pounds with $a+50$ drop strength and an abrasion index of 92.9 wt\%. This pellet should be strong enough to be handled in bulk material handling systems.

Overall, the low-pressure cure step produced superior pellets, so the capital and operating cost of the process on a commercial scale would be greatly reduced. The results from the tests do not necessarily represent the optimum mechanical properties for this char. The binder addition at a calcium oxide/silica ratio of 2.6 should also provide for additional sulfur capture. 


\subsection{2 $\mathrm{SO}_{2}$ Absorption Characteristics}

Four runs were completed on the CFBR to produce activated carbon. Table 88 lists the conditions of the activated carbon production runs. In each case, Wyodak was used as the feed coal.

To test the efiectiveness of the activated carbon produced, thermogravimetric analysis (TGA) was performed with an argon/sulfur dioxide sweep gas. The weight increase of the carbon over time indicated the amount of $\mathrm{SO}_{2}$ picked up by the sample. The results of these tests are listed in Table 89. In addition, the proximate analysis of each carbon sample is listed.

High-surface-area char was also produced when the char was subject to a methanation process. These chars were not tests for $\mathrm{SO}_{2}$ adsorption. The following section describes the methanation process.

\subsection{Methanation of Wyodak Char}

Samples of Wyodak char produced in the CFBR were subjected to methanation tests to determine the potential suitability of the char as a feedstock for the production of pure carbon. Table 90 summarized the analyses of the raw char and the spent chars resulting from the methanation reaction with hydrogen at $300 \mathrm{psig}$ in a bench-scale reactor at AMAX R\&D. The conversion (weight loss) for the Wyodak char during methanation was $45 \%$ at $1380^{\circ} \mathrm{F}\left(750^{\circ} \mathrm{C}\right)$ and $55 \%$ at $1470^{\circ} \mathrm{F}\left(800^{\circ} \mathrm{C}\right)$. The spent chars exhibited reasonable surface areas for activated carbon production.

\section{Table 88}

Conditions for Activated Carbon Production Runs

\begin{tabular}{cccc}
\hline Run Number & Bed Temperature & Pressure, psig & \% Steam \\
\hline M239 & $930^{\circ} \mathrm{F}\left(500^{\circ} \mathrm{C}\right)$ & 10 & 0 \\
M240 & $1380^{\circ} \mathrm{F}\left(750^{\circ} \mathrm{C}\right)$ & 10 & 0 \\
M241 & $1380^{\circ} \mathrm{F}\left(750^{\circ} \mathrm{C}\right)$ & 10 & 26 \\
M242 & $1380^{\circ} \mathrm{F}\left(750^{\circ} \mathrm{C}\right)$ & 10 & 12 \\
\hline
\end{tabular}

Table 89

TGA and Proximate Analysis Results

\begin{tabular}{ccccrc}
\hline Sample & \% Moisture & \% Volatile & $\begin{array}{c}\text { \% Fixed } \\
\text { Carbon }\end{array}$ & \% Ash & $\begin{array}{c}\mathrm{SO}_{2} \% \text { Weight } \\
\text { Increase }\end{array}$ \\
\hline M239 & 0.53 & 19.70 & 73.25 & 6.52 & 4.6 \\
M240 & 0.63 & 4.47 & 84.78 & 10.12 & 5.3 \\
M241 & 0.71 & 4.69 & 84.29 & 10.31 & 8.1 \\
M242 & 1.00 & 5.77 & 80.15 & 13.26 & 6.0 \\
Pelletech & 10.75 & 10.89 & 51.22 & 27.16 & 5.9 \\
\hline
\end{tabular}


TABLE 90

Characterization of EERC Char

\begin{tabular}{lccc}
\hline & $\begin{array}{c}\text { UNDEERC } \\
\text { Char }\end{array}$ & $\begin{array}{c}1380^{\circ} \mathrm{F}\left(750^{\circ} \mathrm{C}\right) \\
\text { Spent Char }\end{array}$ & $\begin{array}{c}1470^{\circ} \mathrm{F}\left(800^{\circ} \mathrm{C}\right) \\
\text { Spent Char }\end{array}$ \\
\hline Proximate Analysis, wt\% & & & \\
Moisture & 3.6 & 2.2 & 2.2 \\
Volatile & 14.7 & 11.1 & 7.1 \\
Fixed Carbon & 75.2 & 70.8 & 70.3 \\
Ash & 10.1 & 18.2 & 22.7 \\
Ultimate Analysis, wt\% & & & \\
Carbon & 78.0 & 78.2 & 74.7 \\
Hydrogen & 2.1 & 1.3 & 0.9 \\
Sulfur & 0.5 & 0.7 & 0.6 \\
Nitrogen & 0.6 & 0.3 & 0.3 \\
Oxygen (BD) & 8.7 & 1.3 & 0.8 \\
Surface Area, $\mathrm{m}^{2} / \mathrm{g}$ & 6.0 & 600.0 & 690.0 \\
\hline
\end{tabular}




\subsection{COAL LIQUID PRODUCTS}

The market survey identified several areas that the liquids could penetrate into current commercial markets. These include anode binders used in the aluminum industry, diesel fuel additives, and chemical feedstocks. The results from analysis of the liquids for these uses are reported below.

\subsection{Anode Binder Production from Indiana No. 3 Condensables}

Liquid collected from Test P027 was separated by AMAX for anode binder production analysis. The results are reported in Table 91, for the three fractions. The heavy fraction contains $18 \mathrm{wt} \%$ in the pitch boiling point range. Given this pitch content, it was decided to perform vacuum distillation to produce a pitch sample.

Pitch vacuum distillation was conducted in a bench-scale glass apparatus. A vacuum of $46 \cdot \mathrm{mmHg}$ absolute pressure was obtained. At this pressure, the final temperature was $529^{\circ} \mathrm{F}\left(276^{\circ} \mathrm{C}\right)$, which yields a pitch boiling above $747^{\circ} \mathrm{F}\left(397^{\circ} \mathrm{C}\right)$ at atmospheric pressure. The pitch yield was $30 \mathrm{wt} \%$, indicating that the single-stage distillation used was fairly inefficient, and the pitch will contain a significant fraction of sub- $747^{\circ} \mathrm{F}\left(397^{\circ} \mathrm{C}\right)$ material. Nonetheless, evaluation of the distillation residue should give a good indication of the potential of this material for use in anode-binder manufacturing.

Several properties of the pitch are shown in Table 92, along with typical aluminum industry specifications for anode-binder-quality material. Based on the elemental analysis, it is apparent that the sulfur content of P027 pitch is high. This is not surprising, given the high sulfur content of the parent coal.

Ash content is also high, but can be reduced by optimizing the cyclone design on the carbonizer to reduce the amount of fines carryover. The carbon and hydrogen analyses were used to compute the $\mathrm{C} / \mathrm{H}$ atomic ratio. For $\mathrm{P} 027$ pitch, this ratio is too low, indicating that the pitch contains some low boiling material and also suggesting that the carbon aromaticity is low. Given that this material was produced at temperatures much lower than used in coke ovens, it is not surprising that the aromaticity is low.

In addition to elemental analysis, the pitch was evaluated for several properties important in anode manufacture. The softening point was measured by the cube-in-air method and is in the acceptable range. Toluene insolubles (TI) are slightly low. Quinoline insolubles (QI), which are suspended solids thought to be similar to carbon black, are also low. Both the TI and QI could be increased by adding a few weight percent of carbon black to this material. This might also increase the coking value into the acceptable range.

Overall, the pitch could not be utilized as an anode binder because of the high sulfur content. However, other properties of the pitch look very promising. Table 92, also presents the Cannelton pitch results. The sulfur is still slightly above the binder pitch specification, but is very close. Ash content is also high, as is calcium, the softening point. The TI and QI are slightly low, but with the addition of carbon black, they should fall within the range. The coking value is also low. The results are within the range of specification where the material should $b$, investigated further. 
TABLE $91^{\circ}$

Analytical Results for P.027 Liquic's

\begin{tabular}{lccc}
\hline & $\begin{array}{c}\text { Oil } \\
\text { Fraction }\end{array}$ & $\begin{array}{c}\text { Light } \\
\text { Fraction }\end{array}$ & $\begin{array}{c}\text { Heavy } \\
\text { Fraction }\end{array}$ \\
\hline Carbon & 87.23 & 88.08 & 86.44 \\
Hydrogen & 11.35 & 9.37 & 7.79 \\
Nitrogen & 1.32 & 0.62 & 0.80 \\
Sulfur & 1.03 & 1.95 & 2.37 \\
Oxygen & 2.20 & 0.95 & 2.79 \\
Distillation & & & \\
$\quad 204^{\circ} \mathrm{C}$ & 85 & 21 & 21 \\
$\quad 11$ & 73 & 61 \\
371. $371^{\circ} \mathrm{C}$ & 4 & 6 & 18 \\
Water Content & $<0.1$ & $<0.1$ & $<0.1$ \\
(ASTM D-95-83) & & & \\
\hline
\end{tabular}

* Values are given in wt\%.

TABLE 92

Sandlick Coal

\begin{tabular}{lcccc}
\hline & $\begin{array}{c}\text { P.027 } \\
\text { Pitch }\end{array}$ & $\begin{array}{c}\text { P.027 }+ \\
\text { Lampblac } \\
\text { k Pitch }\end{array}$ & $\begin{array}{c}\text { Stockton } \\
\text { Pitch }\end{array}$ & $\begin{array}{c}\text { Binder Pitch } \\
\text { Specifications }\end{array}$ \\
\hline Ultimate Analysis & & & & \\
$\quad$ Carbon & 86.17 & 87.32 & 84.22 & - \\
Hydrogen & 5.76 & 5.56 & 6.44 &.- \\
Nitrogen & 1.02 & 1.00 & 1.69 & - \\
Sulfur & 2.57 &.- & 0.8 & $<0.60$ \\
Oxygen (ind.) & 3.65 & 3.30 & 4.86 & - \\
Ash & 1.56 & -- & 1.09 & $<0.35$ \\
C/H Atomic & 1.25 & 1.31 & 1.09 & $>1.70$ \\
Ca, ppm & 318 &.- & 197 & $<100$ \\
Na, ppm & 54 & -- & 59 & $<100$ \\
Softening Point, ${ }^{\circ} \mathrm{C}$ & 114 & 120 & 135 & $108-114$ \\
Toluene Insolubles, wt\% & 24 & 238 & 23 & $>26$ \\
Quinoline Insolubles, wt\% & 8 & 13 & 10 & $12-17$ \\
Coking Value, wt\% & 43 & 46 & 40 & $>54$ \\
\hline
\end{tabular}




\subsection{Specialty Chemical Production}

Merichem, Houston, Texas, is interested in obtaining new sources of cresylic acids. Three samples with the following boiling point distribution were evaluated:
1) Light distillate
ibp to $420^{\circ} \mathrm{F}\left(216^{\circ} \mathrm{C}\right)$
2) Middle distillate
$420^{\circ} \mathrm{F}$ to $720^{\circ} \mathrm{F}\left(216^{\circ}\right.$ to $\left.382^{\circ} \mathrm{C}\right)$
3) Pitch
$720^{\circ} \mathrm{F}+\left(382^{\circ} \mathrm{C}+\right)$

The analysis of the light distillate for Wyodak liquids showed it to contain about $40 \%$ usable cresylic acid by caustic extraction. These liquids were obtained by AMAX from the Western Research Institute (WRI) mild gasification project. The data are included because the liquids produceu in the EERC project from Wyodak coal should be similar.

The extracted acid was contaminated with the expected impurities, primarily neutral oils and nitrogen compounds. The distribution of cresylic acid showed less phenol than found in many coal liquids and a greater amount of ortho- and para-substituted isomers, as compared to meta-substitution. Overall, the crude sodium cresylate obtained by caustic extraction of the light distillate should make an acceptable feedstock to the Houston based plant.

The middle distillate fraction was first distilled to concentrate the cresylic acid boiling range. Distillation to $500^{\circ} \mathrm{F}\left(260^{\circ} \mathrm{C}\right)$ gave an overhead yield of $13 \%$. This fraction was caustic-extracted in a manner similar to the light distillate to yield acid in a quantity representing $6.9 \%$ of the original middle distillate sample. The quality was also similar to the acid isolated from the light distillate.

The pitch contained no usable cresylic acid. Table 93 shows the component breakdown of the cresylic acid distribution.

TABLE 93

Cresylic Acid Distribution

\begin{tabular}{cc}
\hline Component Name & Percent \\
\hline Phenol & 14.42 \\
o-Cresol & 4.80 \\
2,6-Xylenol & 0.78 \\
p-Cresol & 7.96 \\
m-Cresol & 6.40 \\
o-Phenol & 0.80 \\
2,4-/2,5-Xylen & 4.95 \\
2,4,6-TMF & 0.32 \\
2,3-Xylenol & 0.52 \\
p-Phenol & 2.35 \\
m-Phenol & 1.47 \\
3,5-Xylenol & 1.05 \\
3,4-Xylenol & 1.11 \\
C9+ Phenols & 4.14 \\
Total & 51.07 \\
\hline
\end{tabular}



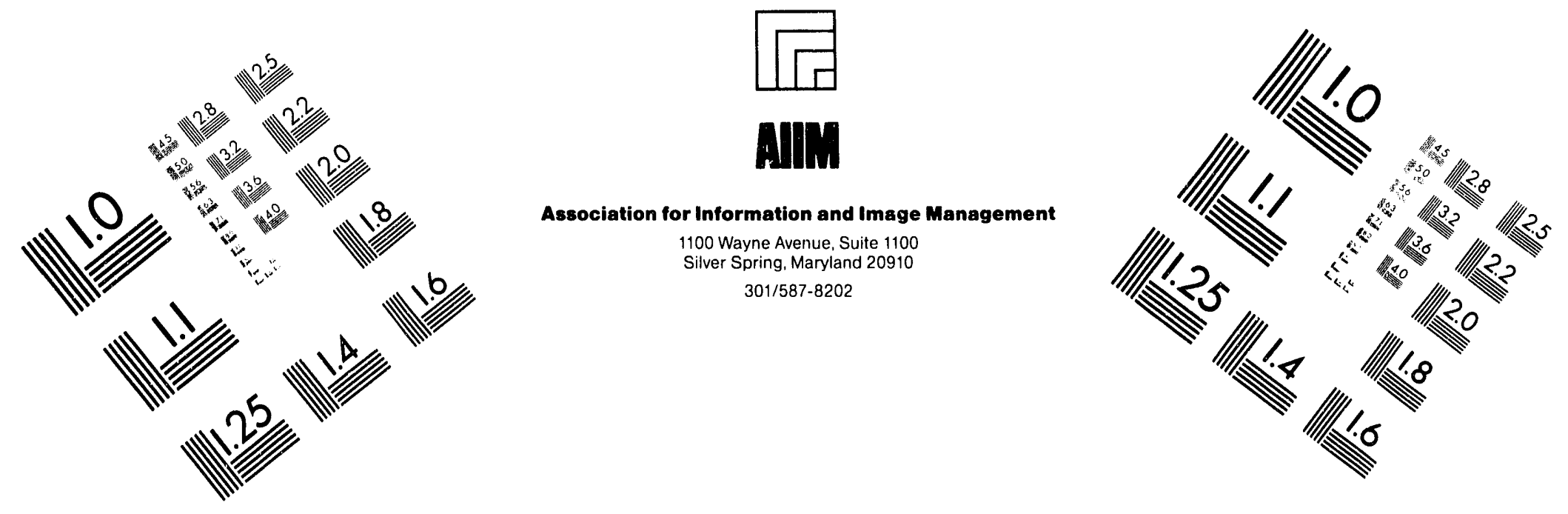

\section{Centimeter}

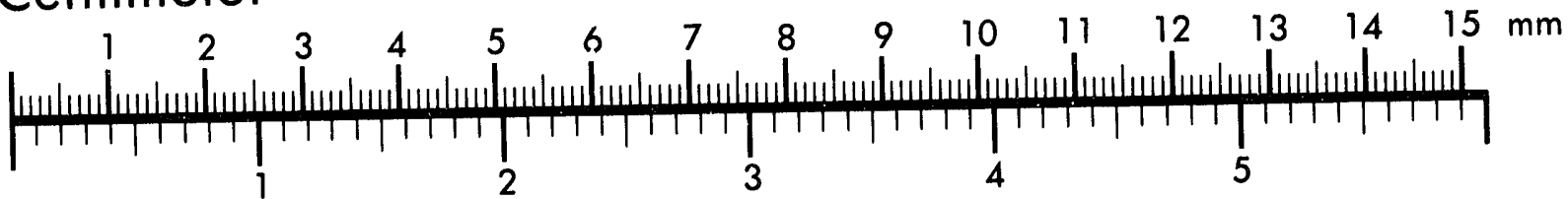
Inches
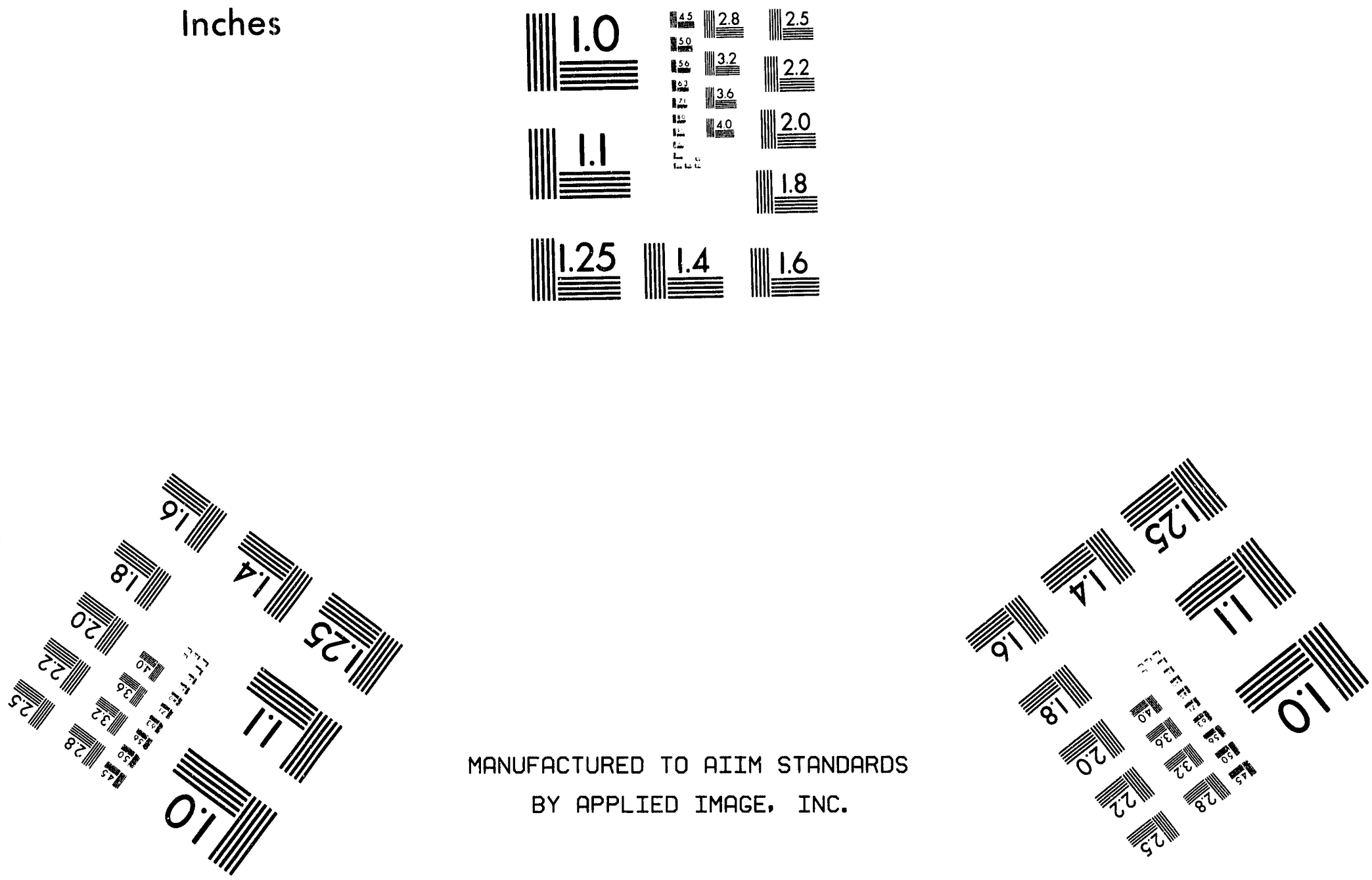

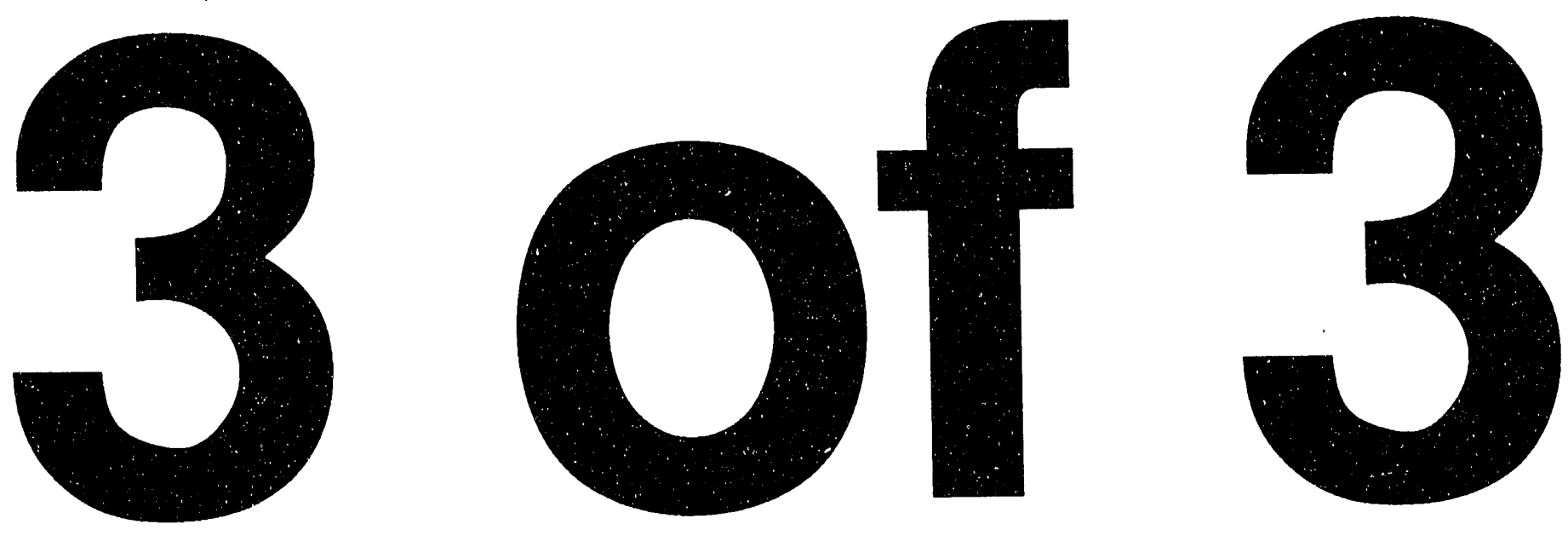
The Indiana No. 3 liquids yielded cresylic acids in quantities less than $5 \%$ of the original sample. The isomer distribution was normal for coal-based feed stocks and contained the expected aromatic contaminants. The lack of acids can be attributed to the lower oxygen content of the Indiana No. 3 coal compared to Wyodak coal, so the lower acid content should be expected.

\subsection{Diesel Fuel Additives}

The results from the diesel fuel testing are being conducted by Oak Ridge National Laboratories under a separate DOE contract and were not available by the publication deadline. 


\subsection{SUMMARIES AND CONCLUSIONS}

The major findings of the work under Tasks 2, 3, and 4 are summarized based on data from the tests on Indiana No. 3, Wyodak, and Cannelton coals in the TGA, the CFBR, and the PRU. All yields reported are as a percent of moisture and ash free coal.

\subsection{The Effect of Process Conditions on Char Yield and Char Quality for Indiana No. 3, Wyodak, and Cannelton Coals}

\subsubsection{PRU Results}

Operability of the PRU carbonizer was satisfactory for both the Indiana No. 3 and Wyodak coals. Table 94 shows the char yields and char quality from tests on the PRU and CFBR. The Indiana char is expressed for cleaned and non-cleaned char. The lower yields for the cleaned char is due to the amount of char that is rejected in each gravity/magnetic separation that occurs between processing steps. No internal oxidation was assumed which raised the carbonizer yield by $16 \%$. Internal oxidation was only used to maintain reactor temperature due to heat leak.

The Wyodak char was the only char that met mettalurgical coke specifications. The volatile content was higher than typical coke; however, this is only a general specification that is tied to the briquet strength only. Typically the higher the volatile content results in lower briquette strength. For the Wyodak char, the volatile content was satisfactory. The Cannelton char is reported without being cleaned. If the relative reduction of the Indiana No. 3 char can be used as a comparison, the Cannelton char could be reduced to $12-13 \%$ which would be slightly higher than the specifications. The volatile content is low which should produce a high strength coke substitute. The Indiana did not meet the ash or sulfur content desired.

\section{TABLE 94}

Char Yields and Quality

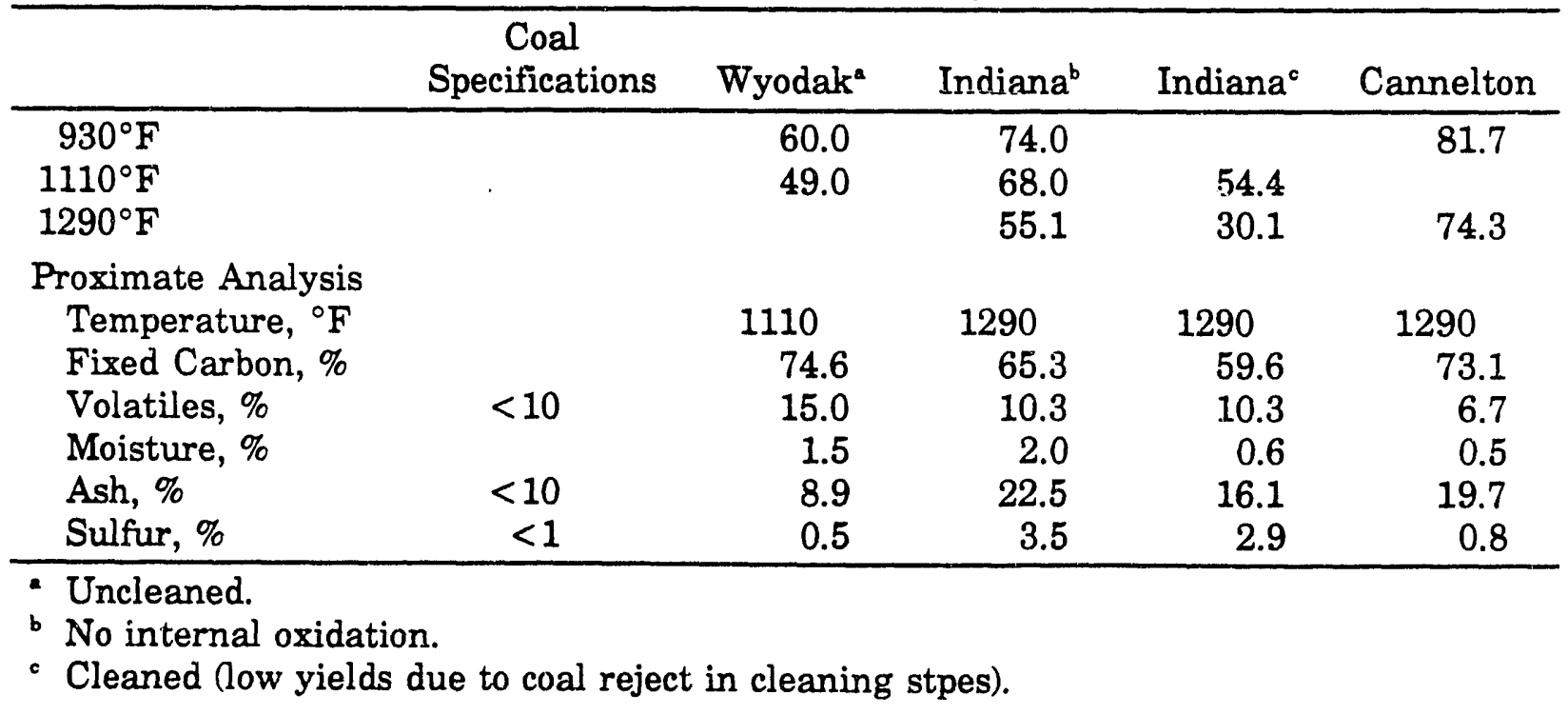


Char yields in the PRU with internal oxidation for the Indiana tests varied from $44.9 \%$ to $59.3 \%$ over a temperature range oi 1,020 to $1,200^{\circ} \mathrm{F}\left(550-650^{\circ} \mathrm{C}\right)$ with limited agglomeration which presented no operational difficulties. The major variation was due to oxidation in the reactor for some test points in order to meet the desired run temperature. Only one mass balance was completed for the Wyodak coal which had a yield of $49 \%$ at $1100^{\circ} \mathrm{F}\left(600^{\circ} \mathrm{C}\right)$.

\subsubsection{CRBR Test Results}

Operability of the CFBR was satisfactory on non-caking Wyodak subbituminous coal. Some problems were experienced with repeatability owing to variation in char residence time and loss of condensables in the indirectly cooled condensers. Satisfactory operation on mildly caking Indiana No. 3 and Cannelton bituminous coal was accomplished only by temperature staging, using char from a lower temperature run as feed for a subsequent run at a higher temperature. Temperature stages used were $660^{\circ}$, $750^{\circ}, 840^{\circ}, 930^{\circ}$, and $1470^{\circ} \mathrm{F}\left(350^{\circ}, 400^{\circ}, 450^{\circ}, 500^{\circ}\right.$, and $\left.800^{\circ} \mathrm{C}\right)$. Other methods that were tried for controlling agglomeration in this small size reactor were of very limited help, including preoxidation of the coal feed, oxidation within the reactor, and use of a limestone bed.

Char yields were determined in the CFBR between $930^{\circ}$ and $1110^{\circ} \mathrm{F}\left(500^{\circ}\right.$ and $600^{\circ} \mathrm{C}$ ) for Wyodak subbituminous coal, at staged temperatures between $660^{\circ}$ and $1470^{\circ} \mathrm{F}$ $\left(350^{\circ}\right.$ and $\left.800^{\circ} \mathrm{C}\right)$ for Indiana No. 3 bituminous coal, and at staged temperatures between $660^{\circ} \mathrm{F}$ and $1290^{\circ} \mathrm{F}\left(350^{\circ} \mathrm{C} \cdot 700^{\circ} \mathrm{C}\right)$ for the Cannelton coal. The char yields decreased along with increasing temperature, and were significantly higher for the Indiana No. 3 coal, which yielded about $74 \mathrm{wt} \%$ char at $930 \mathrm{oF}\left(500^{\circ} \mathrm{C}\right)$ and $61 \mathrm{wt} \%$ at $1470^{\circ} \mathrm{F}\left(800^{\circ} \mathrm{C}\right)$. Corresponding yields for Wyodak were about $60 \mathrm{wt} \%$ at $930^{\circ} \mathrm{F}\left(500^{\circ} \mathrm{C}\right)$ and $50 \mathrm{wt} \%$ at $1110^{\circ} \mathrm{F}\left(600^{\circ} \mathrm{C}\right)$. Yields for the Cannelton coal were $82 \mathrm{wt} \%$ and $74 \mathrm{wt} \%$ at $930^{\circ} \mathrm{F}$ and $1292^{\circ} \mathrm{F}\left(500^{\circ} \mathrm{C} \cdot 700^{\circ} \mathrm{C}\right)$, respectively.

A calcining temperature of $1470^{\circ} \mathrm{F}\left(800^{\circ} \mathrm{C}\right)$ was needed to reduce the volatile matter content of the Indiana No. 3 char below 10\%, as required for use in char pellets or formcoke. At this temperature, a typical analysis for Indiana No. 3 char was $8.5 \%$ volatile matter, $74 \%$ fixed carbon, $19 \%$ ash, and $3.4 \%$ sulfur without upgrading.

\subsection{The Effect of Process Conditions on Condensable and Gas Yields}

\subsubsection{PRU Test Results}

A wide variety of yields and boiling point distributions were observed for the three coals as shown in Table 95. This table has data from the PRU and the CFBR. The Wyodak condensables approximated a liquid that was lighter than a decant oil (\#6 diesel). The Indiana No. 3 liquids were the lightest and produced a 17.8\% yield. Gas yields are shown in Table 96. The Indiana No.3 yields are adjusted for no internal oxidation. which resulted in a reduction of $\mathrm{CO}_{2}$.

Operation difficulties were encounterd with operation of the tar scrubber. After 2030 hours of operation, the tar would solidify. The problems were eliminated by redesigning the scrubber cyclones to eliminated mist entrainment and lowering the outlet temperature of the tar scrubber. This increased the amount of liquid condensed in the 
TABLE 95

Condensable Yields and Quality

\begin{tabular}{|c|c|c|c|c|c|c|c|c|c|}
\hline & \multicolumn{2}{|c|}{$\begin{array}{l}12 \text { Diesel } \\
\text { Decant Oil }\end{array}$} & \multicolumn{2}{|c|}{ Wyodak } & \multicolumn{2}{|c|}{ Indian } & \multicolumn{2}{|c|}{ Cannelton } & \multirow{6}{*}{$\begin{array}{l}\text { Gasoline Octane Enhancers, Benzene } \\
\text { Creoglic Acids, Phenols } \\
\text { Diesel Fuel Blends } \\
\text { Briquetting Binders, Anode Carbon }\end{array}$} \\
\hline & & & Yield & Percent & Yield & Percent & Yield & Percent & \\
\hline ibp $-330^{\circ} \mathrm{F}$ & $10 \%$ & & 0.3 & 3 & 0.7 & 4 & 0.1 & 1 & \\
\hline $330^{\circ}-430^{\circ} \mathrm{F}$ & $86 \%$ & & 3.2 & 34 & 6.2 & 35 & 2.7 & 14 & \\
\hline \multirow{3}{*}{$\begin{array}{l}430^{\circ}-700^{\circ} \mathrm{F} \\
700^{\circ}-1020^{\circ} \mathrm{F}\end{array}$} & $4 \%$ & $44 \%$ & 3.9 & $\begin{array}{l}41 \\
22\end{array}$ & $\begin{array}{r}10.7 \\
0 ?\end{array}$ & 60 & 14.1 & 74 & \\
\hline & 100 & 060 & 2.1 & 22 & & & & & \\
\hline & 100 & 100 & 9.5 & 100 & 17.8 & 100 & 19.0 & 100 & \\
\hline
\end{tabular}

TABLE 96

Gas Yields

\begin{tabular}{rccc}
\hline & Wyodak & Indiana $^{\mathrm{a}}$ & Cannelton \\
$930^{\circ} \mathrm{F}$ & 31.0 & 10.0 & 5.0 \\
$1110^{\circ} \mathrm{F}$ & 42.0 & 19.0 & \\
$1290^{\circ} \mathrm{F}$ & & 22.0 & 8.0 \\
\hline
\end{tabular}

" No internal oxidation.

scrubber so it decreased the coal fines/liquid ratio and also increased the amount of light liquids in the recycle liquids that acted as a solvent for the heavy tars. After the modifications were made, longer operational times were achieved but pluggage eventually occured. The tar heat exchanger surface area needed to be increased so a lower gas exit temperature could be maintained over a longer period of time.

The sieve tower and water scrubber performed very well over a wide range of gas velocities and heat loads. During the coarse of operation, the outlet temperature of the sieve tower was reduced to below the dew point of water, in response to the reduction in outlet temperature of the tar scrubber. This reduced the heat duty on the water scrubber which served as a backup unit to remove entrained organics from the sieve tower.

\subsubsection{CFBR Test Results}

The total yield of volatiles, including gases and condensables, was somewhat higher for Wyodak subbituminous coal than for Indiana No. 3 bituminous coal because of the large amount of $\mathrm{CO}_{2}$ released from the subbituminous coal. Total gas yield for the Wyodak coal ranged from $31 \%$ to $51 \%$ between $930^{\circ}$ and $1110^{\circ} \mathrm{F}\left(500^{\circ}\right.$ and $\left.600^{\circ} \mathrm{C}\right)$, generally increasing along with temperature.

The total yield of gas from Indiana No. 3 coal ranged from a low of $2 \%$ to $5 \%$ at $660^{\circ} \mathrm{F}\left(350^{\circ} \mathrm{C}\right)$ to about $20 \%$ at $1470^{\circ} \mathrm{F}\left(800^{\circ} \mathrm{C}\right)$. Yields of all major gas components generally increased along with temperature. The measured gas compositions varied widely, but typical ranges were $50 \%$ to $70 \%$ for $\mathrm{CO}_{2}, 8 \%$ to $14 \%$ for $\mathrm{CH}_{4}, 3 \%$ to $12 \%$ for $\mathrm{CO}$, and up to $3 \%$ for $\mathrm{H}_{2}$. 
Yields of condensable organic liquids were higher for Indiana No. 3 bituminous coal than for Wyodak subbituminous. The cumulative yields obtained by staged heating of Indiana No. 3 coal increased along with temperature from less than $1 \%$ at $660^{\circ} \mathrm{F}\left(350^{\circ} \mathrm{C}\right)$ to about $18 \%$ at $930^{\circ} \mathrm{F}\left(500^{\circ} \mathrm{C}\right)$, and remained at $18 \%$ at the calcining temperature of $1470^{\circ} \mathrm{F}\left(800^{\circ} \mathrm{C}\right)$ owing to essentially zero liquid yield upon further heating of product char prepared at $930^{\circ}$ to $1470^{\circ} \mathrm{F}\left(500^{\circ}\right.$ to $\left.800^{\circ} \mathrm{C}\right)$. The maximum yield was less than that predicted by the Fischer Assay correlation, possibly due both to the short residence time of the fine coal/char feed fraction in the fast fluidized bed reactor, and to loss of light condensables in the indirectly cooled condensation train.

The liquid yield for Wyodak coal was highest (10.7\%) at the lowest test temperature of $930^{\circ} \mathrm{F}\left(500^{\circ} \mathrm{C}\right)$, and decreased by varying amounts to levels between $0.2 \%$ and $9.7 \%$ depending on the gas atmosphere in the carbonizer (affected mainly by steam partial pressure).

The gas yield for the Cannelton coal was considerable lower than the other two coals. Yields varied from $5 \%$ to $8 \%$ at temperatures from $930^{\circ}$ to $1,920^{\circ} \mathrm{F}\left(500^{\circ}-700^{\circ} \mathrm{C}\right)$. Condensable yields ranged from $14 \%$ to $19 \%$ over the same temperature range with a large quantity in the $430^{\circ} \cdot 700^{\circ} \mathrm{F}\left(221^{\circ} \cdot 371^{\circ} \mathrm{C}\right)$ boiling point range. The most important feature of the Cannelton liquids was the quality. It resembled a \#3 diesel fuel. The Cannelton produced a very low quantity of gases with the amount of gas increasing with coal rank.

\subsection{The Effect of Gas Atmosphere Including Steam on Liquid Yield and Quality (CFBR Test Results)}

The use of steam increased the liquid yield from Wyodak coal in three different gas atmospheres, including: 1) $\left.\mathrm{CO}_{2}, 2\right) \mathrm{N}_{2} / \mathrm{CO}_{2}$ representing flue gas, and 3) $\mathrm{N}_{2} / \mathrm{CO}_{2} / 2 \% \mathrm{O}_{2}$ representing flue gas with excess air. The effect of steam was noted primarily at the highest test temperature of $1110^{\circ} \mathrm{F}\left(600^{\circ} \mathrm{C}\right)$, where in all cases an increase in steam partial pressure caused a monotonic increase in liquid yield - which in the case of the $\mathrm{N}_{2} / \mathrm{CO}_{2}$ gas atmosphere amounted to an increase from $0.2 \%$ liquid at $21 \%$ steam to $9.7 \%$ at $88 \%$ steam. The presence of $2 \% \mathrm{O}_{2}$ surprisingly did not reduce the liquid yield, which was higher with $2 \% \mathrm{O}_{2}$ than that for $\mathrm{N}_{2} / \mathrm{CO}_{2}$ alone at a low steam partial pressure, and about the same at higher levels of steam. At lower temperatures of $1020^{\circ}$ and $930^{\circ} \mathrm{F}$ $\left(550^{\circ}\right.$ and $\left.500^{\circ} \mathrm{C}\right)$, the Wyodak liquid yield varied with steam partial pressure in a manner that did not define a systematic trend.

For Indiana No. 3 coal, liquid yield increased consistently but only slightly along with an increase in steam at lower staging temperature between $660^{\circ}$ and $750^{\circ} \mathrm{F}\left(350^{\circ}\right.$ and $400^{\circ} \mathrm{C}$ ). At higher temperatures, no consistent trend was observed.

The boiling point profiles and compound distributions for the two tesi coals differed, as shown in Table 97 . The 3\% to $4 \%$ low boiling aromatic fraction (BTX) is believed to be lower than the amount actually produced because of losses in the condensation train. Wyodak coal when carbonized without steam produced the highest yield of phenolics boiling between $330^{\circ}$ and $430^{\circ} \mathrm{F}\left(170^{\circ}\right.$ and $\left.220^{\circ} \mathrm{C}\right)$, but with steam the yield was similar to that for Indiana No. 3 coal. The $430^{\circ}$ to $700^{\circ} \mathrm{F}\left(220^{\circ}\right.$ to $\left.370^{\circ} \mathrm{C}\right)$ fraction was higher for Indiana No. 3 coal, but the even higher boiling pitch fraction was nearly missing for this coal as tested. 
TABLE 97

Comparison of Wyodak and Indiana No. 3 Condensable Boiling Point Fractions

\begin{tabular}{lccc}
\hline & \multicolumn{3}{c}{ Percent of Liquid Produced } \\
\cline { 2 - 4 } $\begin{array}{l}\text { Boiling Point Range and } \\
\text { Major Compound Type }\end{array}$ & $\begin{array}{c}\text { Wyodak } \\
1110^{\circ} \mathrm{F} \\
0 \% \text { Steam }\end{array}$ & $\begin{array}{c}\text { Wyodak } \\
1110^{\circ} \mathrm{F} \\
99 \% \text { Steam }\end{array}$ & $\begin{array}{c}\text { Indiana Staged to } \\
1470^{\circ} \mathrm{F} \\
30 \% \text { Steam }\end{array}$ \\
\hline ibp to $330^{\circ} \mathrm{F}, \mathrm{BTX}$ & 4.0 & 3.4 & 3.6 \\
$330^{\circ}$ to $430^{\circ} \mathrm{F}$, phenolic. & 44.0 & 34.1 & 35.4 \\
$430^{\circ}$ to $700^{\circ} \mathrm{F}$, multi-ring & 34.7 & 40.6 & 59.6 \\
$\begin{array}{l}\text { aromatics and alkylated } \\
\text { phenolics }\end{array}$ & & & \\
above $770^{\circ} \mathrm{F}$, crude pitch & 17.4 & 21.9 & 1.4 \\
\hline
\end{tabular}

The most prominent effect of steam was to promote higher liquid yields from Wyodak coal at the higher carbonization temperature of $1110^{\circ} \mathrm{F}\left(600^{\circ} \mathrm{C}\right)$. At this condition, the steam is believed to have prevented the retrograde condensation and polymerization of organic compounds on the highly reactive surface of the Wyodak char. Another possible scenerio is the steam provides a better mechanism for removing the tar from the char pore structures.

At any given temperature, the condensable yield with steam prcauced an equivalent amount of liquids as a higher operating temperature without steam. It is believed that the effect was not as pronounced for Indiana No. 3 coal because of the inherently lower reactivity of bituminous coal compared to subbituminous coals.

\subsection{The Effect of Process Conditions on Sulfur Removal}

Sulfur reduction played a major role in the development of the process as the main feed coal had a sulfur content over $4.2 \%$. Since the program was to provide for engineering data for commercialization, existing sulfur reduction techniques listed in the literature were reviewed and incorported in the process. It was apparent from the initial market assessment and economic projections, that only the most inexpensive sulfur removal techniques would allow the process to be economically viable. This lead to using physical separation techniques and in bed sulfur capture as the only options.

A series of tests were conducted to establish the data base using a TGA and the CFBR in conjunction with analytical techniques that include SEM with elemental mapping. A summary of the findings on in-process sulfur removal includes the following points:

- Pyritic sulfur was effectively reduced to low levels, but organic sulfur as defined by ASTM analytical methods was not.

- Essentially no loss of sulfur occurred in the first stage of heating to $660^{\circ} \mathrm{F}$ $\left(350^{\circ} \mathrm{C}\right)$ that was used to control agglomeration. 
- The extent of pyritic sulfur removal was determined mainly by temperature, with the loss due to conversion of pyrite to pyrrhotite $\left(\mathrm{FeS}_{2}\right.$ to $\left.\mathrm{FeS}\right)$ occurring at or below carbonization temperatures of $840^{\circ}$ to $930^{\circ} \mathrm{F}\left(450^{\circ}\right.$ to $\left.500^{\circ} \mathrm{C}\right)$, and the remainder being lost at char calcining temperatures of $1290^{\circ}$ to $1470^{\circ} \mathrm{F}\left(700^{\circ}\right.$ to $800^{\circ} \mathrm{C}$ ).

- Reaction time had an important influence on the amount of pyritic and total sulfur removed. The effect extended beyond the 20 to 30 minute residence time at staging temperatures in the TGA and CFBR, since the largest reduction in total sulfur content (from $3.9 \%$ to $1.2 \%$ ) was observed after six hours residence time in the $30-1 \mathrm{~b} / \mathrm{hr}$ fluidized bed reactor.

- Gas atmosphere had some effect on sulfur removal, but it was not the primary controlling factor. Larger reductions in total sulfur content in TGA tests were noted in either-reducing ( $\mathrm{CO}$ or $\mathrm{H}_{2} / \mathrm{CO}$ ) or oxidizing atmospheres than in $\mathrm{N}_{2}$. The use of steam in the $1-\mathrm{lb} / \mathrm{hr}$ CFBR did not increase the extent of sulfur removal.

- The percent organic sulfur, determined by difference in the ASTM procedure, was not systematically reduced by increasing either temperature or reaction time under most of the conditions studied, although the level was significantly reduced after the six hours residence time noted above. The decrease observed in TGA tests was greater in an $\mathrm{N}_{2}$ atmosphere rather than in a reducing atmosphere.

- The chemical forms of sulfur in char were found to be more complex and diverse than the pyritic, sulfitic, and organic forms defined by the ASTM procedure. Analysis of char surfaces using SEM/EDS and ESCA indicated that important changes in the physical and chemical form of sulfur occurred at $720^{\circ}$ to $840^{\circ} \mathrm{F}$ $\left(380^{\circ}\right.$ to $\left.450^{\circ} \mathrm{C}\right)$ coincident with the onset of coal agglomeration and with the loss of sulfur from pyrite $\left(\mathrm{FeS}_{2}\right.$ to $\left.\mathrm{FeS}\right)$. The principal change observed was that discrete crystals containing sulfur (possibly pyrite) present at $660^{\circ} \mathrm{F}\left(350^{\circ} \mathrm{C}\right.$ ) had disappeared at $840^{\circ} \mathrm{F}\left(450^{\circ} \mathrm{C}\right)$ and were replaced by a low concentration of sulfur that was detected over the entire char surface. ESCA analysis of bond types at the higher temperature identified $\mathrm{S}-\mathrm{S},-\mathrm{SO}_{2},-\mathrm{SO}_{3}$, and $-\mathrm{SO}_{4}$ bonds, but no S.C bonds. SEM mappings of elements indicated some coincidence in the location of sulfur with $\mathrm{Fe}$ and $\mathrm{Ca}$.

- The evidence in this and other studies suggests that coal sulfur undergoes transformations during carbonization by a variety of reactions, but that in the end it is either removed in the gas or left in the char in a stable form. After heating to calcining temperatures, most of the remaining sulfur is in the ASTM organic form. No combination of time, temperature and gas atmosphere investigated in this study was successful in systematically removing this stable form of "organic sulfur."

Based on the available information, there are several scenerios as to why the sulfur reduction observed in some of the lab and CFBR tests were not observed in the PRU.

- The PRU did not stage the increase in operating temperature that was used in the lab and bench scale units. 
- The initial carbonization temperature was above the agglomeration temperature which may trap the sulfur in the coal pores. In the staged tests, each temperature was below the agglomeration temperature.

- The intital carbonization temperature was above the vaporization temperature of the elemental sulfur.

- The initial carbonization temperature was slightly above the pyrite formation temperture which would cause a decrease in the magnetic separation step.

- The two points that produced the lowest sulfur contents (1.4-1.6\%) had a bed residence time of 6 hours. The carbonizer residence time was 40 minutes.

Further investigation into the afore mentioned list would proceed with the following conditions:

- Process the coal at $660^{\circ} \mathrm{F}\left(350^{\circ} \mathrm{C}\right)$ for 20 minutes to raise the agglomeration temperature

- Process the char at $790^{\circ}$ to $845^{\circ} \mathrm{F}\left(420\right.$ to $\left.450^{\circ} \mathrm{C}\right)$ for residence times ranging from 20 minutes to 6 hours for sulfur reduction and raising the agglomeration temperature of the char

- Eliminate the magnetic separation step unless the amount of pyrite remains high under the new processing scenerio

- Calcine the char at $1470^{\circ}$ to $1650^{\circ} \mathrm{F}\left(800^{\circ}\right.$ to $\left.900^{\circ} \mathrm{C}\right)$ with a precalcined limestone for evaluating sulfur capture.

The afore mentioned scenerios were beyond the scope of this project which was a process development/scale up effort not a research project. In order to use the existing process, a $6.8 \%$ ash, $0.6-0.8 \%$ sulfur coal should be used as the feed coal which would eliminate the sulfur reduction necessity and decrease the amount of ash reduction necessary.

\subsection{Results of Char Upgrading for the Production of Metallurgical Coke Substitutes using Inorganic Binders (PTC Process)}

Table 98 includes a compilation of the compressive strengths, impact numbers, and tumble tests for the green pellets, dried pellets, and hardened pellets for the char with/without limestone. The individual tests for inorganic and organic binders use slightly different methods as described in their respective sections so only general comparisons can be made between the two binders.

The initial Wyodak char submitted to Pellet Technology Corporation (PTC) for testing contained an uncharacteristically high ash content of $27 \%$ owing to contamination from the limestone bed in the $30-\mathrm{lb} / \mathrm{hr}$ fluidized bed reactor used to produce this bulk sample. 


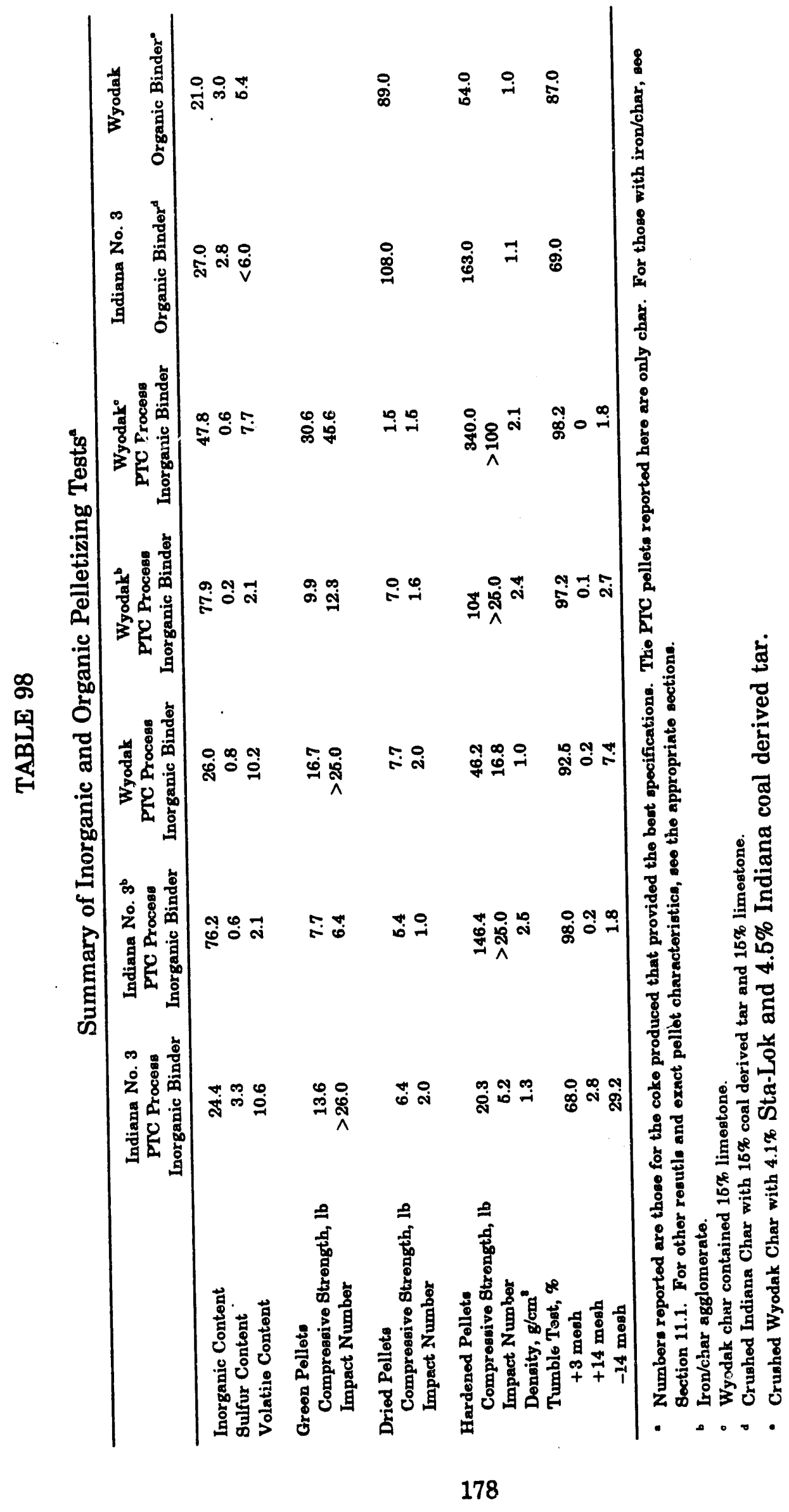


- $\mathrm{CaO}-\mathrm{SiO}_{2}$ bonded carbon pellets and carbon-iron ore pellets of 1-inch diameter were successfully produced by induration in saturated steam at $420^{\circ} \mathrm{F}\left(220^{\circ} \mathrm{C}\right)$ and 300 psig. Larger oval briquettes could not be produced because of the swelling behavior of the char in the green briquette.

- The finished pellets exhibited satisfactory strength, density, and abrasion resistance with $10 \% \mathrm{CaO}-\mathrm{SiO}_{2}$ binder, but not with $5 \%$ binder. Since the addition of inorganic binder increases the amount of slag in the iron smelting process, a smaller amount of binder would be a significant benefit.

- The char-iron ore pellets were reduced to iron metal at very high rates upon heating to $2700^{\circ} \mathrm{F}\left(1480^{\circ} \mathrm{C}\right)$. The 5 minutes required for reduction was estimated to be fivefold less than it would have been using colse-iron ore pellets, owing to the high reactivity of the Wyodak char.

The inorganic tests yielded marginally acceptable compressive strength pellets for the Indiana No. 3 and Wyodak chars. The char-iron ore agglomerates were superior in all categories. The sulfur and volatile contents on the agglomerates are considerably lower since they are made of $25 \%$ char and $75 \%$ iron ore.

\subsection{Results of Char Upgrading for the Production of Metallurgical Coke Substitutes Using Organic Binders}

The Wyodak and Indiana chars were briquetted using a variety of organic binder types and binder levels that ranged from molasses, and starch, acrylic copolymer emulsions to coal-derived liquids. The briquettes were then subjected to compressive strength, tumble, and impact tests for comparison purposes to the PTC pellets. The following is a summary of the organic binder briquette tests:

- The production of briquettes potentially suited for blast furnace fuel requires that Indiana and Wyodak char briquettes made with coal-derived tars/pitches and petroleum-derived asphalts and resids be oven-cured in an oxygen atmosphere to develop strength and be coked in an inert atmosphere to reduce volatile matter content.

- Indiana and Wyodak chars when mixed with the asphalt emulsions, FMC formcoke ${ }^{\otimes}$ pitch, P028 scrubber tar, and P027 scrubber tar distillation resid as binders yielded durable oven-cured tablets with high compressive strengths.

- When the briquettes of Indiana char together with 15 wt\% P027 scrubber tar distillation resid and of Wyodak char and 20 wt\% P028 scrubber tar were coked, their strength approached that of FMC formcoke ${ }^{\oplus}$.

- Indiana char briquettes containing $15 \mathrm{wt} \%$ or less P028 scrubber tar or $15 \mathrm{wt} \%$ asphalt emulsion did not meet the strength criteria. Similarly, Wyodak char briquettes containing 15 wt\% P028 scrubber tar did not meet the strength criteria.

- Coked Indiana and Wyodak char briquettes were resistant to moisture absorption under simulated conditions of water soaking and rain showers. 
- The reactivity towards carbon dioxide of the Indiana and Wyodak formed coke briquettes was somewhat lower than that of the FMC formcoke ${ }^{\otimes}$, but this is probably largely due to the higher ash content of the two tested char materials.

- Wyodak char briquettes, with strength and durability similar or superior to that of a commercial barbecue briquette, can be prepared using starch binders at concentrations of $-4 \mathrm{wt} \%$. Exceedingly strong briquettes with almost complete shatter and abrasion resistance can be prepared with 7 wt\% starch.

- Briquettes made from Wyodak char combined with starch and scrubber tar or petroleum resid have the potential for an industrial, utility, or residential fuel, as they showed good strength, durability, and resistance to moisture absorption.

- Briquettes produced with starch or combinations of starch and other binders develop complete strength and durability within 4 to 7 days of air-curing. The development of strength and durability can be shortened to hours rather than days using oven-curing.

Table 97 included a compilation of the compressive strengths, impact numbers, and tumble tests for the dried pellets, and cured pellets for the two chars. The two examples shown in the table are those with the coal derived liquid. The Wyodak pellet had a high sulfur content due the use of Indiana tar as the binder and the char was produced was a combination of Wyodak and Indiana No. 3 char.

\subsection{Results of Char Upgrading for the Production of Activated Carbon}

The production of activated carbon for use in the the adsorption of $\mathrm{SO}_{2}$ was investigated by producing calcined char with a small amount of steam present in the reactor. The resulting char was pelletized using the PTC process to provide a uniform particle of sufficient size and strength to be used in a filter device.

Sulfur capture was determined by using a TGA with an argon/sulfur dioxide sweep gas. The activated carbon produced at $1380^{\circ} \mathrm{F}\left(750^{\circ} \mathrm{C}\right)$ and with $26 \%$ of the fluidization gas being steam had the highest $\mathrm{SO}_{2}$ adsorption. The char increased in weight by $8.1 \%$. The next highest was the char produced with a $12 \%$ partial pressure of steam. Pelletizing the char had no effect on the adsorption capabilities of the char and produced a product that had much better material handling capabilities. Higher steam partial pressures should be investigated as the experimental matrix did not find the upper limit of steam partial pressure in relations to increased $\mathrm{SO}_{2}$ adsorption.

\subsection{Results of Condensable Upgrading for the Production of Anode Grade Carbon}

Liquid was collected f*om one Indiana No. 3 test. A vacuum distillation was performed on a fraction of liquids that had a boiling point greater than $700^{\circ} \mathrm{F}\left(371^{\circ} \mathrm{C}\right)$ The pitch produced from the distillation was analyzed for comparison to binder pitch specifications. As expected the ash and sulfur content were considerably higher than the established specifications. The sulfur content was $2.57 \%$ compared to $<0.6$ for the binder pitch which the ash content was 1.56 while the binder needed to be $<0.35$. Improving the cyclone efficiency in the commercial facility should drop the ash content to an acceptable 
level. The other properties, except for the sulfur content, are within the ranges exceptable when a small quantity of carbon black is added to the Indiana No. 3 pitch.

\subsection{Results of Condensable Upgrading for the Production of Cresylic Acid}

The Indiana No. 3 liquids yielded cresylic acids in quantities less than $5 \%$ of the original sample. This would not be economical to recover such a small quaritity of crysilic acid from the liquid stream. The Wyodak condensables that were provided to Merichem from the WRI mild gasification project contained $40 \%$ usable cresylic acids. "This amount merits further consideration into the economic merits.

\subsection{Results of Condensable Upgrading for the Production of Diesel Fuel Additives}

The results from the diesel fuel testing were being conducted by Oak Ridge National Laboratories under a separate DOE contract and were not available by the publication deadline.

\subsection{Program Recommendations}

The following list is the recommended requirement for further development on the mild gasification process for the production of co-products:

\section{Feed Coal Selection}

The feed coal selections should be reevaluated in relations to plant location and product selection/specification. The Indiana No. 3 coal was not upgraded to the product specifications necessary. A lower bituminous coal such as the Canneltion coal should be evaluated for mettalurgical coke substitute production.

The product selection in relation to the use of Wyodak coal should be reevaluted. The coal only produced enough liquid for use as a binder for the briquettes. The economics indicate the liquids play an important role plant viability and the condensable yields need to be over $15 \%$ in a plant that uses an organic binder. One alternative is the use of the PTC process and use all the liquids for value added products instead of binder. The advantages to the use of this subbituminous coal was the high oxygen content of the condensables for use as cresylic acid and the amount of pitch produced for the production of anode binder.

Specific coal characteristics should include liquid yields over $15 \%$ when an organic binder is used, the oxygen content of the coal should be high when cresylic acid may be a product, the sulfur content should have a low organic sulfur content and the overall content should be less than $0.8 \%$, and the ash content should be between the $6.8 \%$ range.

\section{Sulfur Reduction Techniques}

Several areas of further development should continue if a high sulfur coal is to be used as the feedstock material. The carbonizer temperature should be lower for the production of pyrite for magnetic separation. A long residence time carbonization step 
should be evaluated for sulfur reduction. Tests should also be conducted at temperatures slightly below the agglomeration temperature for swelling coals.

The magnetic separation step should be eliminated if sulfur rejection can not be improved. The calciner in -bed sulfur capture was not fully evaluted due to the unacceptable sulfur release in the two previous process steps. Physical separation techiques for the capture agent and char need to be developed further and higher temperatures should be investigated.

\section{Unit Operation Improvement}

More testing needs to be done on the tar scrubber. More information is needed on the heat transfer coefficients for the hot tar and the vapor/liquid equilibrium data for coal liquids in dilute concentrations in nitrogen atmospheres. More modeling of the process will provide a better understanding of the operational windows the the condensation train.

\section{Reactor Type}

If a non-agglomerating coal was selected as the main feed coal, a bubbling bed reactor could be used and a significant reduction in capital expense would be realized in the liquid condensation train due to the increase in the dew point of the liquids.

\section{Product Evaluation}

The production of larger quantities of briquetts and condensables is need for better end use evaluation. Briquett quantities need to produce hundreds of tons of material to be evaluated in cupolas and blast furnaces. Large quantities of condensables are needed for more detailed upgrading evaluations.

\section{National Energy and Environmental Policy}

For any new coal technologies to successfully penetrate todays markets, a stable long term national energy and environmental policy is necessary. These processes will always be niche market plants due to the vast infrastructure the United States has developed for oil and electrical production by combustion of coal if a stable economy and environmental regulations are maintained. 


\subsection{REFERENCES}

1. Woessner, P.W. "The Coal Refinery, A Concept," Presented at the Twelfth International Conference on Slurry Technology, New Orleans, LA, Apr. 1987.

2. Willson, W.G.; Ness, R.O.; Hendrikson, J.G.; Entzminger, J.A.; Jha, M.; Sinor, J.E. "Development of an Advanced, Continuous Mild Gasification Process for the Production of Co-Products, Literature Survey Results," DOE METC, DE-AC2187MC24267, Jan. 1988.

3. Sinor, J.E. "Development of an Advanced, Continuous Mild Gasification Process for the Production of Co-Products, Industrial Market Assessment of the Products of Mild Gasification," DOE METC, DE-AC21.87MC24267, Jan. 1988.

4. Smit, F.J. "Preparation and Analysis of Low-Rank Coals for Combustion Applications, Final Report," DOE METC, DE-AC18-84FC10623, AMAX Research and Development Center, Golden, CO, Oct. 1986.

5. Ode, W.H.; Sehrig, W.A. U.S. Bureau of Mines RI \#3748, Mar. 1944.

6. Knell, E.W. et al. "Flash Pyrolysis Coal Liquefaction Process Development," annual report; Fe-7244-20, Jan.-Dec. 1977.

7. Jones, J.F. et al. "Char Oil Energy Development, Final Report," 8/18/71-6/30/75, Vol. VI, Sep. 1975.

8. Internal EERC Memo. Illinois State Geological Survey Meeting Notes, Aug. 16, 1989.

9. Boley, C.C.; Fegley, M.M. "Design and Operation of Two Refractory-Lined, Internally Heated, Entrained-Flow Carbonizers," GFERC/RI-77/1, Jan. 1977.

10. Sondreal, E.A.; Ness, R.O.; Timpe, R.C.; Knudson, C.L.; Tha, M.C.; Berggren, M.H.; Sinor, J.E. "Mild Gasification for Production of Metallurgical Carbon, Diesel Fuel, and Chemicals," Presented at the 6th Korea/U.S.A. Joint Workshop on Coal Utilization Technology, Seoul, Korea, Oct. 1989.

11. Cleyle, P.J.; Caley, W.F.; Stewart, I.; Whiteway, S.G. Fuel 1962, 63, 1579-1582.

12. Stoddard, L.E.; Hughes, J.R.; Kulberg, H.A. "Production of Hydrogen from LowRank Coals: Process Design and Cost Estimate for Hydrogen Production from LowRank Coals," final report for the period ending May 2, 1989; DOE METC, DE-FC2186MC10637, May 1989.

13. Cernic-Simic, S. "A Study of Factors that Influence the Behavior of Coal Sulfur During Carbonization,". Fuel 1962, 41 (2).

14. Wert, C. et al. "Analysis of Organic Sulfur in Coal by Use of Transmission Electron Microscopy," Journal of Coal Quality 1988, 7 (4).

15. Goetz, G., The City of Grand Forks, Department of Water and Wastewater, personal communication, 1989. 
APPENDIX A

TASK 2 MILD GASIFICATION TEST PROGRAM 


\section{TASK 2 MILD GASIFICATION TEST PROGRAM}

The Energy and Environmental Research Center (EERC) performed the various subtasks of the mild gasification study as discussed below. Results from all tests are discussed in detail in the final report. The goals for this program included:

1. Producing sufficient char at each test point for char upgrading and pellet testing.

2. Determining the effect of volatile content on pellet and steel characteristics.

3. Determining the level of sulfur in the char.

4. Determining system operational characteristics and acquiring engineering data to enable scaleup of the gasification system. The following program describes how these goals were accomplished.

\section{Subtask 2.1 - Test Plan for Mild Gasification Study}

A preliminary design, utilizing available equipment and findings from the current EERC mild gasification project, was suggested. The following parameters were to be included:

1. Coal type (Indiana No. 3, Illinois No. 6, Wyodak)

2. Temperature $\left(660^{\circ}\right.$ to $1470^{\circ} \mathrm{F}\left[350^{\circ}\right.$ to $\left.\left.800^{\circ} \mathrm{C}\right]\right)$

3. Solid residence time (minutes)

4. Gaseous environment (steam, $\mathrm{CO}_{2}$, product, or flue gas)

These tests investigated areas of particular importance for economic and operability performance only. An outline for the test program, shown in Table A1, was developed for existing EERC equipment. Matrix 1 determined product distribution as a function of coal, temperature, and residence time. Matrix 2 determined the relationship of temperature and reactive gas atmosphere. Residence time was dependent on the type of coal fed to the unit.

\section{Subtasks 2.2 and 2.3 - Reactor Design, Construction, and Modification}

The EERC used several units for the mild gasification work, including a 1- to 4-lb/hr continuous fluidized-bed reactor (CFBR) and a 30-pound/hour pressurized fluid-bed gasifier (PFBG). The CFBR was used in the Grand Forks Energy Technology Center (GFETC) fast fluid-bed carbonizer mode and later in a bubbling-bed mode. The first segment of testing utilized char and volatiles removal through the top of the reactor. The second segment had a top bed drain for removing solids.

Three other units were used for screening and developing an initial database on coals: two TGA units and a pyrolysis unit coupled to a GC/FID. 
TABLE A1

EERC Mild Gasification Test Matrix

(1- to 4-lb/hr Continuous Fluid-Bed Reactor [CFBR])

Matrix 1, steam atmosphere

2 Coals (Indiana No. 3, Wyodak)

3 Temperatures $\left(930^{\circ}, 1110^{\circ}\right.$, and $1290^{\circ} \mathrm{F}\left[500^{\circ}, 600^{\circ}\right.$, and $\left.\left.700^{\circ} \mathrm{C}\right]\right)$

$\frac{3}{18} \quad$ Residence Times

18 Data Points

Goal:

Produce a variety of chars with different volatile contents for char upgrading and pellet testing.

Matrix 2

3 Types (steam, $\mathrm{CO}_{2}$, product gas composition)

3 Temperatures $\left(930^{\circ}, 1110^{\circ}\right.$, and $1290^{\circ} \mathrm{F}\left[500^{\circ}, 600^{\circ}\right.$, and $\left.\left.700^{\circ} \mathrm{C}\right]\right)$

3 Residence Times

27 Data Points

(Matrix 2 will be performed using $30-\mathrm{lb} / \mathrm{hr}$ PFBG runs)

Goal:

Determine the effect of different fluidizing gases on product yields.

TABLE A2

PRU MIID GASIFICATION SYSTEM EQUTPMENT LIST

VESSELS, MAJOR EQUIPMENT, AND PUMPS

Steani Boiler

Steam Superheater

Boiler Feedwater Treatment

Sparge Tank

Dowtherm System

Carbonizer

Carbonizer Feed Hopper

Carbonizer Feeder

Carbonizer Flue Gas Generator

Primary Carbonizer Cyclone

HV Char Storage Bin

Secondary Carbonizer Cyclone

Char Fines Collection Bin \#1

Calciner

Calciner Feed Hopper 
TABLE A2 (continued)

Calciner Feeder

Calciner Flue Gas Generator

Calciner Cyclone

LV Char Storage Bin

Secondary Carbonizer Cyclone

Char Fines Collection Bin \#2

Tar Venturi Scrubbers

Tar Cooler

Tar Quench Circulation Pump

Venturi Scrubber Cyclone Heater \#1

Water Venturi Scrubber

Tar Oil Cooler

Oil/Water Circulation Pump \#1

Venturi Scrubber Cyclone Heater \#2

Oil Sieve Tower

Oil Cooler

Oil Quench Circulation Pump

Venturi Scrubber

Oil/Water Cooler

Oil/Water Circulation Pump \#2

Tar Transfer Barrel Heater

Tar/Oil Transfer Barrel Heater

Tar Transfer Tank

Tar/Oil Transfer Tank

Oil/Water Transfer Tank \#1

Oil/Water Transfer Tank \#2

Tar Sample Vessel

Tar/Oil Sample Vessel

Oil/Water Sample Vessel

Condensate Transfer Pump

Emergency Tar Quench Vessel

Flare

Flare Knockout Pot

Wastewater Storage Tank

Wastewater Pump

Extraction Column

Spent Solvent Storage Tank

Solvent Condenser

Solvent Recovery Column

Solvent Recovery Reboiler

Crude Phenol Storage Tank

Clean Solvent Receiver Tank

Clean Solvent Feed Tank

Solvent Pump

Solvent Ext. WW Storage Tank

WW Polishing Absorber \#1, \#2, \#3

Activated Sludge Unit 
TABLE A2 (continued)

\section{VALVES}

Area 200

Oxygen Flow Valve

Calciner Tempering Nitrogen Valve

Calciner Natural Gas

Boiler Pressure Valve

Carbonizer Transport Nitrogen Valve

Carbonizer Temporing Nitrogen Valve

Carbonizer Natural Gas

Carbonizer Steam Valve

Area 300

Plenum Vent

Carbonizer Star Feeder

Carbonizer Auger

Carbonizer Coal Hopper Nitrogen Valve

Area 400

Calciner Star Feeder

Calciner Auger

Calciner Coal Hopper Nitrogen Valve

Calciner Back Pressure Valve

Area 500

Tar Scrubber Recycle Pump

Tar Heat Exchanger Fan

Sieve Tower Heat Exchanger Water Valve

Sieve Tower Heat Exchanger Oil Valve

Water Scrubljer 1 Heat Exchanger Water Valve

Water Scrubber 1 Heat Exchanger Oil Valve

Water Scrubber 2 Heat Exchanger Water Valve

Water Scrubber 2 Heat Exchanger Oil Valve

Back Pressure Valve

Area 600

Main Natural Gas Makeup Valve

Calciner Air Valve

Carbonizer Air Valve

Corblin Compressor Valve

Calciner Steam Valve

Area 700

Filter 1 Valve

Filter 2 Valve

Secondary Cyclone Bypass Valve

Primary Exit Valve

Hot Gas Bypass Valve 
APPENDIX B

MILD GASIFICATION - ANALYTICAL TEST PROCEDURES 


\section{MILD GASIFICATION - ANALYTICAL TEST PROCEDURES}

\section{Thermogravimetric and Elemental Analysis Experimental Procedure}

The temperature/pressure conditions of the reactor during mild gasification were simulated as closely as possible in the laboratory by heating each coal sample in a 100-gcapacity thermogravimetric analyzer (TGA) under various atmospheres as rapidly as possible $\left(210^{\circ} \mathrm{F}\left[100^{\circ} \mathrm{C}\right]\right.$ per minute) to $1290^{\circ} \mathrm{F}\left(700^{\circ} \mathrm{C}\right)$. The char was then allowed to cool to room temperature. Data was recorded at 2 -second intervals, and a plot of this data was analyzed to determine yield structure. Carbon, hydrogen, nitrogen, sulfur (CHNS) analyses for the chars were obtained. The wt\% sulfur removed during pyrolysis was determined by difference between wt\% sulfur in the as-run coal and the respective coal char.

\section{Pyrolysis Gas Chromatography/Mass Spectrometry Experimental Procedure}

Figure B1 shows a schematic of the pyrolysis apparatus. Approximately 2 to $4 \mathrm{mg}$ of coal were placed in a $30-\mathrm{cm} \times 4-\mathrm{mm}$-ID quartz tube. The sample was positioned approximately $5 \mathrm{~cm}$ from the outlet of the quartz tube with a plug of quartz wool. The outlet of the tube was attached to a $1 / 4^{\prime \prime} \times 1 / 16^{\prime \prime}$ stainless steel union fitted with a 2 " $\mathrm{x}$ 0.20 -mm-ID needle. The sample tube was placed in a brass block heater preheated to $1290^{\circ} \mathrm{F}\left(700^{\circ} \mathrm{C}\right)$. During pyrolysis, the needle was inserted into the split/splitless injection port, the helium flow was diverted from the injection port (to sweep the pyrolysis products out of the pyrolysis chamber and into the injection port), and the block heater was dropped down around the sample. The injection port was operated at a split ratio of approximately 1:100. The volatiles entering the fused silica capillary chromatographic

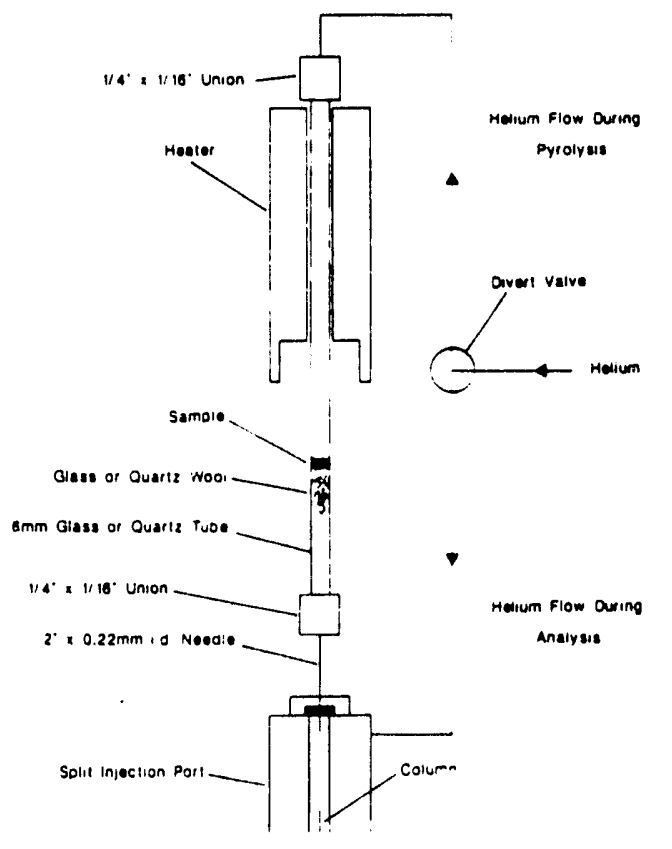

Figure B1. EERC pyrolysis/GC/MS apparatus. 
column were cryogenically trapped by holding the oven temperature at $32^{\circ} \mathrm{F}\left(0^{\circ} \mathrm{C}\right)$ during the 10 -minute pyrolysis. Upon completion of the pyrolysis, the column oven was heated rapidly to $120^{\circ} \mathrm{F}\left(50^{\circ} \mathrm{C}\right)$ followed by temperature programming at $45^{\circ} \mathrm{F}\left(8^{\circ} \mathrm{C}\right)$ per minute to $90^{\circ} \mathrm{F}\left(32^{\circ} \mathrm{C}\right)$. GC/MS analysis of the pyrolysis products was performed with a HewlettPackard model 5985B using a 60-m x 0.25-mm-ID $(0.25 \cdot \mu \mathrm{m}$ film thickness) DB-5 fused silica capillary column (J\&W Scientific, Folsom, California). Helium was used as the carrier gas at an approximate linear flow rate of $50 \mathrm{~cm} / \mathrm{sec}$. Electron impact (EI) mass spectra were generated at $70 \mathrm{eV}$ with a scan range of 50 to 400 amu.

Quantitation was achieved by injecting $1 \mu \mathrm{L}$ of a $1.47-\mu \mathrm{g} / \mu \mathrm{L}$ internal standard into the quartz plug and allowing it to air dry for 15 minutes prior to pyrolysis. The internal standard used was 1-chloronaphthalene. Quantitation is based on the assumption that the electron impact response for each of the compounds in the condensables is the same.

\section{Product Characterization and Data Analysis}

Because of the varit $5 y$ of products, a number of analyses were required. Data from these analyses were also compared with the large, in-house database. This allowed direct comparison with complementary or competing technologies and provided a more complete picture of the process. The largest databases available were the EERC Hydrogen and Jet Fuel programs.

The following tests were conducted for characterization of the products.

\section{Gas Analysis}

1. $\mathrm{H}_{2}, \mathrm{CO}, \mathrm{CO}_{2}, \mathrm{CH}_{4}, \mathrm{C}_{1}-\mathrm{C}_{4}$, and $\mathrm{H}_{2} \mathrm{~S}$

\section{Condensable Analysis}

Figure B2 shows an extraction method that was used in removing organics from the aqueous portion of the product.

\section{Char Analysis}

1. CHN and Sulfur

2. Moisture

3. Ash

4. Volatile Content

The aforementioned arialyses were performed on each run on the $1-$ to $4-\mathrm{lb} / \mathrm{hr}$ and $30-\mathrm{lb} / \mathrm{hr}$ units and on selected samples from the screening study on the analytical units. Special analyses that were done on selected samples included:

Liquid Analysis

- GC/Mass Spec and GC/FID

- Class Separation 


\section{Char Analysis}

- SEM

The special analyses were used to track chemical groups to determine where specific fractions appeared in the feed material and in the product distribution.

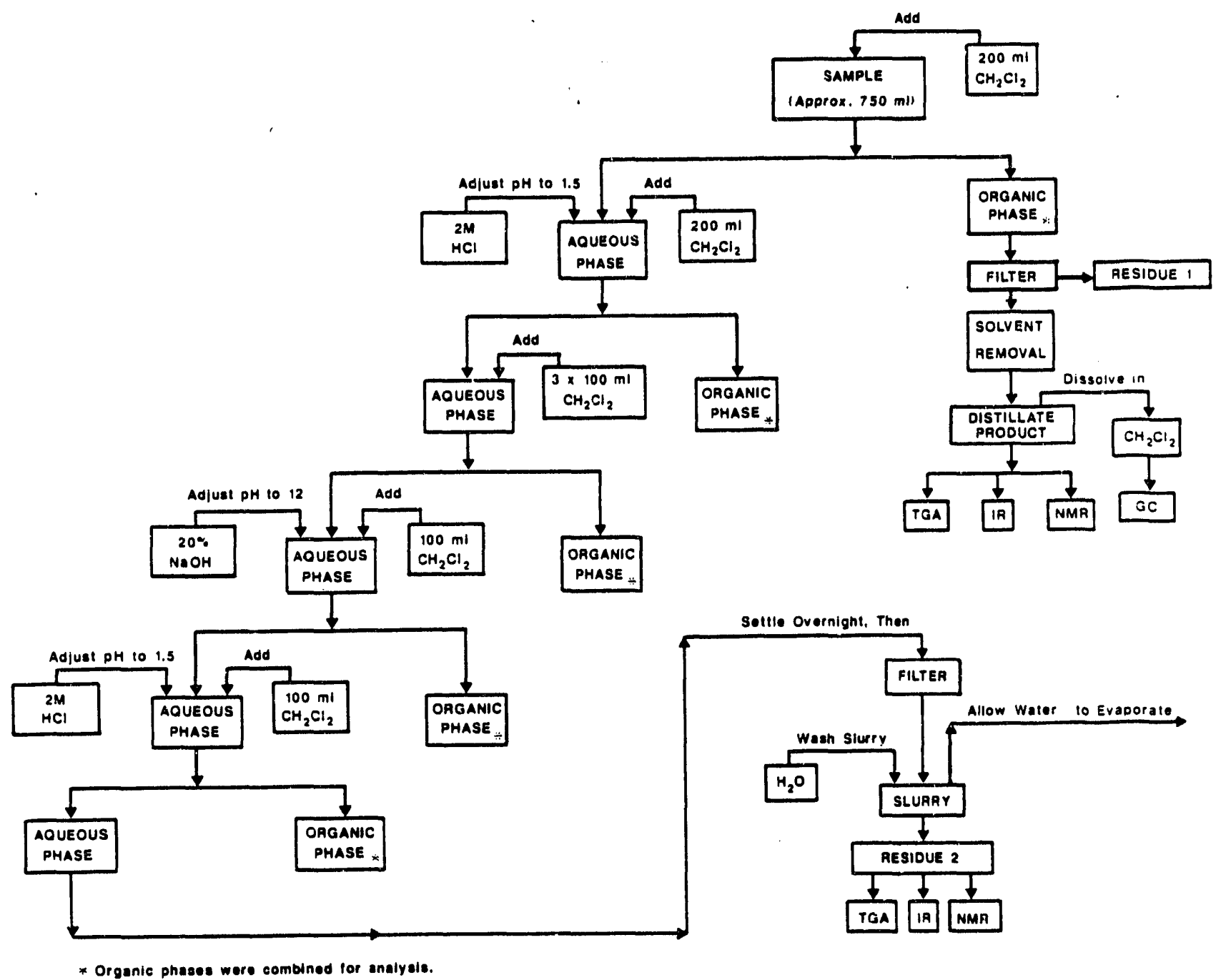

Figure B2. Schematic for the extraction and analysis of mild gasification condensate product. 
APPENDIX C

1- to 4-LB/HR CONTINUOUS FLUIDIZED BED REACTOR (CFBR)

SYSTEM DESCRIPTION 


\section{1. to 4-LB/HR CONTINUOUS FLUIDIZED BED REACTOR (CFBR) SYSTEM DESCRIPTION}

\section{MILD GASIFICATION CFBR DESCRIPTION}

\section{Process Description}

A schematic of the 1- to $4-1 \mathrm{~b} / \mathrm{hr}$ CFBR is shown in Figure C1. Its main components are the coal feed system, gas and/or steam superheater, fluidized-bed reactor, and gas and liquid separation.

Coal is fed continuously into the reactor by a one-sided ball feeder and an auger. The fluidization gas, typically nitrogen or argon, enters the bottom of the reactor after passing through the preheater and superheater. The reactor is externally heated using ceramic fiber heaters and typically operates at temperatures ranging from ambient to $1500^{\circ} \mathrm{F}\left(815^{\circ} \mathrm{C}\right)$ and pressures up to $200 \mathrm{psig}$. Gas, condensable liquids, and char are produced continuously in the fluidized-bed reactor. The coarse char is collected in the char collection pot, and fines are removed from the gas stream in a cyclone. Condensable liquids are removed from the gas stream in a water-cooled condenser followed by two glycol-cooled condensers. The clean gas is finally measured by a gas meter, which is not shown in Figure C1.

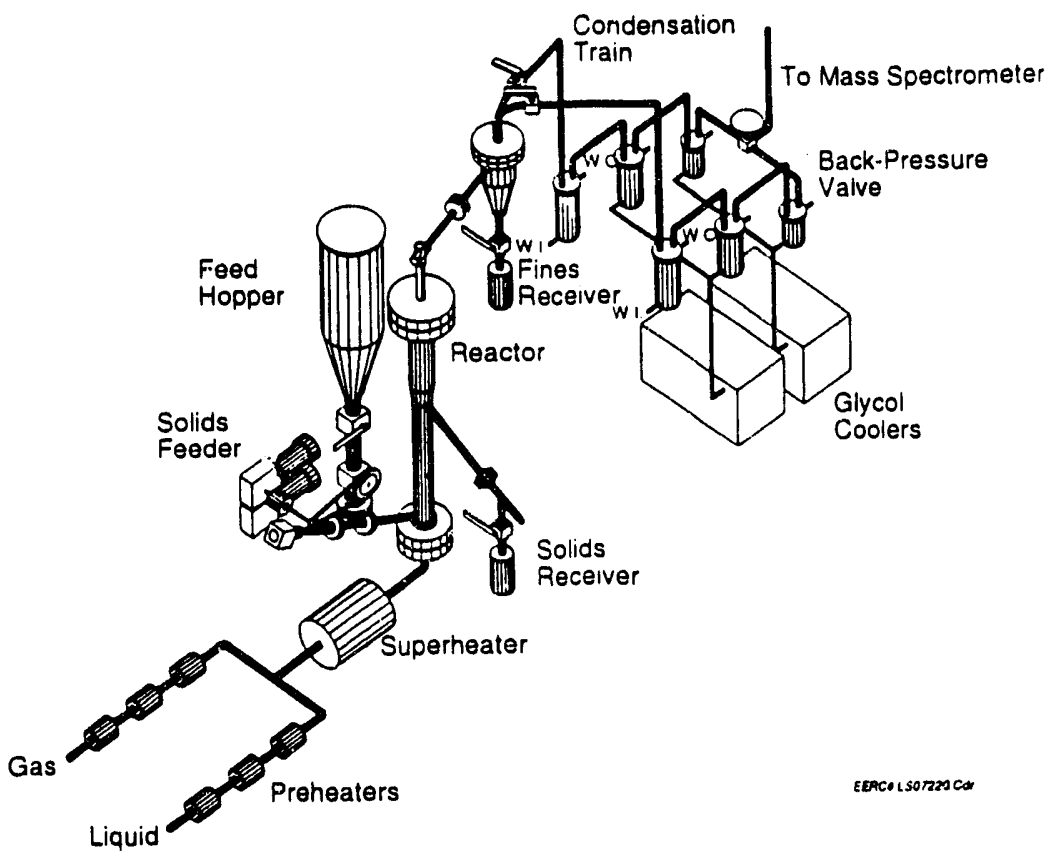

Figure C1. Schematic of the 1- to $4-\mathrm{lb} / \mathrm{hr}$ CFBR. 


\section{Coal Feed System}

The coal feed system is shown in relation to the bottom of the CFBR reactor in Figure C2. A "star" feeder, which is not shown, was placed directly above the 2-inch flange shown in the figure. The star feeder drops a specific volume of coal at selected intervals into the auger system. A small amount of purge gas is also fed into the auger system. The purge gas and high-speed auger swiftly move the coal into the reactor before devolatilization can occur, preventing agglomeration of the coal which could plug the feed system.

Plugging is often a problem in small coal feed systems. Because a small volume of material moves through a very narrow opening, coal particles stick together due to the high moisture content, and backflashing of hot gases from the reactor causes swelling. Plugging had been experienced on the $30-\mathrm{lb} / \mathrm{hr}$ pressurized fluidized-bed gasifier (PFBG) used on the Hydrogen Production from Coal project. The problem was resolved on the PFBG by slightly pressurizing the coal hopper and purging the auger; consequently, those features were added to the design of the $4-1 \mathrm{~b} / \mathrm{hr}$ CFBR.

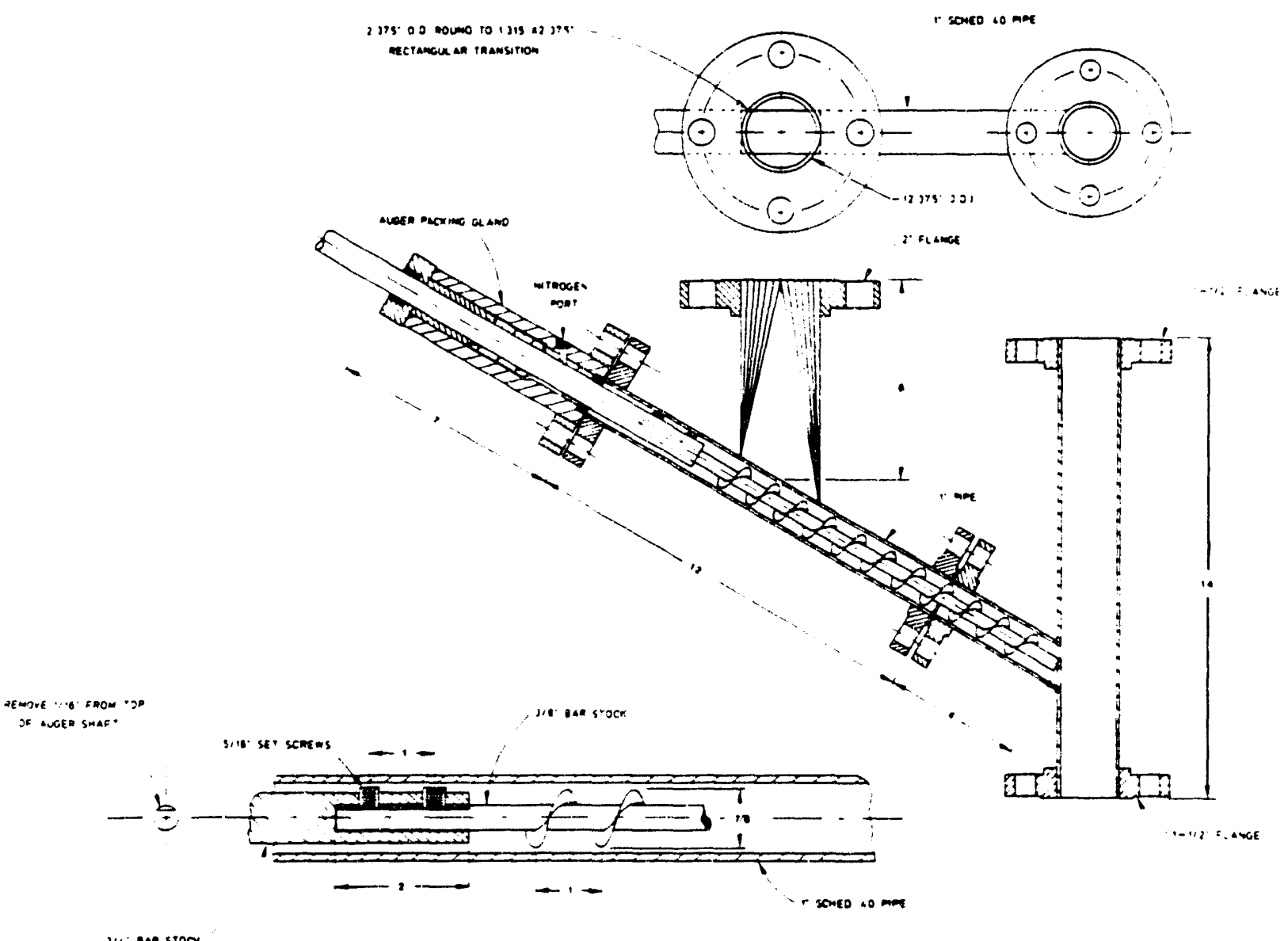

Ju' on sroce

Figure C2. 1- to $4-\mathrm{lb} / \mathrm{hr}$ CFBR coal feed system. 
The coal feed system has been calibrated for mass flow rates for several feed coals. Since the densities of the coals are slightly different, the star feeder revolution rate will vary with coal rank and crush size in order to maintain a constant mass flow rate. Typical mass flow rates for the feed system can range between $0.5 \mathrm{lb} / \mathrm{hr}$ and $8.0 \mathrm{lb} / \mathrm{hr}$.

\section{Mild Gasification Reactor}

The reactor was constructed from two sections of Schedule $80,316 \mathrm{H}$ stainless steel (SS) pipe connected by a $316 \mathrm{H}$ SS weld reducer as shown in Figure C3. The bottom section is a 3-inch-nominal-diameter pipe, 33 inches long, which is connected to the coal feed system, and the top section is a 4-inch-nominal-diameter pipe, 18.75 inches long. The top and bottom flanges are $316 \mathrm{H}$ stainless steel, $1500 \mathrm{lb}$ Reflange flanges with metal gaskets rated at $1500^{\circ} \mathrm{F}\left(815^{\circ} \mathrm{C}\right)$ and 200 psia. The unit was designed so that the top of the fluid bed is 33 inches above the coal injection point. The char off-take leg at the top of the bed is the primary means of solids removal from the reactor. A ball valve lockhopper system facilitates the collection of char product when the system is in operation.

The reactor is heated using two ceramic fiber heaters which are capable of reaching $1800^{\circ} \mathrm{F}\left(980^{\circ} \mathrm{C}\right)$. The bottom heater is rated at 2500 watts, and the top heater is rated at 1775 watts. The heaters maintain the reactor temperature and eliminate hot spots. The use of external heaters allows for evaluation of different internal and external heating methods for process development and scaleup.

\section{Preheat System}

A variety of gases and gas/liquid mixes can be used for fluidization. The gases and liquids commonly used in the system include nitrogen, air, oxygen, carbon monoxide, hydrogen, carbon dioxide, steam, and ethanol.

Gas enters the preheater cart and passes through a series of three tube heaters (Figure C1), which are capable of heating the gas to $842^{\circ} \mathrm{F}\left(450^{\circ} \mathrm{C}\right)$. Liquid is pumped into the system and also passes through a series of three tube heaters, which vaporize the liquid. Vaporized liquid can make up $0 \%$ to $100 \%$ of the fluidization gas.

After the preheaters, the gases and vaporized liquids are mixed together prior to entering the superheater. The superheater consists of a 20 -foot-long section of $3 / 8^{\prime \prime}$-OD 316 SS tubing, coiled to approximately 31/2" OD and 10" long. This coil is inside a 5"-ID ceramic fiber heater, capable of reaching a temperature of $2000^{\circ} \mathrm{F}\left(1093^{\circ} \mathrm{C}\right)$. From the superheater, the fluidization gas enters the bottom of the reactor through a transfer tube heated by cable heaters.

\section{Gas Quench and Liquid Separation}

A cyclone constructed of Schedule 80, 3-inch-diameter $316 \mathrm{H}$ stainless steel is used to remove fines from the gas stream. The fines are collected in a catch pot. A ball valve allows changing of the catch pot for fines removal when the system is in operation. The cyclone is heated with a ceramic fiber heater, capable of reaching $1500^{\circ} \mathrm{F}\left(815^{\circ} \mathrm{C}\right)$ to minimize condensation and plugging by fines. 
After the cyclone, two parallel sets of three 4-inch-diameter vessels are used to remove the condensable material from the gas stream. Two separate trains were installed: one for mass balance sampling, and the other for heatup, un-steady-state conditions, and cooldown. The first condenser pot is water-cooled and typically cools the gas stream from $570^{\circ} \mathrm{F}\left(300^{\circ} \mathrm{C}\right)$ to $200^{\circ} \mathrm{F}\left(95^{\circ} \mathrm{C}\right)$. The last two condenser pots in each set are glycol-cooled. The exit gas temperature is typically $50^{\circ} \mathrm{F}\left(10^{\circ} \mathrm{C}\right)$. A glass wool filter captures aerosols that pass through the condenser system.

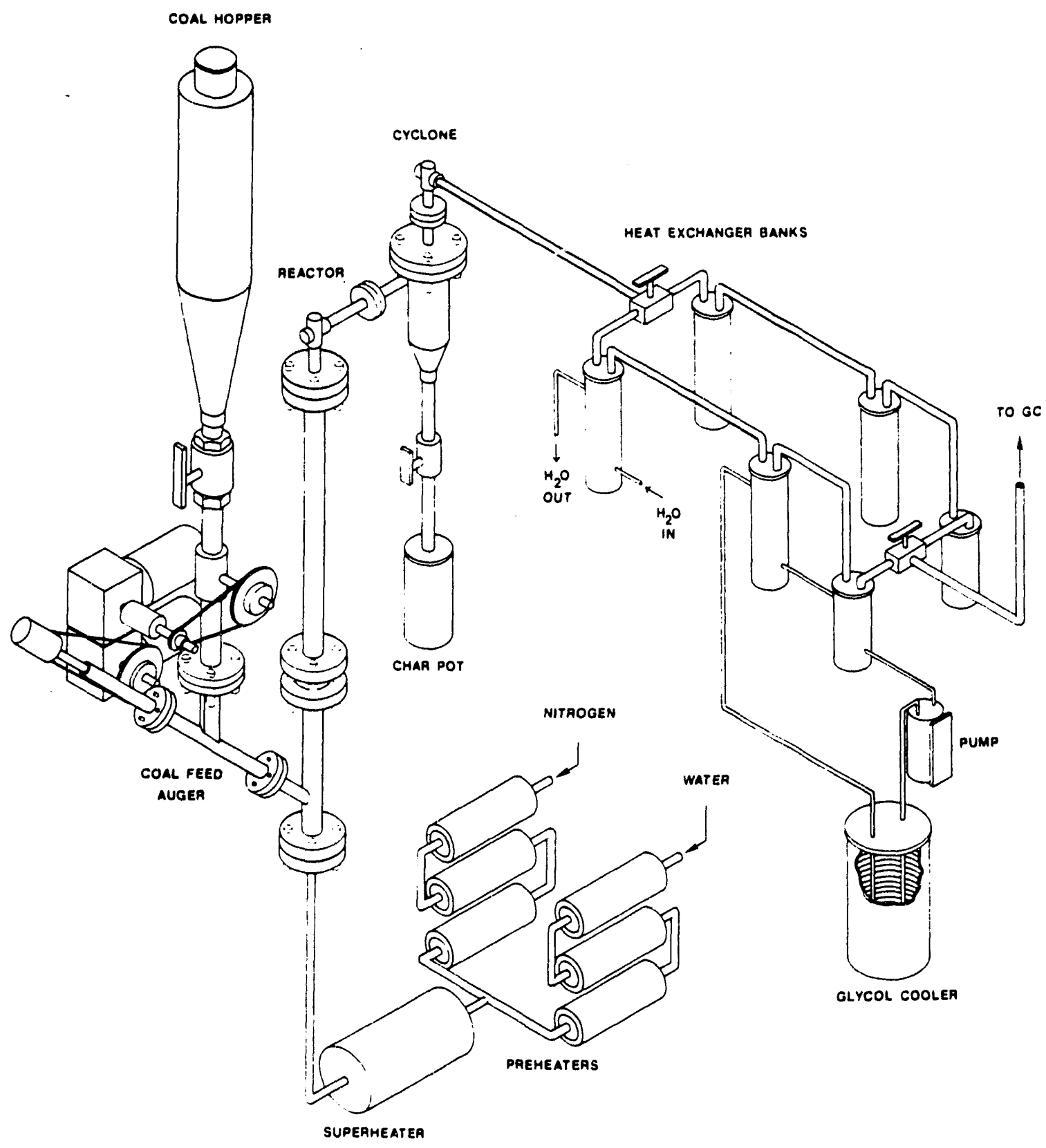

Figure C3. Reactor system of the 1- to $4-1 \mathrm{~b} / \mathrm{hr}$ CFBR. 
APPENDIX D

MILD GASIFICATION PRU DESCRIPTION 


\section{MILD GASIFICATION PRU DESCRIPTION}

\section{Process Description}

Design of the $100-\mathrm{lb} / \mathrm{hr}$ mild gasification process research unit (PRU), shown in Figure D1, was initiated in November 1988. For design purposes, the PRU was divided into eight areas as follows:

$\begin{array}{ll}\text { Area 100 } & \text { Coal Preparation } \\ \text { Area 200 } & \text { Utilities } \\ \text { Area 300 } & \text { Carbonization } \\ \text { Area 400 } & \text { Calcination } \\ \text { Area 500 } & \text { Gas Quench/Liquid Separation } \\ \text { Area 600 } & \text { Wastewater Treatment/Phenol Recovery } \\ \text { Area 700 } & \text { Char Upgrading } \\ \text { Area 800 } & \text { Liquid Upgrading }\end{array}$

Appendix A lists the major pieces of PRU equipment.

Figure D2 shows a three-dimensional flow diagram of the PRU operation. The objectives of the PRU within the development of the mild gasification concept are to 1 ). provide proof of concept for an integrated design operating using specific design coals, and 2) produce char and liquid products for upgrade testing and market evaluation.

The PRU was designed to process $100 \mathrm{lb} / \mathrm{hr}$ of feed coal on a dry basis. The process is capable of drying, carbonizing, and calcining both caking and noncaking coals in fluidized-bed reactors, with provisions for separating char, liquid, and gaseous products. The PRU was designed for integrated operation using both the carbonizer and the calciner; however, it can also be operated using only the carbonizer.

The carbonizer and calciner are heated principally using flue gas from the stoichiometric combustion of natural gas. In a commercial design, heat could be supplied from the combustion of process-derived gas and waste coal from coal cleaning in a fluidbed combustor. Air-blown external combustion is used to heat the gasifiers to avoid the high cost of an oxygen plant in the commercial design.

\section{Coal Preparation}

Area 100 is coal preparation. The two coals tested in the $100-\mathrm{lb} / \mathrm{hr}$ mild gasification PRU were Wyodak from the Eagle Butte mine near Gillete, Wyoming, and Indiana No. 3 from the Chinook mine near Brazil, Indiana. Twenty-five tons of washed coal product from each mine were delivered to the EERC, sized to $2 "$ × 0 , and stored in nitrogen-purged bunkers. Prior to processing in the PRU, the coal was crushed to $1 / 4 " \mathrm{x} 0$. Eight tons of the gravity table-cleaned Indiana No. 3 were also stored in bunkers. 


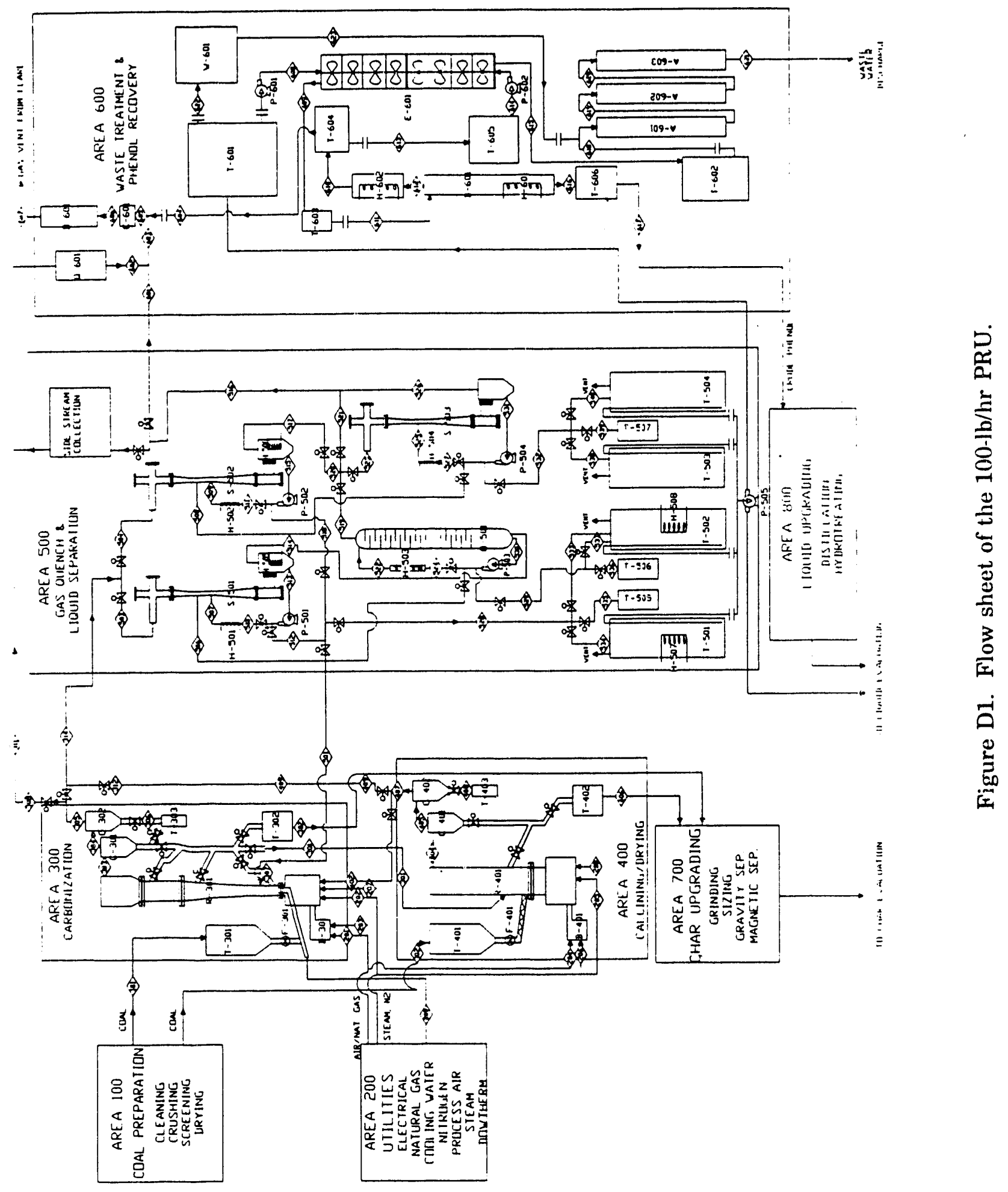




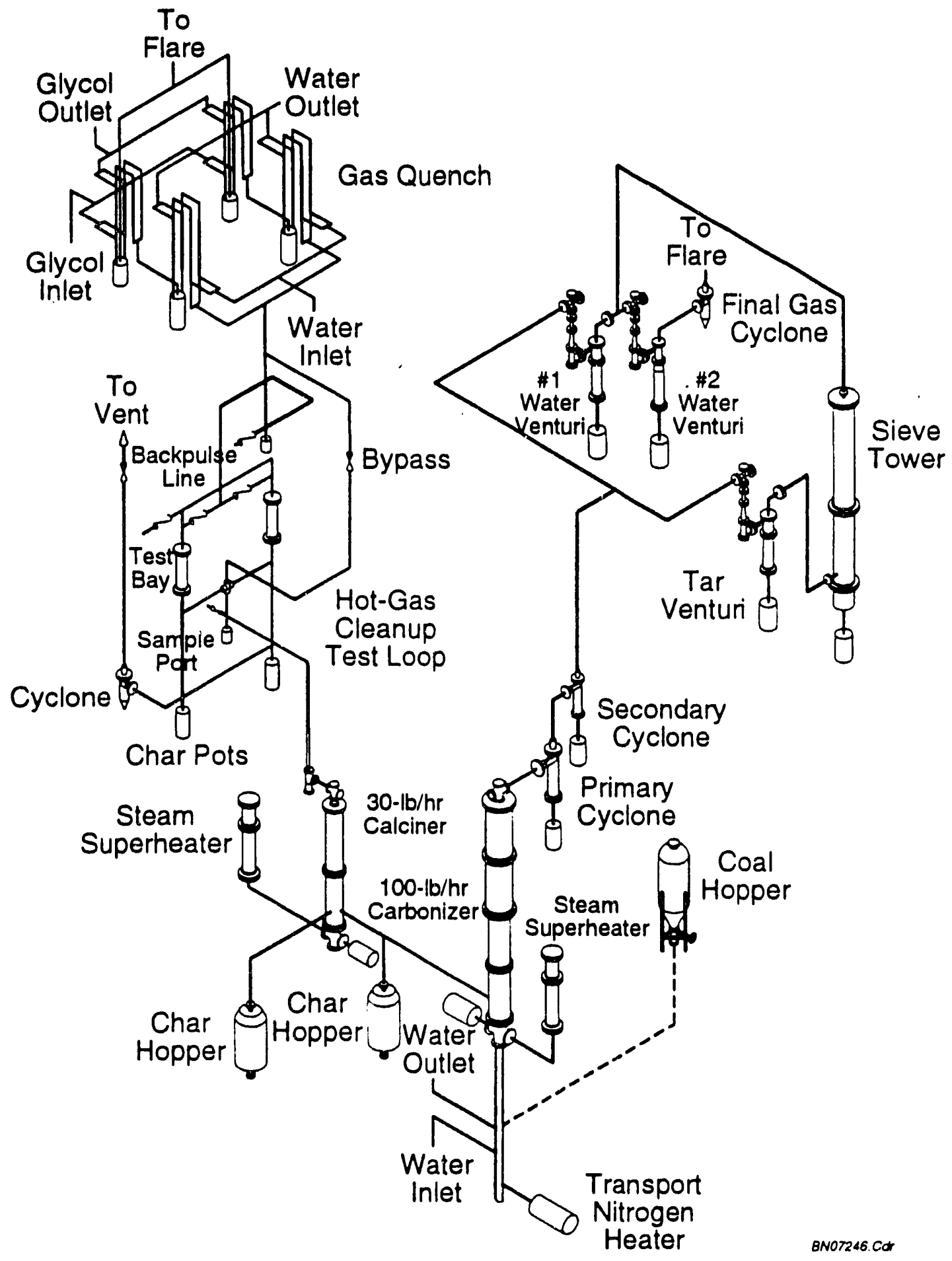

Figure D2. Three-dimensional flow sheet of the PRU operation. 


\section{Utility Requirements}

The utilities area, Area 200, consists of the following:

1) Electrical Service

2) Natural Gas

3) Cooling Water

4) Nitrogen

5) Process Air

A list of the electrical requirements is shown in Table D1. The total requirement is approximately 405 amps, with the majority of the load consumed by heat tracing of the reactor and product gas lines.

\section{TABLE D1}

PRU Electrical Requirements

\begin{tabular}{|c|c|c|c|}
\hline Heaters & Voltage & Amps & Total Amps \\
\hline $\mathrm{N}_{2}$ Transport & $120 \mathrm{~V} 10$ & $15.67 \mathrm{~A}$ & $15.67 \mathrm{~A}$ \\
\hline Superheater & $480 \mathrm{~V} 30$ & $43.40 \mathrm{~A}$ & $43.40 \mathrm{~A}$ \\
\hline Reactor Heaters & $240 \mathrm{~V} 30$ & $166.30 \mathrm{~A}$ & $166.30 \mathrm{~A}$ \\
\hline Drum Heaters & $230 \mathrm{~V} 30$ & $11.10 \mathrm{~A}$ & $11.10 \mathrm{~A}$ \\
\hline Downleg Pipes & $240 \mathrm{~V} 30$ & $14.40 \mathrm{~A}$ & $14.40 \mathrm{~A}$ \\
\hline Primary Cyclone & $240 \mathrm{~V} 10$ & $20.50 \mathrm{~A}$ & $20.50 \mathrm{~A}$ \\
\hline Secondary Cyclone & $240 \mathrm{~V} 10$ & $8.75 \mathrm{~A}$ & $8.75 \mathrm{~A}$ \\
\hline Reactor Cross & $208 \mathrm{~V} 10$ & $21.70 \mathrm{~A}$ & $21.70 \mathrm{~A}$ \\
\hline $750^{\circ} \mathrm{F}$ Venturi/Cyclones & $208 \mathrm{~V} 30$ & $9.20 \mathrm{~A}$ & $36.80 \mathrm{~A}$ \\
\hline $350^{\circ} \mathrm{F}$ Venturi/Cyclones & $208 \mathrm{~V} 30$ & $4.60 \mathrm{~A}$ & $9.20 \mathrm{~A}$ \\
\hline 2" Interconnect Piping & $208 \mathrm{~V} 30$ & $0.70 \mathrm{~A} / \mathrm{ft}$ & $24.50 \mathrm{~A}$ \\
\hline 3" Interconnect Piping & $208 \mathrm{~V} 30$ & $0.70 \mathrm{~A} / \mathrm{ft}$ & $3.50 \mathrm{~A}$ \\
\hline \multirow[t]{2}{*}{ Sieve Tower Heaters } & $208 \mathrm{~V} 30$ & $9.00 \mathrm{~A}$ & $29.00 \mathrm{~A}$ \\
\hline & Voltage & Horsepower & \\
\hline Coal Feed & $208 \mathrm{~V} 30$ & $0.75 \mathrm{HP}$ & \\
\hline Auger & $208 \mathrm{~V} 30$ & $0.75 \mathrm{HP}$ & \\
\hline Tar Recycle Pump & $208 \mathrm{~V} 30$ & $5.00 \mathrm{HP}$ & \\
\hline Tar Transfer Pump & $208 V 30$ & $1.50 \mathrm{HP}$ & \\
\hline 3 Centrifuge Pumps & $208 \mathrm{~V} 30$ & $1.00 \mathrm{HP}$ & \\
\hline
\end{tabular}




\section{Carbonizer}

Area 300 contains the carbonizing reactor, two cyclones, a coal feed system, and a natural gas burner. The carbonizer (shown in Figure D3) is operated as a spouting-bed reactor at temperatures from $900^{\circ} \mathrm{F}\left(480^{\circ} \mathrm{C}\right)$ to $1100^{\circ} \mathrm{F}\left(600^{\circ} \mathrm{C}\right)$. This design was chosen based on favorable results with caking coals in the COALCON and KRW gasifier systems. The operative principle allowing the use of caking coal in this reactor is the dilution of the entering coal by an internal recycle of char back to the bottom of the tapered bed, where high velocity and low bed density also reduce agglomeration. A similar regime existed in the $400-\mathrm{lb} / \mathrm{hr}$ fast fluidized-bed Perry carbonizer previously used with caking coals at the Grand Forks Energy Technology Center (GFETC), Grand Forks, North Dakota (1). The body of the carbonizer consists of four 5 -foot tall sections. The modular design of the carbonizer allows removal of different sections to obtain a variety of gas and char residence times. The lower two sections are constructed of 24" 304L stainless steel pipe. The pipe is lined with 5.25" of insulating refractory and two layers of hard, abrasion-resistant refractory, resulting in an 8" inside diameter, as shown in Figures D4 and D5. The two upper sections are constructed of 30" 304L stainless steel pipe. The pipe is lined with 4.625" of insulating refractory and 2" of hard refractory, resulting in a 16" inside diameter, as shown in Figures D6 and D7.

The smaller diameter of the lower sections of the reactor is intended to increase the velocity and turbulence of the bed, and thus reduce agglomeration of the test coals. When the fast-moving gas jet enters the larger-diameter upper section, its velocity decreases. The char entrained in the gas jet falls back into the lower section and dilutes the fresh coal entering the bottom of the reactor, providing a longer residence time for the char.

The fluidization gases are heated by a stoichiometrically operated natural gas burner. The desired operating temperature was maintained by adding air and/or nitrogen to the burner gas in the carbonizer plenum. The coal is entrained and fed into the bottom of the reactor using preheated nitrogen $\left(570^{\circ} \mathrm{F} / 300^{\circ} \mathrm{C}\right)$ via a system of lock hoppers, augers, and pneumatic transports, as shown in Figure D8. The coal from the lock hopper is gravity-fed into a star feeder that supplies coal at the desired flow rate. The star feeder drops the coal into a 1"-diameter auger that forces the coal into a high-velocity stream of preheated nitrogen, which carries the coal into the bed of the carbonizer. The char can be withdrawn from a variety of locations and sent to the calciner or removed from the system and cooled in a nitrogen-purged tote bin. The char fines entrained by the gases leaving tre top of the carbonizer are separated from the gas stream by a pair of cyclones. The primairy cyclone removes particles greater than $10.7 \mu \mathrm{m}$ in size with $50 \%$ efficiency. The secondary cyclone can remove particles down to $4.02 \mu \mathrm{m}$ in size with $50 \%$ efficiency. 


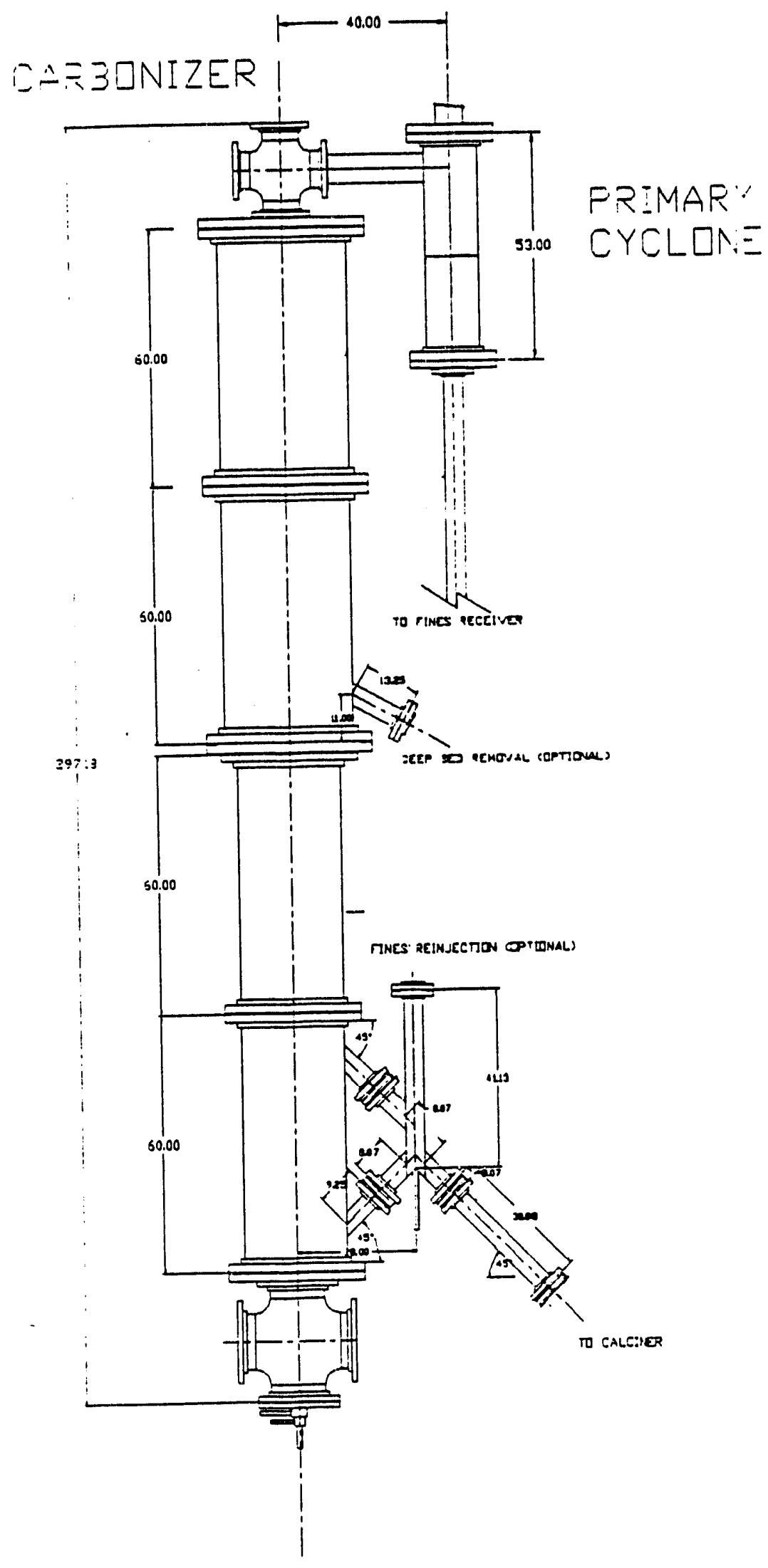

Figure D3. Mild gasification PRU carbonizer. 


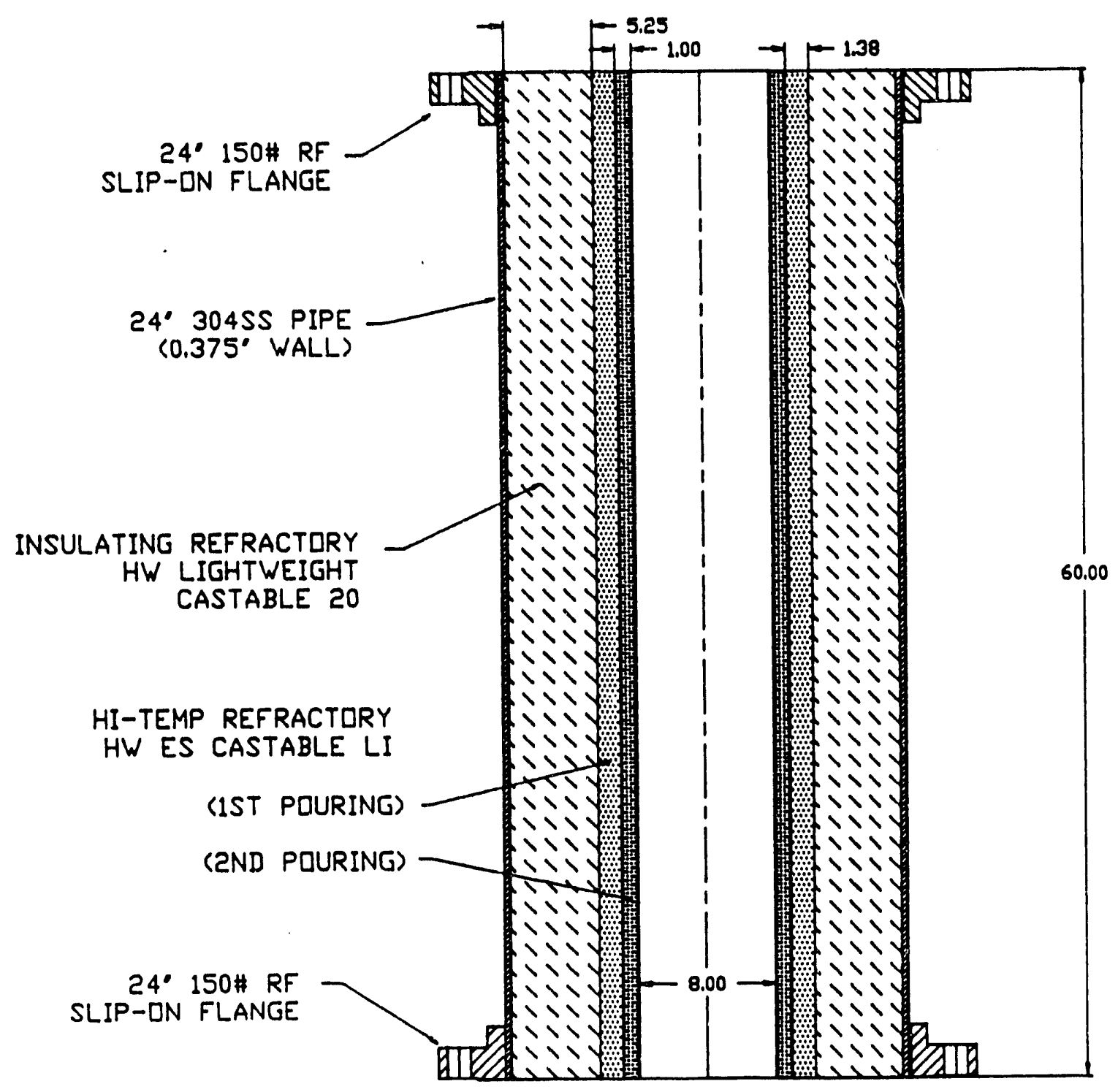

Figure D4. Detail of upper 24"-diameter section. 


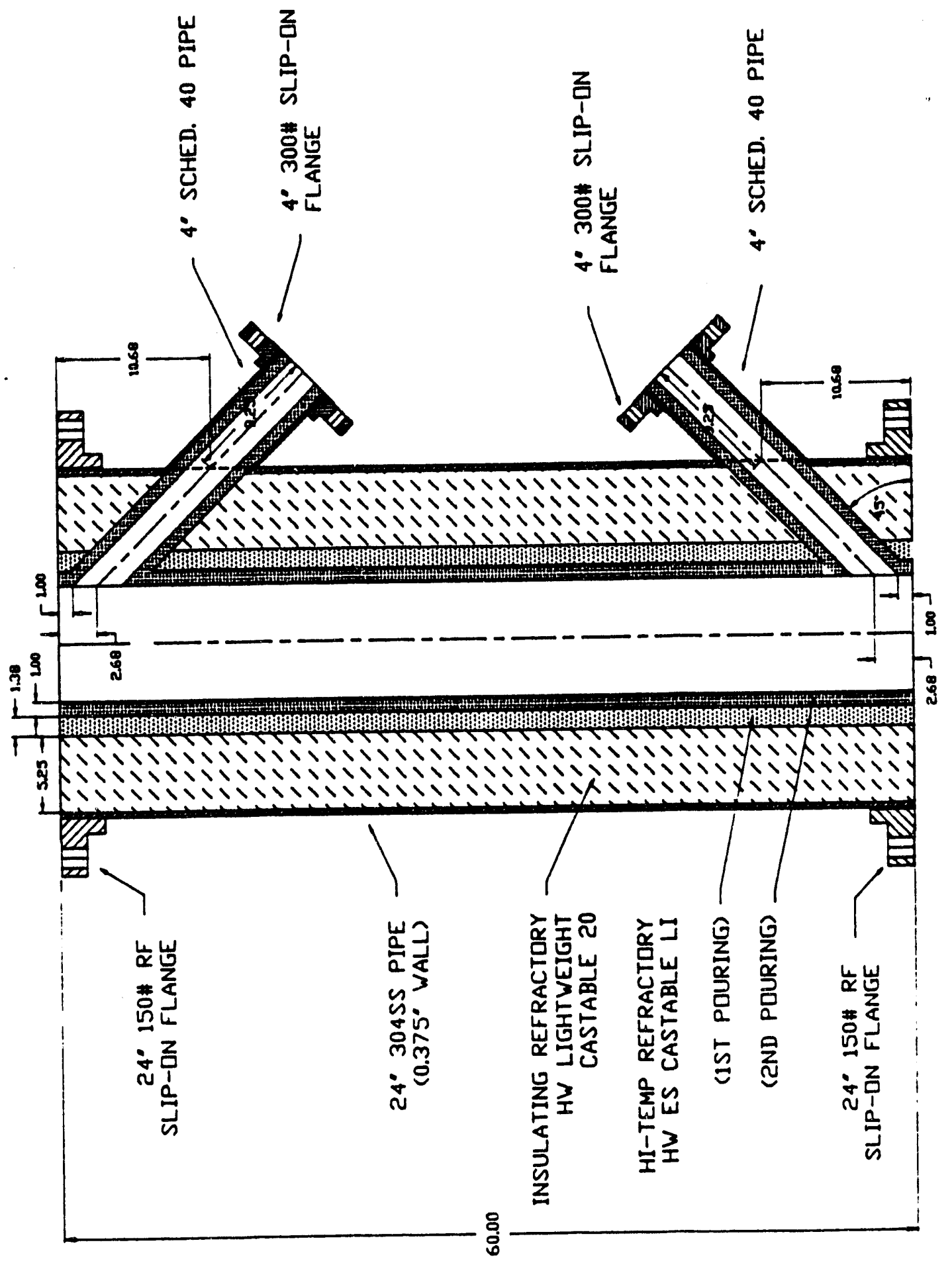

 


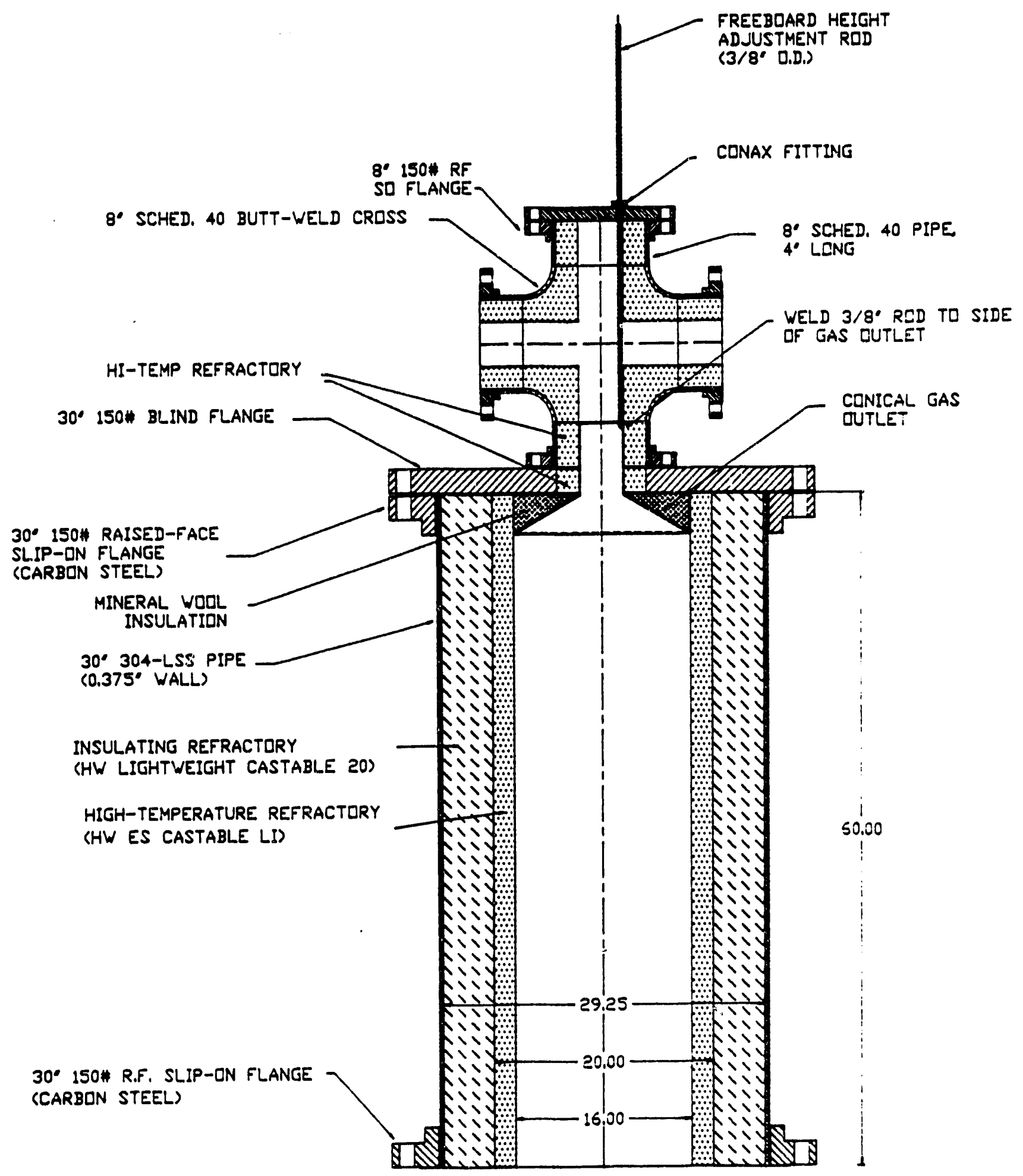

Figure D6. Detail of upper 30"-diameter section. 


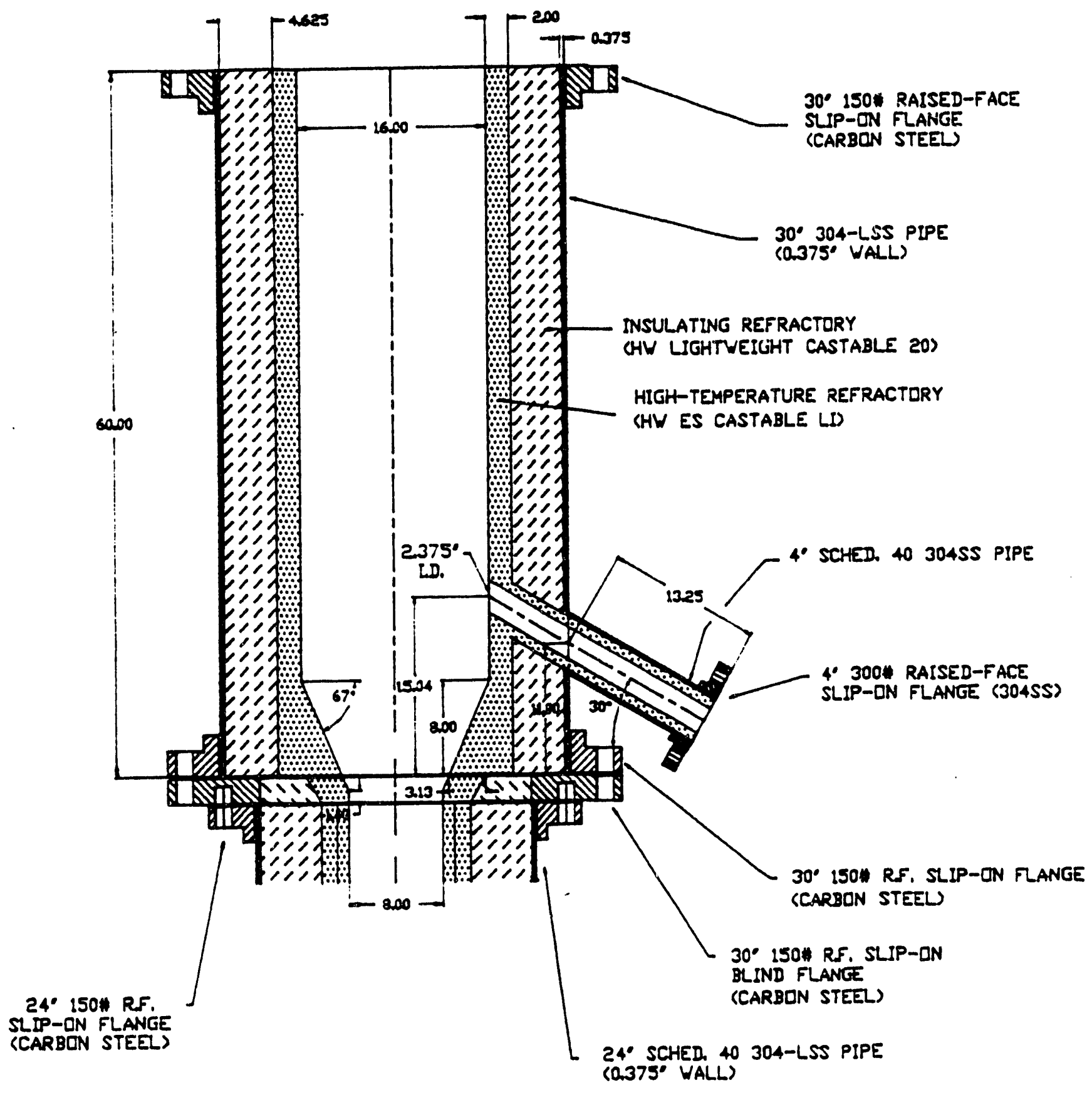

Figure D7. Detail of lower 30"-diameter section. 


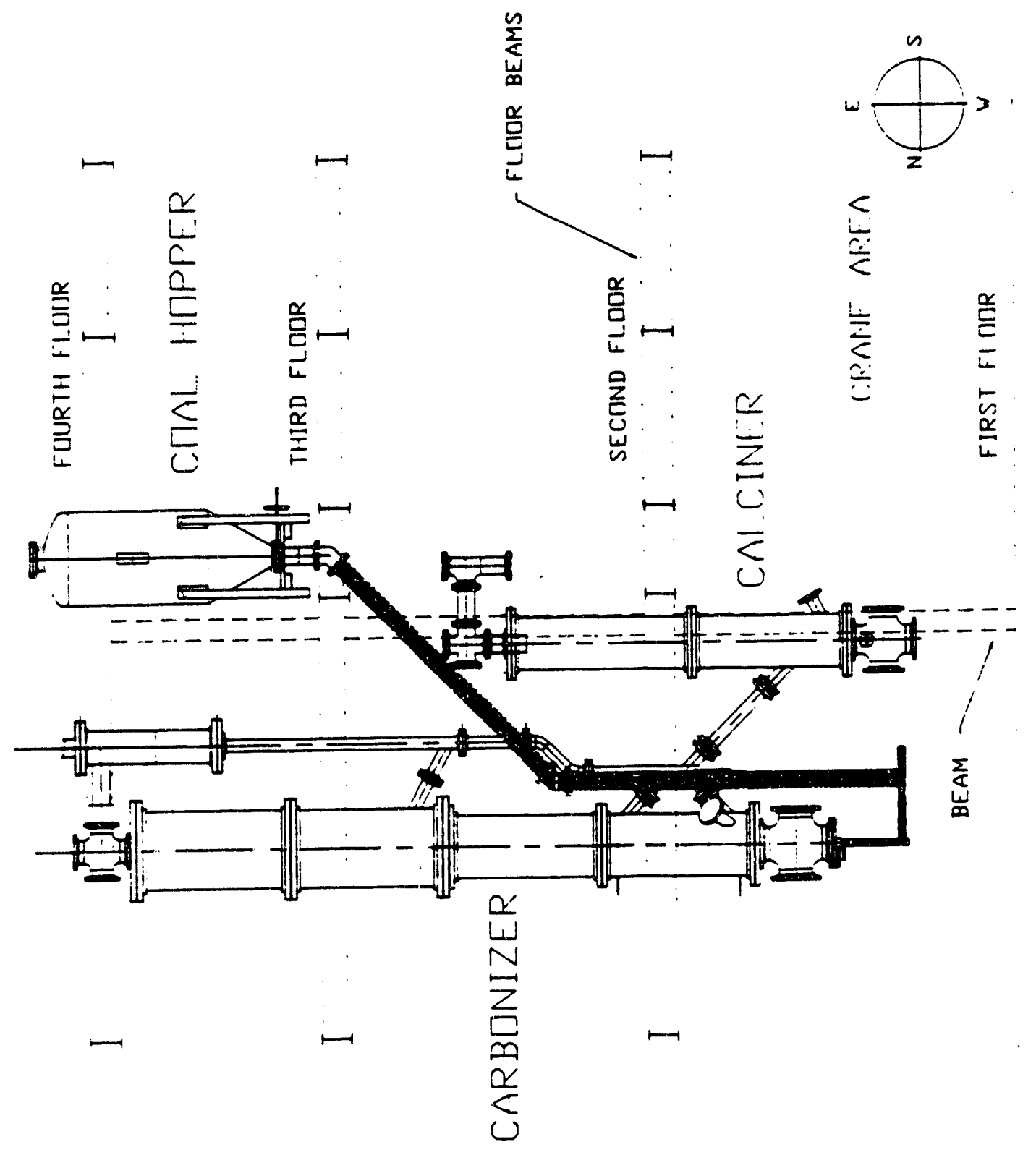

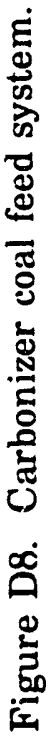


The cyclones are constructed of 304 SS pipe. As shown in Figures D9 and D10, refractory was cast inside the pipes to form the cones at the bottoms of the cyclones. The fines are removed from the hot gas stream by the cyclones and collected in a lock hopper.

\section{Calcining}

The calcining system, Area 400, consists of the calcining reactor (see Figure D11), cyclones, and feed system. Material is fed into the reactor using an auger, or, in the case of integrated operation, through a leg connecting the carbonizer to the calciner. The bubbling fluidized-bed reactor has an inside diameter of $6^{\prime \prime}$ and operates at temperatures up to $1650^{\circ} \mathrm{F}\left(900^{\circ} \mathrm{C}\right)$. The reactor is lined with $4^{\prime \prime}$ of insulating refractory and $2 "$ of hard refractory. A stoichiometrically regulated natural gas burner heats the fluidizing gas. The temperature in the reactor is controlled by adding nitrogen and/or steam in the plenum and by combustion of natural gas/air.

Char is withdrawn from the reactor through a char off-take leg and cooled in a tote bin purged with an inert blanket of nitrogen. The gas from the calciner is flared after passing through the condensation train. The calciner gas can also be diverted to the carbonizer for integrated operation. The calciner may also be used to produce activated carbon from the char produced in the carbonizer, with flue gas at temperatures up to $1475^{\circ} \mathrm{F}\left(802^{\circ} \mathrm{C}\right)$ as the fluidizing gas.

\section{Gas Quench and Liquid Separation}

Area 500 contains the carbonizer and calciner condensation trains. The process includes two independent carbonizer condensation trains, as shown in Figure D12. In the first carbonizer condensation train, the gas stream from the cyclones passes through a venturi tar scrubber, then through a sieve tower, and finally through a water scrubber.

The first condensation train is used when steam is not used in the fluidization gas. Part of the liquid stream from a cyclone located after the venturi tar scrubber is cooled and reinjected into the venturi scrubber. The remainder is stored in 55-gallon barrels. Liquid is reinjected either through two spray nozzles perpendicular to the gas flow at the opening in the venturi throat, or through the top of the venturi (Figure D13). The venturis have interchangeable throats, with throat diameters of 1 ", 11/4", 11/2", and 13/4" available. The 11/2" diameter throat is shown in Figure D14. Figure D15 shows the section above the interchangeable throat, and Figure D16 shows the section below it. The figures are generalized drawings which do not reflect the exact mechanical design. Modifications were made during the program that led to more efficient operation of the unit. The drawings are for descriptive purposes only. The temperature of the gas stream leaving the tar venturi ranges from $500^{\circ} \mathrm{F}$ to $700^{\circ} \mathrm{F}\left(260^{\circ} \mathrm{C}\right.$ to $\left.370^{\circ} \mathrm{C}\right)$. The gas stream from the top of the tar cyclone enters the bottom of the sieve tower (Figure D17), where it passes through a series of perforated plates. The plates in the sieve tower are connected for easy removal in the event of plugging. In the sieve tower, recycle oil from the bottom of the tower is cooled and used to quench the incoming gas. Heat exchangers are used to cool the recycle streams in both the tar venturi and the sieve tower. The tar and oil product is placed in 55-gallon barrels for storage and/or analysis. After the sieve tower, the gas enters a direct contact water scrubber (venturi cyclone). Then the gas, slightly above the water dew point, is sent to the flare. 


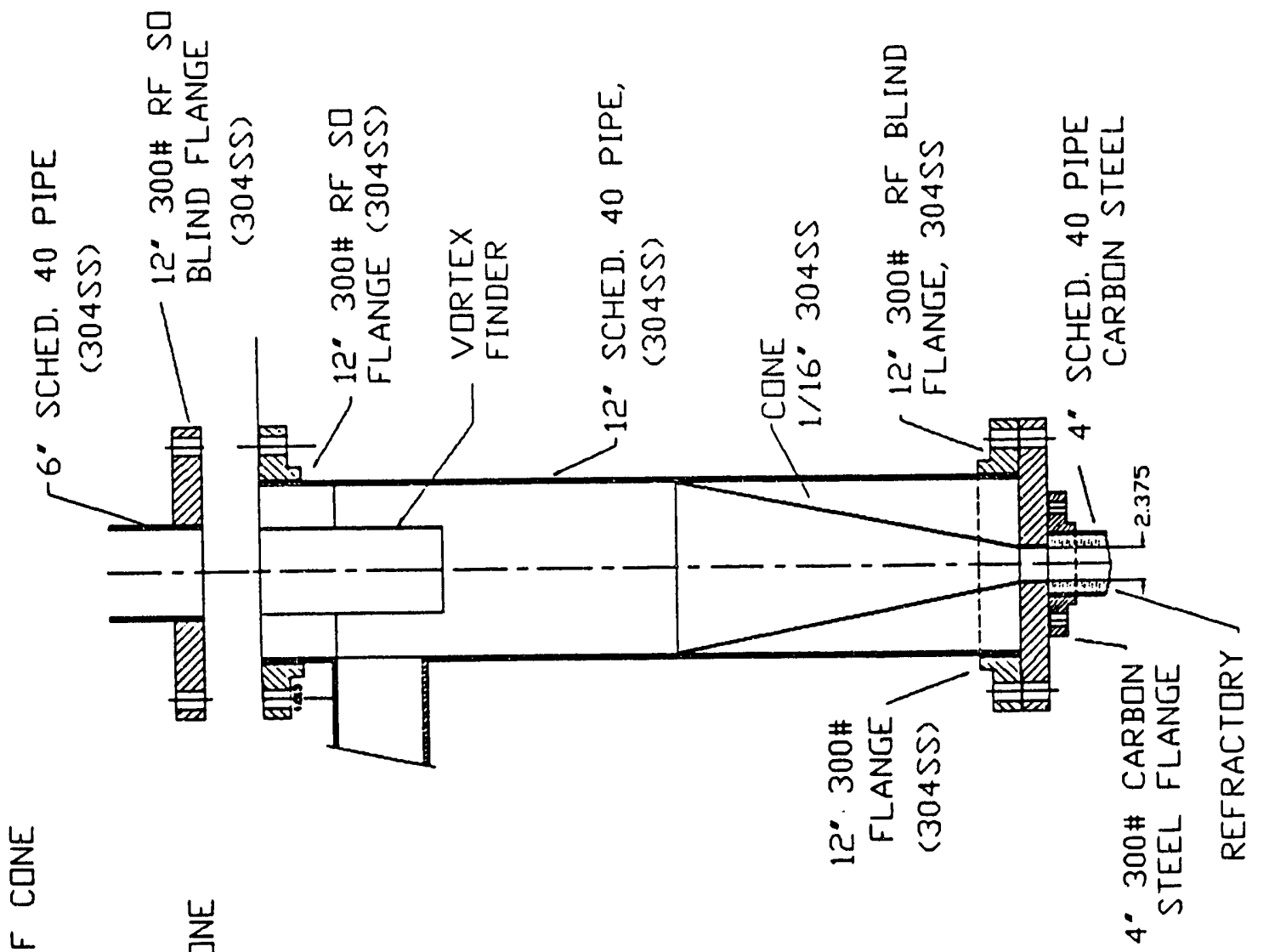

ठే 

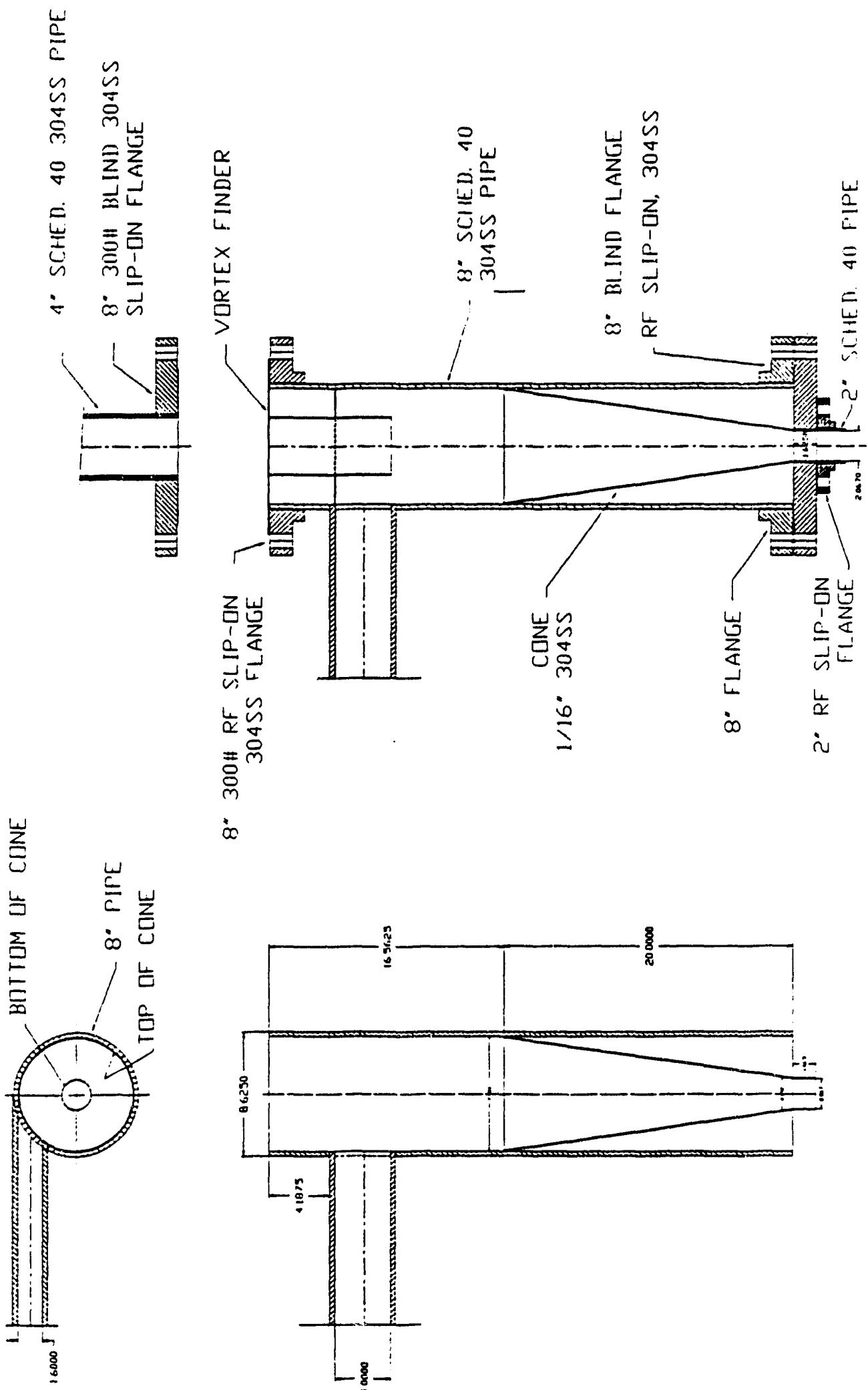

$\dot{\infty}$ 


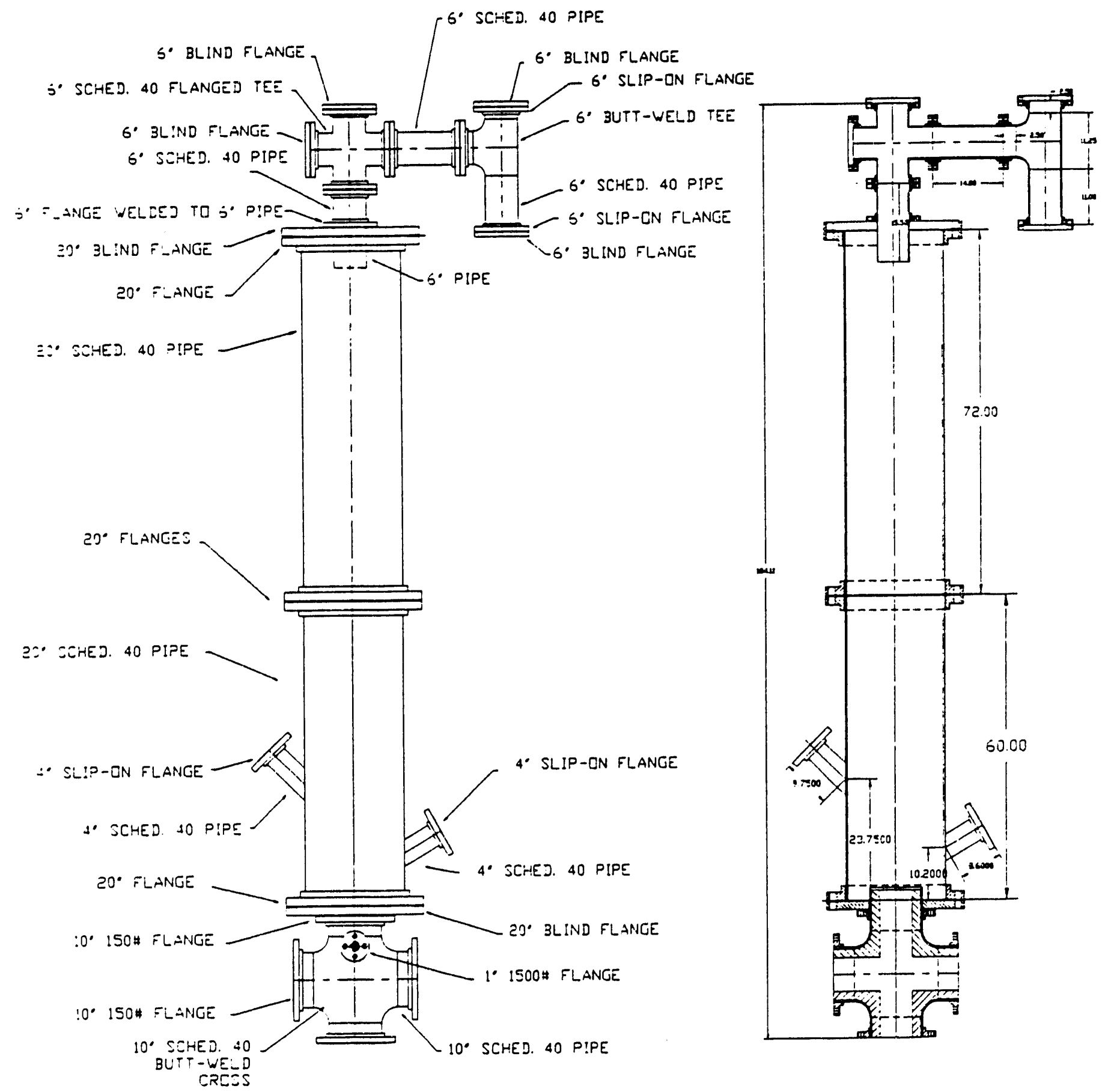

Figure D11. Mild gasification calciner. 


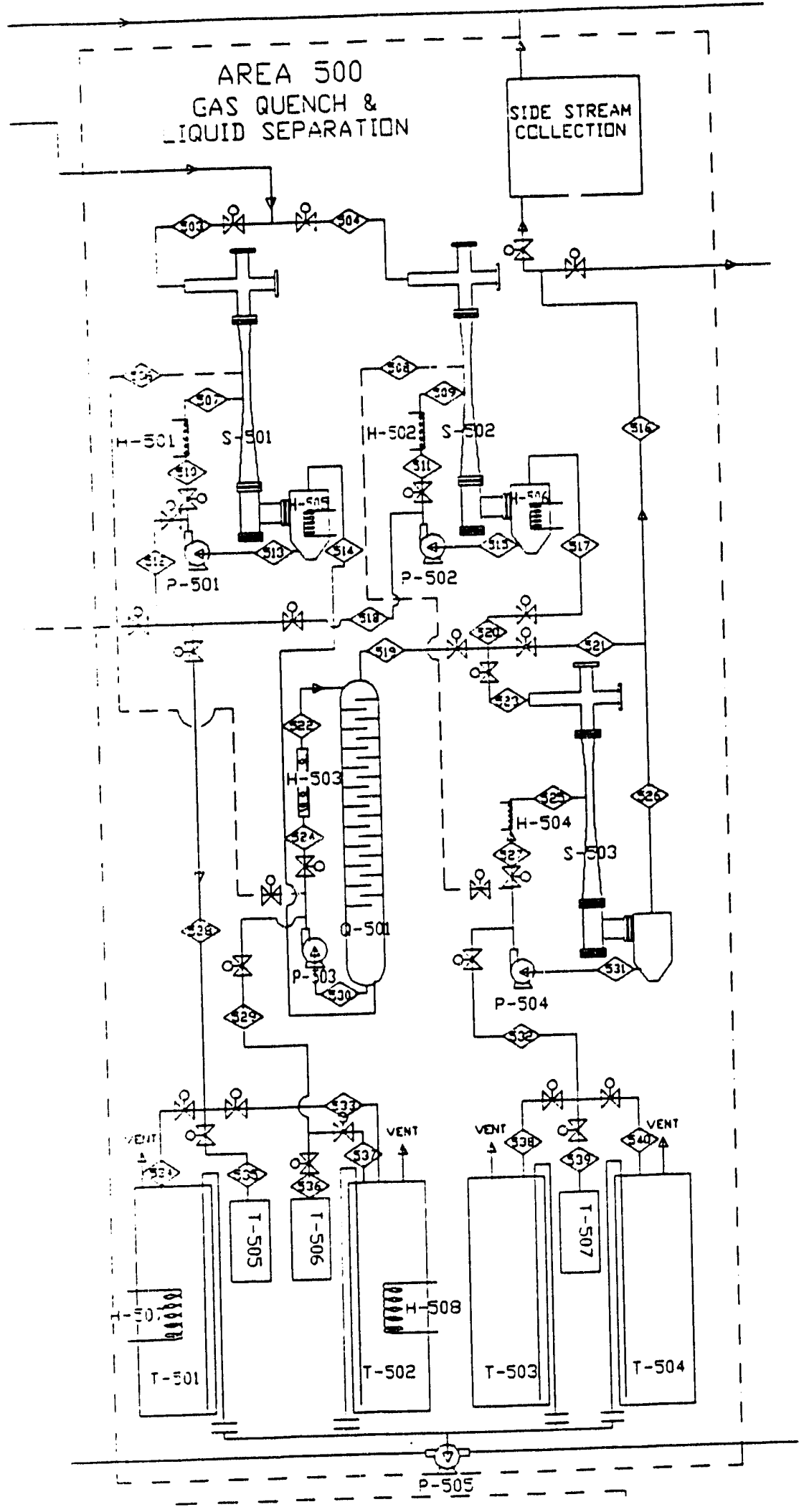

Figure D12. Carbonizer condensation trains. 


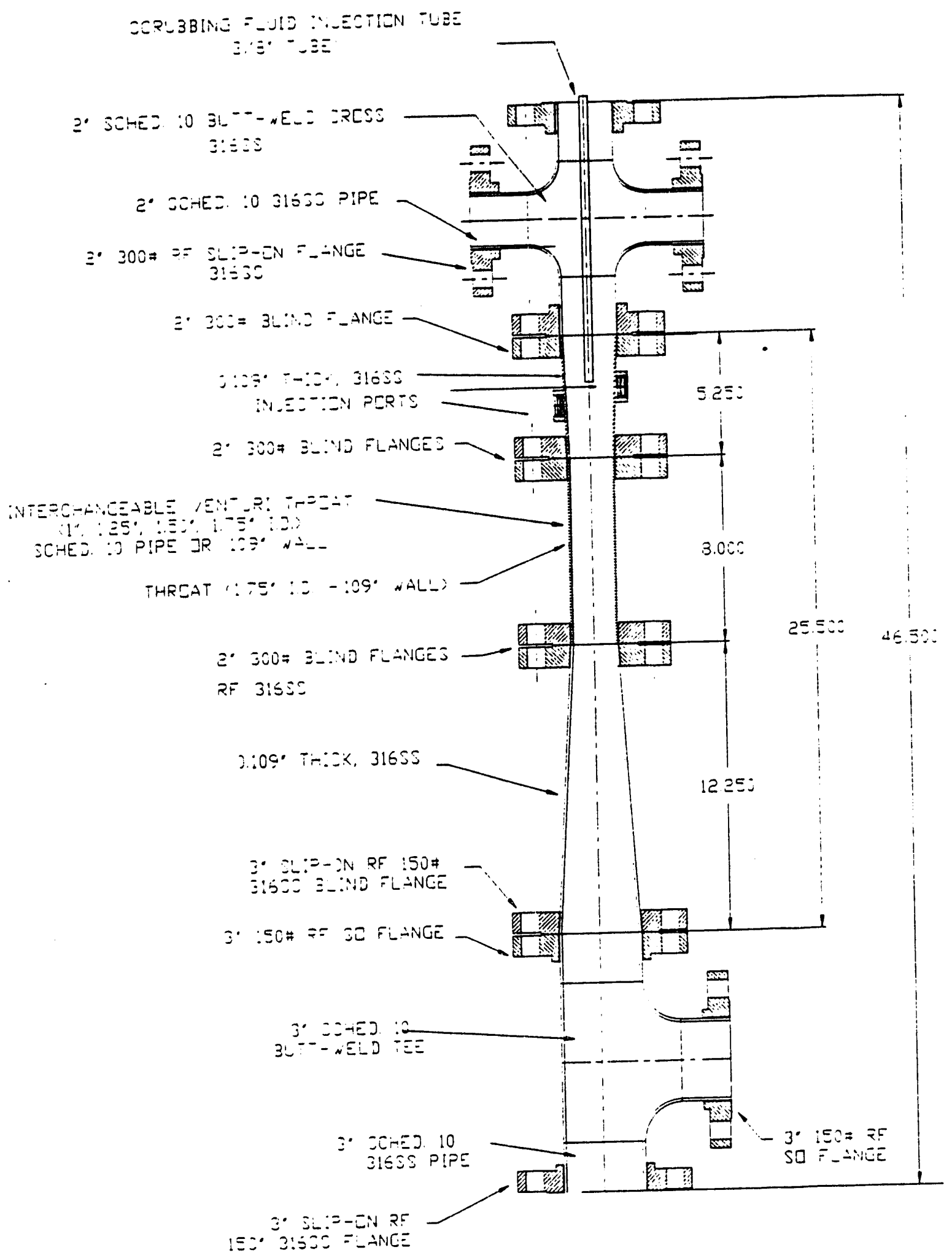

Figure D13. Venturi scrubber.

D.17 

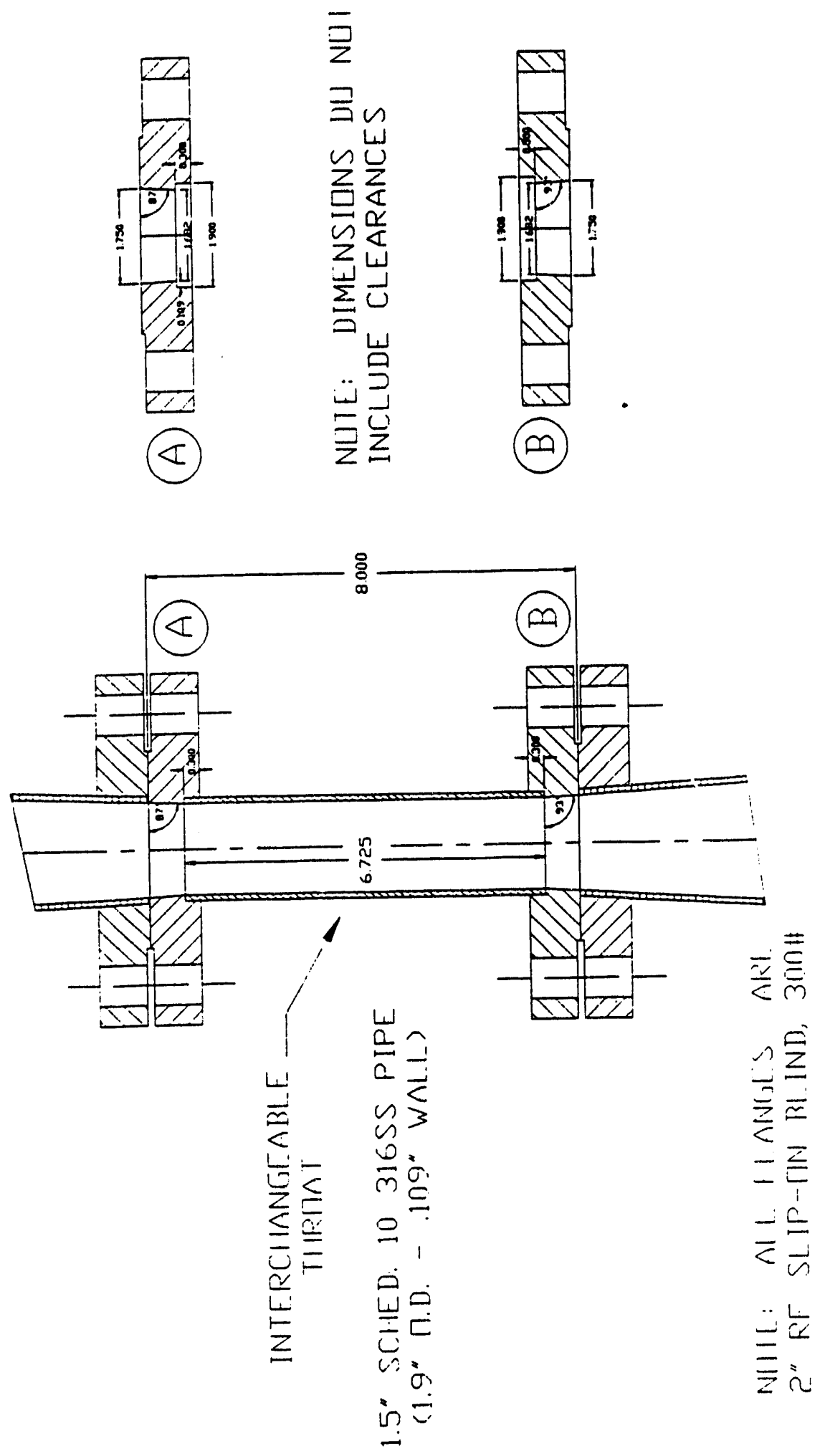


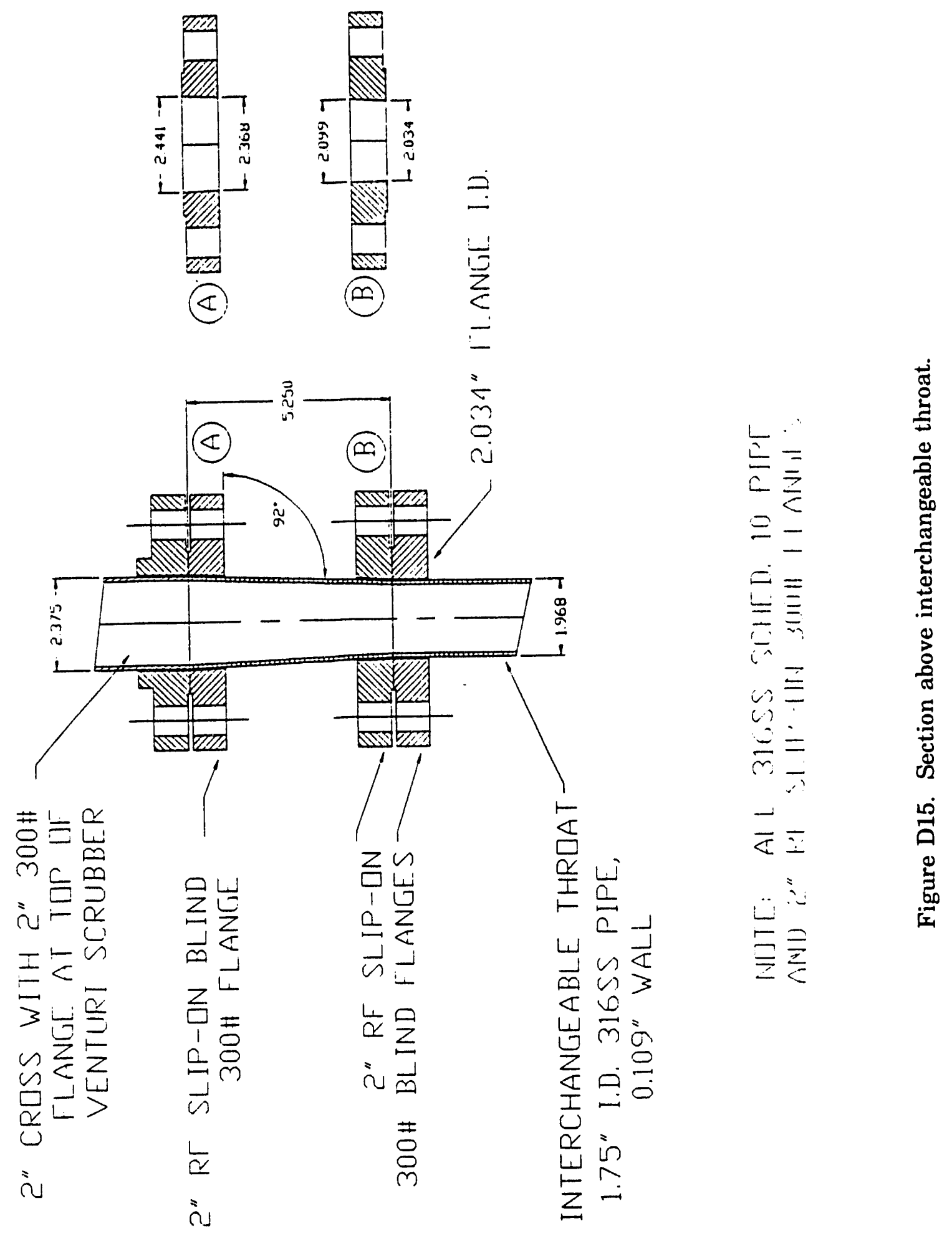



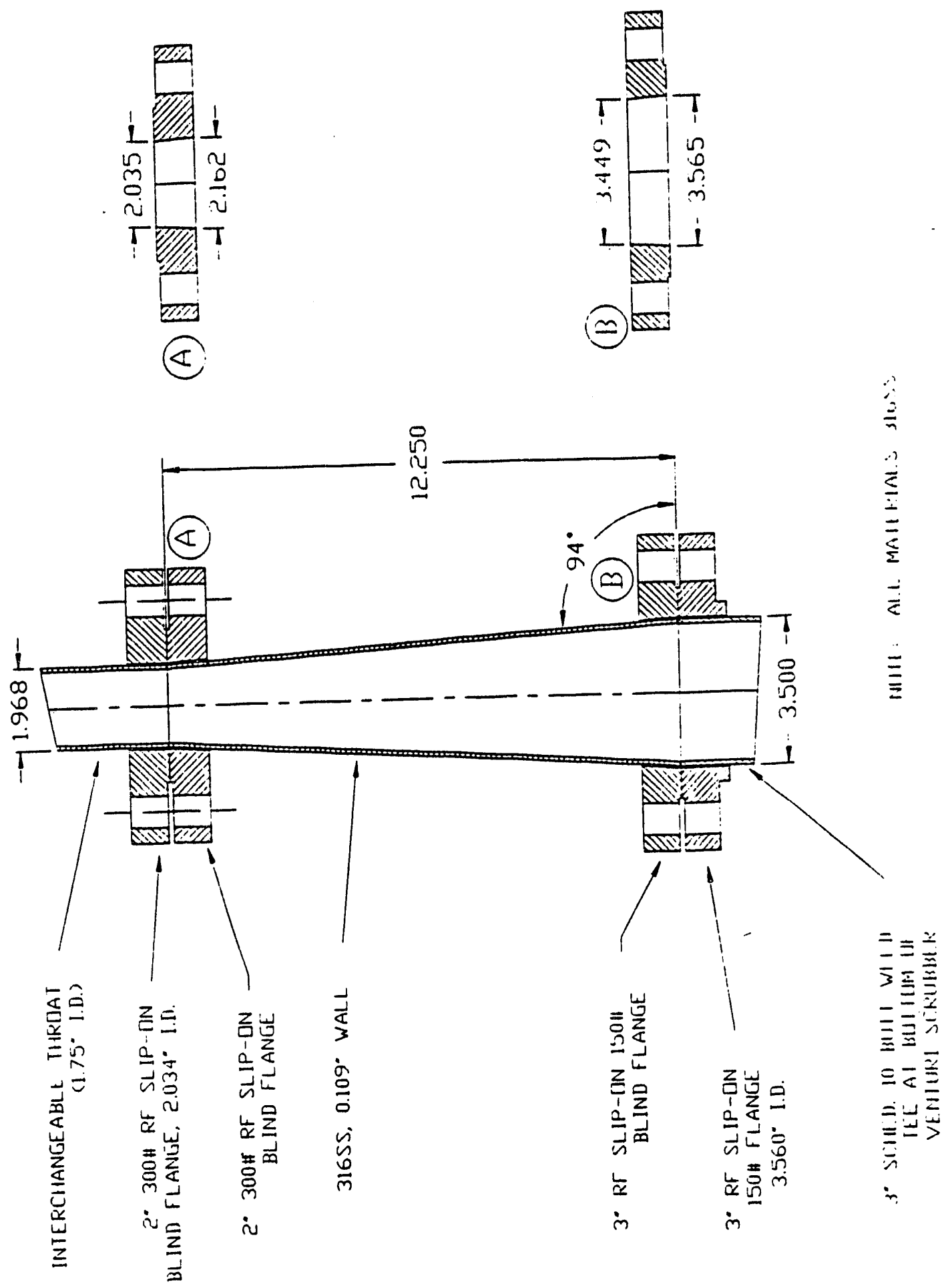

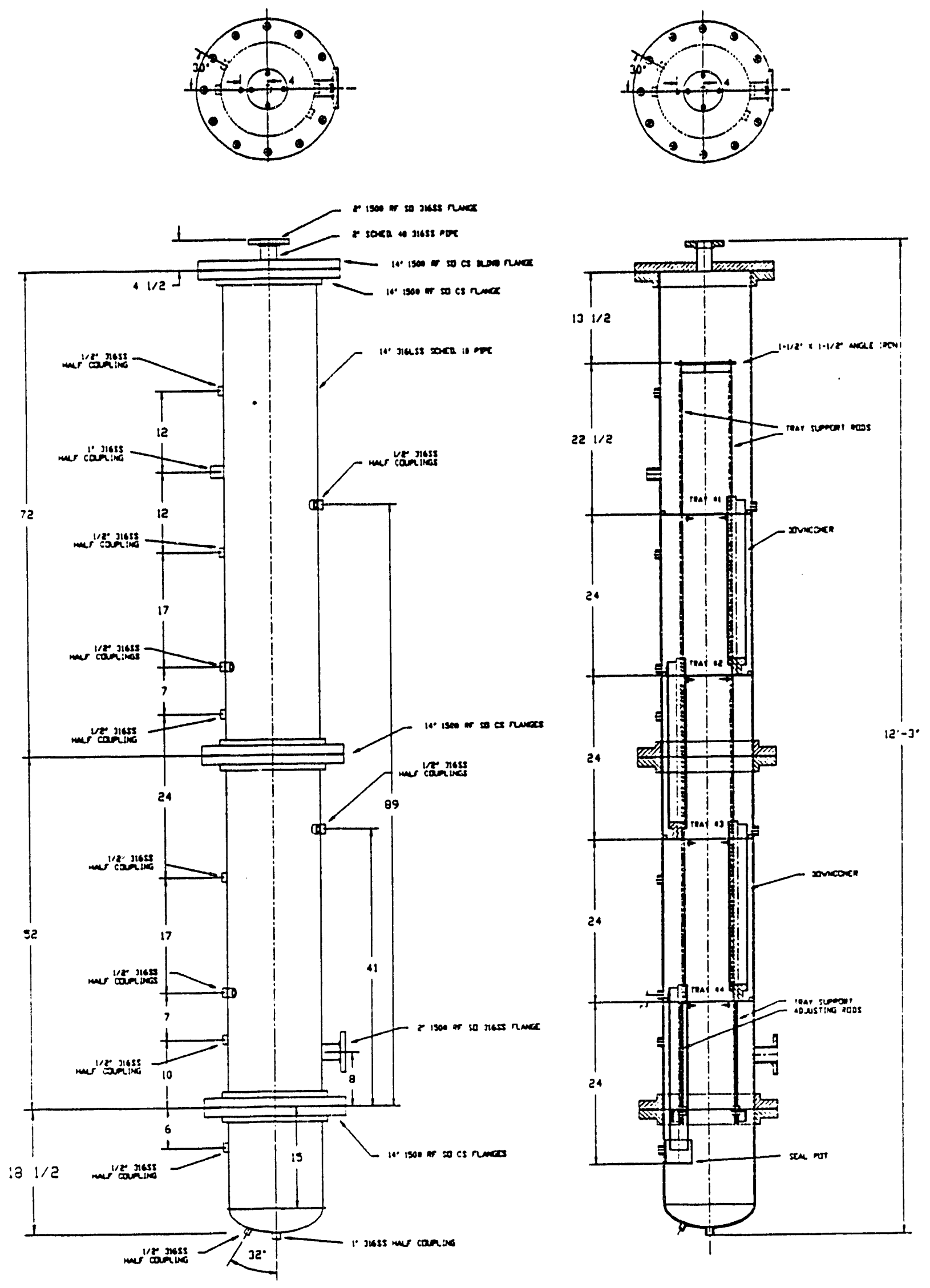

Figure D17. Sieve tower. 

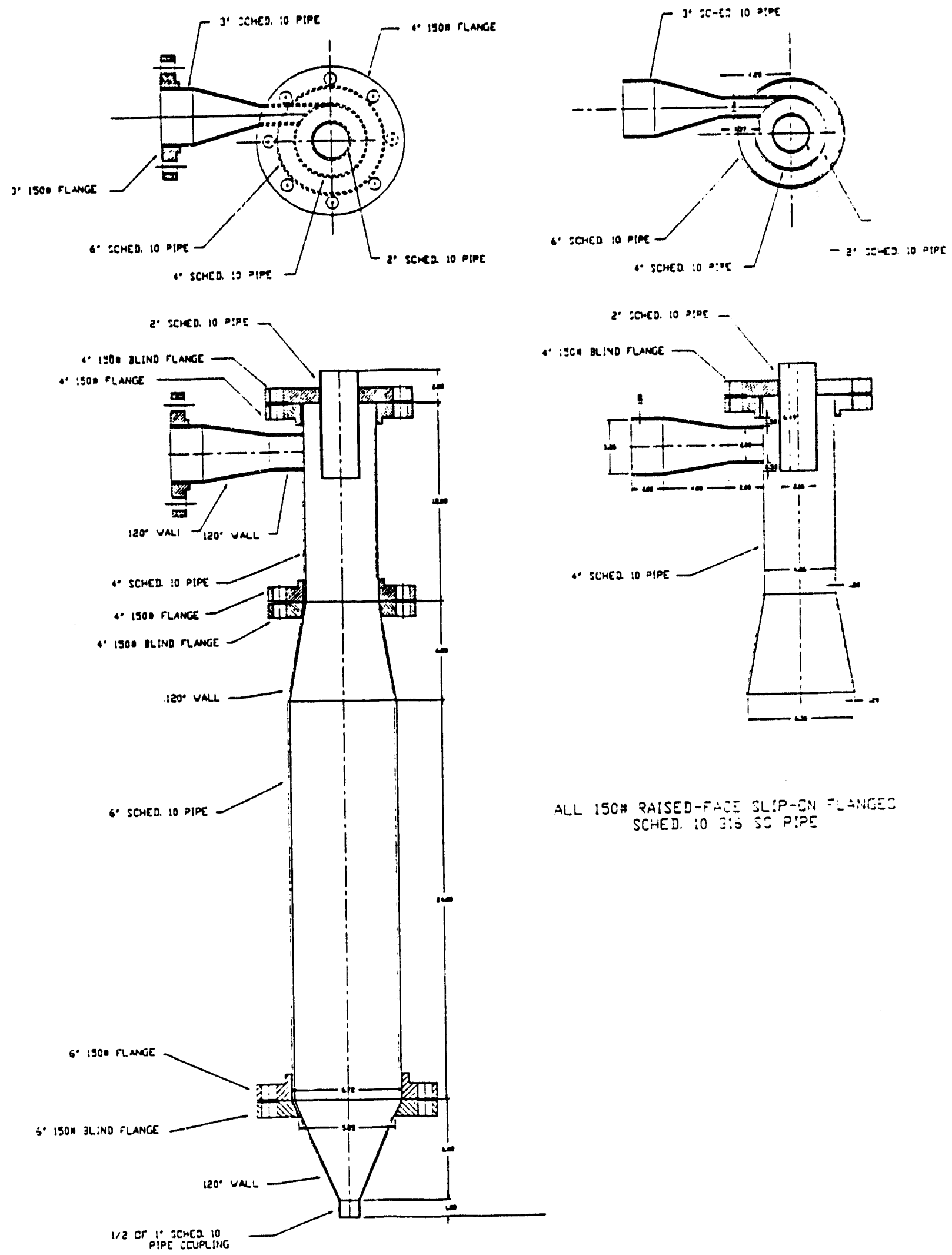

ALL 15OA RAISED-FAE SLIP-EN TANCEO SCHED. :O Z:S SE P!PE

Figure D18. Venturi scrubber 4" cyclone. 
The second carbonizer condensation train consists of a series of two direct contact water scrubbers (venturi cyclones), shown in Figures D18 and D19, which is used when steam is a component of the fluidization gas. These are also generalized drawings as mentioned above. The gas stream is cooled to between $200^{\circ} \mathrm{F}\left(93^{\circ} \mathrm{C}\right)$ and $225^{\circ} \mathrm{F}\left(107^{\circ}\right)$ in the first water scrubber and to below $125^{\circ} \mathrm{F}\left(52^{\circ} \mathrm{C}\right)$ in the second scrubber. The gas from the second venturi is flared, and the liquid products are stored in 55-gallon barrels.

The calciner condensation train, lown in Figure D20, consists of a series of three paired shell and tube heat exchangers for product separation. The first set of heat exchangers is glycol-cooled, and the other two sets are water-cooled. A duplicate train of exchangers was installed so gas flow could be switched to the other side if plugging occurred. Cryogenic traps were placed after the shell and tube heat exchangers to condense lower-boiling point materials out of the gas stream. After passing through the calciner condensation train, the gas was flared.

\section{Waste Treatment and Phenol Recovery}

Wastewater was produced from the inherent moisture in the coal and from the natural gas combustion. Typically, wastewater treatment consists of biotreatment, with or without dilution with clean water. The EERC wastewater treatment and phenol recovery scheme is shown in Figure D21. The process is based on liquid-liquid extraction using diisopropyl ether (DIPE) as the solvent to remove phenols and most trace organics, possibly followed by treatment in granular activated carbon columns to produce water that meets discharge criteria. In a commercial process, the water could be recycled and used as process water (2).

The extract from the liquid-liquid extractor was distilled in a solvent recovery still to separate the DIPE from the crude phenol stream. The oil, light oil, and crude phenol streams were evaluated in upgrading studies. A large wastewater holding tank was included in the PRU scheme since wastewater treatment was not performed concurrently with mild gasification testing. Since this process has been extensively demonstrated, the extraction process was not demonstrated. The amount of phenol was determined in each sample. Raw gas from the carbonizer and calciner during start-up and scrubbed gas from the carbonizer and calciner condensation trains during operation are sent to a flare. The flare operates at a theoretical flame temperature of $1800^{\circ} \mathrm{F}\left(982^{\circ} \mathrm{C}\right)$, with a typical residence time of 0.5 seconds (3).

\section{Equipment Modifications to Quench Train}

During Tests P004 to P007, it became evident that cooling liquid could not be kept in the venturi scrubbers due to the high gas velocities needed to maintain reactor operating temperatures of $1000^{\circ}$ to $1100^{\circ} \mathrm{F}\left(540^{\circ}\right.$ to $\left.595^{\circ} \mathrm{C}\right)$. Since the only heat source is fluidization gas, a combination of factors is involved in keeping the reactor at a specific operating temperature. These factors include the amount of combustion gas, the moisture level of the feed coal, the amount of condensables produced at the operating temperature, and the fluidization gas velocity. During the initial runs, in order to maintain the reactor at a temperature of $1100^{\circ} \mathrm{F}\left(595^{\circ} \mathrm{C}\right), 5000$ to $7000 \mathrm{scfh}$ of gas was needed. At this velocity, it was not possible to maintain liquid levels in any of the venturi scrubber cyclones. As a result, a small amount of start-up cooling liquid was constantly added to each cyclone. The blown over cooling liquid was collected downstream in the demister 

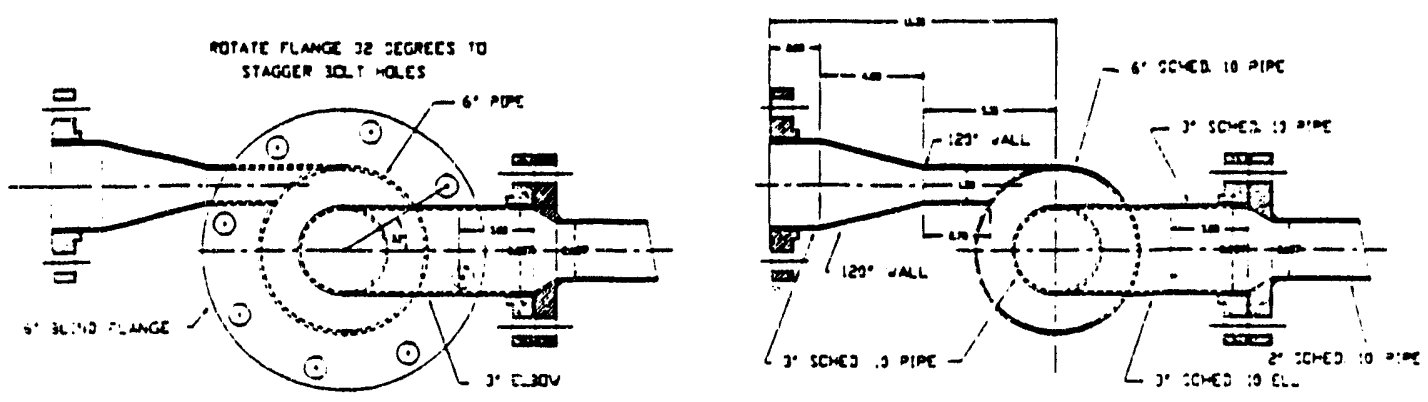

$\underset{1}{\vdots}$
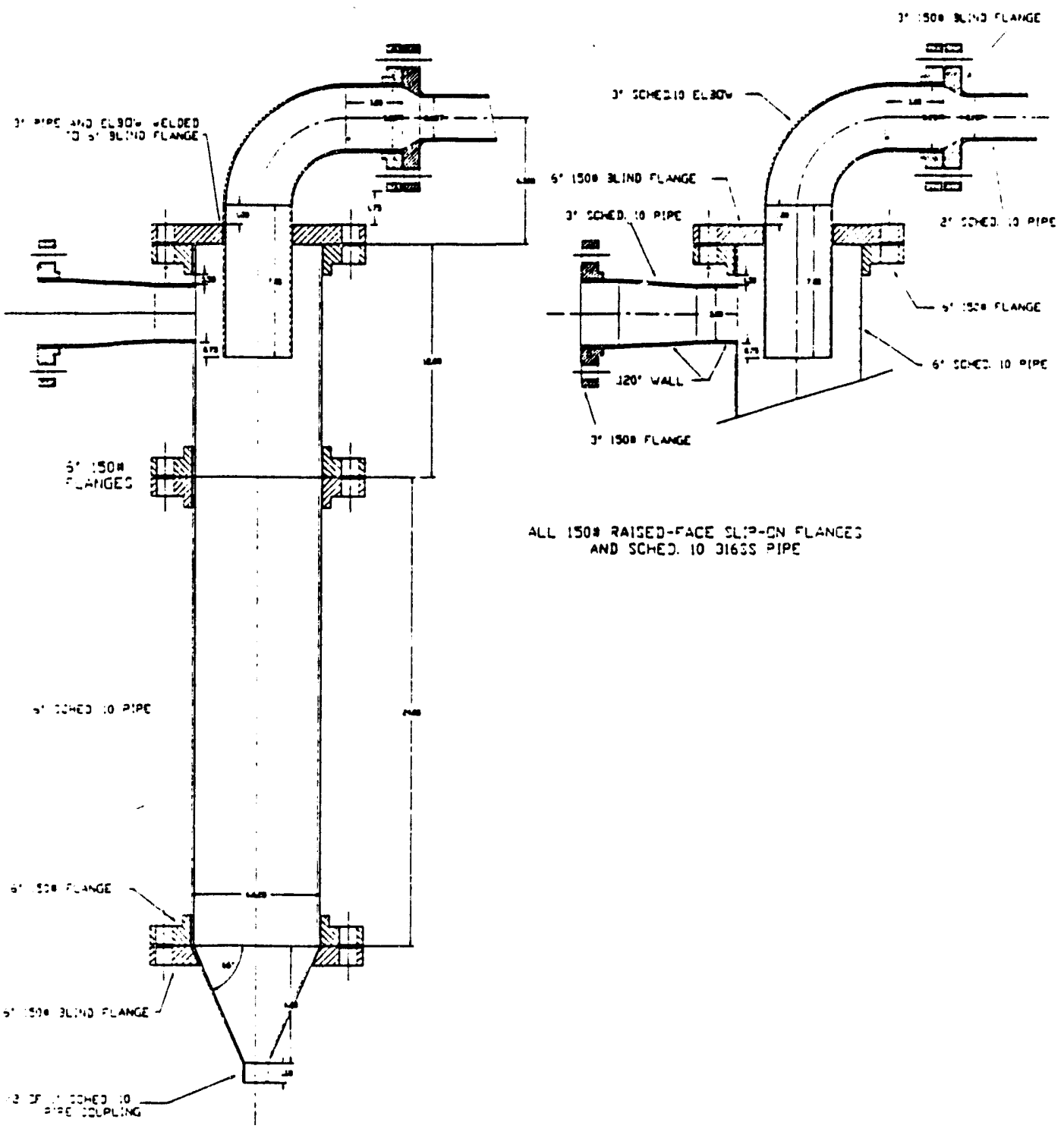

ALL ISOA RAIJED-FACE SL:D-EN FLANCES

AND SCHES. 10 316ذS PIPE

Figure D19. Ven:uri scrubber 6" cyclone. 


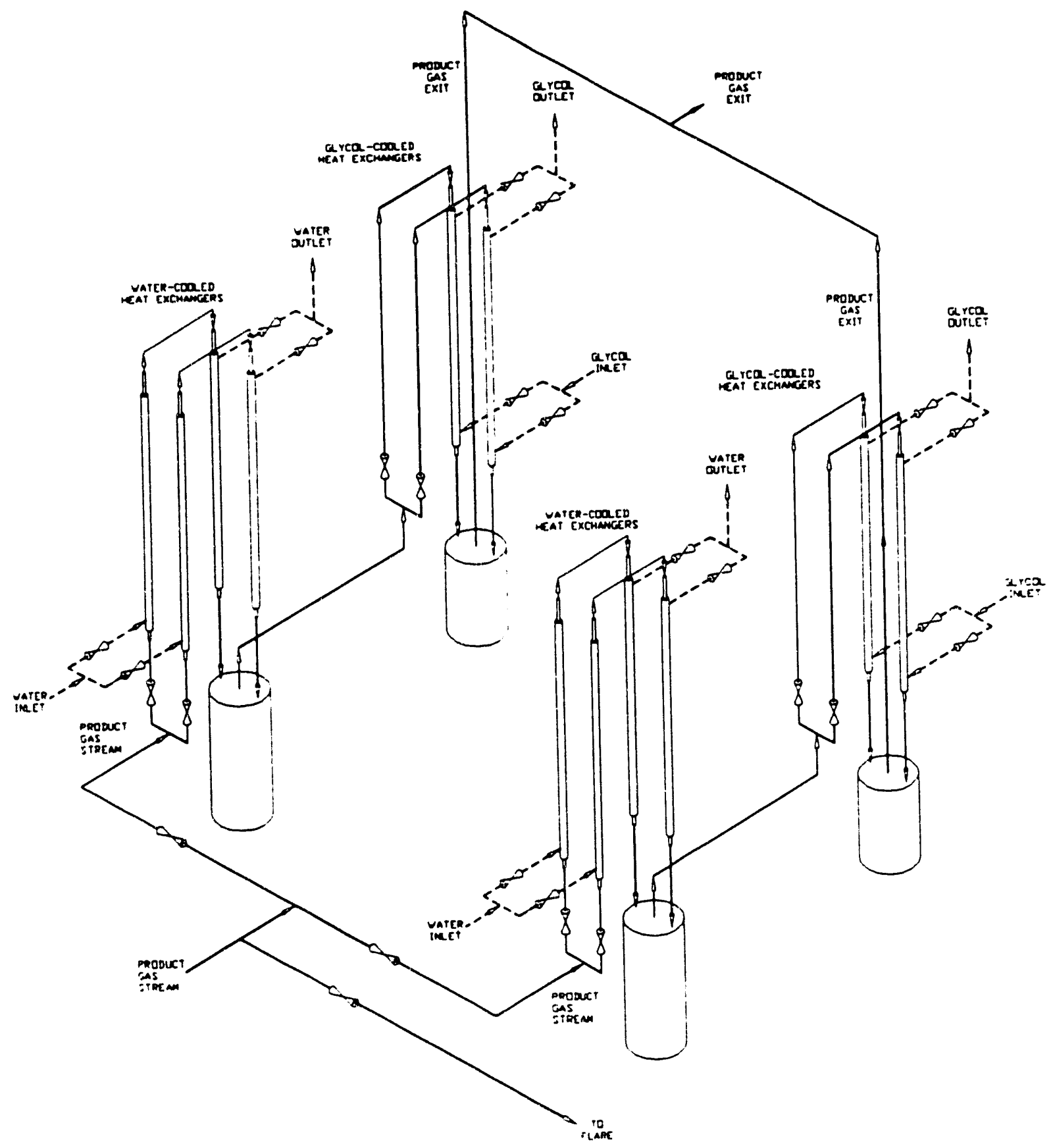

Figure D20. Calciner condensation train. 


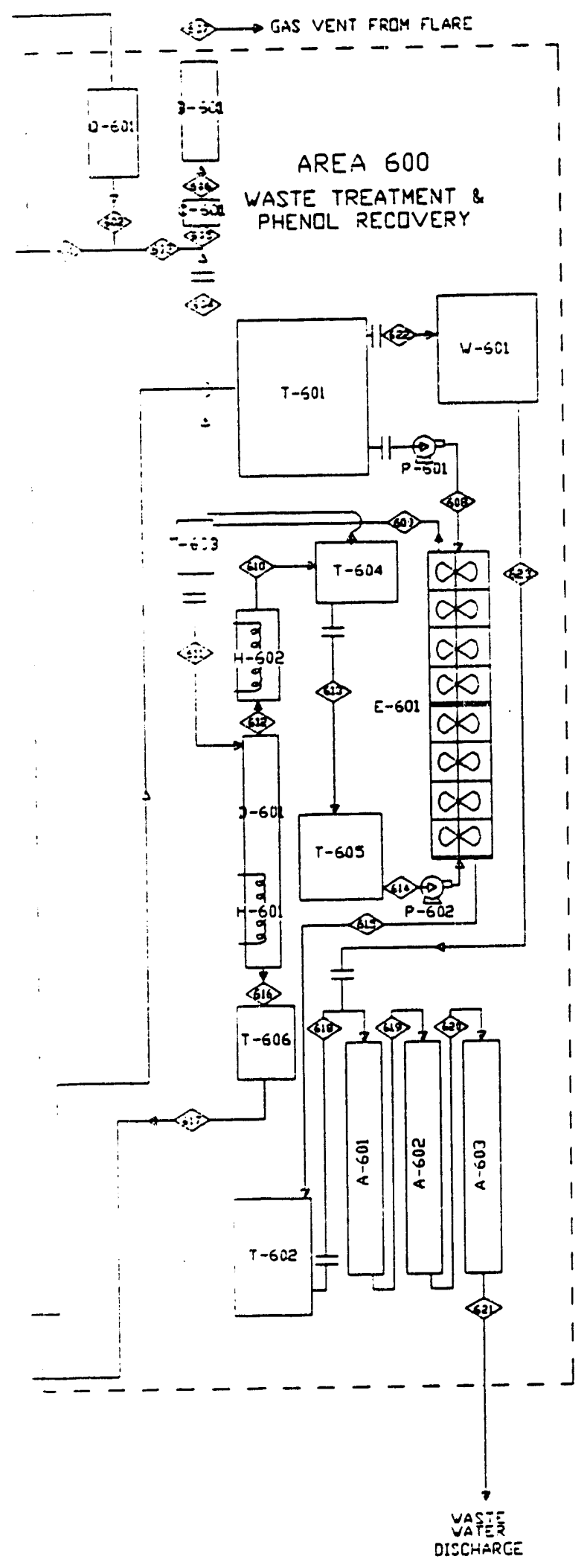

Figure D21. Wastewater cleanup and phenol recovery system. 
vessels. To determine the lower limit of the gas velocity that would cause liquid entrainment, lower temperatures were maintained in the carbonizer during Tests P008 and P009.

Because these lower temperatures do not provide acceptable devolatilization, a cold flow test program was initiated that involved simulating the action of the venturi scrubber cyclones using a cyclone fabricated from plexiglas. Figure D22 shows the cyclone entrainment test stand (CETS) developed for the simulation studies. Table D2 describes the tests performed using the CETS.

During the first two tests, it was evident that the cyclones did not function adequately, as cooling liquid was entrained and removed from the system at a rate of 2 gpm. The entrainment was due to several factors, discovered during the tests, that necessitated a significantly different design for a liquid/gas cyclone as compared to a solid/gas cyclone.

Modifications to the quench train cyclones solved the condensable entrainment problem. A second problem was then encountered, where the amount of fines accumulating in the recycling tar in the tar scrubber eventually plugged the lines. This occurrence, coupled with the extremely high boiling point of the condensables, indicated that a reduction in the operating temperature of the tar scrubber was needed. This would condense more organic material in the tar scrubber, thus reducing the ratio of coal fines to organic liquids, and also condense lower boiling point material. This lowered the solidification temperature of the tar. This reduction in temperature lead to a narrow window of operating conditions between a temperature that was sufficiently high to boil off the lighter organics that acted as a solvent for the heavy tar and a temperature that was low enough to solidify the heavy tar.

Once this approach was used, it was apparent that longer operating times could be achieved. However, upset anywhere in the system usually would push the operating conditions of the tar scrubber outside this narrow window and would cause a system shutdown. Project funding did not allow for further testing to improve system operability. This problem would be better solved by scaling up the system to allow more flexibility in the system due to larger inventories of recycling tar and proportionally lower heat leak from a larger system. 


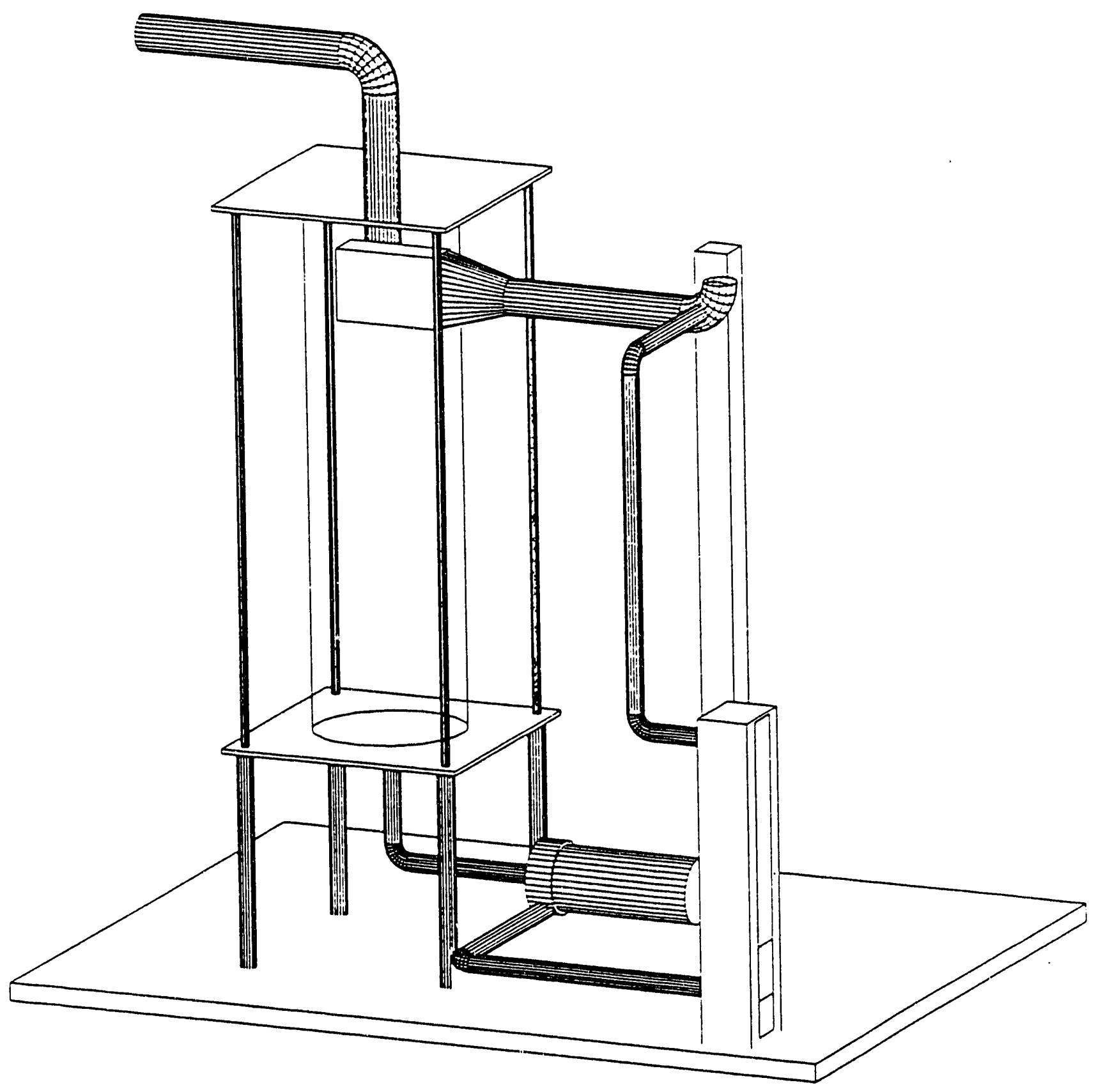

Figure D22. Cyclone entrainment test stand (CETS). 
TABLE D2

Cold Flow Entrainment Studies

\begin{tabular}{ccccc}
\hline Test Number & Cyclone Size & Grs Flow (scfh) & $\begin{array}{c}\text { Recycle Rate } \\
\text { (gph) }\end{array}$ & Parameter \\
\hline T001 & $4^{\prime \prime}$ & 5000 & 22 & Norm. Op. \\
T002 & $6^{\prime \prime}$ & 7000 & 22 & Norm. Op. \\
T003 & $8^{\prime \prime}$ & 7000 & 22 & Norm. Op. \\
T004 & $10^{\prime \prime}$ & 7000 & 22 & Norm. Op. \\
T005 & $12^{\prime \prime}$ & 7000 & 22 & Norm. Op. \\
T006 & $4^{\prime \prime}$ & 5000 & 22 & Modified \\
T007 & $6^{\prime \prime}$ & 7000 & 22 & Modified \\
T008 & $8^{\prime \prime}$ & 7000 & 22 & Modified \\
T009 & $10^{\prime \prime}$ & 7000 & 22 & Modified \\
T010 & $12^{\prime \prime}$ & 7000 & 22 & Modified \\
\hline
\end{tabular}



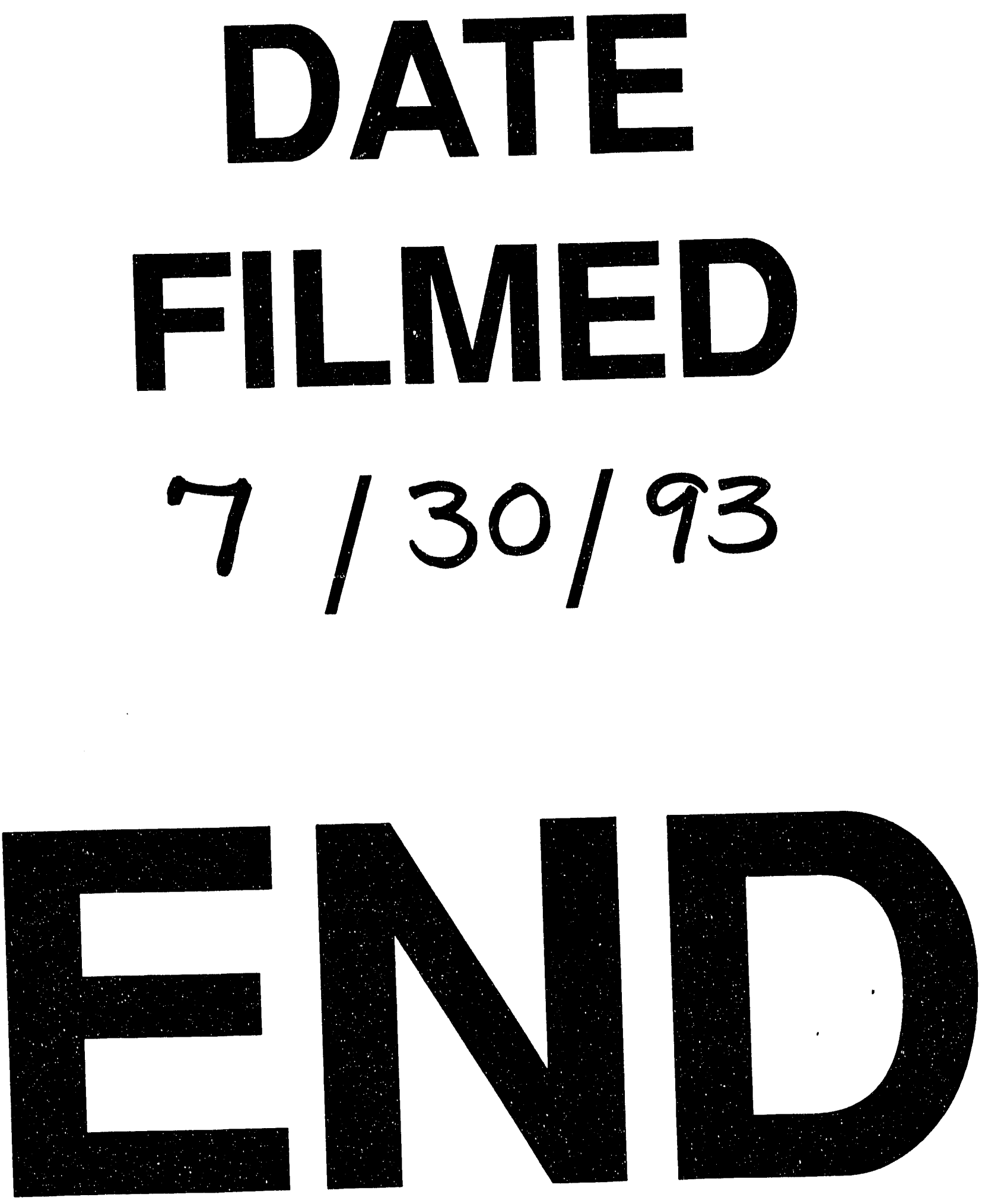


$$
-
$$

